\title{
Next Generation Nuclear Plant Steam Generator and Intermediate Heat Exchanger Materials Research and Development Plan
}

September 2010
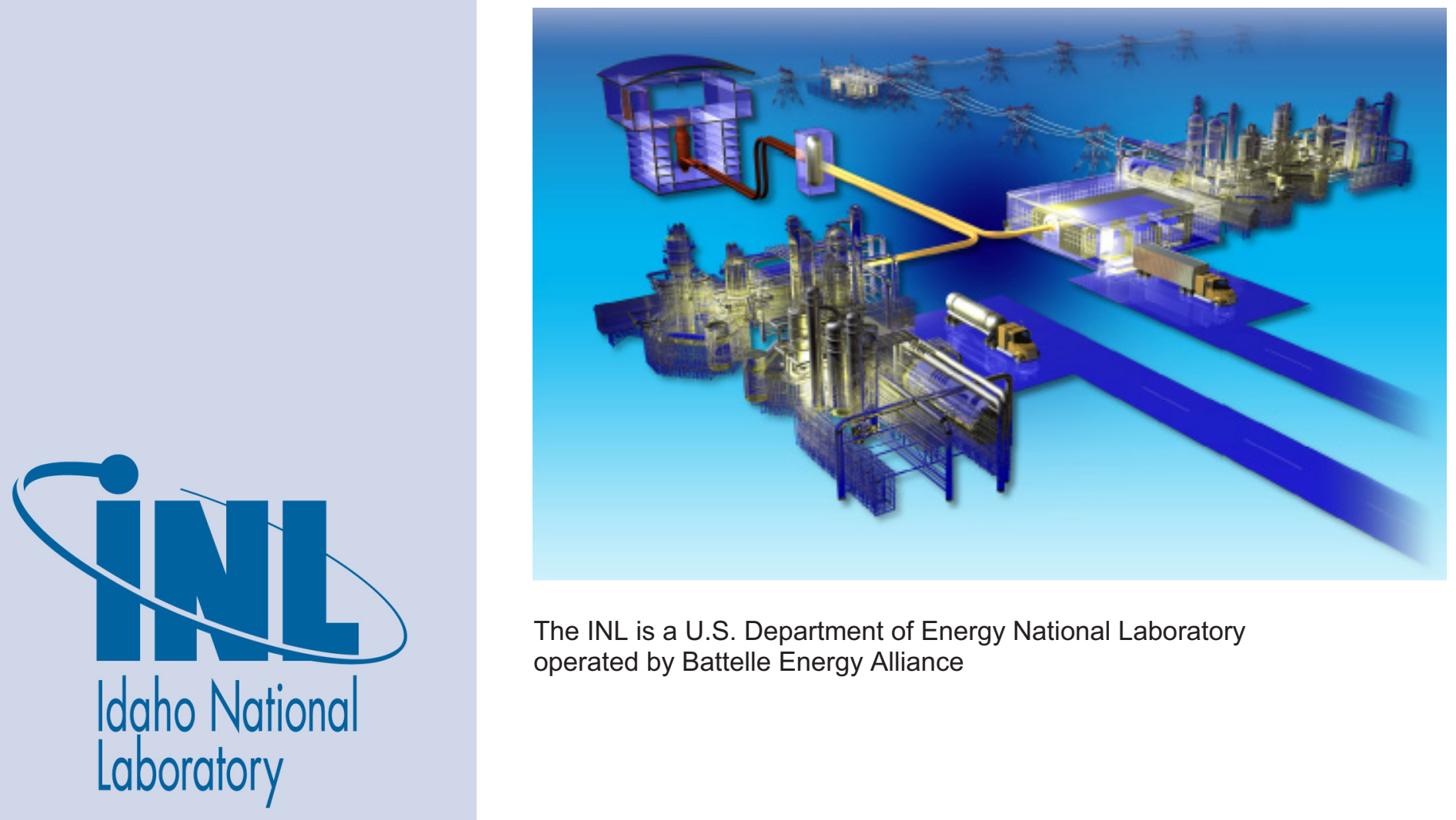

The INL is a U.S. Department of Energy National Laboratory operated by Battelle Energy Alliance 
INL/EXT-08-14107

Rev. 1

Plan-2804

\section{Next Generation Nuclear Plant Steam Generator and Intermediate Heat Exchanger Materials Research and Development Plan}

September 2010

Idaho National Laboratory
Idaho Falls, Idaho 83415

http://www.inl.gov

Prepared for the

U.S. Department of Energy

Office of Nuclear Energy

Under DOE Idaho Operations Office

Contract DE-AC07-05ID14517 
Form 412.09 (Rev. 10)

Idaho National Laboratory

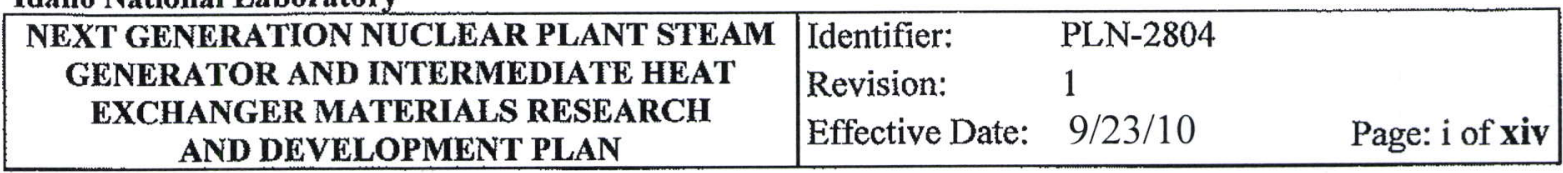

NGNP Project

Plan

CR Number: 583643

Approved by:
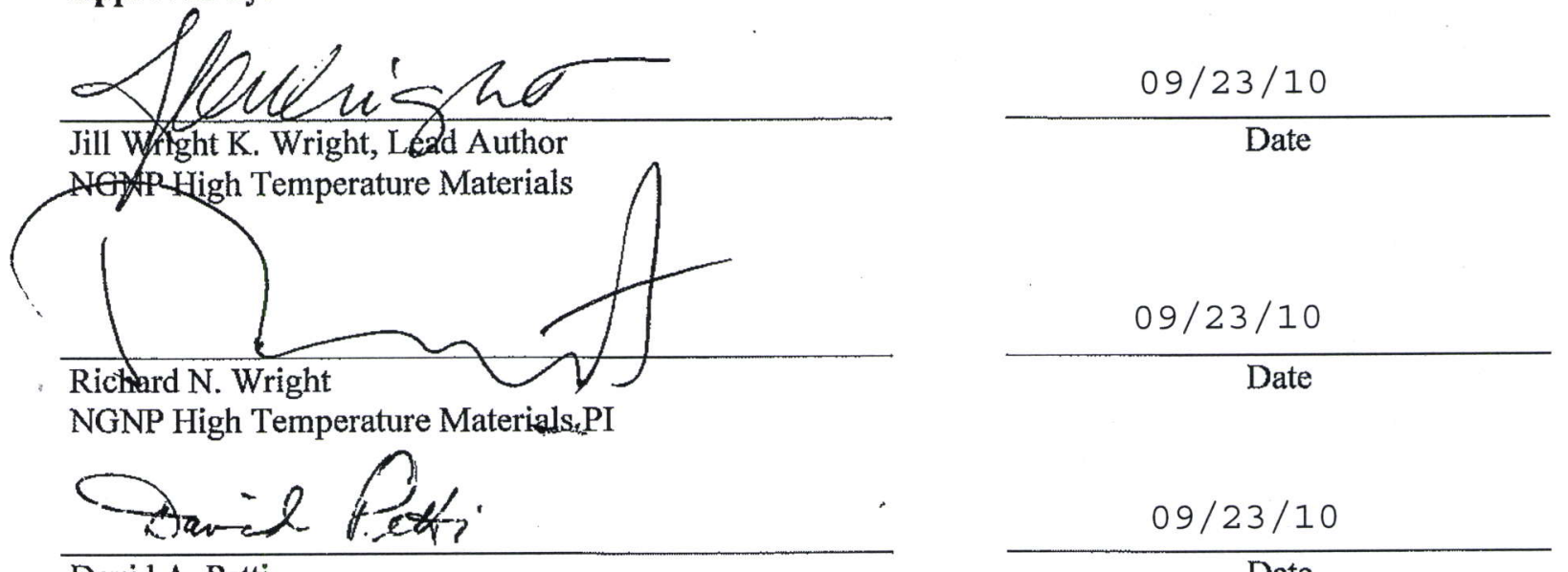

David A. Yeti

Date

VHTR TDO Director 
Idaho National Laboratory

\begin{tabular}{|c|lll|}
\hline $\begin{array}{c}\text { NEXT GENERATION NUCLEAR PLANT STEAM } \\
\text { GENERATOR AND INTERMEDIATE HEAT } \\
\text { EXCHANGER MATERIALS RESEARCH }\end{array}$ & Identifier: & PLN-2804 & \\
AND DEVELOPMENT PLAN & Effective Date: & $09 / 23 / 10$ & Page: ii of xiv \\
\hline
\end{tabular}

REVISION LOG

\begin{tabular}{|c|c|c|c|}
\hline Rev. & Date & Affected Pages & Revision Description \\
\hline 0 & 04-30-08 & All & New issue. See eCR 560588. \\
\hline 1 & $09 / 23 / 10$ & All & Updates throughout document \\
\hline & & & \\
\hline & & & \\
\hline & & & \\
\hline & & & \\
\hline & & & \\
\hline & & & \\
\hline & & & \\
\hline & & & \\
\hline & & & \\
\hline & & & \\
\hline & & & \\
\hline
\end{tabular}




\begin{tabular}{|c|lll|}
\hline NEXT GENERATION NUCLEAR PLANT STEAM & Identifier: & PLN-2804 & \\
$\begin{array}{c}\text { GENERATOR AND INTERMEDIATE HEAT } \\
\text { EXCHANGER MATERIALS RESEARCH } \\
\text { AND DEVELOPMENT PLAN }\end{array}$ & Revision: & 1 & \\
Effective Date: & $09 / 23 / 10$ & Page: iii of xiv \\
\hline
\end{tabular}

\section{SUMMARY}

The U.S. Department of Energy (DOE) has selected the high temperature gas-cooled reactor (HTGR) design for the Next Generation Nuclear Plant (NGNP) Project. The NGNP will demonstrate the use of nuclear power for process heat, hydrogen and electricity production. The reactor will be graphite moderated with helium as the primary coolant. Final design features have not been determined and the reactor may be either prismatic or pebble-bed. It will use low-enriched uranium tri-isotopic (TRISO)-coated fuel. It is likely to have an outlet gas temperature of $750^{\circ} \mathrm{C}$ with a steam generator (SG) and a design service life of 60 years. The plant size, reactor thermal power, and core configuration will ensure passive decay heat removal without fuel damage or radioactive material releases during accidents. Follow-on HTGRs may have outlet temperatures up to $950^{\circ} \mathrm{C}$ and will incorporate a gas-to-gas intermediate heat exchanger (IHX).

The revisions incorporated into this research and development (R\&D) plan reflect technical issues associated with the SG that were not considered for application in the NGNP when the plan was initially developed. This R\&D plan describes work that is necessary for the first-of-a-kind NGNP and follow-on reactors that might have different design parameters. The fundamental challenge for NGNP is to achieve a significant advancement in nuclear technology while setting the stage for an economically viable deployment of the new technology in the commercial sector soon after 2020.

Alloy $800 \mathrm{H}$ is approved in the American Society of Mechanical Engineers (ASME) Codes for nuclear applications up to $760^{\circ} \mathrm{C}$ with a maximum design life of $300,000 \mathrm{~h}$. An SG for $750^{\circ} \mathrm{C}$ service may require longer service life than the currently allowed $300,000 \mathrm{~h}$. Testing and constitutive model development to support extension of the allowable temperature for this alloy and the allowable lifetime to $500,000 \mathrm{~h}$ ( $\sim 60$ years with $95 \%$ of availability) are included in this plan. Due to the high design temperature, the requirements of materials for the IHX are among the most demanding. In addition to the SG, this R\&D plan focuses on tasks that will be required to generate sufficient understanding of materials for successful design and operation of the NGNP IHX for which the prime candidate material is Alloy 617. Requirements for other core internals (e.g., the core barrel or control rod sleeves) are described in less detail in Appendix C.

A number of solid solution strengthened nickel- and iron-based alloys have been considered for application in the NGNP. The primary candidates were Alloy 617, Alloy 230, Alloy 800H and Alloy X. Based on the technical maturity, availability in required product forms, experience base, and high temperature mechanical properties, all of the pre-conceptual design studies prepared by potential reactor vendors have specified Alloy 617 as the material of choice for heat exchangers. Also a draft ASME Code case for Alloy 617 was developed previously. Although action was suspended before the Draft Alloy 617 Code Case was accepted by ASME, it provides a significant head start for achieving codification of the material. Similarly, Alloy $800 \mathrm{H}$ is the primary candidate alloy for the SG. In addition to the above listed considerations, Alloy $800 \mathrm{H}$ is already qualified in the nuclear section of the ASME Code, although the maximum use temperature and time need to be increased to ensure the range of potential designs is adequately supported.

The highest priority $R \& D$ tasks that have been identified in this technology development plan (TDP) are generating sufficient information to incorporate Alloy 617 in the nuclear section of the ASME Code. Specific weaknesses in understanding properties of this material were identified in comments received on the Draft Alloy 617 Code Case and through more recent discussion with ASME. Greater understanding of the creep-fatigue behavior of Alloy 617 and weldments has been ranked as the highest priority for generating additional information prior to submitting an updated ASME Code case.

The NGNP project has also identified a number of areas where additional characterization of the behavior of Alloy 617 is required for high temperature design. These include data to support constitutive 


\begin{tabular}{|c|lll|}
\hline NEXT GENERATION NUCLEAR PLANT STEAM & Identifier: & PLN-2804 & \\
GENERATOR AND INTERMEDIATE HEAT & Revision: & 1 & \\
EXCHANGER MATERIALS RESEARCH & Effective Date: & $09 / 23 / 10$ & Page: iv of xiv \\
AND DEVELOPMENT PLAN &
\end{tabular}

models for behavior of the alloy in tensile loading at elevated temperature, for creep and creep-fatigue. These data are needed for mill annealed material, weldments and after long-term aging. Note that because of the design of NGNP, the heat exchangers will not experience irradiation and no testing of irradiated Alloy 617 is required.

In addition to the requirement for inclusion of Alloy 617 in the ASME Code, it has been determined that additional studies of potential degradation of the properties of this material due to high temperature interaction with the anticipated NGNP helium environment are required. Phenomenological models for environmental degradation and greater understanding of the kinetics of degradation are needed to help bound the requirements for control of impurities in the primary and secondary helium during operation of the NGNP. Tests are specified to determine environmental effects on microstructure and properties.

Although Alloy $800 \mathrm{H}$ is included in the nuclear section of the ASME Code, the need for some additional characterization has been identified in this TDP. The effect of fine grain size associated with the potential for use in thin sections on the creep mechanism and mechanical properties needs to be characterized for both Alloy $800 \mathrm{H}$ and 617. Potential for environmental degradation in prototypical NGNP impure helium environments and in steam will be characterized. Mechanical property characterization for this material after long-term aging is also required.

A large matrix of required testing to support design and licensing of the NGNP has been developed as part of this R\&D plan. The abbreviated table below, ES-1, outlines the scope of the research. If sufficient funding is available, completion of the necessary R\&D can be accomplished to support the NGNP schedule.

Table ES-1. Scope of research.

\begin{tabular}{|c|c|c|c|}
\hline \multirow[t]{2}{*}{ Test Category } & \multirow[t]{2}{*}{ Function/Purpose } & \multicolumn{2}{|c|}{ Test Matrices } \\
\hline & & Alloy 617 & Alloy $800 \mathrm{H}$ \\
\hline Tensile Testing & $\begin{array}{l}\text { Establish heat baseline and confirm existing data. } \\
\text { Determine strain rate sensitivity and aging effects. }\end{array}$ & $\begin{array}{l}\text { A1, A5, } \\
\text { A14, A } 18\end{array}$ & $\begin{array}{l}\text { A } 26, \text { A28, } \\
\text { A } 30\end{array}$ \\
\hline Creep Testing & $\begin{array}{l}\text { Establish heat baseline and confirm existing data. } \\
\text { Determine strength reduction factors for welds. } \\
\text { Determine strength reduction factors for thin sections. } \\
\text { Establish creep regimes and mechanisms. } \\
\text { Support design for long-term service. }\end{array}$ & $\begin{array}{l}\text { A2, A8, } \\
\text { A11, A13a, } \\
\text { A17, A21 } \\
\text { A22, A24, } \\
\text { A25 }\end{array}$ & A27, A29 \\
\hline $\begin{array}{l}\text { Stress } \\
\text { Relaxation }\end{array}$ & $\begin{array}{l}\text { Includes stress dip and ratcheting. } \\
\text { Supports material modeling. }\end{array}$ & $\begin{array}{l}\text { A7, A11, } \\
\text { A13b }\end{array}$ & A26 \\
\hline Cyclic Testing & $\begin{array}{l}\text { Includes fatigue and creep-fatigue. } \\
\text { Support design curves for ASME Code. } \\
\text { Determine environmental effects. } \\
\text { Determine non-isothermal response. }\end{array}$ & $\begin{array}{l}\text { A3, A10, } \\
\text { A12, A16, } \\
\text { A19, A20, } \\
\text { A23 }\end{array}$ & \\
\hline $\begin{array}{l}\text { Fracture } \\
\text { Toughness }\end{array}$ & Characterize embrittlement effects due to aging. & $\mathrm{A} 4 \mathrm{a}, \mathrm{A} 4 \mathrm{~b}$ & \\
\hline $\begin{array}{l}\text { Multiaxial } \\
\text { Testing }\end{array}$ & $\begin{array}{l}\text { Model component stress states. } \\
\text { Verify von Mises assumption. }\end{array}$ & $\begin{array}{l}\text { A6, A10, } \\
\text { A15, A16, } \\
\text { A21 }\end{array}$ & $\mathrm{A} 15, \mathrm{~A} 31$ \\
\hline
\end{tabular}




\begin{tabular}{|c|lll|}
\hline NEXT GENERATION NUCLEAR PLANT STEAM & Identifier: & PLN-2804 & \\
GENERATOR AND INTERMEDIATE HEAT & Revision: & 1 & \\
EXCHANGER MATERIALS RESEARCH & Effective Date: & $09 / 23 / 10$ & Page: v of xiv \\
AND DEVELOPMENT PLAN &
\end{tabular}

\section{ACKNOWLEDGMENTS}

This document was written by J. K. Wright, R. N. Wright (INL) and T.-L. Sham (ORNL). The authors gratefully acknowledge the assistance of the following: D. S. Vandel, D. C. Kunerth, L. J. Carroll from INL and R. K. Nanstad, W. R. Corwin, D. F. Wilson, J. P. Shingledecker, R. L. Battiste, M. L. Santella, and Z. Feng from ORNL. We would also like to thank R. I. Jetter, Chair, ASME Boiler and Pressure Vessel Code, SC-D, Subgroup Elevated Temperature Design; R. W. Swindeman of Cromtech Inc.; K. P. Walker of Engineering Science Software, Inc.; V. K. Vasudevan, Professor, Department of Chemical and Materials Engineering, University of Cincinnati; and W. J. O’Donnell of O'Donnell Consulting Engineers, Inc. 


\begin{tabular}{|c|lll|}
\hline NEXT GENERATION NUCLEAR PLANT STEAM & Identifier: & PLN-2804 & \\
GENERATOR AND INTERMEDIATE HEAT & Revision: & 1 & \\
EXCHANGER MATERIALS RESEARCH & Effective Date: & $09 / 23 / 10$ & Page: vi of xiv \\
AND DEVELOPMENT PLAN &
\end{tabular}

\section{CONTENTS}

REVISION LOG.... ii

SUMMARY . iii

ACKNOWLEDGMENTS . .. $\mathrm{V}$

ACRONYMS xii

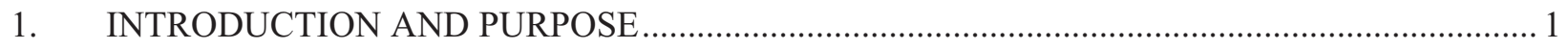

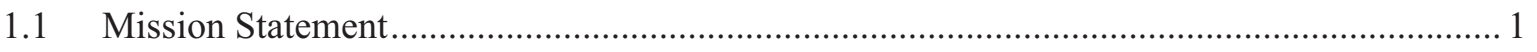

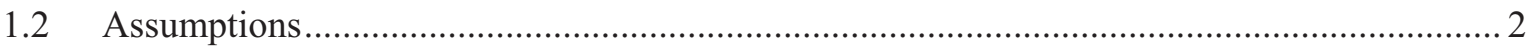

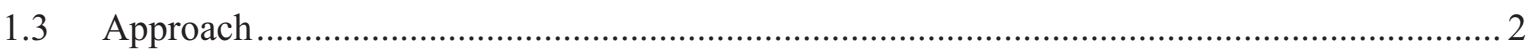

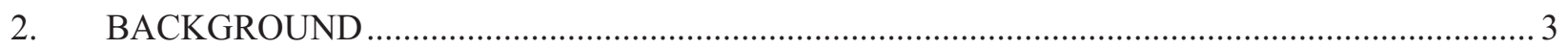

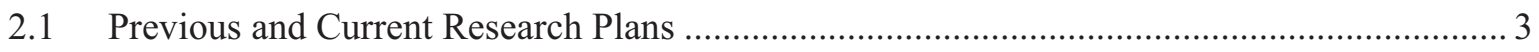

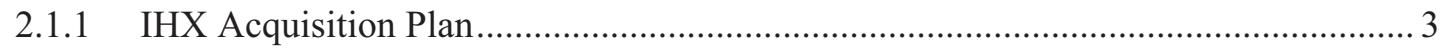

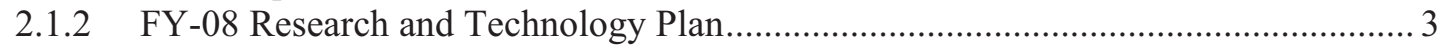

2.2 Reactor Preconceptual HTGR Designs .......................................................................... 3

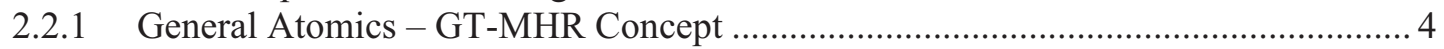

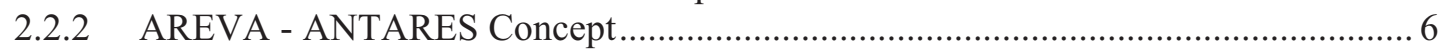

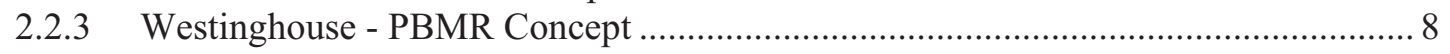

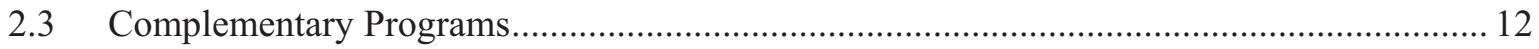

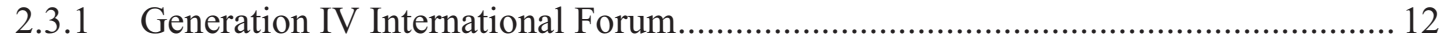

2.3.2 International Nuclear Energy Research Initiative Programs ................................... 12

2.3.3 University Nuclear Engineering Research Initiative Programs ................................ 12

2.3.4 Nuclear Energy University Program Research and Development Awards................ 13

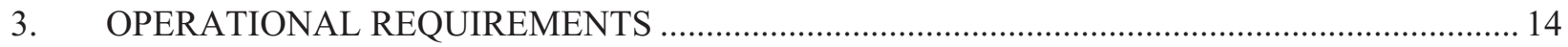

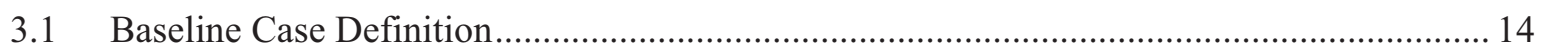

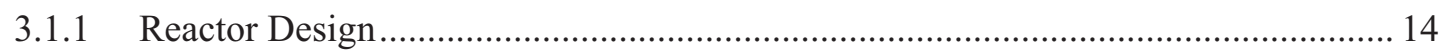

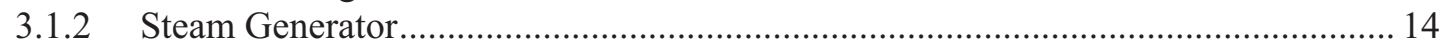

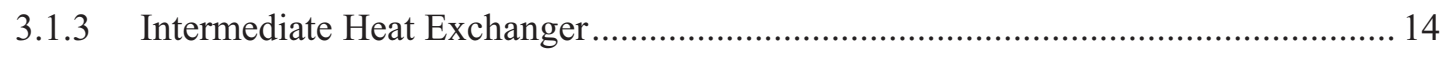

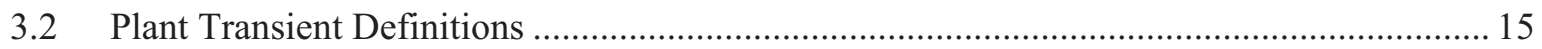

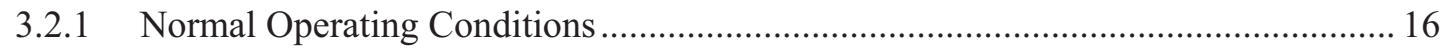

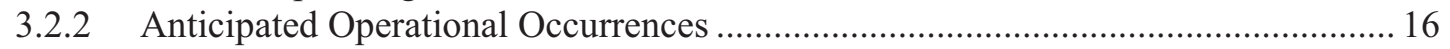

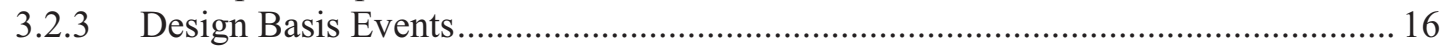

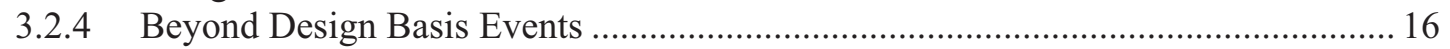

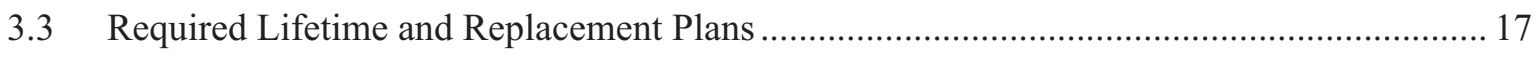

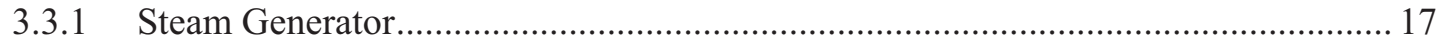

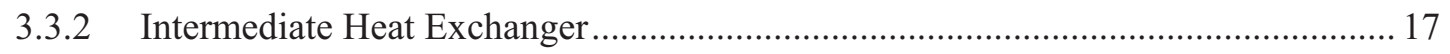

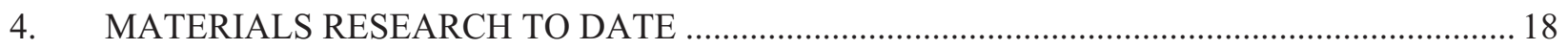

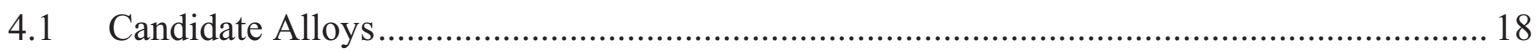

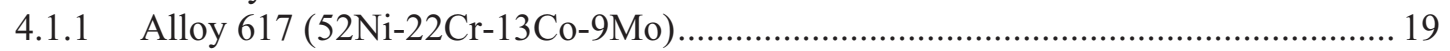

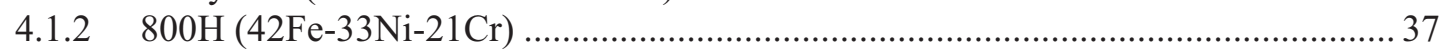




\begin{tabular}{|c|lll|}
\hline $\begin{array}{c}\text { NEXT GENERATION NUCLEAR PLANT STEAM } \\
\text { GENERATOR AND INTERMEDIATE HEAT }\end{array}$ & Identifier: & PLN-2804 & \\
EXCHANGER MATERIALS RESEARCH & Revision: & 1 & \\
AND DEVELOPMENT PLAN & Effective Date: & $09 / 23 / 10$ & Page: vii of xiv \\
\hline
\end{tabular}

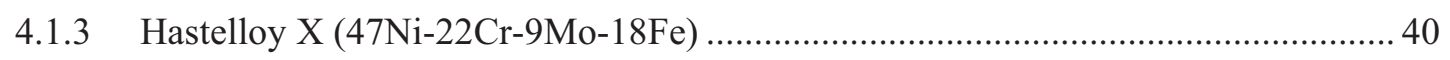

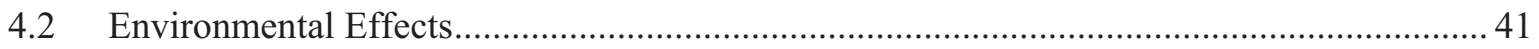

4.2.1 NGNP Research on Environmental Effects ........................................................... 41

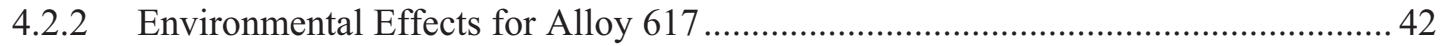

4.2.3 Comparison of Environmental Effects for Candidate Alloys .................................. 43

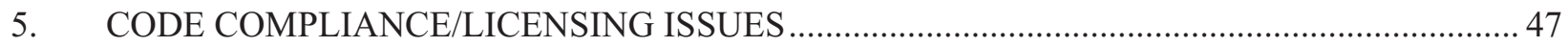

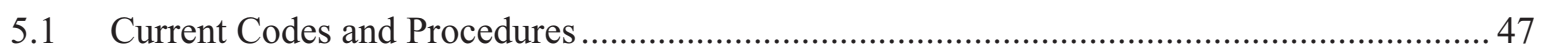

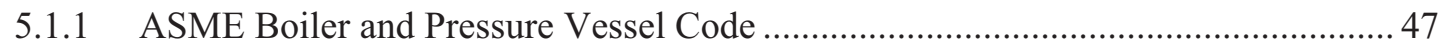

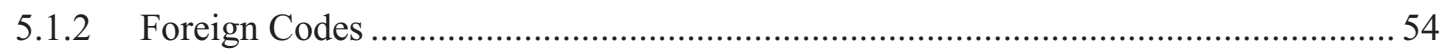

5.1.3 DOE Initiative to Address ASME Code Issues for Gen IV Reactors ....................... 55

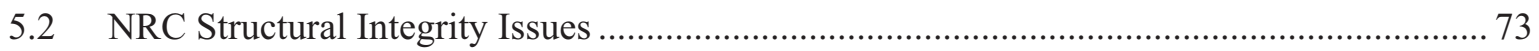

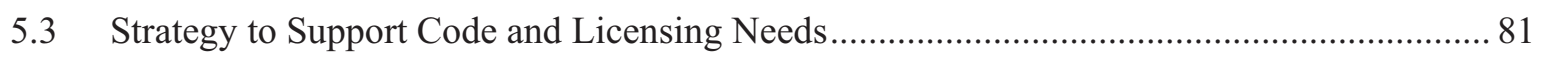

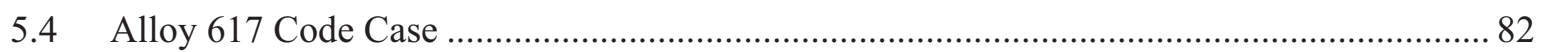

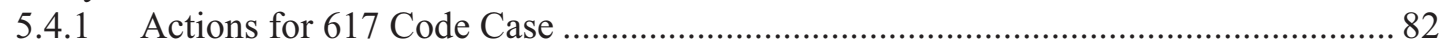

5.4.2 Implication of Code Class Designation for Alloy 617 Code Case........................... 83

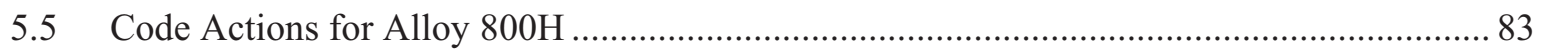

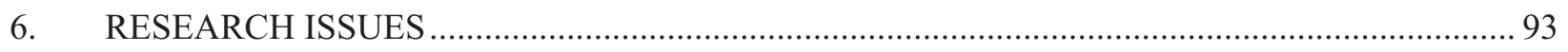

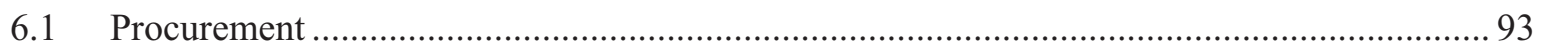

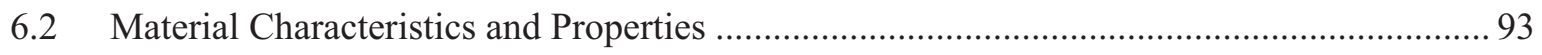

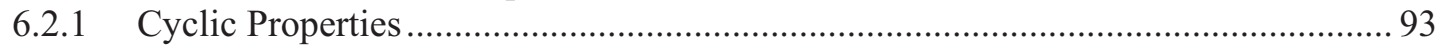

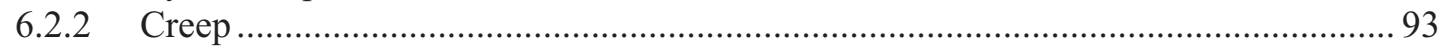

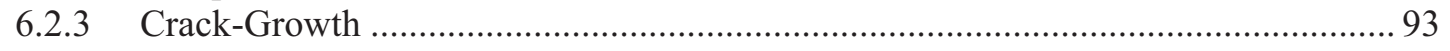

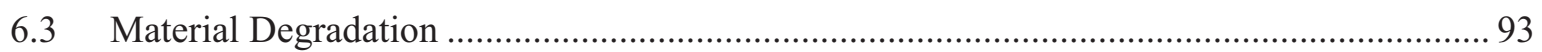

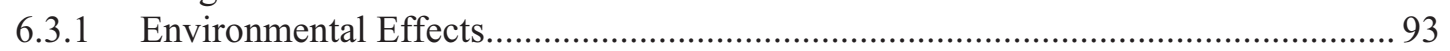

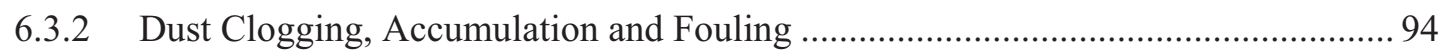

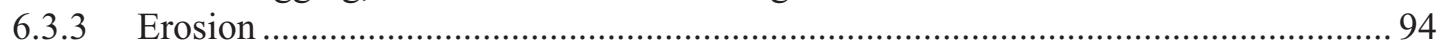

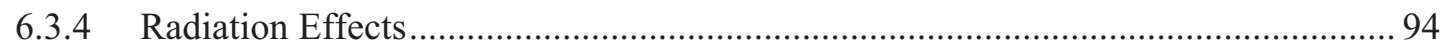

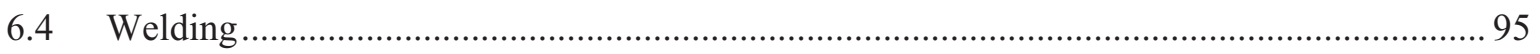

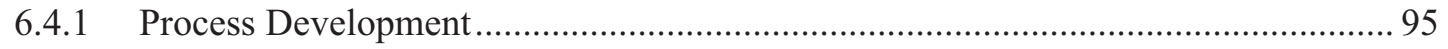

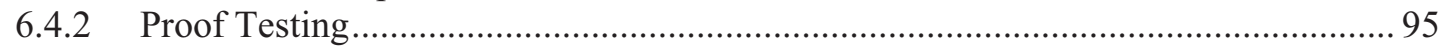

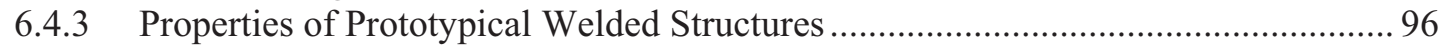

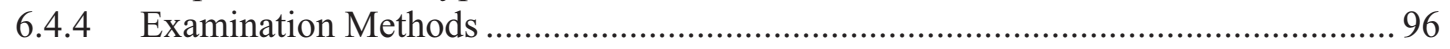

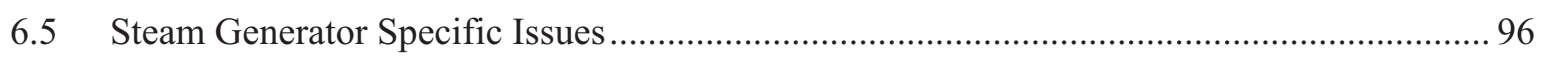

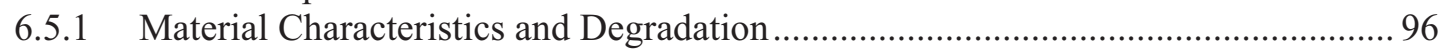

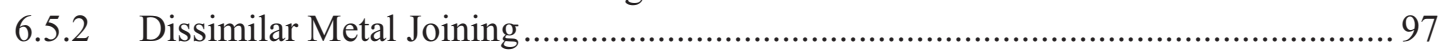

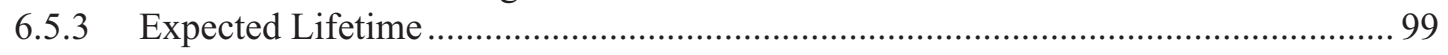

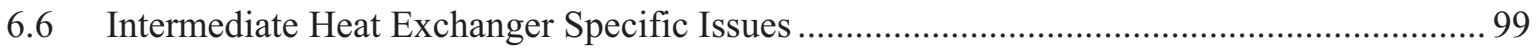

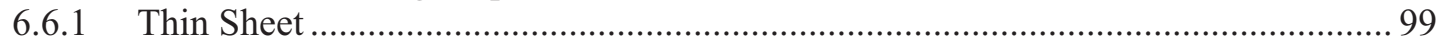

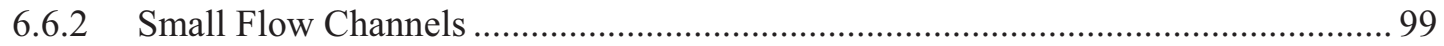

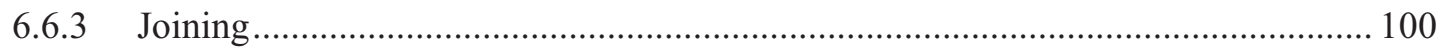

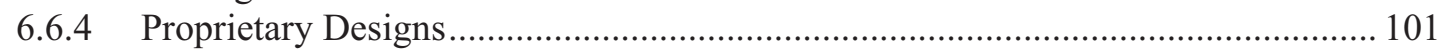

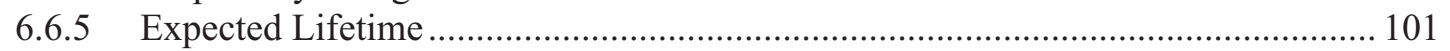




\begin{tabular}{|c|lll|}
\hline $\begin{array}{c}\text { NEXT GENERATION NUCLEAR PLANT STEAM } \\
\text { GENERATOR AND INTERMEDIATE HEAT }\end{array}$ & Identifier: & PLN-2804 & \\
EXCHANGER MATERIALS RESEARCH & Revision: & 1 & \\
AND DEVELOPMENT PLAN & Effective Date: & $09 / 23 / 10$ & Page: viii of xiv \\
\hline
\end{tabular}

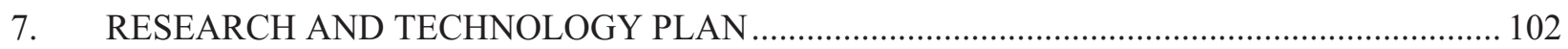

$7.1 \quad$ Required Actions for Code/Licensing Issues ................................................................. 102

7.1.1 Issues Originally Identified for Draft Alloy 617 Code Case.................................... 102

7.1.2 Data Needs Originally Identified in Comments on Draft Alloy 617 Code

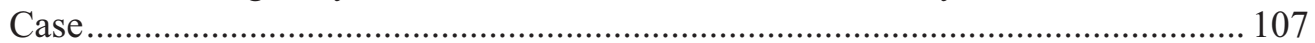

7.1.3 Design Methodology Issues for Alloy 617 ........................................................ 109

7.1.4 Additional Issues to Update Alloy 617 Data for Subsection NH............................ 119

7.1.5 Significant Recently Emerged Issues for Alloy 617 ........................................... 127

7.1.6 Small Grain-Sized Product Form for Alloy 617 ..................................................... 130

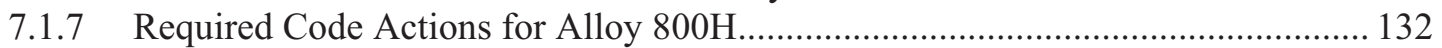

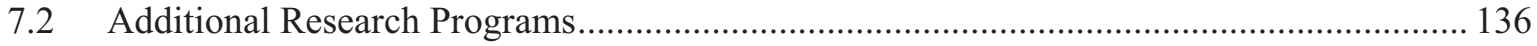

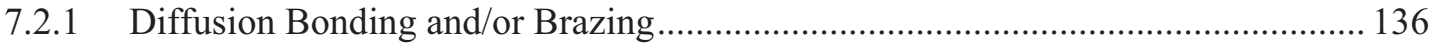

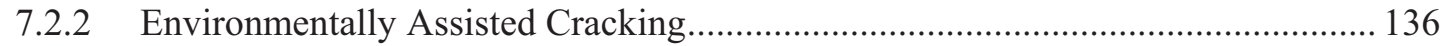

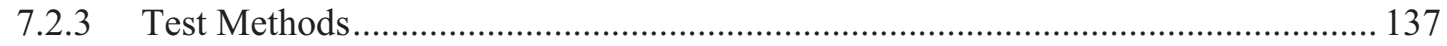

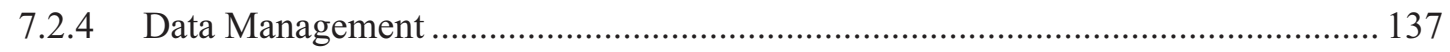

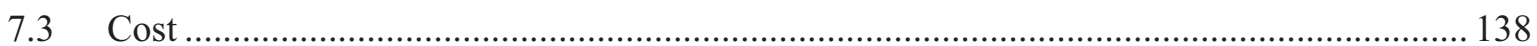

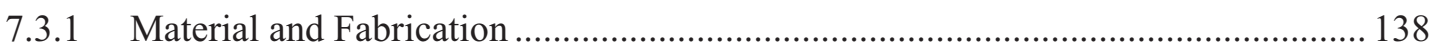

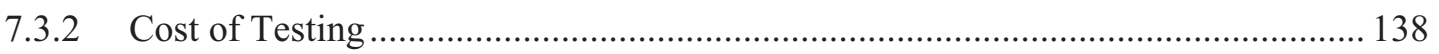

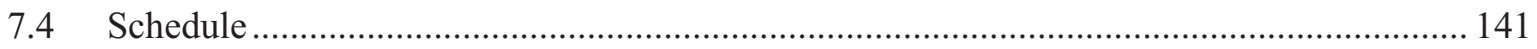

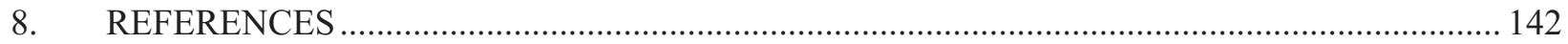

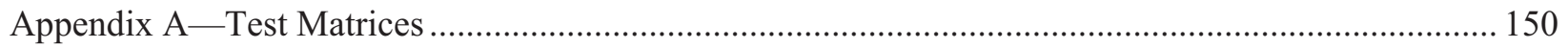

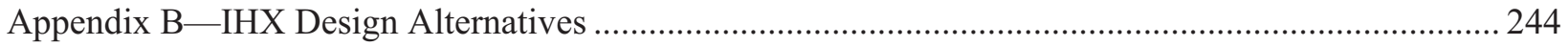

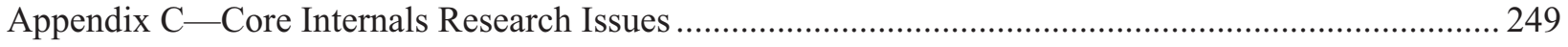

\section{FIGURES}

Figure 1. NGNP configuration as proposed by General Atomics...................................................... 5

Figure 2. NGNP configuration as proposed by AREVA. ....................................................................... 7

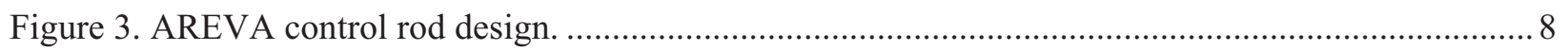

Figure 4. NGNP configuration as proposed by Westinghouse ................................................................ 9

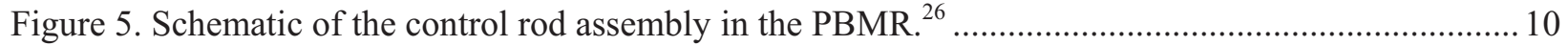

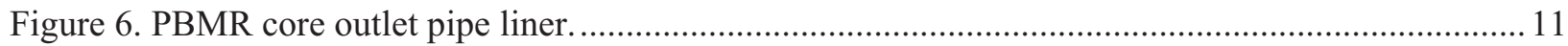

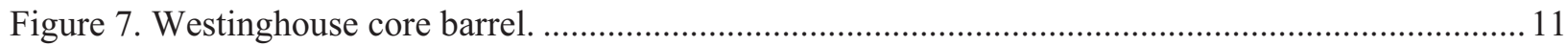

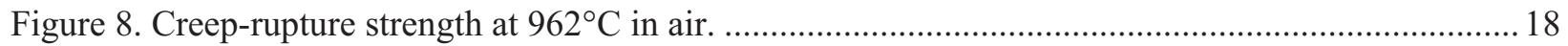

Figure 9. Allowable stress for heat exchanger materials for plate, sheet and strip forms........................ 19

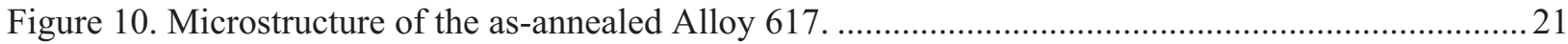

Figure 11. Optical micrograph of a cross-section through Alloy 617 (a) solution annealed, (b) aged for $200 \mathrm{~h}$ at $800^{\circ} \mathrm{C}$. 


\begin{tabular}{|c|lll|}
\hline NEXT GENERATION NUCLEAR PLANT STEAM & Identifier: & PLN-2804 & \\
$\begin{array}{c}\text { GENERATOR AND INTERMEDIATE HEAT } \\
\text { EXCHANGER MATERIALS RESEARCH } \\
\text { AND DEVELOPMENT PLAN }\end{array}$ & Revision: & 1 & \\
Effective Date: & $09 / 23 / 10$ & Page: ix of xiv \\
\hline
\end{tabular}

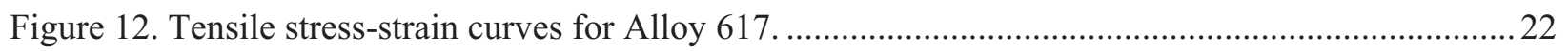

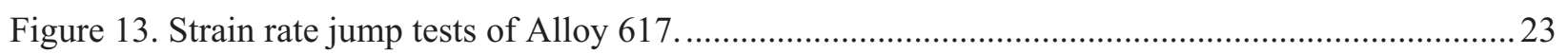

Figure 14. Log flow stress versus log strain rate plot for the various test temperatures............................24

Figure 15. Schematic of strain history for (a) continuous cycle fatigue and (b) creep-fatigue..................22

Figure 16. Peak tensile and compressive stress plotted as a function of cycle for creep-fatigue tests at $950^{\circ} \mathrm{C}$ and (a) $0.3 \%$ total strain range (b) $0.6 \%$ total strain range ................................25

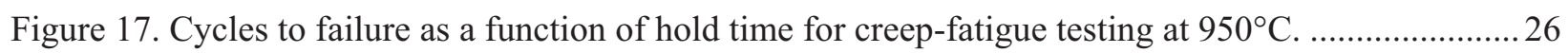

Figure 18. Continuous cycle and creep-fatigue testing at $950^{\circ} \mathrm{C}, 0.3 \%$ total strain for tests done in

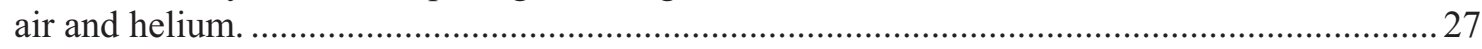

Figure 19. Stress relaxation curves at $950^{\circ} \mathrm{C}$ comparing first cycle of creep-fatigue tests at $0.6 \%$

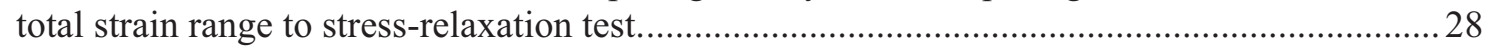

Figure 20. Porosity as a function of creep strain for Alloy 617 ..........................................................2 29

Figure 21. Micrographs showing the porosity resulting from creep of Alloy 617 at $1000^{\circ} \mathrm{C}$ and (a) $5 \%$, (b) $15 \%$, and (c) $25 \%$ creep strain.

Figure 22. TEM micrographs representative of the microstructure in the gage section of a sample crept at $1000^{\circ} \mathrm{C}, 19.5 \mathrm{MPa}$ to a strain of $\sim 10 \%$. 30

Figure 23. J-R Curve for Alloy 617, as received, $700^{\circ} \mathrm{C}$. 30

Figure 24. (a) Values of $\mathrm{J}_{0}$ and (b) tearing modulus for Alloy 617, as received (temperature in Kelvin). 31

Figure 25. Room-temperature CVN energy of Alloy 617 after thermal exposure. ....................................31

Figure 26. CVN energy of aged Alloy 617 measured at room temperature and aging temperature............32

Figure 27. Load vs. crack-mouth opening displacement record and a plot of J versus $\Delta \mathrm{a}$ (crack extension) for a $0.5 \mathrm{~T}$ compact fracture toughness test performed at room temperature.

Figure 28. Charpy impact energies for solution annealed and aged Alloy 617 tested at temperatures from ambient to $900^{\circ} \mathrm{C}$.

Figure 29. Highest observed CVN impact energies of solution annealed and aged Alloy 617.

Figure 30. Low magnification of an etched cross-section through the weldment in Alloy 617 plate showing build-up of the weld metal through approximately 20 total welding passes.

Figure 31. Micrograph showing the weld metal and heat affected zone microstructure in a gas metal arc welded Alloy 617 plate welded with Alloy 617 weld wire.

Figure 32. Microhardness profile across the Alloy 617 weldment (dashed lines indicate the approximate positions of the HAZ regions).

Figure 33. Micrographs of heat 37458 of Alloy $800 \mathrm{H}$ for (a) longitudinal and (b) transverse sections.

Figure 34. Tensile stress-strain curves for Alloy $800 \mathrm{H}$.

Figure 35. (a) Yield strength and (b) ultimate tensile strength values for a large number of heats of Alloy $800 \mathrm{H}$ (red symbols) and approximate values from the current tests (black symbols)...... 


\begin{tabular}{|c|lll|}
\hline $\begin{array}{c}\text { NEXT GENERATION NUCLEAR PLANT STEAM } \\
\text { GENERATOR AND INTERMEDIATE HEAT }\end{array}$ & Identifier: & PLN-2804 & \\
EXCHANGER MATERIALS RESEARCH & Revision: & 1 & \\
AND DEVELOPMENT PLAN & Effective Date: & $09 / 23 / 10$ & Page: x of xiv \\
\hline
\end{tabular}

Figure 36. Cross-sections through GMA weld in Alloy $800 \mathrm{H}$ plate using (a) Alloy 82 filler metal

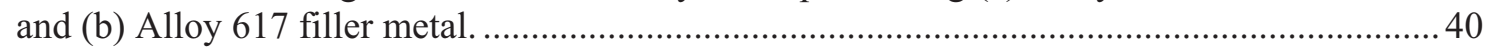

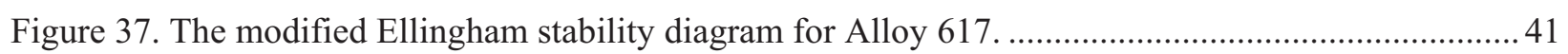

Figure 38. Schematic of the current configuration of the INL controlled chemistry high temperature testing loop.

Figure 39. Optical micrographs of cross-sections through Alloy 617 for the $1000^{\circ} \mathrm{C}$ experiment under (a) oxidizing and (b) carburizing conditions.

Figure 40. Microstructure of Alloy 617 at two different magnifications after exposure in the controlled chemistry loop for $527 \mathrm{~h}$ at $950^{\circ} \mathrm{C}$, illustrating corrosion features quantified in Figure 42.

Figure 41. Microstructure of (a)Alloy $800 \mathrm{H}$ and (b) Alloy X after exposure for $527 \mathrm{~h}$ at $950^{\circ} \mathrm{C}$ in

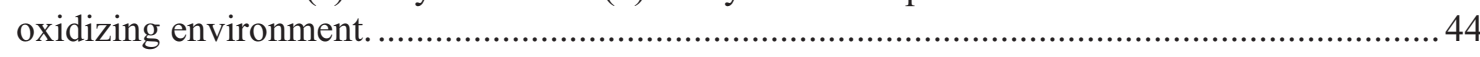

Figure 42. Quantitative measurements of corrosion features of corroded coupons exposed for 527

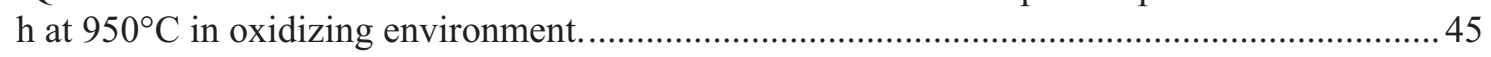

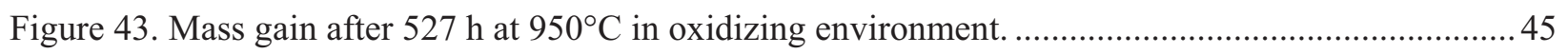

Figure 44. Mass change as a function of time in $\mathrm{H}_{2} 5.5 \% \mathrm{CH}_{4}-4.5 \% \mathrm{CO}_{2}$ carburizing environment

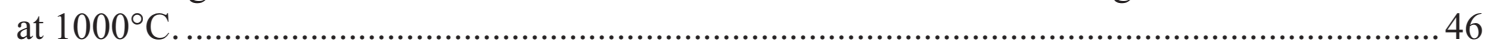

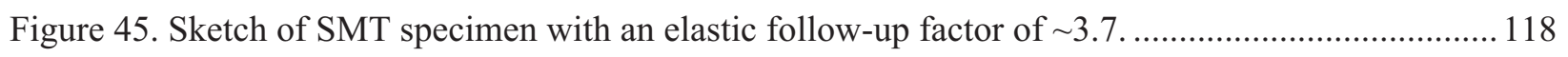

Figure 46. Thermal aging effect on room temperature yield strength. ............................................... 123

Figure 47. Thermal aging effect on room temperature tensile strength.............................................. 124

Figure 48. Effect of aging at $871^{\circ} \mathrm{C}$ on strengths and elongation of Alloy 617................................... 124

Figure 49. Comparison of German and INL creep-fatigue data for Alloy 617 at $950^{\circ} \mathrm{C}$ for $0.6 \%$ strain.

Figure 50. Creep curves as a function of cross-section thickness for (a) HR-120, and (b) Alloy 230.

Figure 51. Strengths comparison of service-exposed (73,500 h) and laboratory-exposed $(18,600$ h) Alloy $800 \mathrm{H}$.

Figure 52. Schedule for NGNP SG and IHX materials R\&D high level activities.

\section{TABLES}

Table 1. Key operating parameters for the NGNP designs and the Fort St. Vrain HTGR. 4

Table 2. Material selections for elevated temperature components in the PBMR demonstration project plant. 10

Table 3. Summary of testing done on Alloy 617 to support previous reactor programs. ..........................20

Table 4. Chemical composition (wt. \%) of Alloy 617 ............................................................................. 21

Table 5. Strain rate sensitivity, $\mathrm{m}$, values at temperatures between $750^{\circ} \mathrm{C}$ and $1000^{\circ} \mathrm{C} \ldots \ldots \ldots \ldots \ldots \ldots \ldots . . . . . . . . . .24$

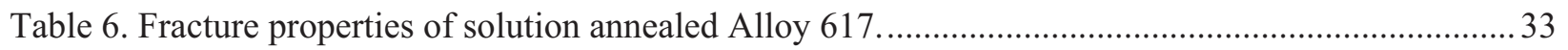

Table 7. Room-temperature tensile properties of joints in as-welded condition. ...................................... 35 


\begin{tabular}{|c|lll|}
\hline NEXT GENERATION NUCLEAR PLANT STEAM & Identifier: & PLN-2804 \\
GENERATOR AND INTERMEDIATE HEAT & Revision: & 1 & \\
EXCHANGER MATERIALS RESEARCH & Effective Date: & $09 / 23 / 10$ & Page: xi of xiv \\
AND DEVELOPMENT PLAN &
\end{tabular}

Table 8. Chemical composition (wt \%) of Alloy $800 \mathrm{H}$.

Table 9. Corrosion features of corroded coupons exposed for approximately $500 \mathrm{hrs}$ at different

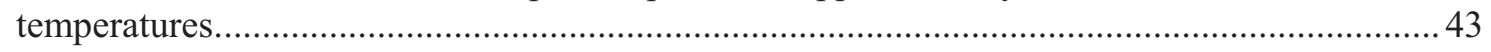

Table 10. Definition of B\&PV Codes for subsections in Section III Division 1.................................... 47

Table 11. Section III, Division 1 ASME Code cases developed for elevated temperature service. ............48

Table 12. Materials specified in NH for elevated temperature service in nuclear applications..................50

Table 13. The temperature and time limits for NH Code materials for bolting........................................51

Table 14. Summary of licensing concerns based on elevated temperature structural integrity

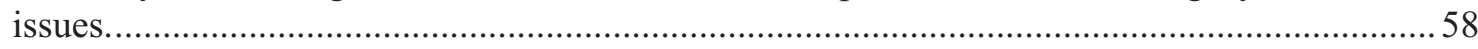

Table 15. Task 6 recommended ASME Code actions for Alloy $800 \mathrm{H}$ and 316 stainless steel. ................65

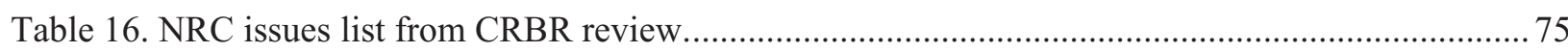

Table 17. Issues originally identified for the Draft Alloy 617 Code Case............................................... 84

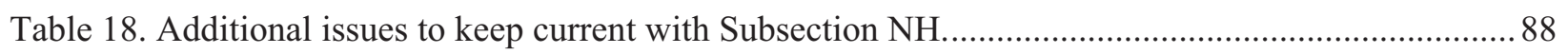

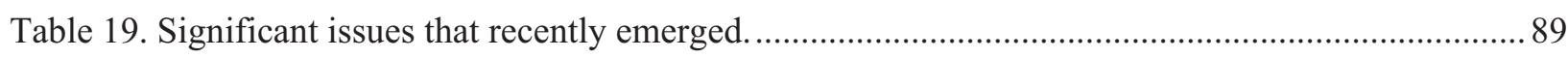

Table 20. Required ASME Code actions for Alloy 800H. .................................................................... 91

Table 21. Summary of testing required to address code and licensing issues. ....................................... 103

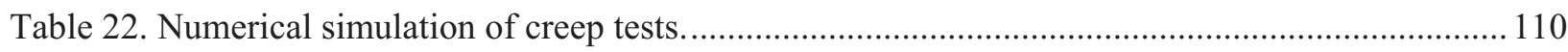

Table 23. Deformation/microstructural behaviors to be modeled by unified constitutive equations. ...... 111

Table 24. Huntington Alloys creep-rupture data for Alloy 617 in air................................................... 119

Table 25. General Electric creep-rupture data for Alloy 617 in air. .................................................... 120

Table 26. ORNL creep-rupture data for Alloy 617 in air. ................................................................ 120

Table 27. European Creep Collaborative Committee creep-rupture data for Alloy 617 in air................ 121

Table 28. Petten creep-rupture data for Alloy 617 in air. .................................................................... 121

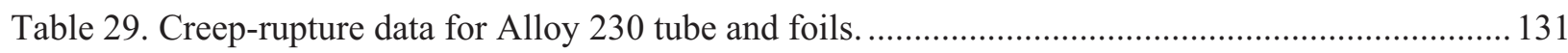

Table 30. Cost breakdown of mechanical property testing.................................................................. 139

Table 31. Cost breakdown for high temperature materials R\&D plan.................................................. 140

Table B-1. Properties of heat exchangers as presented by Velocys....................................................... 248

Table C-1. Estimated operating conditions for NGNP control rods for outlet gas of $950^{\circ} \mathrm{C} \ldots \ldots \ldots \ldots \ldots \ldots . . . . .249$ 


\begin{tabular}{|c|lll|}
\hline NEXT GENERATION NUCLEAR PLANT STEAM & Identifier: & PLN-2804 & \\
GENERATOR AND INTERMEDIATE HEAT & Revision: & 1 & \\
EXCHANGER MATERIALS RESEARCH & Effective Date: & $09 / 23 / 10$ & Page: xii of xiv \\
AND DEVELOPMENT PLAN &
\end{tabular}

\section{ACRONYMS}

\begin{tabular}{|c|c|}
\hline ACRS & Advisory Committee on Reactor Safety \\
\hline AGR & Advanced Gas Reactor \\
\hline $\mathrm{AOO}$ & anticipated operational occurrence \\
\hline ASME & American Society of Mechanical Engineers \\
\hline ASTM & American Society for Testing and Materials \\
\hline AVR & Albeitsgemeinschaft Versuchsreaktor \\
\hline $\mathrm{B} \& \mathrm{PV}$ & Boiler and Pressure Vessel \\
\hline $\mathrm{BDBE}$ & beyond design basis event \\
\hline BWXT & BWX Technologies, Inc. \\
\hline CANDU & Canada Deuterium Uranium reactors \\
\hline $\mathrm{C}_{\mathrm{f}} / \mathrm{C}$ & carbon/carbon fiber composite \\
\hline CMS & controlled material specification \\
\hline CRBR & Clinch River Breeder Reactor \\
\hline $\mathrm{CT}$ & X-ray tomography \\
\hline CTE & coefficient of thermal expansion \\
\hline $\mathrm{CVN}$ & Charpy V-notch \\
\hline DBE & design basis event \\
\hline $\mathrm{DCC}$ & depressurized conduction cool-down \\
\hline DMW & dissimilar metal weld \\
\hline DOE & Department of Energy \\
\hline DSA & dynamic strain aging \\
\hline EBSD & electron back scattered diffraction \\
\hline ECCC & European Creep Collaborative Committee \\
\hline EPACT & Energy Policy Act of 2005 \\
\hline ETD & elevated temperature design \\
\hline FBR & fast breeder reactor \\
\hline FEA & finite element analysis \\
\hline FN & ferrite number \\
\hline FY & fiscal year \\
\hline GA & General Atomics \\
\hline GIF & Generation IV International Forum \\
\hline GTA & gas tungsten arc \\
\hline
\end{tabular}




\begin{tabular}{|c|lll|}
\hline NEXT GENERATION NUCLEAR PLANT STEAM & Identifier: & PLN-2804 \\
GENERATOR AND INTERMEDIATE HEAT & Revision: & 1 & \\
EXCHANGER MATERIALS RESEARCH & Effective Date: & $09 / 23 / 10$ & Page: xiii of xiv \\
AND DEVELOPMENT PLAN &
\end{tabular}

GT-MHR Gas Turbine-Modular Helium Reactor

HAZ heat affected zone

HFIR High-Flux Isotope Reactor

HPCC high pressure conduction cooldown

HTGR high-temperature gas-cooled reactor

HTR High-Temperature Reactor

HTTR High-Temperature Engineering Test Reactor

IHX intermediate heat exchanger

INERI International Nuclear Energy Research Initiative

INL Idaho National Laboratory (formerly the Idaho National Engineering and Environmental Laboratory)

JAEA Japan Atomic Energy Agency

JRC Joint Research Center

KTA Kerntechnischer Ausschuss (German Nuclear Safety Standard Commission)

LBE licensing basis event

LCF low cycle fatigue

LMFBR Liquid Metal Fast Breeder Reactor

LMR liquid metal reactor

LPCC low pressure conduction cooldown

LWR light water reactor

MHTGR modular high-temperature gas-cooled reactor

MLE maximum likelihood event

NDE non-destructive evaluation

NDMAS NGNP Data Management and Analysis System

NERI Nuclear Energy Research Initiative

NEUP Nuclear Energy University Programs

NGNP Next Generation Nuclear Plant

NRC Nuclear Regulatory Commission

OIM orientation imaging microscopy

ORNL Oak Ridge National Laboratory

PBMR Pebble Bed Modular Helium Reactor

PBR pebble bed reactor

PCHE printed circuit heat exchangers

PCS power conversion system

PCU power conversion unit

PFHE plate fin heat exchanger

PHTS primary heat transport system 


\begin{tabular}{|c|lll|}
\hline $\begin{array}{c}\text { NEXT GENERATION NUCLEAR PLANT STEAM } \\
\text { GENERATOR AND INTERMEDIATE HEAT }\end{array}$ & Identifier: & PLN-2804 & \\
EXCHANGER MATERIALS RESEARCH & Revision: & 1 & \\
AND DEVELOPMENT PLAN & Effective Date: & $09 / 23 / 10$ & Page: xiv of xiv \\
\hline
\end{tabular}

PHX

process heat exchanger

PMR

prismatic modular reactor

PRISM Power Reactor Innovative Small Module Liquid-Metal Reactor

PWR pressurized water reactor

QA quality assurance

R\&D research and development

RCC-MR French nuclear code

RCS reactor control system

RPV reactor pressure vessel

SCC stress corrosion cracking

SEM scanning electron microscopy

SG steam generator

SG-ETD Subgroup on Elevated Temperature Design

SHTS secondary heat transport system

$\mathrm{SiC}_{\mathrm{f}} / \mathrm{SiC} \quad$ Silicon-Carbide Fiber/Silicon-Carbide Composite

SI sulfur-iodine

SMT simplified model test

SS stainless steel

SSC safety significant components

TC thermal conductivity

TD thermal diffusivity

TDP technology development plan

TEM transmission electron microscopy

THTR Thorium Hochtemperatur Reaktor

TRISO tri-isotopic (fuel)

U.K. United Kingdom

UT ultrasonic testing

VHTR very high-temperature reactor

WSRF weld strength reduction factor

YT-SRF yield tensile strength reduction factor 


\begin{tabular}{|c|lll|}
\hline NEXT GENERATION NUCLEAR PLANT STEAM & Identifier: & PLN-2804 & \\
GENERATOR AND INTERMEDIATE HEAT & Revision: & 1 & \\
EXCHANGER MATERIALS RESEARCH & Effective Date: & $09 / 23 / 10$ & Page: 1 of 252 \\
AND DEVELOPMENT PLAN &
\end{tabular}

\section{INTRODUCTION AND PURPOSE}

The U.S. Department of Energy (DOE) has selected the high temperature gas-cooled reactor (HTGR) design for the Next Generation Nuclear Plant (NGNP) project. The NGNP will demonstrate the use of nuclear power for electricity, process heat and hydrogen production. Reactor design is not yet finalized but will be a graphite-moderated, helium-cooled, prismatic or pebble-bed, thermal neutron spectrum reactor. The NGNP will use very high burn-up, low-enriched uranium, tri-isotopic (TRISO)-coated fuel, and have a projected plant design service life of 60 years. The HTGR concept is considered to be the nearest-term reactor design that has the capability to efficiently produce process heat or hydrogen. The plant size, reactor thermal power, and core configuration will ensure passive decay heat removal without fuel damage or radioactive material releases during accidents.

The basic technology for the NGNP was established in former HTGRs such as DRAGON, Peach Bottom, Albeitsgemeinschaft Versuchsreaktor (AVR), Thorium Hochtemperatur Reaktor (THTR), and Fort St. Vrain. These reactor designs represent two design categories: the Pebble Bed Reactor (PBR) and the Prismatic Modular Reactor (PMR). Commercial examples of potential NGNP candidates are the Gas Turbine-Modular Helium Reactor (GT-MHR) from General Atomics (GA), the high temperature reactor concept (ANTARES) from AREVA, and the Pebble Bed Modular Reactor (PBMR) from the PBMR consortium. The Japanese High Temperature Engineering Test Reactor (HTTR) and Chinese High Temperature Reactor (HTR-10) are currently in operation demonstrating the feasibility of the reactor components and materials needed for NGNP. Therefore, NGNP is focused on building a first-of-its-kind demonstration plant, rather than simply confirming the basic feasibility of the concept.

The operating conditions for the NGNP represent a major departure from existing water-cooled reactor technologies. Although a significant number of materials and alloys for high temperature applications are in use in the petrochemical, metals processing, and aerospace industries, a very limited number of these materials have been tested or qualified for use in nuclear systems. Several alloys have been approved in American Society of Mechanical Engineers (ASME) Codes for high temperature reactor applications. Alloy $800 \mathrm{H}$ is the only candidate material that can sustain reasonable stresses for a SG application and it is restricted to use up to $760^{\circ} \mathrm{C}$ and $300,000 \mathrm{~h}$, about half the desirable design life of the NGNP. Some primary system components for the NGNP or a higher temperature follow-on HTGR will require use of materials at higher temperatures. Code qualification of materials for successful and long-life application at the high temperature conditions planned for the NGNP is a large portion of the effort in the NGNP Materials Research and Development (R\&D) Program.

The NGNP challenge is to achieve a significant advancement in nuclear technology while setting the stage for an economically viable deployment of the new technology in the commercial sector soon after 2020. This document discusses the technical issues that must be resolved for successful design and licensing of the SG and intermediate heat exchanger (IHX) for the NGNP and presents a detailed R\&D plan, with associated cost and schedule, to resolve these issues. Materials issues associated with other high temperature components in the reactor are noted; however, they are not treated in as much detail.

\subsection{Mission Statement}

The objective of the NGNP Materials R\&D Program is to provide the essential materials R\&D needed to support the design and licensing of the reactor. The balance of plant applications of process heat, such as the hydrogen plant, is currently beyond the scope of the R\&D program. Materials R\&D was initiated prior to finalizing the design effort to ensure that activities are initiated early enough to support the design process. The thermal, environmental, and service life conditions of the NGNP will make selection and qualification of the high temperature materials a significant challenge; thus, different materials and new design approaches may be required. The mission of the NGNP Materials Program must 


\begin{tabular}{|c|lll|}
\hline $\begin{array}{c}\text { NEXT GENERATION NUCLEAR PLANT STEAM } \\
\text { GENERATOR AND INTERMEDIATE HEAT }\end{array}$ & Identifier: & PLN-2804 & \\
EXCHANGER MATERIALS RESEARCH & Revision: & 1 & \\
AND DEVELOPMENT PLAN & Effective Date: & $09 / 23 / 10$ & Page: 2 of 252 \\
\hline
\end{tabular}

support the objectives associated with the NGNP in the Energy Policy Act of 2005 (EPACT) and provide any materials-related support required during the development of the NGNP Program.

A number of NGNP materials R\&D objectives are specifically related to materials for high temperature applications such as the SG and IHX, the core barrel and core internals such as the control rod sleeves. Research is needed to develop improved high temperature design methodologies for high temperature metallic alloys. Currently, the data and models are inadequate for many of the high temperature alloys required and the codes and standards need to be amended and expanded. An improved understanding and models may be needed for the environmental effects and thermal aging of the high temperature alloys. In addition, welding and joining procedures must be developed, evaluated and certified for the various materials and components, including very thick plate and thin sheets. Inspection needs and the procedures for those inspections must be defined and developed. The R\&D Plan also includes support of selected university materials-related R\&D activities and international materials-related collaboration activities that would be of direct benefit to the NGNP Project.

\subsection{Assumptions}

The following assumptions have been incorporated into the mission statements and are fundamental to estimating the scope, cost and schedule for completing the materials R\&D processes:

- NGNP will be a full-sized reactor plant capable of producing process heat for various applications.

- The reactor design will be helium-cooled, graphite-moderated core design fueled with TRISO-design fuel particles in carbon-based compacts or pebbles.

- The design, materials, and construction will need to meet appropriate Quality Assurance (QA) methods and criteria and other nationally recognized codes and standards. NGNP must demonstrate the capability to obtain a Nuclear Regulatory Commission (NRC) operating license.

- The demonstration plant will be designed to operate for a nominal 60 years.

- The NGNP Program, including the materials program, will continue to be directed by Idaho National Laboratory (INL) based on the guidelines given in the EPACT of 2005. The scope of work will be adjusted to reflect the level of congressional appropriations.

- Application for an NRC operating license and fabrication of the NGNP will occur with direct interaction and involvement of one or more commercial organizations.

\subsection{Approach}

Beyond the general assumptions listed above, this TDP will address a baseline design case for the first NGNP and follow-on designs that may have higher outlet temperatures, incorporating the most likely design features and conditions:

- An outlet gas temperature of $750^{\circ} \mathrm{C}$

- A SG

- Possibly a heat exchanger with $\mathrm{He}$ as both the primary and secondary coolant at a temperature up to $950^{\circ} \mathrm{C}$

- A low pressure differential between the primary and secondary loops

- Consideration of section sizes typical of conventional IHX and SG technology and thin sections that might be associated with compact designs. 


\begin{tabular}{|c|lll|}
\hline $\begin{array}{c}\text { NEXT GENERATION NUCLEAR PLANT STEAM } \\
\text { GENERATOR AND INTERMEDIATE HEAT }\end{array}$ & Identifier: & PLN-2804 & \\
EXCHANGER MATERIALS RESEARCH & Revision: & 1 & \\
AND DEVELOPMENT PLAN & Effective Date: & $09 / 23 / 10$ & Page: 3 of $\mathbf{2 5 2}$ \\
\hline
\end{tabular}

\section{BACKGROUND}

\subsection{Previous and Current Research Plans}

\subsubsection{IHX Acquisition Plan}

An acquisition plan has been developed for the IHX. ${ }^{1}$ It considers in some detail issues that have bearing on IHX development and planning. The general conclusion of this study was that there is sufficient availability of the quantities and product forms of high temperature alloys necessary for the NGNP, so there will be no significant impact on the design or schedule.

\subsubsection{FY-08 Research and Technology Plan}

The Fiscal Year (FY)-08 "Next Generation Nuclear Plant Intermediate Heat Exchanger Materials Research and Development Plan," PLN-2804 Rev 0, ${ }^{2}$ is the basis for this document. The reactor gas outlet temperature for the NGNP was $900-950^{\circ} \mathrm{C}$ at the time that document was prepared and PLN-2804 was written under that assumption. Use of a SG was not considered in the previous version of the R\&D plan. In addition, technology readiness levels have been assessed and technology development roadmaps have been devised since the original version of PLN-2804. ${ }^{3,4}$ Uncertainties in material performance are a primary consideration in assigning low technology readiness levels to the IHX and SG.

\subsection{Reactor Preconceptual HTGR Designs}

The viability of a graphite core planned for the NGNP has previously been demonstrated in HTGR plants (e.g., DRAGON, Peach Bottom, AVR, THTR, and FSV). Furthermore, the Japanese High Temperature Engineering Test Reactor (HTTR) and Chinese High Temperature Reactor (HTR-10) are demonstrating the feasibility of the reactor components and materials needed for NGNP (HTTR reached a maximum coolant outlet temperature of $950^{\circ} \mathrm{C}$ in April 2004). These reactor designs represent two categories: the Pebble Bed Reactor (PBR) and the Prismatic Modular Reactor (PMR).

Preconceptual design work was initiated in FY-07 by the NGNP Project. ${ }^{5}$ This work was completed by three contractor teams with extensive experience in HTGR technology, nuclear power applications, and hydrogen production $^{6-8}$ and later updated to reflect lower core gas outlet temperature. ${ }^{9-11}$ Each contractor developed a recommended design for NGNP and a commercial version of the HTGR. Data needs and future research and development required to achieve operation of the NGNP were identified as part of the work. A number of special studies were also requested. ${ }^{12-15}$ Three designs were developed:

- The GT-MHR concept; team led by GA teamed with: Washington Group International; Rolls-Royce (United Kingdom); Toshiba Corporation and Fuji Electric Systems (Japan); Korean Atomic Energy Research Institute and DOOSAN Heavy Industries and Construction (Korea); and OKB Mechanical Design (Russia).

- The ANTARES concept; team led by AREVA NP, Inc. teamed with: Burns \& Roe; Washington Group International, BWX Technologies, Inc. (BWXT), Dominion Engineering, Air Products, Hamilton-Sundstrand-Rocketdyne, Mitsubishi Heavy Industries, Nova Tech, and Energy.

- The PBMR concept; team led by Westinghouse Electric Company, LLC teamed with: Pebble Bed Modular Reactor (Pty) Ltd. and M-Tech Industrial (Pty) Ltd. (South Africa); The Shaw Group; Technology Insights; Air Products and Chemicals, Inc.; Nuclear Fuel Services; and Kadak Associates.

All three designs use TRISO fuel, graphite moderation and high temperature helium coolant in the primary system in the $750^{\circ} \mathrm{C}$ temperature range. All of the concepts have various passive neutronic design features that result in a core with relatively low power density and a negative temperature coefficient of 


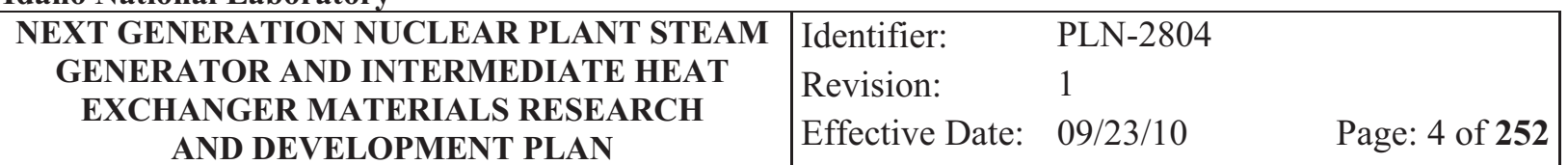

neutron reactivity. The shut-down cooling system, the secondary reactivity shut-down system, and the control rod design are similar in all three designs. All of the reactor concepts could be used as a basis for the NGNP. Although the designs will not be presented in detail here, the features that relate to material selection and challenges will be discussed. The key operating parameters and design features for all three designs are listed in Table 1 along with information for the FSV high-temperature gas reactor, the largest and most recent gas-cooled reactor to operate in the U.S., for comparison.

Table 1. Key operating parameters for the NGNP designs and the Fort St. Vrain HTGR.

\begin{tabular}{|c|c|c|c|c|}
\hline Condition or Feature & $\begin{array}{c}\text { Fort St. Vrain } \\
\text { HTGR }\end{array}$ & $\begin{array}{c}\text { General Atomics } \\
\text { GT-MHR }\end{array}$ & $\begin{array}{c}\text { AREVA } \\
\text { ANTERES }\end{array}$ & $\begin{array}{l}\text { Westinghouse } \\
\text { PBMR PHP }\end{array}$ \\
\hline Power Output (MWt) & 842 & $550-600$ & 565 & 500 \\
\hline Average power density $\left(\mathrm{w} / \mathrm{cm}^{3}\right)$ & 6.3 & 6.5 & & 4.8 \\
\hline Moderator & Graphite & Graphite & Graphite & Graphite \\
\hline Core Geometry & Cylindrical & Annular & Annular & Annular \\
\hline Reactor Type & Prismatic & Prismatic & Prismatic & Pebble Bed \\
\hline Safety Design Philosophy & Active & Passive & Passive & Passive \\
\hline Plant Design Life (Years) & 30 & 60 & 60 & 60 \\
\hline $\begin{array}{l}\text { IHX Design (in some cases for } \\
\text { follow-on higher temperature } \\
\text { reactors) }\end{array}$ & NA & $\begin{array}{l}\text { Printed Circuit } \\
\text { Heat exchanger } \\
\text { (PCHE) }\end{array}$ & $\begin{array}{l}\text { Shell \& Tube } \\
\text { PCHE or } \\
\text { Fin-Plate }\end{array}$ & PCHE \\
\hline Core Outlet Temperature $\left({ }^{\circ} \mathrm{C}\right)$ & 785 & 750 & 750 & 750 \\
\hline Core Inlet Temperature $\left({ }^{\circ} \mathrm{C}\right)$ & 406 & 322 & 325 & 280 \\
\hline Coolant Pressure (MPa) & 4.8 & 7 & 5 & 9 \\
\hline Coolant Flow Rate $(\mathrm{kg} / \mathrm{s})$ & 428 & - & 282 & 204 \\
\hline $\begin{array}{l}\text { Secondary Outlet Temperature } \\
\left({ }^{\circ} \mathrm{C}\right)\end{array}$ & 538 & 540 & 550 & $700 / 541$ \\
\hline $\begin{array}{l}\text { Secondary Inlet Temperature } \\
\left({ }^{\circ} \mathrm{C}\right)\end{array}$ & NA & 200 & - & $267 / 217$ \\
\hline Secondary Fluid & Steam & Steam & Steam & He, Steam \\
\hline IHX Pressure Drop $(\mathrm{kPa})$ & NA & 50 & 55 & 45 \\
\hline IHX Material & NA & Alloy 617 & Alloy 617 & $\begin{array}{l}\text { Alloys } 617 \text { or } \\
800 \mathrm{H}\end{array}$ \\
\hline Core Barrel Material & Steel & Not specified & $800 \mathrm{H}$ & $316 \mathrm{H} \mathrm{SS}$ \\
\hline Control Rod Cladding & $800 \mathrm{H}$ & $\begin{array}{l}800 \mathrm{H} \text { (backup } \\
\mathrm{C}_{\mathrm{f}} / \mathrm{C} \text { composite) }\end{array}$ & $\begin{array}{l}\mathrm{C}_{\mathrm{f}} / \mathrm{C} \\
\text { composite }\end{array}$ & $800 \mathrm{H}$ \\
\hline
\end{tabular}

\subsubsection{General Atomics - GT-MHR Concept}

GA recommends a $600 \mathrm{MWt}$ prismatic reactor design that is essentially a larger version of the GT-MHR. ${ }^{8,16-18}$ The core consists of graphite blocks with an annular-fueled region of 1,020 prismatic fuel blocks arranged in three columns. GA argues that a prismatic reactor inherently allows higher reactor power density levels, resulting in better plant economics, and involves fewer uncertainties (and therefore less risk). ${ }^{5,15}$ 


\begin{tabular}{|c|lll|}
\hline NEXT GENERATION NUCLEAR PLANT STEAM & Identifier: & PLN-2804 & \\
GENERATOR AND INTERMEDIATE HEAT & Revision: & 1 & \\
EXCHANGER MATERIALS RESEARCH & Effective Date: & $09 / 23 / 10$ & Page: 5 of 252 \\
AND DEVELOPMENT PLAN &
\end{tabular}

The temperature rise of the coolant in the various flow paths through the core varies over a wide range. Good mixing of the outlet coolant is needed to avoid excessive thermal stresses in the downstream components resulting from large temperature gradients and fluctuations, and to assure that the gas entering the turbine has a uniform mixed mean temperature.

This test plan assumes a co-generation application. Steam passes from the SG to both turbine-type generators and directly to the application requiring process heat.

\subsubsection{Power Conversion}

GA recommends a $750^{\circ} \mathrm{C}$ gas outlet temperature and a system pressure of about $7 \mathrm{MPa} .{ }^{10}$ The configuration is shown in Figure $1 .{ }^{10}$ This test plan assumes a co-generation application. Steam passes from the SG to both turbine-type generators and directly to the application requiring process heat.

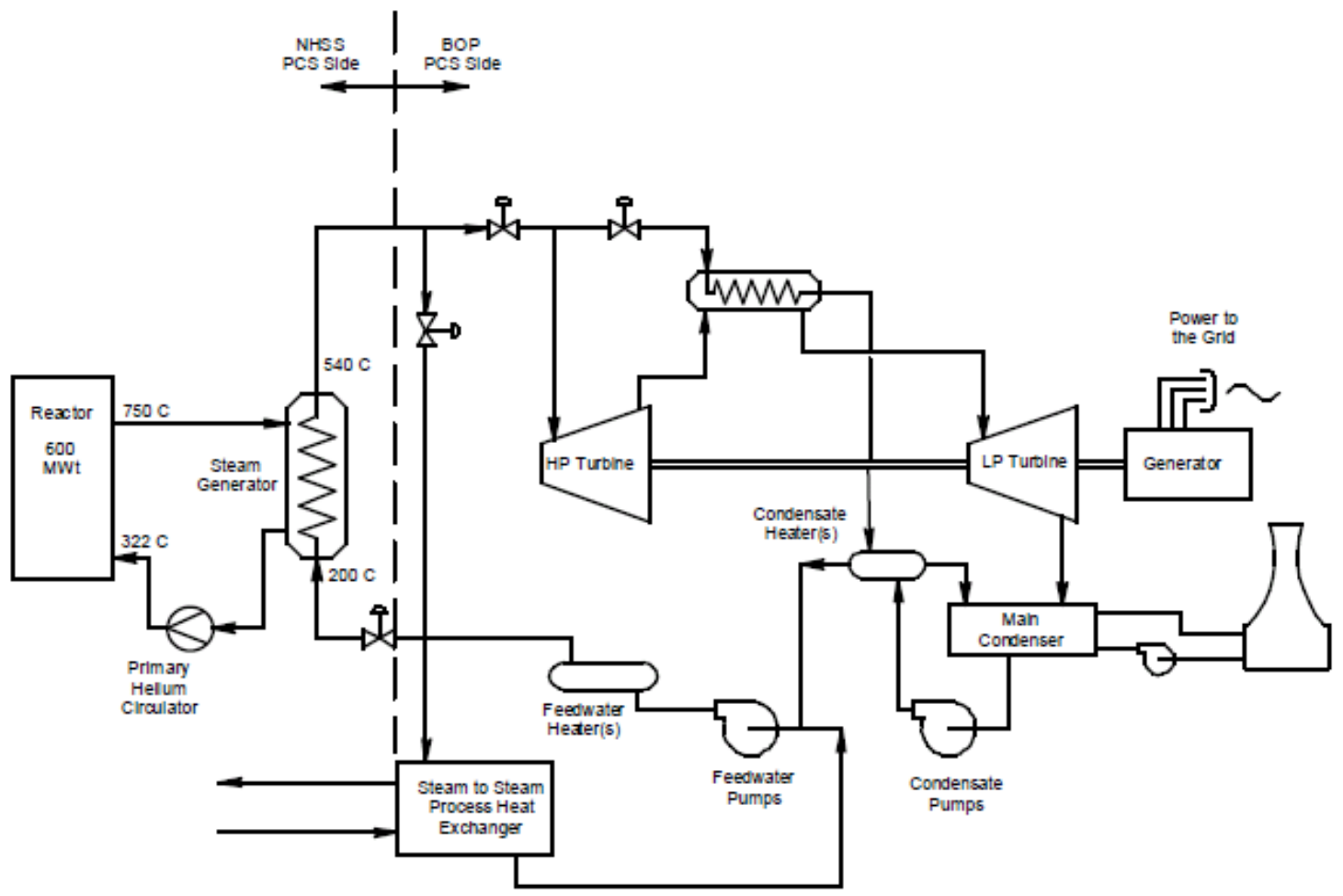

Figure 1. NGNP configuration as proposed by General Atomics.

\subsubsection{Reactivity Control Rods}

The control rods use $\mathrm{B}_{4} \mathrm{C}$ absorbers enclosed in Incoloy $800 \mathrm{H}$ canisters for structural support. Carbon/carbon composite $\left(\mathrm{C}_{\mathrm{f}} / \mathrm{C}\right)$ control rod sleeves may be used as an alternative. The control rod is lowered and raised with a flexible high nickel alloy (not specified) cable.

\subsubsection{Cross Vessel}

GA specifies that the cross vessel and SG/IHX vessel will both be made out of the same material as the reactor pressure vessel (RPV). The cross vessels connect the lower portion of the RPV to the lower portion of the power conversion system and IHX or SG vessels. The cross vessels include a concentric duct (primary hot gas duct) that separates the hot (core exit) and the cold (core inlet) gas flow streams. The hot duct material will be a high temperature alloy (such as $800 \mathrm{H}$ ). The hot gas duct is insulated with a ceramic fiber insulation such as Kaowool. A similar insulation may also be included on the inside 


\begin{tabular}{|c|lll|}
\hline NEXT GENERATION NUCLEAR PLANT STEAM & Identifier: & PLN-2804 \\
GENERATOR AND INTERMEDIATE HEAT & Revision: & 1 \\
EXCHANGER MATERIALS RESEARCH & Effective Date: & $09 / 23 / 10$ & Page: 6 of 252 \\
AND DEVELOPMENT PLAN &
\end{tabular}

diameter of the cross vessel. The insulation is intended to reduce heat losses to the core inlet cold gas stream, and the insulation assemblies are designed to be remotely removed and replaced (if needed) during the 60 -year plant life.

\subsubsection{AREVA - ANTARES Concept}

The AREVA design ${ }^{6,19,20}$ is also based in part on the GT-MHR concept, with 1020 fuel blocks arranged in three columns. AREVA recommends that the NGNP be a $565 \mathrm{MWt}$ prismatic reactor, citing advantages over a pebble-bed reactor design, in part because the concept was previously licensed for FSV. ${ }^{6,21}$ The secondary loop currently uses steam rather than the $20 \% \mathrm{He} / 80 \% \mathrm{~N}_{2}$ gas mixture originally proposed.

\subsubsection{Power Conversion System}

AREVA suggests a gas outlet temperature of $750^{\circ} \mathrm{C}$ and conventional steam cycle with two parallel primary coolant loops feeding one turbine generator. Each loop includes an SG, a main helium circulator, and a hot duct. They have also added a high-pressure reboiler and a low-pressure reboiler and may include an integral reheater in the $\mathrm{SG}^{20}$ The IHX and a number of other elements were removed from the initial design when the reactor outlet temperature was lowered from their original suggestion of $900^{\circ} \mathrm{C}$. The system pressure is about $5 \mathrm{MPa}$, somewhat less than specified by the other vendors. AREVA believes the small operational losses resulting from the lower pressure would be offset by reduced capital costs associated with using thinner vessel walls for pressure containment. ${ }^{6}$ The AREVA configuration, showing only one primary loop for simplicity, is shown in Figure $2 .{ }^{20}$

\subsubsection{Steam Reboiler System}

The steam cycle includes two reboilers that transport heat from the extraction side of the power conversion system steam turbines to a process heat transfer loop. The working fluid on the process heat side returns as liquid, contacts the heat transfer surface, and vaporizes. Most reboilers are shell and tube heat exchangers and are steam heated, although other configurations are also used. This technology is mature and will be in a less severe environment than it is in other industrial applications (for example in terms of corrosive chemicals). Therefore, it will not require technology development for implementation in the NGNP and will not be mentioned further. 


\begin{tabular}{|c|lll|}
\hline NEXT GENERATION NUCLEAR PLANT STEAM & Identifier: & PLN-2804 & \\
GENERATOR AND INTERMEDIATE HEAT & Revision: & 1 & \\
EXCHANGER MATERIALS RESEARCH & Effective Date: & $09 / 23 / 10$ & Page: 7 of 252 \\
AND DEVELOPMENT PLAN &
\end{tabular}

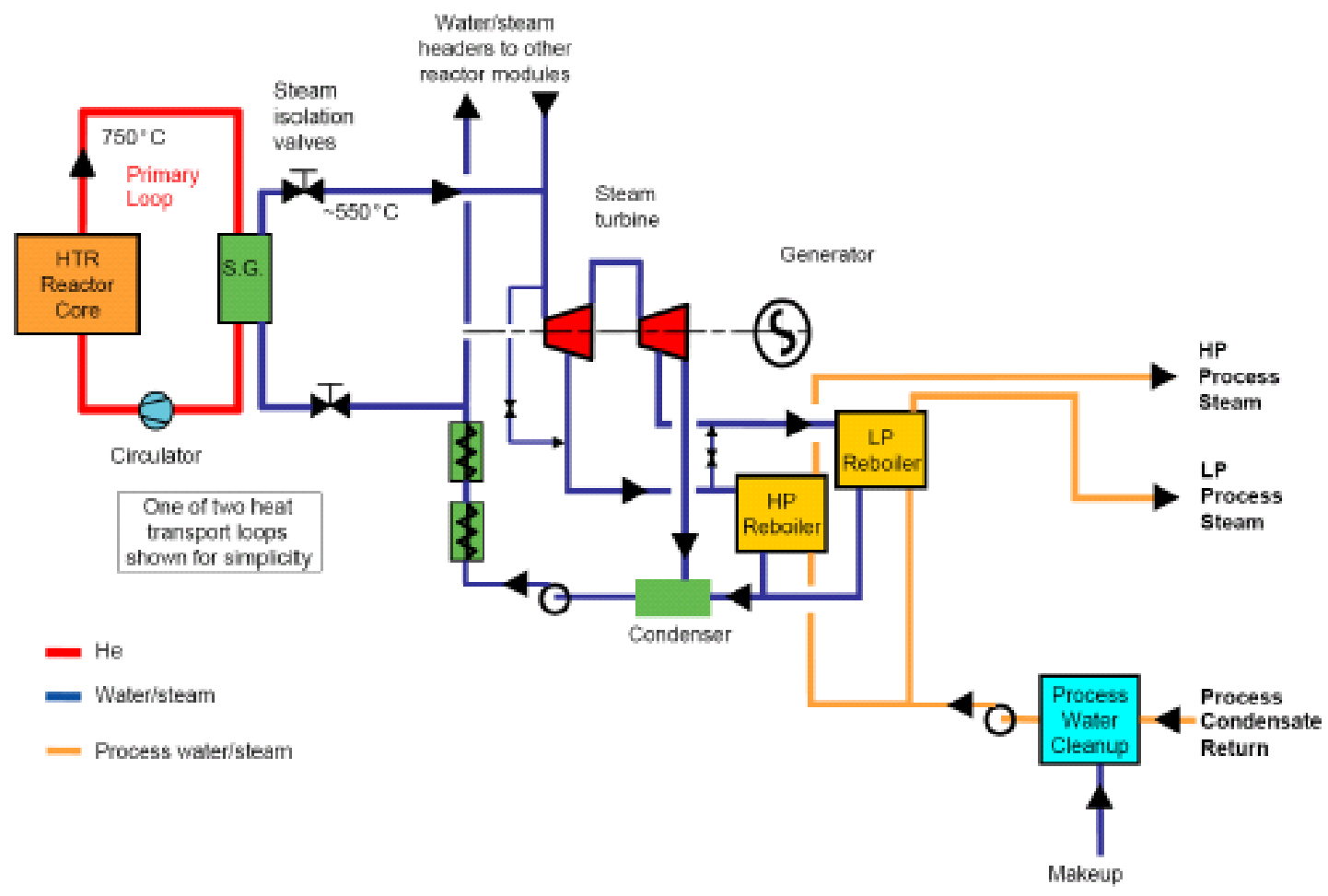

Figure 2. NGNP configuration as proposed by AREVA.

\subsubsection{Reactivity Control Rods}

The control rods in this design employ $\mathrm{B}_{4} \mathrm{C}$ and will be enclosed in $\mathrm{C}_{\mathrm{f}} / \mathrm{C}$ canisters (cladding) as shown in Figure 3.

\subsubsection{Cross Vessel}

Like GA, AREVA has defined cross vessels (rather than pipes), with a concentrically arranged primary hot gas duct that separates the hot (core exit) and the cold (core inlet) gas flow streams. The hot gas duct is insulated to reduce regenerative heat losses to the outer flow stream (core inlet cold gas).

\subsubsection{Core Barrel}

The core barrel suggested is a double-wall structure made from Alloy $800 \mathrm{H}$. 


\begin{tabular}{|c|lll|}
\hline NEXT GENERATION NUCLEAR PLANT STEAM & Identifier: & PLN-2804 & \\
GENERATOR AND INTERMEDIATE HEAT & Revision: & 1 & \\
EXCHANGER MATERIALS RESEARCH & Effective Date: & $09 / 23 / 10$ & Page: 8 of 252 \\
AND DEVELOPMENT PLAN &
\end{tabular}
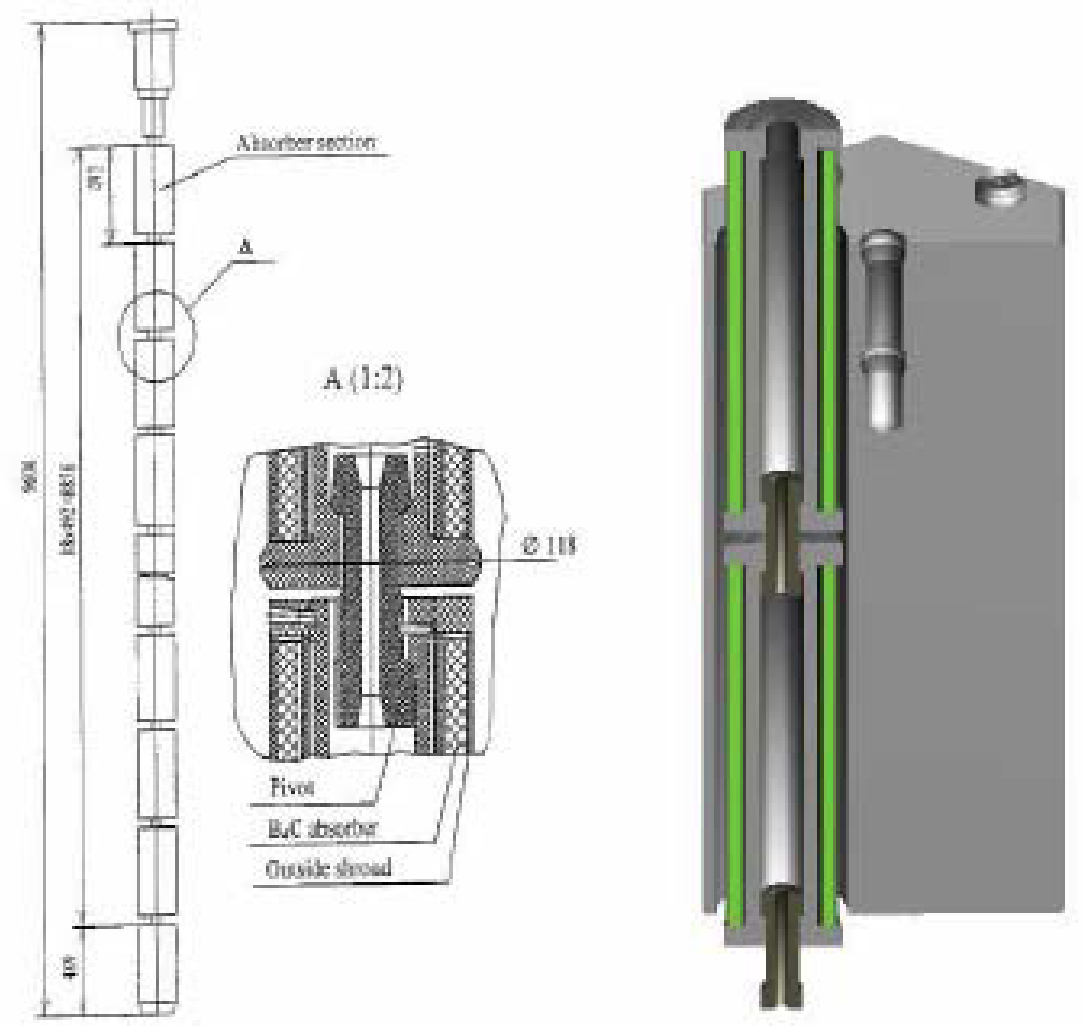

Figure 3. AREVA control rod design.

\subsubsection{Westinghouse - PBMR Concept}

Until recently, a reactor was being developed in South Africa by PBMR (Pty), Ltd., through a world-wide development effort. ${ }^{7,22-25}$ The program included testing of mechanical systems and components and a testing and verification program to support the licensing process. The PBMR design utilizes graphite-based spherical fuel elements, called pebbles, which are approximately 6 centimeters in diameter. Pebbles proceed vertically downward through the reactor vessel until they are removed at the bottom. On removal they are inspected, and if they are intact and not past the burn-up limit, they are circulated to the input queue again. Otherwise, they are replaced with fresh pebbles. This on-line refueling feature makes refueling shutdowns unnecessary and it also allows the reactor to operate with almost no excess reactivity. ${ }^{7}$

\subsubsection{Power Conversion and Intermediate Heat Exchanger}

Westinghouse recommends the use of an IHX to transfer thermal energy between the primary and secondary heat transport systems. Figure 4 illustrates the system. The IHX vessel is part of the helium pressure boundary, and considered part of the primary loop which has a pressure of $9 \mathrm{MPa}$. The IHX is expected to transfer $500 \mathrm{MWt}$ from the primary working fluid to the secondary fluid, with the two sides (primary and secondary loops) being essentially pressure balanced. An SG is incorporated in the secondary loop. 


\begin{tabular}{|c|lll|}
\hline NEXT GENERATION NUCLEAR PLANT STEAM & Identifier: & PLN-2804 & \\
GENERATOR AND INTERMEDIATE HEAT & Revision: & 1 & \\
EXCHANGER MATERIALS RESEARCH & Effective Date: & $09 / 23 / 10$ & Page: 9 of 252 \\
AND DEVELOPMENT PLAN &
\end{tabular}

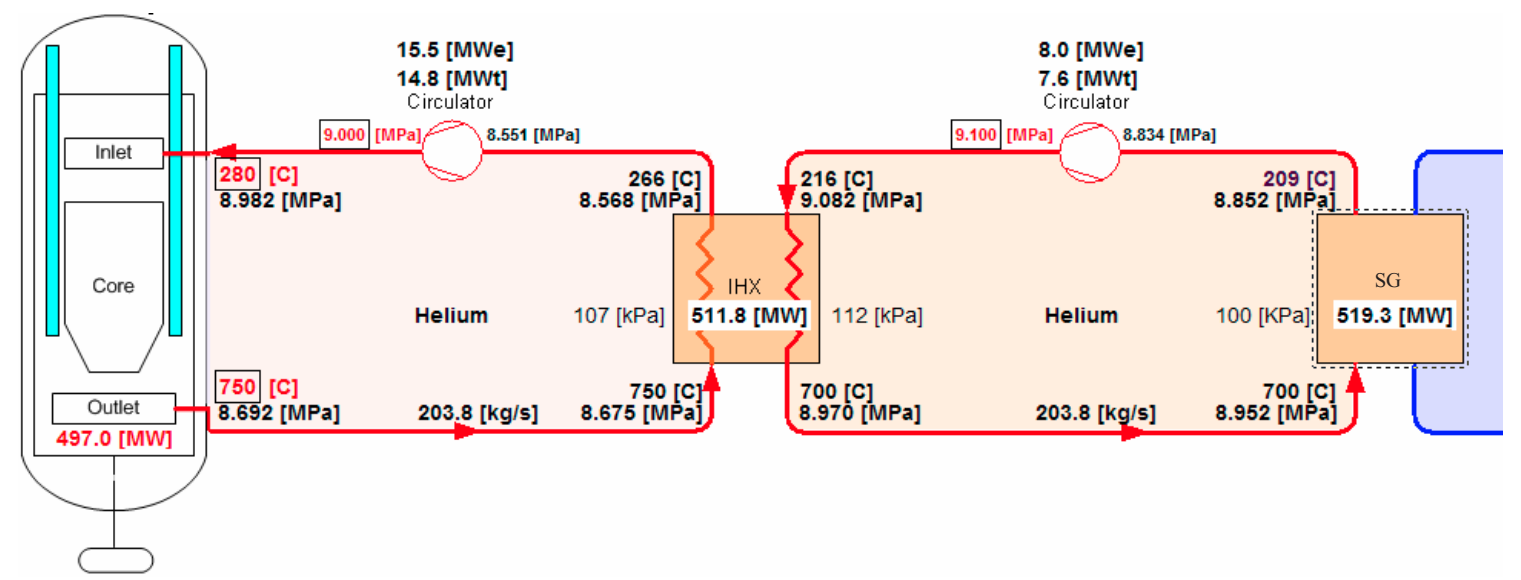

Figure 4. NGNP configuration as proposed by Westinghouse.

A two-part IHX was originally suggested with IHX-A operating at temperatures between 760 and $900^{\circ} \mathrm{C}$ and IHX-B operating at temperatures below $760^{\circ} \mathrm{C} .^{7}$ Now, a single IHX will operate in the range of 750 to $800^{\circ} \mathrm{C}$. ${ }^{9}$ For a reactor outlet temperature of $800^{\circ} \mathrm{C}$, the exit temperatures from the IHX have been calculated as 267 and $217^{\circ} \mathrm{C}$ for the primary and secondary side of the IHX, respectively.

In both the initial and latest design, compact heat exchangers are recommended as Westinghouse believes that tubular heat exchangers would be too large and costly to be economical. Westinghouse has assigned an operational life of 60 years for the IHX, which will require a very thorough examination of corrosion and erosion degradation rates, and high temperature design rules that will address creep and creep-fatigue, influences of transient behaviors, thermal and mechanical failures, and the effects of a loss of pressure on the secondary side.

The inner liner material of the core outlet pipe within the cross duct is specified as Incoloy $800 \mathrm{H}$ which has the following advantages:

- Adequate oxidation resistance to the impure helium

- Adequate high temperature strength and creep resistance

- Extensive fabrication experience in large-diameter pipe sections

- Extensively tested up to $950^{\circ} \mathrm{C}$ as liner material for qualification of the insulated "hot pipe" design in the German High Temperature Reactor (HTR) program. 


\begin{tabular}{|c|lll|}
\hline $\begin{array}{c}\text { NEXT GENERATION NUCLEAR PLANT STEAM } \\
\text { GENERATOR AND INTERMEDIATE HEAT } \\
\text { EXCHANGER MATERIALS RESEARCH }\end{array}$ & Identifier: & PLN-2804 & \\
AND DEVELOPMENT PLAN & Effective Date: & $09 / 23 / 10$ & Page: 10 of 252 \\
\hline
\end{tabular}

Table 2. Material selections for elevated temperature components in the PBMR demonstration project plant.

\begin{tabular}{lcccc}
\hline Components & $\begin{array}{c}\text { Normal Operating } \\
\text { Temperature }\left({ }^{\circ} \mathrm{C}\right)\end{array}$ & $\begin{array}{c}\text { Design Basis Event } \\
\text { Maximum } \\
\text { Temperature }\left({ }^{\circ} \mathrm{C}\right)\end{array}$ & $\begin{array}{c}\text { Maximum Fast } \\
\text { Fluence }[\mathrm{E}>1 \mathrm{MeV}] \\
(\mathrm{n} / \mathrm{cm} 2)\end{array}$ & $\begin{array}{c}\text { Candidate } \\
\text { Materials }\end{array}$ \\
\hline Core Barrel & 400 & 556 & $3 \times 10^{18}$ & $316 \mathrm{SS}$ \\
Control Rods & 700 & 850 & $5 \times 10^{21}$ & $800 \mathrm{H}$ \\
Core Outlet Pipe & 900 & - & Not significant & $800 \mathrm{H}$ \\
Liner & 900 & - & Not significant & 617 \\
IHX & & - & & \\
\hline
\end{tabular}

\subsubsection{Reactivity Control Rods}

The PBMR preconceptual design study has the most detailed discussion of the control rod design. The control rods see the harshest conditions of all of the PBMR metallic materials with respect to high temperature and neutron irradiation. The control rods are part of the Reactivity Control System (RCS). The design aims to limit the stresses in the RCS cylinders to a minimum and the RCS is designed to be replaceable. The life of the RCS is limited by the creep strength of the material and the embrittlement due to temperature and thermal neutron exposure.

There are 24 control rods which are located in the side graphite reflector blocks. Half of the rods are used for control and the other half are used for shutdown. The shutdown rods are longer, running the length of the reflector blocks, while the control rods only run in the upper half of the reflector blocks. The control rod assembly is illustrated in Figure 5. The rods consist of $\mathrm{B}_{4} \mathrm{C}$ rings between two coaxial cladding tubes. Although the clad material was not specified in the preconceptual design report, previous documents list Alloy $800 \mathrm{H}$ as the most suitable material for the control rods for the following reasons:

- Adequate high temperature strength at the normal operating temperature of $700^{\circ} \mathrm{C}$

- Creep resistance sufficiently qualified for long-term operation at $700^{\circ} \mathrm{C}$

- Limited operation at $850^{\circ} \mathrm{C}$ under abnormal events is allowed as per available data

- Irradiation response has been characterized to high levels of fast fluence

- Extensive qualification of Alloy $800 \mathrm{H}$ control rods in previous German HTR programs.

\subsubsection{Core Outlet Pipe Liner}

The arrangement of the RPV core outlet pipe liner is shown in Figure 6. The liner forms an integral part of the insulation held between the liner and the outer pressure-boundary material. The insulation in the core outlet piping is a necessary component of the insulation system required for keeping the outer pressure-boundary (ferritic steel) temperatures within operational limits. 


\begin{tabular}{|c|lll|}
\hline $\begin{array}{c}\text { NEXT GENERATION NUCLEAR PLANT STEAM } \\
\text { GENERATOR AND INTERMEDIATE HEAT }\end{array}$ & Identifier: & PLN-2804 & \\
EXCHANGER MATERIALS RESEARCH & Revision: & 1 & \\
AND DEVELOPMENT PLAN & Effective Date: & $09 / 23 / 10$ & Page: 11 of 252 \\
\hline
\end{tabular}

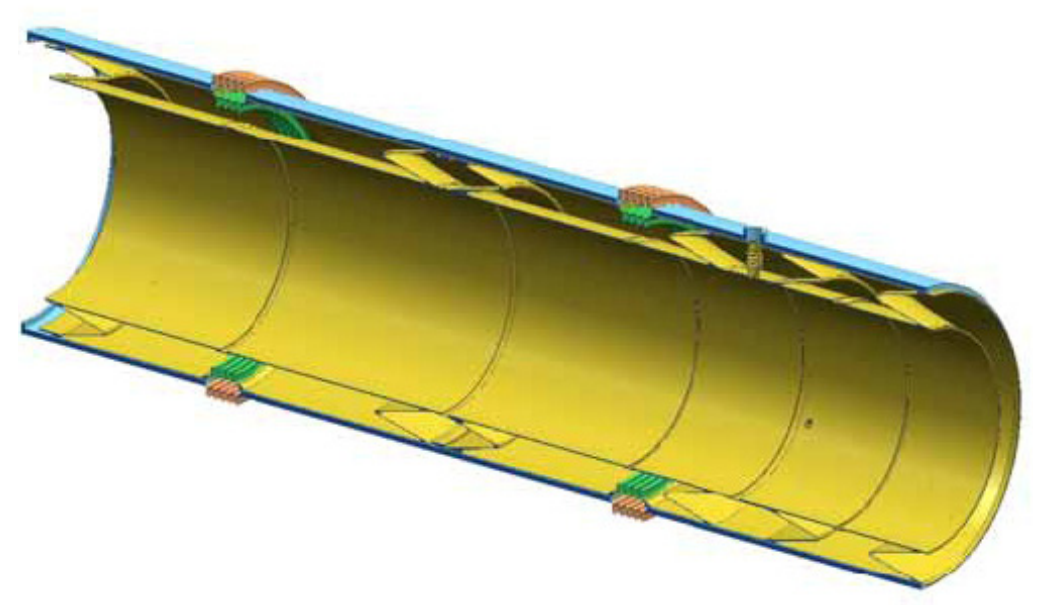

Figure 6. PBMR core outlet pipe liner.

The inner liner material of the core outlet pipe is specified as Alloy $800 \mathrm{H}$. The liner has virtually no load-bearing function and the use of Alloy $800 \mathrm{H}$ is dictated by its oxidation resistance to the impure helium, and adequate high temperature strength. As a liner material, Alloy $800 \mathrm{H}$ has the following advantages:

- Adequate high temperature strength and creep resistance

- Extensive fabrication experience in large diameter pipe sections

- Extensively tested as liner material for qualification of the insulated "hot pipe" design in the German HTR program up to $950^{\circ} \mathrm{C}$.

\subsubsection{Core Barrel}

The core barrel (Figure 7) will be made from $316 \mathrm{H}$ stainless steel, but will not require a core barrel conditioning system because of the low reactor inlet temperature.
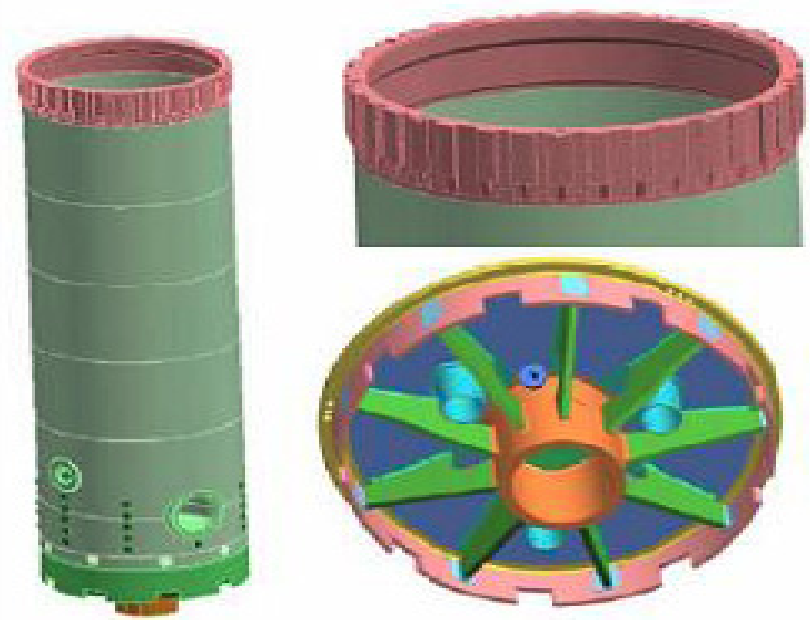

Figure 7. Westinghouse core barrel. 


\begin{tabular}{|c|lll|}
\hline NEXT GENERATION NUCLEAR PLANT STEAM & Identifier: & PLN-2804 & \\
GENERATOR AND INTERMEDIATE HEAT & Revision: & 1 & \\
EXCHANGER MATERIALS RESEARCH & Effective Date: & $09 / 23 / 10$ & Page: 12 of 252 \\
AND DEVELOPMENT PLAN &
\end{tabular}

\subsection{Complementary Programs}

\subsubsection{Generation IV International Forum}

The primary mechanism for international collaboration for materials $R \& D$ activities in support of a HTGR is through the Generation IV International Forum (GIF). The GIF is an international effort working to advance nuclear energy to meet future energy needs. It includes partners that have signed the treaty-level GIF International Framework Agreement: Canada, France, Japan, the Republic of Korea, the Republic of South Africa, Switzerland, the United Kingdom, the United States and the European Union, and China. These partners have agreed on a framework for international cooperation in research necessary to build a future generation of nuclear energy systems.

Generation I nuclear reactor systems are early prototype plants such as Magnox. Generation II plants are the current generation of electricity producing commercial nuclear plants. Generation III plants are advanced light water reactors (LWRs) including advanced boiling water reactors. Generation IV plants are envisioned as highly economical and proliferation resistant and feature enhanced safety and minimal waste; however, they have yet to be commercially operated. The objective is to have HTGR systems available for international deployment by about 2030 when many of the worlds' currently operating nuclear plants will be at or near the end of their operating lifetimes.

Gen IV collaboration is underway. The specific international vehicle that governs the exchange of GIF information on structural materials relevant to the NGNP is the Project Arrangement (PA) on Materials for the International Research and Development of the Very-High-Temperature Reactor (VHTR) Nuclear Energy System. This PA, established by the VHTR Materials Project Management Board, covers both individual and cooperative contributions by the international partners. The initial PA covers the exchange of materials information generated during 2007-2012, as well as historical information that has heretofore not been publicly available. Information is generated and exchanged on three major classes of materials: graphite for core components; metals for pressure boundaries, reactor internals, piping, heat exchangers, and balance of plant; and ceramics and ceramic composites for special needs, such as control rods, insulation, reactor internals, etc. All materials data identified within the PA that is produced by any partner shall be shared with all other partners for use in their national programs. Currently, about $\$ 120 \mathrm{M}$ in VHTR materials data has been committed as contributions by the GIF partners, including about $\$ 52 \mathrm{M}$ in generated metals data, plus significant amounts of proprietary historical data. Detailed assessments will be made of the portion of the GIF VHTR materials data that will be available to meet the data needs of the NGNP and reduce the resources required by the project.

\subsubsection{International Nuclear Energy Research Initiative Programs}

International Nuclear Energy Research Initiatives (INERIs) are designed to allow a free exchange of ideas and data between the U.S. and international researchers working in similar research areas. These international agreements encourage strong collaborations between research institutions where a benefit to both countries is anticipated. INERIs between the U.S. and Korea and between the U.S. and France have been completed.

\subsubsection{University Nuclear Engineering Research Initiative Programs}

Nuclear Engineering Research Initiative (NERI) programs facilitate technical cooperation between the NGNP Materials Program and universities. The University of Michigan has completed work to define strategies for the improvement of high temperature alloys for structural components, such as the NGNP IHX operating at $1000^{\circ} \mathrm{C}$ in helium with NERI support. They investigated the oxidation/carburization behavior and microstructure stability and how these processes affect creep in order to develop a fundamental understanding of how impurities in the He environment affect these degradation processes. 


\begin{tabular}{|c|lll|}
\hline $\begin{array}{c}\text { NEXT GENERATION NUCLEAR PLANT STEAM } \\
\text { GENERATOR AND INTERMEDIATE HEAT }\end{array}$ & Identifier: & PLN-2804 & \\
EXCHANGER MATERIALS RESEARCH & Revision: & 1 & \\
AND DEVELOPMENT PLAN & Effective Date: & $09 / 23 / 10$ & Page: 13 of 252 \\
\hline
\end{tabular}

One NERI project addressing emissivity of candidate NGNP materials will conclude soon at the University of Wisconsin-Madison. Emissivity is being determined as a function of the time and temperature of exposure to impure helium and air. These experiments address materials behavior on the interior and exterior surface of the reactor system.

\subsubsection{Nuclear Energy University Program Research and Development Awards}

Nuclear Energy University Programs (NEUP) R\&D Awards are the current mechanism for cooperative research with universities on NGNP topics. Several of these programs are related to high temperature NGNP materials research.

\subsubsection{FY-09}

- "Creep-Fatigue and Creep-Ratcheting Failures of Alloy 617: Experiments and Unified Constitutive Modeling towards Addressing the ASME Code Issues" - North Carolina State University - Tasnim Hassan

- "Mechanisms Governing the Creep Behavior of High Temperature Alloys for Generation IV Nuclear Energy Systems" - University of Cincinnati - Vijay Vasudevan

- "Understanding Fundamental Material Degradation Processes in High Temperature Aggressive Chemomechanical Environments" - University of Illinois, Urbana-Champaign - James Stubbins

- "Identifying and Understanding Environment-Induced Crack Propagation Behavior in Ni-Based Superalloy 617" - University of Nevada, Las Vegas - Longzhou Ma

- "Corrosion and Creep Candidate Alloys in High Temperature Helium and Steam Environments for the NGNP" - University of Michigan - Gary Was

- "Assessment of Embrittlement of VHTR Structural Alloys in Impure Helium Environments" University of Wisconsin, Madison - Wendy Crone.

\subsubsection{FY-10}

- "Monitoring Microstructural Evolution of Alloy 617 with Nonlinear Acoustics for Remaining Useful Life Prediction; Multiaxial Creep-fatigue and Creep-ratcheting" - Pennsylvania State University

- "Microstructure Evolution in Advanced Structural Materials Under Long-term and Elevated Temperature Irradiation: a Combined Materials Modeling and Experimental Investigation”University of California, Berkeley

- "Development of Barrier Layers for the Protection of Candidate Alloys in the VHTR" - University of California, Santa Barbara

- "Investigation of a Novel NDE Method for Monitoring Thermo-mechanical Damage and Microstructure Evolution in Ferritic-martensitic Steels for Generation IV Nuclear Energy Systems" University of Cincinnati. 


\begin{tabular}{|c|lll|}
\hline $\begin{array}{c}\text { NEXT GENERATION NUCLEAR PLANT STEAM } \\
\text { GENERATOR AND INTERMEDIATE HEAT } \\
\text { EXCHANGER MATERIALS RESEARCH } \\
\text { AND DEVELOPMENT PLAN }\end{array}$ & Revision: & 1 & \\
& Effective Date: & $09 / 23 / 10$ & Page: 14 of 252 \\
\hline
\end{tabular}

\section{OPERATIONAL REQUIREMENTS}

\subsection{Baseline Case Definition}

Definition of the materials design and performance requirements is needed for material research issues to be identified and for correct material selections. Determining the tentative operating parameters is important to aid in identifying testing needs, including design of component test facilities. Sufficient specificity of the range of potential designs is now available to determine most of the materials challenges. This R\&D plan details the materials issues that result from the base case discussed in this section which will be executed for the first-generation NGNP. Eventually the goals are to increase the outlet temperature of the reactor and incorporate a higher temperature heat exchanger. If pursued, these will apply to subsequent VHTRs.

\subsubsection{Reactor Design}

The NGNP program has not yet determined whether the reactor will be a pebble-bed or prismatic design. However, for purposes of this development plan, the base case adequately addresses either configuration.

The temperature of the SG or IHX is determined by the reactor gas outlet temperature and does not depend on the reactor design; however, there is more concern about fouling in a pebble-bed design. Modeling and analysis of the two core configurations has indicated that there are small differences in the expected operating conditions (e.g., temperature) the prismatic core design runs hotter than the pebble-bed design within the RPV. ${ }^{27}$

\subsubsection{Steam Generator}

All vendors have proposed a SG to produce superheated high-pressure steam for either process steam users or the generation of electricity. The SG designs for the NGNP are similar to that for the Modular High Temperature Gas Reactor (MHTGR). ${ }^{10}$ The SG is a vertically oriented, cross-counter flow, once-through shell-and-tube heat exchanger that utilizes helically wound tube bundles. Helium flows downward across the tube bundles, between the inner and outer shrouds. Cooled helium discharged from the SG flows upward through an annulus created by the SG outer shroud and the steam generator vessel wall and after passing through the circulator is sent back to the reactor. Feedwater is introduced at the bottom of the unit and superheated steam exits at or near the top. Double isolation valves are used in the steam and feed water lines at the radionuclide control boundary between the nuclear and non-nuclear portions of the NGNP. This configuration employs a primary coolant system prototypical of a commercial steam-electric co-generation plant, as seen in the LWR industry. The SG includes an evaporator-economizer, made from $2 \frac{1}{4} \mathrm{Cr}-1 \mathrm{Mo}$ steel, in the lower portion and a finishing superheater, made from $800 \mathrm{H}$, in the upper portion. Between these are vertically oriented steam tubes which contain a $2 \frac{1}{4} \mathrm{Cr}-1 \mathrm{Mo} / 800 \mathrm{H}$ dissimilar metal weld (DMW).

\subsubsection{Intermediate Heat Exchanger}

Although only one NGNP pre-conceptual design currently features an IHX, repeated input from potential end-users indicates that process applications, especially for future $\left(\mathrm{n}^{\text {th }}\right.$ of a kind) HTGR deployments, will require delivery of high temperature heat through heat exchangers. Presumably future HTGRs based on the NGNP design will operate at higher temperatures; temperatures as high as $1000^{\circ} \mathrm{C}$ have been targeted. The IHX is likely the component most critically impacted by increased temperatures. The outlet gas temperature does not affect material selection for the IHX in the range of $750-900^{\circ} \mathrm{C}$; however, it may affect the design allowable stresses. 


\begin{tabular}{|c|lll|}
\hline $\begin{array}{c}\text { NEXT GENERATION NUCLEAR PLANT STEAM } \\
\text { GENERATOR AND INTERMEDIATE HEAT } \\
\text { EXCHANGER MATERIALS RESEARCH }\end{array}$ & Identifier: & PLN-2804 & \\
AND DEVELOPMENT PLAN & Effective Date: & $09 / 23 / 10$ & Page: 15 of 252 \\
\hline
\end{tabular}

The IHX transfers thermal energy between the primary and secondary heat transport system (PHTS SHTS). The PHTS includes the primary circulator, primary piping, and primary helium working fluid. The SHTS has secondary piping and a secondary working fluid (such as $\mathrm{He}$ or a $\mathrm{He}-\mathrm{N}_{2}$ mixture) that will transport heat to downstream applications such as $\mathrm{H}_{2}$ production, process heat, and power production (i.e., steam production). The IHX also separates the primary and secondary power generation circuits and will separate the hydrogen generation plant from the major reactor systems. This will minimize the potential for tritium migration, and ensure accident or upset conditions in the hydrogen production facility do not impact the operation of the reactor. Components of the IHX are the heat exchanger cores and/or modules containing the heat transfer surfaces, the IHX vessel, and the headers and/or piping. There are also internal support structures, thermal baffles, and insulation.

\subsubsection{IHX Design}

The IHX reference design has not been selected, but many heat exchanger design options are under consideration:

Standard Designs

- Shell and tube

- Helical tube
Compact Designs

- Involute

- Capillary tube

- Stamped plate

- Machined plate

- Plate fin heat exchangers (PFHE)

- Printed circuit heat exchangers (PCHE).

More detailed information on heat exchanger designs is contained in Appendix B. Trade studies ${ }^{28}$ determined that the PCHE and the PFHE are the most favorable candidates for the IHX reference design if an IHX is included as part of the NGNP.

\subsubsection{IHX Materials}

Material considerations for the different heat exchanger designs are essentially similar, with the exception of some fabrication issues. The high strength and work hardening rate of the candidate alloys could make some plate or fin forming difficult. A gaseous secondary coolant, either $\mathrm{He}$ or a $\mathrm{He} / \mathrm{N}$ mixture is assumed. If a He/ $\mathrm{N}$ mixture is used, traditional gas-turbine technology can be used; otherwise, helium gas turbine technology will need to be developed. Alloy 617 is the leading candidate material considered for the VHTR IHX application. Alloy $800 \mathrm{H}$ may be used if an IHX operates at low enough temperatures.

\subsection{Plant Transient Definitions}

The plant transient definitions below are summarized from the PBMR white paper on Licensing Basis Event (LBE) selection for the purposes of discussing various scenarios. ${ }^{29}$ These definitions have not been endorsed by the NRC, and formal definitions for a HTGR have not been determined. The frequencies of LBEs are expressed in units of events per plant-year where a plant is defined as a collection of up to eight reactor modules having certain shared systems. At the time PBMR developed these LBEs their design incorporated an IHX rather than a steam generator. This distinction is immaterial to the current discussion. 


\begin{tabular}{|c|lll|}
\hline NEXT GENERATION NUCLEAR PLANT STEAM & Identifier: & PLN-2804 & \\
GENERATOR AND INTERMEDIATE HEAT & Revision: & 1 & \\
EXCHANGER MATERIALS RESEARCH & Effective Date: & $09 / 23 / 10$ & Page: 16 of 252 \\
AND DEVELOPMENT PLAN &
\end{tabular}

\subsubsection{Normal Operating Conditions}

The vendor preconceptual designs all recommended using a phased approach to operate the plant at lower temperature in the startup and early operation of the plant to provide more design margin for the available materials of construction. Baseline conditions assume an outlet gas temperature of $750^{\circ} \mathrm{C}$.

The primary and secondary loops will be pressurized to avoid a significant pressure drop across the SG and/or IHX. Primary coolant pressure levels of about 5, 7, or $9 \mathrm{MPa}$, have been recommended in the preconceptual design reports of the three vendors.

\subsubsection{Anticipated Operational Occurrences}

An Anticipated Operational Occurrence (AOO) encompasses planned and anticipated events. AOOs are utilized to set operating limits for normal operation modes and states. AOOs are event sequences with a mean frequency greater than $10^{-2}$ per plant-year.

PBMR gives an example of the loss of the Power Conversion System (PCS) where one of the active core heat removal systems works as specified. Since the heat is successfully removed from the core, this occurrence would have little impact on the IHX or core internals. However, if the loss of the PCS results in a loss of secondary loop pressure, precautions will be necessary to maintain the correct pressure differential. Start-up/shut-down is a relatively frequent AOO that poses the risk of thermal fatigue.

\subsubsection{Design Basis Events}

Design Basis Events (DBEs) encompass unplanned, off-normal events not expected in the plant's lifetime, but which might occur in the lifetimes of a fleet of plants. DBEs are the basis for the design, construction, and operation of the Safety Significant Components (SSCs) during accidents. Separate from the design certification, DBEs are also evaluated in developing emergency planning measures. DBEs have event sequences with mean frequencies less than $10^{-2}$ per plant-year and greater than $10^{-4}$ per plant-year. Any of a number of small break scenarios in the Helium Pressure Boundary are examples of DBEs given by PBMR.

It is likely that a loss of flow leading to a high pressure conduction cooldown (HPCC) and loss of coolant leading to a low pressure conduction cooldown (LPCC) will be defined as DBEs. The HPCC results in decay heat that is more uniformly distributed within the core and vessel than during an LPCC because the system remains at high pressure. The LPCC is typically initiated by a small leak of the primary coolant, resulting in depressurization and initiating a reactor trip. In both events, the shut-down cooling system fails to start and decay heat is removed passively by thermal radiation and natural convection from the reactor vessel. ${ }^{8}$ Peak temperatures for these events have been reported for the fuel, the control rods, and the RPV, but not yet for the IHX.

\subsubsection{Beyond Design Basis Events}

Beyond Design Basis Events (BDBEs) are rare, off-normal events of lower frequency than DBEs. BDBEs are evaluated to ensure that they do not pose an unacceptable risk to the public. Separate from the design certification, BDBEs are also evaluated in developing emergency planning measures. Loss of the PCS where the Reactor Control System (RCS) does not shut down the reactor is the example given by PBMR. BDBEs are defined as event sequences with mean frequencies less than $10^{-4}$ per plant-year and greater than $5 \times 10^{-7}$ per plant-year. BDBEs will not be considered in this report. 


\begin{tabular}{|c|lll|}
\hline $\begin{array}{c}\text { NEXT GENERATION NUCLEAR PLANT STEAM } \\
\text { GENERATOR AND INTERMEDIATE HEAT } \\
\text { EXCHANGER MATERIALS RESEARCH }\end{array}$ & Identifier: & PLN-2804 & \\
AND DEVELOPMENT PLAN & Effective Date: & $09 / 23 / 10$ & Page: 17 of 252 \\
\hline
\end{tabular}

\subsection{Required Lifetime and Replacement Plans}

\subsubsection{Steam Generator}

The design life of the SG is assumed to be $\sim 60$ years. ${ }^{10,30}$ The SG design life has not been established but plant reliability, availability, and economic considerations favor setting it as close to the plant design life of 60 years as data permits. ${ }^{20}$

An extensive review of Alloy 800 operating experience in fossil fired steam plants and other testing experience was performed during the MHTGR program. ${ }^{31}$ This review indicated very favorable (i.e., successful) experience with the use of Alloy 800 material and dissimilar metal welds (i.e., Alloy 800 welded to another metal) with this material but provided insufficient confirmatory data for operating under wet and wetting/drying conditions.

The twelve FSV SG modules collectively experienced a total of only two small tube leaks during their 13 years of operation. However, several cracks were discovered on the outside of the main steam header external to the primary coolant boundary at the end of the operating life. The THTR steam generators experienced no tube leaks during their 4 years of operation. In the total population (including $\mathrm{CO}_{2}$ cooled reactors) of gas-cooled reactor SGs, over $1700 \mathrm{SG}$ years of operation have been accumulated with a low tube leak rate of less than 0.1 per SG year which gives confidence that the SG tube bundles are unlikely to experience significant tube leaks. ${ }^{31}$

\subsubsection{Intermediate Heat Exchanger}

There is no requirement that the $\operatorname{IHX(s)~last~the~design~lifetime~of~the~plant~(60~years),~although~this~}$ would be ideal. Replacing the IHX is possible and in reality, probable. Traditional tube and shell heat exchangers used in the fossil fuel industry can be inspected, and in the event of a leak in the tube, they are plugged. Compact heat exchangers have the advantage that they would be less cumbersome to change; however, they cannot be easily repaired or inspected. Leaks would not be evident until tritium is detected on the secondary side. A two-stage heat exchanger system might present a compromise of these extremes. 


\begin{tabular}{|c|lll|}
\hline $\begin{array}{c}\text { NEXT GENERATION NUCLEAR PLANT STEAM } \\
\text { GENERATOR AND INTERMEDIATE HEAT } \\
\text { EXCHANGER MATERIALS RESEARCH }\end{array}$ & Identifier: & PLN-2804 & \\
AND DEVELOPMENT PLAN & Effective Date: & $09 / 23 / 10$ & Page: 18 of 252 \\
\hline
\end{tabular}

\section{MATERIALS RESEARCH TO DATE}

The majority of materials research and development programs in support of HTGRs were conducted in the 1960 s to early 1980 s. The thrust of these programs was to develop a database on materials for application in steam-cycle and process-nuclear-heat-based HTGRs. There has been a recent upswing in research in materials for HTGR application by the NGNP program and through the GIF. The following overview of material property research contains historical data as well as relevant recent results.

\subsection{Candidate Alloys}

Material selection for an IHX or SG is critical, regardless of the design. For the NGNP IHX, four primary candidate alloys were initially considered: Alloy 617, Alloy $800 \mathrm{H}$, Alloy 230, and Alloy X. An assessment of relevant factors was made including thermal expansion, thermal conductivity, tensile, creep, fatigue, creep-fatigue, and toughness properties for the candidate alloys. Thermal aging effects on the mechanical properties, weldability and performance of the alloys in helium containing a wide range of impurity concentrations is also considered. ${ }^{21}$ In addition, the technical maturity of materials and status of the alloys with respect to the ASME B\&PV Code is of critical importance. Alloy 230 is no longer under consideration, ${ }^{32}$ and although no NGNP research is currently underway for Alloy X, vendors continue to express interest in this alloy and an improved version, XR.

Figure 8 and Figure 9 compare the creep-rupture strength and allowable stress, respectively, for the four original candidate alloys.

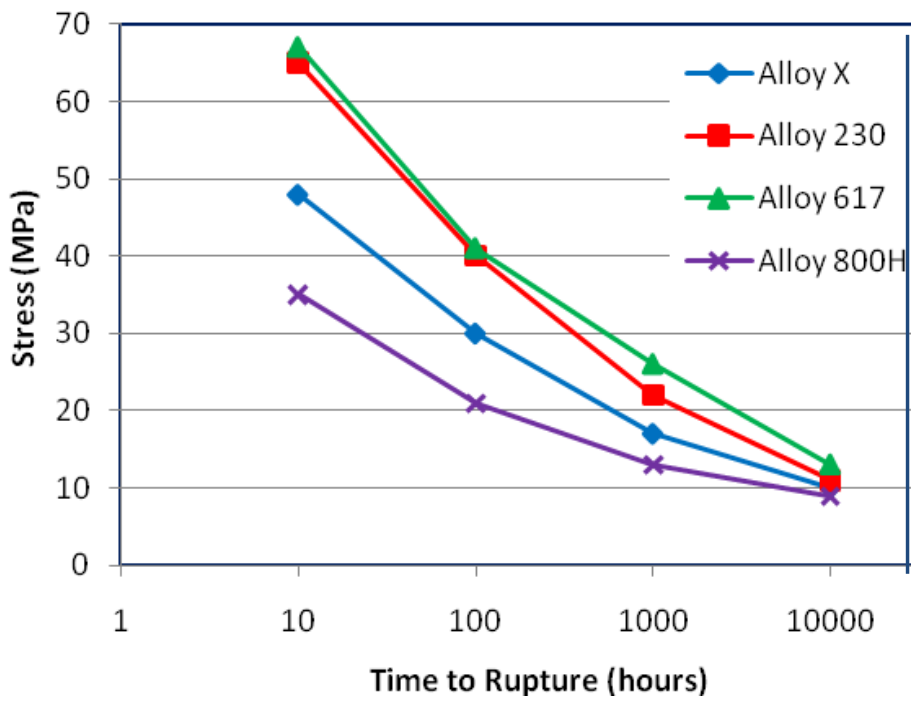

Figure 8. Creep-rupture strength at $962^{\circ} \mathrm{C}$ in air. 


\begin{tabular}{|c|lll|}
\hline $\begin{array}{c}\text { NEXT GENERATION NUCLEAR PLANT STEAM } \\
\text { GENERATOR AND INTERMEDIATE HEAT }\end{array}$ & Identifier: & PLN-2804 & \\
EXCHANGER MATERIALS RESEARCH & Revision: & 1 & \\
AND DEVELOPMENT PLAN & Effective Date: & $09 / 23 / 10$ & Page: 19 of 252 \\
\hline
\end{tabular}

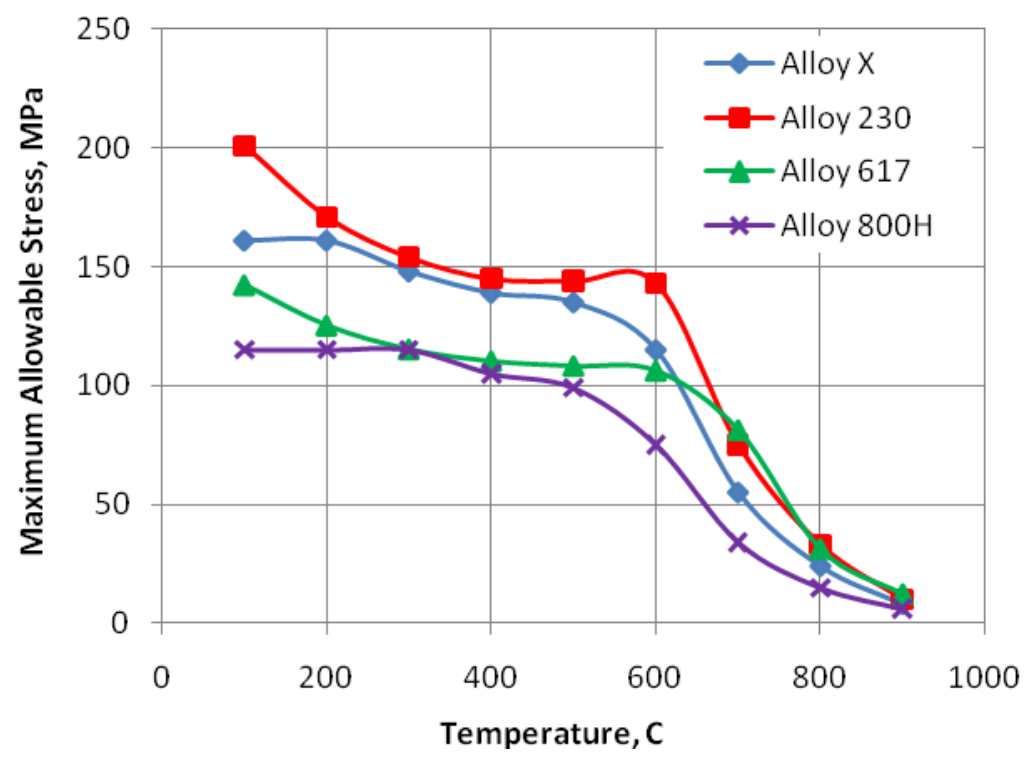

Figure 9. Allowable stress for heat exchanger materials for plate, sheet and strip forms.

\subsubsection{Alloy 617 (52Ni-22Cr-13Co-9Mo)}

Alloy 617, also designated as Inconel 617, UNS N06617, or W. Nr. 2.4663a, was initially developed for high temperature applications above $800^{\circ} \mathrm{C}$. It is often considered for use in aircraft and land-based gas turbines, chemical manufacturing components, metallurgical processing facilities, and power generation structures. The alloy was also considered and investigated for the HTGR programs in the United States and Germany in the late 1970s and early 1980s. Alloy 617 is not currently qualified for use in ASME Boiler and Pressure Vessel (B\&PV) Code Section III, although it is allowed in Section I and Section VIII, Division 1 (non-nuclear service). A draft ASME Code case for incorporating Alloy 617 in Section III was developed but efforts to gain the approval from the ASME Code committees were stopped due to a loss in interest by DOE and its contractor. Efforts required to complete the Alloy 617 Code Case for NGNP applications are discussed further in Section 5.4.

This nickel-based alloy is the primary candidate for construction of a VHTR IHX, and the existing mechanical property database is extensive (Table 3$){ }^{33}$ some of which was used to develop existing ASME B\&PV Code, and the 1980s Draft Alloy 617 Code Case mentioned above. In addition, some studies have generated data from Alloy 617 that had been aged and/or tested in simulated HTGR helium, with more recent efforts preserving all original test curves needed for constitutive modeling efforts. 
Idaho National Laboratory

\begin{tabular}{|c|lll|}
\hline $\begin{array}{c}\text { NEXT GENERATION NUCLEAR PLANT STEAM } \\
\text { GENERATOR AND INTERMEDIATE HEAT } \\
\text { EXCHANGER MATERIALS RESEARCH }\end{array}$ & Identifier: & PLN-2804 & \\
AND DEVELOPMENT PLAN & Effective Date: & $09 / 23 / 10$ & Page: 20 of 252 \\
\hline
\end{tabular}

Table 3. Summary of testing done on Alloy 617 to support previous reactor programs.

\begin{tabular}{|c|c|c|c|c|}
\hline Research Organization & Number of heats & $\begin{array}{c}\text { Number of } \\
\text { samples }\end{array}$ & Test type & $\begin{array}{c}\text { Temperature } \\
\left({ }^{\circ} \mathrm{C}\right)\end{array}$ \\
\hline \multirow[t]{2}{*}{ Huntington Alloys } & $13+1$ wire & 179 & Tensile & $25-1093$ \\
\hline & & 249 & Creep & $593-1093$ \\
\hline \multirow[t]{4}{*}{$\mathrm{ORNL}^{\mathrm{a}}$} & 4 plate +1 wire & 73 & Tensile & $24-871$ \\
\hline & & 51 & Creep & $593-871$ \\
\hline & & 25 & Charpy & 24 \\
\hline & & 1 & Tensile after creep & RT after 871 \\
\hline \multirow[t]{3}{*}{$\mathrm{GE}^{\mathrm{a}}$} & 1 plate +1 bar & 36 & Creep & $750-1100$ \\
\hline & & 7 & Creep-fatigue & 950 \\
\hline & & 40 & Fatigue & 850,950 \\
\hline \multirow[t]{4}{*}{ Germany } & Not specified & 302 & Tensile & RT-1000 \\
\hline & & 1947 & Creep & $500-1000$ \\
\hline & & 29 & Creep crack growth & $700-1000$ \\
\hline & & 261 & Low cycle fatigue & $<500-1000$ \\
\hline Honeywell Aerospace & Not specified & & Not specified & \\
\hline Gen IV program ${ }^{b}$ & Not specified & 80 & Creep-fatigue & 800,1000 \\
\hline $\begin{array}{l}\text { a. some tests exposed to HT } \\
\text { b. air, pure helium and vacu }\end{array}$ & $\begin{array}{l}\mathrm{R} \text { environment. } \\
\mathrm{n} \text { environments. }\end{array}$ & & & \\
\hline
\end{tabular}

Alloy 617 has adequate creep strength at temperatures above $870^{\circ} \mathrm{C}$, good cyclic oxidation and carburization resistance, and good weldability. It also has lower thermal expansion than most austenitic stainless steels and high thermal conductivity relative to the other candidates. It retains toughness after long-time exposure at elevated temperatures and does not form intermetallic phases that can cause embrittlement. Preliminary testing indicates Alloy 617 has the best carburization resistance of the four alloys.

Two $1.397 \mathrm{~m} \times 3.505 \mathrm{~m}(55$ in. $\times 138$ in.) of $38 \mathrm{~mm}(1.5$ in.) thick plates of solution annealed Alloy 617 from a single heat (cast 314626) have been procured from ThyssenKrupp VDM for the NGNP $R \& D$ program. This heat of material will serve as the reference material for the majority of the R\&D called for in this plan. All mechanical test specimens for which results are discussed below were machined from annealed plate; the long axis of the specimen aligned with the rolling direction.

\subsubsection{Chemistry of Alloy 617}

The ASTM specified chemical composition of Alloy 617 and that of the procured heat are given in Table $4 .{ }^{34}$ The high Ni and $\mathrm{Cr}$ contents provide the alloy with high resistance to a variety of reducing and oxidizing environments. The $\mathrm{Al}$, in conjunction with $\mathrm{Cr}$, offers oxidation resistance at high temperatures. In addition, the $\mathrm{Al}$ can also form intermetallic compound $\gamma^{\prime}$ over a range of temperatures, which results in precipitation strengthening on top of the solid solution strengthening imparted by the Co and Mo.

Strengthening is also derived from $\mathrm{M}_{23} \mathrm{C}_{6}, \mathrm{M}_{6} \mathrm{C}, \mathrm{Ti}(\mathrm{C}, \mathrm{N})$ and other precipitates when in appropriate sizes, distributions, and volume fractions. 


\begin{tabular}{|c|lll|}
\hline $\begin{array}{c}\text { NEXT GENERATION NUCLEAR PLANT STEAM } \\
\text { GENERATOR AND INTERMEDIATE HEAT }\end{array}$ & Identifier: & PLN-2804 & \\
EXCHANGER MATERIALS RESEARCH & Revision: & 1 & \\
AND DEVELOPMENT PLAN & Effective Date: & $09 / 23 / 10$ & Page: 21 of 252 \\
\hline
\end{tabular}

Table 4. Chemical composition (wt. \%) of Alloy 617.

\begin{tabular}{lccccccccccccc}
\hline & $\mathrm{Ni}$ & $\mathrm{Cr}$ & $\mathrm{Co}$ & $\mathrm{Mo}$ & $\mathrm{Fe}$ & $\mathrm{Mn}$ & $\mathrm{Al}$ & $\mathrm{C}$ & $\mathrm{Cu}$ & $\mathrm{Si}$ & $\mathrm{S}$ & $\mathrm{Ti}$ & $\mathrm{B}$ \\
\hline Min & 44.5 & 20.0 & 10.0 & 8.0 & - & - & 0.8 & 0.05 & - & - & - & - & - \\
Max & - & 24.0 & 15.0 & 10.0 & 3.0 & 1.0 & 1.5 & 0.15 & 0.5 & 1.0 & 0.015 & 0.6 & 0.006 \\
\hline TK31426 & 54.1 & 22.2 & 11.6 & 8.6 & 1.6 & 0.1 & 1.1 & 0.05 & 0.04 & 0.1 & $<0.002$ & 0.4 & $<0.001$
\end{tabular}

\subsubsection{Microstructure of Alloy 617}

Observations and predictions of which precipitates form in Alloy 617 at given temperature ranges have not been consistent. A comprehensive review of the precipitates in Alloy 617 has been performed by Ren, ${ }^{35,36}$ with additional review by Natesan et al. ${ }^{37}$

The precipitation and coarsening processes are important in determining the effects of aging on properties. It appears precipitates may form at initial exposure and the alloy may become stronger, but most of the precipitates will be dissolved after long-term exposure in the temperature range of interest to the NGNP IHX, and the alloy will depend on solid solution strengthening for long service.

The grain size is also important to the properties of the alloy. For general applications, a grain size of ASTM No. $6(\sim 45 \mu \mathrm{m})$ or coarser is typically preferred, but it has been shown that creep strength increases with increasing grain size so microstructures of 100-200 $\mu \mathrm{m}$ grain size are often produced. A tradeoff exists, however, when fatigue is an issue, since finer grain sizes are preferred for fatigue resistance. In addition, for compact IHX, the thin sheet form restricts large grain size. Whether the grains will significantly coarsen after the dissolution of certain grain boundary precipitates at long-term exposure is not clear. The microstructure of solution annealed Alloy 617 plate processed using current mill practice is shown in Figure 10.

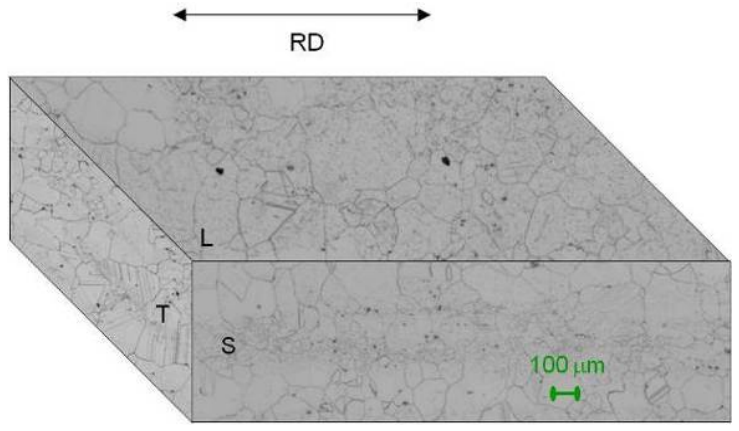

Figure 10. Microstructure of the as-annealed Alloy 617.

Characterization of Alloy 617 material aged for $200 \mathrm{~h}$ at temperatures from 750 to $1000^{\circ} \mathrm{C}$ in $50^{\circ} \mathrm{C}$ increments has recently been carried out using optical microscopy. Precipitation of carbides on grain boundaries was observed in all of the aged specimens compared to the solution treated plate material. At the level of analysis possible using optical microscopy there does not appear to be a large difference in the microstructure as a function of temperature. Optical micrographs illustrating the microstructure from cross-sections through as-received solution treated material and $800^{\circ} \mathrm{C}$ aged specimens are shown in Figure 11. 


\begin{tabular}{|c|c|c|c|}
\hline $\begin{array}{l}\text { NEXT GENERATION NUCLEAR PLANT STEAM } \\
\text { GENERATOR AND INTERMEDIATE HEAT } \\
\text { EXCHANGER MATERIALS RESEARCH } \\
\text { AND DEVELOPMENT PLAN }\end{array}$ & $\begin{array}{l}\text { Identifier: } \\
\text { Revision: } \\
\text { Effective Date: }\end{array}$ & $\begin{array}{l}\text { PLN-2804 } \\
1 \\
09 / 23 / 10\end{array}$ & Page: 22 of 252 \\
\hline
\end{tabular}

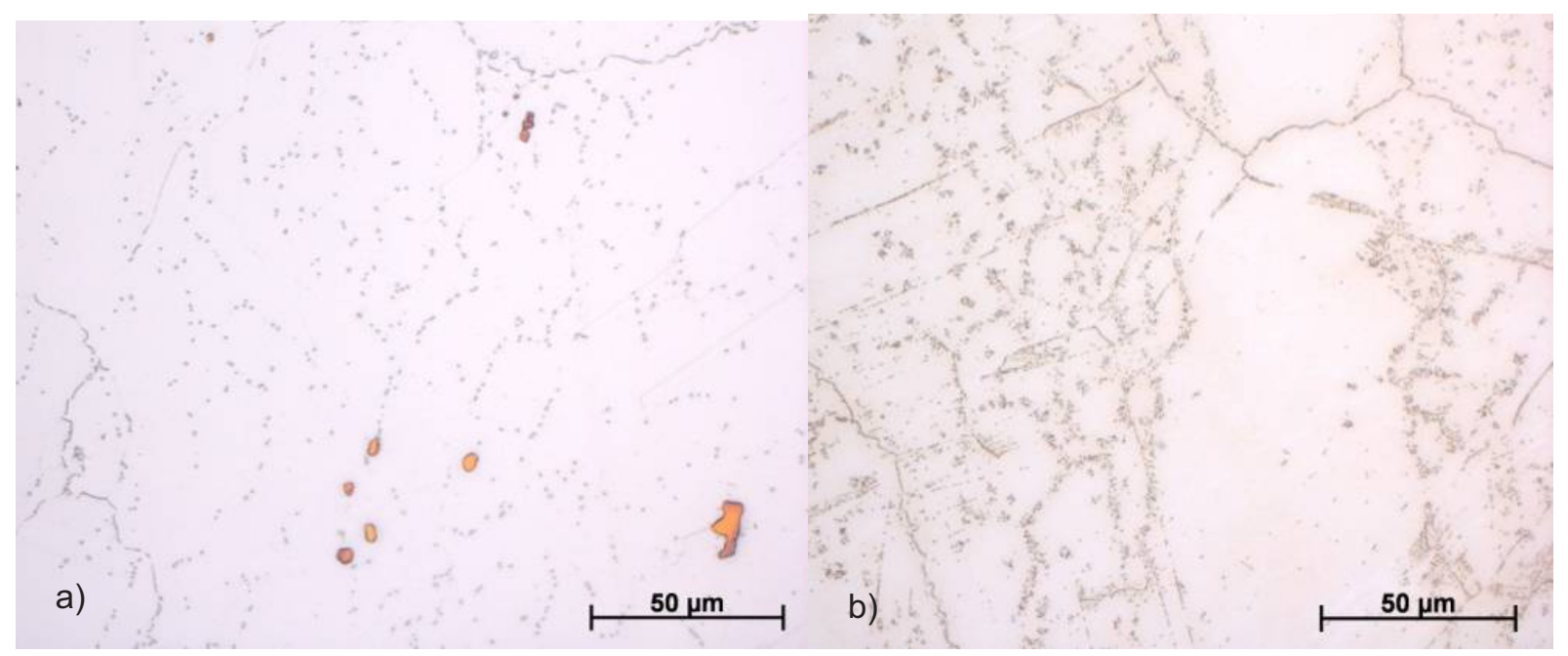

Figure 11. Optical micrograph of a cross-section through Alloy 617 (a) solution annealed, (b) aged for $200 \mathrm{~h}$ at $800^{\circ} \mathrm{C}$.

\subsubsection{Tensile Behavior}

Extensive tensile testing has been performed on Alloy 617 (see Table 3); however, testing of the NGNP heat is required to serve as a basis for analysis of other testing (e.g., creep-fatigue) and constitutive modeling. Elevated temperature tensile properties were measured at $50^{\circ} \mathrm{C}$ intervals for Alloy 617 in the temperature range of $650-1000^{\circ} \mathrm{C}$. Room temperature tensile tests were also done. Testing was performed at an initial strain rate of $1.6 \times 10^{-4} / \mathrm{s}$. Stress-strain curves for these tests are shown in Figure 12 . Above $800^{\circ} \mathrm{C}$ high levels of ductility and no appreciable work hardening are observed.

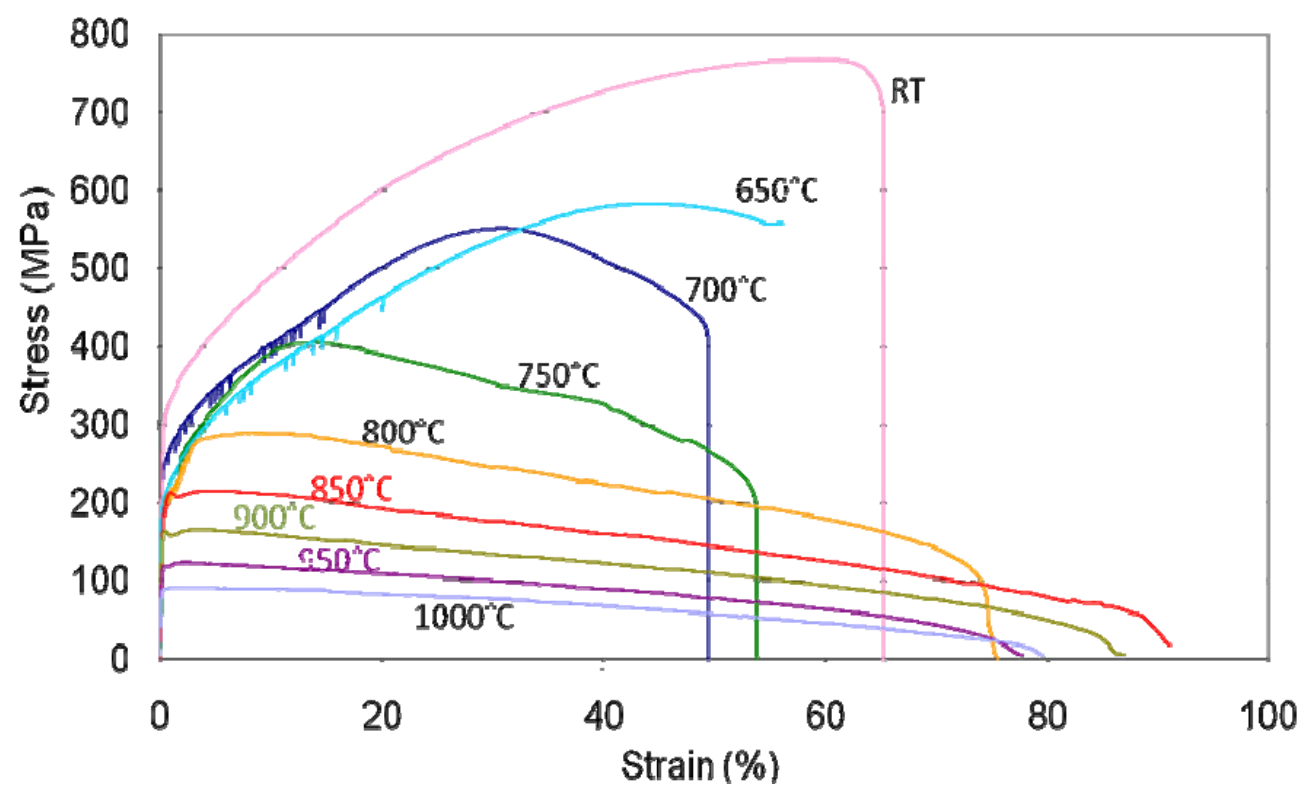

Figure 12. Tensile stress-strain curves for Alloy 617. 


\begin{tabular}{|c|lll|}
\hline $\begin{array}{c}\text { NEXT GENERATION NUCLEAR PLANT STEAM } \\
\text { GENERATOR AND INTERMEDIATE HEAT }\end{array}$ & Identifier: & PLN-2804 & \\
EXCHANGER MATERIALS RESEARCH & Revision: & 1 & \\
AND DEVELOPMENT PLAN & Effective Date: & $09 / 23 / 10$ & Page: 23 of 252 \\
\hline
\end{tabular}

Alloy 617 exhibits dynamic strain aging (DSA) in the temperature regime of 600 to $850^{\circ} \mathrm{C}$. This behavior is manifested as serrated yielding or unstable plastic flow. Occurrence of DSA is temperature, strain and strain rate dependent. An increase in strain rate increases the temperature bounds of the DSA regime.

\subsubsection{Strain Rate Sensitivity}

Strain rate jump tests were conducted on the NGNP heat of Alloy 617 for temperatures of $800-1000^{\circ} \mathrm{C}$ at $50^{\circ}$ intervals. Tests were started at a strain rate of $10^{-6} / \mathrm{s}$ and the strain rate was progressively jumped after $0.5 \%$ strain to $10^{-5}, 10^{-4}, 10^{-3}$, and $10^{-2} / \mathrm{s}$. At the final strain rate, $10^{-2} / \mathrm{sec}$, the servo-hydraulic system had difficulty controlling the strain rate in the $950^{\circ} \mathrm{C}$ and $1000^{\circ} \mathrm{C}$ tests and therefore, the stress-strain curve after yielding is not accurate.

Alloy 617 is highly strain rate sensitive at the highest temperatures. Increasing the strain rates give rise to higher flow stresses. Figure 13 shows results of strain rate jump tests run at temperatures from $800-1000^{\circ}$. As the temperature increases, the shape of the stress-strain curves change and work hardening is only present at the highest strain rate. DSA is observed at lower temperatures and faster strain rates.

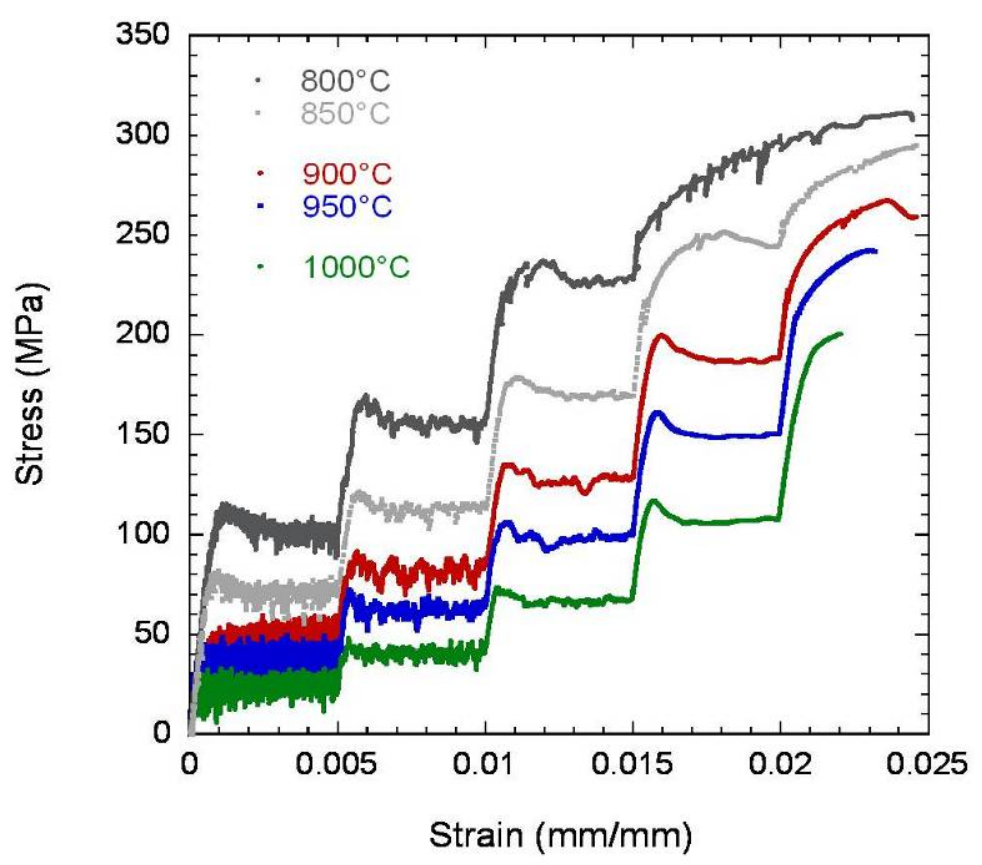

Figure 13. Strain rate jump tests of Alloy 617.

Flow stress and strain rate are related at a constant temperature and strain by the following equation:

\section{$\sigma=\cos )^{m}$}

where $\mathrm{C}$ is a constant, $\sigma$ is the flow stress, $\varepsilon$ is the strain rate, and $\mathrm{m}$ is the strain rate sensitivity. Strain rate sensitivity values are tabulated in Table 5 and plotted in Figure 14 for temperatures from $800^{\circ} \mathrm{C}$ to $1000^{\circ} \mathrm{C}$. The strain at which the flow stresses were determined varies for each strain rate, and determining the stress resulting from the final jump was problematic and therefore no $\mathrm{m}$ values are calculated for those cases. The strain rate sensitivity, $\mathrm{m}$, is about 0.17 for all conditions tested. 


\begin{tabular}{|c|lll|}
\hline NEXT GENERATION NUCLEAR PLANT STEAM & Identifier: & PLN-2804 & \\
GENERATOR AND INTERMEDIATE HEAT & Revision: & 1 & \\
EXCHANGER MATERIALS RESEARCH & Effective Date: & $09 / 23 / 10$ & Page: 24 of 252 \\
AND DEVELOPMENT PLAN &
\end{tabular}

Table 5. Strain rate sensitivity, $\mathrm{m}$, values at temperatures between $750^{\circ} \mathrm{C}$ and $1000^{\circ} \mathrm{C}$.

\begin{tabular}{lcccccc}
\hline & \multicolumn{6}{c}{ Temperature $\left({ }^{\circ} \mathrm{C}\right)$} \\
\cline { 2 - 7 } \multicolumn{1}{c}{ strain rate jump } & \multicolumn{2}{c}{800} & 850 & 900 & 950 & 1000 \\
\hline $10^{-6}$ to $10^{-5} / \mathrm{sec}$ & 0.17 & 0.18 & 0.17 & 0.15 & 0.16 & \\
$10^{-5}$ to $10^{-4} / \mathrm{sec}$ & 0.16 & 0.16 & 0.16 & 0.18 & 0.18 & \\
$10^{-4}$ to $10^{-3} / \mathrm{sec}$ & 0.07 & 0.16 & 0.16 & 0.18 & 0.19 & \\
Figure 14 - regression fit & 0.16 & 0.17 & 0.17 & 0.17 & 0.18 & \\
\hline
\end{tabular}

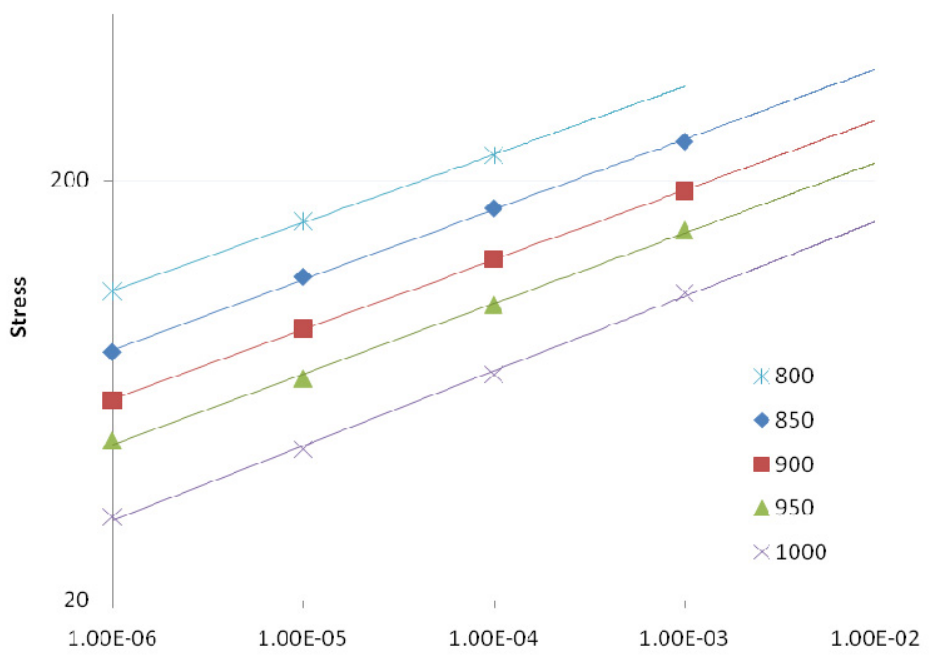

Figure 14. Log flow stress versus log strain rate plot for the various test temperatures.

\subsubsection{Fatigue and Creep-Fatigue Behavior}

Creep-fatigue deformation is a combination of creep damage and fatigue damage and is expected to be the primary damage mode for the NGNP IHX. Creep-fatigue testing of the NGNP heat has been carried out in air at $950^{\circ} \mathrm{C}$ with tensile hold times of up to $1800 \mathrm{sec}(30 \mathrm{~min})$ and continuous low cycle fatigue (LCF) testing (i.e., no hold time) was also done to provide a baseline for the creep-fatigue behavior. LCF tests were fully reversed with a triangular waveform (Figure 15a) and a ramp rate of $10^{-3} / \mathrm{sec}$. Creep-fatigue testing followed the same strain waveform except that a tensile hold ranging from $18 \mathrm{sec}$ to $1800 \mathrm{sec}$ was imposed at the maximum tensile strain (Figure 15b). Three strain ranges have been investigated, $0.3 \%, 0.6 \%$ and $1.0 \%$ total strain. Total test times were as long as one month. 


\begin{tabular}{|c|lll|}
\hline NEXT GENERATION NUCLEAR PLANT STEAM & Identifier: & PLN-2804 & \\
GENERATOR AND INTERMEDIATE HEAT & Revision: & 1 & \\
EXCHANGER MATERIALS RESEARCH & Effective Date: & $09 / 23 / 10$ & Page: 25 of 252 \\
AND DEVELOPMENT PLAN &
\end{tabular}

Continuous Cycle Fatigue

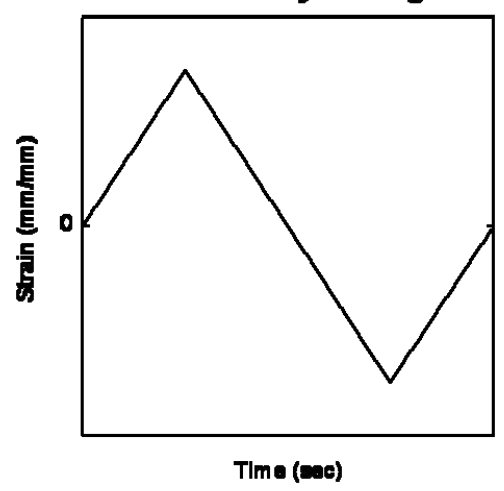

a.

Figure 15. Schematic of strain history for (a) continuous cycle fatigue and (b) creep-fatigue.

The peak tensile and compressive stresses are shown as a function of cycle for the creep-fatigue tests in Figure 16. The peak tensile and compressive stresses observed in the LCF (no hold) tests at $0.3 \%$ and $0.6 \%$ total strain were relatively symmetrical, i.e., the peak tensile and compressive stresses were of the same magnitude. The creep-fatigue peak stresses versus cycle profiles were also relatively symmetric, although the magnitude of the stresses in compression were slightly greater than in tension.

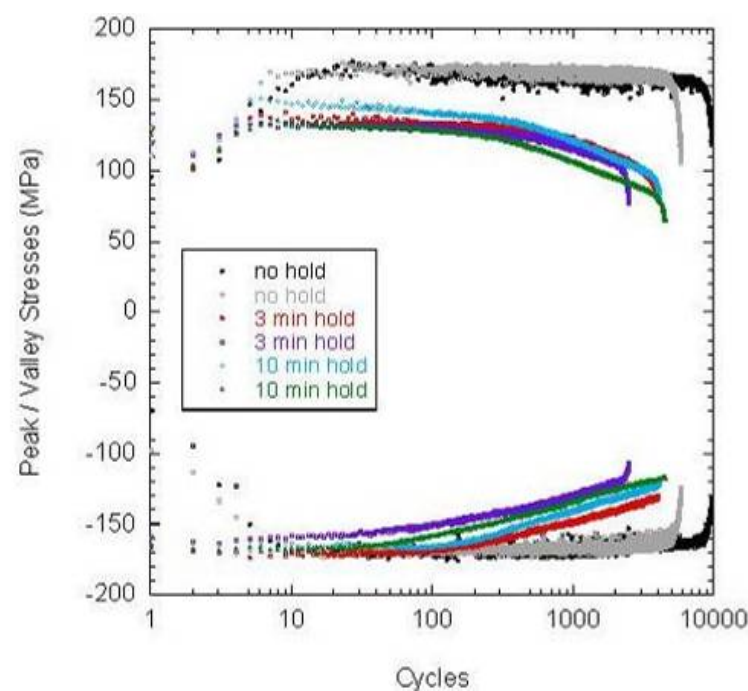

a.

Cycles

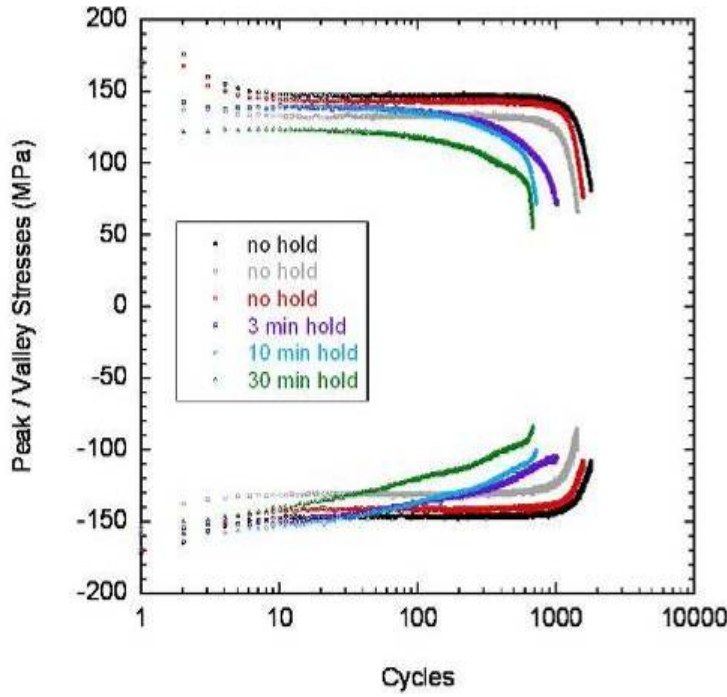

b.

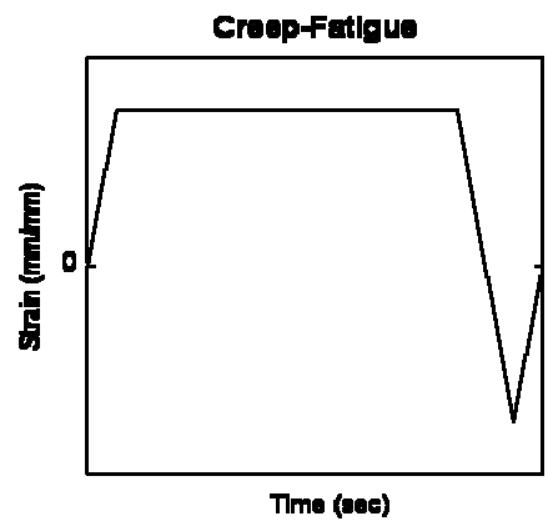

b.

Figure 16. Peak tensile and compressive stress plotted as a function of cycle for creep-fatigue tests at $950^{\circ} \mathrm{C}$ and (a) $0.3 \%$ total strain range (b) $0.6 \%$ total strain range.

The peak tensile stresses as a function of cycle reached a stable value within less than 10 cycles at $0.3 \%$ total strain and within 5 cycles at $0.6 \%$ total strain. In the no-hold tests the steady-state stress remained constant until macrocrack initiation or just prior to failure. In contrast, the peak stresses for tests with hold time did not achieve a steady-state value; instead the peak stresses slowly decreased with cycle and had two transition points, following which a more rapid decrease was observed. Note that the steadystate peak stress in the $0.6 \%$ total strain no-hold test was similar in magnitude to the $0.3 \%$ total strain test. The creep-fatigue peak stresses versus cycle profiles (Figure 16) were similar regardless of the duration of 


\begin{tabular}{|c|lll|}
\hline $\begin{array}{c}\text { NEXT GENERATION NUCLEAR PLANT STEAM } \\
\text { GENERATOR AND INTERMEDIATE HEAT }\end{array}$ & Identifier: & PLN-2804 & \\
EXCHANGER MATERIALS RESEARCH & Revision: & 1 & \\
AND DEVELOPMENT PLAN & Effective Date: & $09 / 23 / 10$ & Page: 26 of 252 \\
\hline
\end{tabular}

the tensile hold. The peak stresses in the longer hold time tests were slightly lower with increasing hold time; however, there was some degree of variability in the peak stresses for identical test conditions.

The introduction of hold times at peak tensile strain in continuous cycle fatigue reduces the fatigue life of Alloy 617, similar to what has been observed for stainless steels and nickel-based alloys. The number of cycles to failure decreased with increasing tensile hold times, as shown in Figure 17. In the case of the $0.3 \%$ total strain range, the addition of a 3 minute hold time reduced the number of cycles to failure by a factor of 2 . An increase in hold time to 10 minutes did not further reduce the cycle life. At the $0.6 \%$ and $1.0 \%$ total strain range, increasing the hold time to 10 minutes caused additional reductions in the cycles to failure, although for the 30 minute hold time, the $0.6 \%$ strain test did not further reduce the creep-fatigue life. Due to the variability observed in fatigue and creep-fatigue more data is necessary to elicit the influence of an increasing hold time on cycle life.

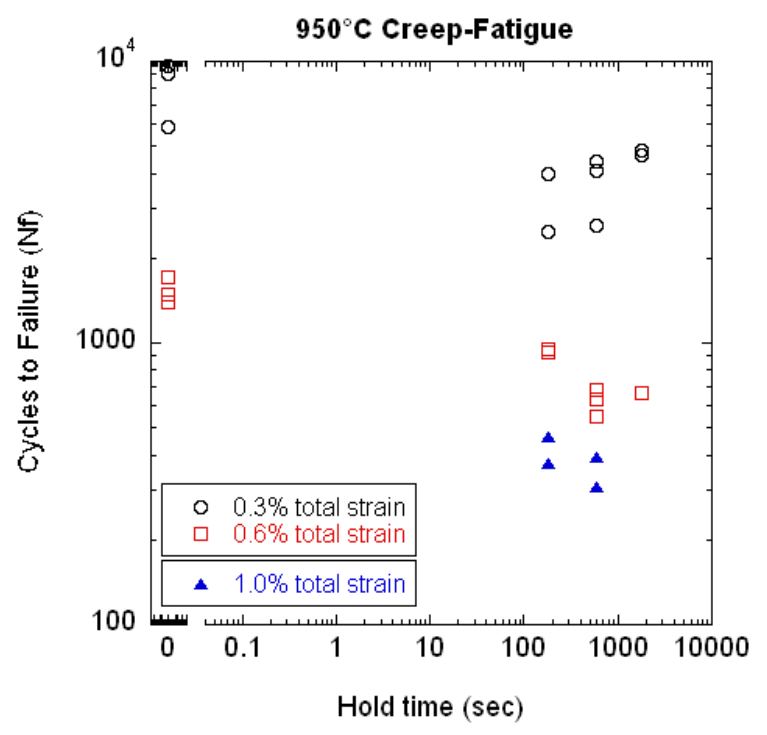

Figure 17. Cycles to failure as a function of hold time for creep-fatigue testing at $950^{\circ} \mathrm{C}$.

Test termination was prior to actual specimen separation. The number of cycles to macrocrack initiation, $\mathrm{N}_{0}$, and the number of cycles to failure, $\mathrm{N}_{20}$, were defined as the point at which the ratio of the peak tensile stress to the peak compressive stress initially declined and the point at which the ratio was $80 \%$ of its stable value, respectively. ${ }^{38}$ Intergranular crack initiation and propagation was observed in all of the low cycle fatigue and creep-fatigue specimens cycled at $950^{\circ} \mathrm{C}$, regardless of strain range. Creep cavitation was not observed on the grain boundaries of any of the specimens tested in air. Chromia was present on both crack and specimen surfaces. Alumina was present at the crack tip and along intersecting grain boundaries.

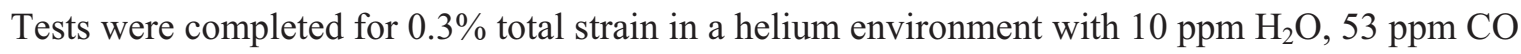
and $352 \mathrm{ppm}_{2}$ at $950^{\circ} \mathrm{C}$. The gas chemistry was selected to be representative of a VHTR environment that does not cause decarburization of the Alloy 617 specimen. The gas chemistry levels achieved closely matched the target chemistry with $\mathrm{H}_{2} \mathrm{O}$ levels resulting in an oxidizing environment during the test. The stress profiles and cycles to failure are similar to the tests performed in air, as shown in Figure 18. A greater effect of the environment is expected in the longer creep-fatigue tests as the failure mechanism changes to intergranular crack initiation and propagation and a greater degree of oxidation damage is observed. 


\begin{tabular}{|c|lll|}
\hline $\begin{array}{c}\text { NEXT GENERATION NUCLEAR PLANT STEAM } \\
\text { GENERATOR AND INTERMEDIATE HEAT }\end{array}$ & Identifier: & PLN-2804 & \\
EXCHANGER MATERIALS RESEARCH & Revision: & 1 & \\
AND DEVELOPMENT PLAN & Effective Date: & $09 / 23 / 10$ & Page: 27 of 252 \\
\hline
\end{tabular}

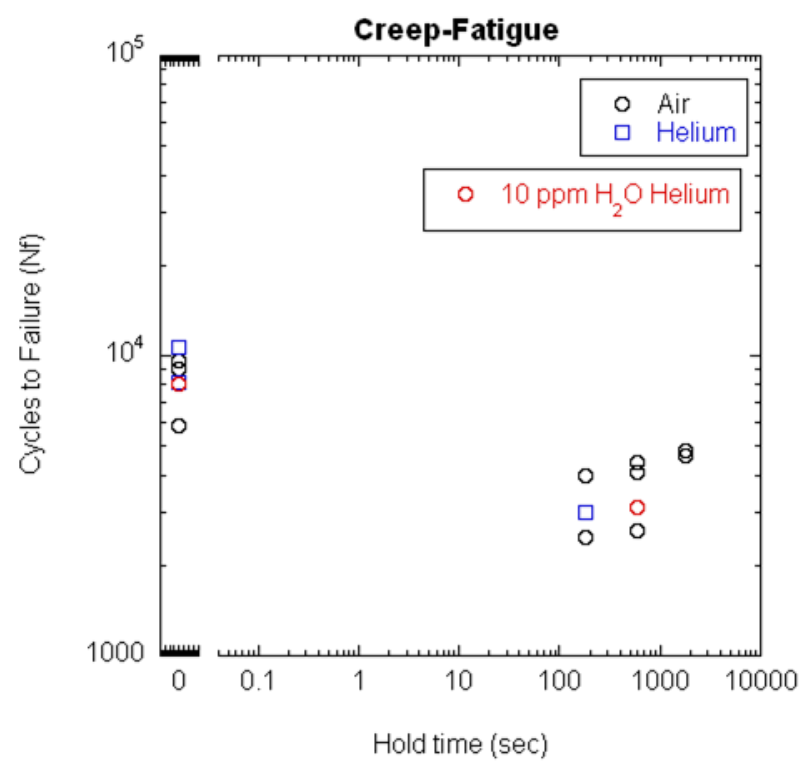

Figure 18. Continuous cycle and creep-fatigue testing at $950{ }^{\circ} \mathrm{C}, 0.3 \%$ total strain for tests done in air and helium.

\subsubsection{Stress Relaxation}

Stress relaxation curves for the NGNP Alloy 617 heat at $950^{\circ} \mathrm{C}$ are shown in Figure 19 for the $0.6 \%$ strain range. Results from the first cycle of creep-fatigue tests with a $180 \mathrm{sec}$ and $600 \mathrm{sec}$ hold time are compared to a dedicated stress relaxation test where the specimen was loaded to $0.6 \%$ strain and the stress necessary to maintain that strain is recorded as a function of time. The stress relaxation during the hold period at constant strain occurred at the same rate for the $180 \mathrm{sec}$ and the $600 \mathrm{sec}$ hold. The stress decreased rapidly until approximately $60 \mathrm{sec}$ into the hold. The creep rate may be calculated from the slope of these curves and the elastic modulus. Regardless of the starting strain/stress, the stresses relaxed in a similar manner. 


\begin{tabular}{|c|lll|}
\hline $\begin{array}{c}\text { NEXT GENERATION NUCLEAR PLANT STEAM } \\
\text { GENERATOR AND INTERMEDIATE HEAT }\end{array}$ & Identifier: & PLN-2804 & \\
EXCHANGER MATERIALS RESEARCH & Revision: & 1 & \\
AND DEVELOPMENT PLAN & Effective Date: & $09 / 23 / 10$ & Page: 28 of 252 \\
\hline
\end{tabular}

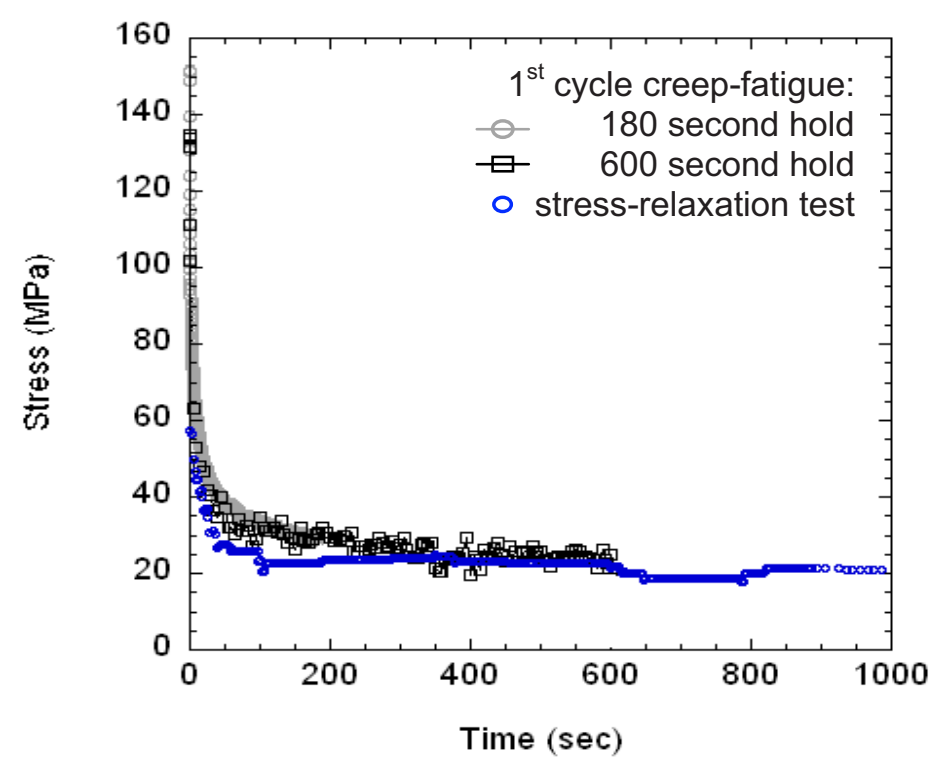

Figure 19. Stress relaxation curves at $950^{\circ} \mathrm{C}$ comparing first cycle of creep-fatigue tests at $0.6 \%$ total strain range to stress-relaxation test.

\subsubsection{Creep}

Although substantial creep data have been gathered on Alloy 617 (Table 3), it does not exhibit classical creep behavior above $800^{\circ} \mathrm{C}$ and testing is needed to determine creep mechanisms for ASME codification. Interrupted creep tests have been conducted in this R\&D program as part of a series of scoping studies on a heat of Alloy 617 that was far less homogeneous than the NGNP material that is currently being used. The creep temperature was controlled to within $\pm 3^{\circ} \mathrm{C}$ of the target creep temperature. When the creep strain had approximately attained a target value, the test was terminated. Samples were then cooled from the test temperature under load. The actual creep strain was determined by measuring the increase in sample length after it had cooled to room temperature. Creep specimens were machined from an earlier heat of material, but will be duplicated using the same heat as other results reported here. The plate from this heat was very inhomogeneous with respect to carbide distribution and grain size, while the new plate is extremely homogeneous.

The transition to tertiary creep typically occurred prior to reaching a creep strain of $0.5 \%$, typically less than $50 \mathrm{~h}$, and the samples spent most of their creep lives, which lasted from 97 to $650 \mathrm{~h}$, in the tertiary regime. Creep tests were terminated between creep strain values of 5 and $41 \%$.

An increase in porosity with strain is evidence of creep damage. Figure 20 shows the amount of porosity as a function of the creep strain for the three different load-temperature conditions; however, no clear differences in the amount of porosity as a function of strain are exhibited for the different loads and temperatures. Figure 21 shows the porosity distribution in Alloy 617 after creep testing at $1000^{\circ} \mathrm{C}$. Creep cavitation did not occur in Alloy 617 until greater than $\sim 10 \%$ creep strain, indicating a substantial amount of tertiary creep can occur before porosity becomes significant. ${ }^{39}$ Very limited cavity formation is observed in this alloy and a critical amount of creep deformation is required before creep cavities nucleate. 


\begin{tabular}{|c|lll|}
\hline NEXT GENERATION NUCLEAR PLANT STEAM & Identifier: & PLN-2804 & \\
GENERATOR AND INTERMEDIATE HEAT & Revision: & 1 & \\
EXCHANGER MATERIALS RESEARCH & Effective Date: & $09 / 23 / 10$ & Page: 29 of 252 \\
AND DEVELOPMENT PLAN &
\end{tabular}

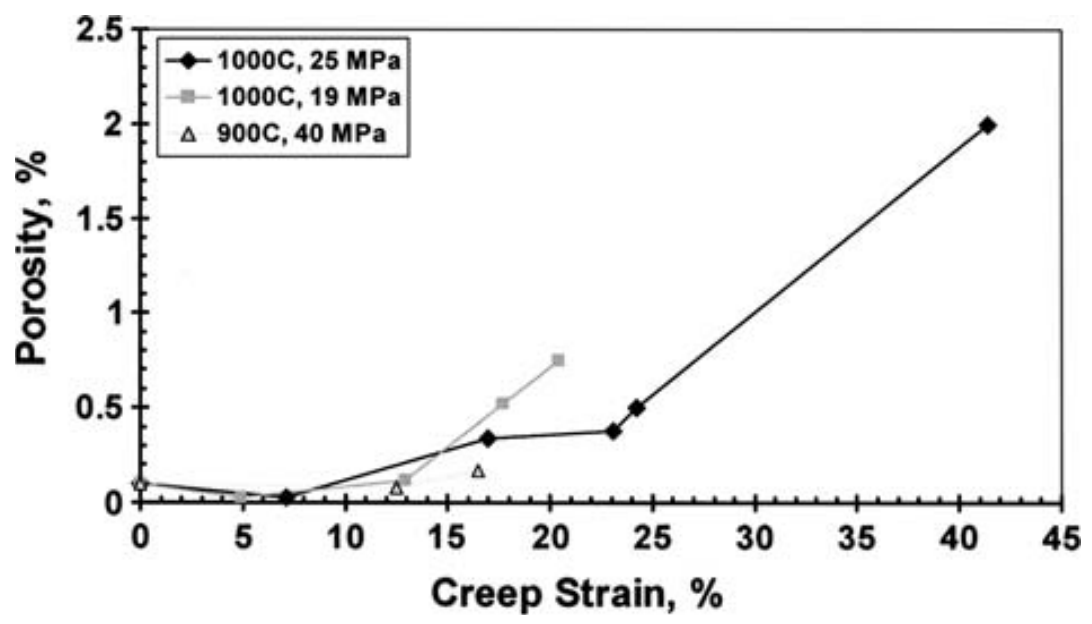

Figure 20. Porosity as a function of creep strain for Alloy 617.
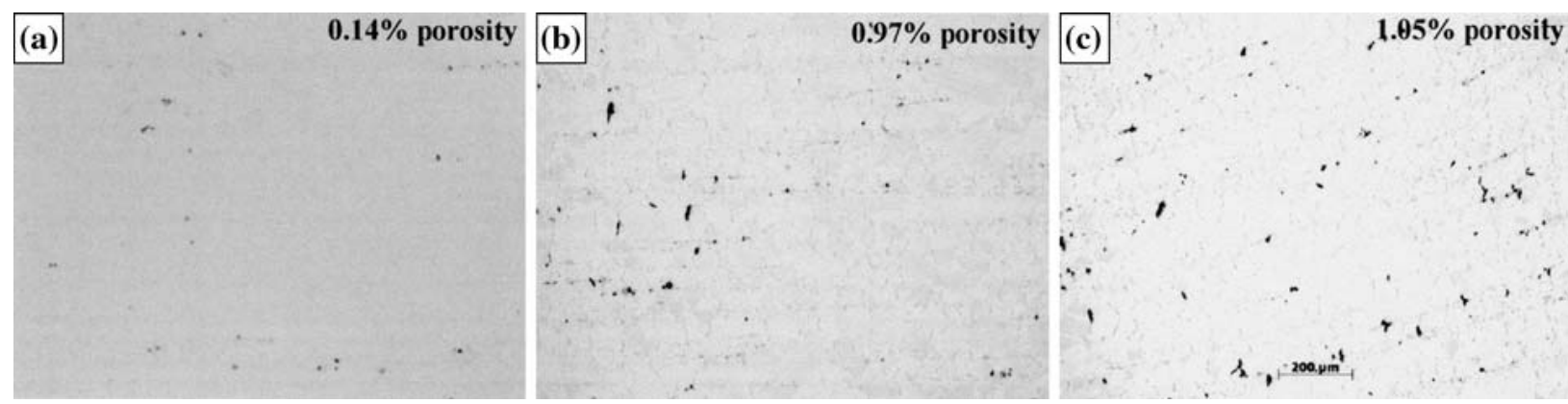

Figure 21. Micrographs showing the porosity resulting from creep of Alloy 617 at $1000^{\circ} \mathrm{C}$ and (a) $5 \%$, (b) $15 \%$, and (c) $25 \%$ creep strain.

Preliminary microstructural characterization was carried out in the gage section of a crept test sample using Transmission Electron Microscopy (TEM) $\left(1000^{\circ} \mathrm{C}, 19.5 \mathrm{MPa}\right.$ to a strain of $\sim 10 \%$ in $193 \mathrm{~h}$, with material from the heat of Alloy 617 used in the creep results presented here). The entire gage length was sectioned perpendicular to the stress axis to produce TEM blanks. Subsequent observation in the TEM did not reveal any creep pore formation at grain boundaries, triple junctions or carbides (Figure 22). A high density of dislocations is seen in the photographs; the dislocation free particles are carbides. The lack of creep voids and wedge cracks on the grain boundaries/triple junctions suggests grain boundary sliding was insignificant during creep and the specimen was likely deforming by dislocation creep prior to the power failure. 


\begin{tabular}{|c|c|c|c|}
\hline $\begin{array}{l}\text { NEXT GENERATION NUCLEAR PLANT STEAM } \\
\text { GENERATOR AND INTERMEDIATE HEAT } \\
\text { EXCHANGER MATERIALS RESEARCH } \\
\text { AND DFVELOPMENT PIAN }\end{array}$ & $\begin{array}{l}\text { Identifier: } \\
\text { Revision: } \\
\text { Effective Date: }\end{array}$ & $\begin{array}{l}\text { PLN-2804 } \\
1 \\
09 / 23 / 10\end{array}$ & Page: 30 of $\mathbf{2 5 2}$ \\
\hline
\end{tabular}
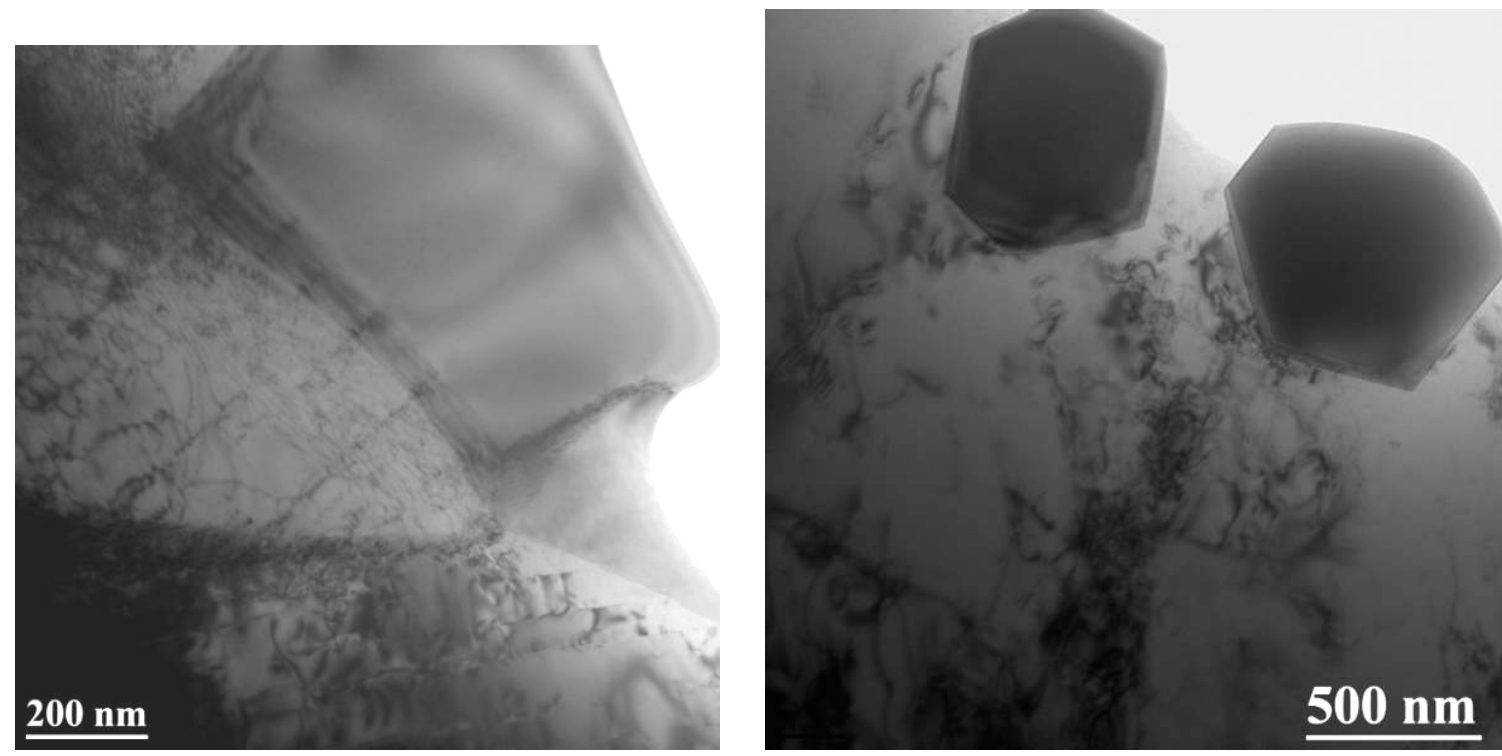

Figure 22. TEM micrographs representative of the microstructure in the gage section of a sample crept at $1000^{\circ} \mathrm{C}, 19.5 \mathrm{MPa}$ to a strain of $\sim 10 \%$.

\subsubsection{Fracture Properties}

Solution annealed Alloy 617 in the as-received condition is very ductile. Because of its high fracture toughness, J-R Curve testing for Alloy 617 is very difficult to conduct; hence, not many fracture toughness data are reported in the literature. Figure 23 shows a J-R Curve at $700^{\circ} \mathrm{C}$, and Figure 24 (a) and (b) show the values of $\mathrm{J}_{0}$ (onset of stable ductile tearing) and the tearing modulus, respectively, as a function of test temperatures from the literature. ${ }^{40}$ The multi-specimen technique was used in determining the J-R Curve. ${ }^{41,42}$

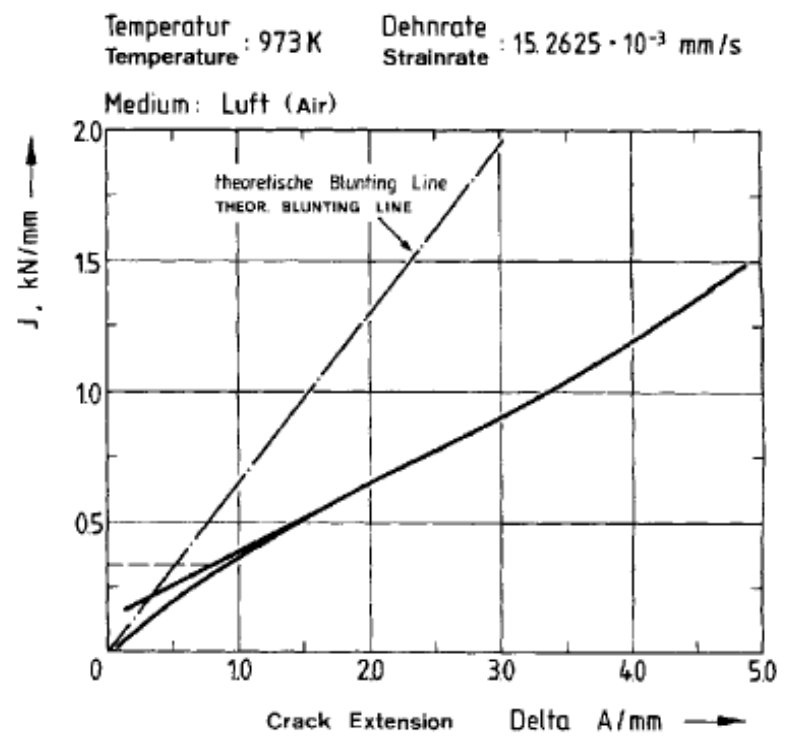

Figure 23. J-R Curve for Alloy 617, as received, $700^{\circ} \mathrm{C}$. 


\begin{tabular}{|c|lll|}
\hline NEXT GENERATION NUCLEAR PLANT STEAM & Identifier: & PLN-2804 & \\
GENERATOR AND INTERMEDIATE HEAT & Revision: & 1 & \\
EXCHANGER MATERIALS RESEARCH & Effective Date: & $09 / 23 / 10$ & Page: 31 of 252 \\
AND DEVELOPMENT PLAN &
\end{tabular}
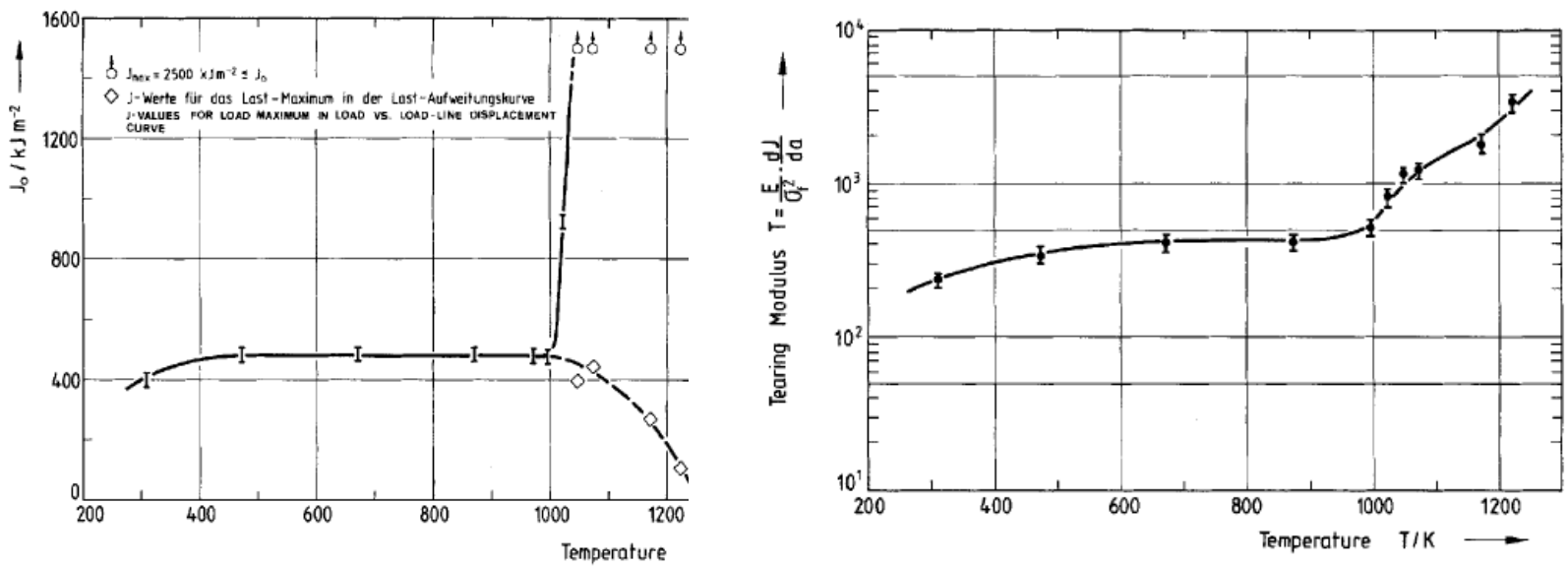

Figure 24. (a) Values of $\mathrm{J}_{0}$ and (b) tearing modulus for Alloy 617, as received (temperature in Kelvin).

As observed from Figure 24 (b), a small increase occurs in $\mathrm{J}_{0}$ between $35^{\circ} \mathrm{C}$ and $200^{\circ} \mathrm{C}$, and it remains constant from $200^{\circ} \mathrm{C}$ to $725^{\circ} \mathrm{C}$, then a strong increase occurs at $750^{\circ} \mathrm{C}$. Krompholz et al ${ }^{40}$ reported that no onset of stable tearing was detectable up to a J-integral value of $2500 \mathrm{~kJ} / \mathrm{m}^{2}$ at temperatures of $775^{\circ} \mathrm{C}$ and above.

No J-R Curve or toughness data were found from the literature on thermally aged Alloy 617. However, data on room-temperature Charpy V-Notch (CVN) energies from thermally aged Alloy 617 have been reported ${ }^{43}$ and are shown in Figure 25. It is seen that the room-temperature CVN energy dropped significantly, depending on the thermal exposure temperature and time, from an averaged unaged value of $170 \mathrm{ft}-\mathrm{lb}$, to as low as $30 \mathrm{ft}-\mathrm{lb}$ for aged Alloy 617. Figure 26 shows the CVN energy for aged Alloy 617 measured at room temperature and aging temperature. ${ }^{44}$ The room-temperature CVN energy dropped to below $10 \mathrm{~J}$ after exposure at $800^{\circ} \mathrm{C}$ and $900^{\circ} \mathrm{C}$ for $10,000 \mathrm{~h}$.

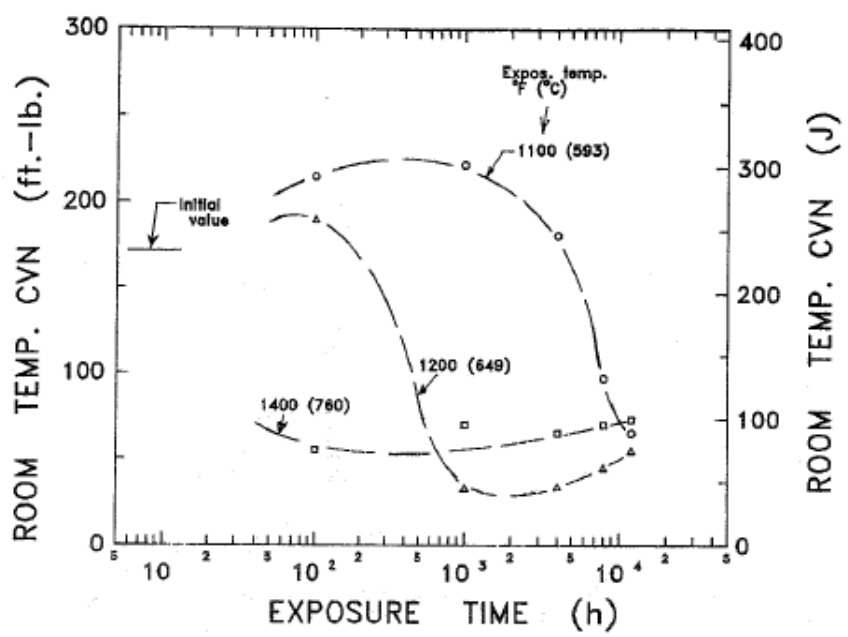

Figure 25. Room-temperature CVN energy of Alloy 617 after thermal exposure. 


\begin{tabular}{|c|lll|}
\hline NEXT GENERATION NUCLEAR PLANT STEAM & Identifier: & PLN-2804 & \\
GENERATOR AND INTERMEDIATE HEAT & Revision: & 1 & \\
EXCHANGER MATERIALS RESEARCH & Effective Date: & $09 / 23 / 10$ & Page: 32 of 252 \\
AND DEVELOPMENT PLAN &
\end{tabular}

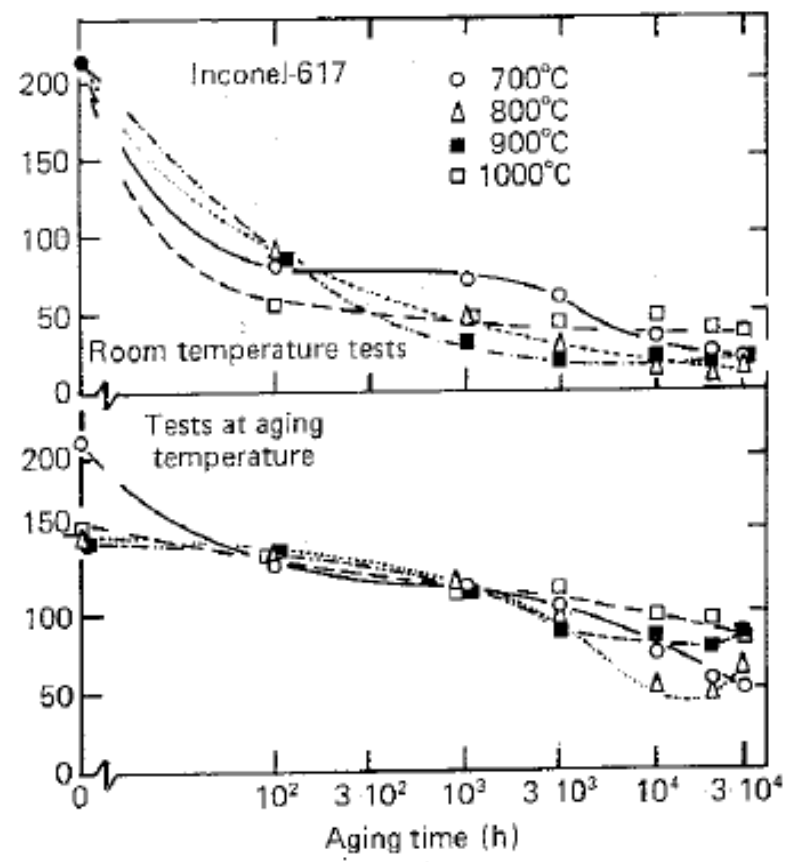

Figure 26. CVN energy of aged Alloy 617 measured at room temperature and aging temperature.

These data show that nonductile failure is a significant failure mode for Alloy 617 for long-term elevated temperature service. The effects of thermal aging on the fracture toughness of Alloy 617 need to be characterized adequately to develop an operating envelope and an ancillary design procedure to protect against nonductile failure. Toughness data from very long thermal exposures, at least 20,000 h, are needed to establish the nonductile failure design procedure and to support the final design and licensing approval. Furthermore, limited CVN data for thermally aged Alloy 617 welds also showed drops in the room temperature $\mathrm{CVN}$ energy for aged material. ${ }^{45}$

ASME codification requires a fracture mechanics analysis to justify the ability of Alloy 617 to withstand the expected service conditions, especially when the component cools down to lower temperatures after extended exposure at elevated temperature. Tests of $0.5 \mathrm{~T}$ compact tension specimens from solution annealed Alloy 617 plate from the NGNP heat have been performed at room temperature, $100,250,750$, and $850^{\circ} \mathrm{C}$. All specimens were fatigue precracked to a crack length/width ratio of about 0.5 . The maximum load during the test, the provisional value of J-integral at onset of crack initiation $\left(\mathrm{J}_{\mathrm{q}}\right)$, and the tearing modulus are tabulated in Table 6 . For the tests at 750 and $850^{\circ} \mathrm{C}$, values of $\mathrm{J}_{\mathrm{q}}$ and tearing modulus could not be calculated because crack extension did not occur in the specimens under these loading conditions. The rows printed in bold font in the table are the average values of multiple tests at the indicated temperature. Additional testing is underway. 


\begin{tabular}{|c|lll|}
\hline NEXT GENERATION NUCLEAR PLANT STEAM & Identifier: & PLN-2804 & \\
GENERATOR AND INTERMEDIATE HEAT & Revision: & 1 & \\
EXCHANGER MATERIALS RESEARCH & Effective Date: & $09 / 23 / 10$ & Page: 33 of 252 \\
AND DEVELOPMENT PLAN &
\end{tabular}

Table 6. Fracture properties of solution annealed Alloy 617.

Test

\begin{tabular}{ccccc}
$\begin{array}{c}\text { Temperature } \\
\left({ }^{\circ} \mathrm{C}\right)\end{array}$ & $\begin{array}{c}\text { Maximum } \\
\text { Load }(\mathrm{lbs})\end{array}$ & \multicolumn{2}{c}{$\begin{array}{c}\mathrm{J}_{\mathrm{q}} \\
(\mathrm{psi}) \\
\left(\mathrm{kJ} / \mathrm{m}^{2}\right)\end{array}$} & $\begin{array}{c}\text { Tearing } \\
\text { Modulus }\end{array}$ \\
\hline $\mathrm{RT}$ & 2900 & 5167 & 904 & 126 \\
RT & $\mathbf{3 0 5 0}$ & $\mathbf{4 8 4 4}$ & $\mathbf{8 4 8}$ & $\mathbf{1 3 1}$ \\
$\mathrm{RT}$ & 3200 & 4520 & 791 & 135 \\
100 & 2750 & 4046 & 708 & 96 \\
$\mathbf{1 0 0}$ & $\mathbf{2 7 7 5}$ & $\mathbf{4 2 7 5}$ & $\mathbf{7 4 8}$ & $\mathbf{1 0 7}$ \\
100 & 2800 & 4504 & 788 & 117 \\
250 & 2800 & 5165 & 904 & 139 \\
$\mathbf{2 5 0}$ & $\mathbf{2 9 0 0}$ & $\mathbf{4 7 2 2}$ & $\mathbf{8 2 6}$ & $\mathbf{1 4 6}$ \\
250 & 3000 & 4278 & 749 & 153 \\
$\mathbf{7 5 0}$ & $\mathbf{2 6 0 0}$ & No CG & No CG & No CG \\
$\mathbf{8 5 0}$ & $\mathbf{1 3 0 0}$ & No CG & No CG & No CG \\
\hline
\end{tabular}

$\mathrm{RT} \equiv$ Room Temperature

$\mathrm{CG} \equiv$ Crack Growth

At room temperature, the ductile initiation fracture toughness, $\mathrm{J}_{\mathrm{q}}$, for this unaged Alloy 617 material is about 800 to $900 \mathrm{~kJ} / \mathrm{m}^{2}$ and the tearing modulus (dimensionless) is about 130 . These values are reflective of a very tough material. The results at test temperatures of 100 and $250^{\circ} \mathrm{C}$ were very similar in behavior and in toughness values to those at room temperature. The load versus crack-mouth opening displacement record and a plot of J versus $\Delta \mathrm{a}$ (crack extension) for one of the fracture toughness tests performed at room temperature are shown in Figure 27.
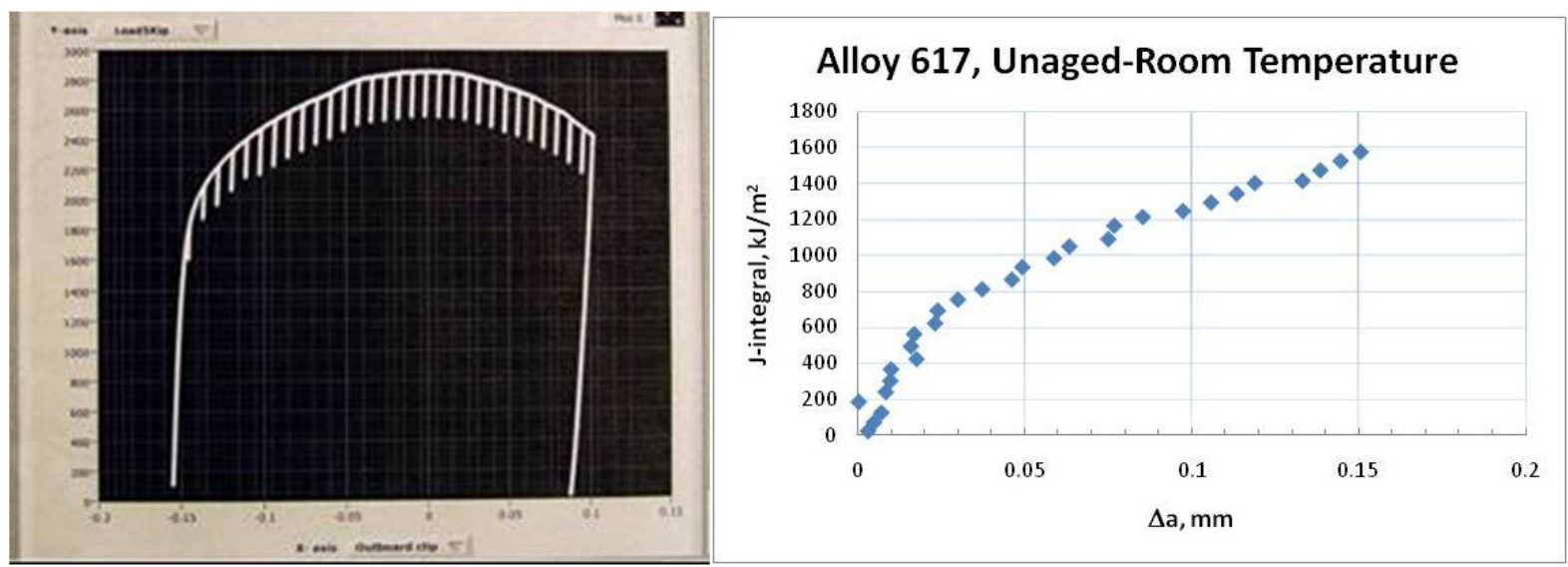

Figure 27. Load vs. crack-mouth opening displacement record and a plot of J versus $\Delta \mathrm{a}$ (crack extension) for a $0.5 \mathrm{~T}$ compact fracture toughness test performed at room temperature.

Eighteen Charpy V-notch (CVN) impact specimens of solution annealed (unaged) Alloy 617 have been tested. Half of these were aligned with the rolling direction, and half transverse to the rolling direction; however, the results indicate no significant effect of notch orientation for this heat of Alloy 617. CVN impact specimens, from Alloy 617 aged for $200 \mathrm{~h}$ at 750, 800, 850, 900, 950, and $1000^{\circ} \mathrm{C}$, have also 


\begin{tabular}{|c|lll|}
\hline NEXT GENERATION NUCLEAR PLANT STEAM & Identifier: & PLN-2804 & \\
GENERATOR AND INTERMEDIATE HEAT & Revision: & 1 & \\
EXCHANGER MATERIALS RESEARCH & Effective Date: & $09 / 23 / 10$ & Page: 34 of 252 \\
AND DEVELOPMENT PLAN &
\end{tabular}

been tested. Figure 28 shows the $\mathrm{CVN}$ results obtained for the solution annealed (unaged) specimens and specimens aged at $950^{\circ} \mathrm{C}$. Figure 29 provides a graphical summary of the test results for all the CVN tests. The diamond symbols represent the absorbed energy measured at room temperature for each case. The square symbols represent a test temperature of $250^{\circ} \mathrm{C}$, the test temperature with the highest absorbed energy measured over the range of test temperatures (up to $950^{\circ} \mathrm{C}$ ) for each aging condition.
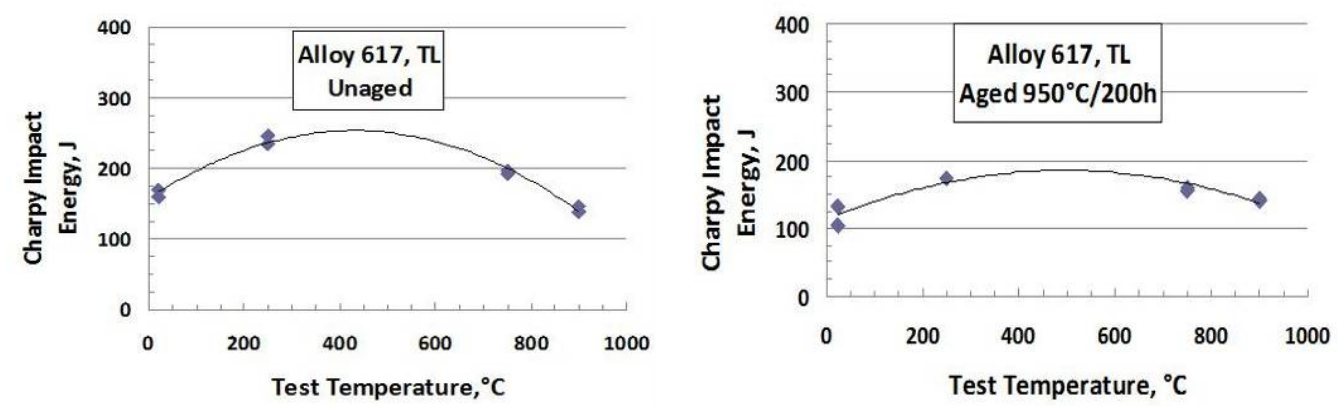

Figure 28. Charpy impact energies for solution annealed and aged Alloy 617 tested at temperatures from ambient to $900^{\circ} \mathrm{C}$.

\section{Room Temperature Energy, J Highest Energy for Series, J}

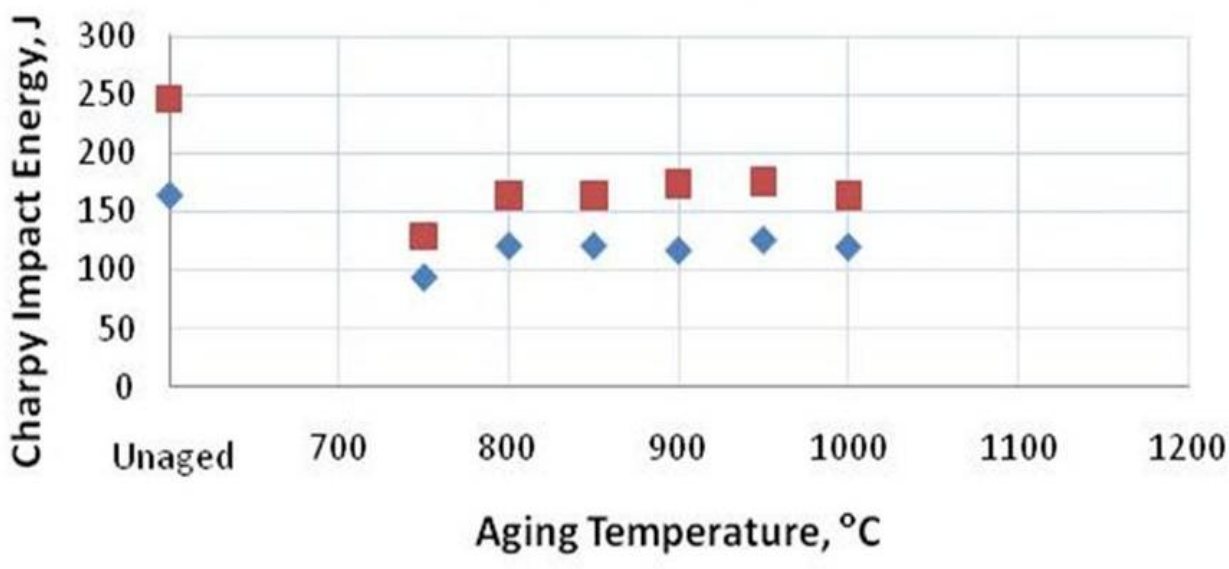

Figure 29. Highest observed CVN impact energies of solution annealed and aged Alloy 617.

\subsubsection{Welding Process Development of Alloy 617}

Alloy 617 has excellent weldability using Alloy 617 filler metal; the composition of the filler metal matches that of the base metal, and deposited weld metal is comparable to the wrought alloy in strength and corrosion resistance. ${ }^{46}$ Gas tungsten arc welding (GTAW), gas metal arc welding (GMAW), shielded metal arc welding, and resistance welding techniques can be used. Submerged-arc welding is not recommended as this process is characterized by high heat input to the base metal and slow cooling of the weld. These factors can increase weld restraint and promote cracking. Typical as-welded properties of these alloys are given in Table $7 .^{46}$ 


\begin{tabular}{|c|lll|}
\hline $\begin{array}{c}\text { NEXT GENERATION NUCLEAR PLANT STEAM } \\
\text { GENERATOR AND INTERMEDIATE HEAT }\end{array}$ & Identifier: & PLN-2804 & \\
EXCHANGER MATERIALS RESEARCH & Revision: & 1 & \\
AND DEVELOPMENT PLAN & Effective Date: & $09 / 23 / 10$ & Page: 35 of 252 \\
\hline
\end{tabular}

Table 7. Room-temperature tensile properties of joints in as-welded condition.

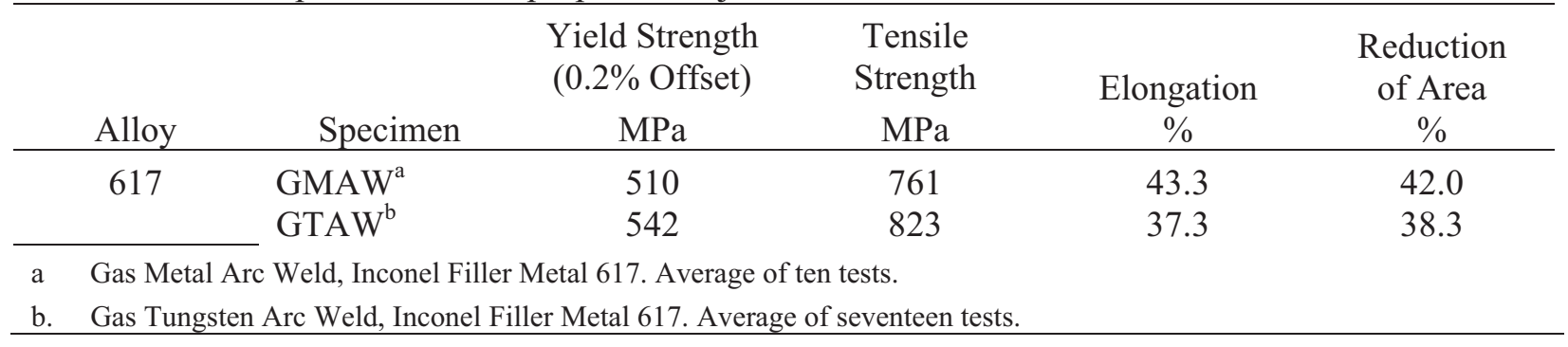

Procedures for Alloy 617 welding using the gas metal arc process have been developed, demonstrated and qualified using the INL Welding Program process for Alloy 617 using Alloy 617 filler wire. ${ }^{47}$ After qualification of the process, multiple weldments were prepared for mechanical testing.

A double groove joint geometry was used and subsequent weld passes were completed on opposite sides of the weld preparation to minimize distortion due to residual stresses. Welds were completed in a total of about 20 passes, with the plate allowed to cool to ambient temperature between passes.

A low magnification micrograph on a polished and etched cross-section of the weld taken at about the midpoint of the plate is shown in Figure 30 and a higher magnification of the weld metal and heat affected zone is shown in Figure 31. It is apparent from the micrographs that there is complete fusion and no porosity or cracking occurred in the weld metal or heat affected zone.

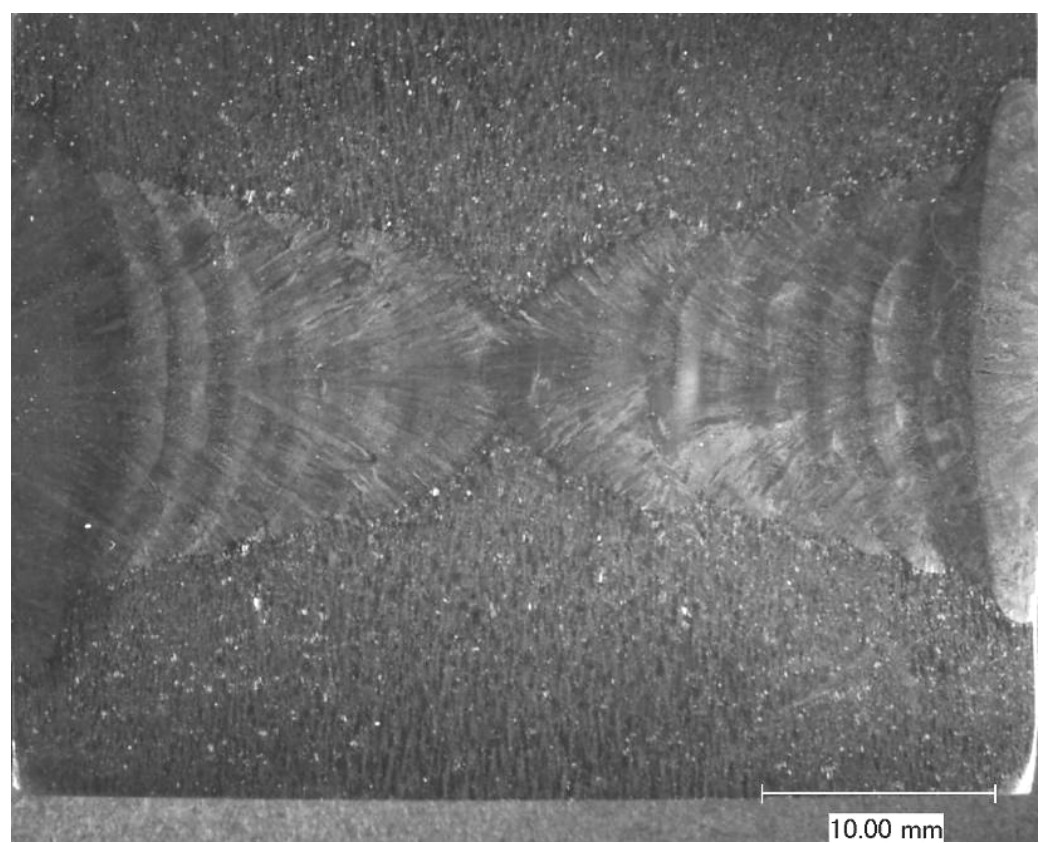

Figure 30. Low magnification of an etched cross-section through the weldment in Alloy 617 plate showing build-up of the weld metal through approximately 20 total welding passes. 


\begin{tabular}{|c|lll|}
\hline NEXT GENERATION NUCLEAR PLANT STEAM & Identifier: & PLN-2804 & \\
GENERATOR AND INTERMEDIATE HEAT & Revision: & 1 & \\
EXCHANGER MATERIALS RESEARCH & Effective Date: & $09 / 23 / 10$ & Page: 36 of 252 \\
AND DEVELOPMENT PLAN & &
\end{tabular}

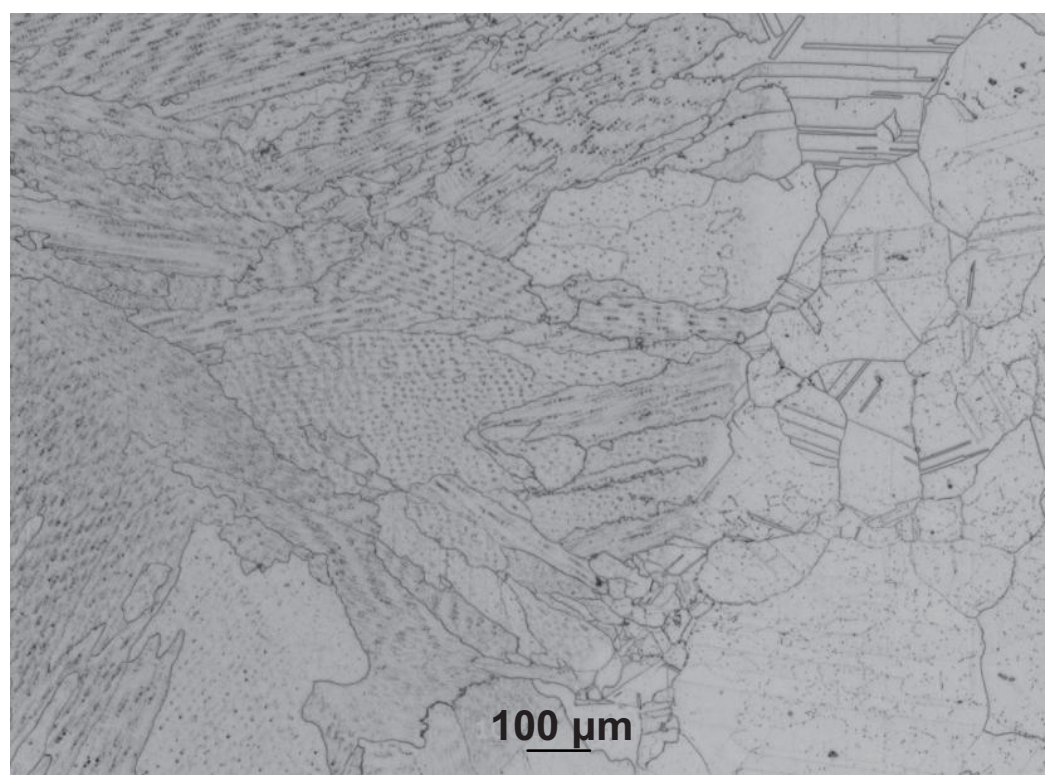

Figure 31. Micrograph showing the weld metal and heat affected zone microstructure in a gas metal arc welded Alloy 617 plate welded with Alloy 617 weld wire.

A microhardness survey was performed across an Alloy 617 weldment in the unaged condition. The microhardness profile is shown in Figure 32, with dashed lines delineating the approximate location of the heat affected zones (HAZs) on each side of the weld metal. The base metal hardness is about 230, rising to about 290 in the HAZ, and with an average of 270 in the weld metal.

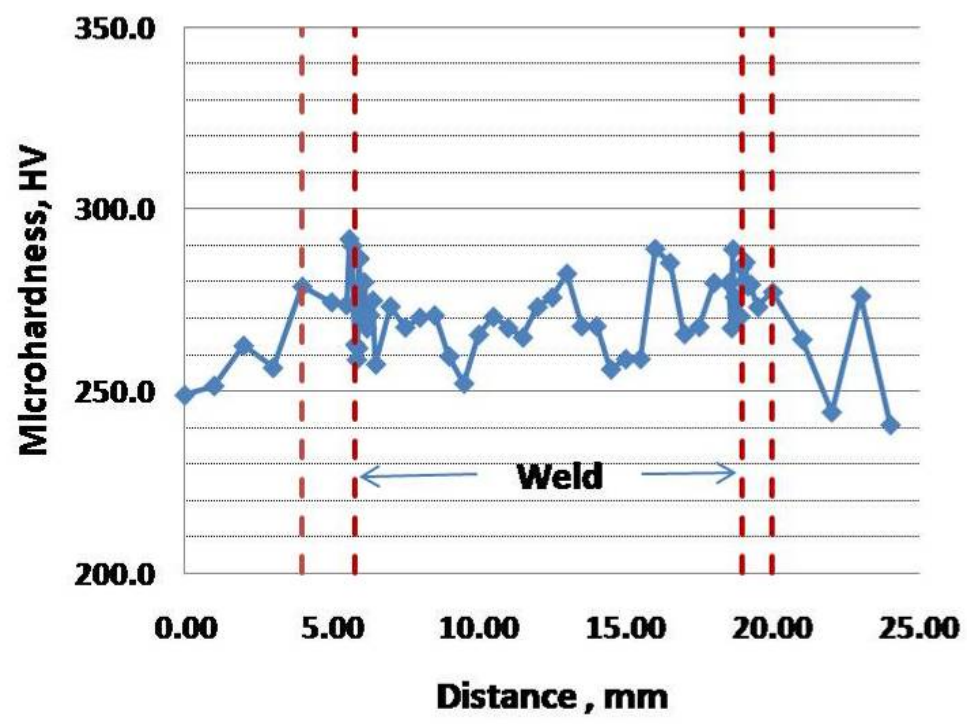

Figure 32. Microhardness profile across the Alloy 617 weldment (dashed lines indicate the approximate positions of the HAZ regions). 


\begin{tabular}{|c|lll|}
\hline $\begin{array}{c}\text { NEXT GENERATION NUCLEAR PLANT STEAM } \\
\text { GENERATOR AND INTERMEDIATE HEAT } \\
\text { EXCHANGER MATERIALS RESEARCH }\end{array}$ & Identifier: & PLN-2804 & \\
AND DEVELOPMENT PLAN & Effective Date: & $09 / 23 / 10$ & Page: 37 of 252 \\
\hline
\end{tabular}

\subsection{2 $800 \mathrm{H}(42 \mathrm{Fe}-33 \mathrm{Ni}-21 \mathrm{Cr})$}

Alloy $800 \mathrm{H}$, also designated as Incoloy $800 \mathrm{H}$, or UNS N08810, is the only alloy among the four candidate materials that is ASME Code qualified for use in nuclear systems, but only for temperatures up to $760^{\circ} \mathrm{C}$ and a maximum service time of $300,000 \mathrm{~h}$. Alloy $800 \mathrm{H}$ was the primary high temperature alloy used in the German HTGR programs and an enormous amount of data was obtained. However, only limited data are currently available on the mechanical properties of this alloy beyond $800^{\circ} \mathrm{C}$, especially in impure helium environments. As summarized in Section 5.1.3, Task 1 of the DOE initiative to address ASME Code issues for Generation IV reactors is to extend the allowable stresses of Alloy $800 \mathrm{H}$ to $900^{\circ} \mathrm{C}$ and $600,000 \mathrm{~h}$.

The 800 series of alloys were developed for high temperature strength and resistance to oxidation, carburization and other forms of high temperature corrosion. Alloy $800 \mathrm{H}$ has the lowest creep-rupture strength and the worst resistance to oxidation of the candidate alloys.

Four $\sim 0.75 \mathrm{~m}$ square plates of $12 \mathrm{~mm}(0.5$ inch) thick plates of solution treated Alloy $800 \mathrm{HT}$ from a single heat (cast 37458) have been obtained for use in this R\&D program. The material, in storage at ORNL, was procured originally from Jessop Steel, the manufacturer when the plate was produced. Jessop Steel was subsequently bought by Allegheny Ludlum. Alloy $800 \mathrm{HT}$ has a more restrictive chemistry and grain size requirement compared to $800 \mathrm{H}$; however, Alloy $800 \mathrm{HT}$ is within the specifications of $800 \mathrm{H}$. It appears that current practice for all of the major alloy vendors is to produce only Alloy 800HT rather than provide all three variants of the material. All mechanical test specimens for which results are presented below were machined from annealed plate; the long axis of the specimen aligned with the rolling direction.

\subsubsection{Chemistry of Alloy $800 \mathrm{H}$}

The ASTM Standard chemical composition of Alloy $800 \mathrm{H}$ and that of the heat obtained by this R\&D program are given in Table $8 .{ }^{48}$ Alloy $800 \mathrm{H}$ is the only iron-based alloy under consideration, although it has a solid-solution strengthened austenitic structure like the other candidate alloys. The iron reduces susceptibility to internal oxidation. Alloy $800 \mathrm{H}$ is free of precipitates in the solution annealed condition; however, upon aging, $\gamma$ ' precipitates can form and reduce the tensile and creep ductility. The volume fraction of precipitates is controlled by limiting the concentration of $\mathrm{Al}$ and $\mathrm{Ti}$ and the carbon content is controlled to produce improved creep-rupture properties.

Table 8. Chemical composition (wt $\%$ ) of Alloy $800 \mathrm{H}$.

\begin{tabular}{lcccccccccc}
\hline & $\mathrm{Ni}$ & $\mathrm{Cr}$ & $\mathrm{Fe}$ & $\mathrm{Mn}$ & $\mathrm{C}$ & $\mathrm{Cu}$ & $\mathrm{Si}$ & $\mathrm{S}$ & $\mathrm{Al}$ & $\mathrm{Ti}$ \\
\hline Min & 35.0 & 19.0 & 39.5 & - & 0.06 & - & - & - & 0.15 & 0.15 \\
Max & 30.0 & 23.0 & - & 1.5 & 0.10 & 0.75 & 1.0 & 0.015 & 0.60 & 0.60 \\
Heat & & & & & & & & & & \\
37458 & 30.5 & 19.3 & 47.1 & 1.3 & 0.06 & 0.21 & 0.4 & 0.001 & 0.43 & 0.45 \\
\hline
\end{tabular}

\subsubsection{Microstructure of Alloy $800 \mathrm{H}$}

Longitudinal and transverse microstructures of the NGNP Alloy $800 \mathrm{H}$ plate are shown in Figure 34, showing little difference between the two orientations. There is little evidence of banding. An annealing treatment is specified for $800 \mathrm{H}$ to produce an ASTM grain size of 5 or coarser. The average grain size of heat 37548 is $\sim 135 \mu \mathrm{m}$ (ASTM grain size of 0 ), well within the specification for $800 \mathrm{H}$. 


\begin{tabular}{|c|c|c|c|}
\hline $\begin{array}{l}\text { NEXT GENERATION NUCLEAR PLANT STEAM } \\
\text { GENERATOR AND INTERMEDIATE HEAT } \\
\text { EXCHANGER MATERIALS RESEARCH } \\
\text { AND DEVELOPMENT PLAN }\end{array}$ & $\begin{array}{l}\text { Identifier: } \\
\text { Revision: } \\
\text { Effective Date: }\end{array}$ & $\begin{array}{l}\text { PLN-2804 } \\
1 \\
09 / 23 / 10\end{array}$ & Page: 38 of $\mathbf{2 5 2}$ \\
\hline
\end{tabular}

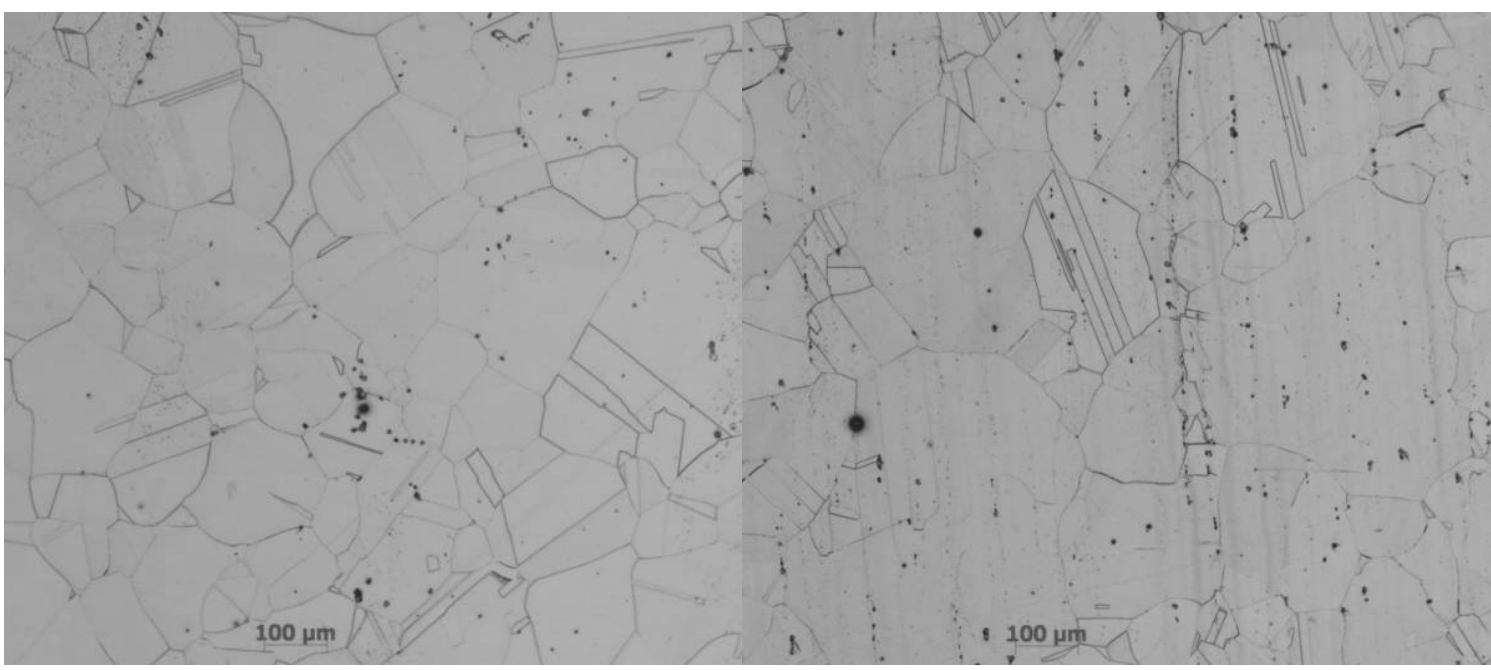

(a)

(b)

Figure 33. Micrographs of heat 37458 of Alloy $800 \mathrm{H}$ for (a) longitudinal and (b) transverse sections.

\subsubsection{Tensile Behavior}

Elevated temperature tensile properties were measured at $50^{\circ} \mathrm{C}$ intervals for the NGNP Alloy $800 \mathrm{H}$ in the temperature range of $500-850^{\circ} \mathrm{C}$. Room temperature tensile tests were also done. Testing was performed at an initial strain rate of $1.6 \times 10^{-4} / \mathrm{s}$. Stress-strain curves for these tests are shown in Figure 34. Several tests were replicated to assess the reproducibility of results; however, the replicated tensile curves are not plotted in Figure 34 to avoid further complexity in the plot. The yield strength values in replicate tests are quite consistent. Measured ductility and ultimate tensile strength exhibit more variability. The latter is related to flow localization, and the variability may reflect inhomogeneity in the microstructure resulting from ingot solidification and hot rolling. The yield strength of the material is not significantly affected by these inhomogeneities.

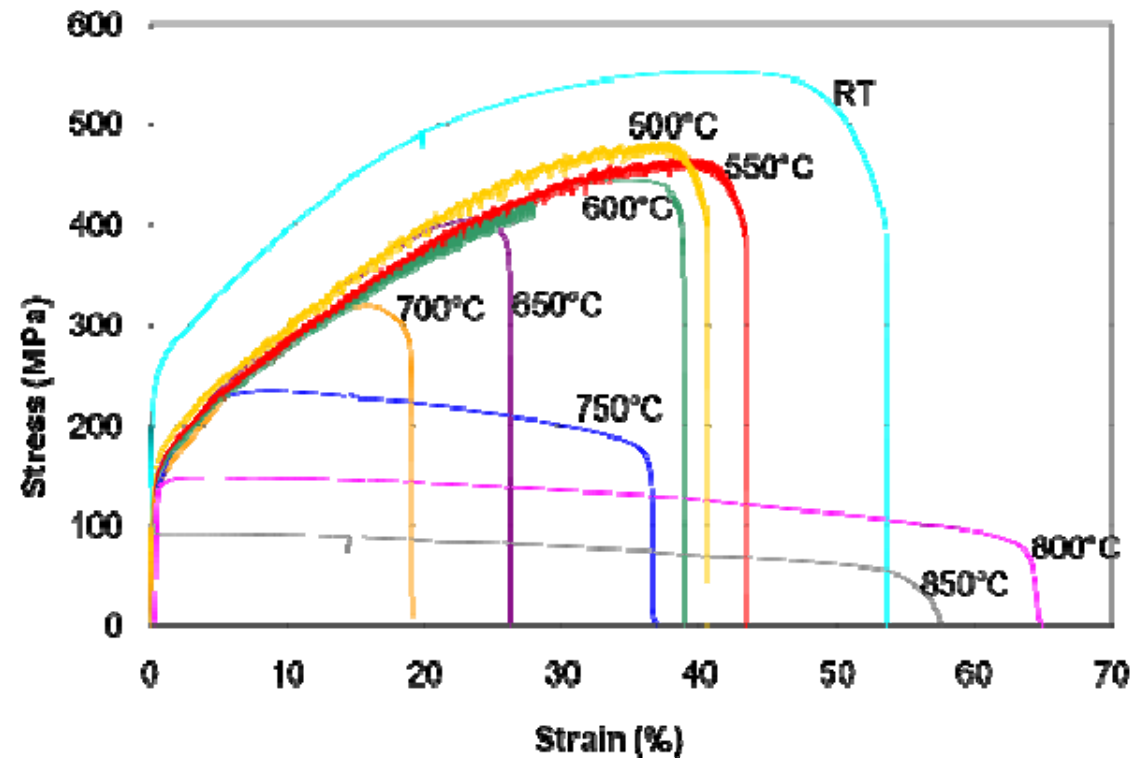

Figure 34. Tensile stress-strain curves for Alloy $800 \mathrm{H}$. 


\begin{tabular}{|c|lll|}
\hline $\begin{array}{c}\text { NEXT GENERATION NUCLEAR PLANT STEAM } \\
\text { GENERATOR AND INTERMEDIATE HEAT }\end{array}$ & Identifier: & PLN-2804 & \\
EXCHANGER MATERIALS RESEARCH & Revision: & 1 & \\
AND DEVELOPMENT PLAN & Effective Date: & $09 / 23 / 10$ & Page: 39 of 252 \\
\hline
\end{tabular}

The yield strength of Alloy $800 \mathrm{H}$ decreases significantly between room temperature and $500^{\circ} \mathrm{C}$, then remains nearly constant before declining at $850^{\circ} \mathrm{C}$. The alloy exhibits work hardening subsequent to yielding up to $750^{\circ} \mathrm{C}$; above this temperature the material is nearly perfectly plastic. At temperatures where there is substantial work hardening the ductility decreases with increasing test temperature. Where the material is approximately perfectly plastic, the ductility increases significantly. Alloy $800 \mathrm{H}$ exhibits DSA in the temperature regime of 500 to $650^{\circ} \mathrm{C}$ at this strain rate.

Figure 35 shows yield strength and ultimate tensile strength data from the literature for a large number of heats of Alloy $800 \mathrm{H} .{ }^{49}$ The approximate values for these properties, measured for the current heat of material, are plotted on the figures as large triangles. It can be seen that the yield strengths measured here fall well within the range measured previously. The ultimate tensile strength values are generally within expected ranges of values except at the highest temperatures, where they are slightly below the range measured previously. It should be noted that data from the literature become sparse at some of the highest test temperatures since the higher temperatures are well above the anticipated application temperature for this alloy. The upper ASME Code qualification temperature in Subsection NH is only $761^{\circ} \mathrm{C}$. With more testing, it is possible that the range of values would be larger.

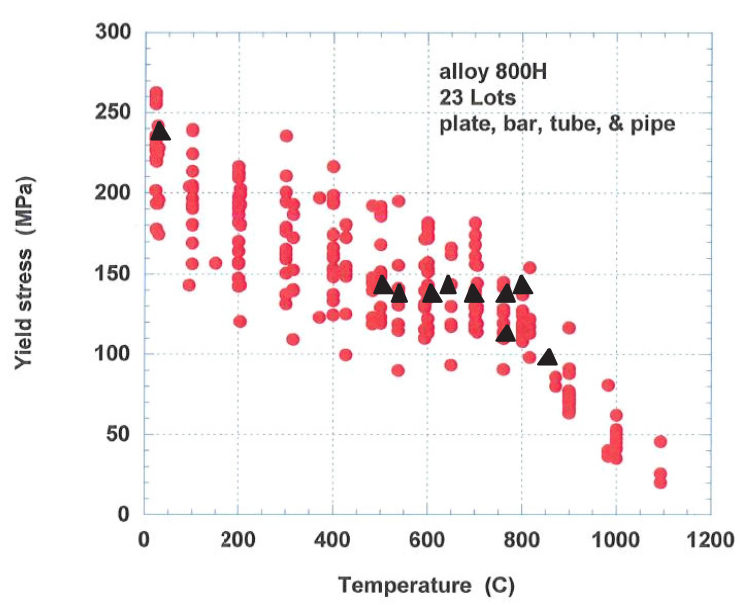

(a)

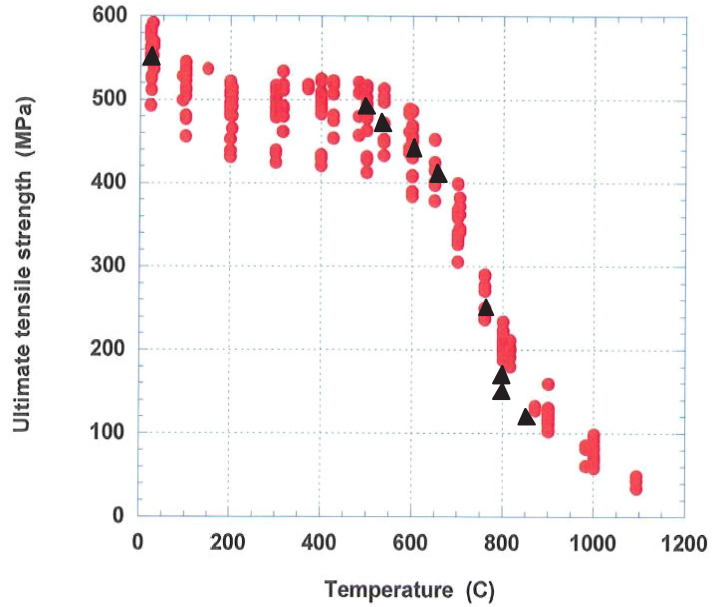

(b)

Figure 35. (a) Yield strength and (b) ultimate tensile strength values for a large number of heats of Alloy $800 \mathrm{H}$ (red symbols) and approximate values from the current tests (black symbols).

\subsubsection{Welding Process Development of Alloy $800 \mathrm{H}$}

Procedures for Alloy $800 \mathrm{H}$ welding using the gas metal arc process have been developed, demonstrated, and qualified using the INL Welding Program process for Alloy $800 \mathrm{H}$ using Alloy $617^{50}$ and Alloy 82 filler wire compositions. ${ }^{51}$ Alloy 82 is commonly used with Alloy $800 \mathrm{H}$, since its properties typically match the base metal properties well. Alloy 617 is typically used for higher temperature applications where increased creep strength is required. The weld procedure meets the requirements of ASME B\&PV Code Section IX. This procedure can be used to process material for testing to extend the Alloy $800 \mathrm{H}$ Code Case as part of the NGNP High Temperature Metals Research and Development Program.

Sound welds with no indication of cracking, lack of fusion or significant porosity were produced. Polished and etched cross sections through the completed welds are shown in Figure 36. 


\begin{tabular}{|c|lll|}
\hline NEXT GENERATION NUCLEAR PLANT STEAM & Identifier: & PLN-2804 & \\
GENERATOR AND INTERMEDIATE HEAT & Revision: & 1 & \\
EXCHANGER MATERIALS RESEARCH & Effective Date: & $09 / 23 / 10$ & Page: 40 of 252 \\
AND DEVELOPMENT PLAN &
\end{tabular}
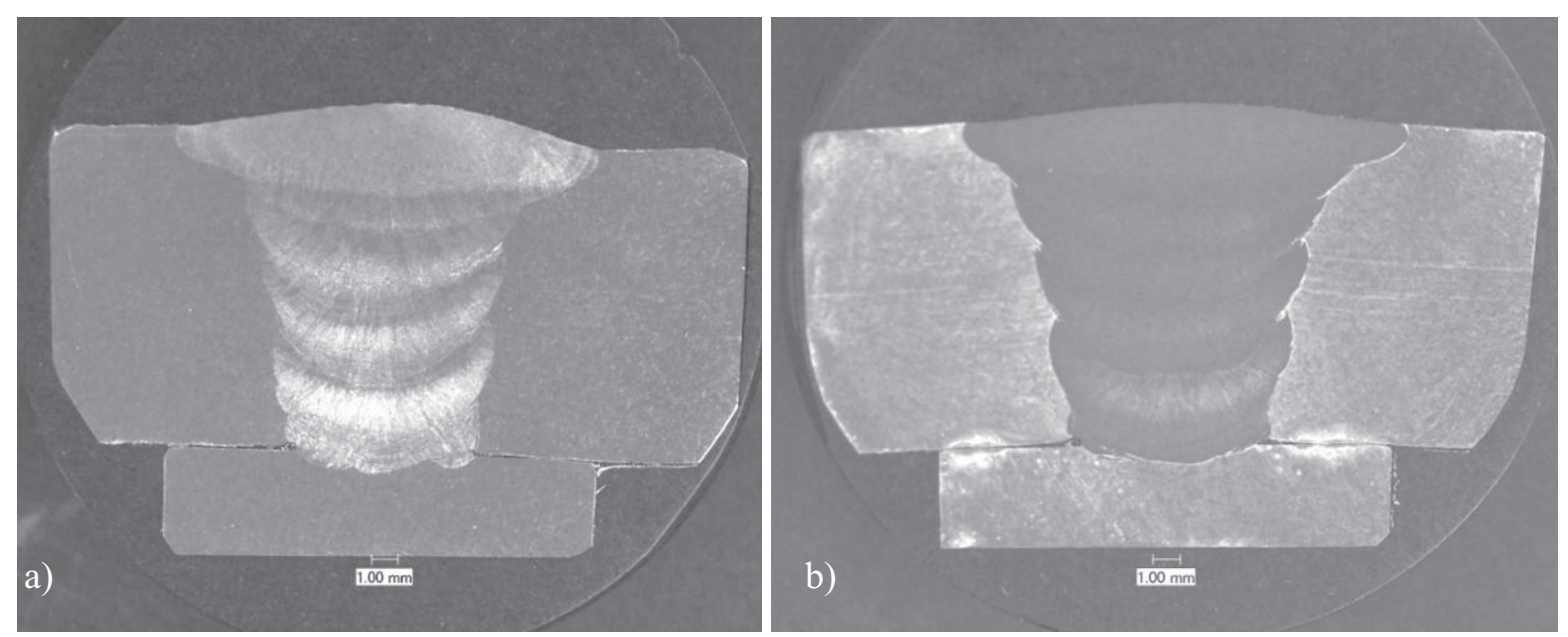

Figure 36. Cross-sections through GMA weld in Alloy $800 \mathrm{H}$ plate using (a) Alloy 82 filler metal and (b) Alloy 617 filler metal.

Two specimens from each weldment were tested in tension at room temperature. All of the specimens failed in the base metal away from the weld with significant ductility and ultimate tensile strengths greater than $550 \mathrm{MPa}$.

\subsubsection{Hastelloy X (47Ni-22Cr-9Mo-18Fe)}

No research is currently being done on Hastelloy X (or XR) within the NGNP or GIF programs; however, vendors continue to list it as a candidate material. Hastelloy $\mathrm{X}$ has the best oxidation resistance of the four alloys in the temperature range relevant to the NGNP, although its carburization resistance is the worst. Above $700^{\circ} \mathrm{C}$, Hastelloy X can form embrittling phases that result in property degradation. The creep-rupture strength at temperatures that might be encountered in the IHX is not as good as Alloy 617 or 230.

A limited database exists for Hastelloy X, but the high temperature scaling in Hastelloy X has not been acceptable. As a result, a modified version, Hastelloy XR, has been developed in Japan; however, the U.S. has little access to XR material, either for evaluation or for ASME Code qualification. The Japanese are currently using Hastelloy XR in a heat exchanger in the HTTR at temperatures of $850-950^{\circ} \mathrm{C}$. The material is codified in Japan for nuclear use, which would likely accelerate code acceptance in ASME. An extensive environmental database and HTGR experience exist. However, the database may be limited to large grain material, similar to the Draft Alloy 617 Code Case. Also, similar to the Draft Alloy 617 Code Case, XR may have issues such as weldments that need to be addressed. 


\begin{tabular}{|c|lll|}
\hline $\begin{array}{c}\text { NEXT GENERATION NUCLEAR PLANT STEAM } \\
\text { GENERATOR AND INTERMEDIATE HEAT } \\
\text { EXCHANGER MATERIALS RESEARCH }\end{array}$ & Identifier: & PLN-2804 & \\
AND DEVELOPMENT PLAN & Effective Date: & $09 / 23 / 10$ & Page: 41 of 252 \\
\hline
\end{tabular}

\subsection{Environmental Effects}

The helium coolant in the primary circuit of any HTGR contains low levels of impurities after steady-state operation that can lead to an environmental degradation of the high temperature alloys used for internals and heat exchangers. Depending on the impurity concentration and the temperature, high temperature alloys can undergo oxidation, carburization, or decarburization. All reactors that have operated to date have had similar impurity levels, producing a stable oxidizing condition (Zone III in Figure 37) for chromia forming alloys like Alloys $800 \mathrm{H}$ and 617 . Consequently there have been no reported problems with failure of components on the primary side associated with environmental effects. Outside of the stable oxidizing regime,

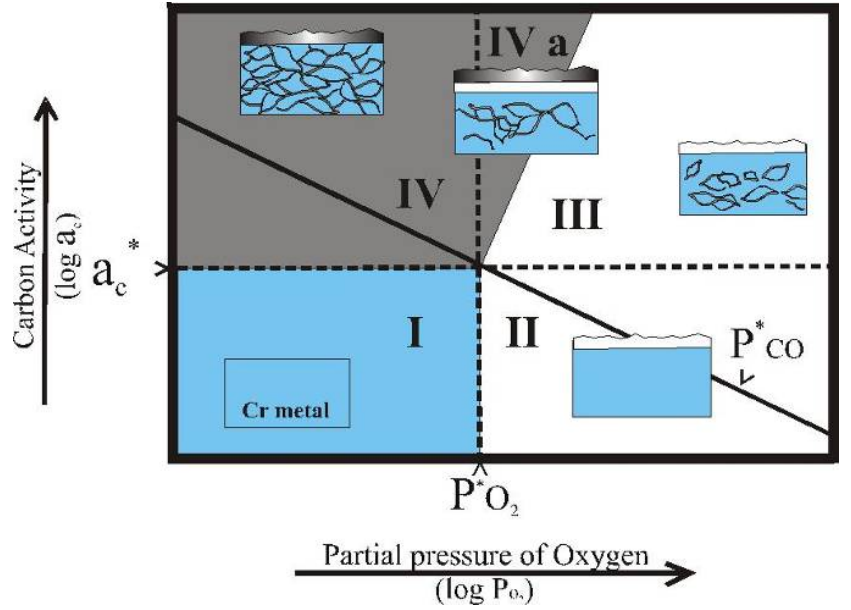

Figure 37. The modified Ellingham stability diagram for Alloy 617. carburization can be associated with low temperature embrittlement and decarburization is linked to reduced creep-rupture strength.

The optimum coolant chemistry for long-term stability of high temperature alloys is slightly oxidizing and results in formation of a tenacious and protective $\mathrm{Cr}_{2} \mathrm{O}_{3}$ scale. The concentrations of $\mathrm{H}_{2} \mathrm{O}$ and $\mathrm{CO}$ are of particular interest because they essentially control the oxygen partial pressure and carbon activity, respectively. The massive amounts of graphite in the reactor play a major role in maintaining the gas chemistry, and a SG inevitably influences the $\mathrm{H}_{2} \mathrm{O}$ levels. Model chemistries used in many of the controlled studies tend to have higher levels of some impurities than those found in operating reactors.

While the mechanisms of degradation are relatively well-known, the kinetics of the reactions for reactor conditions of high helium pressure and velocity are not well characterized. Most laboratory studies have been at very low flow rates to approach thermodynamic equilibrium for fundamental studies of corrosion mechanisms. Similarly, typical test protocols have employed a pressure of $2 \mathrm{~atm}$, while the NGNP will operate at approximately $60 \mathrm{~atm}$.

\subsubsection{NGNP Research on Environmental Effects}

The NGNP materials program has extended previous studies on environmental effects of prototype impure helium on Alloy 617, and to a lesser extent Alloy $800 \mathrm{H}$, by increasing temperatures and using test coupons that incorporate fusion welds in controlled chemistry test loops. The ultimate goal is to be able to predict the corrosion mechanism in effect for a particular gas chemistry at a given temperature for the selected alloy.

A closed-circuit, low-flow velocity test loop has been designed and assembled at INL. A schematic of the loop is shown in Figure 38. It has the potential to continuously getter excess impurities and add necessary trace impurities based on mass spectroscopy measurements in a closed loop system. The system volume is about 20 liters, can be heated to $1000^{\circ} \mathrm{C}$, evacuated to a pressure of $10^{-6}$ torr and subjected to a flow rate of $40 \mathrm{l} / \mathrm{m}$. All impurities are added to the system as individual gases using a precisely controlled automated valve set-up. Impurities are controlled at parts per million levels in helium that flows in the closed loop at a flow rate of approximately $0.21 / \mathrm{s}$. 


\begin{tabular}{|c|lll|}
\hline $\begin{array}{c}\text { NEXT GENERATION NUCLEAR PLANT STEAM } \\
\text { GENERATOR AND INTERMEDIATE HEAT } \\
\text { EXCHANGER MATERIALS RESEARCH } \\
\text { AND DEVELOPMENT PLAN }\end{array}$ & Revision: & 1 & \\
Effective Date: & $09 / 23 / 10$ & Page: 42 of 252 \\
\hline
\end{tabular}

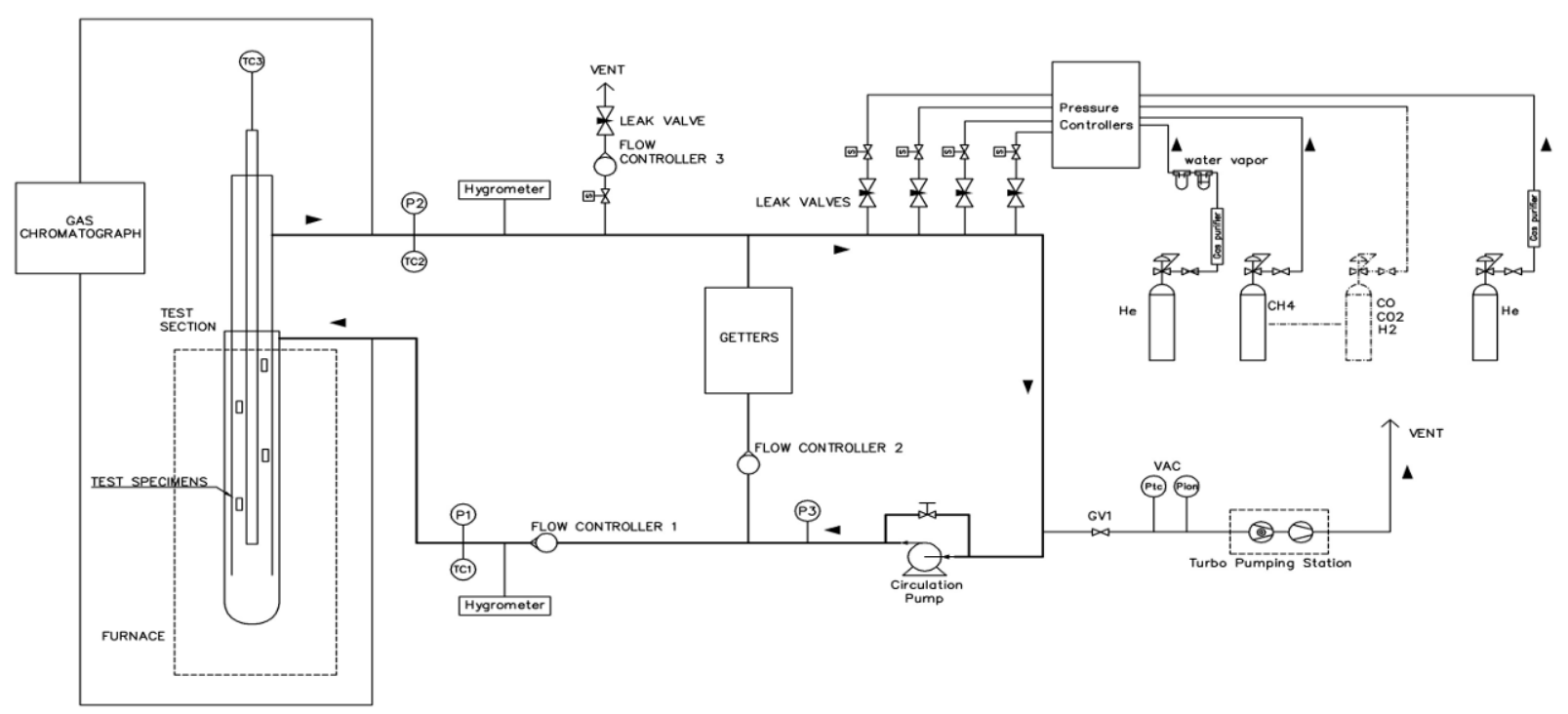

Figure 38. Schematic of the current configuration of the INL controlled chemistry high temperature testing loop.

\subsubsection{Environmental Effects for Alloy 617}

The mechanisms of environmental interaction between Alloy 617 and prototype HTGR helium chemistries have been extensively studied. A modified type of Ellingham diagram that maps the ranges of carbon activity and oxygen partial pressure that result in each of the degradation mechanisms has been developed (Figure 37). Zone III in the Ellingham stability diagram is preferred for optimal chromia layer protection against corrosion. In addition, there is a maximum service temperature above about $950^{\circ} \mathrm{C}$ for each alloy determined by the microclimate reaction or volatilization of $\mathrm{Cr}_{2} \mathrm{O}_{3}$.

Micrographs of cross-sections from Alloy 617 plate material after exposure to oxidizing/decarburizing and carburizing atmospheres at $1000^{\circ} \mathrm{C}$ are shown in Figure 39. Alloy 617 exhibits a relatively thick chromium oxide scale and significant formation of grain boundary aluminum oxides, with a decarburization region, as shown in Figure 39a. In contrast, the carburizing environment, Figure 39b, results in little formation of a surface oxide scale. Carbon uptake in the material is manifested by increased grain boundary carbide precipitate volume fraction, consistent with behavior reported in the literature. ${ }^{52-55} \mathrm{X}$-ray diffraction was used to determine that the carbide formed in the surface region during testing in a carburizing atmosphere is of the $\mathrm{Cr}_{3} \mathrm{C}_{2}$ type. 


\begin{tabular}{|c|lll|}
\hline NEXT GENERATION NUCLEAR PLANT STEAM & Identifier: & PLN-2804 & \\
GENERATOR AND INTERMEDIATE HEAT & Revision: & 1 & \\
EXCHANGER MATERIALS RESEARCH & Effective Date: & $09 / 23 / 10$ & Page: 43 of 252 \\
AND DEVELOPMENT PLAN &
\end{tabular}

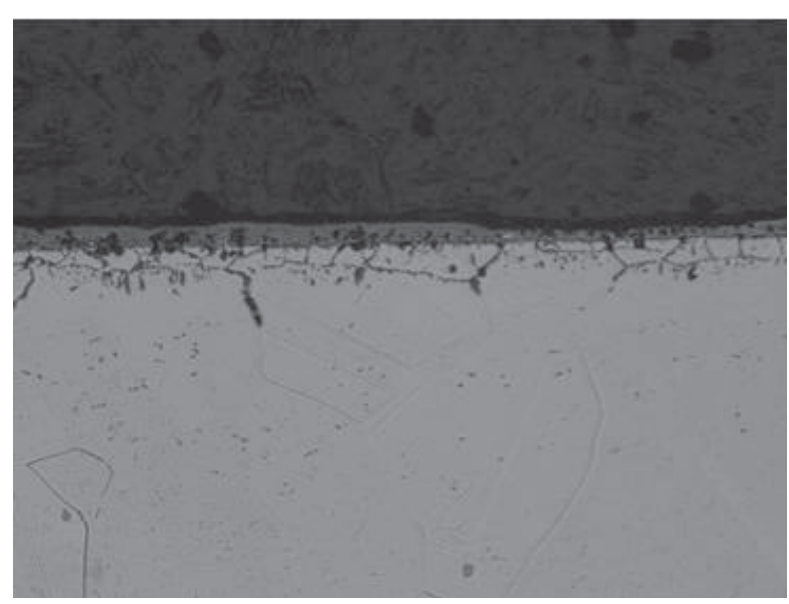

(a)

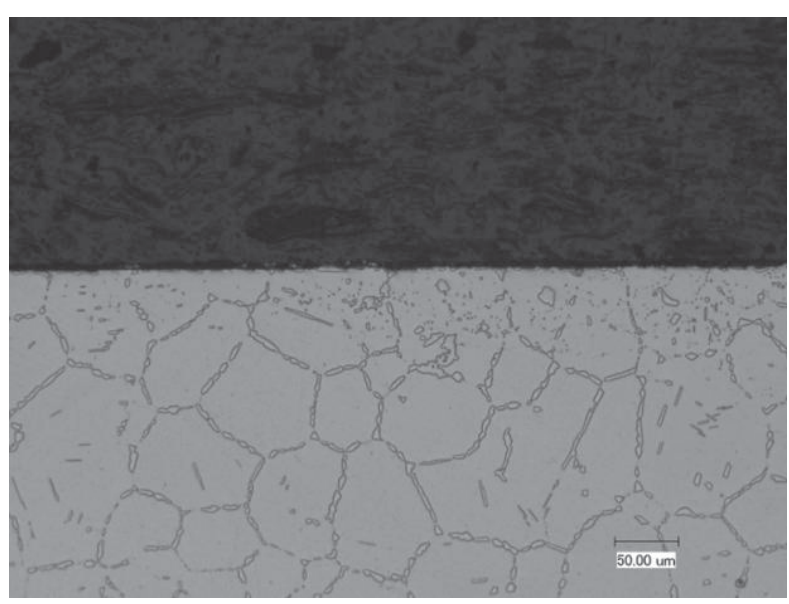

(b)

Figure 39. Optical micrographs of cross-sections through Alloy 617 for the $1000^{\circ} \mathrm{C}$ experiment under (a) oxidizing and (b) carburizing conditions.

Test coupons were exposed at $950^{\circ} \mathrm{C}$ in the controlled chemistry loop for $527 \mathrm{~h}$ to characterize the quasi-static corrosion behavior of Alloy 617 for comparison to specimens exposed to identical conditions during creep-fatigue testing. The atmosphere, containing $30 \mu$ bar partial pressure of carbon monoxide and $4 \mu$ bar partial pressure of water vapor, was selected to be oxidizing for Cr-rich alloys such as Alloy 617 . All corrosion features greatly increased with the test temperature: external oxide thickness, internal oxidation frequency and depth and decarburized zone (Table 9). These features are illustrated for Alloy 617 in Figure 40.

Table 9. Corrosion features of corroded coupons exposed for approximately $500 \mathrm{hrs}$ at different temperatures.

\begin{tabular}{rcrc} 
& Mean Surface & & Mean Decarburized \\
Test T, t & Oxide Thickness & \multicolumn{1}{c}{ Internal Oxidation } & Depth \\
\hline $750^{\circ} \mathrm{C}, 672 \mathrm{~h}$ & $2 \mu \mathrm{m}$ & up to $10 \mu \mathrm{m}$ at gb & $20 \mu \mathrm{m}$ \\
$900^{\circ} \mathrm{C}, 548 \mathrm{~h}$ & $8 \mu \mathrm{m}$ & up to $25 \mu \mathrm{m}$ within grains and at gb & $45 \mu \mathrm{m}$ \\
$950^{\circ} \mathrm{C}, 527 \mathrm{~h}$ & $10 \mu \mathrm{m}$ & up to $30 \mu \mathrm{m}$ within grains and at gb & $80 \mu \mathrm{m}$ \\
\hline
\end{tabular}

\subsubsection{Comparison of Environmental Effects for Candidate Alloys}

In addition to Alloy 617 several other alloys including $800 \mathrm{H}$ and Hastelloy $\mathrm{X}$ were included in the $527 \mathrm{~h} 950^{\circ} \mathrm{C}$ oxidizing experiment described in Section 4.2.2. Previous experiments with Alloy $800 \mathrm{H}$ and Hastelloy $\mathrm{X}$ in oxidizing and carburizing environments indicated that these alloys had behavior similar to Alloy 617. This similarity was attributed to the chromium content of the alloys all falling in the range of 20 to $22 \mathrm{wt} \%$. Micrographs, exhibiting surface and internal oxidation, are shown in Figure 41. Corrosion features are quantitatively compared for several alloys in Figure 42. All specimens gain mass over the oxidizing exposure, as shown in Figure 43, with Alloy 617, gaining more specific mass per surface unit than the other alloys exposed. However, in carburizing environments Alloy 617 gains less mass than other candidate alloys, as shown in Figure 44. 


\begin{tabular}{|c|c|c|c|}
\hline $\begin{array}{c}\text { NEXT GENERATION NUCLEAR PLANT STEAM } \\
\text { GENERATOR AND INTERMEDIATE HEAT } \\
\text { EXCHANGER MATERIALS RESEARCH } \\
\text { AND DEVELOPMENT PLAN }\end{array}$ & $\begin{array}{l}\text { Identifier: } \\
\text { Revision: } \\
\text { Effective Date }\end{array}$ & $\begin{array}{l}\text { PLN-2804 } \\
1 \\
09 / 23 / 10\end{array}$ & Page: 44 of $\mathbf{2 5 2}$ \\
\hline
\end{tabular}
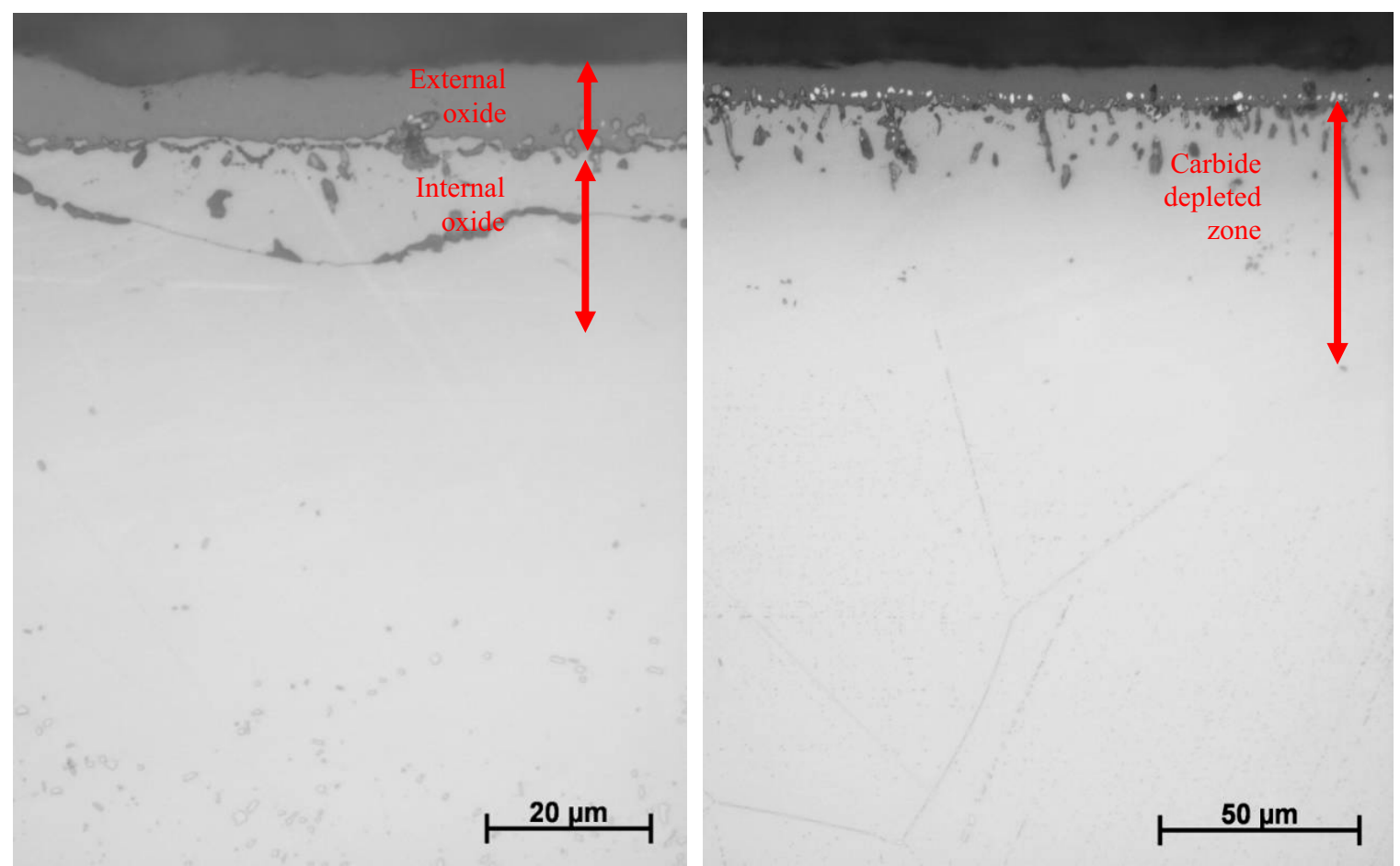

Figure 40. Microstructure of Alloy 617 at two different magnifications after exposure in the controlled chemistry loop for $527 \mathrm{~h}$ at $950^{\circ} \mathrm{C}$, illustrating corrosion features quantified in Figure 42.

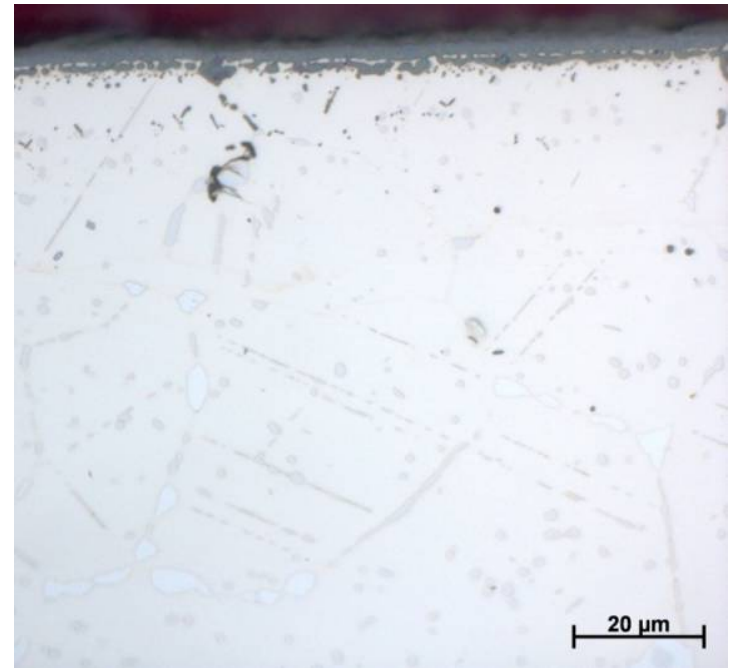

(a)

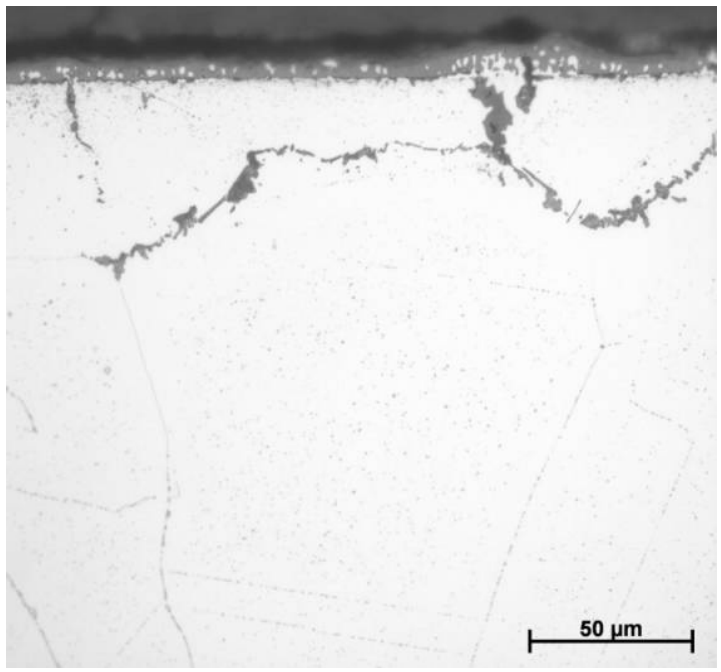

(b)

Figure 41. Microstructure of (a)Alloy $800 \mathrm{H}$ and (b) Alloy X after exposure for $527 \mathrm{~h}$ at $950^{\circ} \mathrm{C}$ in oxidizing environment. 


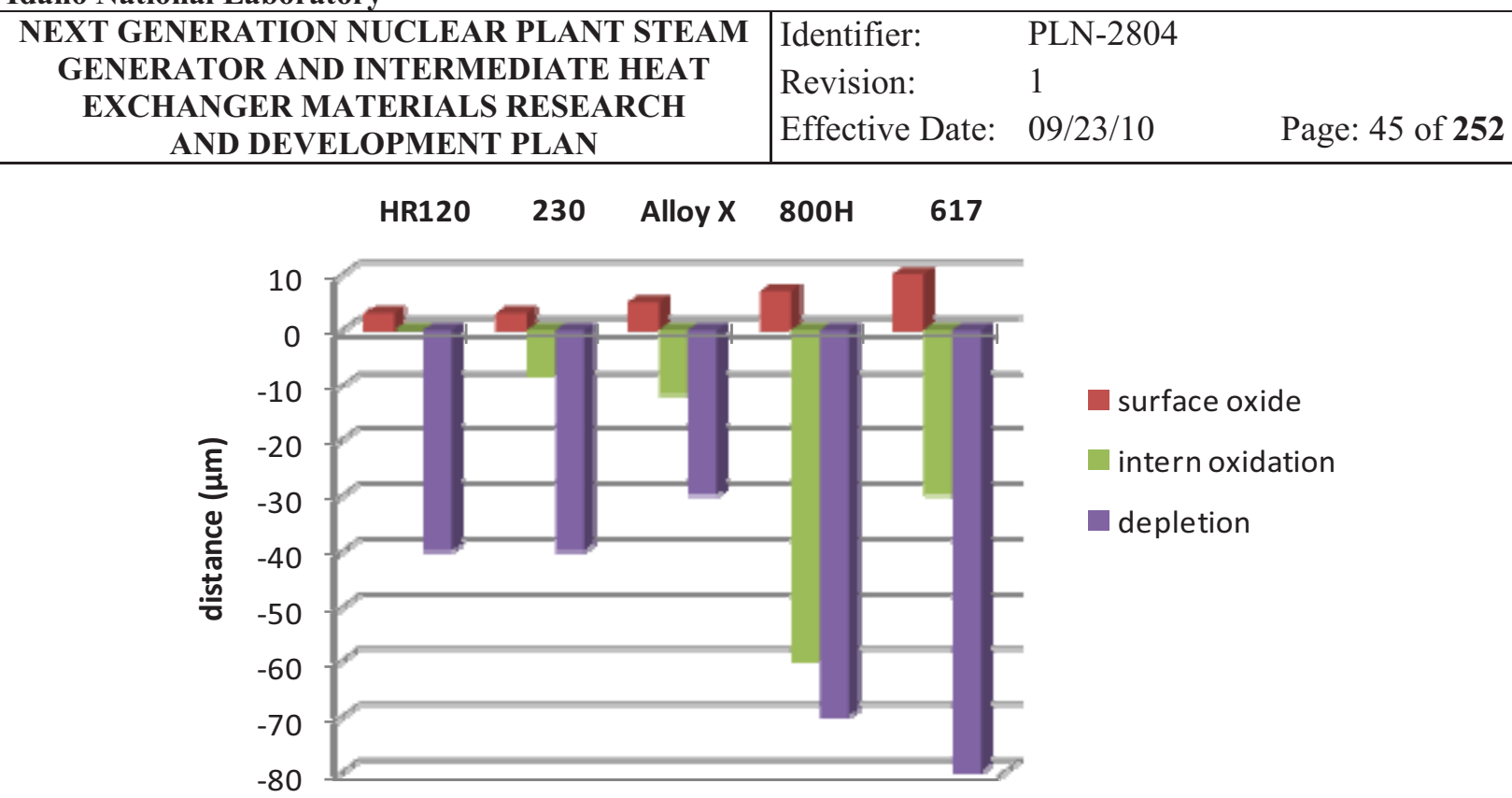

Figure 42. Quantitative measurements of corrosion features of corroded coupons exposed for $527 \mathrm{~h}$ at $950^{\circ} \mathrm{C}$ in oxidizing environment.

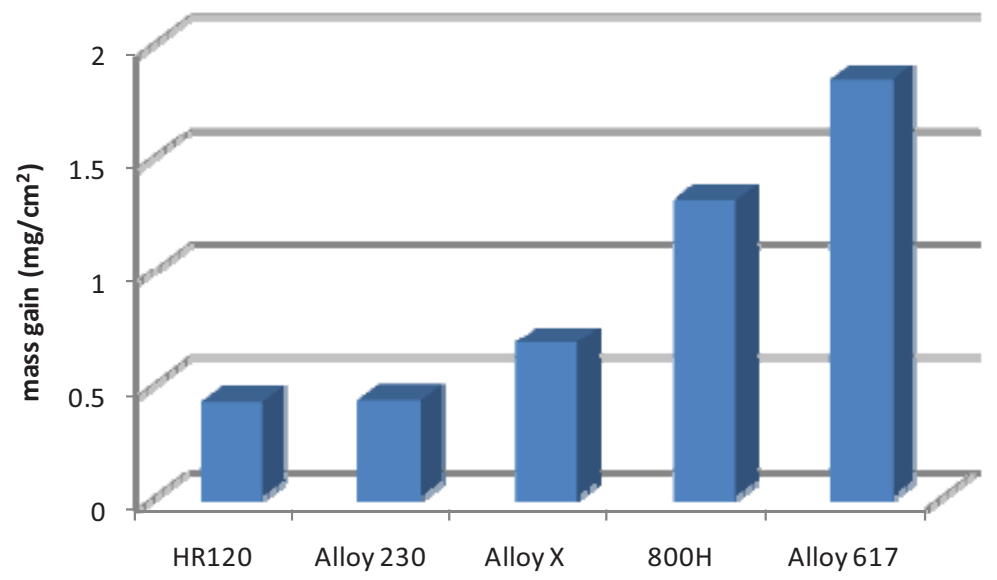

Figure 43. Mass gain after $527 \mathrm{~h}$ at $950^{\circ} \mathrm{C}$ in oxidizing environment. 


\begin{tabular}{|c|c|c|}
\hline $\begin{array}{l}\text { NEXT GENERATION NUCLEAR PLANT STEAM } \\
\text { GENERATOR AND INTERMEDIATE HEAT } \\
\text { EXCHANGER MATERIALS RESEARCH } \\
\text { AND DEVEIOPMENT PLAN }\end{array}$ & $\begin{array}{ll}\text { Identifier: } & \text { PLN-2804 } \\
\text { Revision: } & 1 \\
\text { Effective Date: } & 09 / 23 / 10\end{array}$ & Page: 46 of $\mathbf{2 5 2}$ \\
\hline
\end{tabular}

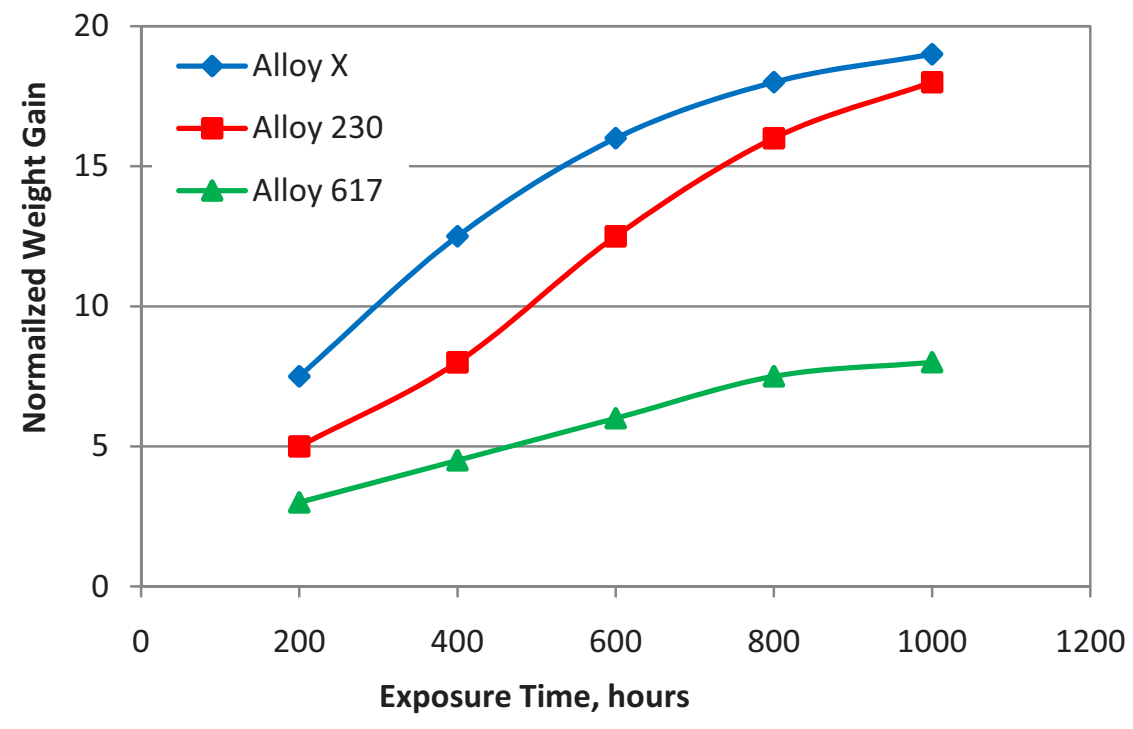

Figure 44. Mass change as a function of time in $\mathrm{H}_{2} 5.5 \% \mathrm{CH}_{4}-4.5 \% \mathrm{CO}_{2}$ carburizing environment at $1000^{\circ} \mathrm{C}$. 


\begin{tabular}{|c|lll|}
\hline $\begin{array}{c}\text { NEXT GENERATION NUCLEAR PLANT STEAM } \\
\text { GENERATOR AND INTERMEDIATE HEAT } \\
\text { EXCHANGER MATERIALS RESEARCH }\end{array}$ & Identifier: & PLN-2804 & \\
AND DEVELOPMENT PLAN & Effective Date: & $09 / 23 / 10$ & Page: 47 of 252 \\
\hline
\end{tabular}

\section{CODE COMPLIANCE/LICENSING ISSUES}

This section addresses issues with ASME Code qualification of a material or materials that are common to IHX and other core internals. It also addresses application of the ASME Code to design of the IHX and core internals.

\subsection{Current Codes and Procedures}

\subsubsection{ASME Boiler and Pressure Vessel Code}

Due to the anticipated cyclic operation at elevated temperatures, the service conditions for the NGNP IHX are very severe. One of the current issues for NGNP IHX is that, as new systems, the system safety criteria and regulatory guidelines are less well founded than for the more established reactor systems.

The general requirements for Divisions 1 and 2 rules for construction of nuclear facility components are given in Section III, Subsection NCA of the ASME B\&PV Code. Section III, Division 1 of the B\&PV Code contains specific rules for the construction of different nuclear facility components. The coverage of these construction rules by various subsections in Section III, and the Code cases developed for elevated temperature service are shown in Table 10 and Table 11, respectively.

Per ASME Section III, Subsection NCA, construction rules are specified for components that are designated ASME Code classes 1, 2, 3, core support (CS) structures, and metal containment (MC) vessels for Division 1, and concrete containments (CC) for Division 2. The various class distinctions designate "...the different levels of importance associated with the function of each item as related to the safe operation of the nuclear power plant" (with Class 1 requiring the highest level of safety). The intent of these ASME Code classes is to allow a choice of rules by the "Owner" (NGNP in this case) that provides assurance of structural integrity and quality commensurate with the relative importance assigned to the individual components of a nuclear power plant. Designation of ASME Code classes for nuclear components by the "Owner" is based on assessment of public safety as implemented through system safety criteria and regulatory guidelines. Component classification shall be included in the Design Specification.

Table 10. Definition of B\&PV Codes for subsections in Section III Division 1.

Subsection of Section III,

Div 1, B\&PV Code Coverage

\begin{tabular}{ll}
\hline NB & Class 1 Components \\
NC & Class 2 Components \\
ND & Class 3 Components \\
NE & Class MC-Metal Containment Vessels \\
NF & Supports \\
NG & Class CS-Core Support Structures \\
NH & Class 1 Components in Elevated Temperature Service \\
\hline
\end{tabular}




\begin{tabular}{|c|lll|}
\hline $\begin{array}{c}\text { NEXT GENERATION NUCLEAR PLANT STEAM } \\
\text { GENERATOR AND INTERMEDIATE HEAT } \\
\text { EXCHANGER MATERIALS RESEARCH }\end{array}$ & Identifier: & PLN-2804 & \\
AND DEVELOPMENT PLAN & Effective Date: & $09 / 23 / 10$ & Page: 48 of 252 \\
\hline
\end{tabular}

Table 11. Section III, Division 1 ASME Code cases developed for elevated temperature service.

Code Case,

\begin{tabular}{cl} 
Section III, Div 1 & \multicolumn{1}{c}{ Coverage } \\
\hline N-201-5 & Class CS (Core Support) Components in Elevated Temperature Service. \\
N-290-1 & Expansion Joints in Class 1, Liquid Metal Piping. \\
N-253-14 & Construction of Class 2 or Class 3 Components for Elevated Temperature Service. \\
N-254 & Fabrication and Installation of Elevated Temperature Components, Class 2 and 3. \\
N-257 & Protection Against Overpressure of Elevated Temperature Components, Classes 2 \\
& and 3. \\
N-467 & Testing of Elevated Temperature Components, Classes 2 and 3. \\
N-499-2 & Use of SA-533 Type B, Class 1 Plate and SA-508 Grade 1 Forgings and their \\
& Weldments for Limited Elevated Temperature Service.
\end{tabular}

A decision on the ASME Code class designation of NGNP IHX components has not been made. In the following sections, the rules of construction for potentially relevant codes and code cases for elevated temperature service will be reviewed. The rules include Subsection NH and ASME Code cases N-253-14, N-254, N-257, and N-467. A Draft Alloy 617 ASME Code Case for high temperature gas-cooled reactor applications was developed in the 1980s but the effort was stopped due to the redirection of DOE priorities. This draft ASME Code case is very relevant to the NGNP IHX components and it will also be reviewed.

For elevated temperature metallic core support structures, Code Case N-201 provides the relevant rules of construction.

\subsubsection{Subsection $\mathrm{NH}$}

The current Subsection NH criteria and material coverage originate largely from the liquid-metal reactor (LMR) program of the late 1960s to early 1980s. In the late 1960s, the Atomic Energy Commission initiated a Materials and Structures Technology program and simultaneously asked the ASME B\&PV Code Committee to charge an expanded Subgroup on Elevated Temperature Design with developing the design rules that eventually provided the basis for Subsection NH.

\subsection{Load and Deformation Controlled Quantities}

The purpose of the early code cases for elevated temperature service was to provide rules for construction that account for the effects of deformation and damage due to creep with the same rigor that Subsection NB addressed the temperature regime below for which creep effects are significant. As in Subsection NB, the rules of construction in Subsection NH are based on the Design-by-Analysis approach. Stresses are still categorized into primary, secondary and peak stresses. However, due to the significant difference in the structural behavior at elevated temperature as compared with that at low temperature, Subsection NH has adopted the approach of placing limits on two basic types of controlled quantities: (1) load-controlled, and (2) deformation-controlled.

The structural failure modes covered by Subsection NH for elevated temperature service include the time-independent structural failure modes of Subsection NB:

- Ductile rupture from short-term loading.

- Gross distortion due to incremental collapse and ratcheting. 


\begin{tabular}{|c|lll|}
\hline NEXT GENERATION NUCLEAR PLANT STEAM & Identifier: & PLN-2804 & \\
GENERATOR AND INTERMEDIATE HEAT & Revision: & 1 & \\
EXCHANGER MATERIALS RESEARCH & Effective Date: & $09 / 23 / 10$ & Page: 49 of 252 \\
AND DEVELOPMENT PLAN &
\end{tabular}

- Loss of function due to excessive deformation.

- Buckling due to short-term loading and new time-dependent structural failure modes.

- Creep-rupture from long-term loading.

- Creep-fatigue failure.

- Creep-buckling due to long-term loading.

Load-controlled quantities are primary stresses. But at elevated temperatures, some stresses that would have been considered as secondary per the familiar classification of Subsection NB take on the characteristics of primary stresses due to elastic follow-up. To account for differing loads, times and temperatures, the stress allowable $S_{m}$ from Subsection NB is retained for time-independent loads, and a new time-dependent stress allowable $S_{t}$ is introduced for time-dependent loads and is based on the time to $1 \%$ total strain, time to start of tertiary creep and creep-rupture strength. The stress $S_{m t}$ defined as the lower of $S_{m}$ and $S_{t}$ is also introduced.

These allowable stresses are used to set different primary stress limits for Level A (normal), B (upset), C (emergency), and D (faulted) service events, similar to Subsection NB. But time-of-loading is an additional variable that needs to be considered due to the time dependency. A different criterion is used to set the primary stress limits for Design Conditions. It is adopted from Sections I and VIII and is based on 100,000-hour creep-rupture properties and a creep rate of $0.01 \%$ per $1000 \mathrm{~h}$. Only elastic analysis results are required to satisfy the primary stress limits. The primary stress limits cover structural failure modes (1) and (5) listed above.

The deformation-controlled quantities are stresses, strains, and deformations resulting from load, deflection and strain compatibility. Acceptable deformation-controlled limits are given in Appendix T of Subsection NH and they cover strain limits/ratcheting, creep-fatigue damage, and buckling and welds. Strain limits and creep-fatigue damage rules can be satisfied using either elastic or inelastic analysis methods. Elastic analysis rules, sometimes referred to as Simplified Methods, were originally envisioned as simpler, more conservative and a less costly screening method. Inelastic rules that required inelastic analyses were envisioned as more costly and time consuming, but an adequately conservative "gold standard." Failure modes (2), (3), and (6) listed above are covered by the strain limits and creep-fatigue damage rules of Appendix T.

In addition to deformation-controlled limits, Appendix $\mathrm{T}$ also includes rules for general loading conditions evaluated with inelastic analysis, including the time-dependent effects of creep. Rules to address structural failure modes (4) and (7) on short-term and long-term buckling are given in Appendix T.

\subsection{Weld and Component Requirements}

Subsection NH provides analysis requirements for the design and location of all pressure retaining and other primary structural welds under elevated temperature service. Special examination requirements are included for welded joints. Permissible weld materials are limited. Creep stress-rupture reduction factors for weldments are given as a function of temperature and time. Subsection NH further provides special limits on strain accumulations in the weld regions by limiting the weld strains to be one-half of the strain limits permitted for the parent material. The allowable number of design cycles for weldments is restricted to one-half that of the parent metal. The allowable time for creep-rupture damage is also reduced by multiplying the stress by the weld strength reduction factor (WSRF) when determining the time-to-rupture. Subsection NH also imposes additional examination requirements on Category A, B, C and $\mathrm{D}$ vessel weld joints. 


\begin{tabular}{|c|lll|}
\hline $\begin{array}{c}\text { NEXT GENERATION NUCLEAR PLANT STEAM } \\
\text { GENERATOR AND INTERMEDIATE HEAT }\end{array}$ & Identifier: & PLN-2804 & \\
EXCHANGER MATERIALS RESEARCH & Revision: & 1 & \\
AND DEVELOPMENT PLAN & Effective Date: & $09 / 23 / 10$ & Page: 50 of 252 \\
\hline
\end{tabular}

Subsection NH also provides component design rules that cover vessels, pumps, valves and piping. These design rules permit the use of Subsection NB component rules, charts, and formulas for meeting the design and service limits for some applications. Generally, Subsection NH permits the use of Subsection NB procedures for the satisfaction of primary (load-controlled) stress limits and when creep effects are negligible. For vessels and piping the stress indices from Subsection NB may also be used in evaluation of Subsection NH's limits on deformation-controlled loading with restrictions to ensure their relevance in the creep regime.

The guidance on fabrication and installation, welding and brazing qualifications, examination, and testing are all provided in Subsection NH as a supplement, referral or replacement to Subsection NB. Cold work effects such as loss of ductility, particularly for 304 and 316 stainless steels, and loss of creep-rupture strength, particularly at low strain and long times, are emphasized. For welding, NH references Subsection NB, which invokes Section IX. Since a crack-like defect is more likely to propagate at elevated temperature, additional volumetric examinations that include ultrasonic, eddy current, and radiography from two angles are required in addition to the single radiography of NB. NH makes a pneumatic test an equal alternative to hydrostatic test and a helium leak test is required only on certain closure welds. The use of an internal pressure test is permitted as the basis to test components and appurtenances that will be subjected to external pressure loads in service. NH incorporates changes to better reflect the characteristics of sodium systems and the use of a rupture disk test as a sole means of overpressure protection is permitted.

\subsection{NH Code Materials}

The number of Subsection NH Code materials for elevated temperature service is much smaller than that of Subsection NB. The temperature limits for NH Code materials, other than bolting, at 300,000 h are listed in Table 12. The maximum temperatures at which fatigue curves are provided are also listed. Bolting materials are shown in Table 13.

Table 12. Materials specified in NH for elevated temperature service in nuclear applications.

\begin{tabular}{|c|c|c|}
\hline \multirow{2}{*}{$\begin{array}{l}\text { NH Code Materials } \\
\text { (other than bolting) }\end{array}$} & \multicolumn{2}{|c|}{ Maximum temperature } \\
\hline & $\begin{array}{c}\text { For Stress Allowables } S_{0}, S_{m t}, S_{t}, S_{r} \\
\text { up to } 300,000 \text { Hours }^{\mathrm{a}}\end{array}$ & For Fatigue Curves \\
\hline $\begin{array}{l}304 \text { stainless steels } \\
\text { (UNS S30400, S30409) }\end{array}$ & $816^{\circ} \mathrm{C}$ & $704^{\circ} \mathrm{C}$ \\
\hline $\begin{array}{l}316 \text { stainless steel } \\
\text { (UNS S31600, S31609) }\end{array}$ & $816^{\circ} \mathrm{C}$ & $704^{\circ} \mathrm{C}$ \\
\hline Alloy 800H (UNS N08810) & $760^{\circ} \mathrm{C}$ & $760^{\circ} \mathrm{C}$ \\
\hline $\begin{array}{l}\text { 21/4Cr } 1 \text { Mo steel, annealed condition } \\
\text { (UNS K21590) }\end{array}$ & $593^{\circ} \mathrm{C}^{\mathrm{b}}$ & $593^{\circ} \mathrm{C}$ \\
\hline $\begin{array}{l}\text { Grade } 91 \text { steel } \\
\text { (UNS K90901) }^{\mathrm{c}}\end{array}$ & $649^{\circ} \mathrm{C}$ & $538^{\circ} \mathrm{C}$ \\
\hline \multicolumn{3}{|c|}{$\begin{array}{l}\text { a. The primary stress limits are very low at } 300,000 \mathrm{~h} \text { and the maximum temperature limit. } \\
\text { b. Temperatures up to } 649^{\circ} \mathrm{C}\left(1200^{\circ} \mathrm{F} \text { ) are allowed up to } 1,000 \mathrm{~h} \text {. }\right. \\
\text { c. The specifications for Grade } 91 \text { steel covered by Subsection NH are SA-182 (forgings), SA-213 (small tube), SA-335 } \\
\text { (small pipe), and SA-387 (plate). The forging size for SA-182 is not to exceed } 4540 \mathrm{~kg} \text {. }\end{array}$} \\
\hline
\end{tabular}




\begin{tabular}{|c|lll|}
\hline NEXT GENERATION NUCLEAR PLANT STEAM & Identifier: & PLN-2804 & \\
$\begin{array}{c}\text { GENERATOR AND INTERMEDIATE HEAT } \\
\text { EXCHANGER MATERIALS RESEARCH } \\
\text { AND DEVELOPMENT PLAN }\end{array}$ & Revision: & 1 & \\
Effective Date: & $09 / 23 / 10$ & Page: 51 of 252 \\
\hline
\end{tabular}

Table 13. The temperature and time limits for NH Code materials for bolting.

\begin{tabular}{lcc}
\multicolumn{1}{c}{ NH Code Materials for Bolting } & $\begin{array}{c}\text { Maximum Temperature for } \\
\text { Stress Allowables } S_{0}, S_{m t}\end{array}$ & $\begin{array}{c}\text { Maximum Duration for } \\
\text { Stress Allowables } S_{0}, S_{m t}\end{array}$ \\
\hline $\begin{array}{l}304 \text { stainless steels } \\
\text { (B8 Class 1, and B8A, Class 1A) }\end{array}$ & $704^{\circ} \mathrm{C}$ & $200,000 \mathrm{~h}$ \\
316 stainless steel & & $200,000 \mathrm{~h}$ \\
(B8M Class 1, and B8MA, Class 1A) & $704^{\circ} \mathrm{C}$ & $300,000 \mathrm{~h}$ \\
Alloy 718 (UNS N07718) & $566^{\circ} \mathrm{C}$ & \\
\hline
\end{tabular}

The delta ferrite limits are defined by the ferrite number (FN), a magnetic means of measuring the amount of ferrite in a stainless steel. The designated minimum of 5-FN in Subsection NB is changed to a range of 3-FN to 10-FN in Subsection NH. Reduction in the yield and tensile strength due to aging is required in Subsection NH. In addition to meeting other materials acceptance requirements specified in Subsection NB, creep-fatigue acceptance test is required for 304 and 316 stainless steels. The creep-fatigue acceptance test requirement was implemented in response to problems encountered in the field where a heat of 304 stainless steel passed the then-required acceptance tests but exhibited very low creep ductility, $0.5 \%$ in a $10,000 \mathrm{~h}$ test. The creep-fatigue acceptance test involves fatigue test in air at $595^{\circ} \mathrm{C}$ at an axial strain range of $1.0 \%$ with a one-hour hold period at the maximum positive strain point in each cycle. Test should be performed to ASTM Standard E 606. The material lot is acceptable if the test exceeds 200 cycles without fracture or a $20 \%$ drop in the load range.

Data in support of the development of various stress allowables in Subsection NH are based on tests in air. Similar to Subsection NB, rules that govern the deterioration of material caused by service are not covered by Subsection NH. It is the responsibility of the Owner to account for such effects. Currently, design correlations to account for the environmental effects due to neutron irradiation or impure helium coolant are not available.

The criteria documents for Class 1 components covered by Subsection NH are given in the literature ${ }^{56-58}$ and a detailed summary of the Subsection $\mathrm{NH}$ rules is given in the Companion Guide to the B\&PV Code. ${ }^{59}$ A recent overview of the Subsection NH rules is given in an NRC NUREG report. ${ }^{60}$

\subsection{Recent Code Activities on Subsection $\mathrm{NH}$}

The task activities carried out in the first round of the DOE/ASME Generation IV project, as summarized in Section 5.1.3, have had the most significant and positive impact on the Subsection NH ASME Code rules.

\subsubsection{Code Cases for Class 2 and 3 Components}

The extension of the rules of construction of Class 2 and 3 components in Subsection NC and ND to elevated temperature service is provided in a series of Section III Code cases. The rules for materials and design are provided in Code Case N-253-14, fabrication and installation in Code Case N-254, overpressure protection in Code Case N-257, and testing in Code Case N-467.

The materials of construction covered by Code Case N-253-14 are required to meet the acceptance requirements in Subsection NC (Class 2) and Subsection ND (Class 3). For welds, the minimum acceptable delta ferrite is FN-5 for design temperatures of $427^{\circ} \mathrm{C}$ and below, and limited to the range FN-3 to FN-10 for design temperature above $427^{\circ} \mathrm{C}$. For statically and centrifugally cast products, in 


\begin{tabular}{|c|lll|}
\hline $\begin{array}{c}\text { NEXT GENERATION NUCLEAR PLANT STEAM } \\
\text { GENERATOR AND INTERMEDIATE HEAT } \\
\text { EXCHANGER MATERIALS RESEARCH } \\
\text { AND DEVELOPMENT PLAN }\end{array}$ & Revision: & 1 & \\
& Effective Date: & $09 / 23 / 10$ & Page: 52 of 252 \\
\hline
\end{tabular}

addition to the requirements of Subsection $\mathrm{NC}$ and $\mathrm{ND}$, the delta ferrite is limited to a maximum of FN-12 for design temperature exceeding $427^{\circ} \mathrm{C}$.

Code Case N-253-14 provides allowable stresses for both negligible creep regime (Table C-1.1) and creep regime (Table C-1.2). Time-temperature limits for negligible creep regime are provided for carbon steels, low alloy steels, 304 and 316 wrought and cast stainless steels, and Alloy $800 \mathrm{H}$ among others. The allowable stresses for the negligible creep regime protect the components against those failure modes that are due to short-term load applications such as those in Subsections NC and ND.

The allowable stresses for the creep regime are based on the same criteria as those for Sections I and VIII, Division 1 which are based on 100,000 hour properties. WSRFs are provided for weldments in the creep regime.

The structural design criteria for vessel, pump and valve are based on the design-by-formula rules of Subsections NC and ND, but using the extended allowable stresses in Table C-1.1 or Table C-1.2, depending on whether the negligible creep criteria are satisfied. These rules do not explicitly address fatigue damage (creep-fatigue) from cyclic service. The time-dependent buckling procedure from Subsection NH is adopted when creep is not negligible.

For piping design, rules from Subsections NC and ND can be used with the extended allowable stresses in Table C-1.1 when the component is in the negligible creep regime. When the piping is in the creep regime, the "stress reduction factor for cyclic service" for evaluation of expansion stresses is further reduced to account for the effects of creep damage incurred as the restrained thermal expansion stresses relax. The allowable stresses are from Table C-1.2. It is noted that these piping rules that account for the effects of creep-fatigue damage are different from those in Subsection NH.

Code Cases N-254, N-257, and N-467 supplement the rules for fabrication and installation, overpressure protection, and testing of Subsections NC and ND for elevated temperature service, respectively.

\subsubsection{Draft Alloy 617 Code Case}

The draft Code Case for Alloy 617 provides design rules for HTGRs with reactor outlet temperatures of about $950^{\circ} \mathrm{C}$. The original request to the ASME B\&PV Code Committee for design rules for very high temperature nuclear components came from the U.S. DOE and one of its contractors. An ad hoc task force of the ASME Code was established in 1983 to address the design of reactors operating at very high temperatures. The task force was organized under the jurisdiction of the Subgroup on Elevated Temperature Design of the Subcommittee on Design. The task force completed the Draft Alloy 617 Code Case in 1989 and submitted it to the Subgroup, which later approved the it. No further work was done on the Draft Alloy 617 Code Case because of the lack of further interest from the U.S. DOE and its contractor.

The draft ASME Code case focused on Alloy 617 because it was a leading candidate of designers, and there was a significant material properties database at the temperature of interest. Draft Alloy 617 Code Case focused on all the failure modes that are addressed by Subsections NB and NH, including non-ductile failure, because of the significant loss of fracture toughness in Alloy 617 after long-term exposure to high temperatures.

Draft Alloy 617 Code Case was patterned after relevant portions of Code Case N-47 (the predecessor of the current elevated temperature design [ETD] ASME Code Subsection NH) and was limited to $982^{\circ} \mathrm{C}$, and a maximum service life (total life at temperatures $>427^{\circ} \mathrm{C}$ ) of $100,000 \mathrm{~h}$ or less. This design life (shorter than the 300,000 h specified in Subsection NH) was selected because of the uncertainties of data 


\begin{tabular}{|c|lll|}
\hline NEXT GENERATION NUCLEAR PLANT STEAM & Identifier: & PLN-2804 & \\
GENERATOR AND INTERMEDIATE HEAT & Revision: & 1 & \\
EXCHANGER MATERIALS RESEARCH & Effective Date: & $09 / 23 / 10$ & Page: 53 of 252 \\
AND DEVELOPMENT PLAN &
\end{tabular}

extrapolation at very high temperatures, and the lack of experience in designing reliably at low allowable stresses for long times. The allowable stresses are less than $1 \mathrm{ksi}$ at the highest temperature.

Most of the design rules provided by Draft Alloy 617 Code Case are similar to those provided by Subsection NH, although some are different because the Draft Alloy 617 Code Case considers higher temperatures and a different material. Alloy 617 exhibits unique behavior that includes:

- Lack of clear distinction between time-independent and time-dependent behavior

- High dependence of flow stress on strain rate

- Softening with time, temperature, and strain.

Therefore, design rules of Subsection NH that are time- and rate-independent, or strain-hardening idealizations of material behavior, required careful consideration in the draft case. For example, the case specifies that inelastic design analyses for temperatures above $649^{\circ} \mathrm{C}$ must be based on unified constitutive equations, which do not distinguish between time-independent plasticity and time-dependent creep.

Extended exposure at elevated temperature may cause a significant reduction in fracture toughness of Alloy 617. The draft case requires a fracture mechanics analysis to justify the ability of the component to withstand the expected service conditions, especially when the component cools down to lower temperatures. Because of this concern for potential loss of fracture toughness, Alloy 617 bolting is excluded from the draft case. In addition, exposure of cold worked material to very high temperatures results in recrystallization. Therefore, cold worked Alloy 617 is also excluded from the draft case.

\subsubsection{Code Case $\mathrm{N}-201-5$}

Section III, Subsection NG establishes rules of construction for materials, design, fabrication, examination, and preparation of reports required in the manufacture and installation of core support structures, internal structures, threaded structural fasteners, and temporary attachments. The rules of construction in Subsection NG are for low temperature service $\left(371^{\circ} \mathrm{C}\right.$ for ferritic steels and $427^{\circ} \mathrm{C}$ for austenitic steels). Code Case N-201-5 extends the rules of construction of Subsection NG to elevated temperature service.

Code Case N-201-5 contains two parts. Part A involves the extension of the Subsection NG rules of construction to restricted service at elevated temperature without explicit consideration of creep and stress-rupture. Part B extends the Subsection NG rules of construction to service at elevated temperature to suitably account for creep and stress-rupture effects. The negligible creep criteria are similar to Appendix E in Code Case N-253-14, which is more restrictive, as the limit on the temperature-dependent time-use fraction is 0.9 for Code Case N-253-14 and 1.0 for Code Case N-201-5.

Part A supplements the rules of construction in Subsection NG. The same allowable stress basis, Sm, and design rules as Subsection NG, with some modification, are used in Part A. The materials of construction include 304 and 316 stainless steels, and Alloy $800 \mathrm{H}$ for structural materials and 304 and 316 stainless steels and Alloy 800 for threaded fasteners. Time-independent rules similar to those in Subsection NH are introduced for buckling and instability.

Part B replaces the rules of construction in Subsection NG by those in Subsection NH, but adapted to core support structures. The structural failure modes covered by N-201-5 Part B are the same as those covered by Subsection NH:

- Ductile rupture from short-term loading

- Gross distortion due to incremental collapse and ratcheting 


\begin{tabular}{|c|lll|}
\hline $\begin{array}{c}\text { NEXT GENERATION NUCLEAR PLANT STEAM } \\
\text { GENERATOR AND INTERMEDIATE HEAT }\end{array}$ & Identifier: & PLN-2804 & \\
EXCHANGER MATERIALS RESEARCH & Revision: & 1 & \\
AND DEVELOPMENT PLAN & Effective Date: & $09 / 23 / 10$ & Page: 54 of 252 \\
\hline
\end{tabular}

- Loss of function due to excessive deformation

- Buckling due to short-term loading

- Creep-rupture from long-term loading

- Creep-fatigue failure

- Creep-buckling due to long-term loading.

The Subsection NH materials and allowable stresses are provided in Part B. However, the Subsection $\mathrm{NH}$ methodology for deterioration due to time-at-temperature is not implemented. The $\mathrm{K}$ ' factor in the creep damage portion of the creep-fatigue evaluation is set at 0.9 in Part B. In the latest addenda of Subsection NH, $\mathrm{K}^{\prime}$ is equal to 0.9 when simplified analysis method (elastic) is used and 0.67 when inelastic analysis method is used.

Consistent with Subsection NG, the design condition is not used in both Parts A and B, and pressure difference instead of pressure is considered.

Task 4 of the first round of the DOE/ASME Generation IV project, as summarized in Section 5.1.3.1.4, has produced a draft to update Code Case N-201-5.

\subsubsection{Code Rules for Shell and Tube IHX Designs}

Section VIII, Divisions 1 and 2 (for non-nuclear service) have design rules for shell and tube heat exchangers. Section VIII Division 2 also has analysis formulas for perforated plates. The Section VIII, Division 1 rules may be used in the creep regime. The Section VIII, Division 2 rules may only be used in the creep regime if exempted from fatigue analysis by the rules for similar equipment in similar service. Neither Section VIII, Division 1 nor Division 2 rules address creep-fatigue.

Subsection NH does not have specific rules for shell and tube heat exchangers but the design--by--analysis procedures in NH-3200 as supplemented by Appendix T are conceptually applicable to any component. The Clinch River Breeder Reactor (CRBR) SG and IHX were both designed using Code Case N-47, the Subsection NH precursor. The SG was a shell and tube heat exchanger as was the IHX.

In summary, Subsection NH covers the shell and tube IHX for both creep and creep-fatigue based on design-by-analysis. Section VIII, Division 1 has design-by-rule procedures for shell and tube heat exchangers that may be used in the creep regime.

\subsubsection{Foreign Codes}

\subsubsection{French Code RCC-MR}

The RCC-MR Code was developed in France as a high temperature extension to RCC-M for the French breeder reactor program. The basic rules in RCC-MR are similar to those in ASME Code Subsection NH and the choice of materials is also limited. RCC-MR provides more detailed instructions for fatigue and creep-fatigue design analysis than given in the ASME Codes. It also uses a somewhat different approach for analysis of creep ratcheting without the use of isochronous stress-strain curves, but the basic safety factors used in the generation of design curves in the two codes are comparable.

\subsubsection{British Procedure R5}

Procedure R5 is a comprehensive assessment procedure for the high temperature response of structures. The procedure addresses several aspects of high temperature behavior, including creep and creep-fatigue crack growth, and both similar and dissimilar metal welds. The main objective of the procedure is to ensure that failure of both defect-free and defective components by creep-rupture is 


\begin{tabular}{|c|lll|}
\hline $\begin{array}{c}\text { NEXT GENERATION NUCLEAR PLANT STEAM } \\
\text { GENERATOR AND INTERMEDIATE HEAT }\end{array}$ & Identifier: & PLN-2804 & \\
EXCHANGER MATERIALS RESEARCH & Revision: & 1 & \\
AND DEVELOPMENT PLAN & Effective Date: & $09 / 23 / 10$ & Page: 55 of 252 \\
\hline
\end{tabular}

avoided. The calculation of the expected lifetime is performed by conservative approximations based on reference stress techniques. Procedure R5 permits use of ductility exhaustion for creep-fatigue evaluation, if the material data are available. If appropriate data are not available, linear damage summation, similar to that recommended by ASME Code Subsection NH, is used.

Procedure R5, which is a guideline and not a code, considers creep cracking explicitly. Neither the ASME Code nor the RCC-MR Code addresses the subject because creep cracking is more of an issue in residual life assessment than design. Therefore, the use of this procedure in the design of HTGR components is limited. However, the procedure presents the use of ductility exhaustion as an alternative to the linear damage rule for calculating the creep component of damage. The use of ductility exhaustion instead of the linear damage rule may be more suitable for estimating creep damage in the HTGR materials and should be evaluated for incorporation in Subsection NH.

\subsubsection{DOE Initiative to Address ASME Code Issues for Gen IV Reactors}

Nuclear structural component construction in the U.S. complies with Section III of the ASME B\&PV Code, although licensing is granted by the NRC. A number of technical topics were identified by DOE, Oak Ridge National Laboratory (ORNL), INL, and ASME to have particular value with respect to the ASME Code. A three-year collaboration between DOE and ASME was established that addresses twelve topics in support of an industrial stakeholder's application for licensing of a Gen IV nuclear reactor.

The majority of these tasks are relevant to action items within ASME Section III Subsection NH, and the nature of the topics inherently includes significant overlap, and in some cases parallel activities on the same issue.

\subsubsection{First Round Tasks}

The first five topics were funded in the first round of the DOE/ASME Gen IV project. All of these tasks are now complete and final reports have been submitted by the task investigators to ASME. The results of the investigations are summarized below.

\subsection{TASK 1: Verification of Allowable Stresses}

The ASME Section III, Subsection NH criteria for estimating the time-dependent allowable stress $S_{t}$ include the average strength for $1 \%$ total strain, $80 \%$ of the minimum strength for tertiary creep, and $67 \%$ of the minimum rupture strength values. The extension in temperature and/or time for the stress allowables established in Task 1 is of significance to the NGNP project.

\subsection{Part I. Alloy $800 \mathrm{H}$ base metal}

The objective of Part I of this task was to review Alloy $800 \mathrm{H}$ stress allowables in Subsection $\mathrm{NH}$ and to perform a data gap analysis to assess the possibilities of extending the time-dependent allowable stresses to $900^{\circ} \mathrm{C}$ and $600,000 \mathrm{~h}$.

\section{Results}

Procedures for analyzing creep and creep-rupture data for Subsection NH were reviewed and compared to the procedures used to develop the current Subsection NH $S_{t}$ values for Alloy $800 \mathrm{H}$. Procedures used by Section II were also compared with those of Subsection NH.

Databases summarizing the creep and creep-rupture properties of Alloy $800 \mathrm{H}$ were collected. The data were carefully reviewed to show compliance with the requirements of the Alloy $800 \mathrm{H}$ specifications applicable to Subsection NH. A subset in the temperature range of $750^{\circ} \mathrm{C}$ to $900^{\circ} \mathrm{C}$ were selected and used to estimate the strength in conformance with the Subsection NH criteria that were the basis for estimating $S_{t}$. 


\begin{tabular}{|c|lll|}
\hline $\begin{array}{c}\text { NEXT GENERATION NUCLEAR PLANT STEAM } \\
\text { GENERATOR AND INTERMEDIATE HEAT } \\
\text { EXCHANGER MATERIALS RESEARCH }\end{array}$ & Identifier: & PLN-2804 & \\
AND DEVELOPMENT PLAN & Effective Date: & $09 / 23 / 10$ & Page: 56 of 252 \\
\hline
\end{tabular}

It was concluded that there are sufficient creep-rupture data for Alloy $800 \mathrm{H}$ to permit the extension of the creep-rupture strengths in time and temperature. Creep-rupture strengths to $900^{\circ} \mathrm{C}$ and $600,000 \mathrm{~h}$ were developed.

For the $1 \%$ strain criterion, it was found that the variability in the primary creep behavior complicated the development of a temperature-stress-time model needed for the evaluation of $1 \%$ strain criterion for long times at temperatures of $800^{\circ} \mathrm{C}$ and above. A low value for the stress exponent caused the estimated stresses to fall rapidly at long times, and at $850^{\circ} \mathrm{C}$ and $900^{\circ} \mathrm{C}$ the model reached its stress-based extrapolation limit before reaching the $600,000 \mathrm{~h}$ life target. Similar difficulties were encountered in estimating the tertiary creep criterion.

An alternate correlation between the time to tertiary creep and the rupture life produced a favorable model for estimating $80 \%$ of the minimum strength for tertiary creep. The estimated strengths from this tertiary creep model based on rupture life were very close to those estimated from $67 \%$ of the minimum rupture strength. Both the Larson-Miller parameter and the Orr-Sherby-Dorn parameter were used to estimate the stresses for $100 \%$ of the average time to $1 \%$ strain and $80 \%$ of the stress for the initiation of tertiary creep. Both global and lot centering analysis methods were investigated for the Larson-Miller parameter but it was observed that the polynomial stress function that accompanied the model was not suitable for extrapolation.

Tables were developed that compared the strengths produced by the three criteria and analysis methods. The Orr-Sherby-Dorn parameter in combination with a well-behaved stress function was selected for the estimation of the long-time strength for $1 \%$ strain. With this choice, it was found that the minimum rupture strength criterion controlled $S_{t}$ for most times at $750^{\circ} \mathrm{C}$, for the first $100,000 \mathrm{~h}$ at $800^{\circ} \mathrm{C}$, and for shorter times at $850^{\circ} \mathrm{C}$ and $900^{\circ} \mathrm{C}$. The average stress to produce $1 \%$ creep controlled the long time stress limits at $850^{\circ} \mathrm{C}$ and $900^{\circ} \mathrm{C}$.

\section{Recommendations}

- Collect additional data to better assess the stress for $1 \%$ creep at long times and above $800^{\circ} \mathrm{C}$, since a possibility for diffusional creep may exist.

- Determine time-independent allowable stresses $S_{m}$, up to $900^{\circ} \mathrm{C}$ in addition to the time-dependent allowable stresses $S_{t}$. MPC will provide these required tensile and yield strengths.

- Perform tensile tests to assess the strain-rate effect on the tensile and yield strengths.

\subsection{Part II. Alloy 800H weldment}

The objective of Part II of Task 1 was to review the strength of weldments for Alloy $800 \mathrm{H}$ and to perform a data gap analysis to assess the possibilities of extending the time-dependent allowable stresses to $900^{\circ} \mathrm{C}$ and $600,000 \mathrm{~h}$.

\section{Results}

Filler metals for joining Alloy $800 \mathrm{H}$ were reviewed and references bearing on the tensile and stress-rupture behavior of deposited weld metal and weldments were summarized. Data were collected for several coated and bare-wire electrodes. They include stress-rupture data for Alloy A deposited weld metal and deposited cross-welds, Alloy 21-33Nb weld metal, Alloy 182 deposited weld metal and cross-welds, and Alloy 82 deposited weld metal and cross-welds.

Yield data for several weld and weldment materials were compared to the Y-1 and $S_{y l}$ versus temperature trends for Alloy $800 \mathrm{H}$. Similarly, ultimate tensile strength data were compared to the $\mathrm{U}$ and $S_{U}$ versus temperature trend for Alloy $800 \mathrm{H}$. It was observed that weld metal and weldments always exceeded the strength of the Alloy $800 \mathrm{H}$ base metal. 


\begin{tabular}{|c|lll|}
\hline $\begin{array}{c}\text { NEXT GENERATION NUCLEAR PLANT STEAM } \\
\text { GENERATOR AND INTERMEDIATE HEAT } \\
\text { EXCHANGER MATERIALS RESEARCH }\end{array}$ & Identifier: & PLN-2804 & \\
AND DEVELOPMENT PLAN & Effective Date: & $09 / 23 / 10$ & Page: 57 of 252 \\
\hline
\end{tabular}

The stress-rupture strengths of several weld and weldment materials were compared to the rupture strength of Alloy $800 \mathrm{H}$ for the temperature range $750^{\circ} \mathrm{C}$ to $1000^{\circ} \mathrm{C}$ on the basis of the Larson-Miller parametric curve using a common parametric constant characteristic of Alloy $800 \mathrm{H}$. It was found that weld metals and weldments were stronger than Alloy $800 \mathrm{H}$ at low temperatures and high stresses but appeared to be weaker at high temperatures. Alloy $21 / 33 \mathrm{Nb}$ was an exception and the deposited filler metal was stronger or equivalent to Alloy $800 \mathrm{H}$ over the range of temperatures and stresses where data were available.

An attempt was made to estimate the WSRFs for weldments made with Alloy A (ENiCrFe-2) and Alloy 82 (ERNiCrFe-3). It was found that the lack of long-time, high temperature data made it difficult to produce reliable results. Analysis was undertaken using the Larson-Miller parametric procedure. Both global (batch) and lot-centered methods were applied. It was found that for Alloy 82, estimates of WSRFs were reasonably close to those provided in ASME III-NH Table I-10 C-2 for $760^{\circ} \mathrm{C}$. Values for Alloy A were higher than expected and well above the WSRFs provided in ASME III-NH Table I-10 C-1.

\section{Recommendation}

A creep-rupture experimental program was recommended to address WSRF for weldments in Alloy $800 \mathrm{H}$ for service above $750^{\circ} \mathrm{C}$. The recommended test temperatures are between $900^{\circ} \mathrm{C}$ and $1000^{\circ} \mathrm{C}$, in $25^{\circ} \mathrm{C}$ increments. A minimum of $10,000 \mathrm{~h}$ test time was recommended. The test matrix includes Alloy 82 , Alloy A, and Alloy $800 \mathrm{H}$ weldments, and Alloy 117, Alloy 617, and Alloy 21/33Nb weld metals.

\subsection{Part III. Grade 91 steel}

Grade 91 steel is not relevant to components considered in this report and will not be discussed here.

\subsection{TASK 2: Regulatory Safety Issues in Structural Design Criteria}

The objective of Task 2 was to identify issues relevant to ASME Section III Subsection NH and related code cases that must be resolved for licensing purposes for HTGR concepts and to develop a description of how Subsection NH of the ASME Code addresses these issues and the further need to add criteria to cover unresolved safety concerns for HTGR.

The EPACT of 2005 stated that NGNP shall be licensed by the NRC and by July 2008 the NRC and DOE shall jointly submit a licensing strategy to Congress. This task directly supports the activities related to the licensing of NGNP.

\section{Results}

The task report included the description of (1) NRC and Advisory Committee on Reactor Safety (ACRS) safety concerns raised during the licensing process of CRBR and other subsequent high temperature reactor concepts, (2) how some of these issues are addressed by the current Subsection NH of the ASME Code, and (3) the material models, design criteria, and analysis methods that need to be added to the ASME Code and Code Cases to cover unresolved regulatory issues for very high temperature service. The NRC and ACRS issues which were raised in conjunction with the licensing of CRBR and the Power Reactor Innovative Small Module (PRISM) Liquid Metal Reactor, and more recent NRC efforts on licensing issues for high temperature reactors were summarized.

The CRBR license application for a construction permit was approved by NRC, subject to project R\&D activities to address concerns identified by NRC and ACRS. However, due to the abrupt cancellation of the project that led to the cessation of all activities, NRC had not progressed to a point to either approve or disapprove the ASME Code Case N-47, a precursor to Subsection NH, which was the basis for the design of Class 1 pressure-retaining components for elevated temperature service for CRBR. This remains the status of Subsection NH to date. 
Idaho National Laboratory

\begin{tabular}{|c|lll|}
\hline $\begin{array}{c}\text { NEXT GENERATION NUCLEAR PLANT STEAM } \\
\text { GENERATOR AND INTERMEDIATE HEAT } \\
\text { EXCHANGER MATERIALS RESEARCH }\end{array}$ & Identifier: & PLN-2804 & \\
AND DEVELOPMENT PLAN & Effective Date: & $09 / 23 / 10$ & Page: 58 of 252 \\
\hline
\end{tabular}

Table 14 (shown here in the draft form) is being prepared by the NRC staff. It summarizes the current understanding of the licensing concerns by the task investigators, based on the elevated temperature structural integrity issues identified by the NRC licensing review of CRBR. The order is not ranked.

Table 14. Summary of licensing concerns based on elevated temperature structural integrity issues.

\begin{tabular}{|c|c|c|c|c|}
\hline \multirow[b]{2}{*}{$\begin{array}{c}\text { Elevated Temperature Structural } \\
\text { Integrity Issues }\end{array}$} & \multicolumn{4}{|c|}{$\begin{array}{l}\text { Priority Level: } \\
\text { (1) Issue to be of higher concern or safety significance } \\
\text { (2) Issue addressed by ASME B\&PV Code or of a lower concern } \\
\text { (3) Issue beyond scope of Subsection NH } \\
\text { (4) Issue considered to be of no concern. }\end{array}$} \\
\hline & CRBR & $\begin{array}{c}\text { Pebble-Bed Reactor } \\
\text { (\& Cold Vessel } \\
\text { Option for VHTR) }\end{array}$ & $\begin{array}{c}\text { VHTR } \\
\text { (Hot Vessel } \\
\text { Option) } \\
\end{array}$ & Gen IV \\
\hline Transition joints & $(1)$ & $(4)$ & $(1)$ & $(1)$ \\
\hline Weld residual stresses & (1) & $(4)$ & $(1)$ & $(1)$ \\
\hline Design loading combinations & $(1)$ & $(3)$ & $(3)$ & $(3)$ \\
\hline Creep-rupture and fatigue damage & $(1)$ & $(2)$ & $(1)$ & $(1)$ \\
\hline Simplified bounds for creep ratcheting & (1) & $(2)$ & $(1)$ & $(1)$ \\
\hline Thermal striping & (1) & $(2)$ & $(2)$ & $(1)$ \\
\hline $\begin{array}{l}\text { Creep-fatigue analysis of Class } 2 \text { and } 3 \\
\text { piping }\end{array}$ & (1) & (2) & (2) & (2) \\
\hline $\begin{array}{l}\text { Are limits of Case N-253-14 for elevated } \\
\text { temp. Class } 2 \text { and } 3 \text { components met? }\end{array}$ & (1) & (2) & (2) & (2) \\
\hline $\begin{array}{l}\text { Creep buckling under axial compression } \\
\text { - design margins }\end{array}$ & (1) & (2) & (2) & (2) \\
\hline $\begin{array}{l}\text { Identify areas where Appendix T rules } \\
\text { are not met }\end{array}$ & (1) & (2) & (1) & (1) \\
\hline $\begin{array}{l}\text { Rules for component supports at } \\
\text { elevated temperature }\end{array}$ & (1) & (2) & (2) & (2) \\
\hline $\begin{array}{l}\text { Strain and deformation limits at elevated } \\
\text { temperature }\end{array}$ & (1) & (2) & (4) & (1) \\
\hline Evaluation of weldments & (1) & (1) & (1) & $(1)$ \\
\hline $\begin{array}{l}\text { Material acceptance criteria for elevated } \\
\text { temperature }\end{array}$ & (1) & (2) & (2) & (1) \\
\hline $\begin{array}{l}\text { Creep-rupture damage due to forming } \\
\text { and welding }\end{array}$ & (1) & (2) & (1) & (1) \\
\hline Mass transfer effects & (1) & $(2)$ & $(2)$ & (2) \\
\hline Environmental effects & (1) & $(1),(3)$ & (1), (3) & $(1),(3)$ \\
\hline Fracture toughness criteria & $(1)$ & $(2)$ & $(1)$ & $(1)$ \\
\hline Thermal aging effects & $(1)$ & $(1)$ & $(1)$ & $(1)$ \\
\hline Irradiation effects & $(1)$ & $(1),(3)$ & $(1),(3)$ & $(1),(3)$ \\
\hline $\begin{array}{l}\text { Use of simplified bounding rules at } \\
\text { discontinuities }\end{array}$ & (1) & (1) & (1) & (1) \\
\hline
\end{tabular}


Idaho National Laboratory

\begin{tabular}{|c|lll|}
\hline $\begin{array}{c}\text { NEXT GENERATION NUCLEAR PLANT STEAM } \\
\text { GENERATOR AND INTERMEDIATE HEAT }\end{array}$ & Identifier: & PLN-2804 & \\
EXCHANGER MATERIALS RESEARCH & Revision: & 1 & \\
AND DEVELOPMENT PLAN & Effective Date: & $09 / 23 / 10$ & Page: 59 of 252 \\
\hline
\end{tabular}

Table 14. (continued).

\begin{tabular}{|c|c|c|c|c|}
\hline \multirow[b]{2}{*}{$\begin{array}{c}\text { Elevated Temperature Structural } \\
\text { Integrity Issues } \\
\end{array}$} & \multicolumn{4}{|c|}{$\begin{array}{l}\text { Priority Level: } \\
\text { (1) Issue to be of higher concern or safety significance } \\
\text { (2) Issue addressed by ASME B\&PV Code or of a lower concern } \\
\text { (3) Issue beyond scope of Subsection NH } \\
\text { (4) Issue considered to be of no concern. }\end{array}$} \\
\hline & CRBR & $\begin{array}{c}\text { Pebble-Bed Reactor } \\
\text { (\& Cold Vessel } \\
\text { Option for VHTR) }\end{array}$ & $\begin{array}{c}\text { VHTR } \\
\text { (Hot Vessel } \\
\text { Option) } \\
\end{array}$ & Gen IV \\
\hline Elastic follow-up & (1) & (4) & (4) & $(4)$ \\
\hline $\begin{array}{l}\text { Design criteria for elevated temp. core } \\
\text { support structures and welds }\end{array}$ & (1) & (2) & (2) & (1) \\
\hline $\begin{array}{l}\text { Elevated temperature database for } \\
\text { mechanical properties }\end{array}$ & (1) & (1) & (1) & (1) \\
\hline $\begin{array}{l}\text { Basis for leak-before-break at elevated } \\
\text { temperatures }\end{array}$ & (1) & (4) & (1) & (1) \\
\hline
\end{tabular}

The task investigators provided an account of the manner in which NRC licensing issues for the structural design of HTGR and Gen IV systems are addressed in the current ASME Subsection NH and Code cases. The creep behavior, creep-fatigue, and environmental effects are addressed in Subsection NH and Code cases largely in terms of design criteria and allowable stress and strain values. The detailed material properties needed for cyclic finite element creep design analyses are generally not provided in the ASME Code. The NRC perspective is that the ASME Code and/or Code cases currently do not adequately cover the material behavior under cyclic loads in the creep regime, and creep-fatigue and creep-rupture interaction effects.

It is noted that for CRBR, the guidance on inelastic finite element analyses, external to the ASME Code, was provided in NE F9-5T, Nuclear Standard, Guidelines and Procedures for Design of Class 1 Elevated Temperature Nuclear System Components.

Subsection NH has rules for the design of welded joints separated into Categories A through D. The permissible types of welded joints and their dimensional requirements are specified. Paragraph 3353 of Subsection NH provides analysis requirements for the design and location of all pressure retaining welds operating at temperatures where creep effects are significant. Reduction factors for creep stress rupture are given as a function of time and temperature. Permissible weld metals are limited and special examination requirements are imposed.

Probably the most restrictive Subsection NH requirement for welds is that the inelastic accumulated strains are limited to one-half the allowable strain limits for the base metal. This has forced designers to keep welds out of high stress areas. The allowable fatigue at weldments is limited to one-half the design cycles allowed for the base metal. The allowable creep-rupture damage at weldments is limited in Subsection NH by requiring that the rupture strength be reduced by the WSRF when determining the time-to-rupture. The ASME Code also imposes additional examination requirements on Categories A through D welded joints. The adequacy of these and other ASME Code weldment structural design requirements has been questioned by the NRC, even for the temperatures currently covered, which are lower than the HTGR and Gen IV high temperature systems. 


\begin{tabular}{|c|lll|}
\hline NEXT GENERATION NUCLEAR PLANT STEAM & Identifier: & PLN-2804 & \\
$\begin{array}{c}\text { GENERATOR AND INTERMEDIATE HEAT } \\
\text { EXCHANGER MATERIALS RESEARCH } \\
\text { AND DEVELOPMENT PLAN }\end{array}$ & Revision: & 1 & \\
Effective Date: & $09 / 23 / 10$ & Page: 60 of 252 \\
\hline
\end{tabular}

Because of the importance of potential elevated temperature cracking of weldments, NRC wanted the designer to account for potential creep strain concentrations due to metallurgical notch effects. Subsection $\mathrm{NH}$ does not include methods for analyzing the effects of varying properties between the base metal, weld metal and HAZ, or even how to determine these properties after welding and post weld heat treatment (PWHT). Moreover, NRC expressed concern with potential early crack initiation at the inside wall surface in the HAZ, how crack propagation can be quantified, and the stability of the remaining uncracked wall section.

Methods for evaluating the structural integrity of welds essentially parallels the Section XI flaw evaluation methods which are only applicable below the creep regime. The NRC has also requested confirmation of the creep-rupture, creep-fatigue, and interaction evaluation procedures at weldments, accounting for load sequence effects.

Verification testing was carried out on representative structural features of CRBR as part of the licensing effort. HTGR temperatures are much higher than the CRBR temperatures. Existing simplified design analysis methods have proven to be very valuable in providing assurance of structural integrity in the moderate creep regime and have been used in France, Germany, Japan, and the U.S. for this purpose. Cyclic finite element creep analysis results are difficult to trust without having comparative results of simplified design analysis methods.

\section{Recommendations (data needs)}

The task report provides a discussion on the material models, design criteria, and analysis methods that need to be added to the ASME Code and Code Cases to cover unresolved regulatory issues for very high temperature service.

Needs for material creep behavior, creep-fatigue and environmental effects:

- Extended temperature and/or time for current Code materials to cover HTGR conditions.

- Addition of new materials to the ASME Code to cover HTGR applications.

- Appropriate databases for calculating fatigue, creep, creep-fatigue, and stress corrosion cracking (SCC) lifetimes, including environmental effects of impure helium and crevice concentration.

- Aging behavior of alloys.

- Degradation by carburization, decarburization, and oxidation.

- Sensitization of austenitic alloys and weldments.

Needs for design methods:

- Treatment of connecting pipe as a vessel for ASME Code application.

- In-service inspection plans and methods.

- Probabilistic risk assessment methodologies for vessels, pipes, and components.

Needs for developing methods of evaluating the structural integrity of welds and safety margins:

- Materials models.

- Cyclic creep analysis methods.

- Crack growth analyses.

- Remaining ligament enhanced creep stability analysis methods. 


\begin{tabular}{|c|lll|}
\hline $\begin{array}{c}\text { NEXT GENERATION NUCLEAR PLANT STEAM } \\
\text { GENERATOR AND INTERMEDIATE HEAT }\end{array}$ & Identifier: & PLN-2804 & \\
EXCHANGER MATERIALS RESEARCH & Revision: & 1 & \\
AND DEVELOPMENT PLAN & Effective Date: & $09 / 23 / 10$ & Page: 61 of 252 \\
\hline
\end{tabular}

Verification of the simplifications and approximations of simplified design analysis method:

- Linear thermal through-wall stresses.

- Bending stresses considered as secondary stress.

- Homogeneous weldment properties.

- Absence of metallurgical notch effects.

Additional verification testing to validate the elevated temperature designs of HTGRs:

- Validation of the material models needed to perform cyclic creep analyses.

- Validation of the finite element software capabilities to handle cyclic creep at structural discontinuities.

- Elastic follow-up.

- Creep-rupture at notches.

- Weldment behavior.

- Possibly flaw tolerance evaluation methods.

\subsection{TASK 3: Improvement of Subsection NH Rules for Grade 91 Steel}

Grade 91 steel is not relevant to components considered in this report and will not be discussed here.

\subsection{TASK 4: Update Code Case N-201-5 to Accommodate HTGRs}

The objective of this task was to expand the scope of Code Case N-201-5 to include the materials with higher allowable temperatures or extend the temperature limits of current materials, and to confirm that the design methodology used is acceptable for design of core support structure components at the appropriate elevated temperatures. Task 4 was embarked upon in recognition of the number of ongoing reactor designs utilizing high temperature technology in their designs of metallic core support structures. Update and improvement of Code Case N-201 will support the design effort for core support structures in all three vendor designs for NGNP.

\section{Results}

A questionnaire concerning materials of interest and operating conditions for the core support structures of Gen IV high temperature gas-cooled reactors was developed and distributed to PBMR, GA, AREVA, and the Japan Atomic Energy Agency (JAEA). The responses received from PBMR, JAEA, and GA indicated that the metal temperatures for normal operation are such that the creep effects will be minimal, but still must be considered in the analysis. It was concluded that it should be possible for these designs to make extensive use of the simplified analysis and bounding methods provided in Part B of the applicable Code Case N-201-5. The design procedures in Part B are essentially the same as Subsection $\mathrm{NH}$. The normal operating metal temperature stated for the high temperature gas reactor metallic core support structures for AREVA is well below the creep range; therefore, explicit consideration of creep and stress rupture is not necessary.

The identified off-normal conditions for the HTGR metallic core support structures were in the fringes, where creep effects may also need to be considered. At these short duration elevated temperature conditions, it was concluded that significant creep-accelerated crack growth is unlikely. However, proving unlikely growth quantitatively, particularly creep crack growth at weldments and notches might be very difficult. Based on the results of the survey, it was concluded that additional work must be done 


\begin{tabular}{|c|lll|}
\hline $\begin{array}{c}\text { NEXT GENERATION NUCLEAR PLANT STEAM } \\
\text { GENERATOR AND INTERMEDIATE HEAT }\end{array}$ & Identifier: & PLN-2804 & \\
EXCHANGER MATERIALS RESEARCH & Revision: & 1 & \\
AND DEVELOPMENT PLAN & Effective Date: & $09 / 23 / 10$ & Page: 62 of 252 \\
\hline
\end{tabular}

to update Code Case N-201-5. The results of Task 4 activities provided the framework for the Code Case N-201-5 update, as well as future work to provide material input.

Since Code Case N-201-5, "Class CS Components in Elevated Temperature Service," ASME Section III, Division 1, has not seen a major revision since December 1994, a comprehensive review of this Code case was performed against the latest Edition and Addenda of ASME Code Subsection NG and Subsection NH. Many errors, omissions, and substantive questions were identified in Code Case N-201-5, especially when compared to Subsection NH. This partially stems from the fact that it was issued in essentially its present form 15 to 20 years ago, and has had little, if any, use since then. In conjunction with the preliminary responses and recommended actions to these identified issues, the Task 4 report provided a compilation of these findings for consideration by the ASME Subgroup on Elevated Temperature Design (SG-ETD). Draft recommended changes to the latest issued revision to CC N-201-5 were presented as an Appendix to the Task 4 report and transmitted to SG-ETD for comments.

Upon the receipt of the proposed changes to CC N-201-5, SG-ETD had provided the Task 4 team members detailed technical and editorial comments. Actions on these comments are currently being taken by Task 4 as a follow-on task, using the original first round budget.

It is noted that the survey was performed before the vendors (Westinghouse/PBMR, AREVA and GA) had delivered the NGNP preconceptual design reports. The operating conditions stated in the survey were somewhat different than those given for the NGNP preconceptual designs. However, the conclusions from the Task 4 report remain generally valid.

\section{Recommendations}

- Obtain experimental data for very long duration loading at the threshold of creep. It was recommended that this issue be addressed as a part of the complete Task 2 effort.

- Add Type 321 and Type 347 austenitic stainless steels and Grade 91 steel to Code Case N-201-5 for core support construction.

- Add Alloy 718 to Code Case N-201-5 for threaded structural fasteners.

- Address design life beyond 300,000 h, especially in consideration of 60-year design life.

- Develop detailed recommended changes to CC N-201-5 for consideration to ASME SG-ETD.

A revised CC N-201-5 has been drafted, and it is currently under consideration by the ASME Code committees for approval.

\subsection{TASK 5: Collect Creep-Fatigue Data and Study Evaluation Procedures for Grade 91 Steel and Hastelloy XR}

Grade 91 steel is not relevant for components considered in this report and will not be discussed here. Hastelloy XR was a potential IHX material, although a lack of accessible data (because most of the data were generated by JAEA) has eliminated it from consideration. However, the studies reported in this task on Hastelloy XR provide valuable information on the design and materials issues for an IHX with He as a coolant. This information could possibly be used for other nickel-based alloys such as Alloy 617.

\subsection{Part II. Hastelloy XR}

Material characterizations for Hastelloy XR suggested that special considerations should be made to account for dynamic recrystallization at high temperatures. A new tensile test procedure with a change in strain rate to $100 \% / \mathrm{min}$ at temperatures over $800^{\circ} \mathrm{C}$ to obtain the time-independent elastic-plastic property for Hastelloy XR was proposed. Further material characterization and component-wise structural mechanics research works revealed that design rules for austenitic stainless steels can be applied to 


\begin{tabular}{|c|lll|}
\hline $\begin{array}{c}\text { NEXT GENERATION NUCLEAR PLANT STEAM } \\
\text { GENERATOR AND INTERMEDIATE HEAT }\end{array}$ & Identifier: & PLN-2804 & \\
EXCHANGER MATERIALS RESEARCH & Revision: & 1 & \\
AND DEVELOPMENT PLAN & Effective Date: & $09 / 23 / 10$ & Page: 63 of 252 \\
\hline
\end{tabular}

Hastelloy XR; therefore, the high temperature structural design guideline was established with reference to the Fast Breeder Reactor (FBR) Design Code.

\section{Results}

The High Temperature Structural Design Guideline for HTGR, used for the design of the structural components of the HTTR, is described in the task report. A creep analysis method was established for Hastelloy XR through several Japanese research works, in which the creep equation was generated from Garofalo's version of the time function. It was demonstrated that the strain hardening rule and von Mises' flow rule are applicable to Hastelloy XR.

Cumulative creep strain and cumulative creep and fatigue damage factors, based on the high temperature structural design guideline for the Hastelloy XR components of the HTTR IHX, were evaluated based on inelastic analysis.

The linear summation rule of cycle and time fractions is applicable to Hastelloy XR with large safety margins, even at very high temperatures. It was suggested that the same conclusion would be expected of other nickel-based superalloys such as Alloy 617. However, testing would be required to either confirm this expectation or to suggest the need for developing new methods.

In the design of the IHX for HTTR, inelastic analysis was necessary to evaluate creep strain and creep damage at very high temperatures. Similarly, in the design of high temperature components such as IHX made of Alloy 617 for NGNP, inelastic analysis would be inevitable. In the design of HTTR IHX, conventional Garofalo's expression was used as a creep constitutive equation because the high temperature structural design guideline was developed in the 1980s. Since then, significant advances have been made in the development of unified viscoplasticity constitutive equations such as those given by Chaboche, ${ }^{61}$ Tachibana and Krempl ${ }^{62-64}$ Walker, ${ }^{65}$ etc. In the future design of high temperature components, use of unified inelastic constitutive equations should be investigated.

Impurities in the primary coolant of the HTTR are controlled so that primary coolant is in a regime where a stable oxide is formed with mild underlying carburization. For this purpose, R\&D is underway in the HTTR to develop methods to control the helium purification system. Similarly, R\&D will be needed for future HTGRs on Alloy 617 to determine the optimum level of impurities in the primary coolant as well as to control the helium purification system to maintain the optimum level.

\section{Recommendations}

- Perform tests to confirm that the linear summation rule of cycle and time fractions is applicable to Alloy 617.

- Investigate use of unified inelastic constitutive equations.

- Develop methods to control the helium purification system.

- Determine the optimum level of impurities in the primary coolant.

\subsubsection{Second Round Tasks}

The original twelve topics developed in the DOE/ASME Gen IV project to address ASME Code issues were drafted a few years ago. With the completion of the NGNP preconceptual design reports from the vendors, the remaining topics from the original list were re-prioritized, some work scopes were modified, and new work scopes were added. Six new tasks in the second round of the DOE Initiative were initiated and these tasks have now been completed. 


\begin{tabular}{|c|lll|}
\hline $\begin{array}{c}\text { NEXT GENERATION NUCLEAR PLANT STEAM } \\
\text { GENERATOR AND INTERMEDIATE HEAT } \\
\text { EXCHANGER MATERIALS RESEARCH }\end{array}$ & Identifier: & PLN-2804 & \\
AND DEVELOPMENT PLAN & Effective Date: & $09 / 23 / 10$ & Page: 64 of 252 \\
\hline
\end{tabular}

\subsection{TASK 6: Operating Condition Allowable Stress Values}

A spot check of minimum stress to rupture values provided in Subsection $\mathrm{NH}$ revealed that there was disagreement between the minimum stress to rupture values, $S_{r}$, at 100,000 h and the values of Design Condition stress intensity, $S_{o}$. Based on the allowable stress criteria, the values of $S_{o}$ should be no greater than $80 \%$ of $S_{r}$ at $100,000 \mathrm{~h}$. However, for all the listed Subsection NH materials, there were values of $S_{o}$ which exceeded $80 \%$ of $S_{r}$, often significantly, at higher temperature. Since the Subsection NH values of $S_{o}$ are in agreement with the allowable stress values listed in Section II, Part D, the expectation is that the values of $S_{r}$ arelower than expected if they were derived from the same data as the values for $S_{o}$. Further, the values of $S_{t}$, the allowable stresses for Operating Conditions, appear consistent with the values of $S_{r}$, thus throwing in doubt all the allowable Operating Condition stress values for both load-controlled stress limits and displacement-controlled limits in Subsection NH. Task 6 was developed to address these discrepancies for the Subsection NH materials. This is an important issue for NGNP as the Operating Condition allowable stresses are required for the design of high temperature structural components, and Alloy $800 \mathrm{H}$ and 316 stainless steel, two of the five Subsection NH materials considered by this task, have been suggested as core internal materials.

In Part I, a review of current values of $S_{r}, S_{o}$ and $S_{t}$ in Subsection NH was conducted for the five Subsection materials. The original databases from which these Subsection NH values were derived were retrieved from ASME Code committee records. In order to undertake a more detailed evaluation of issues related to allowable stresses, the available data from the latest sources for these Subsection NH materials were reviewed, and substantially larger databases were assembled. In Part II, the data from these databases were analyzed, and recommendations were made in Part III to address the issues identified. Results pertaining to Alloy $800 \mathrm{H}$ will be discussed here.

\section{Results, Part I}

The consistency criteria were applied to the Subsection NH values of $S_{o}, S_{t}$, and $S_{r}$. The $S_{o}$ values in Subsection NH for Alloy $800 \mathrm{H}$ and 316 stainless steel were found to be consistent with the $S$ values in Section II Part D. The stress values based on the criterion of $80 \%$ of the minimum rupture strength at $100,000 \mathrm{~h}\left(0.80 S_{r}\right)$ were less than $S_{o}$ for some temperatures for 316 stainless steel; hence, they need to be corrected. Stress values for Alloy $800 \mathrm{H}$ appeared to be consistent with the criteria on which $S_{o}$ values were established for all temperatures.

The original database for Alloy $800 \mathrm{H}$ consisted of 241 data lines from 15 lots, with the temperatures from 538 to $982^{\circ} \mathrm{C}\left(1000-1800^{\circ} \mathrm{F}\right)$, and the longest life was $22,000 \mathrm{~h}$. The expanded database consisted of 762 additional data lines from 79 lots, and the temperatures ranged from 500 to $816^{\circ} \mathrm{C}\left(932-1500^{\circ} \mathrm{F}\right)$. The longest life was $83,000 \mathrm{~h}$.

The original database for 316 stainless steel consisted of 348 data lines from 15 lots, with the temperatures from 538 to $871^{\circ} \mathrm{C}\left(1000-1600^{\circ} \mathrm{F}\right)$, and the longest life was $26,000 \mathrm{~h}$. The expanded database consisted of a total of more than 1900 data lines covering temperatures ranging from 427 to $1093^{\circ} \mathrm{C}\left(800-2000^{\circ} \mathrm{F}\right)$ and times to $224,000 \mathrm{~h}$. Most of the data for long times came from the National Research Institute for Metals (NIMS) in Japan.

\section{Results, Parts II and III}

The expanded creep-rupture database for Alloy $800 \mathrm{H}$ was judged to be adequate to meet the needs in extending the time-dependent properties for Subsection $\mathrm{NH}$ to $900^{\circ} \mathrm{C}\left(1650^{\circ} \mathrm{F}\right)$ and 500,000 or perhaps $600,000 \mathrm{~h}$. No additional issues beyond those already identified in the Task 1 report were found for Alloy $800 \mathrm{H}$. The issues identified in Task 1 that pertain to Alloy $800 \mathrm{H}$ will be addressed in this report. 


\begin{tabular}{|c|lll|}
\hline $\begin{array}{c}\text { NEXT GENERATION NUCLEAR PLANT STEAM } \\
\text { GENERATOR AND INTERMEDIATE HEAT }\end{array}$ & Identifier: & PLN-2804 & \\
EXCHANGER MATERIALS RESEARCH & Revision: & 1 & \\
AND DEVELOPMENT PLAN & Effective Date: & $09 / 23 / 10$ & Page: 65 of 252 \\
\hline
\end{tabular}

While the expanded database for 316 stainless steel is significantly larger than the original database used to develop the Subsection NH values, relatively few lines in the expanded database provided the time to $1 \%$ strain and time to tertiary creep. Also, not all lines included rupture points. The values of the minimum stress-to-rupture, $S_{r}$, obtained from the expanded database compare quite well with the Subsection NH values that were produced from a much smaller database. The differences were small and insufficient to justify changes to the $S_{r}$ values in Subsection NH.

The expanded 316 stainless steel database was judged to be adequate for setting the allowable stress intensity values for temperatures to at least $649^{\circ} \mathrm{C}\left(1200^{\circ} \mathrm{F}\right)$. It was concluded that additional test data covering very long times and above $649^{\circ} \mathrm{C}$ would be helpful in addressing some concerns on extrapolating data trends to times beyond $100,000 \mathrm{~h}$.

It is noted that since the publication of the Task 6 final report, some long-term creep-rupture data from NIMS for 316 stainless steel were found to be lower than the extrapolated creep-rupture lifetimes in Subsection NH. Hence, there is a potential of non-conservatism in the Subsection NH allowable stress values for 316 stainless steel. This is a high priority item for investigation. Corrective ASME Code action needs to be taken, if needed. A new task of the DOE/ASME Gen IV project has been developed to address this issue.

\section{Recommendations}

The recommended ASME Code actions for Alloy $800 \mathrm{H}$ and 316 stainless steel are summarized in Table 15.

Table 15. Task 6 recommended ASME Code actions for Alloy $800 \mathrm{H}$ and 316 stainless steel.

\begin{tabular}{ccl}
\hline Alloy & Item & \\
\hline $800 \mathrm{H}$ & $S_{o}$ & Extend $S_{o}$ values to $850^{\circ} \mathrm{C}$ \\
& $S_{t}$ & Extend $S_{t}$ values to $850^{\circ} \mathrm{C}$ and $500,000 \mathrm{~h}$ \\
& $S_{t}$ & Develop a creep model for estimating $1 \%$ strain and onset of tertiary creep \\
& $S_{r}$ & Extend $S_{r}$ values to $850^{\circ} \mathrm{C}$ and $500,000 \mathrm{~h}$ \\
& $S_{o}$ & Base $S_{o}$ values on the current $0.80 S_{r}$ values \\
& $S_{t}$ & Reduce $S_{t}$ values if new tertiary creep data show a need for reduced values \\
& $S_{r}$ & Re-examine $S_{r}$ values at $1,000 \mathrm{~h}$ for $\geq 700^{\circ} \mathrm{C}$ \\
\hline
\end{tabular}

\subsection{TASK 7: Considerations for the Intermediate Heat Exchanger (IHX)}

The intent of this task is to recommend how and where within ASME codes and standards, the IHX, safety valve, etc., would be addressed and to provide guidance to equipment suppliers on potential critical code issues to be addressed.

Part I of the task report briefly reviewed two tubular helical coil heat exchangers and some compact IHX concepts. The tubular helical coil heat exchangers described include a $10 \mathrm{MWt}$ mock-up in the KVK, (a former HTR component testing facility in Germany) that was tested in the 1980s, and a 10 MWt IHX that is currently being operated in the High Temperature Test Reactor (HTTR) in Japan. The compact IHX concepts described include a corrugated stamped plate design, a printed circuit design, and a plate-fin design, in which narrow gap laser welding, diffusion bonding, and brazing are the respective joining process. These compact IHXs are characterized by much smaller flow channels, 0.1 in. or less, than conventional tubular heat exchangers, resulting in greatly enhanced heat transfer. In addition, the micro-channel configuration provides more heat transfer area for a given volume than conventional tubular heat exchangers. 


\begin{tabular}{|c|lll|}
\hline NEXT GENERATION NUCLEAR PLANT STEAM & Identifier: & PLN-2804 & \\
GENERATOR AND INTERMEDIATE HEAT & Revision: & 1 & \\
EXCHANGER MATERIALS RESEARCH & Effective Date: & $09 / 23 / 10$ & Page: 66 of 252 \\
AND DEVELOPMENT PLAN &
\end{tabular}

Generally, the tubular helical coil heat exchangers are much more mature because the technology has been demonstrated in mock-up and demonstration units at very high temperatures and in the HTGR helium environment. The compact designs offer the potential of greater efficiency and better economy, but the technology has yet to be demonstrated for HTGRs.

A survey was conducted to collect input from vendors who specialized in heat exchanger components. The survey consisted of five categories: general information, design, material, fabrication, and non-destructive examination. The vendors responding to the survey were AREVA, Westinghouse, and General Atomics. All recommended the use of ASME Code as a guideline for all aspects of design and fabrication of the IHX. Code allowables of IHX materials, design guidelines to $950^{\circ} \mathrm{C}$, and fabrication, non-destructive testing and material properties for diffusion bonded components are the issues identified for the ASME Code.

Part II of the task report briefly summarized the features of the Draft ASME Alloy 617 Code Case, the draft Kerntechnischer Ausschuss (KTA - German Nuclear Safety Standard Commission) rules for the German HTR program, the High Temperature Structural Design Guideline for HTTR from Japan, and the European Standard EN 13445-3 for U-tube, fixed or floating tubesheet heat exchangers.

The Part II task report also summarized the events that would occur in a loss of flow or a loss of coolant accident scenario and concluded that the reactor forced cooling systems that include the shutdown cooling system, the primary circulator or the IHX are not required for the safe shutdown and cooldown of the reactor because of the passive safety feature of HTGRs. Hence the task report concluded that the IHX should be classified as a non-safety related component. However, since an IHX is a significant capital investment, it was recommended that Subsection NH for Class 1 (safety related) nuclear components should be employed for the IHX.

In addition, the Part II task report described issues related to the codification of Alloy 617 in Subsection NH. They are similar to those addressed in this report. The task report concluded that the ASME Code rules are essentially adequate for the tubular heat exchanger design. Other considerations described in the task report include fabrication, examination of joints, and testing. Required in-service inspection and associated non-destructive testing of the tubular and compact IHXs were discussed. Due to the difficulty of in-service inspection of compact IHXs, it was suggested that periodic replacement should be considered. Relevant ASTM material specifications and testing standards were also described.

The Task 7 results represent a step forward in understanding issues relating to the design, fabrication, examination, testing, and in-service inspection of compact IHXs. However, these recommendations need to be implemented in an ASME Code case. To insure that the rules will be generally applicable, it is suggested that a peer review panel of task reviewers be established representing key stakeholders, i.e., reactor suppliers/designers, owner/operators, heat exchanger suppliers, and regulators. Among the issues to be resolved are compact IHX configurations to be covered, time and temperature limits, definition and control of fabrication processes, consideration (or not) of environmental effects in the ASME Code case, limitations to design-by-analysis due to configuration constraints, design verification testing, inspectability, safety considerations for primary to secondary leakage, in-service inspection/replacement requirements, and the need for development of supporting ASTM standards.

\subsection{TASK 8: Creep and Creep-Fatigue Crack Growth at Structural Discontinuities and Welds}

The lack of a quantitative methodology for evaluating the potential for creep and creep-fatigue crack growth at structural discontinuities and weldments has been identified in NRC reviews as a shortcoming of Subsection NH. Subsection NH does provide a number of design factors and procedures to ensure elevated temperature weldments and stress risers will perform satisfactorily but does not provide for a 


\begin{tabular}{|c|lll|}
\hline NEXT GENERATION NUCLEAR PLANT STEAM & Identifier: & PLN-2804 & \\
$\begin{array}{c}\text { GENERATOR AND INTERMEDIATE HEAT } \\
\text { EXCHANGER MATERIALS RESEARCH } \\
\text { AND DEVELOPMENT PLAN }\end{array}$ & Revision: & 1 & \\
Effective Date: & $09 / 23 / 10$ & Page: 67 of 252 \\
\hline
\end{tabular}

quantitative assessment of creep crack growth. Although desirable for design, such a methodology is especially critical for evaluation of potential cracks and crack growth detected during in-service inspection. During the early years of the evolution of the current Subsection NH, such methodologies for evaluation of creep crack growth were in their infancy. However, there have been advances in the technology in recent years, for both nuclear and non-nuclear applications. A key issue for nuclear applications is whether these methodologies are sufficiently well established. They must give the required assurances without undue conservatism which would preclude designs and/or operating parameters that are actually not susceptible to premature failure.

The scope of Part I involves the review of currently used methods for predicting creep and creep-fatigue crack growth and the assessment of their applicability for design and in-service inspection assessment of Subsection NH components. The procedures examined by the task investigator include the British R5 procedure, the A16 procedure of the French RCC-MR Code, the API 579 method, the British BS-7910 Code, and the German draft KTA Code. It was concluded that all of these methods are very similar and many are based on the R5 methodology. A detailed summary of the R5 method was provided in the Part I task report. The task investigator concluded that R5 has well established and validated rules, a team of experts continually improving and updating the rules, software that can be used by designers, and extensive validation in many parts with available data that can be procured from sources in the United Kingdom (U.K.) Thus, it was recommended that the R5 creep and creep-fatigue crack growth procedure be considered for implementation in Subsection NH. The task report did highlight the concerns expressed during the report review process on the applicability of the R5 approach for very high temperature applications. Since the R5 methodology was developed for the British Advanced Gas Reactor (AGR) fleet, verification and validation of its methodology for applications that are outside the operating conditions and experience base of the AGRs were recommended. This is especially essential when these rules are applied to materials that have very different creep deformation characteristics than those used for the AGRs.

In Part II of the task effort, a step-by-step procedure for assessing a detected or postulated defect under creep-fatigue loading was developed for the consideration of Subsection NH implementation:

1. Establish the expected or actual cause of cracking and characterize initial defect.

2. Define service conditions for the component.

3. Collect materials data.

4. Perform basic stress analysis.

5. Check stability under time-independent loads.

6. Check significance of creep and fatigue.

7. Calculate rupture life based on the initial defect size.

8. Calculate crack nucleation or incubation time.

9. Calculate crack growth for the desired lifetime.

10. Re-calculate rupture life after crack growth.

11. Check stability under time-independent loads after crack growth.

12. Assess significance of results.

13. Report results. 


\begin{tabular}{|c|lll|}
\hline NEXT GENERATION NUCLEAR PLANT STEAM & Identifier: & PLN-2804 & \\
$\begin{array}{c}\text { GENERATOR AND INTERMEDIATE HEAT } \\
\text { EXCHANGER MATERIALS RESEARCH } \\
\text { AND DEVELOPMENT PLAN }\end{array}$ & Revision: & 1 & \\
Effective Date: & $09 / 23 / 10$ & Page: 68 of 252 \\
\hline
\end{tabular}

The material data requirements for using the R5 rules were outlined in the task report. Guidelines for the development of an ASME-based remaining life defect assessment procedure, and a compendium of relevant data for Cr-Mo steels and stainless steels for use in fracture-mechanics-based life assessment procedures were provided by K. Nikbin and R. Ainsworth in the Appendices of the Part II task report.

It is noted that the AGRs are $\mathrm{CO}_{2}$-cooled, graphite-moderated high temperature reactors that were developed as the second generation gas-cooled reactors in the U.K. The gas outlet temperature is about $640^{\circ} \mathrm{C}$, and special high temperature structural materials developed for the AGR environment and operating conditions were used as the materials of construction. The AGR fleet has been operated successfully for many years and the R5 flaw assessment procedures were developed specifically for the maintenance of the AGR fleet. Like many existing code procedures, the R5 methods are essentially empirically based. Thus a robust database and rigorous verification and validation efforts are necessary for the rules to be successful. Due to the continual operation of the AGR fleet, there are ample opportunities to update the R5 rules whenever plant data indicate that the rules are non-conservative. Because of this valuable feedback, the R5 rules are now well-tuned for the AGRs. However, such successful operating experience might or might not be transferable to different environments, temperatures, material systems and operating conditions.

In a recent review, ${ }^{66}$ it was pointed out that the $\mathrm{R} 5$ creep crack growth procedure is based on a steady-state secondary creep model which is a reasonable model for Cr-Mo steels and austenitic stainless steels, but not for some candidate nickel-based and iron-based superalloys at elevated temperatures. The use of time-dependent fracture mechanics methodology is necessary for such applications.

\subsection{TASK 9: Update and Improve Subsection $\mathrm{NH}$ - Simplified Elastic and Inelastic Design Analysis Methods}

Current design analysis rules in Subsection NH were developed during the decades ending in the late 1980s. Since then there have been notable advances in computing technology that permit evaluation methodologies not previously considered. There have also been advances in the understanding of elevated temperature material behavior and failure mechanisms. The following scope was stated during the definition of Task 9:

"Review and compare current design methods and assessment techniques in ASME NH, RCC-MR, BC5500, DIN, and JNC, R5, API 579 and other relevant sources. Propose a range of design analysis methods consisting of: (i) elastic analysis, (ii) reference stress method, and (iii) limit load, shakedown, and ratcheting analysis. Recommend requisite requirements for codification, including data generation, data extrapolation strategies, round-robin structural analyses, and feature testing to validate methods."

\section{Background}

The first line of attack in Subsection NH for evaluation of structural failure modes is based on the results of elastic analysis. This was a natural choice, particularly in the time frame in which $\mathrm{NH}$ was developed, because that was the baseline for analysis of structures below the creep regime. Traditionally, structures are separated into simplified "free bodies" subject to external loading. First, the stresses required for equilibrium with external loads are determined and used to assess the adequacy of the component thickness to carry the applied external forces, e.g., pressure. These stresses are categorized as "primary" and their allowable stress criteria are set to prevent rupture. Next, the boundary deformations of the free bodies are determined and used to calculate the forces and associated stresses to restore structural continuity to the reassembled structure. These stresses are categorized as "secondary" and limited to ensure shakedown to elastic behavior, thus validating the use of elastic analysis and preventing 


\begin{tabular}{|c|lll|}
\hline NEXT GENERATION NUCLEAR PLANT STEAM & Identifier: & PLN-2804 & \\
$\begin{array}{c}\text { GENERATOR AND INTERMEDIATE HEAT } \\
\text { EXCHANGER MATERIALS RESEARCH } \\
\text { AND DEVELOPMENT PLAN }\end{array}$ & Revision: & 1 & \\
Effective Date: & $09 / 23 / 10$ & Page: 69 of 252 \\
\hline
\end{tabular}

ratcheting and incremental collapse. Finally, peak stresses due to local stress concentrations and thermal stresses are added in, and the alternating stress range is evaluated for fatigue failure. At elevated temperatures where creep must be considered, the deformation and failure modes are more complex. In order to use the results of elastic analysis to account for inelastic creep deformation and time-dependent failure, it was necessary to identify applicable but simplified models which would represent the particular failure mode of interest. Hence the use of the terminology "simplified elastic" and "inelastic" design analysis methods.

There are some disadvantages and limitations to the use of conventional elastic analysis methods. First, because of the approximations used in the simplified models to bound the inelastic response, the results are generally conservative and have limitations on geometric applicability and cycle definition. Second, they all require that the results of finite element analysis (FEA) be deconstructed to determine the classification of the stress components into primary, secondary and peak values for comparison to the stress limits applicable to that stress category. (Note that the use of FEA is now the industry standard. The use of hand analysis with equilibrium loading and discontinuity stresses is becoming, or perhaps has become a lost art.) While straightforward for simple configurations such as a cylindrical shell remote from structural discontinuities, the classification process becomes much more difficult and subjective for more complex configurations such as nozzles and flanges. Furthermore, the current Subsection NH method doesn't accommodate stress redistribution in redundant structures and can lead to over design which can become increasingly significant as operating temperatures increase.

If components cannot satisfy the elastic-analysis-based criteria, the alternative is to use inelastic analysis which accounts for both plasticity and time-dependent creep deformations. While generally considered to be more accurate, there are also disadvantages to this method. First, particularly at the time the rules were developed, inelastic analysis was quite expensive and severely taxed the computer capabilities of the era. Even now, with our greatly expanded computational capabilities, implementation of time-dependent inelastic analyses requires considerable insight and experience, qualities in short supply with the hiatus in elevated temperature nuclear design activities. Second, inelastic analysis in the creep regime requires validated analytical representations of time-dependent material response under a range of temperatures and loading conditions. (Note that this also requires the specification of timedependent loading and temperature histories.) At the time, the development and validation of these material models was quite expensive and time consuming. So much so that this information was restricted to DOE contractors who had access to Nuclear Standard NE F9-5T. As a result, there is only general guidance in Subsection NH on the required characteristics of inelastic material models. The use of the models from Nuclear Standard NE F9-5T for inelastic analysis was a supplemental contractual requirement. This is also one of the reasons that Subsection NH has such a limited number of materials.

Also, in the current Subsection NH rules, the use of inelastic analysis is restricted to the evaluation of secondary and peak stresses, referred to as deformation controlled (covered in Appendix T of Subsection $\mathrm{NH}$ ). The load-controlled, primary stress limits currently in Subsection NH are based on elastic analysis only.

\section{Results}

Task 9 was subdivided into a number of subtasks, summarized as follows: ${ }^{67}$

- Subtask 9.1 attempted, without reference to any specific code, standard or guideline currently in existence, to map out what is believed an "ideal" ETD code should encompass.

- Subtask 9.2 reviewed a number of existing, internationally recognized codes (to the extent that it was possible to obtain information on other codes and standards), independently and without comparison to ASME Subsection NH. The review encompassed guidelines for scope, and for the use of methods 


\begin{tabular}{|c|lll|}
\hline $\begin{array}{c}\text { NEXT GENERATION NUCLEAR PLANT STEAM } \\
\text { GENERATOR AND INTERMEDIATE HEAT }\end{array}$ & Identifier: & PLN-2804 & \\
EXCHANGER MATERIALS RESEARCH & Revision: & 1 & \\
AND DEVELOPMENT PLAN & Effective Date: & $09 / 23 / 10$ & Page: 70 of 252 \\
\hline
\end{tabular}

of analysis, with particular emphasis on the use of simplified methods. This task was carried out in the belief that some of the best lessons about what should be included in an ETD code could be learned by examining what had been done elsewhere, i.e., benchmarking.

- Subtask 9.3 attempted to identify areas where Subsection NH could benefit by following or drawing from the practices advocated in other codes and guidelines, i.e., conducting a direct comparison of the findings in Subtask 9.2.

- Subtask 9.4 reviewed a group of more recent analysis methods which have appeared in some form in the technical literature but have yet to be fully absorbed into established design code practice.

- Subtask 9.5 is a viewpoint, based on these four preceding subtasks, on changes that are believed to offer some benefit to continued development of Subsection NH.

- Subtask 9.6 surveyed the technical literature and identified experimental programs, and when available, associated analyses suitable for benchmarking and verification of current and proposed simplified methods including minimum data requirements.

\section{Recommendations}

The recommendations for Task 9.5 fall into three general categories:

1. Procedural and organizational issues, i.e., a website for round robin analyses (of interest in code deliberations, but no direct impact on NGNP)

2. Revisions and improvements to simplified methods

These are not currently high profile issues because the design process is in its early stages and typical detailed analyses with their attendant design and operating impacts have not surfaced. Furthermore, though not emphasized in Task 9, confirmatory structural testing and analyses are likely to play an important role in obtaining NRC concurrence with the rules in Subsection NH. Three general areas were covered:

A. Primary or load-controlled limits

Include reference stress methodologies to avoid stress classification and take credit for stress redistribution, although specific (e.g., code ready) wording was not provided. These recommendations are currently under consideration and development by the SG-ETD but progress is resource limited.

B. Corrections and clarification of the current NH Appendix T approaches to deformation-controlled limits

Identified specific problem areas with the current simplified methods for ratcheting and strain limits building on earlier work at ORNL on the impact of the reduction in yield strength at very high temperatures and cycle definition. Again, specific wording was not suggested in Task 9. Recently, specifically worded proposals have been developed and reviewed by the SG-ETD, some of which have been approved to move forward to higher level committees. Others are still under consideration because they tend to make the rules more conservative, impacting NGNP design. These rules are based on comparisons between simplified methods and not on actual structural response. Supporting analytical studies are needed to resolve this issue and provide support for NRC acceptance.

Reported on analytical studies indicating that the current methods could be safely used at very high temperatures, e.g., Alloy 617 at $900^{\circ} \mathrm{C}$. The current Draft Alloy 617 Code Case limits the applicability of the current methods to $650^{\circ} \mathrm{C}\left(1200^{\circ} \mathrm{F}\right)$. The applicability of current simplified 


\begin{tabular}{|c|lll|}
\hline $\begin{array}{c}\text { NEXT GENERATION NUCLEAR PLANT STEAM } \\
\text { GENERATOR AND INTERMEDIATE HEAT } \\
\text { EXCHANGER MATERIALS RESEARCH }\end{array}$ & Identifier: & PLN-2804 & \\
AND DEVELOPMENT PLAN & Effective Date: & $09 / 23 / 10$ & Page: 71 of 252 \\
\hline
\end{tabular}

methods to high temperatures requires further corroboration before they can be incorporated in the ETD rules.

C. Application of modern methods to ratcheting and strain limits.

Identified and demonstrated several approaches to a methodology for simplified analyses that does not require stress classification. Recently, other conceptually similar but more robust approaches have been identified and reviewed in SG-ETD with the potential to greatly simplify and expedite elevated temperature design assessments. They have potential applicability across a wide temperature range from ambient to very high temperatures where "yielding" is strongly influenced by strain rate, a key enabling factor for the development of an "all-temperature" code that will eliminate the current discontinuity between the lower temperature Subsection NB design requirements and the elevated temperature, creep range requirements in Subsection NH. Again, progress is resource limited.

D. Material data requirements.

Identified parameters such as minimum creep rate, time to rupture, \% elongation and \% reduction in area as required for load-controlled assessments. For failure prediction using creep behavior models, other parameters such as reduction of area at failure, at locations remote from the failure site, or at the neck (if necking occurs) would be useful. For cyclic loading, cyclic stress-strain data and stress relaxation curves are needed in addition to the usual parameters.

\subsection{TASK 10: Update and Improve Subsection NH - Alternative Simplified} Creep-Fatigue Design Methods

To address some of the identified deficiencies of the Subsection NH creep-fatigue procedure identified in Tasks 3 and 5, this task was initiated to assess other creep-fatigue methodologies. The focus of the assessment was on Grade 91 steel, which is not relevant for components considered in this report, and will not be discussed here.

\subsection{TASK 11: New Materials for $\mathrm{NH}$}

The goal of this task is to review the information available for new Subsection NH materials that have been identified as candidate or alternate materials of construction for various HTGR concepts, and to scope out the requirements for codification in Subsection NH. Many nickel-based and iron-based superalloys and austenitic stainless steels were reviewed. It was concluded that Alloy 617 is the primary candidate material that satisfies the NGNP bounding conditions. Alloy 230, Alloy X, and Alloy XR were specifically considered as candidates, along with a long list of alternate materials.

An overview of the available data was conducted with respect to the Subsection NH requirements. The materials reviewed include Alloys 617, 230, 556, XR and $800 \mathrm{H}$ and data needs for these materials were assessed. In particular, the testing plans for Alloy 617 and Alloy $800 \mathrm{H}$ developed in this report were considered. It was concluded that these testing plans are very comprehensive and have identified the data needs for both codification of Alloy 617 and the complementary database needed for the application of the Subsection NH ASME Code rules.

\subsection{TASK 12: NDE and ISI Technology for HTRS}

This task is not related to construction code rules and will not be discussed here.

\subsubsection{Third Round Tasks}

Two new tasks that address emergent needs for ASME Code actions have been developed. The background and work scope for these tasks are summarized below. 


\begin{tabular}{|c|lll|}
\hline NEXT GENERATION NUCLEAR PLANT STEAM & Identifier: & PLN-2804 & \\
GENERATOR AND INTERMEDIATE HEAT & Revision: & 1 & \\
EXCHANGER MATERIALS RESEARCH & Effective Date: & $09 / 23 / 10$ & Page: 72 of 252 \\
AND DEVELOPMENT PLAN &
\end{tabular}

\subsection{TASK 13: Recommend Allowable Stress Values}

The main objective of this task is to develop draft ASME Code rules for the ASME Code committees' consideration. Task 13 corrects errors and discrepancies in the current allowable stress values and it extends the time and temperatures for which allowable stresses are provided to be compatible with NGNP/GEN IV needs. The ASME High Temperature Gas Reactor (HTGR) Roadmap project identified a specific interest in extending the limits for Alloy $800 \mathrm{H}$.

The current materials and the time and temperatures for which allowable stresses are listed in Subsection NH and Code Case N-201-5 do not support all the identified needs of the HTGR program. The identified HTGR design life extends to 60 years in some instances, whereas allowable stresses in Subsection NH are only provided to $300,000 \mathrm{~h}$. In addition to extending the allowable stresses to accommodate the normal operating design life, there is also a need to establish allowable stresses at higher temperatures for significantly shorter time durations associated with off normal excursions, conceptually similar to what was done in Code Case N-499-2 for SA-508/533, the reference reactor pressure vessel material. For the near term, emphasis is placed on extending the allowable stress values for Alloy $800 \mathrm{H}$. Short duration, higher temperature allowable stresses for Alloy $800 \mathrm{H}$ will benefit the design of certain in-core components and heat transport system components exposed to hot gas temperatures.

\section{Part 1}

Develop a data package for consideration by applicable ASME Code committees supporting the use of Alloy $800 \mathrm{H}$ for extended time and temperature compatible with NGNP design objectives, primarily associated with in-core structures and heat transport systems exposed to hot gas temperatures. The established objective is $850^{\circ} \mathrm{C}$ and $500,000 \mathrm{~h}$, although higher temperatures are desirable as permitted based on available data.

\section{Part 2}

Develop a data package to support an ASME Code case or modification to CC N-201-5and NH that supports the use of Alloy $800 \mathrm{H}$ for infrequent, off-normal temperature excursions compatible with NGNP design objectives. The number of events can tentatively be based on what is specified in CC N-499-2. Allowable stresses should be provided for times and temperatures bounded by times for $100 \mathrm{~h}$ to $10,000 \mathrm{~h}$ and associated temperature limits as high as possible consistent with current data.

\section{Part 3}

Submit draft ASME Code rules with data packages developed in Parts 1 and 2 above to BPV SC-II and III and applicable subgroups for additions to, and revisions of, material properties information contained in Section II and Subsection NH. These submittals shall follow the guidance provided in Appendices 4 and 5 of Section II, Part D and are a formal proposed standards action with complete supporting information.

\subsection{TASK 14: Corrections to Stainless Steel Allowable Stresses}

A thorough review was conducted of current allowable stress values in Subsection NH, and errors and potential limitations on the use of some current values in Subsection NH for austenitic stainless steel were identified. More specifically, long term creep tests on 304 and 316SS, completed after the current allowable stress values were established, identified some heats whose rupture life fell below currently published allowable values, particularly above $650^{\circ} \mathrm{C}\left(1200^{\circ} \mathrm{F}\right)$. Because some of these errors and limitations could impact near-term design activities, there is an urgent need to address this issue. 


\begin{tabular}{|c|lll|}
\hline NEXT GENERATION NUCLEAR PLANT STEAM & Identifier: & PLN-2804 & \\
$\begin{array}{c}\text { GENERATOR AND INTERMEDIATE HEAT } \\
\text { EXCHANGER MATERIALS RESEARCH } \\
\text { AND DEVELOPMENT PLAN }\end{array}$ & Revision: & 1 & \\
Effective Date: & $09 / 23 / 10$ & Page: 73 of 252 \\
\hline
\end{tabular}

\section{Part 1}

Assess available data on 304 and 316SS (Note: 316 SS is the primary material of interest in this assessment) to determine if there are restrictions that could be placed on specifications and procurement packages or additional acceptance test and examination requirements, e.g., chemistry, physical or mechanical properties or processing variables, that would exclude from use those heats of material that are not representative of the database from which the currently published allowable stress values were derived. (Note: The effectiveness of existing restrictions and requirements shall also be included in the assessment.)

\section{Part 2}

In the event that the results of the Part 1 assessment do not identify applicable restrictions and/or additional acceptance requirements, the time and temperature limits beyond which the validity of the current allowable stress values cannot be guaranteed shall be determined. Allowable stresses beyond their range of validity should be recommended for deletion.

\section{Part 3}

Based on the results from Parts 1 and 2 above, prepare a submittal of draft ASME Code rules with supporting information. Recommendations should include specific code words or modification to tables implementing the restrictions which are ready for consideration as an ASME Code Case or Code revision. This submittal shall be a formal proposed standards action and shall have an assigned tracking number.

\subsection{NRC Structural Integrity Issues}

The ASME B\&PV Code Section III, Division 1, Subsections NB, NC, ND, NE, NF, and NG, are incorporated by reference into Section 50.55a of Title 10 of the Code of Federal Regulations (10 CFR 50.55a) as the rules of construction for LWR nuclear power plant components. Section III Code cases, which provide alternatives to the Section III, Division 1 Code requirements under special circumstances, are reviewed by the NRC staff and its findings are published in the regulatory guides. The acceptable and conditionally acceptable Section III Code cases listed in the regulatory guides are then incorporated by reference into 10 CFR 50.55a.

While the rules of construction of the ASME Code and Code Cases cover many aspects related to structural integrity, they do not explicitly address issues such as degradation of properties because of service conditions or environment. However, these structural integrity issues are highlighted in the ASME Code and it is the responsibility of the "Owner" to demonstrate to NRC that these additional issues are adequately addressed.

Section III, Subsection NH and its Code cases contain rules of construction for metallic components under elevated temperature service. Code Case N-47, a precursor to Subsection NH, had been reviewed by NRC during the application of a construction permit by the CRBR Project in the late 70s and early $80 \mathrm{~s}$. The licensing process was stopped because of the abrupt cancellation of the CRBR project. However, a list of safety related issues was identified by NRC. NRC had also performed a pre-application safety evaluation of the PRISM) liquid-metal reactor design in the mid 90s and similar issues were raised. These NRC issues have been documented in Task 2 of the DOE/ASME Gen IV project and the task report was summarized in Section 5.1.3.

The code/licensing issues for NGNP can be grouped into two major areas: existing Subsection NH Code procedures, and issues that are the responsibility of the "Owner," which would be the NGNP Project. Strategies and plans to address these two areas are to be established in this TDP to support project schedule. It is important to note that there are added burdens in licensing NGNP as Subsection NH and its Code cases have not been approved by NRC. 


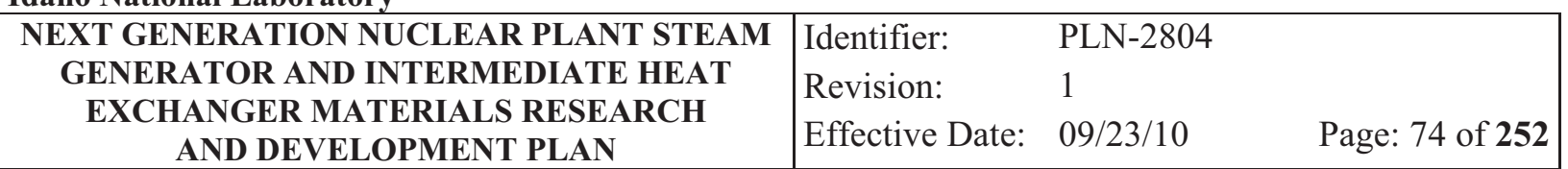

The NGNP elevated temperature metallic components including core internals, control-rod cladding, hot-gas primary piping, and intermediate heat exchangers (IHX) are subject to cyclic service. The CRBR safety related issues identified by NRC are discussed with respect to these NGNP applications. Most of the issues on the NRC list are addressed in one form or another by the current rules in Subsection NH, with the exception of environmental effects, which are considered as the "Owner" responsibility and are beyond the scope of the Code.

An assessment of the NRC issues with respect to the NGNP elevated temperature metallic components and the corresponding recommended actions are given in Table 16. It is noted that the NRC issues list is not ranked relative to the severity of the concerns. 


Idaho National Laboratory
\begin{tabular}{|c|lll|}
\hline NEXT GENERATION NUCLEAR PLANT STEAM & Identifier: & PLN-2804 & \\
GENERATOR AND INTERMEDIATE HEAT & Revision: & 1 & \\
EXCHANGER MATERIALS RESEARCH & Effective Date: & $09 / 23 / 10$ & Page: 75 of $\mathbf{2 5 2}$ \\
AND DEVELOPMENT PLAN & &
\end{tabular}

Table 16. NRC issues list from CRBR review.

\begin{tabular}{|c|c|c|c|}
\hline Issue \# & $\begin{array}{c}\text { Structural Integrity Issues } \\
\text { Identified by NRC for } \\
\text { CRBR }\end{array}$ & $\begin{array}{l}\text { Assessment with Respect to IHX, Hot-gas Piping } \\
\text { and Core Internals }\end{array}$ & Required Actions \\
\hline 1 & $\begin{array}{l}\text { Transition joints } \\
\text { (i.e., dissimilar metals) }\end{array}$ & $\begin{array}{l}\text { Code specified approach is to model joint with base } \\
\text { metal properties to the weld centerline, then include } \\
\text { differences in connecting base metal properties in } \\
\text { the weldment stress analysis. }\end{array}$ & $\begin{array}{l}\text { This issue needs to be addressed if such transition } \\
\text { joints are present in the down-selected vendor design } \\
\text { concept. }\end{array}$ \\
\hline 2 & Weld residual stresses & $\begin{array}{l}\text { Not considered in Subsection NH methodology - } \\
\text { current approach implies selection of weld wires } \\
\text { and welding process produce ductile welds, and } \\
\text { subsequent load cycling and creep reduce residual } \\
\text { stresses. }\end{array}$ & $\begin{array}{l}\text { This is a lower-tier issue for elevated temperature } \\
\text { service. No immediate action is recommended. }\end{array}$ \\
\hline 3 & $\begin{array}{l}\text { Design loading } \\
\text { combinations }\end{array}$ & $\begin{array}{l}\text { Owner/regulator issue - beyond scope of } \\
\text { Subsection NH. }\end{array}$ & This is an action for the reactor vendor. \\
\hline 4 & $\begin{array}{l}\text { Creep-rupture and fatigue } \\
\text { damage }\end{array}$ & This is a valid concern. & $\begin{array}{l}\text { Proposed new work (Task 10) in DOE/ASME Gen } \\
\text { IV project will address this issue. } \\
\text { Recommended testing from Task } 10 \text { will be assessed } \\
\text { and relevant testing will be proposed. } \\
\text { Creep-fatigue tests for Alloy } 617 \text { base metal, weld } \\
\text { metals and weldments are proposed in this TDP. }\end{array}$ \\
\hline 5 & $\begin{array}{l}\text { Simplified bounds for } \\
\text { creep ratcheting }\end{array}$ & This is a valid concern. & $\begin{array}{l}\text { Proposed new work (Task 9) in DOE/ASME Gen IV } \\
\text { project addresses this issue. } \\
\text { Recommended testing from Task } 9 \text { will be assessed } \\
\text { and relevant testing will be proposed. }\end{array}$ \\
\hline 6 & Thermal striping & $\begin{array}{l}\text { Current Subsection NH rules provide framework } \\
\text { for assessment of structural response. Generally, } \\
\text { the issue is determining thermal hydraulic response. } \\
\text { Not an issue for gas-cooled reactors. Assess recent } \\
\text { R\&D in Japan for relevance and incorporation. }\end{array}$ & No action is required. \\
\hline
\end{tabular}




\section{Idaho National Laboratory}

\begin{tabular}{|c|lll|}
\hline $\begin{array}{c}\text { NEXT GENERATION NUCLEAR PLANT STEAM } \\
\text { GENERATOR AND INTERMEDIATE HEAT } \\
\text { EXCHANGER MATERIALS RESEARCH }\end{array}$ & Identifier: & PLN-2804 & \\
AND DEVELOPIion: & 1 & \\
ANDENT PLAN & Effective Date: & $09 / 23 / 10$ & Page: 76 of 252 \\
\hline
\end{tabular}

Table 16. (continued).

\begin{tabular}{|c|c|c|c|}
\hline Issue \# & $\begin{array}{l}\text { Structural Integrity Issues } \\
\text { Identified by NRC for } \\
\text { CRBR }\end{array}$ & $\begin{array}{l}\text { Assessment with Respect to IHX, Hot-gas Piping } \\
\text { and Core Internals }\end{array}$ & Required Actions \\
\hline 7 & $\begin{array}{l}\text { Creep-fatigue analysis of } \\
\text { Class } 2 \text { and } 3 \text { piping }\end{array}$ & $\begin{array}{l}\text { As summarized in Section 5.1.1.2, piping is only } \\
\text { component with Code Case N-253-14 specified } \\
\text { creep-fatigue analysis procedure. Candidate piping } \\
\text { materials (Alloy } 617 \text { \& 230) not covered by this } \\
\text { Code case. }\end{array}$ & $\begin{array}{l}\text { New work in Task } 7 \text { of the DOE/ASME Gen IV } \\
\text { project addresses generic issue of code rules for IHX. } \\
\text { Approach to code rule development and material } \\
\text { codification is proposed in this TDP. }\end{array}$ \\
\hline 8 & $\begin{array}{l}\text { Limits of Case N-253-14 } \\
\text { for elevated temperature } \\
\text { Class } 2 \& 3 \text { components } \\
\text { met? }\end{array}$ & $\begin{array}{l}\text { Creep-fatigue analysis for piping in Code Case } \\
\text { N-253-14 only deals with pipe loads and does not } \\
\text { default to the creep-fatigue design-by-analysis } \\
\text { procedure in Subsection NH (see Section 5.1.1.2). }\end{array}$ & $\begin{array}{l}\text { The issue is related to Item } 7 \text { above and will be } \\
\text { addressed collectively. }\end{array}$ \\
\hline 9 & $\begin{array}{l}\text { Creep buckling under } \\
\text { axial compression - } \\
\text { design margins }\end{array}$ & $\begin{array}{l}\text { Code committee responsible for Subsection NH not } \\
\text { aware of any generic issues or inconsistencies } \\
\text { within the creep buckling rules - particularly for } \\
\text { thick walled components. Should consider French } \\
\text { concerns; it may be a local crimpling issue for very } \\
\text { large diameter, thin-walled vessels. }\end{array}$ & $\begin{array}{l}\text { This is a lower-tier issue. No immediate action is } \\
\text { recommended. }\end{array}$ \\
\hline 10 & $\begin{array}{l}\text { Identify areas where } \\
\text { Appendix T rules are not } \\
\text { met }\end{array}$ & $\begin{array}{l}\text { Appendix T provides procedures to determine } \\
\text { strain range using elastic analysis. If these rules } \\
\text { cannot be satisfied, additional rules are provided, } \\
\text { based on results of inelastic analyses. However, } \\
\text { inelastic analysis requires detailed constitutive } \\
\text { models of material behavior under time varying } \\
\text { loading conditions. For the CRBR these behavioral } \\
\text { models were based on Nuclear Standard NE F9-5T. } \\
\text { Standards no longer maintained and numerous } \\
\text { technical developments made since. Development } \\
\text { of material models for materials not currently } \\
\text { covered or for temperatures beyond original range } \\
\text { of verification will be considerable effort. }\end{array}$ & $\begin{array}{l}\text { Development of experimentally verified unified } \\
\text { constitutive model for Alloy } 617 \text { is among highest } \\
\text { priority recommended actions. Will provide inelastic } \\
\text { analysis tools for components like IHX expected to } \\
\text { have low design margins in critical locations. Also } \\
\text { provides "gold standard" to benchmark simplified } \\
\text { methods to be developed under new tasks of } \\
\text { DOE/ASME Gen IV project. } \\
\text { Establishment of guidelines similar to Nuclear } \\
\text { Standard NE F9-5T, developed specifically for high } \\
\text { temperature design of liquid metal fast breeder } \\
\text { reactor components, is recommended in this TDP. }\end{array}$ \\
\hline
\end{tabular}




\section{Idaho National Laboratory}

\begin{tabular}{|c|lll|}
\hline $\begin{array}{c}\text { NEXT GENERATION NUCLEAR PLANT STEAM } \\
\text { GENERATOR AND INTERMEDIATE HEAT } \\
\text { EXCHANGER MATERIALS RESEARCH }\end{array}$ & Identifier: & PLN-2804 & \\
AND DEVELOPIion: & 1 & \\
ANPENT PLAN & Effective Date: & $09 / 23 / 10$ & Page: 77 of 252 \\
\hline
\end{tabular}

Table 16. (continued).

\begin{tabular}{|c|c|c|c|}
\hline Issue \# & $\begin{array}{l}\text { Structural Integrity Issues } \\
\text { Identified by NRC for } \\
\text { CRBR }\end{array}$ & $\begin{array}{l}\text { Assessment with Respect to IHX, Hot-gas Piping } \\
\text { and Core Internals }\end{array}$ & Required Actions \\
\hline 11 & $\begin{array}{l}\text { Rules for component } \\
\text { supports at elevated } \\
\text { temperature }\end{array}$ & $\begin{array}{l}\text { Rules are provided in Code Case N-201-5 for core } \\
\text { support structures. Supports other than core support } \\
\text { structures are not covered in the creep regime nor } \\
\text { has there been any indication that they need be. }\end{array}$ & $\begin{array}{l}\text { As summarized in Section 5.1.3.1, this has been } \\
\text { addressed in Task } 4 \text { of the DOE/ASME Gen IV } \\
\text { project. Code Case N-201-5 has been updated to } \\
\text { make it consistent with current ASME Code edition } \\
\text { of Subsection NH and has been forwarded to relevant } \\
\text { Code committees for action. } \\
\text { No immediate action is required. }\end{array}$ \\
\hline 12 & $\begin{array}{l}\text { Strain and deformation } \\
\text { limits at elevated } \\
\text { temperature }\end{array}$ & $\begin{array}{l}\text { Extrapolation of creep-fatigue data is a challenge, } \\
\text { particularly at the extremes of the creep regime. At } \\
\text { the low temperature end the concern involves the } \\
\text { definition of negligible creep and at the very high } \\
\text { temperature end one of the issues is whether } \\
\text { plasticity and creep can be separated. The major } \\
\text { issues identified for Subsection NH is that NH is } \\
\text { too conservative for materials such as Grade } 91 \\
\text { steel, particularly with respect to other international } \\
\text { codes. }\end{array}$ & $\begin{array}{l}\text { Creep and creep-fatigue testing for Alloy } 617 \text { to } \\
\text { support development of design rules with appropriate } \\
\text { conservatism is proposed in this TDP. }\end{array}$ \\
\hline 13 & Evaluation of weldments & $\begin{array}{l}\text { A number of provisions in Subsection } \mathrm{NH} \text { and } \\
\text { related documents ensure reliable weld joints. NH } \\
\text { methods exceed current requirements for } \\
\text { nonnuclear applications as well as nuclear } \\
\text { applications below the creep regime. }\end{array}$ & $\begin{array}{l}\text { The issue of creep and creep-fatigue crack growth in } \\
\text { geometric (notches) and material (welds) } \\
\text { discontinuities will be addressed in Task } 8 \text { of the } \\
\text { DOE/ASME Gen IV project. } \\
\text { Recommended testing from this task will be assessed } \\
\text { and relevant testing will be proposed. }\end{array}$ \\
\hline
\end{tabular}




\section{Idaho National Laboratory}

\begin{tabular}{|c|lll|}
\hline $\begin{array}{c}\text { NEXT GENERATION NUCLEAR PLANT STEAM } \\
\text { GENERATOR AND INTERMEDIATE HEAT } \\
\text { EXCHANGER MATERIALS RESEARCH }\end{array}$ & Revifier: & PLN-2804 & \\
AND DEVELOPMENT PLAN & Effective Date: & $09 / 23 / 10$ & Page: 78 of 252 \\
\hline
\end{tabular}

Table 16. (continued).

\begin{tabular}{|c|c|c|c|}
\hline Issue \# & $\begin{array}{c}\text { Structural Integrity Issues } \\
\text { Identified by NRC for } \\
\text { CRBR } \\
\end{array}$ & $\begin{array}{l}\text { Assessment with Respect to IHX, Hot-gas Piping } \\
\text { and Core Internals }\end{array}$ & Required Actions \\
\hline 14 & $\begin{array}{l}\text { Material acceptance } \\
\text { criteria for elevated } \\
\text { temperature }\end{array}$ & $\begin{array}{l}\text { A } 60 \text {-year design life at } 850-950^{\circ} \mathrm{C} \text { for the } \\
\text { candidate IHX materials such as Alloy } 617 \text { is very } \\
\text { challenging. The reliability of extrapolating shorter } \\
\text { term data to various design life times for Alloy } 617 \text {, } \\
\text { Alloy } 230 \text {, and Alloy } 800 \mathrm{H} \text { is a valid issue. } \\
\text { The ability to demonstrate confidence in using } \\
\text { accelerated test data to predict performance for } \\
\text { NGNP design life time is paramount for licensing } \\
\text { success. }\end{array}$ & $\begin{array}{l}\text { Task } 1 \text { of the DOE/ASME Gen IV project addresses } \\
\text { the issue of extending the stress allowables for Alloy } \\
800 \mathrm{H} \text { and its associated weldments. The testing } \\
\text { recommended in the task report has been assessed } \\
\text { and is proposed in this TDP. } \\
\text { A two-pronged approach is needed: (1) develop a } \\
\text { strategy to generate longer-term data, (2) leverage the } \\
\text { advancement in understanding of deformation and } \\
\text { failure mechanisms to transition from current } \\
\text { empirical practice in the ASME Code to a more } \\
\text { science-based approach. } \\
\text { A long-term aging facility is proposed in this TDP } \\
\text { for performing very long-term, aging, creep-rupture, } \\
\text { crack growth tests to address this issue. }\end{array}$ \\
\hline 15 & $\begin{array}{l}\text { Creep-rupture damage due } \\
\text { to forming and welding }\end{array}$ & $\begin{array}{l}\text { This issue is also covered under Issue } 2 \text {. Issues } \\
\text { related to forming/cold work are addressed in } \\
\text { NH- } 4000 \text {. }\end{array}$ & $\begin{array}{l}\text { This needs to be addressed as part of the ASME } \\
\text { Code case for new Subsection NH Code material. } \\
\text { Cold worked material was excluded from the Draft } \\
\text { Alloy } 617 \text { Code Case because of possible } \\
\text { recrystallization during elevated temperature service. } \\
\text { It will also be excluded from new Alloy } 617 \text { Code } \\
\text { Case because of concerns of reduced tensile ductility. }\end{array}$ \\
\hline 16 & Mass transfer effects & $\begin{array}{l}\text { This is an issue for liquid metal and molten salt } \\
\text { reactors but not for a gas-cooled (helium) reactor. }\end{array}$ & No action is required. \\
\hline 17 & Environmental effects & $\begin{array}{l}\text { This is an important area not covered by specific } \\
\text { ASME Code rules in Subsection NH. This is an } \\
\text { Owner/regulator issue. }\end{array}$ & $\begin{array}{l}\text { Testing of Alloy } 617 \text { in NGNP coolant (helium) } \\
\text { chemistry is proposed in this TDP. }\end{array}$ \\
\hline
\end{tabular}




\section{Idaho National Laboratory}

\begin{tabular}{|c|c|c|c|}
\hline $\begin{array}{c}\text { NEXT GENERATION NUCLEAR PLANT STEAM } \\
\text { GENERATOR AND INTERMEDIATE HEAT } \\
\text { EXCHANGER MATERIALS RESEARCH } \\
\text { AND DEVELOPMENT PLAN }\end{array}$ & $\begin{array}{l}\text { Identifier: } \\
\text { Revision: } \\
\text { Effective Date: }\end{array}$ & $\begin{array}{l}\text { PLN-2804 } \\
1 \\
09 / 23 / 10\end{array}$ & Page: 79 of $\mathbf{2 5 2}$ \\
\hline
\end{tabular}

Table 16. (continued).

\begin{tabular}{|c|c|c|c|}
\hline Issue \# & $\begin{array}{l}\text { Structural Integrity Issues } \\
\text { Identified by NRC for } \\
\text { CRBR }\end{array}$ & $\begin{array}{l}\text { Assessment with Respect to IHX, Hot-gas Piping } \\
\text { and Core Internals }\end{array}$ & Required Actions \\
\hline 18 & Fracture toughness criteria & $\begin{array}{l}\text { The formation of embrittling phases, e.g., gamma } \\
\text { prime, during long-term thermal exposure of Alloy } \\
617 \text { in a certain temperature range (below the } \\
\text { intended steady-state operating temperature for } \\
\text { IHX components) has a negative impact on the } \\
\text { toughness. }\end{array}$ & $\begin{array}{l}\text { A combination of toughness testing on thermally } \\
\text { exposed compact-tension specimens and } \\
\text { thermodynamics modeling of the formation of } \\
\text { embrittling phases over the service lifetime is } \\
\text { needed; testing is proposed in this TDP to } \\
\text { characterize the fracture toughness degradation due } \\
\text { to thermal aging. }\end{array}$ \\
\hline 19 & Thermal aging effects & $\begin{array}{l}\text { Thermal aging effects on stress allowables are } \\
\text { addressed in Subsection NH. Thermal aging and } \\
\text { cyclic softening are important issues for } \\
\text { creep-fatigue evaluation. }\end{array}$ & $\begin{array}{l}\text { Creep-fatigue evaluation methods for dealing with } \\
\text { these issues are addressed in the DOE/ASME Gen IV } \\
\text { project. } \\
\text { A test plan is proposed in this TDP to address } \\
\text { modeling of thermal aging in unified constitutive } \\
\text { equations for Alloy } 617 \text {. } \\
\text { Testing to address thermal aging effect on yield and } \\
\text { tensile strengths for } 617 \text { is proposed in this TDP. }\end{array}$ \\
\hline 20 & Irradiation effects & $\begin{array}{l}\text { This is an important area not covered by specific } \\
\text { ASME Code rules in Subsection NH. This is an } \\
\text { Owner/regulator issue and is relevant for the } \\
\text { metallic cladding of the control rods. }\end{array}$ & $\begin{array}{l}\text { Action is proposed in the TDP to address irradiation } \\
\text { effects for core internals. }\end{array}$ \\
\hline 21 & $\begin{array}{l}\text { Use of simplified } \\
\text { bounding rules at } \\
\text { discontinuities }\end{array}$ & $\begin{array}{l}\text { This important issue is the subject of ongoing } R \& D \\
\text { efforts. }\end{array}$ & $\begin{array}{l}\text { Similar to Issue } 5 \text {, this will be addressed by the } \\
\text { proposed work (Task 9) in the DOE/ASME Gen IV } \\
\text { project. } \\
\text { Recommended testing from this task will be assessed } \\
\text { and relevant testing will be proposed. }\end{array}$ \\
\hline
\end{tabular}




\section{Idaho National Laboratory}

\begin{tabular}{|c|lll|}
\hline NEXT GENERATION NUCLEAR PLANT STEAM & Identifier: & PLN-2804 & \\
GENERATOR AND INTERMEDIATE HEAT & Revision: & 1 & \\
EXCHANGER MATERIALS RESEARCH & Effective Date: & $09 / 23 / 10$ & Page: 80 of $\mathbf{2 5 2}$ \\
AND DEVELOPMENT PLAN &
\end{tabular}

Table 16. (continued).

\begin{tabular}{|c|c|c|c|}
\hline Issue \# & $\begin{array}{c}\text { Structural Integrity Issues } \\
\text { Identified by NRC for } \\
\text { CRBR }\end{array}$ & $\begin{array}{c}\text { Assessment with Respect to IHX, Hot-gas Piping } \\
\text { and Core Internals }\end{array}$ & Required Actions \\
\hline 22 & Elastic follow-up & $\begin{array}{l}\text { This is part of Issue } 21 \text { as accounting for the effects } \\
\text { of elastic follow-up is a significant part of } \\
\text { simplified bounding rules. }\end{array}$ & $\begin{array}{l}\text { Similar to Issues } 5 \text { and } 21 \text {, this will be addressed by } \\
\text { the proposed work (Task 9) in the DOE/ASME } \\
\text { Gen IV project. } \\
\text { Recommended testing from this task will be assessed } \\
\text { and relevant testing will be proposed. }\end{array}$ \\
\hline 23 & $\begin{array}{l}\text { Design criteria for } \\
\text { elevated temperature core } \\
\text { support structures and } \\
\text { welds }\end{array}$ & $\begin{array}{l}\text { The elevated temperature core support rules where } \\
\text { creep is significant are based on Subsection NH. } \\
\text { The duration and temperature for the stress } \\
\text { allowables of candidate core structural materials } \\
\text { need to be increased. }\end{array}$ & $\begin{array}{l}\text { There is an ongoing effort to directly reference } \\
\text { Subsection NH for much of the N-201-5 data and } \\
\text { rules through the Task } 4 \text { work of the DOE/ASME } \\
\text { Gen IV project. } \\
\text { Task } 1 \text { of the DOE/ASME Gen IV project has } \\
\text { addressed this issue for Alloy } 800 \mathrm{H} \text { and its } \\
\text { weldment. } \\
\text { Recommended test matrix from Task } 1 \text { will be } \\
\text { assessed and relevant testing will be proposed. }\end{array}$ \\
\hline 24 & $\begin{array}{l}\text { Elevated temperature data } \\
\text { base for mechanical } \\
\text { properties }\end{array}$ & This issue is similar to Issues $13,14,18,19$ and 23. & $\begin{array}{l}\text { This and the related issues need to be addressed in an } \\
\text { integrated manner. }\end{array}$ \\
\hline 25 & $\begin{array}{l}\text { Basis for } \\
\text { leak-before-break at } \\
\text { elevated temperatures }\end{array}$ & This is closely related to Issues 13 and 18 . & $\begin{array}{l}\text { This needs to be addressed together with Issues } 13 \\
\text { and } 18 \text { in an integrated manner. }\end{array}$ \\
\hline
\end{tabular}




\begin{tabular}{|c|lll|}
\hline NEXT GENERATION NUCLEAR PLANT STEAM & Identifier: & PLN-2804 & \\
GENERATOR AND INTERMEDIATE HEAT & Revision: & 1 & \\
EXCHANGER MATERIALS RESEARCH & Effective Date: & $09 / 23 / 10$ & Page: 81 of 252 \\
AND DEVELOPMENT PLAN &
\end{tabular}

\subsection{Strategy to Support Code and Licensing Needs}

The elevated temperature design analysis methodologies in Subsection NH are predicated on the concept of protection against applicable structural failure modes. Stress and deformation states for different component geometries and load and temperature histories are obtained by elastic and inelastic analyses. These analysis results are parsed into different categories and compared against different deformation and failure criteria to ascertain the structural integrity.

Unlike the design-by-rule methods, which are applicable only to specific component geometry and loading, the design-by-analysis methodology of Subsection NH provides a more general approach to the structural design of elevated temperature components. This is illustrated by the treatment of elevated temperature core support structures where the applicable structural failure modes are judged to be similar to those considered in Subsection NH. This provides the technical basis for which appropriately adapted Subsection NH design-by-analysis procedures are used in Code Case N-201-5 for elevated temperature core support structures even though they are not necessarily pressure-boundary components or shell-like geometries.

For IHX components, there are added burdens in the design analyses because of the geometric complexity of some IHX designs. But the same basic approach of Subsection NH can be employed for the IHX designs in guarding against structural failure modes. Such a design-by-analysis approach for elevated temperature IHX components would have the advantage that the resulting design criteria are applicable to different IHX design concepts. Detailed design analyses would address the structural integrity issues of specific design features of a down-selected IHX concept. Thus, work to establish an Alloy 617 Code Case can be initiated immediately so the project schedule can be supported.

IHX design studies are currently being pursued by different reactor vendors where broad spectrums of design concepts ranging from relatively thick to very thin component cross-sections are being considered. The desirable grain size varies with product form required for the IHX design. A minimum number of grains are required through the cross-section to achieve average material properties that are representative of those in a test database from which design stress allowables are developed. However, the grain size has a strong influence on the tensile and creep strengths, and hence design stress allowables. This poses a dilemma in developing a testing campaign because a down-selection of the IHX design concepts has not been made. The pros and cons of various strategies had been delineated, ${ }^{68}$ but without a clear path to success.

A different paradigm is recommended herein as a path forward to address data needs of the design and the eventual license approval of elevated temperature hot-gas piping and IHX components while adhering to the project schedule. The key elements of the new strategy involve:

1. Leverage standard grain size Alloy 617 databases:

A. Currently accessible databases:

(1) Huntington Alloys database where the ASME Draft Alloy 617 Code Case was based.

(2) General Electric database from the DOE HTGR Program.

(3) The ORNL dataset.

B. Needed database acquisition:

(1) Petten (data from the German HTGR program of the 80s).

(2) European Creep Collaborative Committee (ECCC) databases. 


\begin{tabular}{|c|lll|}
\hline NEXT GENERATION NUCLEAR PLANT STEAM & Identifier: & PLN-2804 \\
GENERATOR AND INTERMEDIATE HEAT & Revision: & 1 & \\
EXCHANGER MATERIALS RESEARCH & Effective Date: & $09 / 23 / 10$ & Page: 82 of 252 \\
AND DEVELOPMENT PLAN & ENDEN
\end{tabular}

C. Potential additional Alloy 617 databases: from signatory members of the Gen IV International Forum (GIF) Metals and Design Methods Working Group.

(1) Start test program in earnest to fill data gap in the above aggregate database for standard grain size.

(2) Develop smaller database for Alloy 617 product forms with small grain sizes to establish grain size rupture factors for stress allowables for ASME Code use.

The aggregate Alloy 617 database for standard grain size material from Item 1 above will be used to develop interim design allowable stresses to support conceptual and preliminary design activities.

Confirmatory data developed from Item 2 will be used to support final design activities and final license approval. Therefore, pursuing Items 1 and 2 would allow the early project need dates to be met, and also would afford the project time to generate needed long-term data to fill any data gaps and to support final license approval. This new strategy should also provide relief in testing requirements as compared with the enormous task of codifying a new elevated temperature material.

The concept of developing grain size rupture factors for stress allowables follows the approach employed in Subsection NH for the treatment of strength of weldments. The strategy is to leverage the larger Alloy 617 standard grain size database to determine reduction factors using a smaller database from reduced grain size product forms. However, the creep-rupture strength of Alloy 617 could be significantly reduced for small grain size material as discussed in Section 6.2. The creep-rupture strength envelope for small grain-sized product form of Alloy 617 has not been mapped out. A scoping study is proposed in Section 7.1.6 for this purpose.

The success of this new strategy relies heavily on accomplishing Item $1 \mathrm{~b}$. The detailed plan for waging such a campaign will be described in Section 7.1.

\subsection{Alloy 617 Code Case}

\subsubsection{Actions for 617 Code Case}

As reviewed in Section 5.1.1.3, it took six years for the ASME Ad Hoc Task Force to develop the Draft Alloy 617 Code Case, using Alloy 617 data that had already been generated by the materials vendor Huntington Alloys, and DOE contractor General Electric through the HTGR Program. The extended development time was in part caused by a significant difference in the elevated temperature deformation behavior of Alloy 617 from 304 and 316 stainless steels; as many procedures in Code Case N-47, the fore-runner of Subsection NH, were established based on the behavior of 304 and 316 stainless steels.

A code case for a new class of Subsection NH material such as Alloy 617 involves more than just establishing the stress allowables. The full scope of ASME Code rules of construction-materials, design, fabrication and installation, examination, and overpressure protection-need to be considered.

When the DOE programs supporting the need for the ASME Code case were canceled, the progression of the Draft Alloy 617 Code Case through the ASME Code committees was halted. A number of issues to be resolved were identified at that time, ${ }^{69}$ and additional issues have emerged since. The issues identified by Blass and Corum ${ }^{69}$ are shown in Table 17. Additional issues that need to be addressed to bring the construction rules in the ASME Code case up-to-date with the current edition of Subsection $\mathrm{NH}$ are given in Table 18. Some significant issues that are raised recently and required immediate actions are provided in Table 19. 


\begin{tabular}{|c|lll|}
\hline NEXT GENERATION NUCLEAR PLANT STEAM & Identifier: & PLN-2804 \\
GENERATOR AND INTERMEDIATE HEAT & Revision: & 1 & \\
EXCHANGER MATERIALS RESEARCH & Effective Date: & $09 / 23 / 10$ & Page: 83 of 252 \\
AND DEVELOPMENT PLAN & &
\end{tabular}

\subsubsection{Implication of Code Class Designation for Alloy 617 Code Case}

As mentioned in Section 5.1.1, a decision on the ASME Code class designation of NGNP hot-gas piping and IHX components has not been made. Designation of ASME Code classes for nuclear components by the Owner is based on assessment of public safety as implemented through system safety criteria and regulatory guidelines. Class designation probably would not be required by NRC if there is truly no public or plant operator safety implication owing to structural failure of these components. However, even under such a scenario, the Owner could still decide to assign a Class designation for these components based on plant reliability considerations.

Irrespective of whether a component is designated by the Owner as Class 1, 2, or 3, or having no designation at all, based on the assessment of public safety implication, the structural failure modes for the component would remain the same, granted that implementing safety systems for these ASME Code classes could be different. As the Alloy 617 Code Case will be built on the foundation of protection against structural failure modes using the design-by-analysis approach, the resulting construction rules would be mostly independent of ASME Code classes. Thus, work to establish an Alloy 617 Code Case could be initiated before the issue on ASME Code class designation of these elevated temperature components is resolved. In fact, to support the project schedule, it is recommended that test programs for this Code case be initiated as soon as possible.

\subsection{Code Actions for Alloy $800 \mathrm{H}$}

Table 20 presents issues that require action for Alloy $800 \mathrm{H}$. 


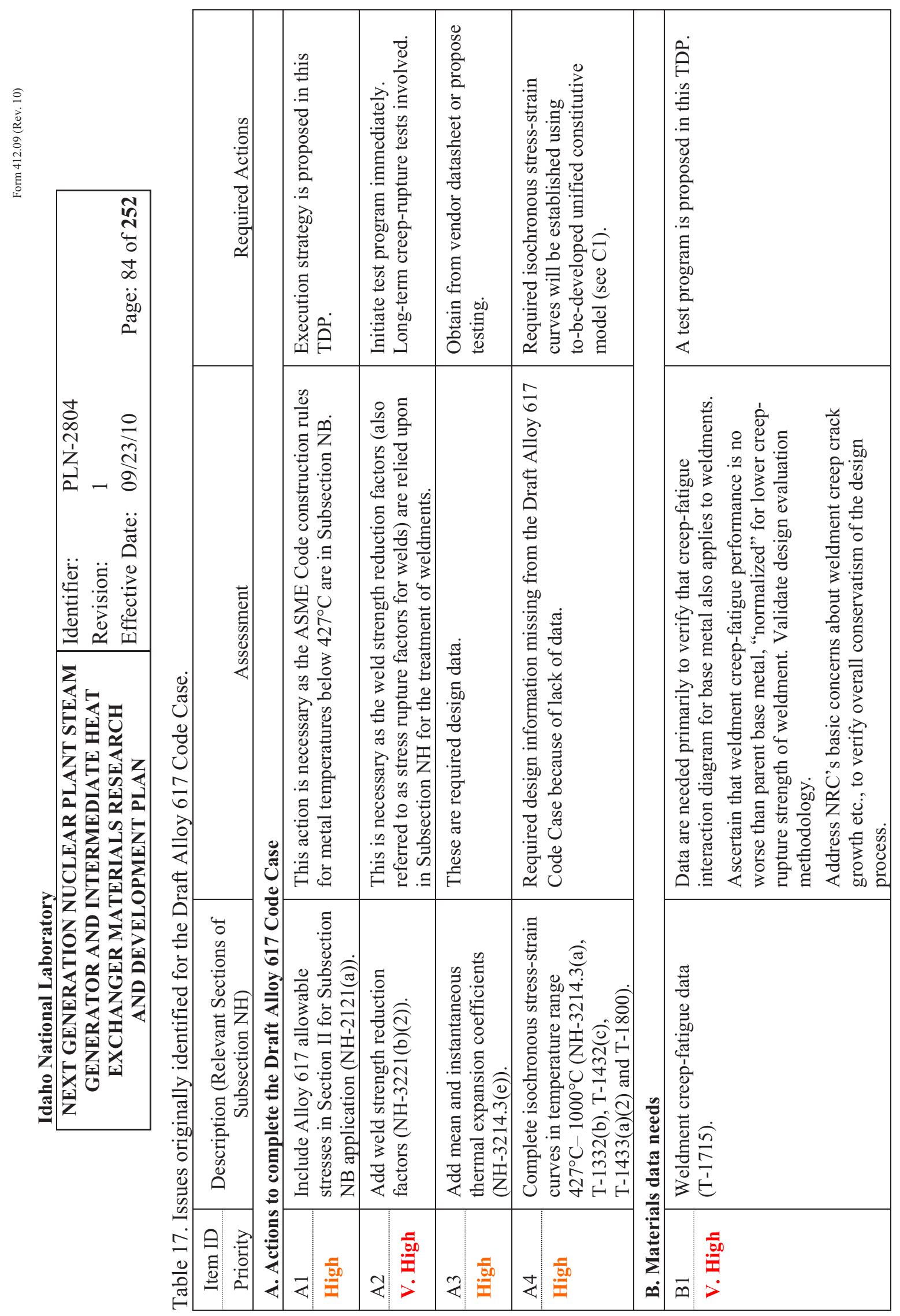




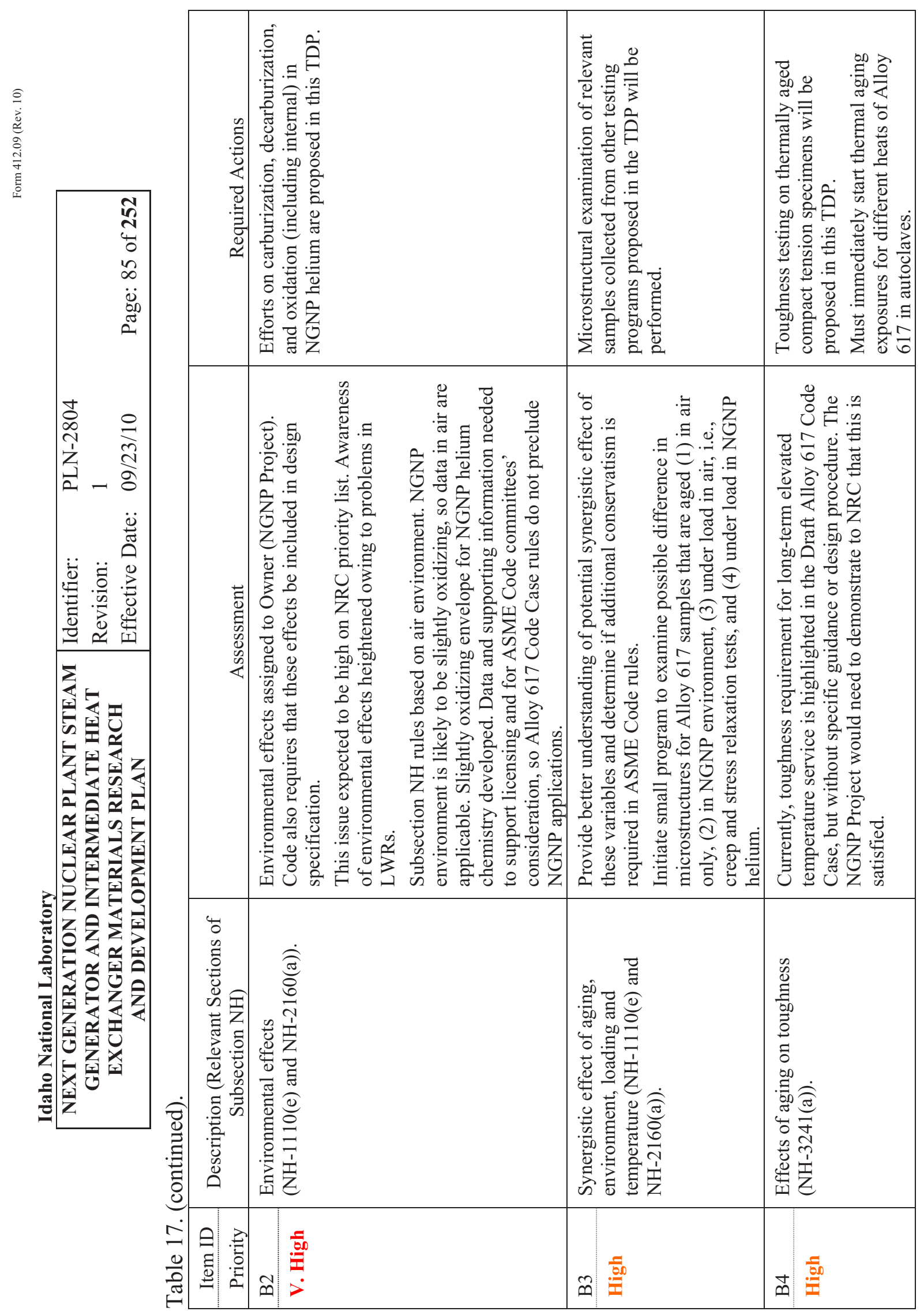




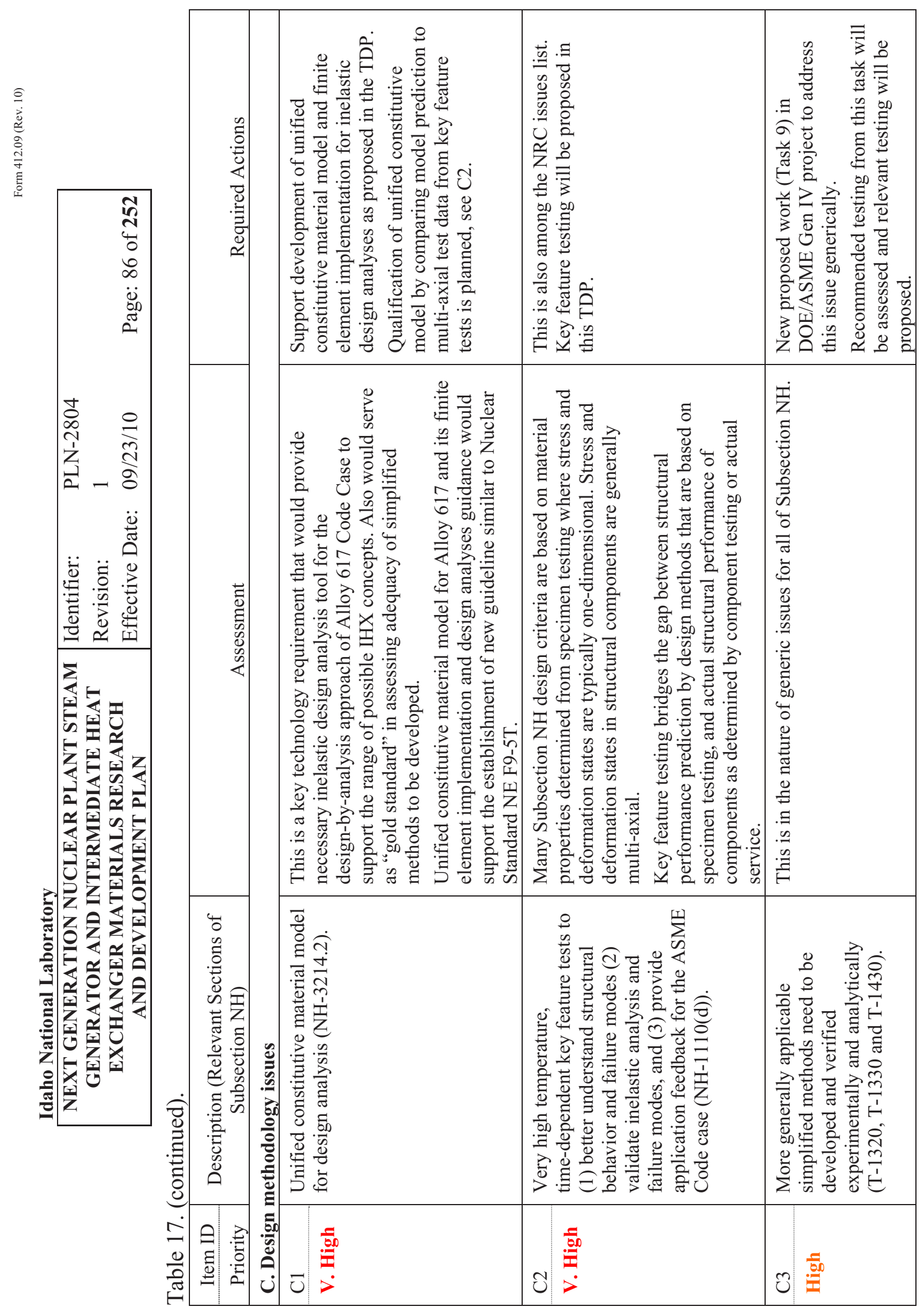




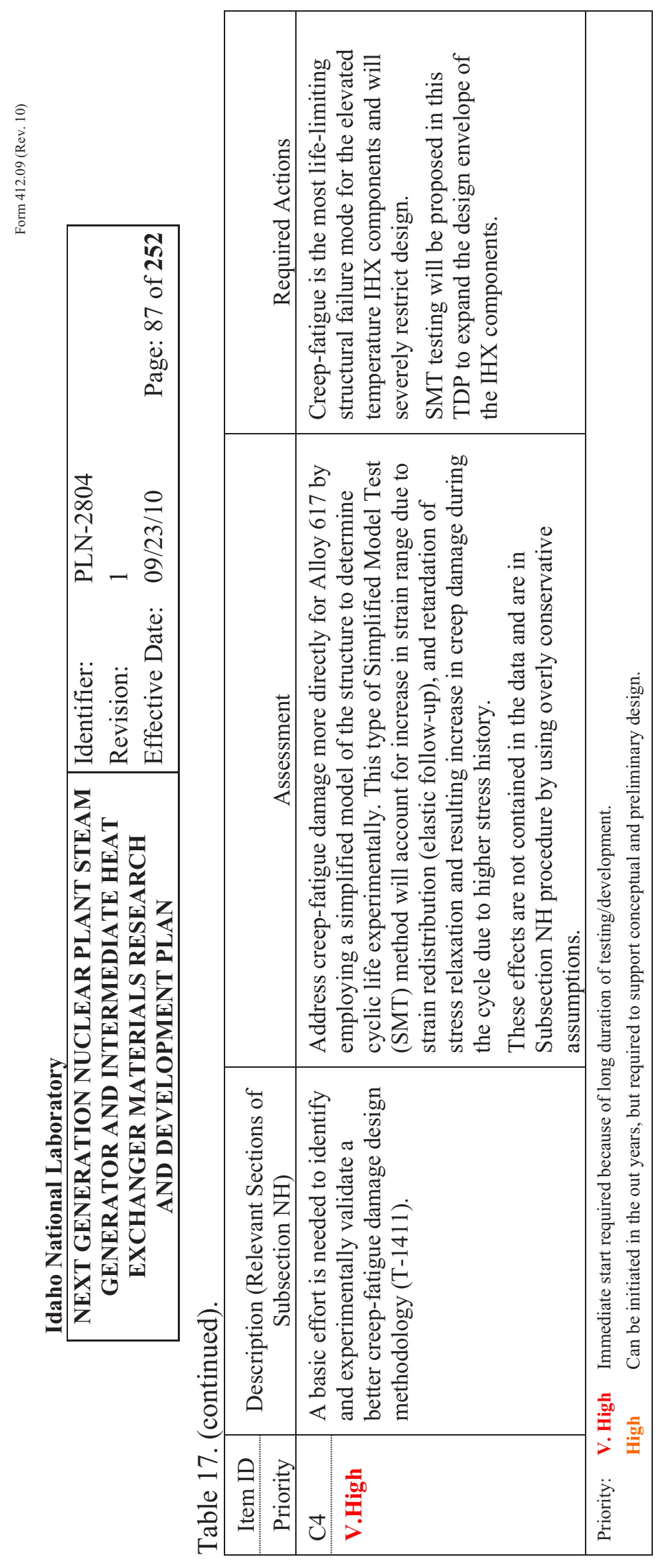




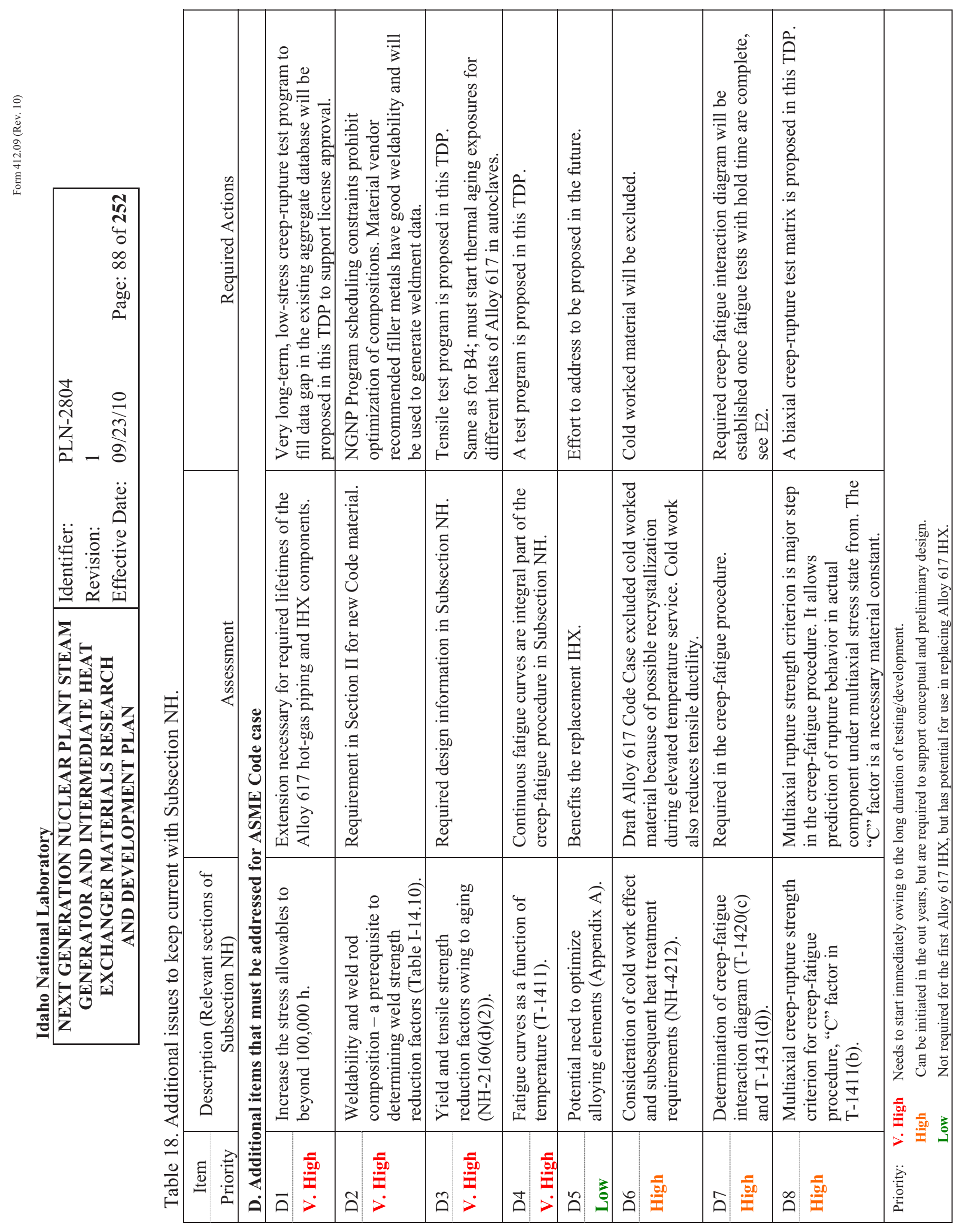




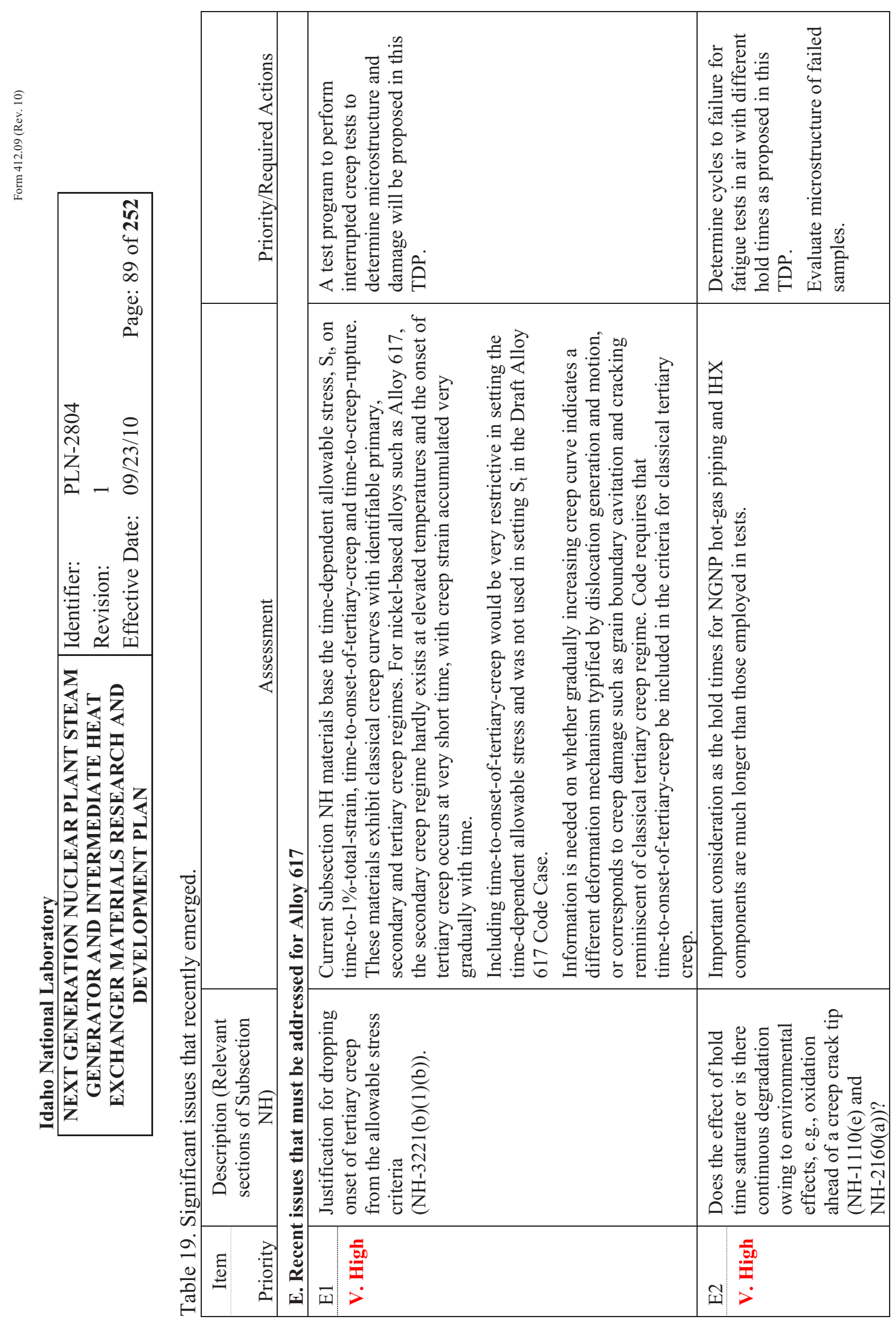




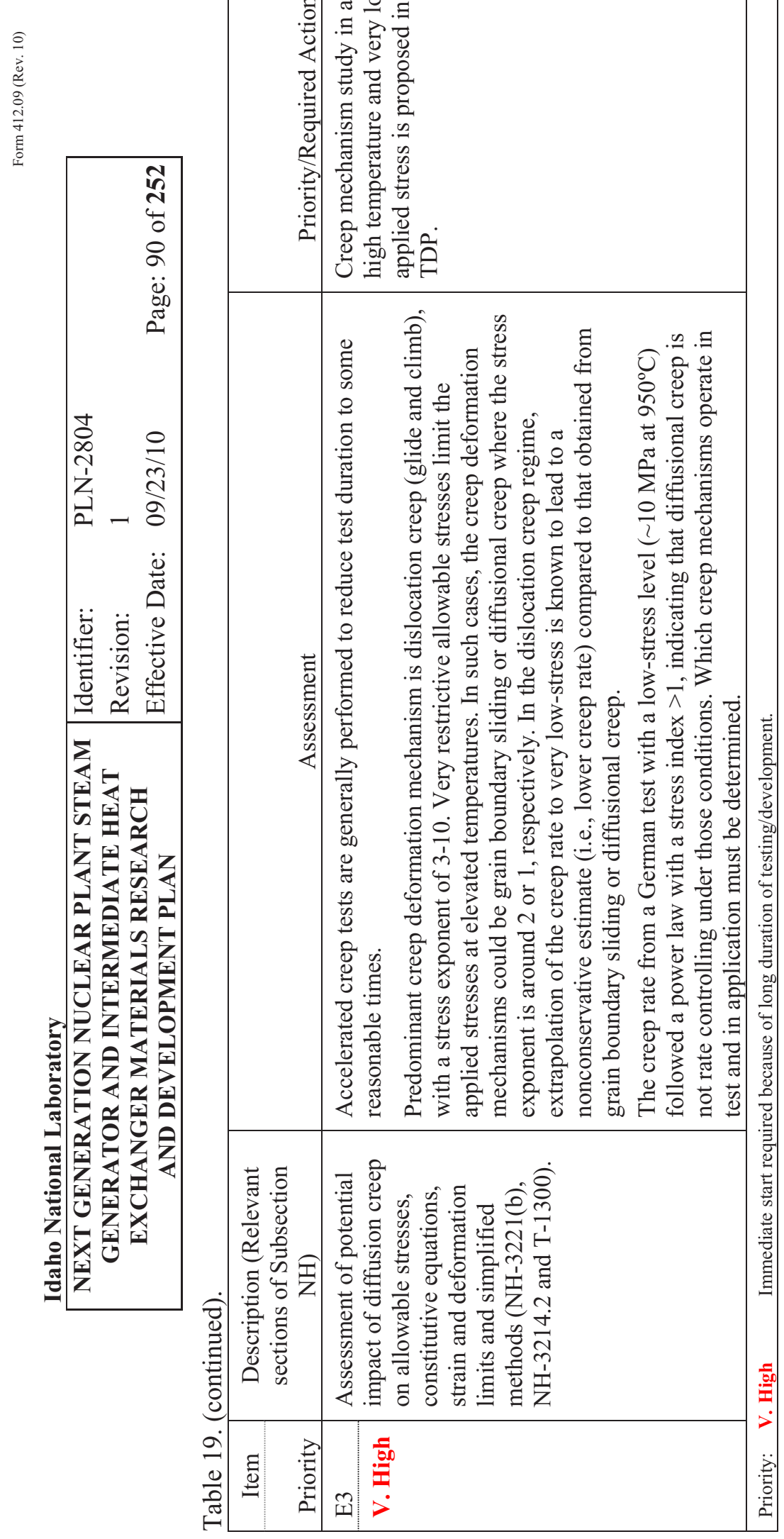




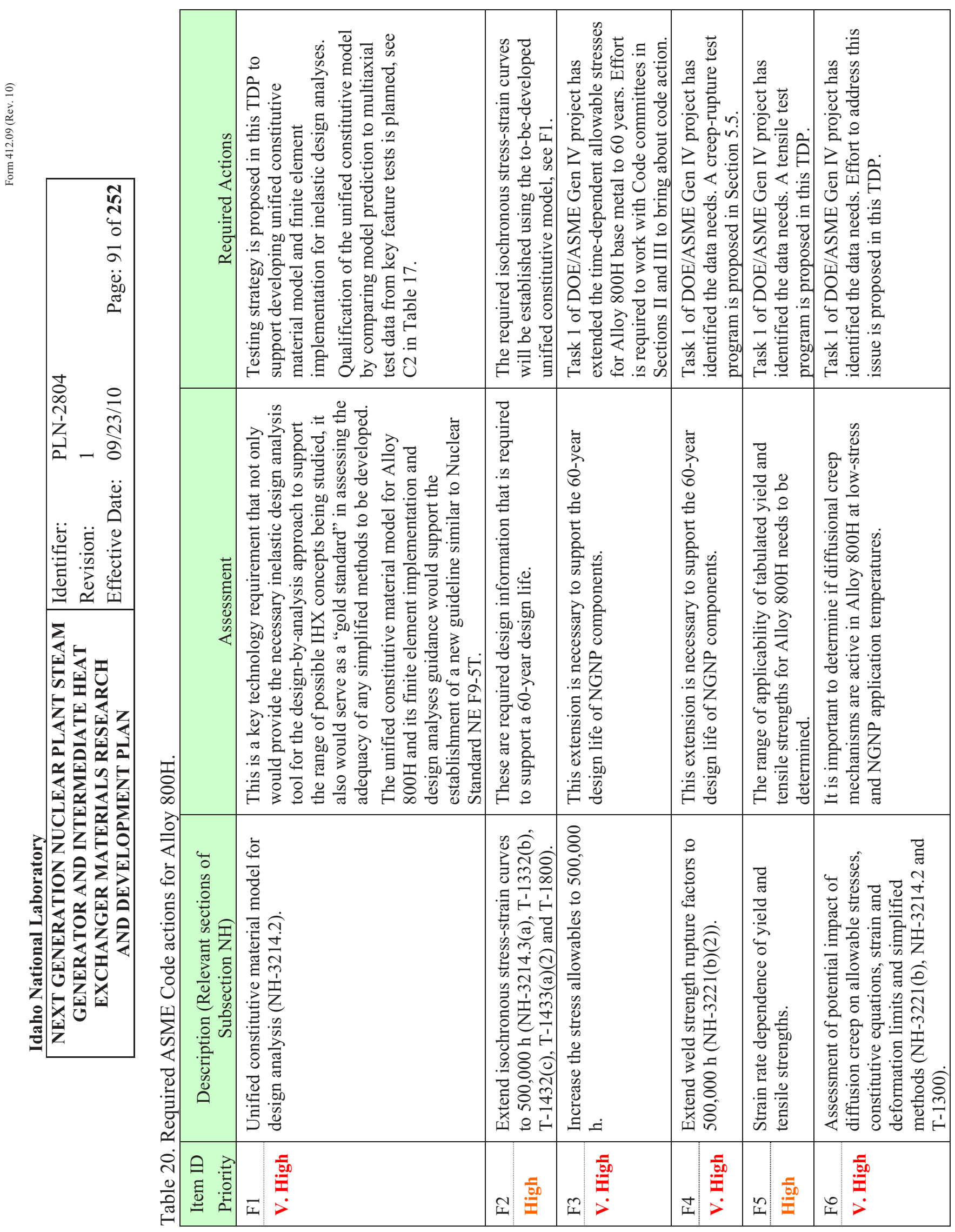




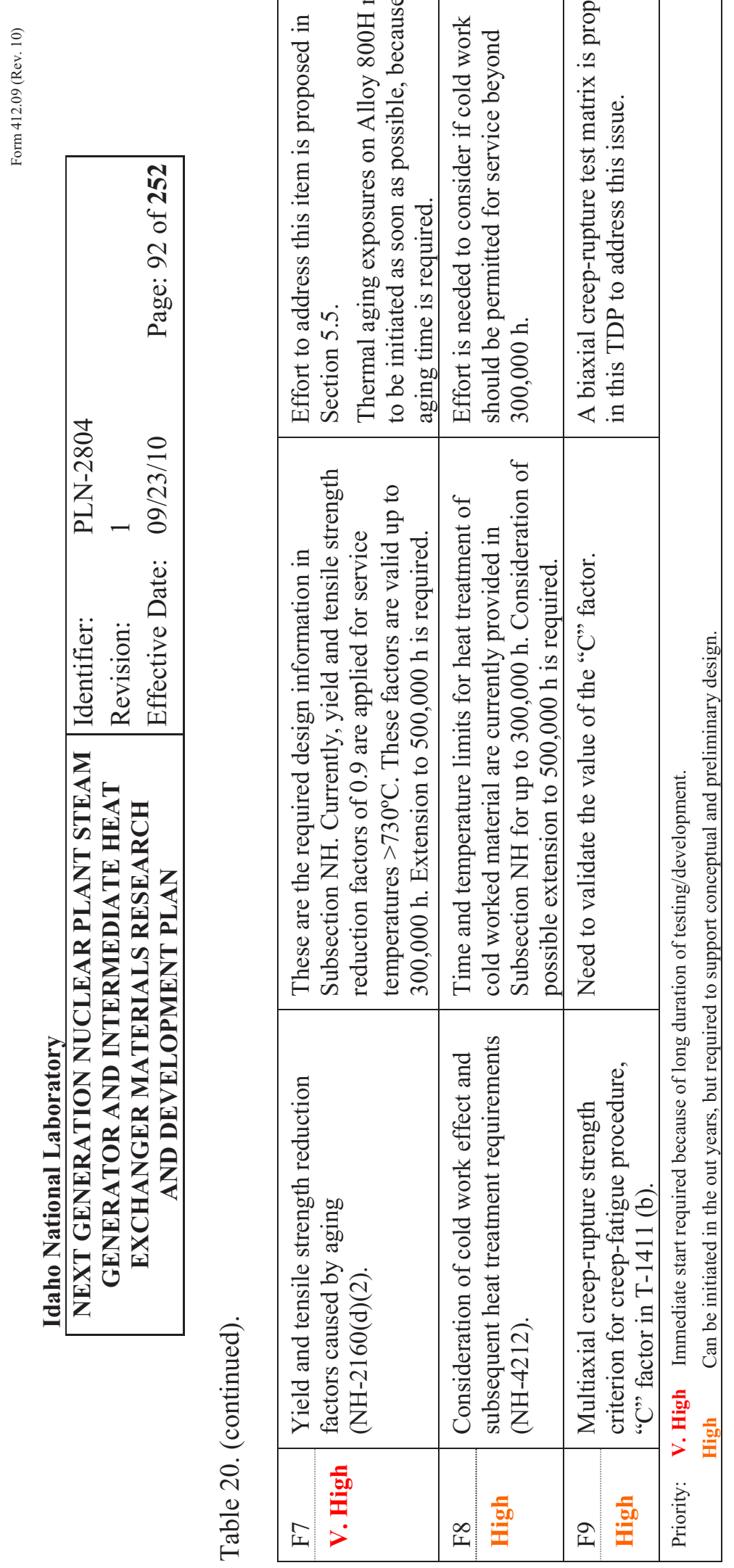




\begin{tabular}{|c|lll|}
\hline $\begin{array}{c}\text { NEXT GENERATION NUCLEAR PLANT STEAM } \\
\text { GENERATOR AND INTERMEDIATE HEAT } \\
\text { EXCHANGER MATERIALS RESEARCH }\end{array}$ & Identifier: & PLN-2804 & \\
AND DEVELOPMENT PLAN & Effective Date: & $09 / 23 / 10$ & Page: 93 of 252 \\
\hline
\end{tabular}

\section{RESEARCH ISSUES}

This section will detail issues that are common to IHX and SGs in addition to issues that arise with respect to design in the ASME Code discussed in Section 5.

\subsection{Procurement}

Procurement and transportation was addressed in detail in a separate acquisition report. ${ }^{1}$ It does not appear that these issues are important to the R\&D plan. Both Alloy 617 and Alloy $800 \mathrm{H}$ are widely available as plate, sheet and tube from a number of vendors. It is possible that field assembly issues may arise if a large heat exchanger design or a steam generator is selected.

There are still some vendor-raised concerns about cold and hot workability at the compositional high end of the Alloy 617 specification. ${ }^{70}$ These concerns were raised when development of the CSM 617 was discussed in FY-05.

\subsection{Material Characteristics and Properties}

The material property testing is covered in detail in Section 7 and will be briefly summarized here, emphasizing SG and heat exchanger issues.

\subsubsection{Cyclic Properties}

Nonlinear temperature profiles, particularly during transient cycles such as start-up and shutdown, can result in high local thermal stresses in areas of constraint that ultimately limit fatigue life. Fatigue and creep-fatigue of the material testing will proceed as outlined in Section 7.1 while the IHX design is being finalized. Thermal cycling of certain features or components may be required at a later date and will be coordinated with engineering efforts. ${ }^{71}$

\subsubsection{Creep}

The properties of Alloy 617 and $800 \mathrm{H}$ have been characterized to more than 10 years in air and anticipated NGNP environments. The deleterious affects of the environment are well understood for those conditions. A phenomenon of carbide redistribution under creep load has been observed for Alloy 617 . New constitutive models will be developed as discussed in Section 7.1.3.1. This information will be essential for accurate finite element modeling of NGNP IHX and other high temperature designs such as hot gas piping.

\subsubsection{Crack-Growth}

Crack growth is primarily an issue when the component is at temperatures below $850^{\circ} \mathrm{C}$ where creep crack growth and environmentally assisted crack growth are concerns. At elevated temperatures creep and creep-fatigue crack growth can occur, and are addressed through the DOE/ASME Task 8. Any proposed testing from Task 8 will be assessed and additional testing recommended if needed. Creep crack growth tests in NGNP helium are proposed in Section 7.1.2.4 to investigate the environmental effect.

\subsection{Material Degradation}

\subsubsection{Environmental Effects}

Because of the relatively pure $\mathrm{He}$ as the primary coolant, corrosion issues are generally of less concern than the high temperature strength issues. As discussed in Section 4.2, the behavior expected in the NGNP environment has been studied at some length. The primary concern is carburization if there is reduced oxygen partial pressure. 


\begin{tabular}{|c|lll|}
\hline $\begin{array}{c}\text { NEXT GENERATION NUCLEAR PLANT STEAM } \\
\text { GENERATOR AND INTERMEDIATE HEAT }\end{array}$ & Identifier: & PLN-2804 & \\
EXCHANGER MATERIALS RESEARCH & Revision: & 1 & \\
AND DEVELOPMENT PLAN & Effective Date: & $09 / 23 / 10$ & Page: 94 of 252 \\
\hline
\end{tabular}

The objective of this work is to determine the effect of the $\mathrm{H}_{2} \mathrm{O}$ and $\mathrm{CO}$ concentrations on the corrosion mechanism, and the range of gas chemistries that gives rise to stable oxide formation for these alloys at temperatures potentially up to $1000^{\circ} \mathrm{C}$. This will experimentally verify the Ellingham diagram (Figure 38).

Two significant issues remain to be investigated with respect to possible environmental interactions in the NGNP: environmental interaction at reactor pressure and the influence of very high velocity gas on the environmental interaction. While it is anticipated that the reaction mechanism determined using low-pressure test loops will also be observed at high pressure, there is some concern that the kinetics of reaction will be altered. It is possible that the steady-state gas chemistry at the specimen surface could be considerably different with high velocity flow.

\subsubsection{Dust Clogging, Accumulation and Fouling}

This is primarily a concern for compact heat exchangers with small tortuous flow channels, as discussed in Section 6.6.2. This testing is not part of this plan. It is considered in the test plan for the heat transport system. ${ }^{71}$

\subsubsection{Erosion}

This is primarily a concern with pebble-bed designs. The concern is that wear on the pebbles during movement can generate dust that will act as a means for transporting fission products during loss of coolant, and therefore could be related to the radiation exposure to the heat exchanger. To determine the amount of dust to be generated, the tribological properties of the graphite must be determined. Erosion testing is not part of this plan. It is considered in the test plan for the heat transport system. ${ }^{71}$

\subsubsection{Radiation Effects}

The expected exposure to radiation of the IHX or SG is very small. Radiation effects are not expected to be an issue. The potential effects are discussed briefly below, but no testing is suggested in this plan.

\subsubsection{Tritium}

The primary nuclide contaminant of concern is tritium. Most of the tritium is produced from ternary fission, but that will be largely retained in the fuel particles. The major source of tritium in the primary loop will likely be the activation of the He-3 in the He coolant. A large portion of the circulating tritium is adsorbed within the core graphite. ${ }^{8}$ The most cost effective means of controlling tritium contamination would be addition of a He purification system to the secondary coolant loop. Tritium removed from the NGNP He coolant is predicted to be about $115 \mathrm{Ci} / \mathrm{yr}$.

Given its high mobility at high temperatures, some tritium will migrate through the IHX or SG regardless of the primary and secondary cycle concept. ${ }^{14}$ Although there is extensive literature on tritium permeation through these alloys, there is concern that the testing conditions were poorly specified and controlled. Testing is currently underway in the NGNP program to further characterize tritium transport. This should help in predicting tritium permeation from the primary to the secondary coolant loops. Coating the IHX between the primary and secondary loops to reduce tritium migration has been proposed. Coatings represent a significant challenge and available information is insufficient to make a judgment as to whether pursuing this approach is warranted. ${ }^{72}$

\subsubsection{Activated Materials}

The IHX or SG should experience little to no radiation; therefore activated materials should not be an issue for this component. 


\begin{tabular}{|c|lll|}
\hline $\begin{array}{c}\text { NEXT GENERATION NUCLEAR PLANT STEAM } \\
\text { GENERATOR AND INTERMEDIATE HEAT } \\
\text { EXCHANGER MATERIALS RESEARCH }\end{array}$ & Identifier: & PLN-2804 & \\
AND DEVELOPMENT PLAN & Effective Date: & $09 / 23 / 10$ & Page: 95 of 252 \\
\hline
\end{tabular}

\subsubsection{Fission Products}

Depending on the fuel performance, it is possible that some low-level fission products might be released into the primary coolant and come in contact with the heat exchanger. Some of these products, like silver, may be corrosive to the nickel-rich alloys.

\subsection{Welding}

Most high temperature structural failures occur at weldments. Welded pipe, for example, has failed in high temperature fossil plants after many years of operation. Reliably guarding against weldment failures is particularly challenging at high temperatures, where variations in the inelastic response of the constituent parts of the weldment (i.e., weld metal, heat-affected zone, and base metal) can result in a strong metallurgical discontinuity. In the hearings for a construction permit for Clinch River Breeder Reactor (CRBR), early weldment cracking was identified by the NRC as the foremost structural integrity concern. The NRC and ACRS believed that designers should have a better understanding of the metallurgical interactions that take place in weldments and their effects on weldment life. The CRBR project committed to a five-year development program to address these issues before issuance of a plant operating license. The program was never carried out because of the subsequent demise of the project. This issue will certainly resurface with NGNP and other Gen IV reactors.

Cross-weld creep testing indicates that weldment strengths are usually in the range of $50-80 \%$ of those of base metals. Consequently, significant performance reductions are required for design of welded constructions of most nickel-based alloys. Failures at the reduced loadings are usually in the weld deposits.

One potential problem often found in welding nickel-based alloys with fully austenitic weld deposits is the occurrence of micro-fissuring in the HAZ and final passes in heavy-section, multi-pass welds. Weld failure can happen in service if the inherent micro-fissuring propagates into cracks when subjected to thermal stresses. The micro-cracks in HAZ are intergranular associated with liquefied and resolidified products on grain boundaries. The cracks were often observed to be connected with the weld pool by a liquated grain boundary with a continuous string of precipitates on it. The tendency to micro-fissuring is attributed to liquation owing to high local concentrations of some minor elements as well as to $\delta$ phase-assisted liquation cracking. Chemical composition of the filler metal can significantly affect the tendency to micro-fissuring. Also, cracking of liquated regions can only occur in the presence of tensile stresses. Therefore, the degree of cracking will be influenced by welding and local tensile stresses during cooling of the welds.

\subsubsection{Process Development}

The welding process for Alloy 617 and Alloy $800 \mathrm{H}$ are well established. ${ }^{46}$ Refer to Sections 4.1.1.9 and 4.1.2.4, respectively.

\subsubsection{Proof Testing}

A fair amount of welded coupons have been tested in the laboratory. The uniaxial strength is well established; however, additional work is needed to characterize the fracture toughness and creep properties and to develop constitutive models for the welds. Some work on fatigue and creep-fatigue has been done, but the Draft Alloy 617 Code Case submitted in the 1990s specifically noted insufficient understanding of creep-fatigue in weldments. Testing of welds is a substantial portion of this test plan. 


\begin{tabular}{|c|lll|}
\hline $\begin{array}{c}\text { NEXT GENERATION NUCLEAR PLANT STEAM } \\
\text { GENERATOR AND INTERMEDIATE HEAT } \\
\text { EXCHANGER MATERIALS RESEARCH }\end{array}$ & Identifier: & PLN-2804 & \\
AND DEVELOPMENT PLAN & Effective Date: & $09 / 23 / 10$ & Page: 96 of 252 \\
\hline
\end{tabular}

\subsubsection{Properties of Prototypical Welded Structures}

At this point, little has been done in this area. A review of the existing weld reduction factors for materials currently in $\mathrm{NH}$ will be required to begin to address the NRC concerns. ${ }^{69} \mathrm{~A}$ significant development program will be required to support ASME Code activities for welding.

Owing to various geometric details of IHX or SG structures, the welds will be subjected to stress conditions much more complicated than those in a regular lab mechanical testing specimen. The mechanical response of welds under such conditions should be evaluated to verify the integrity of the weldment. To characterize the welds for such conditions, customized specimens representing major characteristics of the prototypical welded structures in the component should be designed and tested. Design of the customized specimens must balance the characterization needs, the viability, and the cost. Whenever possible, the testing must be conducted in a working environment representative of the NGNP helium. This type of testing will be coordinated with NGNP testing for heat transport components. ${ }^{71}$

Depending on the design, the NGNP IHX may be joined to piping or components of dissimilar materials for example, $800 \mathrm{H}$. Therefore, welding metallurgy and behavior of dissimilar weld joints must be studied. Emphasis should be put on the microstructure stability of the weld during long-time, elevated-temperature exposure. Extended annealing of mixed-metal joints, both austenitic-austenitic and austenitic-ferritic, can lead to unique microstructures that produce unexpected results. Chemical gradients in representative mixed-metal weld joints should be characterized and their long-term aging behavior should be assessed. Approaches should be developed to adjust weld filler metal compositions to eliminate diffusion of critical alloying elements.

\subsubsection{Examination Methods}

No unique issues for examining welds in the IHX or SG have been identified. The ASME rules for inspection are applicable to this welding application.

\subsection{Steam Generator Specific Issues}

This section will detail issues specific to the SG.

\subsubsection{Material Characteristics and Degradation}

Creep properties are less significant for the SG than the IHX because of the lower operating temperature.

The presence of a SG in the system changes the anticipated corrosion issues. In addition to direct exposure to the steam on the secondary side, the moisture content in the primary fluid (helium) is expected to be higher than for an IHX. The AVR reactor, for example, reported that the moisture content in the primary coolant could only be accounted for by migration from the SG.

Experience has shown that stress corrosion cracking is a potential issue. Although a significant number of SGs in the U.S. have their original mill-annealed Alloy 600 tubes, they are gradually being replaced by either Alloy 600TT or Alloy 690TT. Alloy 800M has been used successfully in Europe and Canada, but not in the U.S. ${ }^{73}$

\subsubsection{Alloys 600 and 690}

A succession of failure processes has continued to afflict SGs in the United States and worldwide since the widespread use of Alloy 600 tubing in the late 1960s. ${ }^{74-76}$ There has been a legacy of SG degradation, dominated by Alloy 600 issues, that has affected operation of all types of SGs, and has impacted regulatory and design decisions, as well as operational practices. Degradation is predominantly 


\begin{tabular}{|c|lll|}
\hline NEXT GENERATION NUCLEAR PLANT STEAM & Identifier: & PLN-2804 & \\
$\begin{array}{c}\text { GENERATOR AND INTERMEDIATE HEAT } \\
\text { EXCHANGER MATERIALS RESEARCH } \\
\text { AND DEVELOPMENT PLAN }\end{array}$ & Revision: & 1 & \\
Effective Date: & $09 / 23 / 10$ & Page: 97 of 252 \\
\hline
\end{tabular}

stress-corrosion cracking (and most of that inter-granular), but pitting has also been an issue, primarily when salt-water-cooled condensers are used.

Depending on microstructure and processing history, Alloy 600 can and does experience Intergranular stress corrosion cracking (IGSCC) when exposed to high-purity aerated or deaerated high-temperature water; ${ }^{77}$ however, the exact mechanisms remain elusive. ${ }^{78}$ The evolution of IGSCC-related problems in the SG tubes in the primary and the secondary sides differs. Although the bulk water in both the primary and the secondary sides of Pressurized Water Reactors (PWR) is pure and deaerated with dilute additives to control $\mathrm{pH}$, impurity concentration processes can significantly alter the local chemical environment where IGSCC occurs.

Persistent issues of corrosion degradation led to efforts to optimize the metallurgical characteristics of Alloy 600. A special thermal treatment was performed and the thermally treated Alloy 600 (Alloy 600TT) exhibited enhanced resistance to SCC. The thermal treatment required that the tubes experience a final mill anneal at a temperature sufficient to dissolve all carbides, followed by a rapid cooldown to room temperature, and subsequent exposure of the alloy in the intergranular precipitation range (approximately $700-725^{\circ} \mathrm{C}$ ) for times sufficient to effect intergranular carbide precipitation and redistribution of the matrix chromium to the regions adjacent to the grain boundaries in order to avoid sensitization. Beginning around 1980, this material dominated SG tubing applications in the U.S., Europe, and Japan for both new and replacement SGs. The performance of these units has been excellent, with an extremely low number of corrosion-related repairs after more than twenty years of service.

Continued efforts by the nuclear industry to optimize SG heat transfer tubing led to qualification and selection of thermally treated Alloy 690 (Alloy 690TT) in the late 1980s. The corrosion-testing programs that ultimately led to the selection of Alloy 690TT involved long-term exposures at a variety of chemical environments, evaluating the effects of carbon concentration, final mill annealing, thermal treatment temperatures, and other metallurgical parameters on the corrosion resistance. With the exception of German-designed and built PWRs, which use a modified version of Alloy 800, all new and replacement SGs placed into service since mid 1989 have been equipped with Alloy 690TT tubes.

\subsubsection{Alloy 800}

After reviewing Alloy 600 data and in consultation with developments elsewhere, Ontario Hydro specified SG tubing made from nuclear grade or "modified" Alloy $800 \mathrm{M}$, with a Ti/C ratio $>12$ to prevent sensitization. This ratio has changed slightly since the late 1970s, but current CANDU 6 (a Canadian deuterium uranium PWR) and Darlington reactors each have four SGs with stainless steel supports and Alloy 800 tubing, with relatively little history of corrosion-related degradation. At Point Lepreau, which has Alloy 800 tubes and uses phosphate water chemistry, pits (including some throughwall pits) have been observed on the hot leg side. The pitting has been attributed to acidic oxidizing conditions.

Although the performance of Alloy 800 tubes in German PWRs has been without incident for over 30 years, recently axial cracking within the tubesheet region of the tube in Biblis has been reported. Also, circumferential crack-like indications attributed to SCC initiated at the outer diameter have been detected recently in the transition zone at the top of the tubesheet of 29 tubes in the cold leg of Almaraz Unit II in Spain. This is a replacement SG, which has been in operation since 1997. The tubes are made of Alloy 800 with hydraulic expansion.

\subsubsection{Dissimilar Metal Joining}

DMWs will be needed to join the Alloy $800 \mathrm{H}$ superheater section to the $2.25 \mathrm{Cr}-1 \mathrm{Mo}$ steel evaporator-economizer section. It is well known that failure of DMWs can occur well below the expected creep life of either base metal and well below the design life of the plant. The failure time depends on a wide range of factors related to service conditions, welding parameters, and alloys involved in the 
Idaho National Laboratory

\begin{tabular}{|c|lll|}
\hline NEXT GENERATION NUCLEAR PLANT STEAM & Identifier: & PLN-2804 & \\
$\begin{array}{c}\text { GENERATOR AND INTERMEDIATE HEAT } \\
\text { EXCHANGER MATERIALS RESEARCH }\end{array}$ & Revision: & 1 & \\
AND DEVELOPMENT PLAN & Effective Date: & $09 / 23 / 10$ & Page: 98 of 252 \\
\hline
\end{tabular}

DMW. ${ }^{79}$ The DMW between the $2.25 \mathrm{Cr}-1 \mathrm{Mo}$ steel and Alloy $800 \mathrm{H}$ is expected to experience about $400^{\circ} \mathrm{C}$ during normal operation.

In the as-welded condition, the DMW has a sharp chemical concentration gradient across the fusion line that separates the ferritic and austenitic alloys. As the weld cools, a band of martensite forms within this concentration gradient due to high hardenability and the relatively rapid cooling rates associated with welding. Upon aging during PWHT and/or high temperature service, $\mathrm{C}$ diffuses from the ferritic 2.25Cr-1Mo steel toward the austenitic alloy. This can lead to formation of a soft $\mathrm{C}$ denuded zone near the interface on the ferritic steel, and nucleation and growth of carbides on the austenitic side. A band of carbides also forms along the fusion line in the ferritic side of the joint. The result is large differences in microstructure and hardness that occur over very short distances $(\sim 50-100 \mu \mathrm{m})$ across the fusion line. The differences in hardness increase with increasing aging time due to nucleation and growth of the interfacial carbides. The difference in creep life between the DMW and the base metal is also expected to increase with increasing aging time, indicating that the creep life of the DMW is expected to be significantly less than that of $2.25 \mathrm{Cr}-1 \mathrm{Mo}$ base metal. ${ }^{79}$

The sharp change in microstructure and mechanical properties across the fusion line, and the large differences in coefficient of thermal expansion (CTE) between the alloys can lead to stress concentrations along the fusion line where a creep-susceptible microstructure has evolved during aging. The chemical gradients can lead to preferential oxidation in the same region, concentrating the stress even further. In thin walled tubing, the oxide notch can penetrate a relatively large fraction of the tube wall. In addition, interfacial carbides can lead to creep cavity formation. All these factors can lead to premature failure and mixed modes of failure can be observed. Nickel-based filler metals offer a significant improvement over stainless steel filler metals due to reduced C migration and improved CTE matching. ${ }^{79}$

The effects of NGNP environment on the DMW are unknown. Creep testing for purposes of acquiring design data need to be conducted in an environment that closely simulates that expected in service. In addition, applied stress levels must simulate service conditions; creep testing at stress levels above $80 \mathrm{MPa}$ (or above $50 \mathrm{MPa}$ for aged welds) do not properly simulate the failure mechanisms observed in the field. Creep tests conducted at stresses significantly higher than those expected in service often produce short failure times in which the microstructure partially responsible for failure does not have enough time to properly develop. Also, time-dependent degradation mechanisms, such as preferential oxidation, carburization or decarburization cannot play their representative roles in the failure. The impact of these degradation mechanisms is also affected by the specimen diameter. Creep testing of DMWs requires careful consideration in order to ensure tests that provide meaningful data within reasonable test times. For laboratory samples that properly simulate creep fractures in the field, failure occurs along the fusion line between the $2.25 \mathrm{Cr}-1 \mathrm{Mo}$ and Alloy $800 \mathrm{H} .^{79}$

FEM stress analysis has indicated that peak thermal stresses occur at the Alloy $800 \mathrm{H} / 2^{1 / 4} \mathrm{Cr}-1 \mathrm{Mo}$ tube joint because of incompatibility of mechanical properties between the two materials. ${ }^{73,80}$ The peak stresses at this location could be a possible source for creep-fatigue damage; however, they do not exceed the allowable limits in Subsection NH of the ASME Code. Furthermore, failure is not observed along this interface in service. Instead failure occurs at a lower stress location with a susceptible microstructure that develops from the welding and subsequent aging. ${ }^{79}$

Although DMW properties degrade with aging, it does not appear that PWHT is as detrimental to service life as previously thought. ${ }^{81}$ The deleterious effects of PWHT cited to date were the result of data generated from higher stress tests with failure mechanisms that were not representative of service failures. More recent results of well-controlled studies have shown the use of a PWHT does not significantly impact the creep life, ${ }^{82,83}$ having a minor effect on carbide size and distribution compared to subsequent 


\begin{tabular}{|c|lll|}
\hline $\begin{array}{c}\text { NEXT GENERATION NUCLEAR PLANT STEAM } \\
\text { GENERATOR AND INTERMEDIATE HEAT } \\
\text { EXCHANGER MATERIALS RESEARCH }\end{array}$ & Identifier: & PLN-2804 & \\
AND DEVELOPMENT PLAN & Effective Date: & $09 / 23 / 10$ & Page: 99 of 252 \\
\hline
\end{tabular}

aging in service. ${ }^{84,85}$ Since the PWHT provides relief of residual stresses that form in the DMW during welding, it provides a net benefit.

\subsubsection{Expected Lifetime}

From the point of view of the utility, maximizing the inspection interval without jeopardizing tube integrity is an important economic goal. To achieve this goal it is important to select a tube material that is structurally strong (i.e., has high mechanical strength and has high resistance to corrosion), has good thermal properties and is amenable to inspection by non-destructive evaluation (NDE) (typically eddy current testing).

Beyond material selection, there are several factors to consider when striving for a $\geq 40$ year SG life. Perhaps the most important, after good chemistry control (and specifications and equipment to ensure this), is the need for a leak-tight condenser. For seawater-cooled sites a titanium-tubed condenser with leak-tight tube-to-tubesheet joints is recommended to minimize any risk of impurity in-leakage, although few utilities have these. It is often assumed that on fresh water sites the condenser requirements can be relaxed, but experience at CANDUs and PWRs indicates that this assumption is false. Although the risk of chloride ingress from lake water in-leakage may be lower, the concentration of chloride in SG crevices over time will eventually reach the same levels as seawater in leakage. ${ }^{73}$

\subsection{Intermediate Heat Exchanger Specific Issues}

This section will detail issues specific to the IHX. Furthermore, most of the issues are unique to particular compact heat exchanger designs. Details of various IHX designs can be found in Appendix B.

\subsubsection{Thin Sheet}

Although Alloy 617 offers good fabrication capabilities, the fabrication of thin sheets and foils requires very carefully controlled processing parameters different from those for other product forms such as plate and tubing. Plate material has been shown to have microstructural stability after 10 years of aging in air at temperatures up to $1000^{\circ} \mathrm{C}$. However, sheet material is received in the cold rolled condition with the potential for recrystallization and abnormal grain growth either during diffusion bonding or during service. Grain growth is of particular concern in thin sections because properties may degrade if there are a sufficient number of grains in the through-thickness direction. Acceptable grain sizes should be specified for as-received sheet and maintained throughout aging to ensure proper creep resistance of such product forms. To achieve desired microstructures in the thin sheets or foils needed for compact heat exchanger, fabrication of such thin sheets and foils must be evaluated. Microstructural and mechanical property characterizations are needed for thin section materials, especially for use in PCHEs.

\subsubsection{Small Flow Channels}

All compact exchangers are to some extent susceptible to fouling and clogging because of their small and tortuous flow channels. Fouling refers to the formation of unwanted deposits on the heat transfer surfaces which can inhibit fluid flow as well as impede heat transfer. For this application the fluid (He) is essentially clean compared with many hydrocarbon applications where PCHE and plate with fin heat exchangers are used. The only fouling agent anticipated is carbon particulate from the reactor. Because all parts of the IHX will be at least $100^{\circ} \mathrm{C}$, there should be no moisture to act as a binding agent, so particle agglomeration is improbable. The anticipated particulate load is on the order of $0.1 \mathrm{~kg} / \mathrm{MW}$ at the end of reactor life. ${ }^{86}$

It is reasonable to assume that particles smaller than $1 / 3$ the channel diameter will pass through the IHX. The graphite particulate should be less than $1 \mu \mathrm{m}$ across. The PCHE will have a semicircular channel of approximately $600 \mu \mathrm{m}$, so particles of about $200 \mu \mathrm{m}$ should pass through. This value is two orders of magnitude greater than the anticipated graphite particles. PCHE passages are continuous with no 


\begin{tabular}{|c|lll|}
\hline NEXT GENERATION NUCLEAR PLANT STEAM & Identifier: & PLN-2804 & \\
$\begin{array}{c}\text { GENERATOR AND INTERMEDIATE HEAT } \\
\text { EXCHANGER MATERIALS RESEARCH } \\
\text { AND DEVELOPMENT PLAN }\end{array}$ & Revision: & 1 & \\
Effective Date: & $09 / 23 / 10$ & Page: 100 of 252 \\
\hline
\end{tabular}

breaks or discontinuities. Combined with high wall shear, this ensures that there are no dead areas or areas of low velocity, and consequently particles should not settle or adhere to the walls. ${ }^{86}$

For plate with fin heat exchangers, designs with multiple fin pads and/or serrated fins have the greatest potential for fouling. The minimum passage dimension is not the fin height, but the distance between fins. A high-performance model would have a fin density of about 850 fins/meter and a foil thickness of about $0.2 \mathrm{~mm}$, so the clearance between fins is about $1 \mathrm{~mm}$. However, for serrated fins, this clear pathway is interrupted, with an actual clearance of about $0.4 \mathrm{~mm}$. Particles $1 / 3$ this size, about $130 \mu \mathrm{m}$, will pass through the exchanger. Although the clearance is smaller than for the PCHE, it is still about two orders of magnitude greater than the graphite particles. ${ }^{86}$

It is anticipated that any dust-clogging accumulation or fouling problems would have engineering solutions; however, related materials issues could arise.

\subsubsection{Joining}

\subsubsection{Diffusion Bonding}

Diffusion-bonding is a solid-state joining process where metal surfaces are brought together under load at an elevated temperature (about $50-90 \%$ of the absolute melting point of the parent material) for a period ranging from a few minutes to a few hours. Under carefully controlled conditions neither metallurgical discontinuities nor porosity exist across the interface, and the diffusion-bonded joints can reach parent metal properties. Ultimately, the joint is formed through atomic diffusion, thereby promoting grain growth between the surfaces. Good dimensional tolerances for the products can be attained resulting in high-precision components with intricate shapes or cross sections without the need for subsequent machining. However, microstructural stability during the high temperature exposure associated with the diffusion bonding process is a concern.

Great care is required in the surface preparation stage. Excessive oxidation or contamination of the faying surfaces can decrease the joint strength drastically. The reformation of the surface oxide is virtually instantaneous for many metallic alloys because they contain elements with a high affinity for oxygen (e.g., Ni, Cr, Al, Co, Ti, and W). Diffusion bonding of materials with stable oxide layers is very difficult. Precise fitting-up of the mating parts is also critical. Production of large components is limited by the size of the bonding equipment used.

For fabrication of a compact IHX, diffusion bonding may be used for joining the core (PCHE). However, because of the complex shapes of the channels on the stacking sheet surface and relatively large size of the stacking sheets, applying the load evenly to the contact interface to form bonds of uniformly high quality can be a great challenge.

A number of materials are being qualified by Heatric for IHX manufacture, including all candidate alloys discussed in Section 4.1. ${ }^{87,88}$ While some diffusion bonding of Alloy 617 has been demonstrated, the optimum process parameters are not well defined. Adequate processing parameters must be developed including diffusion bonding temperature, applied loading level, and holding time. A significant portion of this effort has been carried out by the compact heat exchanger vendors, and at present they choose to hold this information as proprietary.

\subsubsection{Brazing}

Brazing is a joining process where a metallic filler material is heated to melting temperature (above $427^{\circ} \mathrm{C}$ ) and distributed between closely fitted surfaces to be joined by capillary action. The molten filler material interacts with the base metal and cools to form a bond from grain structure interaction. Because of the melting flux in the joining process, the surface preparation for brazing is much easier than that for diffusion bonding. However, significant process development is needed to develop adequate filler 


\begin{tabular}{|c|lll|}
\hline $\begin{array}{c}\text { NEXT GENERATION NUCLEAR PLANT STEAM } \\
\text { GENERATOR AND INTERMEDIATE HEAT }\end{array}$ & Identifier: & PLN-2804 & \\
EXCHANGER MATERIALS RESEARCH & Revision: & 1 & \\
AND DEVELOPMENT PLAN & Effective Date: & $09 / 23 / 10$ & Page: 101 of 252 \\
\hline
\end{tabular}

material, especially for the high temperature application desired for the IHX. Little is known about brazing these alloys.

Plate fin heat exchangers are made by stacking corrugated sheets (fins) separated by planar sheets. The planar separation sheet usually has a clad alloy that will melt at a lower temperature than the parent alloy during brazing to bond the various sheets. The heat exchanger is assembled from the stacked sheets, placed within a fixture to exert force to keep the individual pieces in contact, then vacuum brazed in an environmentally controlled room. After brazing, the core is typically heat treated or aged to increase its strength. A quality braze joint can be stronger than the parent material being brazed. However, any braze alloy must have a lower melting point, so metallurgical stability and joint strength below that of the parent alloy is a concern.

\subsubsection{Proof Testing of Joints}

Testing should include tensile, creep, creep-fatigue and fatigue properties of the diffusion bonded or brazed joint. In addition, resistance to thermal fatigue, long-term exposure to high temperature, and the impure helium environment should be investigated. Because the real components will require joining of thin walls, adequate specimen designs must be considered to facilitate testing. Brazed material is expected to have a low melting temperature and to behave quite differently from the base metal.

\subsubsection{Properties of Prototypical Bonded Structures}

Properties of prototypical diffusion-bonded or brazed structures face the same issues as the welded structures (see Section 6.4.3). The joints will be subjected to stress conditions much more complicated than that in a regular lab mechanical testing specimen. Therefore, customized specimens representing major characteristics of the prototypical joined structures in the IHX should be designed and tested. At this point, little has been done in this area. A significant development program would be required to support ASME Code activities for diffusion bonding or brazing.

\subsubsection{Examination Methods for Bonded Sheets}

There are no ASME Code requirements for diffusion-bonded or brazed joints; therefore, inspection criteria must be developed. Compact heat exchangers use multiple layers of bonded sheets or plates, and inspection methods are lacking for these structures.

\subsubsection{Proprietary Designs}

Certain compact heat exchangers, where fabrication and design details are considered proprietary by the vendor, may potentially restrict our understanding and could impact the likeliness of that compact heat exchanger being selected. Heat exchanger vendors may have data on mechanical properties of their sheet and joints, but they consider all such information proprietary, so significant testing may be required.

\subsubsection{Expected Lifetime}

Ideally the IHX would last for the life of the plant; however, the expected lifetime is unknown and a subject of some debate. Inspection methods will be crucial in determining repairs or replacements required for this component.

Inspection of any heat exchanger is restricted to leak tests. As noted above, ASME Code rules for in-service inspection for weldments will determine acceptable service conditions. There are currently no defined failure criteria for diffusion-bonded or brazed material. Acceptance criteria must be developed for any of the joints or IHX designs. 


\begin{tabular}{|c|lll|}
\hline $\begin{array}{c}\text { NEXT GENERATION NUCLEAR PLANT STEAM } \\
\text { GENERATOR AND INTERMEDIATE HEAT } \\
\text { EXCHANGER MATERIALS RESEARCH }\end{array}$ & Identifier: & PLN-2804 & \\
AND DEVELOPMENT PLAN & Effective Date: & $09 / 23 / 10$ & Page: 102 of 252 \\
\hline
\end{tabular}

\section{RESEARCH AND TECHNOLOGY PLAN 7.1 Required Actions for Code/Licensing Issues}

This section discusses the detailed plans to address the ASME Code and NRC licensing issues highlighted in Section 5 for Alloy 617 and Alloy 800H. Table 21 gives a summary of the testing proposed in this plan. Very detailed test plans, giving the conditions and testing of each individual specimen, are included in Appendix A.

\subsubsection{Issues Originally Identified for Draft Alloy 617 Code Case}

\subsubsection{Time-Independent Allowable Stresses, Yield and Tensile Strengths}

This effort addresses Item A1 in Table 17 of Section 5.4.

A new draft guideline on approving new materials in Section II, Part D, Appendix 5, recommends, for ASME Code committee consideration, the submittal of tensile strength, yield strength, reduction of area, and elongation at $50^{\circ} \mathrm{C}$ intervals, from room temperature to $50^{\circ} \mathrm{C}$ above the maximum intended use temperature for three heats of appropriate product forms and sizes.

Allowable stresses, $S$, for all product forms of Alloy 617 are provided in Section II, Part D, Table 1B for Section I (up to $899^{\circ} \mathrm{C}$ ) and Section VIII, Division 1 (up to $982^{\circ} \mathrm{C}$ ) non-nuclear applications. However, $S$ is based on 100,000-hour extrapolated allowable stresses and construction rules in Sections I and VIII do not consider creep-fatigue interaction.

While allowable stresses for Alloy 617 are currently not covered in Section II for Section III nuclear applications, it should hardly be considered as a "new material" because of a wealth of user experience based in non-nuclear applications. User experience would be leveraged in pursuing the establishment of allowable stresses for Alloy 617 with appropriate ASME Code committees to lessen the burden on testing.

\subsection{Subsection NB Temperature Regime}

Incorporating Alloy 617 into Section III, Subsection NB was one of the original required actions for the Draft Alloy 617 Code Case. Time-independent design allowable stresses, $S_{m}$, for standard-grain-sized, annealed, Alloy 617 are not tabulated in Section II, Part D, Table 2B for use by the construction rules in Subsection NB. However, yield and tensile strengths for Alloy 617 are tabulated in Section II, Part D, Tables $\mathrm{Y} 1$ and $\mathrm{U}$, respectively, from room temperature to $525^{\circ} \mathrm{C}$. These ASME Code values cover specifications SB-166 (bar and rod), SB-167 (seamless pipe and tube), SB-168 (plate, sheet, and strip), and SB-564 (forging).

Subsection NB covers nonferrous materials up to $427^{\circ} \mathrm{C}$. The existing database that supported the development of Tables Y1 and U of the Draft Alloy 617 Code Case is judged to be adequate for developing an ASME Code case in Section II for Subsection NB applications. The Task Force on Allowable Stresses of the SG-ETD must be approached to initiate this code process for such a development. 


\section{PLN-2804}

GENERATOR AND INTERM

\begin{tabular}{c}
$\begin{array}{c}\text { EXCHANGER MATERIALS RESEARCH } \\
\text { AND DEVELOPMENT PLAN }\end{array}$ \\
\hline
\end{tabular}

Table 21. Summary of testing required to address code and licensing issues.

\begin{tabular}{|c|c|c|c|c|c|c|c|c|c|}
\hline $\begin{array}{l}\text { Test Matrix } \\
\text { Shown in detail in Appendix A }\end{array}$ & $\begin{array}{l}\text { Specimen } \\
\text { Type }\end{array}$ & $\begin{array}{c}\text { Number } \\
\text { Specimens }\end{array}$ & Environment & $\begin{array}{c}\text { Temperature } \\
\left({ }^{\circ} \mathrm{C}\right)\end{array}$ & $\begin{array}{l}\text { Product } \\
\text { Form }\end{array}$ & $\begin{array}{l}\text { Strain Rate } \\
(\mathrm{m} / \mathrm{m} / \mathrm{s})\end{array}$ & $\begin{array}{l}\text { Time (h) } \\
\text { (or as given) }\end{array}$ & $\begin{array}{c}\text { Exposure Temp } \\
\left({ }^{\circ} \mathrm{C}\right) / \\
\text { Time (h) }\end{array}$ & Notes \\
\hline A1 Tensile Test Matrix for $\mathrm{S}_{m}$ Confirmatory Testing & Tensile & 40 & Air & TBD & $2 \mathrm{pfs}$ & & & & \\
\hline \multirow{2}{*}{$\begin{array}{l}\text { A2 Test Matrix to Determine Weld Strength Rupture } \\
\text { Factor }\end{array}$} & \multirow{2}{*}{$\begin{array}{l}\text { Weld } \\
\text { (GTA) }\end{array}$} & \multirow[t]{2}{*}{66} & \multirow[t]{2}{*}{ Air } & \multirow[t]{2}{*}{$750-1000$} & \multirow{2}{*}{$\begin{array}{l}\mathrm{W} \\
1 \mathrm{~h}\end{array}$} & & \multirow{2}{*}{$\begin{array}{l}1341-62743 \\
\text { estimated rupture time }\end{array}$} & & 8.5-135.0 MPa app. $\sigma$ \\
\hline & & & & & & & & & test deposited, longitudinal, and cross-welds \\
\hline \multirow[t]{2}{*}{ A3 Creep-fatigue Tests for Welds } & \multirow{2}{*}{$\begin{array}{l}\text { Weld } \\
\text { (GTA) }\end{array}$} & \multirow[t]{2}{*}{48} & \multirow{2}{*}{$\begin{array}{l}\text { Air \& } \\
\text { NGNP He }\end{array}$} & \multirow[t]{2}{*}{950} & \multirow{2}{*}{$\begin{array}{l}\text { WP } \\
1 \mathrm{~h}\end{array}$} & \multirow[t]{2}{*}{ TBD } & \multirow{2}{*}{$\begin{array}{l}0-600 \mathrm{~min} \\
\text { hold time in tension }\end{array}$} & & $\%$ strain range \\
\hline & & & & & & & & & test deposited and cross-welds \\
\hline $\begin{array}{l}\text { A4(a) Aging Effects on Fracture Toughness of Wrought } \\
\text { Metal }\end{array}$ & $0.5 \mathrm{~T}-\mathrm{CT}$ & 384 & Air & $0-950$ & $\begin{array}{c}\mathrm{P} \\
2 \mathrm{~h}\end{array}$ & & & $\begin{array}{l}\text { none- } 1000 / \\
\text { none- } 120000\end{array}$ & \\
\hline $\begin{array}{l}\text { A4(b) Aging Effects on Fracture Toughness of GTA } \\
\text { Weld from Filler } 617 \text { Metal }\end{array}$ & $\begin{array}{l}0.5 \mathrm{~T}-\mathrm{CT} \\
\text { (GTA) }\end{array}$ & 384 & Air & $0-950$ & $\begin{array}{c}\mathrm{P} \\
1 \mathrm{~h}\end{array}$ & & & $\begin{array}{l}\text { none- } 1000 / \\
\text { none- } 120000\end{array}$ & test deposited and cross-welds \\
\hline A5 Determine Strain Rate Sensitivity in Support of UCM & Tensile & 45 & Air & $20-1000$ & $\begin{array}{c}\mathrm{P} \\
1 \mathrm{~h}\end{array}$ & & & & $2.5 \%$ strain range \\
\hline $\begin{array}{l}\text { A6 Torsion Test Matrix for Validating von Mises } \\
\text { Criterion to Support UCM }\end{array}$ & Tubular & 15 & Air & $600-1000$ & $\begin{array}{c}\mathrm{P} \\
1 \mathrm{~h}\end{array}$ & & & & \\
\hline A7 Stress Dip Matrix to Support UCM & Tensile & 27 & Air & $600-1000$ & $\begin{array}{c}\mathrm{P} \\
1 \mathrm{~h}\end{array}$ & & & & \\
\hline A8 Short-Term (Days) Creep Tests to Support UCM & Tensile & 27 & Air & $600-1000$ & $\begin{array}{c}\mathrm{P} \\
1 \mathrm{~h} \\
\end{array}$ & & & & \\
\hline A9 Uniaxial Ratcheting Tests to Support UCM & Tensile & 27 & Air & $600-1000$ & $\begin{array}{c}\mathrm{P} \\
1 \mathrm{~h} \\
\end{array}$ & & & & \\
\hline A10 Torsional Cycling w/ Constant Axial Strain for UCM & Tubular & 36 & Air & 850,950 & $\begin{array}{c}\mathrm{P} \\
1 \mathrm{~h} \\
\end{array}$ & $\begin{array}{c} \pm 1 \mathrm{E}-03 \\
\pm 1 \mathrm{E}-05 \text { shear }\end{array}$ & & & $0.0-0.3 \%$ axial strain range \\
\hline A11 Loading-Unloading-Creep Sequence for UCM & Tensile & 45 & Air & 600-1000 & $\begin{array}{c}\mathrm{P} \\
1 \mathrm{~h}\end{array}$ & & & & $\begin{array}{l}1 \mathrm{E}+00,1 \mathrm{E}-01,1 \mathrm{E}-02 \\
\mathrm{MPa} / \text { s load-unload rate }\end{array}$ \\
\hline A12 Thermomechanical Cycling for UCM & Fatigue & 18 & Air & 600,1000 & $\begin{array}{c}\mathrm{P} \\
1 \mathrm{~h} \\
\end{array}$ & $1 \mathrm{E}-05$ & & & $\begin{array}{l}0.6-1.8 \% \text { strain range } \\
\text { isothermal \& non-isothermal }\end{array}$ \\
\hline A13(a) Test Matrix for Creep Curves to Qualify UCM & Tensile & 24 & Air & 800-1000 & $\begin{array}{c}\mathrm{P} \\
1 \mathrm{~h}\end{array}$ & & $\begin{array}{l}4998-31615 \\
\text { est. rupture t }\end{array}$ & & 11-80 MPa applied $\sigma$ \\
\hline $\begin{array}{l}\text { A13(b) Stress Relaxation Test Matrix for Qualifying } \\
\text { UCM }\end{array}$ & Tensile & 24 & Air & $800-1000$ & $\begin{array}{c}\mathrm{P} \\
1 \mathrm{~h}\end{array}$ & & 6000-20000 relax. time & & 11-80 MPa (Initial) applied $\sigma$ \\
\hline $\begin{array}{l}\text { A14 Uniaxial Tests on Thermally aged Alloy } 617 \text { for } \\
\text { UCM }\end{array}$ & Tensile & 108 & Air & 750-1000 & $\begin{array}{c}\mathrm{P} \\
1 \mathrm{~h}\end{array}$ & & & $\begin{array}{l}750-1000 / \\
200-120000\end{array}$ & loading/unloading/creep strain rate change, stress dip testing \\
\hline
\end{tabular}


GENERATOR AND NCLEAR PLANT STEAM Identifie

EXCHANGER MATERIALS RESE HCA

Revision:

AND DEVELOPMENT PLAN

PLN-2804

Page: 104 of $\mathbf{2 5 2}$

Table 21. (continued).

Test Matrix

Shown in detail in Appendix

A15 Tube Burst Tests for Alloy 617 and Alloy $800 \mathrm{H}$

(w/ \& w/o welds \& notches)

A16 Creep-Fatigue Test Matrix for SMT Specimens

A17 Long Term Alloy 617 Creep-rupture Tests for

Qualification

A18 Thermal Aging Test Matrix for Strength Reduction Factors

A19 Fatigue Tests to Support Curve Development of

Alloy 617 Code Case

A20 Creep-Fatigue for Determination of Creep-Fatigue Interaction Diagram

A21 Determine " $C$ " Factor in Multiaxial Creep-rupture Strength Criterion for Alloy 617

\section{A22 Interrupted Creep Tests}

A23 Creep-Fatigue Saturation with Hold Time (ht)

A24 Test Matrix to Explore Creep Mechanisms of Alloy 617

A25 Determining Grain Size Rupture Factors for Alloy 617

A26 Tensile Tests Supporting UCM for Alloy 800H

A27 Weld Strength Rupture Factor for Alloy 800 Weldments

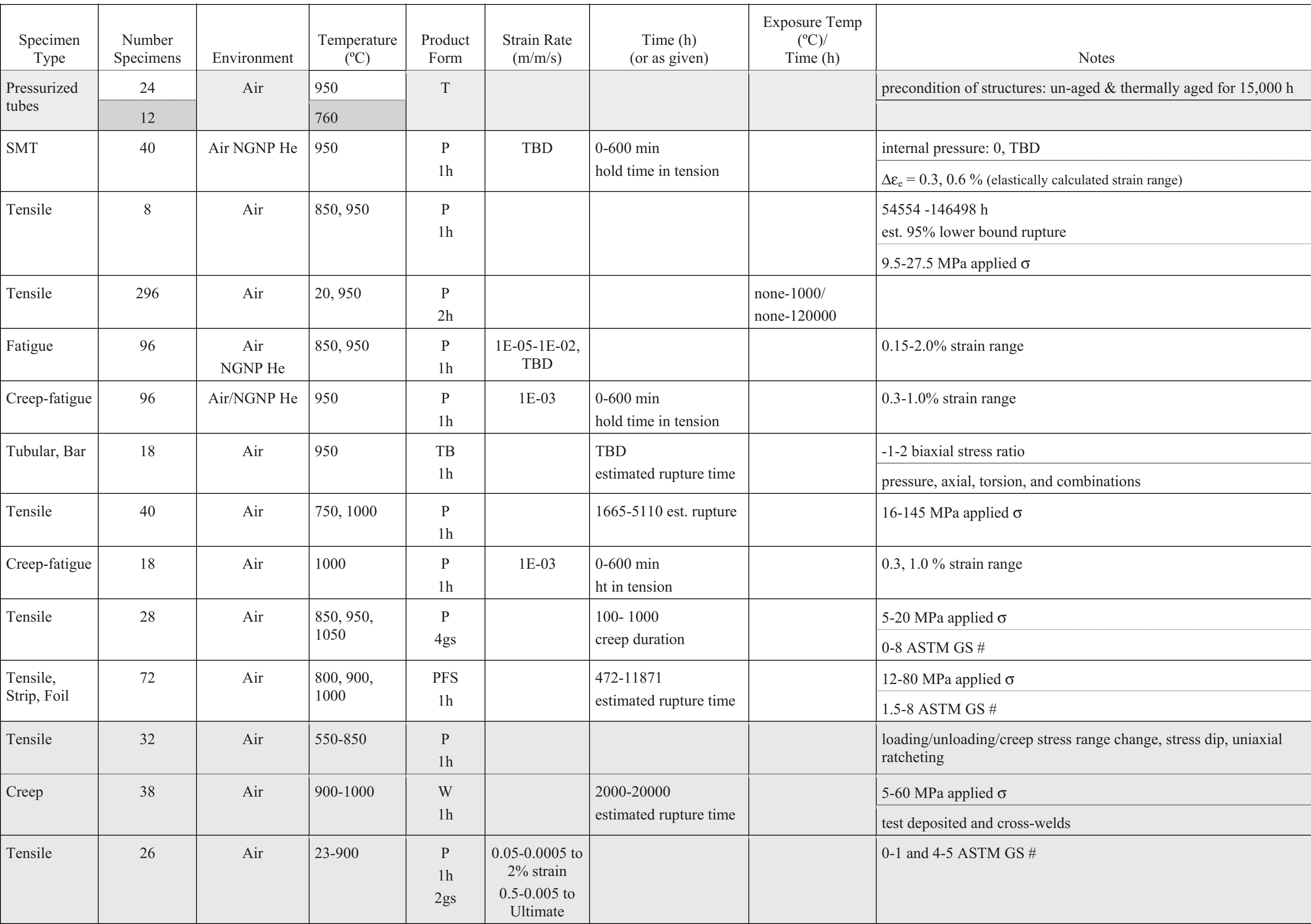


Idaho National Laboratory

\begin{tabular}{|l|l}
\hline NEXT GENERATION NUCLEAR PLANT STEAM & Identifier:
\end{tabular}

GENERATOR AND INTERMEDIATE HEAT Revision:

AND DEVELOPMENT PLAN

PLN-2804

AND DEVELOPMENT PLAN

Effective Date: $09 / 23 / 10$

Page: 105 of $\mathbf{2 5 2}$

Table 21. (continued).

\begin{tabular}{|c|c|c|c|c|c|c|c|c|}
\hline $\begin{array}{l}\text { Specimen } \\
\text { Type }\end{array}$ & $\begin{array}{c}\text { Number } \\
\text { Specimens }\end{array}$ & Environment & $\begin{array}{c}\text { Temperature } \\
\left({ }^{\circ} \mathrm{C}\right)\end{array}$ & $\begin{array}{l}\text { Product } \\
\text { Form }\end{array}$ & $\begin{array}{c}\text { Strain Rate } \\
(\mathrm{m} / \mathrm{m} / \mathrm{s})\end{array}$ & $\begin{array}{c}\text { Time (h) } \\
\text { (or as given) }\end{array}$ & $\begin{array}{c}\text { Exposure Temp } \\
\left({ }^{\circ} \mathrm{C}\right) / \\
\text { Time }(\mathrm{h})\end{array}$ & Notes \\
\hline Tensile & 14 & Air & $850,900,950$ & $\begin{array}{c}S \\
1 \mathrm{~h} 2 \mathrm{gs}\end{array}$ & & $\begin{array}{l}\text { 50-1000 } \\
\text { creep duration }\end{array}$ & & 5-20 MPa applied $\sigma$ \\
\hline Tensile & 60 & Air & $650,750,850$ & $\begin{array}{c}\mathrm{P} \\
1 \mathrm{~h}\end{array}$ & & & $\begin{array}{l}\mid \begin{array}{l}\text { none-850/ } \\
\text { none-70000 }\end{array} \\
\text { | }\end{array}$ & \\
\hline Tubular, Bar & 18 & Air & 850 & $\begin{array}{l}\text { TB } \\
1 \mathrm{~h}\end{array}$ & & $\begin{array}{l}\text { TBD } \\
\text { estimated rupture time }\end{array}$ & & TBD applied $\sigma$ \\
\hline $\begin{array}{l}\text { fs - product for } \\
\text { - heats } \\
\text { s - grain sizes }\end{array}$ & ns & $\begin{array}{l}\text { Alloy } 617 \\
\text { Alloy } 800 \mathrm{H} \\
\text { oth alloys }\end{array}$ & & & & & & \\
\hline
\end{tabular}

GTA - Gas tungsten arc welding $\quad \mathrm{B}$ - bar $\mathrm{P}$ - plate

UCM - Unified Constitutive Model F - foil $\mathrm{S}$ - strip

gs - grain size

both alloys 


\begin{tabular}{|c|lll|}
\hline $\begin{array}{c}\text { NEXT GENERATION NUCLEAR PLANT STEAM } \\
\text { GENERATOR AND INTERMEDIATE HEAT } \\
\text { EXCHANGER MATERIALS RESEARCH }\end{array}$ & Identifier: & PLN-2804 & \\
AND DEVELOPMENT PLAN & Effective Date: & $09 / 23 / 10$ & Page: 106 of 252 \\
\hline
\end{tabular}

\subsection{Subsection NH Temperature Regime}

For temperatures above $427^{\circ} \mathrm{C}$, the appropriate values for the time-independent allowable stress are under the jurisdiction of Subsection NH. An approach similar to that for establishing allowable stresses in Subsection NB should be recommended to the Task Force on Allowable Stresses of SG-ETD on the development of $S_{m}$ for Subsection NH, using existing Huntington Alloys tensile data and tensile data generated by the DOE/HTGR program. For planning purposes, a supplementary test matrix is given in Table A1 (in Appendix A) to accommodate any possible request for confirmatory tensile data from the Allowable Stresses Task Force. The Tensile Test Matrix for $S_{m}$ Confirmatory Testing will utilize 40 tensile specimens. The specimens will be tested in air at 10 different temperatures, to be determined. Two different product forms will be used. Results for some of the tests in this matrix are presented in Section 4.1.1.3.

While the time-dependent primary stress limits, $S_{m t}$, of Subsection NH is generally controlled by the creep properties rather than $S_{m}$ under sustained loadings at elevated temperatures, $S_{m}$ at elevated temperature is used to ensure no tensile failure owing to short duration loading at temperature, for example, during an earthquake.

\subsection{Strain Rate Effects}

Many test results, including those shown in Figure 13, Section 4.1.1.4 of this plan, have shown the tensile curves of Alloy 617 are highly dependent on strain rates, with flow stress increasing with strain rate at temperatures above $650^{\circ} \mathrm{C}$. Thus, strain rate will affect the values of $S_{m}$ in the temperature range of interest to NGNP hot gas piping and IHX components.

The full spectrum of strain rate effects on flow stress will be investigated in developing a unified constitutive model for Alloy 617 (see Section 7.1.3.1.4). Inelastic analyses on prototypical component geometry and transient will be performed using this unified constitutive model to scope out the range of prototypical strain rates encountered in components. To protect against various failure modes which depend on tensile properties, these results will be used to develop a procedure to account for the strain rate effects in protecting against different failure modes that depend on yield and tensile strengths.

\subsubsection{Tests to Determine Weld Strength Rupture Factor for Alloy 617 Code Case}

This effort addresses Item A2 in Table 17 of Section 5.4.

The WSRF is required in applying the creep-fatigue procedure in Subsection NH. WSRF is defined as the ratio of the creep-rupture strength of the weldment to that of the base metal. It is time and temperature dependent in general. If the creep-rupture strength of the weldment is higher than that of the base metal, WSRF is set to one.

Tests for both deposited filler metal and cross-weld using Gas Tungsten Arc (GTA) welding with filler metal 617 are required. Table A2 presents the test matrix that supports the WSRF determination. The test matrix to determine WSRF will utilize 66 weld test specimens. The specimens will be tested in air from 750 to $1000^{\circ} \mathrm{C}$. Applied stress will range from 8.5 to $135.0 \mathrm{MPa}$. Estimated rupture time ranges from 1349 to $60968 \mathrm{~h}$. Product form will be plate from a single heat (W-heat 1). The first part of the test program would generate creep-rupture data for determining the WSRF. Every attempt will be made to develop WSRFs in time to support the conceptual and preliminary design activities, using this data. The second part of the test program is comprised of very long-term creep tests. Data from these tests are needed to qualify the WSRFs for final design activities and to support final licensing approval. 


\begin{tabular}{|c|lll|}
\hline $\begin{array}{c}\text { NEXT GENERATION NUCLEAR PLANT STEAM } \\
\text { GENERATOR AND INTERMEDIATE HEAT }\end{array}$ & Identifier: & PLN-2804 & \\
EXCHANGER MATERIALS RESEARCH & Revision: & 1 & \\
AND DEVELOPMENT PLAN & Effective Date: & $09 / 23 / 10$ & Page: 107 of 252 \\
\hline
\end{tabular}

\subsubsection{Physical Properties to Support Alloy 617 Code Case}

This effort addresses Item A3 in Table 17 of Section 5.4.

The physical properties that will be measured to support the Alloy 617 Code Case are as follows:

- Values of the Young modulus from $850^{\circ} \mathrm{C}$ to $1000^{\circ} \mathrm{C}$ to supplement those from room temperature up to $850^{\circ} \mathrm{C}$, available in Section II.

- Poisson's ratio at $20^{\circ} \mathrm{C}$ and from $50^{\circ} \mathrm{C}$ to $1000^{\circ} \mathrm{C}$ in $25^{\circ} \mathrm{C}$ intervals.

- Instantaneous coefficient of thermal expansion at $20^{\circ} \mathrm{C}$ and from $50^{\circ} \mathrm{C}$ to $1000^{\circ} \mathrm{C}$ in $25^{\circ} \mathrm{C}$ intervals.

- Mean coefficient of thermal expansion in going from $20^{\circ} \mathrm{C}$ to indicated temperature, $\mathrm{T}$, where $\mathrm{T}=$ $50^{\circ} \mathrm{C}$ to $1000^{\circ} \mathrm{C}$ in $25^{\circ} \mathrm{C}$ intervals.

- Linear thermal expansion in going from $20^{\circ} \mathrm{C}$ to indicated temperature, $\mathrm{T}$, where $\mathrm{T}=50^{\circ} \mathrm{C}$ to $1000^{\circ} \mathrm{C}$ in $25^{\circ} \mathrm{C}$ intervals.

- Thermal conductivity (TC) at $20^{\circ} \mathrm{C}$ and from $50^{\circ} \mathrm{C}$ to $1000^{\circ} \mathrm{C}$ in $25^{\circ} \mathrm{C}$ intervals.

- Thermal diffusivity (TD) at $20^{\circ} \mathrm{C}$ and from $50^{\circ} \mathrm{C}$ to $1000^{\circ} \mathrm{C}$ in $25^{\circ} \mathrm{C}$ intervals.

- Density at $20^{\circ} \mathrm{C}$ and from $50^{\circ} \mathrm{C}$ to $1000^{\circ} \mathrm{C}$ in $25^{\circ} \mathrm{C}$ intervals.

Note that TC, TD, density and specific heat are related by:

$$
\mathrm{TD}=\frac{\mathrm{TC}}{\text { density } \times \text { specific heat }}
$$

\subsubsection{Isochronous Stress-Strain Curves}

This effort addresses Item A4 in Table 17 of Section 5.4.

The isochronous stress-strain curves are required design information and will be constructed to support development of the Alloy 617 Code Case once the unified constitutive model is developed. They are obtained by using a qualified material model to simulate uniaxial creep response under constant stress. Based on these series of creep curves for different constant stresses, the strains are cross-plotted with stresses for a fixed time, resulting in the isochronous stress-strain curve construction.

\subsubsection{Data Needs Originally Identified in Comments on Draft Alloy 617 Code Case}

\subsubsection{Assess Creep-Fatigue Procedure for Alloy 617 Welds}

This effort addresses Item B1 in Table 17 of Section 5.4 and NRC concerns 4 and 12 in Table 16 of Section 5.2.

The creep-fatigue procedure in Subsection NH is established based on creep-fatigue data for base metal. It does not have a separate creep-fatigue procedure for welds. Instead, a number of conservative requirements are relied upon including (1) limiting the inelastic accumulated strains to one-half the allowable strain limits for the base metal, (2) limiting the allowable fatigue at weldments to one-half the design cycles allowed for the base metal, and (3) reducing the allowable creep-rupture strength at weldments to a fraction of the base metal value through the WSRF when determining the time-to-rupture.

Thus, creep-fatigue data for Alloy 617 weldments are needed to assess the adequacy of the treatment of welds per the Subsection NH procedure under creep-fatigue conditions. They are also needed to ascertain that the weldment creep-fatigue performance is no worse than the parent base metal, 


\begin{tabular}{|c|lll|}
\hline $\begin{array}{c}\text { NEXT GENERATION NUCLEAR PLANT STEAM } \\
\text { GENERATOR AND INTERMEDIATE HEAT }\end{array}$ & Identifier: & PLN-2804 & \\
EXCHANGER MATERIALS RESEARCH & Revision: & 1 & \\
AND DEVELOPMENT PLAN & Effective Date: & $09 / 23 / 10$ & Page: 108 of 252 \\
\hline
\end{tabular}

"normalized" for lower creep-rupture strength of the weldment, to validate the design evaluation methodology. From a licensing perspective, the availability of the creep-fatigue data for welds will help to address NRC's basic concerns about weldment creep crack growth, etc., to verify overall conservatism of the design process.

Gas tungsten arc welding with Alloy 617 filler metal will be used to develop the weldment creep-fatigue data. Both deposited filler metal and cross-weld will be tested. The strain rate will be the same as that selected from the continuous fatigue task. Table A3 shows the test matrix with various hold times. Testing in NGNP helium is included in the test matrix to qualify the "helium benefit" in the creep-fatigue procedure as discussed in Section 7.1.4.7. The creep-fatigue test matrix for Alloy 617 welds will utilize 48 weld specimens. Half of the specimens will be tested in air while the other half will be tested in NGNP He. The specimens will be tested at $950^{\circ} \mathrm{C}$ at $1 \%$ strain. Hold times will range from 0 to 600 minutes. Product form will be plate from a single heat (W-heat 1). Some of the tension holds in the test matrix might be revised to compression holds when the test program commences.

\subsubsection{Environment Effect}

This effort addresses Item B2 in Table 17 of Section 5.4 and NRC concern 17 in Table 16 of Section 5.2.

Characterizing environmental effects on the microstructure and mechanical properties of Alloy 617 will continue. The substantial German programs from the 1980s have demonstrated that if the helium impurity chemistry is controlled to be slightly oxidizing, the material properties under HTGR helium are equivalent to those determined in air. Testing will continue under the NGNP program to complete characterizing the impact of decarburizing or carburizing conditions on the microstructure and properties of Alloy 617 for quasistatic conditions at one atmosphere pressure. Tensile and creep-rupture properties will be measured post-exposure to gas chemistries that are either decarburizing or carburizing to develop a qualitative understanding of the impact of these gas chemistries.

Gas velocities on the order of 50 to $75 \mathrm{~m} / \mathrm{s}$ are anticipated in some sections of the NGNP and it is possible that particulate will be entrained in the gas. When a component test loop becomes available, the impact of high velocity impure helium on the corrosion and erosion behavior of Alloy 617 will be characterized. This effort will be coordinated with the NGNP Heat Transport System Components Engineering Test Plan. ${ }^{71}$

\subsubsection{Synergistic Effect of Aging, Environment, Loading and Temperature}

This addresses Item B3 in Table 17 of Section 5.4.

Microstructural examination of relevant samples collected from other testing programs proposed in the TDP will be performed. After preliminary analysis a small program may be initiated to examine possible differences in microstructures for Alloy 617 samples that are aged (1) in air only, (2) in the NGNP environment, (3) under load in air, i.e., creep and stress relaxation tests, and (4) under load in NGNP helium.

\subsubsection{Characterize Aging Effects on Fracture Toughness}

This addresses Item B4 in Table 17 of Section 5.4 and NRC concern 18 in Table 16 of Section 5.2.

The formation of embrittling phases, e.g., gamma prime, during long-term thermal exposure of Alloy 617 in a certain temperature range (below the intended steady-state operating temperature for IHX components) has a negative impact on the toughness. Test matrices for fracture toughness testing of Alloy 617 base metal and GTA welds are shown in Tables A4(a) and A4(b), respectively. Results for some of the tests in test matrix A4(a) are presented in Section 4.1.1.8. Both deposited filler metal welds and cross-welds will be tested. The tests will be performed to the ASTM Standard E1820. E1820 permits 


\begin{tabular}{|c|lll|}
\hline $\begin{array}{c}\text { NEXT GENERATION NUCLEAR PLANT STEAM } \\
\text { GENERATOR AND INTERMEDIATE HEAT }\end{array}$ & Identifier: & PLN-2804 & \\
EXCHANGER MATERIALS RESEARCH & Revision: & 1 & \\
AND DEVELOPMENT PLAN & Effective Date: & $09 / 23 / 10$ & Page: 109 of 252 \\
\hline
\end{tabular}

the generation of test data that can be used either for J-R Curve or fracture toughness determination. The aging effects test matrix on fracture toughness of alloy 617 wrought metal will utilize 384 0.5-T-CT specimens. The specimens will be tested in air from 0 to $950^{\circ} \mathrm{C}$. Product form will be plate with two different heats (Aged -1, Aged -2). Exposure temperatures and times range from none to $1000^{\circ} \mathrm{C}$ and none to $120,000 \mathrm{~h}$.

The aging effects test matrix on fracture toughness of GTA weld from filler metal 617 will utilize 384 0.5T-CT weld specimens. The specimens will be tested in air from 0 to $950^{\circ} \mathrm{C}$. Product form will be plate with from a single heat (BM-1). Exposure temperatures and times range from none to $1000^{\circ} \mathrm{C}$ and none to $120,000 \mathrm{~h}$.

The planned thermal exposure times are $200 \mathrm{~h} ; 650 \mathrm{~h} ; 2000 \mathrm{~h} ; 5,300 \mathrm{~h}$; and 20,000 h for establishing the data to support conceptual and preliminary design activities. Longer thermal exposures of 32,000 h; $50,000 \mathrm{~h} ; 76,000 \mathrm{~h}$; and 120,000 $\mathrm{h}$ are planned to develop toughness data for qualifying the non-ductile failure design procedure.

A best effort was made to include adequate specimen counts in the test matrices to cover the change in the failure mode from ductile to brittle as thermal aging progresses. However, experience from aging test programs of this type suggests it is necessary to have ample aged materials to cover any emergent testing needs as the test program progresses over a long period.

\subsubsection{Design Methodology Issues for Alloy 617}

\subsubsection{Alloy 617 Unified Constitutive Model Development}

This effort addresses Items A4 and C1 in Table 17 of Section 5.4 and supports developing a new guideline for inelastic stress analysis similar to the Standard NE F9-5T. It also addresses NRC concern 10 in Table 16 of Section 5.2.

A literature survey has yielded two papers on unified constitutive equations for Alloy 617 for very high temperature applications. One was given by Schwertel et al. ${ }^{89}$ where models based on Roberson ${ }^{90}$ and Chaboche ${ }^{61}$ were developed, using the same dataset. The equations for both models are one-dimensional and capable of modeling cyclic response. The predictions from both models compared quite well with short-term data. Schwertel et al. gave preference to Chaboche's formulation as it is more amenable to finite element implementation.

The second unified model appeared in a paper by Corum and Blass ${ }^{69}$ who attributed the development of the unified constitutive model to ORNL's S.-J. Chang, whose model was based on Roberson's formulation. ${ }^{91}$ The Chang model was used to simulate creep curves at different temperatures and loads. The results were cross-plotted in the format of isochronous stress-strain curves to support the Draft Alloy 617 Code Case. The equations from the Chang model are also one-dimensional but as presented the equations do not accommodate load reversal, and hence cannot be used to model cyclic loading.

The Schwertel model (based on the Chaboche formulation) and the Chang model were used to simulate the creep tests preformed by GE. ${ }^{92}$ The time-to- $1 \%$ strain as computed from the two models under various applied loads and the test results are shown in Table 22. The comparisons are poor, even with allowance for data scatter. 


\begin{tabular}{|c|lll|}
\hline $\begin{array}{c}\text { NEXT GENERATION NUCLEAR PLANT STEAM } \\
\text { GENERATOR AND INTERMEDIATE HEAT }\end{array}$ & Identifier: & PLN-2804 & \\
EXCHANGER MATERIALS RESEARCH & Revision: & 1 & \\
AND DEVELOPMENT PLAN & Effective Date: & $09 / 23 / 10$ & Page: 110 of 252 \\
\hline
\end{tabular}

Table 22. Numerical simulation of creep tests.

\begin{tabular}{cccc}
\hline & \multicolumn{3}{c}{ Time to 1\% Total Strain (h) } \\
\cline { 2 - 4 } $\begin{array}{c}\text { Applied Load } \\
(\mathrm{MPa})\end{array}$ & Schwertel Model & Chang Model & GE Data \\
\hline 96.6 & 6.1 & 0.029 & 2.4 \\
79.3 & 8.5 & 0.059 & 16.5 \\
75.9 & 189 & 0.067 & 8.5 \\
72.4 & 469 & 0.086 & 20.5 \\
66.2 & 3091 & 0.12 & 26.0 \\
64.8 & 4819 & 0.14 & 13.8 \\
56.6 & 128300 & 0.29 & 55 to 1100 \\
\hline
\end{tabular}

A renewed effort in developing a new unified constitutive model for Alloy 617 is necessary. It is essential that the new unified constitutive model make accurate predictions, particularly for longer times, and be qualified by test data from key feature tests.

\subsection{General Framework for Unified Constitutive Model}

An extensive survey of unified constitutive models shows that all have the same basic form. Generally, each will have a "flow rule," which gives an expression for the inelastic strain rate, $\dot{\varepsilon}^{\text {in }}$, in terms of three internal variables: the back stress, $X$, the yield stress, $Y$, and the drag stress, $D$. An additional internal variable $Y^{*}$ can be introduced to model aging. Evolution equations in the form of first order differential equations are then defined for the internal variables. Each of these internal variables may be composed of one or several terms, and each new term brings with it its own additional material constants. For example, in one-dimensional form, the inelastic strain rate and the evolution of the back stress can be represented as:

$$
\begin{aligned}
& \dot{\mathcal{E}}^{\text {in }}=F\left[\left\langle\frac{|\sigma-X|-Y-Y^{*}}{D}\right\rangle\right] \operatorname{sign}(\sigma-X) \\
& \dot{X}=\underbrace{c \dot{\varepsilon}^{\text {in }}}_{\text {strain hardening }}-\overbrace{c \frac{\dot{\varepsilon}^{\text {in }} \mid X}{L}}^{c}-\underbrace{A|X|^{m-1} X}_{\text {static recovery }}
\end{aligned}
$$

where $\sigma$ is the stress, $F$ the flow function, \langle\rangle the Macaulay bracket, and $c, L, A$, and $m$ are material constants or functions.

\subsection{Alloy 617 Deformation Behaviors}

Table 23 summarizes the essential deformation/microstructural behaviors of Alloy 617 that are important to model. 


\begin{tabular}{|c|lll|}
\hline NEXT GENERATION NUCLEAR PLANT STEAM & Identifier: & PLN-2804 & \\
$\begin{array}{c}\text { GENERATOR AND INTERMEDIATE HEAT } \\
\text { EXCHANGER MATERIALS RESEARCH } \\
\text { AND DEVELOPMENT PLAN }\end{array}$ & Revision: & 1 & \\
Effective Date: & $09 / 23 / 10$ & Page: 111 of 252 \\
\hline
\end{tabular}

Table 23. Deformation/microstructural behaviors to be modeled by unified constitutive equations.

Deformation/Microstructural

Behaviors

Remarks

Strain rate sensitivity

Strain hardening and softening

Creep behavior

Stress relaxation

Ratcheting

Thermo-mechanical behavior

Hardening under different strain ranges

Microstructure effects
Stress-strain curves change significantly when strain rates are changed.

Significant hardening at low temperatures, and little hardening is observed in monotonic and cyclic tests at elevated temperatures.

Exhibits classical primary, secondary, and tertiary creep below $800^{\circ} \mathrm{C}$. Secondary creep (constant creep rate) is hardly noticeable at $800^{\circ} \mathrm{C}$ and above. After the initial primary regime, the creep rate increases gradually until rupture.

Important in modeling creep-fatigue interaction.

Very challenging to model but essential for application.

Model will be developed largely based on test data from constant temperature tests, but applications involve thermal transients (temperature change).

Increasing hardening under increasing strain amplitude cycling.

Grain coarsening, grain boundary migration, etc., affect yield and tensile strengths (aging).

\subsection{Finite Element Implementation of Unified Constitutive Equations}

Implementing the Alloy 617 unified constitutive equations in finite element solvers such as ABAQUS and ANSYS will be carried out so that the unified constitutive model can be used by designers to perform inelastic analyses. This will be an important task in supporting the development of analysis guidelines similar to the Nuclear Standard NE F9-5T.

It is also important to note that unified constitutive equations and finite element implementation methodology (i.e., time integration algorithm) need to be developed in an integrated manner. Frequently, unified constitutive equations developed without the consideration of time integration method are too stiff numerically to be solvable by the finite element method.

The hierarchical structure of the unified constitutive model will be exploited in the finite element implementation so that it is more straightforward to extend them to other candidate materials such as Alloy $800 \mathrm{H}$, hence reducing R\&D costs.

\subsection{Testing to Develop Unified Constitutive Equations}

Testing to support the development of unified constitutive equations for Alloy 617 can be divided into two groups, A and B. Tests in Group A last for a relatively short duration, from minutes to weeks, and are designed to probe the rate (time-dependent) response of Alloy 617. They include tests at different strain and stress rates, rate change, loading/unloading, cyclic, short-term creep and stress relaxation etc., all at uniform temperatures. Thermo-mechanical tests are also included in Group A. Data from testing in Group A will be used to set the material constants and material functions of the unified constitutive equations. 


\begin{tabular}{|c|lll|}
\hline NEXT GENERATION NUCLEAR PLANT STEAM & Identifier: & PLN-2804 & \\
$\begin{array}{c}\text { GENERATOR AND INTERMEDIATE HEAT } \\
\text { EXCHANGER MATERIALS RESEARCH } \\
\text { AND DEVELOPMENT PLAN }\end{array}$ & Revision: & 1 & \\
Effective Date: & $09 / 23 / 10$ & Page: 112 of 252 \\
\hline
\end{tabular}

However, as demonstrated by the results in Table 22, models based on short-term data need to be supplemented with longer-term data. The testing in Group B includes longer-term creep and stress relaxation tests and will provide such information for the Alloy 617 unified constitutive model.

Generating the test data from the same heat and product form, if possible, is advantageous to obtaining more consistent results by removing heat-to-heat and product-form variability. The required testing to support the development of the unified constitutive model for Alloy 617 is outlined below. Note that the test matrices are developed based on the best current information. Minor changes could take place as the testing program progresses.

\subsection{Strain Rate Change Tensile Tests}

These tensile tests are designed to obtain data to determine the strain rate sensitivity of Alloy 617 . A wide range of strain rates is sampled within a single test. The tests cover the full range of temperatures, from room temperature to $1000^{\circ} \mathrm{C}$. The following loading sequence is applied to each test:

1. Load at a constant strain rate of $1.0 \mathrm{E}-6 \mathrm{~m} / \mathrm{m} / \mathrm{s}$ until the total strain reaches $0.5 \%$.

2. Change to a constant strain rate of $1.0 \mathrm{E}-5 \mathrm{~m} / \mathrm{m} / \mathrm{s}$ and load to a total strain of $1 \%$.

3. Change to a constant strain rate of $1.0 \mathrm{E}-4 \mathrm{~m} / \mathrm{m} / \mathrm{s}$ and load to a total strain of $1.5 \%$.

4. Change to a constant strain rate of $1.0 \mathrm{E}-3 \mathrm{~m} / \mathrm{m} / \mathrm{s}$ and load to a total strain of $2 \%$.

5. Change to a constant strain rate of $1.0 \mathrm{E}-2 \mathrm{~m} / \mathrm{m} / \mathrm{s}$ and load to a total strain of $2.5 \%$.

6. Unload to zero load at a stress rate of $-0.1 \mathrm{MPa} / \mathrm{s}$.

The test matrix is presented in Table A5 and will utilize 45 tensile specimens. The specimens will be tested in air with a temperature range of 20 to $1000^{\circ} \mathrm{C}$. Total strain will be $2.5 \%$. Product form will be plate from a single heat (xyz-CF). Results for some of the tests in test matrix A5 are presented in Section 4.1.1.4.

\subsection{Strain Rate Change Torsion Tests}

These tests are designed to gather data on the strain rate sensitivity of Alloy 617. The data in shear will be used to verify whether the frequently used von Mises assumption, used to generalize one-dimensional constitutive equations to multi-dimensions, is adequate. Tubular specimens will be used as test articles to approximate uniform deformation in the cylinder wall. The loading sequence applied to each test is as follows:

1. Load at a constant shear rate of $1.0 \mathrm{E}-6 \mathrm{~m} / \mathrm{m} / \mathrm{s}$ until the total shear strain reaches $0.5 \%$.

2. Change to a constant shear rate of $1.0 \mathrm{E}-5 \mathrm{~m} / \mathrm{m} / \mathrm{s}$ and load to a total shear strain of $1 \%$.

3. Change to a constant shear rate of $1.0 \mathrm{E}-4 \mathrm{~m} / \mathrm{m} / \mathrm{s}$ and load to a total shear strain of $1.5 \%$.

4. Change to a constant shear rate of $1.0 \mathrm{E}-3 \mathrm{~m} / \mathrm{m} / \mathrm{s}$ and load to a total shear strain of $2 \%$.

5. Change to a constant shear rate of $1.0 \mathrm{E}-2 \mathrm{~m} / \mathrm{m} / \mathrm{s}$ and load to a total shear strain of $2.5 \%$.

6. Unload to zero load at a stress rate of $-0.1 \mathrm{MPa} / \mathrm{s}$.

The test matrix is given in Table A6 and will utilize 15 tubular specimens. The specimens will be tested in air with a temperature range of 600 to $1000^{\circ} \mathrm{C}$. Product form will be plate from a single heat (xyz-CF). 


\begin{tabular}{|c|lll|}
\hline NEXT GENERATION NUCLEAR PLANT STEAM & Identifier: & PLN-2804 & \\
$\begin{array}{c}\text { GENERATOR AND INTERMEDIATE HEAT } \\
\text { EXCHANGER MATERIALS RESEARCH } \\
\text { AND DEVELOPMENT PLAN }\end{array}$ & Revision: & 1 & \\
Effective Date: & $09 / 23 / 10$ & Page: 113 of 252 \\
\hline
\end{tabular}

\subsection{Stress Dip Tests}

These tensile tests are designed to obtain data for determining the materials constants related to the internal variables. During the stress dip period, the test samples a wide range of inelastic strain rates. The loading sequence applied to each test is as follows:

1. Load at a constant strain rate of $1.0 \mathrm{E}-6 \mathrm{~m} / \mathrm{m} / \mathrm{s}$ until the total strain reaches $0.5 \%$, then hold the total strain constant at $0.5 \%$ for a period of B hours, where B will be on the order of 6 to $12 \mathrm{~h}$, to be determined when the test program commences. The stress relaxes during this hold time, hence the term "stress dip."

2. At the end of the relaxation period, reload at a constant strain rate of $1.0 \mathrm{E}-5 \mathrm{~m} / \mathrm{m} / \mathrm{s}$ until the total strain reaches $1 \%$, then perform stress relaxation for B hours.

3. At the end of the relaxation period, reload at a constant strain rate of $1.0 \mathrm{E}-4 \mathrm{~m} / \mathrm{m} / \mathrm{s}$ until the total strain reaches $1.5 \%$, then perform stress relaxation for B hours.

4. At the end of the relaxation period, reload at a constant strain rate of $1.0 \mathrm{E}-3 \mathrm{~m} / \mathrm{m} / \mathrm{s}$ until the total strain reaches $2 \%$, then perform stress relaxation for B hours.

5. At the end of the relaxation period, reload at a constant strain rate of $1.0 \mathrm{E}-2 \mathrm{~m} / \mathrm{m} / \mathrm{s}$ until the total strain reaches $2.5 \%$, then perform stress relaxation for B hours.

6. Unload the tensile specimen to zero load at a stress rate of $-0.1 \mathrm{MPa} / \mathrm{s}$.

The test matrix is presented in Table A7 and will utilize 27 tensile specimens. The specimens will be tested in air with a temperature range of 600 to $1000^{\circ} \mathrm{C}$. Product form will be plate from a single heat (xyz-CF).

\subsection{Short-term Creep Tests}

These tensile tests are designed to obtain data for determining the materials constants related to the internal variables. The loading sequence applied to each test is as follows:

1. Load at a constant stress rate of $0.01 \mathrm{MPa} / \mathrm{s}$ until the stress reaches $\mathrm{X} 1 \mathrm{MPa}$, then hold the load constant for a period of B hours. The specimen will creep.

2. At the end of the creep period, reload at a constant stress rate of $0.05 \mathrm{MPa} / \mathrm{s}$ until the stress reaches $\mathrm{X} 2$ $\mathrm{MPa}$, then hold the load constant for a period of B hours.

3. At the end of the creep period, reload at a constant stress rate of $0.1 \mathrm{MPa} / \mathrm{s}$ until the stress reaches $\mathrm{X} 3$ $\mathrm{MPa}$, then hold the load constant for a period of B hours.

4. Unload the tensile specimen to zero load at a stress rate of $-0.1 \mathrm{MPa} / \mathrm{s}$.

The duration of short-term creep period, B, will be on the order of 6 to $12 \mathrm{~h}$. The stress levels X1, X2, and $\mathrm{X} 3$ are different for different test temperatures and scoping will be required to determine their values when the test program commences. Care will be taken to ensure that they do not exceed the corresponding tensile strengths. The test matrix is presented in Table A8 and will utilize 27 Alloy 617 tensile specimens. The specimens will be tested in air with a temperature range of 600 to $1000^{\circ} \mathrm{C}$. Product form will be plate from a single heat (xyz-CF).

\subsection{Uniaxial Ratcheting}

These ratcheting tests are designed to obtain data for determining the materials constants related to the internal variables. The loading sequence applied to each test is as follows: 


\begin{tabular}{|c|lll|}
\hline NEXT GENERATION NUCLEAR PLANT STEAM & Identifier: & PLN-2804 & \\
GENERATOR AND INTERMEDIATE HEAT & Revision: & 1 & \\
EXCHANGER MATERIALS RESEARCH & Effective Date: & $09 / 23 / 10$ & Page: 114 of 252 \\
AND DEVELOPMENT PLAN &
\end{tabular}

1. Preload at a constant strain rate of $1 . \mathrm{E}-3 \mathrm{~m} / \mathrm{m} / \mathrm{s}$ to a strain of $1 \%$. Unload to zero stress at a strain rate of $-1 . \mathrm{E}-3 \mathrm{~m} / \mathrm{m} / \mathrm{s}$.

2. Start at zero stress, load at a constant stress rate of $0.01 \mathrm{MPa} / \mathrm{s}$ to the stress level of X1 MPa, then unload to zero stress at a stress rate of $-0.01 \mathrm{MPa} / \mathrm{s}$. Repeat this loading/unloading sequence for $\mathrm{M}$ cycles.

3. Continue test and repeat Step 2 except with loading rate of $0.1 \mathrm{MPa} / \mathrm{s}$ and unloading at a stress rate of $-0.1 \mathrm{MPa} / \mathrm{s}$.

4. Continue test and repeat Step 2 except with loading rate of $1.0 \mathrm{MPa} / \mathrm{s}$ and unloading at a stress rate of $-1.0 \mathrm{MPa} / \mathrm{s}$.

The stress level X1 is equal to or slightly less than the maximum preload stress. It will be different for different test temperatures. The number of cycles, M, will be on the order of 20 . The test matrix is presented in Table A9 and will utilize 27 tensile specimens. The specimens will be tested in air with a temperature range of 600 to $1000^{\circ} \mathrm{C}$. Product form will be plate from a single heat (xyz-CF).

\subsection{Torsional Cycling with Constant Axial Strain}

These biaxial tests are designed to obtain data for determining the materials constants related to the internal variables. The loading sequence applied to each test is as follows:

1. Load specimen axially at a constant axial strain rate of $1 \mathrm{E}-3 \mathrm{~m} / \mathrm{m} / \mathrm{s}$ until $\mathrm{A} \%$ axial strain is reached. Hold axial strain at $\mathrm{A} \%$.

2. Torsionally cycle the specimen at the shear strain rates of $\pm \mathrm{T} \mathrm{m} / \mathrm{m} / \mathrm{s}$ and a shear strain range of $0.04 \%$ until hysteresis loops stabilize.

3. Increase the shear strain range to a value of $\mathrm{f}$ while torsionally cycle the specimen at the same shear strain rates of $\pm \mathrm{T} \mathrm{m} / \mathrm{m} / \mathrm{s}$ until hysteresis loops stabilize.

4. Execute Step 3 for $\mathrm{f}=0.1,0.2,0.3,0.4,0.5,0.6,0.7,0.8,0.9$, and $1 \%$, consecutive.

5. Perform Steps $1-4$ at $\mathrm{T}=1 . \mathrm{E}-3$, and for each of $\mathrm{A}=0,0.15,0.3$, respectively.

6. Repeat Steps $1-4$ at $\mathrm{T}=1 . \mathrm{E}-5$, and for each of $\mathrm{A}=0,0.15,0.3$, respectively.

The test matrix is presented in Table A10 and will utilize 36 tubular specimens. The specimens will be tested in air at 850 and $950^{\circ} \mathrm{C}$. Shear strain rates of $\pm 1 \mathrm{E}-03$ and $\pm 1 \mathrm{E}-05 \mathrm{~m} / \mathrm{m} / \mathrm{s}$ will be used ax axial strains of $0.00,0.15$, and $0.30 \%$. Product form will be plate from a single heat (xyz-CF).

\subsection{Tensile Loading-Unloading-Creep Sequence}

These tensile tests are designed to obtain data for determining the materials constants related to the internal variables. The loading sequence applied to each test is as follows:

1. Loading and unloading rates for each test are kept at the same magnitude of $\mathrm{YMPa} / \mathrm{s}$.

2. Load tensile specimen at constant stress rate $\mathrm{Y} \mathrm{MPa/s}$ until the stress reaches $\mathrm{X} \mathrm{MPa}$, then unload specimen at to a stress level equal to a fraction, $\mathrm{f}$, of $\mathrm{X}$ at the same stress rate magnitude. Let the specimen creep for B hours.

3. Perform Step 1 consecutively for $\mathrm{f}=0,0.1,0.2,0.3,0.4,0.5,0.6,0.65,0.7,0.75,0.8,0.85,0.9$, and 0.95 .

4. At the end of the last creep period, unload specimen to zero load.

5. Perform Steps 1-3 for $\mathrm{Y}=1$.E-2, 1.E-1, 1, respectively. 


\begin{tabular}{|c|lll|}
\hline $\begin{array}{c}\text { NEXT GENERATION NUCLEAR PLANT STEAM } \\
\text { GENERATOR AND INTERMEDIATE HEAT } \\
\text { EXCHANGER MATERIALS RESEARCH }\end{array}$ & Identifier: & PLN-2804 & \\
AND DEVELOPMENT PLAN & Effective Date: & $09 / 23 / 10$ & Page: 115 of 252 \\
\hline
\end{tabular}

The stress level $\mathrm{X}$ and the creep period $\mathrm{B}$ will be determined when the test program commences. It could be different for different temperature. Care will be taken to ensure that the stress $\mathrm{X}$ does not exceed the corresponding tensile strength.

Dependent on the stress level that the specimen is unloaded to, the creep rate during the creep period could be positive, zero, or negative, because the back stress lies somewhere below the flow curve and the inelastic strain rate is proportional to the sign of $(\sigma-\mathrm{X})$. Hence, if creep takes place at a stress level that is lower than the back stress, negative creep rate results. Otherwise, the creep rate could be zero or positive depending on whether the creep stress is equal to or greater than the back stress. The test matrix is presented in Table A11 and will utilize 45 tensile specimens. The specimens will be tested in air with a temperature range of 600 to $1000^{\circ} \mathrm{C}$. Loading-unloading rates of $1 \mathrm{E}-02,1 \mathrm{E}-01$, and $1 \mathrm{E}+00 \mathrm{MPa} / \mathrm{s}$ will be used. Product form will be plate from a single heat (xyz-CF).

\subsection{Thermomechanical Cycling Tests}

Out-of-phase thermomechanical cycling tests are proposed to determine the nonisothermal response of Alloy 617. Each specimen is cycled at a constant strain rate of $\mathrm{E} \mathrm{m} / \mathrm{m} / \mathrm{s}$ and a strain range of $\mathrm{y} \%$ for 100 cycles. The temperature is cycled between temperatures A1 and A2 and is out of phase with the strain cycles. The specific test parameters will be determined when the test program commences. Examples parameters are: strain rate $=1 . \mathrm{E}-5 \mathrm{~m} / \mathrm{m} / \mathrm{s}$, strain range $=0.6 \%, 1.2 \%$ and $1.8 \%, \mathrm{~A} 1=600^{\circ} \mathrm{C}, \mathrm{A} 2=$ $1000^{\circ} \mathrm{C}$. Baseline isothermal cycling data will also be required. A test matrix is presented in Table A12 and will utilize 18 fatigue specimens. The specimens will be tested in air using isothermal conditions at $600^{\circ}$ and $1000^{\circ} \mathrm{C}$ and non-isothermal at $600 / 1000^{\circ} \mathrm{C}$. A strain rate of $1 \mathrm{E}-05 \mathrm{~m} / \mathrm{m} / \mathrm{s}$ will be used over a strain range of 0.6 to $1.8 \%$. Product form will be plate from a single heat (xyz-CF).

\subsection{Creep and Relaxation Curves}

The short-term data discussed above will be used to determine the material constants. However, longer term creep and stress relaxation responses are needed to qualify the long-term predictability of the unified constitutive model. To support the early need dates of the conceptual/preliminary design activities, data from the data log at four-month intervals will be used to calibrate/fine-tune the material constants of the unified constitutive equations for Alloy 617. This is done to gain confidence in the unified constitutive equations to support conceptual/preliminary design activities.

Table A13(a) shows the test matrix for the creep tests. The estimated rupture times and their 95\% lower and upper bounds for the given applied stresses are tabulated in the table for reference. A total of 24 specimens will be tested in air at 800,900 , and $1000^{\circ} \mathrm{C}$. Applied stresses will range from 11 to $80 \mathrm{MPa}$. Estimated ruptures times for the specimens range from 4998 to $31615 \mathrm{~h}$. Product form will be plate from a single heat (xyz-CF). The test matrix for the stress relaxation tests is shown in Table A13(b) and will utilize 24 tensile specimens. The specimens will be tested in air at 800,900 , and $1000^{\circ} \mathrm{C}$. Initial stress values will range from 11 to $80 \mathrm{MPa}$. Product form will be plate from a single heat (xyz-CF).

\subsection{Thermal Aging Effects}

The data will be used to determine the influence of thermal aging on the material constants of the unified constitutive model. This effort also addresses NRC concern 19 in Table 16 of Section 5.2.

Alloy 617 undergoes thermal aging when exposed to elevated temperatures for long-time service. Tensile specimens prepared from thermally aged material will be used to perform (1) strain rate change tests, (2) stress dip tests, and (3) loading/unloading/creep tests at the aging temperatures.

Table A14 gives the test matrix utilizing 108 tensile specimens. The aging temperatures are 750,850 , 950 , and $1000^{\circ} \mathrm{C}$, and the exposure times are $200 ; 650 ; 2000 ; 5,300 ; 20,000 ; 32,000 ; 50,000 ; 76,000$; and $120,000 \mathrm{~h}$. The specimens will be tested in air with a temperature range of 750 to $1000^{\circ} \mathrm{C}$. Exposure 


\begin{tabular}{|c|lll|}
\hline NEXT GENERATION NUCLEAR PLANT STEAM & Identifier: & PLN-2804 & \\
GENERATOR AND INTERMEDIATE HEAT & Revision: & 1 & \\
EXCHANGER MATERIALS RESEARCH & Effective Date: & $09 / 23 / 10$ & Page: 116 of 252 \\
AND DEVELOPMENT PLAN &
\end{tabular}

temperature and times range from 750 to $1000^{\circ} \mathrm{C}$ and 200 to $120000 \mathrm{~h}$. Product form will be plate from a single heat (xyz-CF).

\subsubsection{Key Feature Testing}

This effort addresses Item C2 in Table 17 of Section 5.4.

Many of the design criteria in Subsection NH are based on material properties determined from specimen testing where the stress and deformation states are typically one-dimensional. However, these criteria are used in structural design to establish the theoretical structural adequacy of a particular component design configuration subjected to a particular set of loading conditions. The stress and deformation states in the structural components are generally multi-axial. Key feature testing is a way to bridge the gap between structural performance prediction by design methods which are established based on specimen testing, and the actual structural performance of the component as determined from component testing or actual service.

The idea behind a key feature test is to identify a particular failure mode(s) of interest and then identify a test article configuration and testing condition that will demonstrate the appropriateness of the criteria selected to guard against that failure mode. For example, in Subsection NH, in a cylindrical section remote from discontinuities, the material property parameter is the allowable stress based on the governing value of creep-rupture strength, creep rate or onset of tertiary creep. The criterion for protection against failure owing to internal pressure loading is the elastically calculated membrane stress intensity. An appropriate key feature test would be an internally pressurized cylinder operating in the creep regime. By measuring the time to failure, it can be determined whether the allowable stress used with the elastically calculated membrane stress provides an appropriate margin of safety.

Another use of the key feature test is to determine an allowable loading parameter, such as internal pressure, for use with a particular configuration that is too complex for reliable determination of an allowable value. Examples include using burst tests to determine the pressure-temperature rating of valve bodies, flanged joints and piping components. In this case, the results are sometimes incorporated in ASME Code design rules by reference to the appropriate component standard.

\subsection{Verification of Unified Constitutive Equations for Alloy 617}

Subsection NH, Appendix $\mathrm{T}$ is structured to permit using the results of elastic analyses to bound the effects of creep on strain, deformation and cyclic damage at elevated temperature. These elastic results are used in conjunction with simplified mechanistic models that are approximations of real component and material behavior; thus, the resultant design criteria are conservative, in some cases quite conservative. When the criteria based on elastic analyses cannot be satisfied, the potentially more accurate results of inelastic analyses can be used in conjunction with criteria based on using such analytical models. Generally, these criteria are less conservative than those based on elastic analyses.

The Simplified Model Test (SMT) can be used as a key feature test for evaluating the validity of inelastic analysis using the unified constitutive model for Alloy 617. The SMT incorporates elastic follow-up characteristics representative of the stress and strain redistribution occurring in more complex structures. However, unlike the complex structure, the SMT article is amenable to direct measurement of both stress and strain throughout the cyclic life, thus providing an excellent test bed for evaluating the unified constitutive equations for Alloy 617. As discussed in Section 7.1.3.4, SMT testing is part of the effort to remove unnecessary conservatism in the Subsection NH creep-fatigue procedure. Stress and strain measurements from those tests will be used to qualify the unified constitutive model for Alloy 617. 


\begin{tabular}{|c|lll|}
\hline $\begin{array}{c}\text { NEXT GENERATION NUCLEAR PLANT STEAM } \\
\text { GENERATOR AND INTERMEDIATE HEAT } \\
\text { EXCHANGER MATERIALS RESEARCH }\end{array}$ & Identifier: & PLN-2804 & \\
AND DEVELOPMENT PLAN & Effective Date: & $09 / 23 / 10$ & Page: 117 of 252 \\
\hline
\end{tabular}

\subsection{Model Tube Burst Tests - Alloy 617 and Alloy $800 H$}

This is envisioned as a series of model tube burst tests to demonstrate the adequacy of the criteria and adjusted allowable stress values to address NRC concerns for (a) long-term thermal aging and (b) crack initiation and subcritical crack growth, respectively. Note that these test results will also address NRC concern regarding weld integrity. Table A15 gives a test matrix that will utilize 24 Alloy 617 tube specimens and 12 Alloy $800 \mathrm{H}$ tube specimens. Internal tube pressures are to be determined. The specimens will be tube, tube with stressed welds and tube with stressed welds and Electrical Discharge Machining (EDM) slots. The specimens will be tested in air at $950^{\circ} \mathrm{C}$ (Alloy 617) and $760^{\circ} \mathrm{C}$ (Alloy $800 \mathrm{H})$. Pre-conditioning of the structures will be either un-aged or thermally aged at temperature for $15,000 \mathrm{~h}$.

\subsection{Vessel and Piping Ratcheting Tests - Alloy 617 and Alloy $800 \mathrm{H}$}

These tests address NRC concerns on whether the current simplified bounding methods in Appendix $\mathrm{T}$ of Subsection NH are appropriate not only for the geometry and conditions for which they were derived, a pressurized cylinder with cyclic linear through-the-wall thermal gradients, but also for the more general geometries and loading conditions for which they are currently permitted.

Prior testing has been done here and abroad for materials and geometries used in the Liquid Metal Fast Breeder Reactor (LMFBR) program, so part of this task is to assess those tests for applicability to NGNP. An issue not addressed in previous testing is the effect of strain rate-dependent yield strength at high to very high temperatures on creep ratcheting models. Also, continuing improvements are being developed for bounding techniques for strain limits owing to cyclic loading. These tests results can also be used to verify these new technologies.

\subsection{Reference Stress Verification Tests - Alloy 617 and Alloy $800 H$}

Subsection NH currently relies on the results of elastic analysis and stress classification to establish required wall thicknesses, not only for simple cylindrical geometries but also for more complex geometries such as vessel nozzles subjected to both internal pressure and external piping loads.

To avoid undue conservatism using the results of detailed elastic finite element analysis, it is necessary to categorize the results into stress components relevant to the failure mode under consideration. For complex structures and loading, this process is more of an art than a science and is fraught with opportunities for error.

Another problem with the current approach is that it does not take into consideration the extra load capacity of redundant structures. These objections can be addressed by reference stress methods that do not require stress classification and do consider redundancy. Currently used in British nuclear elevated temperature structural design criteria, there has been limited key feature testing to demonstrate the validity of reference stress methods, but apparently no tests consider significantly unbalanced systems or those with combined loading.

\subsubsection{More General Simplified Methods}

This is in the nature of generic issues for all of Subsection NH. New work in the Task 9 of the DOE/ASME Gen IV Materials Project will address this issue. Recommended testing from the task will be assessed and tests relevant to NGNP will be proposed.

\subsubsection{Improve Alloy 617 Creep-Fatigue Procedure}

This effort addresses Item C4 in Table 17 of Section 5.4 and NRC concern 22 in Table 16 of Section 5.2. 


\begin{tabular}{|c|lll|}
\hline $\begin{array}{c}\text { NEXT GENERATION NUCLEAR PLANT STEAM } \\
\text { GENERATOR AND INTERMEDIATE HEAT }\end{array}$ & Identifier: & PLN-2804 & \\
EXCHANGER MATERIALS RESEARCH & Revision: & 1 & \\
AND DEVELOPMENT PLAN & Effective Date: & $09 / 23 / 10$ & Page: 118 of 252 \\
\hline
\end{tabular}

The current Subsection NH creep-fatigue procedure was established by (1) analytically obtaining a detailed stress-strain history, (2) comparing the stress and strain components to cyclic test results deconstructed into stress and strain quantities, and (3) recombining the results to obtain a damage function. Instead of these steps, elastic follow-up testing uses a simplified model of the structure to determine the cyclic life experimentally — thus the name "Simplified Model Test" or "SMT" approach.

Subject to the constraints and procedures identified in Jetter, the approach reduces to a procedure similar to that used in the early elevated temperature ASME Code cases where creep damage owing to pure stress relaxation was built into the cyclic design life curves. However, those curves did not account for the increase in strain range owing to strain redistribution (elastic follow-up) nor did they account for the retardation of stress relaxation and resulting increase in creep damage during the cycle owing to the higher stress history. These two effects were compensated by conservative assumptions that undoubtedly resulted in large and sometimes unworkable conservatism in the Subsection NH rules based on elastic analysis. In the SMT approach, the strain range enhancement and retardation of stress relaxation are built into the test results and do not require the previous conservative assumptions. The rational for the follow-up test specimen and test procedure is a major feature of the approach. ${ }^{93}$

A key feature of the SMT approach is the test procedure in which the controlled input is displacement, not strain. Practically, this means it is necessary to accurately measure and control the relative displacement of the ends of the test section. Figure 45 shows a sketch of a SMT specimen, sized for Alloy 617 with an elastic follow-up factor in the range of 3.5 to 4.0. It is the longer, thicker sections on either end that supply the elastic follow-up to the center section. The relative displacement of the ends is analogous to the relative thermal displacement in an actual component. The cylindrical specimen shown has the added advantage that sustained loading caused by internal pressure can be superimposed on the displacement-controlled axial loading to more fully model actual component behavior. The results of elastically predicted stress and strain in the test specimen are analogous to the elastically predicted stress and strain in the component. Thus, test results are tabulated as cycles to failure versus the elastically calculated strain from the applied displacement, not a measured strain as is the procedure in a conventional test.

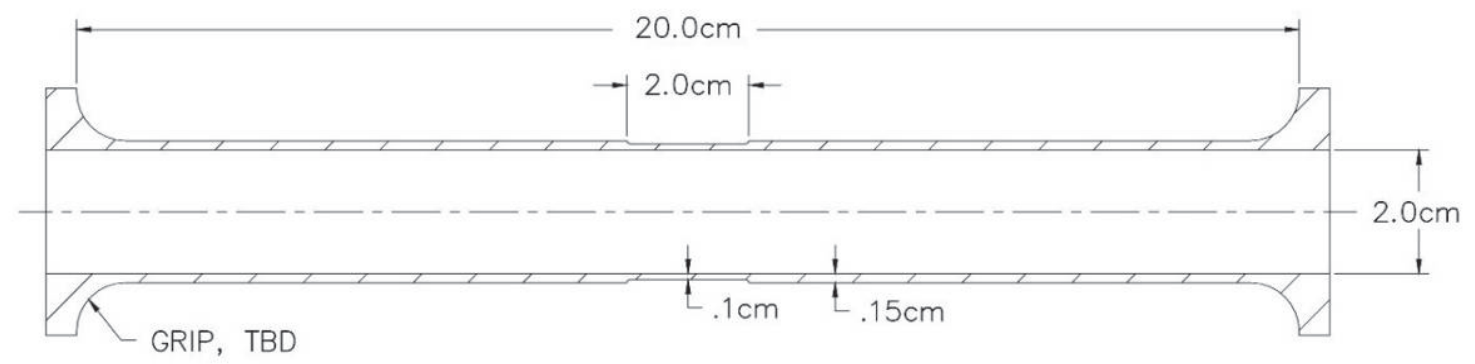

Figure 45. Sketch of SMT specimen with an elastic follow-up factor of $\sim 3.7$.

In its simplest form, only the elastically computed strain and the cyclic life at a given temperature are required parameters from an SMT approach test. However, because the load and areas are readily known, if strains are measured, the test results also provide an accurate vehicle for calibrating or verifying the results of a full-scale inelastic analysis and failure prediction in a specimen with representative strain redistribution.

Table A16 shows a test matrix for generating creep-fatigue data using 40 SMT specimens. The strain rate $\mathrm{S} 1$ listed in the table will be selected from the strain-rate study of the continuous fatigue task. Half 


\begin{tabular}{|c|lll|}
\hline $\begin{array}{c}\text { NEXT GENERATION NUCLEAR PLANT STEAM } \\
\text { GENERATOR AND INTERMEDIATE HEAT }\end{array}$ & Identifier: & PLN-2804 & \\
EXCHANGER MATERIALS RESEARCH & Revision: & 1 & \\
AND DEVELOPMENT PLAN & Effective Date: & $09 / 23 / 10$ & Page: 119 of 252 \\
\hline
\end{tabular}

the specimens will be tested in air while the second half will be tested in NGNP He. Both sets will be tested at $950^{\circ} \mathrm{C}$. Strain rate and internal pressure is TBD. All specimens will be held in tension with hold times ranging from 0 to 600 minutes. The $\Delta \varepsilon_{\mathrm{e}}$ (elastically calculated strain range in percent) will be 0.3 and 0.6. Product form will be plate from a single heat (xyz-CF).

Testing in NGNP helium environment is proposed to obtain data to support the inclusion of a less restrictive design curve in the Alloy 617 Code Case. The stresses and strains measured from the SMT specimens will be used as key feature test results to qualify the Alloy 617 unified constitutive equations.

\subsubsection{Additional Issues to Update Alloy 617 Data for Subsection NH}

\subsubsection{Time-Dependent Allowable Stresses}

This effort addresses Item D1 in Table 18 of Section 5.4.

The ASME Section III Subsection NH criteria for estimating the time-dependent allowable stress $S_{t}$ include (1) the average strength for $1 \%$ total strain, (2) $80 \%$ of the minimum strength for tertiary creep, and (3) $67 \%$ of the minimum rupture strength values. The Draft Alloy 617 Code Case had established the time-dependent allowable stress $S_{t}$ based only on criteria (1) and (3) and for 100,000 h.

While the design life of NGNP is 60 years, it is highly unlikely that the material properties are sufficient to support this goal for the IHX. It is likely that the IHX will be designed for replacement during the lifetime of the plant. The design goal for the replaceable IHX is a lifetime longer than 100,000 h. The hot-gas piping, while not as severely stressed as the IHX components, will likely be designed as a nonreplaceable component for the full NGNP design life. Thus in either case, the time-dependent allowable stresses in the Draft Alloy 617 Code Case would have to be extended.

The time-dependent allowable stresses in the Draft Alloy 617 Code Case were established using a database developed by Huntington Alloys. Table 24 presents a summary of the Huntington database. The longest creep-rupture time is about 40,000 $\mathrm{h}$. Because the required data to support the establishment of time-dependent allowable stresses take a very long time to develop, it would severely impact the schedule of conceptual and preliminary design activities if new creep tests longer than 40,000 h are relied upon to support these activities.

Table 25 and Table 26 give a summary of the datasets developed by General Electric under the DOE HTGR program and by ORNL, respectively. The Huntington, General Electric and ORNL data are currently accessible in the Gen IV Materials Handbook. Table 27 and Table 28 summarize two large European databases from the ECCC and the ODIN database of the Joint Research Centre (JRC) of the European Commission at Petten, the Netherlands. While details of the creep-rupture times from the Petten database are not currently available, efforts are being made through the GIF to obtain these data. The size of this database is substantially larger than the combined dataset from the Huntington, General Electric and ORNL databases.

Table 24. Huntington Alloys creep-rupture data for Alloy 617 in air.

\begin{tabular}{|c|c|c|c|c|c|c|c|c|c|}
\hline \multicolumn{10}{|c|}{ Huntington Alloys Database ${ }^{45}$} \\
\hline $\begin{array}{l}\text { Temp } \\
\left({ }^{\circ} \mathrm{C}\right)\end{array}$ & \multicolumn{5}{|c|}{$\begin{array}{l}\text { Number of tests with specified durations } \\
\text { (unfailed tests in parenthesis) }\end{array}$} & \multirow{2}{*}{$\begin{array}{l}\text { Max. } \\
\text { Rupture } \\
\text { Duration } \\
\text { (h) }\end{array}$} & \multirow{2}{*}{$\begin{array}{c}\text { Max. } \\
\text { Duration of } \\
\text { Unfailed } \\
\text { Test (h) }\end{array}$} & \multirow{2}{*}{$\begin{array}{l}\text { Min. } \\
\text { Applied } \\
\text { Stress } \\
(\mathrm{MPa})\end{array}$} & \multirow{2}{*}{$\begin{array}{l}\text { Max. } \\
\text { Applied } \\
\text { Stress } \\
(\mathrm{MPa})\end{array}$} \\
\hline & $<10 \mathrm{kh}$ & $\begin{array}{c}10- \\
20 \mathrm{kh}\end{array}$ & $\begin{array}{c}20- \\
30 \mathrm{kh}\end{array}$ & $\begin{array}{l}30- \\
40 \mathrm{kh}\end{array}$ & $\begin{array}{l}40- \\
50 \mathrm{kh}\end{array}$ & & & & \\
\hline 593 & 5 & 0 & 2 & 0 & 0 & 28,735 & & 324.1 & 537.8 \\
\hline 649 & $16(3)$ & (2) & 1 & 0 & 0 & 24,482 & 16,562 & 241.3 & 517.1 \\
\hline 704 & 6 & (1) & 1 & 0 & 0 & 20,023 & 15,700 & 137.9 & 310.3 \\
\hline 760 & $14(4)$ & $2(2)$ & 0 & (1) & 1 & 40,127 & 35,647 & 62.1 & 255.1 \\
\hline
\end{tabular}


Idaho National Laboratory

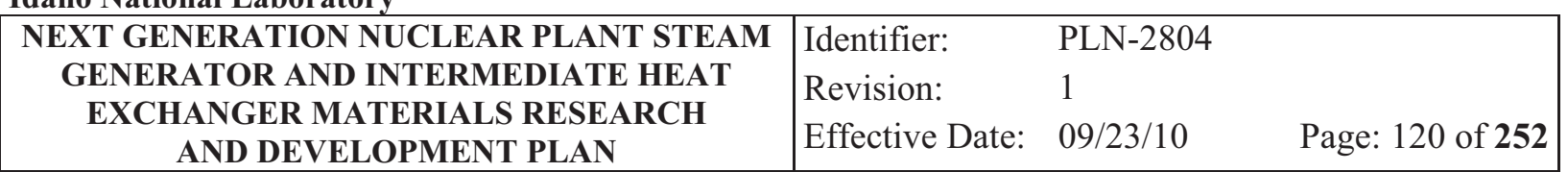

\begin{tabular}{|c|c|c|c|c|c|c|c|c|c|}
\hline \multicolumn{10}{|c|}{ Huntington Alloys Database ${ }^{45}$} \\
\hline \multirow[t]{2}{*}{$\begin{array}{l}\text { Temp } \\
\left({ }^{\circ} \mathrm{C}\right)\end{array}$} & \multicolumn{5}{|c|}{$\begin{array}{l}\text { Number of tests with specified durations } \\
\text { (unfailed tests in parenthesis) }\end{array}$} & \multirow{2}{*}{$\begin{array}{c}\text { Max. } \\
\text { Rupture } \\
\text { Duration } \\
\text { (h) }\end{array}$} & \multirow{2}{*}{$\begin{array}{c}\text { Max. } \\
\text { Duration of } \\
\text { Unfailed } \\
\text { Test (h) }\end{array}$} & \multirow{2}{*}{$\begin{array}{l}\text { Min. } \\
\text { Applied } \\
\text { Stress } \\
(\mathrm{MPa})\end{array}$} & \multirow{2}{*}{$\begin{array}{l}\text { Max. } \\
\text { Applied } \\
\text { Stress } \\
\text { (MPa) }\end{array}$} \\
\hline & $<10 \mathrm{kh}$ & $\begin{array}{c}10- \\
20 \mathrm{kh}\end{array}$ & $\begin{array}{c}20- \\
30 \mathrm{kh}\end{array}$ & $\begin{array}{c}30- \\
40 \mathrm{kh} \\
\end{array}$ & $\begin{array}{c}40- \\
50 \mathrm{kh}\end{array}$ & & & & \\
\hline 816 & $22(1)$ & 1 & 0 & 0 & 0 & 19,008 & 3,023 & 55.2 & 165.5 \\
\hline 871 & $41(20)$ & 3 & $(1)$ & 0 & 0 & 3,552 & 26,680 & 21.4 & 117.2 \\
\hline 927 & $3(3)$ & 0 & 0 & 0 & 0 & 1,590 & 3,000 & 27.6 & 89.6 \\
\hline 982 & $14(11)$ & 0 & 0 & 0 & 0 & 4,788 & 3,088 & 12.4 & 48.3 \\
\hline 1000 & $12(6)$ & 0 & 0 & 0 & 0 & 3,552 & 5,466 & 10.3 & 34.5 \\
\hline 1038 & 5 & 0 & 0 & 0 & 0 & 2,621 & & 13.8 & 41.4 \\
\hline 1093 & $24(7)$ & 0 & 0 & 0 & 0 & 5,323 & 1,612 & 6.2 & 20.7 \\
\hline Total & $162(55)$ & $6(5)$ & $4(1)$ & $(1)$ & 1 & \multicolumn{4}{|c|}{ Total data $=173(62)$} \\
\hline
\end{tabular}

Table 25. General Electric creep-rupture data for Alloy 617 in air.

\begin{tabular}{|c|c|c|c|c|c|c|c|c|}
\hline \multicolumn{9}{|c|}{ General Electric Dataset, ${ }^{92}$ Gen IV Materials Handbook } \\
\hline \multirow[b]{2}{*}{$\begin{array}{l}\text { Temp } \\
\left({ }^{\circ} \mathrm{C}\right)\end{array}$} & \multicolumn{5}{|c|}{ Number of tests with specified durations } & \multirow[b]{2}{*}{$\begin{array}{l}\text { Max. rupture } \\
\text { duration (h) }\end{array}$} & \multirow[b]{2}{*}{$\begin{array}{l}\text { Min. applied } \\
\text { stress (MPa) }\end{array}$} & \multirow[b]{2}{*}{$\begin{array}{l}\text { Max. applied } \\
\text { stress (MPa) }\end{array}$} \\
\hline & $<1 \mathrm{kh}$ & $1-3 \mathrm{kh}$ & $3-10 \mathrm{kh}$ & $\begin{array}{l}10-20 \\
\mathrm{kh}\end{array}$ & $\begin{array}{l}20-30 \\
\text { kh }\end{array}$ & & & \\
\hline 750 & 1 & 0 & 0 & 0 & 0 & 625 & 200 & 200 \\
\hline 850 & 4 & 3 & 2 & 1 & 0 & 12,207 & 44.8 & 96.6 \\
\hline 950 & 5 & 3 & 1 & 0 & 1 & 22,188 & 20.7 & 55.2 \\
\hline 1050 & & 1 & 2 & 0 & 0 & 9,285 & 10.7 & 20.7 \\
\hline 1100 & 1 & 0 & 0 & 0 & 0 & 723 & 15.2 & 15.5 \\
\hline Total & 11 & 7 & 5 & 1 & 1 & \multicolumn{3}{|c|}{ Total Data $=25$} \\
\hline
\end{tabular}

Table 26. ORNL creep-rupture data for Alloy 617 in air.

\begin{tabular}{|c|c|c|c|c|c|c|c|c|c|}
\hline \multicolumn{10}{|c|}{ ORNL Dataset, Gen IV Materials Handbook } \\
\hline $\begin{array}{c}\text { Temp } \\
\left({ }^{\circ} \mathrm{C}\right)\end{array}$ & \multicolumn{6}{|c|}{ Number of tests with specified durations } & \multirow{2}{*}{$\begin{array}{c}\text { Max. } \\
\text { rupture } \\
\text { duration } \\
\text { (h) }\end{array}$} & \multirow{2}{*}{$\begin{array}{c}\text { Min. } \\
\text { applied } \\
\text { stress } \\
(\mathrm{MPa}) \\
\end{array}$} & \multirow{2}{*}{$\begin{array}{c}\text { Max. } \\
\text { applied } \\
\text { stress } \\
(\mathrm{MPa}) \\
\end{array}$} \\
\hline & $<1 \mathrm{kh}$ & $1-3 \mathrm{kh}$ & $3-10 \mathrm{kh}$ & $\begin{array}{c}10-20 \\
\mathrm{kh}\end{array}$ & $\begin{array}{c}20-30 \\
\mathrm{kh}\end{array}$ & $30-50 \mathrm{kh}$ & & & \\
\hline 593 & 0 & 1 & 1 & 0 & 0 & 0 & 3,570 & 345 & 414 \\
\hline 649 & 1 & 1 & 0 & 0 & 1 & 0 & 25,566 & 276 & 276 \\
\hline 704 & 0 & 1 & 0 & 0 & 0 & 0 & 2,621 & 207 & 207 \\
\hline 750 & 1 & 0 & 0 & 0 & 0 & 0 & 625 & 200 & 200 \\
\hline 760 & 0 & 1 & 0 & 0 & 1 & 0 & 20,702 & 103 & 138 \\
\hline 850 & 4 & 3 & 2 & 1 & 0 & 0 & 12,207 & 44.8 & 96.6 \\
\hline 871 & 1 & 0 & 0 & 0 & 0 & 1 & 34,231 & 35 & 69 \\
\hline 950 & 5 & 3 & 1 & 0 & 1 & 0 & 22,188 & 20.7 & 55.2 \\
\hline 1050 & 0 & 1 & 2 & 0 & 0 & 0 & 9,285 & 10.7 & 20.7 \\
\hline 1100 & 1 & 0 & 0 & 0 & 0 & 0 & 723 & 15.2 & 15.2 \\
\hline Total & 13 & 11 & 6 & 1 & 3 & 1 & Total Da & $=35$ & \\
\hline
\end{tabular}


Idaho National Laboratory

\begin{tabular}{|c|lll|}
\hline $\begin{array}{c}\text { NEXT GENERATION NUCLEAR PLANT STEAM } \\
\text { GENERATOR AND INTERMEDIATE HEAT }\end{array}$ & Identifier: & PLN-2804 & \\
EXCHANGER MATERIALS RESEARCH & Revision: & 1 & \\
AND DEVELOPMENT PLAN & Effective Date: & $09 / 23 / 10$ & Page: 121 of 252 \\
\hline
\end{tabular}

Table 27. European Creep Collaborative Committee creep-rupture data for Alloy 617 in air.

\begin{tabular}{|c|c|c|c|c|c|c|c|c|c|c|}
\hline \multicolumn{11}{|c|}{ European Creep Collaborative Committee (ECCC) Database ${ }^{94}$} \\
\hline \multirow[t]{2}{*}{$\begin{array}{c}\text { Temp } \\
\left({ }^{\circ} \mathrm{C}\right)\end{array}$} & \multicolumn{7}{|c|}{$\begin{array}{l}\text { Number of tests with specified durations } \\
\text { (unfailed tests in parenthesis) }\end{array}$} & \multirow{2}{*}{$\begin{array}{l}\text { Max. } \\
\text { rupture } \\
\text { duration } \\
\text { (h) }\end{array}$} & \multirow{2}{*}{$\begin{array}{l}\text { Min. } \\
\text { applied } \\
\text { stress } \\
(\mathrm{MPa})\end{array}$} & \multirow{2}{*}{$\begin{array}{c}\text { Max. } \\
\text { applied } \\
\text { stress } \\
(\mathrm{MPa})\end{array}$} \\
\hline & $<1 \mathrm{kh}$ & $1-3 \mathrm{kh}$ & $\begin{array}{c}3-10 \\
\mathrm{kh}\end{array}$ & $\begin{array}{c}10-20 \\
\text { kh }\end{array}$ & $\begin{array}{c}20-30 \\
\mathrm{kh}\end{array}$ & $\begin{array}{c}30-50 \\
\text { kh }\end{array}$ & $\begin{array}{c}50-70 \\
\mathrm{kh}\end{array}$ & & & \\
\hline 595 & 3 & 1 & 1 & & 2 & & & 28,500 & 332 & 540 \\
\hline 600 & 2 & 2 & 2 & 1 & & & & 10,355 & 330 & 480 \\
\hline 650 & 11 & 5 & $5(2)$ & $(1)$ & (1) & $(1)$ & & 9,660 & 201 & 201 \\
\hline 700 & 2 & & & 1 & & & & 19,926 & 100 & 298 \\
\hline 750 & 6 & 3 & 3 & & & & & 9,986 & 110 & 301 \\
\hline 800 & 3 & 1 & & & & & & 2,500 & 81 & 303 \\
\hline 850 & 27 & 13 & $15(3)$ & 2 & (3) & $2(3)$ & (2) & 40,321 & 36 & 198 \\
\hline 900 & 9 & 3 & 4 & 1 & & & & 12,302 & 30 & 81 \\
\hline 950 & 13 & 9 & 7 & 2 & & & & 15,036 & 15 & 40 \\
\hline 1000 & 11 & 6 & 8 & $2(1)$ & 1 & $1(4)$ & & 41,747 & 4.1 & 50 \\
\hline 1100 & 1 & 1 & & (1) & & & & 1,022 & 10.3 & 15 \\
\hline Total & 88 & 44 & $45(5)$ & $9(3)$ & $3(4)$ & $3(8)$ & (2) & Total Data & $=192(22$ & \\
\hline
\end{tabular}

Table 28. Petten creep-rupture data for Alloy 617 in air.

\begin{tabular}{|c|c|c|c|c|c|c|c|c|c|}
\hline \multicolumn{10}{|c|}{ Petten Database, From ODIN at JRC of European Commission, Petten, the Netherlands ${ }^{95}$} \\
\hline \multirow[b]{2}{*}{ Source } & \multirow[b]{2}{*}{$\begin{array}{l}\text { Material } \\
\text { Type }\end{array}$} & \multirow[b]{2}{*}{$\begin{array}{c}\text { Total } \\
\text { No. of } \\
\text { Tests }\end{array}$} & \multicolumn{7}{|c|}{ Number of creep tests in temperature intervals } \\
\hline & & & $\begin{array}{l}<500 \\
{ }^{\circ} \mathrm{C}\end{array}$ & $\begin{array}{c}500^{\circ} \mathrm{C} \\
\text { to } \\
600^{\circ} \mathrm{C}\end{array}$ & $\begin{array}{c}600^{\circ} \mathrm{C} \\
\text { to } \\
700^{\circ} \mathrm{C}\end{array}$ & $\begin{array}{c}700^{\circ} \mathrm{C} \\
\text { to } \\
800^{\circ} \mathrm{C}\end{array}$ & $\begin{array}{l}800^{\circ} \mathrm{C} \\
\text { to } \\
900^{\circ} \mathrm{C}\end{array}$ & $\begin{array}{c}900^{\circ} \mathrm{C} \\
\text { to } \\
1000^{\circ} \mathrm{C}\end{array}$ & $>1000^{\circ} \mathrm{C}$ \\
\hline $\begin{array}{l}\text { FZJ - } \\
\text { COST/MATFO }\end{array}$ & Base Metal & 267 & 0 & 13 & 26 & 29 & 99 & 64 & 36 \\
\hline $\begin{array}{l}\text { FZJ - HTR - } \\
617\end{array}$ & Base Metal & 1134 & 0 & 58 & 71 & 173 & 506 & 326 & 0 \\
\hline $\begin{array}{l}\text { PE - TUD - } \\
\text { Alloy } 617\end{array}$ & Base Metal & 60 & 0 & 7 & 33 & 20 & 0 & 0 & 0 \\
\hline $\begin{array}{l}\text { FZJ - HTR - } \\
617\end{array}$ & $\begin{array}{l}\text { Base Metal } \\
\text { (Irradiated) }\end{array}$ & 175 & 0 & 23 & 17 & 46 & 51 & 38 & 0 \\
\hline $\begin{array}{l}\text { FZJ - } \\
\text { COST/MATFO }\end{array}$ & $\begin{array}{l}\text { Similar } \\
\text { Metal Joint }\end{array}$ & 159 & 0 & 2 & 23 & 7 & 62 & 65 & 0 \\
\hline $\begin{array}{l}\text { FZJ - HTR - } \\
617\end{array}$ & $\begin{array}{l}\text { Similar } \\
\text { Metal Joint }\end{array}$ & 152 & 0 & 4 & 9 & 25 & 73 & 41 & 0 \\
\hline \multicolumn{3}{|c|}{ Total Base Metal Data = 1461} & \multicolumn{4}{|c|}{$\begin{array}{l}\text { Total Irradiated Base Metal Data }= \\
175\end{array}$} & \multicolumn{3}{|c|}{$\begin{array}{l}\text { Total Cross Weld Data } \\
=311\end{array}$} \\
\hline
\end{tabular}




\begin{tabular}{|c|lll|}
\hline NEXT GENERATION NUCLEAR PLANT STEAM & Identifier: & PLN-2804 & \\
GENERATOR AND INTERMEDIATE HEAT & Revision: & 1 & \\
EXCHANGER MATERIALS RESEARCH & Effective Date: & $09 / 23 / 10$ & Page: 122 of 252 \\
AND DEVELOPMENT PLAN &
\end{tabular}

\subsection{Acquisition of Alloy 617 Databases}

Section 5.3 highlights a strategy to overcome the schedule issue for the conceptual and preliminary design activities. This strategy relies on the successful acquisition of the Petten and ECCC databases, in particular the entire Petten Alloy 617 database. The combined data will be used to develop time-dependent allowable stresses to support the conceptual and preliminary designs of the high temperature IHX and hot-gas piping.

Extrapolation of data would still be necessary even with the combined dataset from the Huntington, ${ }^{45}$ General Electric, ${ }^{92}$ ORNL, ECCC ${ }^{94}$ and Petten databases. ${ }^{95}$ A more rigorous statistical approach as employed by Eno et al., ${ }^{96}$ in analyzing the Huntington creep data for the NASA Space Reactor applications will be used to develop the allowable stresses. This approach involves using the method of maximum likelihood estimation (MLE) to yield more precise model parameter estimates.

MLE is an established statistical methodology, with well-understood statistical properties based on asymptotic theory, and in particular, the MLE method is asymptotically efficient, meaning that for large datasets, no other estimation procedure will yield more precise model parameter estimates. Furthermore, formal quantitative inferences can be made through MLE theory, such as confidence interval estimation of model parameters and hypothesis tests to determine the statistical significance of individual model terms. By comparing the optimized likelihood function for different formulations (based on the different engineering creep parameters), the goodness-of-fit of the formulations can be objectively and quantitatively compared.

MLE has the advantage of being readily able to accommodate censored data, which can occur in two distinct forms. Right-censored data, or runouts, are specimens that have not ruptured the conclusion of the experiment; the specimens' rupture time is longer than the test duration. Left-censored data arise from an experiment in which the lack of in-situ monitoring prevents direct observation of rupture time. If specimens are tested for a fixed time $t$, and are found to be ruptured at the conclusion, it can be stated their lifetimes were less than the fixed test duration $t$.

Lower-bound curves for time to creep-rupture can be computed based on the fitted model and the observed variability ("data scatter") in measured times. A lower-bound curve should also account for uncertainty in the fitted model parameters. Accounting for uncertainties creates a lower bound that is backed off from the best estimate by a different amount at different stress-temperature combinations. The propagation of uncertainties depends on the degree to which the model is extrapolated relative to the database. The distance of the back-off is the smallest near the middle of the database and the greatest at the temperature and stress extremes of the database. Conceptually, this is because predictions surrounded by supporting data are more reliable than predictions near the ends of the database, which have less locally supporting data. This is particularly useful as it provides a quantitative means to extrapolate data to different conditions with different prediction bounds (wider or narrower) with the same level of confidence. Of course, care must be exercised in judging whether the engineering creep model is applicable at those extrapolated conditions.

Based on the MLE methodology, design curves for allowable stresses can be developed for different applications and for different stages of the design cycle by adopting, e.g., different confidence levels $(95 \%$ or $98 \%)$ in constructing the design curves.

\subsection{Long-term Creep}

To support ASME Code acceptance, final design activities and final licensing approval, long-term creep-rupture tests at low-stress levels are required. Such data will also serve to qualify the conservatism of the allowable stresses established for the conceptual and preliminary designs. Finally, a few very long-term creep-rupture tests at prototypical operating stress levels should be initiated to provide creep- 


\begin{tabular}{|c|lll|}
\hline NEXT GENERATION NUCLEAR PLANT STEAM & Identifier: & PLN-2804 & \\
GENERATOR AND INTERMEDIATE HEAT & Revision: & 1 & \\
EXCHANGER MATERIALS RESEARCH & Effective Date: & $09 / 23 / 10$ & Page: 123 of 252 \\
AND DEVELOPMENT PLAN &
\end{tabular}

rupture data that would lead the NGNP. Test matrix for this long-term testing is given in Table A17 and will utilize 8 tensile specimens. The specimens will be tested in air at 850 and $950^{\circ} \mathrm{C}$. Applied stress will range from 9.5 to $27.5 \mathrm{MPa}$. The estimated 95\% Lower Bound Rupture time will range from 6.2 to 16.2 years. Product form will be plate from a single heat (xyz-CF).

\subsubsection{Selection of Weld Consumables and Welding Processes}

This effort addresses Item D2 in Table 18 of Section 5.4. Procedures for Alloy 617 welding have been developed, demonstrated and qualified using the INL Welding Program process for Alloy 617 using Alloy 617 filler wire compositions and GTA welding. ${ }^{47}$ The recommendations from Special Metals ${ }^{97}$ were used to develop weld parameters for the qualified procedure. Data from materials welded using the approved procedure will be valid for code and licensing purposes and can be considered to be conservative values if improved welding procedures are developed at a later date. The weld procedure meets the requirements of ASME B\&PV Code Section IX. Micrographs (Figure 30 and Figure 31) and a hardness profile (Figure 32) are presented in Section 4.1.1.9. This effort has been completed.

\subsubsection{Yield and Tensile Strength Reduction Factors}

This effort addresses Item D3 in Table 18 of Section 5.4 and NRC concerns List 19 in Table 16 of Section 5.2.

For extended elevated temperature service, Subsection NH requires using yield and tensile strength-reduction factors that are functions of exposure time and exposure temperature to account for possible decrease in the yield and tensile strengths caused by thermal aging.

A review of the aging effects in Alloy 617 has been provided by Swindeman and Ren. ${ }^{98}$ Figure 46 and Figure 47 show thermal aging data in air from the Special Metals Data Sheet for room temperature yield and tensile strengths, respectively, as a function of exposure time at various exposure temperatures.

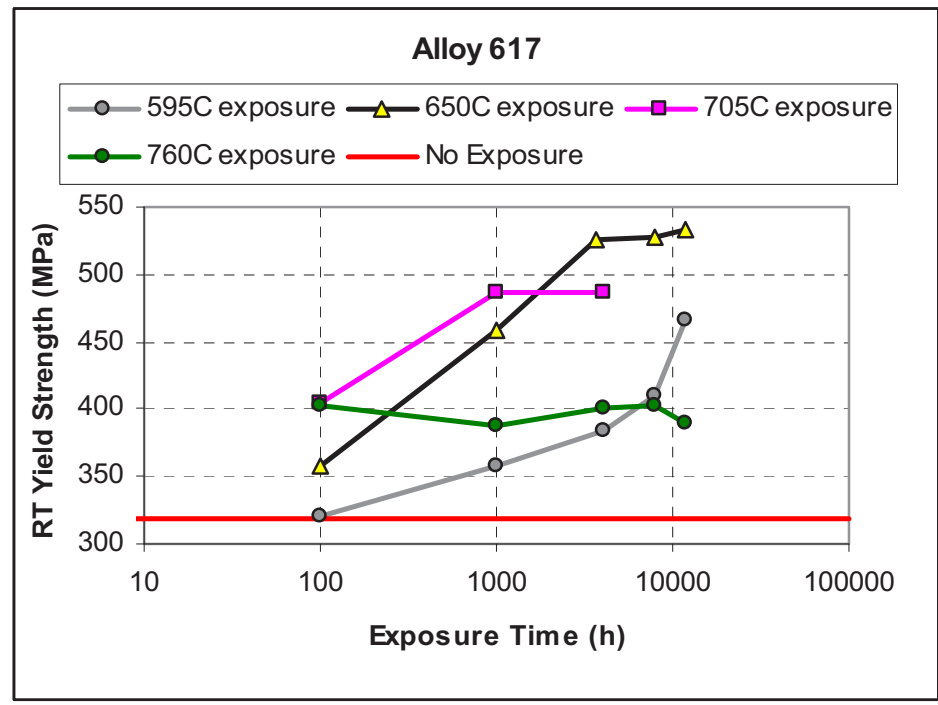

Figure 46. Thermal aging effect on room temperature yield strength. 


\begin{tabular}{|c|lll|}
\hline NEXT GENERATION NUCLEAR PLANT STEAM & Identifier: & PLN-2804 & \\
GENERATOR AND INTERMEDIATE HEAT & Revision: & 1 & \\
EXCHANGER MATERIALS RESEARCH & Effective Date: & $09 / 23 / 10$ & Page: 124 of 252 \\
AND DEVELOPMENT PLAN &
\end{tabular}

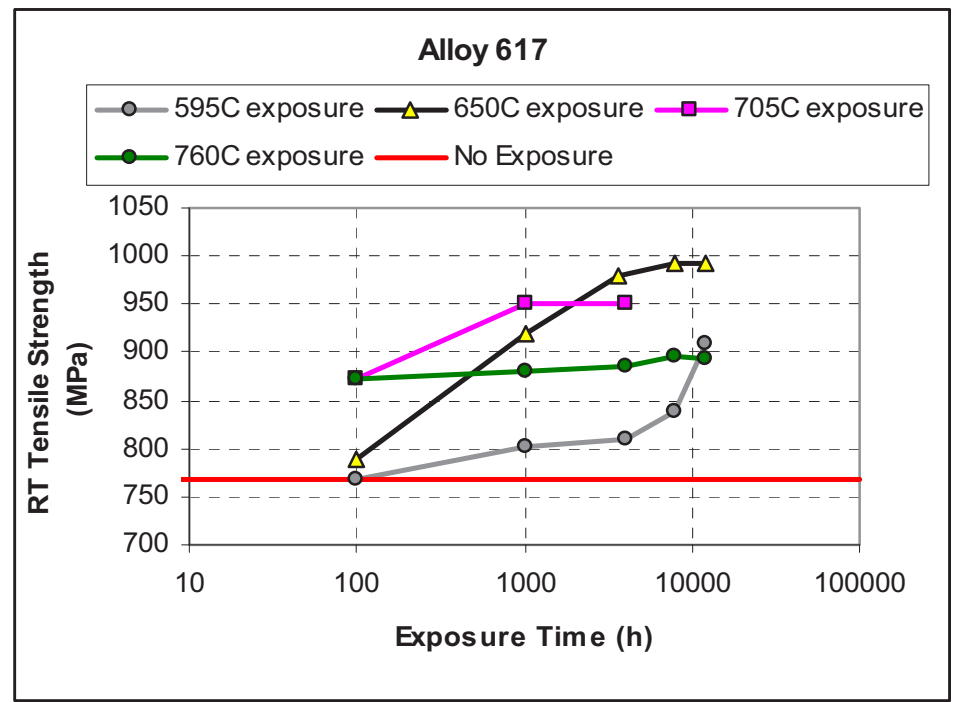

Figure 47. Thermal aging effect on room temperature tensile strength.

The strengthening shown in the data was attributed by Special Metals to carbide formation at $595^{\circ} \mathrm{C}$, and to precipitation of gamma prime phase at exposure temperatures of 650 to $760^{\circ} \mathrm{C}$. The strengthening tapers off in this temperature range as exposure time increases. The strengthening effect decreases as the exposure temperature is increased toward the normal operating metal temperature of NGNP hot-gas piping and IHX components.

Quoting the data from McCoy and King, Swindeman and Ren ${ }^{98}$ showed a plot of the strength data after $871{ }^{\circ} \mathrm{C}$ thermal exposure at different exposure times. Figure 48 shows their plot and the reduction in yield strength.

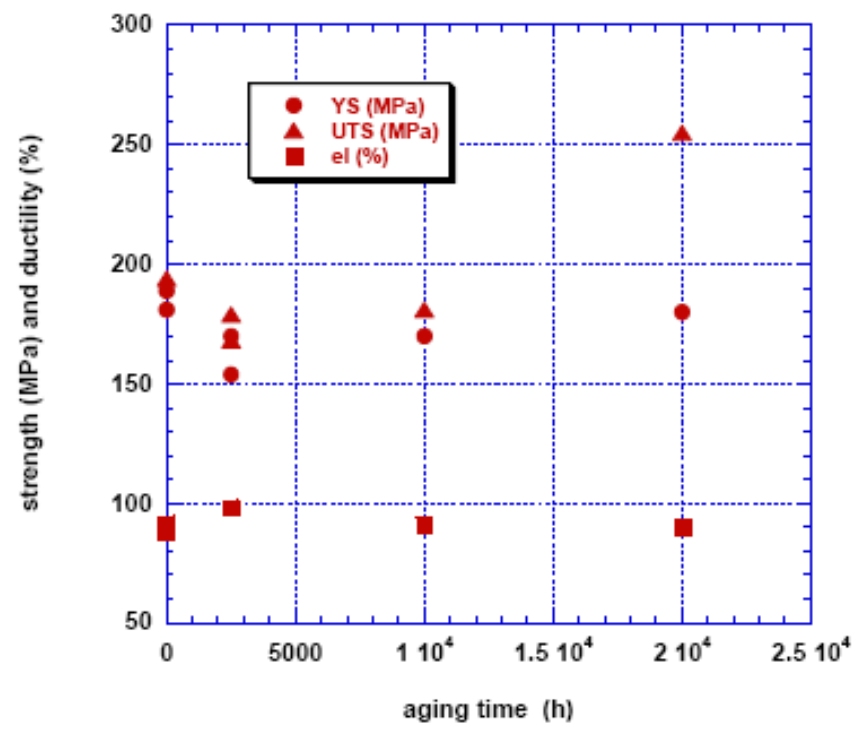

Figure 48. Effect of aging at $871^{\circ} \mathrm{C}$ on strengths and elongation of Alloy 617. 


\begin{tabular}{|c|lll|}
\hline $\begin{array}{c}\text { NEXT GENERATION NUCLEAR PLANT STEAM } \\
\text { GENERATOR AND INTERMEDIATE HEAT } \\
\text { EXCHANGER MATERIALS RESEARCH }\end{array}$ & Identifier: & PLN-2804 & \\
AND DEVELOPMENT PLAN & Effective Date: & $09 / 23 / 10$ & Page: 125 of 252 \\
\hline
\end{tabular}

Thermodynamics calculations have also been performed to investigate the thermal aging issue, as discussed in Section 4, but no consensus has emerged on the stability ranges of various precipitates. It is likely that aging is highly dependent on the chemistry of the particular heat that is characterized.

Testing of long-term thermally exposed Alloy 617 in air is required to determine the yield and tensile strength- reduction factors. A test matrix is proposed in Table A18 for such determination and will utilize 296 tensile specimens. The specimens will be tested in air with exposure temperatures of none to $1000^{\circ} \mathrm{C}$ and exposure times from none to $120,000 \mathrm{~h}$. Tensile testing of the specimens will be performed at 20 and $950^{\circ} \mathrm{C}$. Product form will be plate from two different heats (Aged-3 and Aged-4). Two heats are included in the test matrix to cover variability. Two specimens will be used for each of the exposure time, exposure temperature and test temperature combination for each heat. The planned thermal exposure temperatures are $750,850,950$, and $1000^{\circ} \mathrm{C}$, and the exposure times are $200 ; 650 ; 2000 ; 5,300 ; 20,000 ; 32,000 ; 50,000$; 76,000; and 120,000 h. The tensile test temperatures are 20 and $950^{\circ} \mathrm{C}$. All the tensile tests will be conducted in strain-control and at a strain rate of $1 . E-3 \mathrm{~m} / \mathrm{m} / \mathrm{s}$.

Tensile specimens will be machined from thermally exposed materials. Samples will also be prepared from the thermally exposed materials to investigate the effects of thermal aging on the microstructure. Together with the strength data from the aged materials, structural-property relation can also be studied.

The testing is divided into two parts. The yield and tensile strength reduction factors (YT-SRF) for conceptual and preliminary design activities will be developed using data from the YT-SRF Test Program with thermal exposure times up to $20,000 \mathrm{~h}$. A tentative model for the change in strength for each of the yield and tensile strengths of the form

$\Delta($ Strength $)=A \times t^{m} \times \exp \left(-\frac{Q}{R}\left[\frac{1}{T}-\frac{1}{T_{0}}\right]\right)$

will be used to correlate with the data. Here $t$ is time, $T$ is the exposure temperature in absolute temperature scale, $R$ is the universal gas constant, $T_{0}$ is a scaling constant, and $A, Q$, and $m$ are fitting constants. Other correlation models will also be investigated when necessary. Data from the YT-QUAL (yield tensile code qualification) Test Program with thermal exposure times up to $120,000 \mathrm{~h}$ will be used to qualify the yield and tensile strength reduction factors developed from the YT-SRF Test Program.

\subsubsection{Fatigue Design Curves for Alloy 617 Code Case (Standard Grain Size)}

This effort addresses Item D4 in Table 18 of Section 5.4.

The continuous fatigue design curves are an integral part of the creep-fatigue procedure in Subsection NH. At higher temperatures and lower strain rates, crack growth change from transgranular to intergranular, and there is a significant effect of strain rate. Table A19 presents a test matrix that will utilize 96 fatigue specimens. Half the samples will be tested in air and the other half in NGNP He. The specimens will be tested at 850 and $950^{\circ} \mathrm{C}$ with strains ranging from 0.15 to $2.0 \%$. Strain rates of $1 \mathrm{E}-02$ to $1 \mathrm{E}-05 \mathrm{~m} / \mathrm{m} / \mathrm{s}$ for a limited number of samples will be used. The rest are TBD. Product form will be plate from a single heat (xyz-CF). Some continuous fatigue results are included in Section 4.1.1.5.

The strain rate effect is first investigated by keeping the strain range constant and varying the strain rates. Electron scanning microscopy would then be used on the failed specimens to identify the failure mechanism transition from predominately transgranular by striation to intergranular cracking. A strain rate is then selected to generate continuous fatigue data to support developing the fatigue design curves in the Alloy 617 Code Case. The temperatures are selected to support an initial metal temperature of $850^{\circ} \mathrm{C}$ and future increase to $950^{\circ} \mathrm{C}$. 


\begin{tabular}{|c|lll|}
\hline $\begin{array}{c}\text { NEXT GENERATION NUCLEAR PLANT STEAM } \\
\text { GENERATOR AND INTERMEDIATE HEAT } \\
\text { EXCHANGER MATERIALS RESEARCH } \\
\text { AND DEVELOPMENT PLAN }\end{array}$ & Revision: & 1 & \\
& Effective Date: & $09 / 23 / 10$ & Page: 126 of 252 \\
\hline
\end{tabular}

Testing in NGNP helium is also proposed in Table A19, using the same testing strategy as for the air tests. This is part of an overall strategy as has been discussed, to generate fatigue data in supporting the inclusion of a less restrictive creep-fatigue design procedure in the Alloy 617 Code Case.

\subsubsection{Potential Need to Optimize Alloying Elements}

This addresses Item D5 in Table 18 of Section 5.4.

Appendix X of Subsection NH provides guidelines for restricted material specifications to improve performance in certain service applications. For Alloy 617, an effort to define a Controlled Material Specification (CMS) within the standard specification to improve performance for NGNP applications has been made. ${ }^{36}$ Preliminary results on testing and characterization of CMS Alloy 617 were reported in Ren et al. ${ }^{70}$ There have also been efforts in France to refine the compositions of Alloy 617. The difficulty of improving the overall properties using the chemistry refinement approach is illustrated by the differences in the NGNP and the French alloys. The effort supported by NGNP was aimed at improving the creep properties by increasing the $\gamma^{\prime}$ formers $\mathrm{Al}$ and $\mathrm{Ti}$. The French alloy was intended to reduce loss of load-bearing area due to formation of intrusive grain boundary oxides by reducing the Al content to the minimum level.

If higher allowable stresses were to be leveraged based on the improved properties of materials with restricted compositions, a rather extensive database from long-term creep tests for materials with such restricted compositions would have to be generated, increasing the time to develop the Alloy 617 Code Case. Therefore, it is recommended to use the Alloy 617 data from standard specifications to develop the Alloy 617 Code Case.

\subsubsection{Cold Work Effect and Heat Treatment Requirement}

This addresses Item D6 in Table 18 of Section 5.4.

At high homologous temperatures $(\geq 0.6)$ power law creep may be accompanied by repeated waves of recrystallizaton $^{99}$ that drastically change the dislocation structure with each passage, allowing a period of primary creep that would lead to an acceleration of the overall creep rate. Because of concerns that cold worked Alloy 617 would undergo recrystallization during elevated temperature service, it was excluded from use in the Draft Alloy 617 Code Case.

$\mathrm{Cook}^{100}$ had conducted creep tests of $\sim 3000 \mathrm{~h}$ at $850^{\circ} \mathrm{C}$ in helium on specimens with prior cold work of $5 \%$ to $20 \%$. Prior cold work reduced the initial creep rate, but it also reduced the room temperature tensile ductility of these crept specimens.

Owing to the concerns on recrystallization and loss of tensile ductility, the restriction on cold worked material in the Draft Alloy 617 Code Case will be retained in the new Alloy 617 Code Case. This restriction could be relaxed in the future for applications where these concerns could be mitigated.

\subsubsection{Creep-Fatigue Interaction Diagram for Alloy 617}

This effort addresses Item D7 in Table 18 of Section 5.4 and NRC Lists 4 and 12 in Table 16 of Section 5.2.

The creep-fatigue interaction diagram is an integral part of the creep-fatigue procedure of Subsection $\mathrm{NH}$. A test matrix for generating creep-fatigue data to support the determination of the creep-fatigue interaction diagram in the Alloy 617 Code Case is proposed and presented in Table A20 and will utilize 96 creep-fatigue specimens. Half the samples will be tested in air and the other half in NGNP He. The specimens will be tested in tension at $950^{\circ} \mathrm{C}$. Strain will range from 0.3 to $1 \%$ with hold time ranging from 0 to 600 minutes. Product form will be plate from a single heat (xyz-CF). Results for some of the tests in this matrix are presented in Section 4.1.1.5. 


\begin{tabular}{|c|lll|}
\hline $\begin{array}{c}\text { NEXT GENERATION NUCLEAR PLANT STEAM } \\
\text { GENERATOR AND INTERMEDIATE HEAT } \\
\text { EXCHANGER MATERIALS RESEARCH } \\
\text { AND DEVELOPMENT PLAN }\end{array}$ & Revision: & 1 & \\
& Effective Date: & $09 / 23 / 10$ & Page: 127 of 252 \\
\hline
\end{tabular}

Jetter and McGreevy ${ }^{101}$ concluded that the fatigue performance of Alloy 617 in impure helium is approximately five times better than that in air. Testing in NGNP helium environment is proposed to quantify the benefit for NGNP applications and to obtain data to support the inclusion of this less restrictive creep-fatigue procedure in the Alloy 617 Code Case. Without generating adequate creep-fatigue data in NGNP helium for inclusion in the Alloy 617 Code Case, the NGNP Project could only justify to NRC that the creep-fatigue performance of Alloy 617 in NGNP helium is no worse than that in air. The benefit of the NGNP helium environment on the creep-fatigue performance of Alloy 617 could not be factored explicitly into the design under such a scenario. Some of the tension holds in the test matrix might be revised to compression holds when the test program commences.

\subsubsection{Multiaxial Creep-rupture Failure Criterion for Alloy 617}

This effort addresses Item D8 in Table 18 of Section 5.4.

Creep-rupture data that support the creep-fatigue design procedure of Subsection $\mathrm{NH}$ are based on uniaxial testing. Structural components generally undergo multiaxial loading. In Subsection NH, an effective stress defined with respect to a multiaxial rupture strength criterion ${ }^{102}$ is used to relate the multiaxial stress state in a component determined by inelastic analysis to the uniaxial creep-rupture data. This effective stress, $\sigma$, is defined as:

$$
\sigma_{e}=\sqrt{\frac{\left(\sigma_{1}-\sigma_{2}\right)^{2}+\left(\sigma_{2}-\sigma_{3}\right)^{2}+\left(\sigma_{3}-\sigma_{1}\right)^{2}}{2}} \cdot \exp \left[C\left(\frac{\sigma_{1}+\sigma_{2}+\sigma_{3}}{\sqrt{\sigma_{1}^{2}+\sigma_{2}^{2}+\sigma_{3}^{2}}}-1\right)\right]
$$

where $\sigma_{1}, \sigma_{2}$, and $\sigma_{3}$ are the principal stresses and $C$ is a material constant. A value of $C=0.24$ for 304 and 316 stainless steels was selected for Alloy 617 in the Draft Alloy 617 Code Case. Biaxial creeprupture tests at $950^{\circ} \mathrm{C}$ are proposed in Table $\mathrm{A} 21$ of Appendix $\mathrm{A}$ to validate the value of $\mathrm{C}=0.24$ or to arrive at a new value for $\mathrm{C}$. Biaxial stress ratios of $2,1,0.5,0,-0.5$ and -1 are planned. They are achieved by different combinations of pressure, axial, and torsional loads.

\subsubsection{Significant Recently Emerged Issues for Alloy 617}

\subsubsection{Microstructural Determination of the Onset of Tertiary Creep}

This effort addresses Item E1 in Table 19 of Section 5.4.

The ASME Section III Subsection NH criteria for estimating the time-dependent allowable stress $S_{t}$ include (1) the average strength for $1 \%$ total strain, (2) $80 \%$ of the minimum strength for tertiary creep, and (3) $67 \%$ of the minimum rupture strength values. These criteria are based on materials that exhibit the classical creep response with identifiable primary, secondary, and tertiary creep regimes in the creep curves.

Alloy 617 exhibits classical primary, secondary, and tertiary regimes in the creep response at temperatures below $800^{\circ} \mathrm{C}$. But secondary creep (constant creep rate) is hardly noticeable in the creep curves at $800^{\circ} \mathrm{C}$ and above. After the initial primary creep regime, the creep rate increases gradually until rupture. Thus the onset of tertiary creep based on the classical definition occurs at a very short time. The inclusion of time-to-onset-of-tertiary-creep in setting the time-dependent allowable stress $S_{t}$ would be very restrictive. This criterion was not used in setting $S_{t}$ in the Draft Alloy 617 Code Case.

Information is needed on whether the gradually increasing creep curve is a manifestation of different deformation mechanisms typified by dislocation generation and motion, or if it corresponds to creep damage such as grain boundary cavitation and cracking reminiscent of those occurring in the classical tertiary creep regime. 


\begin{tabular}{|c|lll|}
\hline NEXT GENERATION NUCLEAR PLANT STEAM & Identifier: & PLN-2804 & \\
GENERATOR AND INTERMEDIATE HEAT & Revision: & 1 & \\
EXCHANGER MATERIALS RESEARCH & Effective Date: & $09 / 23 / 10$ & Page: 128 of 252 \\
AND DEVELOPMENT PLAN &
\end{tabular}

A test matrix is proposed in Table A22 for interrupted creep tests and will utilize 40 tensile specimens. The specimens will be tested in air at 750 and $1000^{\circ} \mathrm{C}$. Applied stress ranges from 16 to 145 $\mathrm{MPa}$. Estimated rupture time ranges from 1665 to $5110 \mathrm{~h}$. Product form will be plate from a single heat (xyz-CF). The temperatures of $750^{\circ} \mathrm{C}$ and $1000^{\circ} \mathrm{C}$ are selected to capture the two different creep behaviors. Microstructural evaluations (TEM, scanning electron microscopy [SEM], etc.) will be performed on crept specimens at certain strain levels or periods along the creep curves. The test specimens should be cooled under load before their removal from the test frame to preserve the existing microstructure. The objective is to identify different microstructural processes such as dislocation interactions, subgrain formations, dislocation multiplication, dislocation-carbide interactions, diffusional creep mechanism, grain boundary cavitation, cracking, etc., at different locations along a creep curve. This will differentiate the contributions of deformation and damage in the part of the creep curve usually considered to be in the tertiary creep regime. The results from this effort will provide input to the ASME Code committee on whether time to onset of tertiary creep needs to be included in the criteria for defining the time-dependent allowable stress, $S_{t}$. Preliminary results of this type from a different heat of Alloy 617 are presented in Section 4.1.1.7.

\subsubsection{Fatigue with Hold Time for Alloy 617}

This effort addresses Item E2 in Table 19 and NRC concerns 4 and 12 in Table 16 of Section 5.4.

The baseline operating temperature for an Alloy $617 \mathrm{IHX}$ is $850^{\circ} \mathrm{C}$, with possible future up-rating to $950^{\circ} \mathrm{C}$. Owing to the low design allowable stresses at these elevated temperatures, sustained stress levels in these components are low. A preliminary evaluation of the NGNP operating transients indicates the normal cyclic service will consist of several hundred very slow transients with hold times on the order of $1,000 \mathrm{~h}$. There is also the possibility of a limited number (less than 10) of off-normal cycles with more rapid ramp rates and shorter hold times.

The above brings up the critical issue of whether the creep-fatigue behavior of Alloy 617 saturates with increasing hold time. In this context, saturation means that the number of cycles to failure is no longer increasing, as the hold time increases (or increasing very little).

Figure 49 shows a plot of the cycle-to-failure the German HTGR Alloy $6170.6 \%$ strain creep-fatigue tests at $950^{\circ} \mathrm{C}$ in impure, decarburizing helium, ${ }^{103}$ and recent INL creep-fatigue tests at $950^{\circ} \mathrm{C}$ in air. The plot shows that the German data do not indicate saturation. If the German data are extrapolated linearly on the log-log plot there is a dramatic reduction in cycles to failure for very long hold times. This is one of the reasons the design curves in Jetter and McGreevy ${ }^{101}$ appear so conservative. The reduction in cycles is less dramatic for the INL data but additional testing is needed to determine if saturation will occur.

Accordingly, a creep-fatigue test matrix as shown in Table A23 is recommended to clarify this critical issue. The strain rate $\mathrm{S} 1$ listed in the table will be selected from the strain rate study of the continuous fatigue task. The 18 tensile specimens will be held in tension in air at $1000^{\circ} \mathrm{C}$ at strains of 0.3 and $1.0 \%$. Hold times will be 0,150 , and 600 minutes. The strain rate will be $1 \mathrm{E}-03 \mathrm{~m} / \mathrm{m} / \mathrm{s}$. Product form will be plate from a single heat (xyz-CF).

\subsubsection{Assessment of Diffusional Creep for Alloy 617}

This effort addresses Item E3 in Table 19 of Section 5.4.

Accelerated creep tests are generally performed to reduce the test durations to reasonable times. Stress-time-temperature correlation is then used to extrapolate accelerated creep-rupture data to long time and low-stress service conditions. The data from the accelerated creep-rupture tests in the Huntington Alloy 617 database are mainly in the dislocation creep (glide and climb) regime, with a stress exponent ranging from approximately 3 to 10 for the minimum creep rates. However, for elevated temperature 


\begin{tabular}{|c|lll|}
\hline $\begin{array}{c}\text { NEXT GENERATION NUCLEAR PLANT STEAM } \\
\text { GENERATOR AND INTERMEDIATE HEAT }\end{array}$ & Identifier: & PLN-2804 & \\
EXCHANGER MATERIALS RESEARCH & Revision: & 1 & \\
AND DEVELOPMENT PLAN & Effective Date: & $09 / 23 / 10$ & Page: 129 of 252 \\
\hline
\end{tabular}

applications, the applied stresses must be very low owing to the very restrictive allowable stresses. In such cases, the creep deformation mechanisms could be grain boundary sliding or diffusional creep where the stress exponent is around 2 or 1 , respectively.

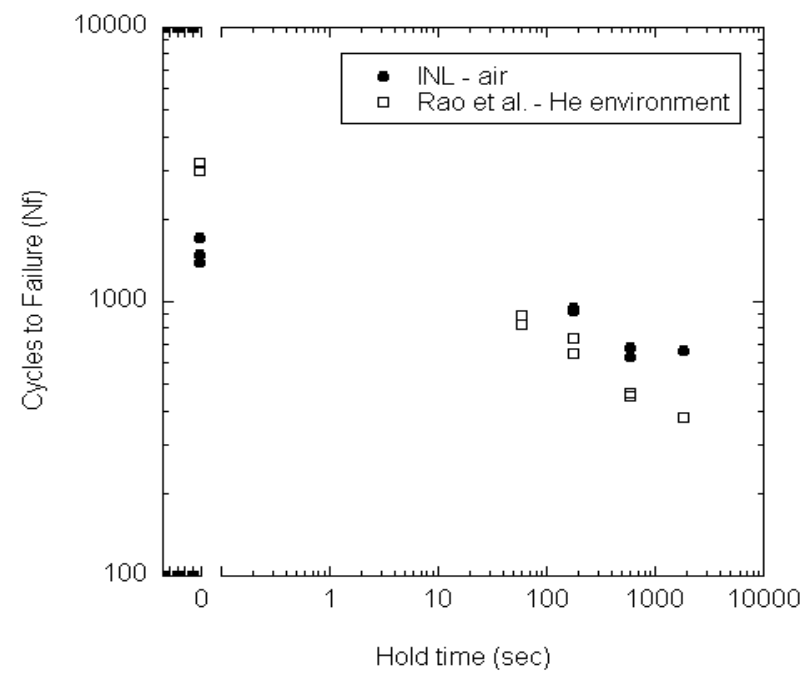

Figure 49. Comparison of German and INL creep-fatigue data for Alloy 617 at $950^{\circ} \mathrm{C}$ for $0.6 \%$ strain.

Extrapolation of the creep rate in the dislocation creep regime to very low-stress could lead to a nonconservative estimate (i.e., lower creep rate) relative to that obtained from the diffusional creep regime for the same low-stress level. On the other hand, results from Schubert et al. ${ }^{104}$ showed that the creep rate from a stress level as low as $\sim 10 \mathrm{MPa}$ at $950^{\circ} \mathrm{C}$ still followed a power law with a stress index greater than one. This indicates that diffusional creep was not rate controlling under those conditions. However, whether the creep mechanisms operating in test is the same as the in application is an important issue. Thus, both experimental and theoretical studies are proposed.

The issue of diffusional creep was also highlighted in the Task 1 report of the DOE/ASME Gen IV Materials Project for Alloy $800 \mathrm{H} .{ }^{105}$ A plan to investigate diffusional creep for Alloy $800 \mathrm{H}$ was developed and the same plan has been adapted for Alloy 617. The motivation for the proposed plan of study is as follows.

For dislocation creep, which includes power law creep by dislocation glide alone, power law creep by dislocation glide-plus-climb, and the Harper Dorn creep, the creep rate is independent of the grain size, $d$, and proportional to stress raised to a power $n$, with $n>1$ except for the Harper Dorn creep where $n=1$. Diffusional creep includes Coble creep and Nabarro-Herring creep. Coble creep operates at a lower temperature with grain boundary diffusion being the rate-controlling mechanism. The Coble creep rate is inversely proportional to $d^{3}$ and linearly proportional to stress. Nabarro-Herring creep operates at high temperature where lattice diffusion is the rate-controlling mechanism. The Nabarro-Herring creep rate is inversely proportional to $d^{2}$ and linearly proportional to stress. With different dependence on grain size and stress for the creep mechanisms, creep tests on specimens with different grain sizes and different stress could lead to significant difference in the measured creep rates. Hence, the creep mechanisms for Alloy 617 at very high temperatures and low-stress can be explored using the creep test plan shown in Table A24 of Appendix A. Note that the applied stresses and creep times shown in Table A24 might require adjustment when the study commences. 


\begin{tabular}{|c|lll|}
\hline NEXT GENERATION NUCLEAR PLANT STEAM & Identifier: & PLN-2804 & \\
$\begin{array}{c}\text { GENERATOR AND INTERMEDIATE HEAT } \\
\text { EXCHANGER MATERIALS RESEARCH } \\
\text { AND DEVELOPMENT PLAN }\end{array}$ & Revision: & 1 & \\
Effective Date: & $09 / 23 / 10$ & Page: 130 of 252 \\
\hline
\end{tabular}

A portion of the work necessary to accomplish this task is underway at the University of Cincinnati with NEUP support. Heat treatment studies would be required to produce specimens with the desired range of grain sizes for creep testing. The data from testing per Table A24 will be analyzed to determine the stress exponents, activation energies and operative creep mechanisms, as well as to obtain values for the material constant for the minimum creep rate in the relevant creep regime. This analysis will serve as the theoretical basis for establishing deformation mechanism maps to predict the creep behavior (strain rates, operative mechanisms, stress and temperature dependence) over a wider range of temperatures and stress levels.

It is anticipated that the nature of the grain boundaries (random versus special), as well as the presence of carbides along the boundaries will play important roles in diffusional creep, grain boundary sliding and void formation. Thus, electron back scattered diffraction (EBSD)/orientation imaging microscopy (OIM) in the SEM will be utilized for accurate determination of grain size, grain size distribution, texture, the nature of grain boundaries and the occurrence of grain boundary migration, recrystallization and grain growth. In addition, the structure, chemistry, size and distribution of carbides will be characterized in detail to establish the effects of these precipitates on the creep and damage mechanisms. Furthermore, the development of damage in the form of voids at grain boundaries, their size and size distribution and relationship to the nature of grain boundaries will be carefully studied. The finer details of microstructural changes following creep will be studied by TEM:

- Dislocation characterization

- Burgers vectors

- Line directions

- Slip planes

- Density

- Presence of dislocation loops and occurrence of climb

- Dislocation dissociations and formation of stacking faults and twins

- Dislocation interactions with each other, second phase particles and grain boundaries

- Characteristics of grain boundary migration, recrystallization, and grain growth

\subsubsection{Small Grain-Sized Product Form for Alloy 617}

A wide spectrum of design concepts are being considered by reactor vendors for the IHX (see Appendix B). A key issue for the Alloy 617 ASME Code allowable stresses is the component cross-sectional thickness for the new compact IHX concepts. As the cross-sectional thickness is reduced, the grain size would need to be reduced accordingly as a minimum number of grains are required through the cross-section to retain the properties of polycrystalline materials. An estimate of a grain size as fine as ASTM GS No. 8 (approximately $20 \mu \mathrm{m}$ ) is required for the thinnest cross section considered by reactor vendors.

The impact of grain size on creep properties is illustrated in Figure 50(a) and (b) ${ }^{106}$ where the creep response of two commercial high temperature alloys, HR-120 and Alloy 230, are shown for different cross-section thicknesses: foils of 3.2 mils $(0.08 \mathrm{~mm})$ and 4 mils $(0.1 \mathrm{~mm})$ and standard product forms. The creep rate is increased as the cross-sectional thickness is reduced, resulting in shortened creep-rupture life. In addition to mechanical properties, it is expected that grain size will affect fabricability, weldability, and corrosion behavior. 


\begin{tabular}{|c|lll|}
\hline NEXT GENERATION NUCLEAR PLANT STEAM & Identifier: & PLN-2804 & \\
GENERATOR AND INTERMEDIATE HEAT & Revision: & 1 & \\
EXCHANGER MATERIALS RESEARCH & Effective Date: & $09 / 23 / 10$ & Page: 131 of 252 \\
AND DEVELOPMENT PLAN &
\end{tabular}

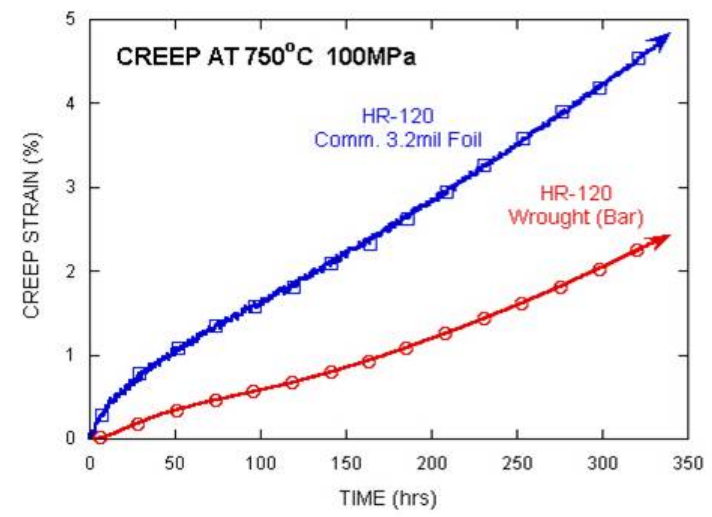

(a)

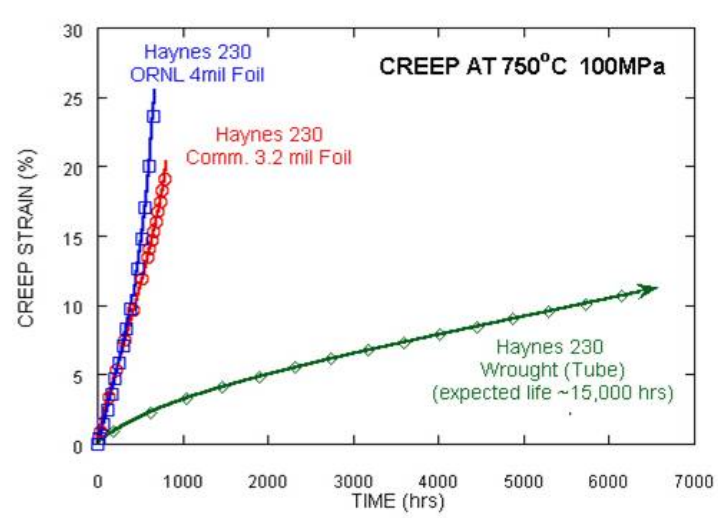

(b)

Figure 50. Creep curves as a function of cross-section thickness for (a) HR-120, and (b) Alloy 230.

Additional data for the creep-rupture tests on standard grain-sized tube and small grain-sized foils for Alloy 230 provided by Shingledecker ${ }^{107}$ are shown in Table 29. Based on the measured creep-rupture time, a correlation for standard grain size Alloy 230 is used to compute the best estimate creep-rupture stress. ${ }^{96}$ The grain size rupture factor is calculated as the ratio of the applied stress to the computed creeprupture stress.

Table 29. Creep-rupture data for Alloy 230 tube and foils.

\begin{tabular}{lllccccc}
\hline $\begin{array}{c}\text { Product } \\
\text { Form }\end{array}$ & $\begin{array}{l}\text { Thickness } \\
(\mathrm{mils} / \mathrm{mm})\end{array}$ & $\begin{array}{c}\text { Heat } \\
\text { Treatment }\end{array}$ & $\begin{array}{c}\text { Temp } \\
\left({ }^{\circ} \mathrm{C}\right)\end{array}$ & $\begin{array}{c}\text { Applied } \\
\text { Stress } \\
(\mathrm{MPa})\end{array}$ & $\begin{array}{c}\text { Rupture } \\
\text { Time } \\
(\mathrm{h})\end{array}$ & $\begin{array}{c}\text { Computed Best } \\
\text { Est. Rupture } \\
\text { Stress (MPa) }\end{array}$ & $\begin{array}{c}\text { Grain Size } \\
\text { Rupture } \\
\text { Factor }\end{array}$ \\
\hline Foil & $3.2 / 0.08$ & as-received & 750 & 100 & 800.9 & 158 & 0.63 \\
Foil & $3.2 / 0.08$ & as-received & 704 & 152 & 514.0 & 227 & 0.67 \\
Foil & $4 / 0.1$ & not known & 750 & 100 & 672.2 & 163 & 0.61 \\
Tube & Standard & as-received & 750 & 100 & 16725.6 & 98 & 1.02 \\
& Grain Size & & & & & & \\
\hline
\end{tabular}

The grain size rupture factor is approximately one for the standard grain-sized tube specimen, providing a consistency check. The grain size rupture factors are on the order of 0.6 for the 4 mil $(0.1 \mathrm{~mm})$ and $3.2 \mathrm{mil}(0.08 \mathrm{~mm})$ thick foils. The expected grain size rupture factor for Alloy 617 would be similar to those for Alloy 230. While data at higher temperatures are not available, the grain size rupture factor could be lower at higher temperatures.

While a compact IHX has many advantages in terms of heat transfer efficiency, size, cost of material of construction, etc., the reduced creep-rupture strength owing to grain size effects could present a significant challenge, and in particular, a potential technical risk that might not be alleviated through testing. A significant reduction in creep strength is expected, although it is based on a few data points from Alloy 230, and the rupture strength envelope for Alloy 617 foils has not been quantified.

The following scoping R\&D effort is needed to provide supporting data for the down-selection of the IHX designs from the perspective of structural integrity. 


\begin{tabular}{|c|lll|}
\hline $\begin{array}{c}\text { NEXT GENERATION NUCLEAR PLANT STEAM } \\
\text { GENERATOR AND INTERMEDIATE HEAT }\end{array}$ & Identifier: & PLN-2804 & \\
EXCHANGER MATERIALS RESEARCH & Revision: & 1 & \\
AND DEVELOPMENT PLAN & Effective Date: & $09 / 23 / 10$ & Page: 132 of 252 \\
\hline
\end{tabular}

\subsubsection{Scoping Study for Creep-rupture Strength of Alloy 617 Foils}

Accelerated creep-rupture tests on foils with different grain sizes need to be initiated as soon as possible. The resulting creep-rupture times from small grain-sized specimens are to be compared with those from standard grain-sized specimens under the same temperature and stress conditions. It may not be possible to identify a vendor that will supply materials with the appropriate thickness and grain size for the scoping study; however, ORNL has the capability and facility to perform hot rolling to produce creep specimens with the required thickness and grain size. A creep-rupture test procedure for foils has been established successfully through prior programs.

This study will scope out the creep-rupture strength penalty associated with small grain-sized product form, at least for the accelerated test conditions. This effort needs to be integrated with the task described in Section 7.1.5.3 on diffusional creep to establish if power-law, dislocation creep persists in the small grain-sized product form. Based on these data, if a sufficient performance envelope exists and the creep deformation mechanism is similar to the standard grain-sized product forms, steps will be taken to support ASME Code qualification.

\subsubsection{Creep-rupture Tests to Develop Grain Size Rupture Factors}

The test matrix that supports the determination of the grain size rupture factors is proposed in Table A25 of Appendix A. One standard grain size, ASTM GS No. $1.5(\sim 200 \mu \mathrm{m})$, and three smaller grain sizes, ASTM GS No. $3.5(\sim 110 \mu \mathrm{m})$, No. $4.5(75 \mu \mathrm{m})$, and No. $8(22 \mu \mathrm{m})$, are included. The test temperatures are $800^{\circ} \mathrm{C}, 900^{\circ} \mathrm{C}$ and $1000^{\circ} \mathrm{C}$. The best estimate and $95 \%$ upper and lower prediction bounds from the standard-grain-sized Alloy 617 creep-rupture time correlations are used to estimate the rupture times for various smaller grain sizes by assuming grain size rupture factors shown in Table A25. These assumed grain size rupture factors will be updated and the applied stresses revised once the scoping study described in Section 7.1.6.1 is concluded.

\subsubsection{Required Code Actions for Alloy $\mathbf{8 0 0 H}$}

\subsubsection{Unified Constitutive Model}

This effort addresses Item F1 in Table 20 of Section 5.5.

To develop the unified constitutive equations for Alloy $800 \mathrm{H}$, appropriate data are required to determine the material constants of the model. Task 1 of the DOE/ASME Gen IV Materials Project performed a detailed review of the Alloy $800 \mathrm{H}$ creep database (see Section 5.1.3). It found that some but not all of the original creep curves are available. ${ }^{92,108-114}$ The Electric Power Research Institute (EPRI) commissioned a very extensive survey of the high temperature mechanical behavior of Alloy $800 \mathrm{H} .{ }^{115}$ All properties were included in the survey and there were hundreds of references. Plots of creep curves were reproduced from various papers and reports but no tabulations of new data were included. Only yield and tensile strength data (not the stress-strain curves) are provided.

A unified constitutive model based on the overstress concept was developed by Tachibana and $\mathrm{Krempl},{ }^{62-64}$ using Alloy $800 \mathrm{H}$ creep and tensile test data from JAEA between $750^{\circ} \mathrm{C}$ and $1050^{\circ} \mathrm{C}$. The longest creep time accumulated in the test data for use in the unified constitutive model development was approximately $1700 \mathrm{~h}$. The model predictions compare reasonably with test data. However, comparison with long time low-stress data was not possible as they were not available.

Many tests have been carried out for Alloy $800 \mathrm{H}$ since the 1970s and creep information needed for unified constitutive model development could be synthesized from open literature sources. However, tensile data that would allow some of the material constants in the unified constitutive equations to be determined are not available. A small test program is proposed in Table A26 of Appendix A to supplement the open literature data. The tensile tests proposed include (1) strain-rate change, (2) stress 


\begin{tabular}{|c|lll|}
\hline $\begin{array}{c}\text { NEXT GENERATION NUCLEAR PLANT STEAM } \\
\text { GENERATOR AND INTERMEDIATE HEAT }\end{array}$ & Identifier: & PLN-2804 & \\
EXCHANGER MATERIALS RESEARCH & Revision: & 1 & \\
AND DEVELOPMENT PLAN & Effective Date: & $09 / 23 / 10$ & Page: 133 of 252 \\
\hline
\end{tabular}

dip, (3) loading/unloading/creep at a stress rate of $0.01 \mathrm{MPa} / \mathrm{s}$, and (4) uniaxial ratcheting. The selected test temperatures are $550^{\circ} \mathrm{C}, 650^{\circ} \mathrm{C}, 750^{\circ} \mathrm{C}$, and $850^{\circ} \mathrm{C}$.

The general unified constitutive model framework described in Section 7.1.3.1 will also be employed for Alloy $800 \mathrm{H}$. This will allow the module/subroutine for Alloy $800 \mathrm{H}$ to be embedded in the same hierarchical structure of the Alloy 617 finite element implementation, hence reducing R\&D costs. Alloy $800 \mathrm{H}$ will also be included in the new analysis guideline that is similar to the Nuclear Standard NE F9-5T.

\subsubsection{Extend Isochronous Stress-Strain Curves to 500,000 hours}

This effort addresses Item F2 in Table 20 of Section 5.5.

Isochronous stress-strain curves are required in applying the Subsection NH design procedures. These curves are provided in Subsection NH for Alloy $800 \mathrm{H}$ up to $300,000 \mathrm{~h}$. Thus in support of those Alloy $800 \mathrm{H}$ applications that require the full 60-year NGNP design life, the isochronous stress-strain curves up to $500,000 \mathrm{~h}$ will be generated for incorporation into Subsection $\mathrm{NH}$ once the unified constitutive model described in Section 7.1.7.1 is developed.

\subsubsection{Time-Dependent Allowable Stresses}

This effort addresses Item F3 in Table 20 of Section 5.5.

Task 1 of the DOE/ASME Gen IV Materials Project (see Section 5.1.3) has extended the time-dependent allowable stresses for Alloy $800 \mathrm{H}$ to $500,000 \mathrm{~h}$. Effort will be made to ensure that ASME Code action will be taken to incorporate the extended allowable stresses into Subsection NH to support NGNP conceptual and preliminary design activities.

\subsubsection{Alloy $800 \mathrm{H}$ Weldments}

This effort addresses Item F4 in Table 20 of Section 5.5.

A creep-rupture experimental program was recommended in the Task 1 report (see Section 5.1.3) to extend Subsection NH WSRFs for Alloy $800 \mathrm{H}$ weldments, filler metals 82 (ERNiCr-3) and A (ENiCrFe-2), to 60 years of service and above the current temperature limit of $760^{\circ} \mathrm{C}$. Subject area experts judge that developing WSRFs for 60 years and up to $850^{\circ} \mathrm{C}$ is an achievable goal. Based on the Task 1 recommendation, a test plan is proposed in Table A27 of Appendix A to generate creep-rupture data for Alloy $800 \mathrm{H}$ weldments to support extending the time and temperature limits of Alloy $800 \mathrm{H}$ WSRF in Subsection NH. Limited testing is also proposed to study other Alloy $800 \mathrm{H}$ welds for elevated temperature service. In the test plan, filler metals 82 (ERNiCr-3) and 617 (ERNiCrCoMo-1) will be used for GTA welding.

The testing plan for filler metal 82 and electrode A deposited weld metal and cross weld specimens is designed to supplement existing data, which have been identified in the Task 1 report. No testing below $900^{\circ} \mathrm{C}$ is included in the test matrix as the existing database is adequate to establish WSRFs at lower temperatures and the test data recommended will be used to estimate WSRFs for long times by means of time-temperature parametric prediction methods.

The testing plan for Alloy 617 filler metal is directed toward understanding the effect of the mismatch in strength on the high temperature performance of weldments. Only cross welds with Alloy $800 \mathrm{H}$ base metal are included. Testing for 617 and 117 deposited welds at $750^{\circ} \mathrm{C}$ and above is included in the task on establishing WSRFs for Alloy 617 weldments. 


\begin{tabular}{|c|lll|}
\hline $\begin{array}{c}\text { NEXT GENERATION NUCLEAR PLANT STEAM } \\
\text { GENERATOR AND INTERMEDIATE HEAT }\end{array}$ & Identifier: & PLN-2804 & \\
EXCHANGER MATERIALS RESEARCH & Revision: & 1 & \\
AND DEVELOPMENT PLAN & Effective Date: & $09 / 23 / 10$ & Page: 134 of 252 \\
\hline
\end{tabular}

\subsubsection{Strain Rate Effect on Yield and Tensile Strengths}

This effort addresses Item F5 in Table 20 of Section 5.5.

ASME Section III Subsection NH provides values for the minimum yield strength, $S_{Y 1}$, and minimum tensile strength, $S_{U}$, for the range of temperatures applicable for construction with specific alloys. Currently, Alloy $800 \mathrm{H}$ is approved for construction to $760^{\circ} \mathrm{C}$. Task 1 of the DOE/ASME Gen IV Materials Project was charged to consider extending the applicable temperature range for Alloy $800 \mathrm{H}$ to $900^{\circ} \mathrm{C}$. Average and minimum stresses were determined and recommended for ASME Code action in the Task 1 report, as summarized in Section 5.1.3. Although generally not very sensitive to strain rate at lower temperatures, the yield and tensile strengths depend on the strain rate at $760^{\circ} \mathrm{C}$ and above, with lower strengths expected for lower strain rates. Notes will be needed in the appropriate tables for yield and tensile strengths in Subsection NH to alert the user that the tabulated values for Alloy $800 \mathrm{H}$ only apply to specific ranges of strain rates. To better understand the range of applicability of the recommended values, further testing at various strain rates is needed. Table A28 in Appendix A provides 26 recommended tests to define this range.

Two metallurgical conditions are included to cover the range of acceptable grain sizes (ASTM GS Numbers $\leq 0$ to 5). Room temperature tests will be performed to characterize the materials and form a basis for hot-to-room temperature strength ratios. Temperatures need to cover only the range of interest because the data will not be used to set any allowable stresses but only to help in defining the limits in the notes. The strain rates cover three orders of magnitude for both yield and tensile strengths. The strengths may be produced by changing the applied rate after reaching $2 \%$ strain or performing constant rate tests to the ultimate at $0.5,0.05,0.005 / \mathrm{min}$ and testing to the yield at $0.0005 / \mathrm{min}$. The flow stress is expected to vary by $\pm 25 \%$ about the flow strength for the standard rate $(0.005 / \mathrm{min})$.

\subsubsection{Effects of Diffusional Creep Mechanism on Allowable Stresses}

This effort addresses Item F6 in Table 20 of Section 5.5.

According to the literature survey conducted by Task 1 of the DOE/ASME Generation IV Materials Project (see Section 5.1.3), diffusional creep mechanisms are active in Alloy $800 \mathrm{H}$ at $800^{\circ} \mathrm{C}$ and higher at stresses typical of long time service. ${ }^{116}$ Data produced by NIMS for several lots of Alloy $800 \mathrm{H}$ indicate rapid linear creep at low stresses and high temperatures to strains in excess of $1 \% .{ }^{113,114}$ The creep rate appears to be proportional to stress.

Two diffusional creep processes, Nabarro-Herring and Coble creep, produce linear stress dependence as well as the Harper-Dorn mechanism. The Coble and Nabarro-Herring mechanisms differ in regard to the activation energy for creep and the grain size dependency of creep. The Harper-Dorn mechanism does not depend on grain size. Because one of the criteria in ASME III-NH for setting $S_{t}$ is the stress to produce $1 \%$ strain in a specific time, some testing of Alloy $800 \mathrm{H}$ is needed to clearly establish the temperature, stress, and grain size dependency of the early creep process at temperatures above $800^{\circ} \mathrm{C}$.

The Task 1 report observed that Alloy $800 \mathrm{H}$ grain sizes generally range from ASTM GS No. 0 to 5 which corresponds to a range from 360 to $64 \mu \mathrm{m}$. This size difference produces a factor of 200 in creep rate from coarse to fine, so this aspect of diffusional creep can be easily assessed from this perspective. A factor of two in stress corresponds to a factor of two in the diffusional creep rate and a factor of 16 for dislocation creep rate, so testing at stresses that are a factor of two apart would accurately assess this aspect of diffusional creep. Regarding temperature sensitivity, a difference of $\pm 50^{\circ} \mathrm{C}$, say between 850 and $950^{\circ} \mathrm{C}$, would produce an increase in the diffusional creep rate of a factor of four and an increase in the dislocation creep rate of a factor around 20. 


\begin{tabular}{|c|lll|}
\hline NEXT GENERATION NUCLEAR PLANT STEAM & Identifier: & PLN-2804 \\
GENERATOR AND INTERMEDIATE HEAT & Revision: & 1 & \\
EXCHANGER MATERIALS RESEARCH & Effective Date: & $09 / 23 / 10$ & Page: 135 of 252 \\
AND DEVELOPMENT PLAN & &
\end{tabular}

Based on these observations, a test plan was developed by Task 1 to explore the creep mechanisms of Alloy $800 \mathrm{H}$. The test matrix is shown in Table A29 of Appendix A. A portion of this work is underway at University of Cincinnati with NEUP support.

\subsubsection{Yield and Tensile Strength Reduction Factor}

This effort addresses Item F7 in Table 20 of Section 5.5.

Thermal aging is not a significant concern within the specified temperature limit of $760^{\circ} \mathrm{C}$ for Alloy $800 \mathrm{H}$. Yield and tensile strength reduction factors are both required to be 0.9 for service temperatures greater than $730^{\circ} \mathrm{C}$ in Subsection NH. These factors are valid up to $300,000 \mathrm{~h}$. Extension of these factors to $500,000 \mathrm{~h}$ is required to support the NGNP intermediate temperature IHX and core internal application.

The longest aging time in the original dataset that supported the current strength reduction factors was $\sim 20,000$ h. Recently, Swindeman et al. ${ }^{117}$ have compared the yield and tensile strengths of service-exposed Alloy $800 \mathrm{H}\left(73,500 \mathrm{~h}\right.$ at $752^{\circ} \mathrm{C}$ to $\left.774^{\circ} \mathrm{C}\right)$ with laboratory results from Alloy $800 \mathrm{H}$, thermally aged for $18,600 \mathrm{~h}$ at $760^{\circ} \mathrm{C}$ (see Figure 51). Only very small drops in strengths, within the typical data scatter, are observed.

A database from the literature that includes the original dataset that supported the current strength reduction factors has been completed in ASME Task 1. Strength reduction factors up to 500,000 h will be developed by extrapolating the data using statistical methods to support conceptual and preliminary design activities. These reduction factors will be qualified for final design and licensing approval using data from a small-scale long-term aging qualification test program as proposed in Table A30 of Appendix A. Results for some of the baseline (unaged) tests in test matrix A30 are presented in Section 4.1.2.3.

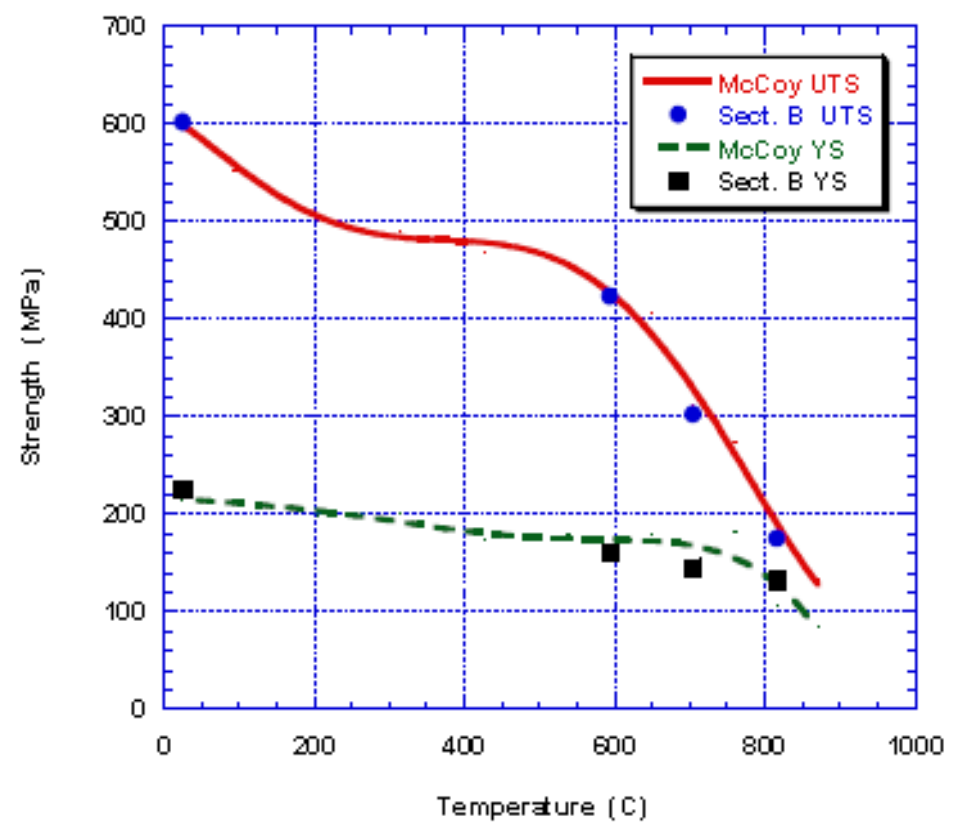

Figure 51. Strengths comparison of service-exposed (73,500 h) and laboratory-exposed (18,600 h) Alloy $800 \mathrm{H}$. 


\begin{tabular}{|c|lll|}
\hline $\begin{array}{c}\text { NEXT GENERATION NUCLEAR PLANT STEAM } \\
\text { GENERATOR AND INTERMEDIATE HEAT }\end{array}$ & Identifier: & PLN-2804 & \\
EXCHANGER MATERIALS RESEARCH & Revision: & 1 & \\
AND DEVELOPMENT PLAN & Effective Date: & $09 / 23 / 10$ & Page: 136 of 252 \\
\hline
\end{tabular}

\subsubsection{Cold Work Effect and Subsequent Heat Treatment Requirements}

This effort addresses Item F8 in Table 20 of Section 5.5.

The Alloy $800 \mathrm{H}$ time-temperature curve that governs short-term temperature excursion beyond the maximum allowable temperature for the purpose of heat treatment needs to be extended to 500,000 $\mathrm{h}$. Research into how the original curve for up to $300,000 \mathrm{~h}$ was created will be performed. Additional tests will be proposed in the future if it is determined that testing is necessary to support the extension of the time-temperature curve. Prohibiting cold work for service beyond $300,000 \mathrm{~h}$ is an option under consideration.

\subsubsection{Effect of Multiaxial Stress State on Creep-Fatigue Procedure}

This effort addresses Item F9 in Table 20 of Section 5.5.

The "C" factor in the multiaxial creep-rupture strength criterion has a value of $\mathrm{C}=0$ for Alloy $800 \mathrm{H}$ in Subsection NH. Biaxial creep-rupture tests similar to those proposed for Alloy 617 in Section 7.1.4.8, but at $850^{\circ} \mathrm{C}$, are proposed in Table A31 of Appendix A to validate the value of $\mathrm{C}=0$ for Alloy $800 \mathrm{H}$.

\subsection{Additional Research Programs}

\subsubsection{Diffusion Bonding and/or Brazing}

The potential for detrimental effects associated with high temperature thermal cycles during brazing and diffusion bonding will be determined. A scoping study on diffusion bonding for compact heat exchangers has been initiated using Alloy $800 \mathrm{H}^{118}$ and will be expanded to include Alloy 617 as part of the NGNP Heat Transport System Components Engineering Test Plan. ${ }^{71}$ The purpose of the scoping study is to evaluate diffusion bonding process parameters and the resultant mechanical properties of sample diffusion bonded joints, with the long-term goal of fabricating small diffusion bonded heat exchanger unit cells for testing.

\subsubsection{Define adequate bonds}

A test program must be developed to determine mechanical properties of the diffusion bonds or brazed joints. In addition it must be verified that the environmental effects in the joined regions are similar to the base metal, that the microstructure is stable with no chemical inhomogeneity, and that the grain size is acceptable. Any microstructural instability associated with the braze material or chemical interaction between the braze material and the base metal must be investigated.

\subsubsection{Determine process and procedures}

The optimum atmosphere, time, temperature and applied pressure must be defined for the diffusion bonding process, and the impact of any of these parameters on the microstructural stability must be determined. This process has begun in the diffusion bonding scoping study ${ }^{118}$ and will ultimately require extensive testing for ASME code development. The composition of any braze material must also be defined.

\subsubsection{Environmentally Assisted Cracking}

Experiments must be designed to test materials and components in gas representative of the NGNP gas. The chemical composition including anticipated impurities and moisture levels, the pressure $(\sim 7 \mathrm{MPa})$ and velocities up to $75 \mathrm{~m} / \mathrm{s}$ must all be accounted for. Under these conditions there is an increased potential for erosion. This effort will be coordinated with the NGNP Heat Transport System Components Engineering Test Plan. ${ }^{71}$ 


\begin{tabular}{|c|lll|}
\hline NEXT GENERATION NUCLEAR PLANT STEAM & Identifier: & PLN-2804 & \\
GENERATOR AND INTERMEDIATE HEAT & Revision: & 1 & \\
EXCHANGER MATERIALS RESEARCH & Effective Date: & $09 / 23 / 10$ & Page: 137 of 252 \\
AND DEVELOPMENT PLAN &
\end{tabular}

Assuming Alloy 617 is selected, the following tests will be required.

1. Conduct controlled chemistry creep crack growth measurements on plate, weldments and carburized material. Tests will be done at temperatures in the range of about 650 to $800^{\circ} \mathrm{C}$ where the material will flow but maintains enough strength to prevent flow that blunts crack growth.

2. Measure environmentally assisted crack growth rates as a function of oxygen partial pressure in the vicinity of $600^{\circ} \mathrm{C}$. Tests will include plate, weldments and carburized material.

3. Test plate and weldments in expected NGNP environmental conditions including NGNP pressure ( $7 \mathrm{MPa}$ or so) from 800 to $1000^{\circ} \mathrm{C}$ in quasi-static gas and with gas velocity from 25 to $75 \mathrm{~m} / \mathrm{s}$. Particle erosion effects will be included in the high velocity tests using particles selected to represent relatively soft graphite dust as well as harder oxides spalled from alloy surfaces (pressure vessel and IHX).

4. Conduct carburization and microclimate testing on $800 \mathrm{H}$ in the controlled chemistry loop, assuming it is chosen for control rods.

The other area of possible concern was creep crack growth in regions of the heat exchanger that experience temperatures intermediate between those that give rise to stress assisted grain boundary oxidation $\left(<700^{\circ} \mathrm{C}\right)$ and the creep-fatigue regime $\left(>850^{\circ} \mathrm{C}\right)$. In this temperature range, there is sufficient creep deformation to drive crack growth and sufficient material strength to prevent crack blunting by massive deformation. Experimental validation of an environmental effects model in controlled chemistry He will be completed for Alloy 617. The stability of microstructures and mechanical properties will be characterized for temperatures ranging from $800-1000^{\circ} \mathrm{C}$, with impurity contents expected in the NGNP environment.

\subsubsection{Test Methods}

\subsubsection{Lab-scale}

Section 7.1 details the laboratory scale testing planned.

\subsubsection{Pilot and component scale}

Conceptual design for a facility to test pumps, valves and heat exchangers will be completed. Prototype IHXs will be tested in a high velocity flow loop to confirm the performance is consistent with the design rules on scaled down components. Construction of test loops is discussed in the Heat Transport System Component Test Plan. ${ }^{71}$

\subsubsection{Engineering scale}

There are no engineering scale issues from a materials point of view. There will be engineering tests to determine the flow, pressure drop, etc., of the IHX are satisfactory.

\subsubsection{Data Management}

Data management for this program should consist of at least three major parts: (1) plans for efficient data generation in resources, time, and cost; (2) maintenance of data to achieve maximum benefits to the present reactor development and future reactor operation; (3) quality assurance.

In data maintenance and quality assurance, the technical information produced from the R\&D activities in this program will need to be kept retrievable for the entire period of the reactor development, plus the reactor service life of 60 years and beyond. Therefore, all the information generated should be documented in the NDMAS (NGNP Data Management and Analysis System) in compliance with relevant QA requirements. Some of the data generated through this R\&D plan will be incorporated into the Gen IV 


\begin{tabular}{|c|lll|}
\hline $\begin{array}{c}\text { NEXT GENERATION NUCLEAR PLANT STEAM } \\
\text { GENERATOR AND INTERMEDIATE HEAT }\end{array}$ & Identifier: & PLN-2804 & \\
EXCHANGER MATERIALS RESEARCH & Revision: & 1 & \\
AND DEVELOPMENT PLAN & Effective Date: & $09 / 23 / 10$ & Page: 138 of 252 \\
\hline
\end{tabular}

Materials handbook as specified by the GIF agreements. An introduction of the Gen IV Materials Handbook development can be found in Ren. ${ }^{119}$

\subsection{Cost}

\subsubsection{Material and Fabrication}

The following additional materials will need to be purchased:

- $2500 \mathrm{lbs}$. of each of two additional heats of Alloy 617 plate at an estimated price of $\$ 30 / \mathrm{lb}$. In addition, a $3 \mathrm{~mm}$ sheet of the heats must be obtained for experiments in case a thin sheet IHX is used.

- About $500 \mathrm{lbs}$. of an additional heat of $800 \mathrm{H}$ plate for testing at an estimated price of $\$ 30 / \mathrm{lb}$.

- Miscellaneous consumables such as atmospheric gases and welding wire.

From the purchased Alloy 617 plate material, hundreds of test specimens of various types must be prepared, some of which require careful polishing, or more complex geometries than the typical tensile specimen. Preliminary processing such as pre-cracking, welding, heat treating, irradiation, etc. is required for many of the specimens.

Extra material must be purchased to allow for future testing from the same heats. This will provide for additional testing deemed necessary during the NGNP design and development phase after preliminary data has been gathered. In addition, it must be sufficient for any future testing needs that may arise during the life of the plant. It could also support future modifications or additions to the ASME Code.

\subsubsection{Cost of Testing}

Appropriate test facilities are rare, especially for controlled impure $\mathrm{He}$ and at elevated temperatures. Refurbishing or modification of existing equipment requires careful planning, time, and resources, and new equipment can be costly.

Some of the proposed tests are fairly unique and sophisticated with variations in strain rate, load magnitude or direction, cycle frequency, hold times, etc. It appears that only limited irradiation testing is required; however, that testing is particularly costly as sample time in a reactor is extremely hard to obtain and very expensive. It is anticipated that some engineering design will be required for fixturing and test set-up.

With testing comes analysis. The microstructure and/or fracture surfaces will require metallurgical analysis for many of the samples. Data must be analyzed for individual specimens to ensure valid testing and extract necessary quantities, for groups of specimens to ensure statistical significance and make comparisons, produce figures and the like.

Constitutive modeling is a significant task and current plans are to subcontract much of that work. Efforts to support ASME Code modifications will also be substantial. As always, analysis and reporting will be ongoing tasks.

The cost break down is shown in Table 30 and Table 31. 


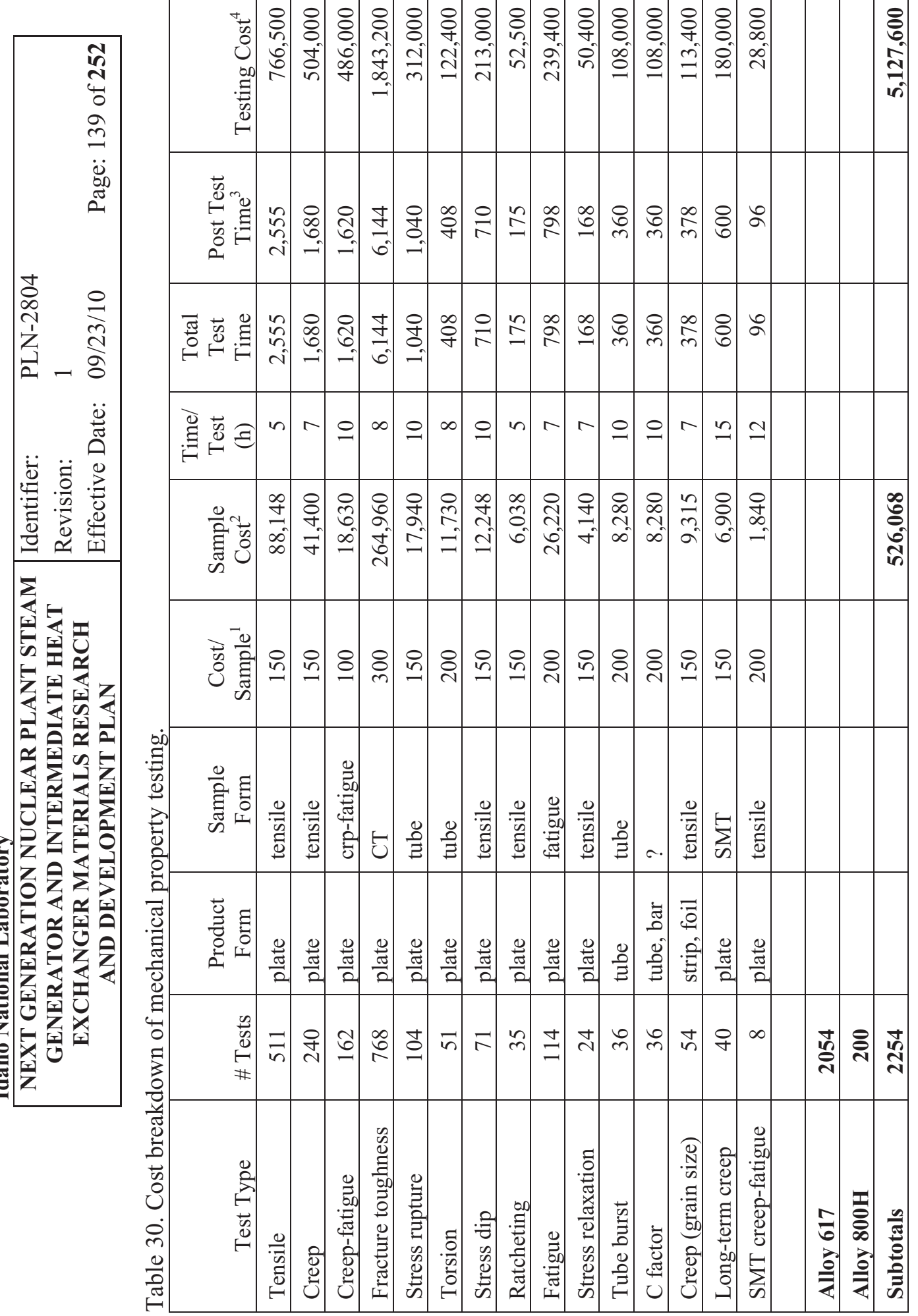


Idaho National Laboratory

\begin{tabular}{|c|lll|}
\hline $\begin{array}{c}\text { NEXT GENERATION NUCLEAR PLANT STEAM } \\
\text { GENERATOR AND INTERMEDIATE HEAT }\end{array}$ & Identifier: & PLN-2804 & \\
EXCHANGER MATERIALS RESEARCH & Revision: & 1 & \\
AND DEVELOPMENT PLAN & Effective Date: & $09 / 23 / 10$ & Page: 140 of 252 \\
\hline
\end{tabular}

Table 31. Cost breakdown for high temperature materials R\&D plan.

\begin{tabular}{|c|c|c|}
\hline (All values in FY-09 burdened \$) & $\operatorname{Cost}(\$)$ & Subtotals \\
\hline Material Cost & & $1,593,888$ \\
\hline 617 & 400,000 & \\
\hline $800 \mathrm{H}$ & 100,000 & \\
\hline cost to machine samples & 526,068 & \\
\hline consumables & 200,000 & \\
\hline Adder for purchasing $(30 \%)$ & 367,820 & \\
\hline Labor for Testing & & $7,377,600$ \\
\hline test method development and validation & 250,000 & \\
\hline mechanical property testing & $5,127,600$ & \\
\hline physical property testing & 500,000 & \\
\hline corrosion testing & 500,000 & \\
\hline irradiation testing & $1,000,000$ & \\
\hline Equipment Purchase & & $4,322,500$ \\
\hline load frames & $1,500,000$ & \\
\hline fixtures & 75,000 & \\
\hline furnaces & 250,000 & \\
\hline repair, upgrade and refurbishing & $1,500,000$ & \\
\hline adder for purchasing $(30 \%)$ & 997,500 & \\
\hline Other Labor & & $5,400,000$ \\
\hline analysis and reporting & 900,000 & \\
\hline engineering design support & 600,000 & \\
\hline project engineer & 900,000 & \\
\hline constitutive modeling & 800,000 & \\
\hline ASME Code interface & $1,600,000$ & \\
\hline modification of ASME Subsection NH & 600,000 & \\
\hline Subcontracts & $1,100,000$ & \\
\hline Subtotal for Labor & & $12,777,600$ \\
\hline Subtotal for Materials \& Equipment & & $5,916,388$ \\
\hline Subtotal & & $18,693,988$ \\
\hline Quality Assurance (10\%) & $1,869,399$ & \\
\hline Program Management (10\%) & $1,869,399$ & \\
\hline Total & & $22,432,786$ \\
\hline
\end{tabular}


Idaho National Laboratory

\begin{tabular}{|c|lll|}
\hline NEXT GENERATION NUCLEAR PLANT STEAM & Identifier: & PLN-2804 & \\
GENERATOR AND INTERMEDIATE HEAT & Revision: & 1 & \\
EXCHANGER MATERIALS RESEARCH & Effective Date: & $09 / 23 / 10$ & Page: 141 of 252 \\
AND DEVELOPMENT PLAN &
\end{tabular}

\subsection{Schedule}

A large matrix of required testing to support design and licensing of the NGNP has been developed as part of this TDP. A detailed schedule for completion of the necessary R\&D has been developed. A summary of the high-level activities described by this schedule is shown in the table below.

\begin{tabular}{|c|c|c|c|}
\hline Activity & Start & Finish & 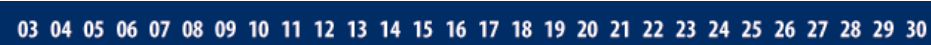 \\
\hline HIGH TEMPERATURE MATERIALS & $10 / 2 / 06$ & $9 / 3 / 30$ & \\
\hline IHX Code Activities & 10/1/07 & $9 / 3 / 30$ & $\square$ \\
\hline High Temperature Design & $10 / 1 / 07$ & $3 / 22 / 16$ & High Temperature Design \\
\hline Inconel 617 & $4 / 16 / 08$ & $9 / 3 / 30$ & \\
\hline Inconel 617 Testing & $10 / 1 / 08$ & $6 / 28 / 16$ & $\square$ Inconel 617 Testing \\
\hline Inconel 617 Modeling & $6 / 3 / 15$ & $5 / 29 / 18$ & $\square$ Inconel 617 Modeling \\
\hline Inconel 617 Long-term Creep Testing & 2/4/09 & $9 / 3 / 30$ & 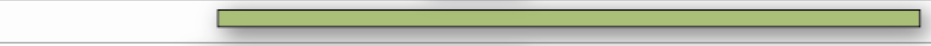 \\
\hline Inconel 617 ASME Code Case & $4 / 16 / 08$ & $5 / 1 / 18$ & Inconel 617 Code Case \\
\hline Alloy $800 \mathrm{H}$ Plate & $7 / 30 / 09$ & $10 / 9 / 19$ & Alloy $800 \mathrm{H}$ Plate \\
\hline Alloy $800 \mathrm{H}$ Testing & $7 / 30 / 09$ & $8 / 21 / 14$ & Alloy $800 \mathrm{H}$ Testing \\
\hline Alloy $800 \mathrm{H}$ Aging & $6 / 11 / 10$ & $3 / 22 / 18$ & $\square$ Alloy $800 \mathrm{H}$ Aging \\
\hline Alloy $800 \mathrm{H}$ Characterization & $10 / 15 / 15$ & $10 / 9 / 19$ & $\square$ Alloy $800 \mathrm{H}$ Characterization \\
\hline Licensing Support & $10 / 9 / 19$ & $10 / 9 / 19$ & $>$ Licensing Support \\
\hline HTM Data Qualification and Analysis & $10 / 1 / 09$ & $4 / 4 / 18$ & HTM Data Qualification and Analysis \\
\hline ASME Code Case for HTM & $4 / 1 / 13$ & $3 / 24 / 17$ & $\square$ ASME Code Case for HTM \\
\hline NRC HTM Licensing Support & $9 / 24 / 19$ & $9 / 24 / 19$ & $\triangle N R C$ HTM Licensing Support \\
\hline
\end{tabular}

Figure 52. Schedule for NGNP SG and IHX materials R\&D high level activities. 


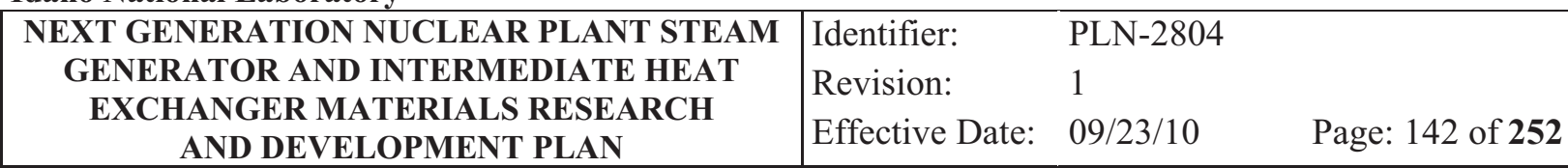

\section{REFERENCES}

1. Mizia R. E., INL, Next Generation Nuclear Plant Intermediate Heat Exchanger Acquisition Strategy; INL/EXT-08-14051; April 2008.

2. Wright J. K., et al., INL, Next Generation Nuclear Plant Intermediate Heat Exchanger Materials Research and Development Plan; PLN-2804 Revision 0; April 2008.

3. Collins J. W., INL, Next Generation Nuclear Plant Project Technology Development Roadmaps: The Technical Path Forward; INL/EXT-08-15148; January 2009.

4. Collins J. W., INL, Next Generation Nuclear Plant Project Technology Development Roadmaps: The Technical Path Forward for $750-800^{\circ} \mathrm{C}$ Reactor Outlet Temperature; INL/EXT-09-16598; August 2009.

5. INL, Next Generation Nuclear Plant Pre-Conceptual Design Report; INL/EXT-07-12967 Revision 1; November 2007.

6. AREVA NP Inc., NGNP with Hydrogen Production Preconceptual Design Studies Report Executive Summary; 12-9052076-000; June 2007.

7. Caspersson S. A., Westinghouse Electric Company LLC, Nuclear Power Plants, NGNP and Hydrogen Production Preconceptual Design Report Executive Summary Report; NGNP-ESRRPT-001 Revision 1; June 2007.

8. General Atomics, Preconceptual Engineering Services for the Next Generation Nuclear Plant (NGNP) with Hydrogen Production; PC-000544; 7/10/2007.

9. Koekemoer W., Westinghouse Electric Company LLC, Next Generation Nuclear Plant Report on Update of Technology Development Roadmaps for NGNP Steam Production at $750^{\circ} \mathrm{C}-800^{\circ} \mathrm{C}$; NGNP-TDI-TDR-RPT-G- 00003 Revision 0; April 2009.

10. Crozier J., General Atomics, Engineering Services for the Next Generation Nuclear Plant (NGNP) with Hydrogen Production Test Plan-Steam Generator for $750^{\circ} \mathrm{C}$ Reactor Outlet Helium Temperature; 911174, Revision 0; December 16, 2008.

11. Saurwein, General Atomics, Technology Development Road Mapping Report for NGNP with $750^{\circ} \mathrm{C}$ Reactor Outlet Helium Temperature; PC-000586/0; November 2009.

12. Schultz R. R., Idaho National Laboratory, INL, NGNP Engineering White Paper: Power Conversion System Trade Study; INL/EXT-07-12727; April 2007.

13. Sherman S. R., Idaho National Laboratory, INL, NGNP Engineering White Paper: NGNP Project Pre-Conceptual Heat Transfer and Transport Studies; INL/EXT-07-12730; April 2007.

14. Vandel D. S., Idaho National Laboratory, INL, NGNP Engineering White Paper: Primary and Secondary Cycle Trade Study; INL/EXT-07-12732; April 2007.

15. Weaver K. D., Idaho National Laboratory, NGNP Engineering White Paper: Reactor Type Trade Study; INL/EXT-07-12729.

16. GA Technologies Inc., DOE, Reactor Core Subsystem Design Description (Modular HTGR Plant); DOE-HTGR-86-036; July 1987.

17. Shenoy A. S., General Atomics, Gas Turbine - Modular Helium Reactor (GT-MHR) Conceptual Design Description Report; RGE-910720; July 1996. 


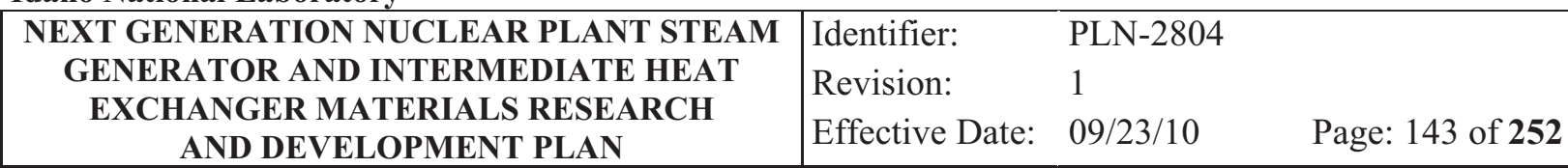

18. Turner R. F., et al., "Annular Core for the Modular High-Temperature Gas-Cooled Reactor (MHTGR),” Nuclear Engineering and Design, Vol. 109, 1988, p. 227-231.

19. Hittner D., "The European Programme of Development of HTR/VHTR Technology," Proceedings of the Conference on High Temperature Reactors HTR-2004, Beijing, China, 22-24 September 2004, International Atomic Energy Agency, Vienna, Austria: p. 1-17.

20. AREVA Federal Services, LLC, NGNP Technology Development Road Mapping Report; TDR3001031-002; April 2009.

21. Natesan K., et al., Argonne National Laboratory, Materials Behavior in HTGR Environments; ANL-02/37 NUREG/CR-6824; February 2003.

22. Fazluddin S., et al., "The Use of Advanced Materials in VHTR's," 2nd International Topical Meeting on High Temperature Reactor Technology, Beijing, China, September 22-24, 2004.

23. Ion S., et al. "Pebble Bed Modular Reactor the First Generation IV Reactor to Be Constructed," http://www.world-nuclear.org/sym/2003/matzie.htm.

24. Matzner D., "PBMR Project Status and the Way Ahead," Proceedings of the 2nd International Topical Meeting on High Temperature Reactor Technology, Beijing China, September 22-24, 2004, International Atomic Energy Agency: p. 1-13.

25. Koster A., et al., "PBMR: A Generation IV High Temperature Gas Cooled Reactor," Proc. Instn Mech. Engrs, J. Power and Energy, 2004: Vol. 218, Part A.

26. Broom N. and Smit K., "PBMR Design Methodology," slides, Oak Ridge, TN, 12th April 2005.

27. Davis C. B., Revised RELAP5-3D Thermal Analysis Results for Prismatic VHTR, 2006, unpublished work.

28. Westinghouse Electric Company, LLC, NGNP Technology Development Road Mapping Report; NGNP-CTF MTECH-TDRM-003; December 2008.

29. PBMR, PBMR, Licensing Basis Event Selection for the Pebble Bed Modular Reactor; PBMR040251 .

30. Carosella D., et al., General Atomics, Test Plan - Steam Generator Helical-Coil Design; 911142, Revision 0;12/16/2008.

31. Campbell D. J., Steam Generator Technical Development Status Report; CEGA-002781.

32. Wright R. N., INL, Inconel 617 and Haynes 230 Down-Select; ECAR-346; 9/2/2008.

33. Ren W. and Swindeman R., "Preliminary Consideration of Alloys 617 and 230 for Generation IV Nuclear Reactor Applications," Proceedings of the 2007 ASME Pressure Vessels and Piping Division Conference, San Antonio, TX, July 22-26, 2007.

34. B 168 - 08, Standard Specification for Nickel-Chromium-Iron Alloys (UNS N06600, N06601, N06603, N06690, N06693, N06025, N06045, and N06696) and Nickel-Chromium Cobalt Molybdenum Alloy (UNS N06617) Plate, Sheet, and Strip, ASTM International, 2008.

35. Ren W. and Swindeman R. W., "A Review of Aging Effects in Alloy 617 for Gen IV Nuclear Reactor Applications," Proceedings of the 2006 ASME Pressure Vessels and Piping Division Conference, Vancouver, BC Canada, July 23 - 27, 2006. 


\begin{tabular}{|c|lll|}
\hline $\begin{array}{c}\text { NEXT GENERATION NUCLEAR PLANT STEAM } \\
\text { GENERATOR AND INTERMEDIATE HEAT }\end{array}$ & Identifier: & PLN-2804 \\
EXCHANGER MATERIALS RESEARCH & Revision: & 1 & \\
AND DEVELOPMENT PLAN & Effective Date: & $09 / 23 / 10$ & Page: 144 of 252 \\
\hline
\end{tabular}

36. Ren W. and Swindeman M. J., ORNL, Development of a Controlled Material Specification for Alloy 617 for Nuclear Applications; ORNL/TM-2005/504; May 30, 2005.

37. Natesan K., et al., Argonne National Laboratory, Preliminary Issues Associated with the Next Generation Nuclear Plant Intermediate Heat Exchanger Design; ANL/EXT-06-46; September 2006.

38. Totemeier T. and Tian H., "Creep-Fatigue-Environment Interactions in Inconel 617," Materials Science and Engineering A, Vol. 468-470, 2007, p. 81-87.

39. Lillo T., et al., "Influence of Grain Boundary Character on Creep Void Formation in Alloy 617," Metallurgical and Materials Transactions A, Vol. 40A, 12, 2009, p. 2803-2811.

40. Krompholz K., et al., "Determination of J-Integral R-Curves for Hastelloy X and Inconel 617 up to 1223k Using the Potential Drop Technique,” Werkstofftech., Vol. 13, 1982, p. 236-244.

41. Clarke G. A., et al., "A Procedure for Determination of Ductile Fracture Toughness Values Using J-Integral Techniques," Journal of Testing and Evaluation, Vol. 7, 1979, p. 49-56.

42. Landes J. D. and Begley J. A., ASTM, Test Results from J-Integral Studies; an Attempt to Establish a JIC Testing Procedure; STP 560.

43. Bassford T. H. and Schill T. V., "A Review of Inconel Alloy 617 and Its Properties after LongTime Exposure to Intermediate Temperatures" in Applications of Materials for Pressure Vessels and Piping, Smith G. V., Ed. ASME: 1979; Vol. MPC-10, p. 1-12.

44. Bruch U., et al., "Tensile and Impact Properties of Candidate Alloys for High-Temperature GasCooled Reactor Applications," Nuclear Technology, Vol. 66, 1984, p. 357-362.

45. Bassford T. H., Data Package Provided by Huntington Alloys to ASME Code Committee for Use in the Development of the Draft Alloy 617 Code Case.

46. High Temp Metals Inc., "Inconel 617 Technical Data," http://www.hightempmetals.com/techdata/hitempInconel617data.php (2/5/08).

47. Kofford K. G., INL, Inconel 617 (P-43) - GTAW; I5.0; 08/05/09.

48. B 409 - 06, Standard Specification for Nickel-Chromium Alloy Plate, Sheet, and Strip, ASTM International, 2007.

49. Swindeman R. W., et al., Cromtech Inc. et al., Task 1. Report on the Review of Databases, Data Analysis Procedures and Verification of Minimum and Ultimate Strengths for Alloy $800 \mathrm{H}$ in ASME Section III, Subsection NH; March, 2007.

50. Kofford K. G., INL, Alloy 800H - GTAW (ERNiCrCoMo-1 / UNS N06617 Filler Metal); I5.1; $06 / 02 / 10$.

51. Kofford K. G., INL, Alloy 800H - GTAW (ERNiCr-3/ UNS N06082 Filler Metal); I5.2; 06/02/10.

52. Christ H. J., et al., "Mechanisms of High-Temperature Corrosion in Helium Containing Small Amounts of Impurities. II. Corrosion of Nickel- Base Alloy Inconel 617,” Oxidation of Metals, Vol. 30, 1988, p. 27-51. 


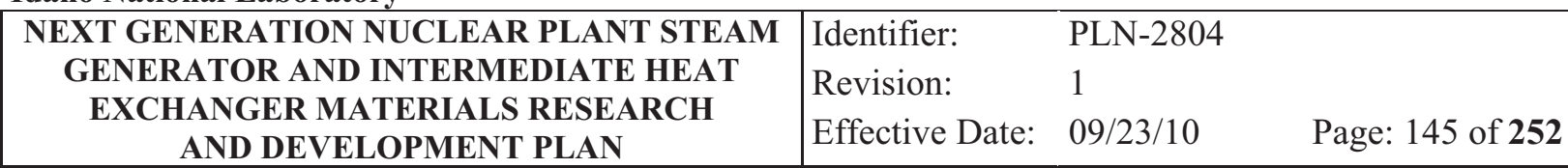

53. Christ H. J., et al., "High Temperature Corrosion of the Nickel-Based Alloy Inconel 617 in Helium Containing Small Amounts of Impurities," Materials Science and Engineering, Vol. 87, 1987, p. 161-168.

54. Graham L. W., "Corrosion of Metallic Materials in HTR-Helium Environments," Journal of Nuclear Materials, Vol. 171, 1977, p. 155-178.

55. Brenner K. G. E. and Graham L. W., "The Development and Application of a Unified Corrosion Model for High-Temperature Gas-Cooled Reactor Systems," Nuclear Technology, Vol. 66, 1984, p. 404-414.

56. Berman I. and Gupta G. D., "Buckling Rules for Nuclear Components “ Journal of Pressure Vessel Technology, Vol. 98, 1976, p. 229-231.

57. Jakub M. T., "New Rules for Construction of Section III, Class 1 Components for Elevated Temperature Service," Journal of Pressure Vessel Technology, Vol. 98, 1976, p. 214-222.

58. Jetter R. I., "Elevated Temperature Design - Development and Implementation of Code Case 1592," Journal of Pressure Vessel Technology, Vol. 98, 1976, p. 222-229.

59. Companion Guide to the ASME Boiler \& Pressure Vessel Code. New York, NY: ASME Press, 2002 .

60. Shah V. N., et al., Argonne National Laboratory, Review and Assessment of Codes and Procedures for HTGR Components; NUREG/CR-6816; June 2003.

61. Chaboche J. L. and Nouailhas D., "A Unified Constitutive Model for Cyclic Viscoplasticity and Its Applications to Various Stainless Steels," Journal of Engineering Materials and Technology, Vol. 111, 1989, p. 424-430.

62. Tachibana Y. and Krempl E., "Modeling of High Homologous Temperature Deformation Behavior Using the Viscoplasticity Theory Based on Overstress (Vbo): Part III -a Simplified Model," Journal of Engineering Materials and Technology, Vol. 120, 1998, p. 193-196.

63. Tachibana Y. and Krempl E., "Modeling of High Homologous Temperature Deformation Behavior Using the Viscoplasticity Theory Based on Overstress (Vbo): Part II - Characteristics of the Vbo Model," Journal of Engineering Materials and Technology, Vol. 119, 1997, p. 1-6.

64. Tachibana Y. and Krempl E., "Modeling of High Homologous Temperature Deformation Behavior Using the Viscoplasticity Theory Based on Overstress (Vbo): Part I - Creep and Tensile Behavior," Journal of Engineering Materials and Technology, Vol. 117, 1995, p. 456-461.

65. Walker K. P., “A Uniformly Valid Asymptotic Integration Algorithm for Unified Viscoplastic Constitutive Models “ in Advances in Inelastic Analysis, Amd, Nakazawa S.al., Eds. American Society of Mechanical Engineers: New York, 1987; Vol. 28, p. 13-27.

66. Sham T.-L., Oak Ridge National Laboratory, Creep and Creep-Fatigue Crack Growth Processes in HTGR and VHTR Materials; ORNL/TM-2009/034, Draft; January 2009.

67. Abou-Hanna J. J., et al., Advanced Consulting Engineering Services, Inc., Task 9. Update and Improve Subsection NH - Simplified Elastic and Inelastic Design Analysis Methods, Subtask 9.5 - Recommendations for Revisions of ASME Elevated Temperature Design (ETD) Code; 10/27/2009. 


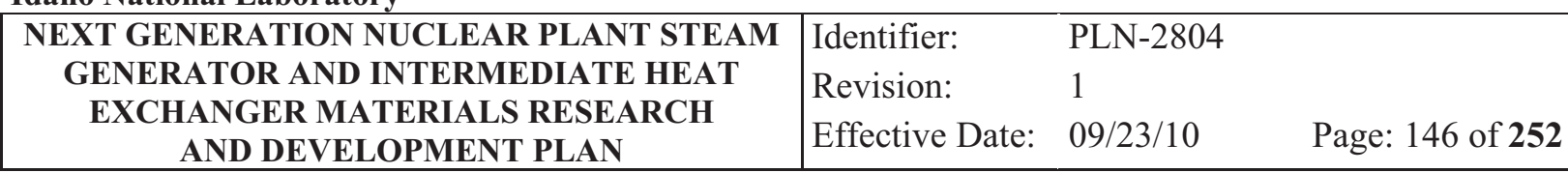

68. Hayner G. O., et al., INL, Next Generation Nuclear Plant Materials Research and Development Program Plan, Revision 4; INL/EXT-06-11701; 10/03/2007.

69. Corum J. M. and Blass J. J., "Rules for Design of Alloy 617 Nuclear Components to Very High Temperatures," PVP (Pressure Vessel and Piping), Vol. 215, Fatigue, Fracture, and Risk ASME, 1991, p. 147-153.

70. Ren W., et al., U. S. Department of Energy Generation IV Nuclear Reactor Program, Status of Testing and Characterization of CMS Alloy 617 and Alloy 230; ORNL/TM-2006-547; August 31, 2006.

71. Wright J. K. and Landman W. H., INL, NGNP Heat Transport System Components Engineering Test Plan; PLN-3305 Revision 1; June 28, 2010.

72. Vandel D. S. and Bader S., Idaho National Laboratory (INL), NGNP Engineering White Paper: By-Products Trade Study; INL/EXT - 07-12728; April 2007.

73. Majumdar S., et al., Argonne National Laboratory, Candidate Materials and Potential in-Service Degradation Issues for Steam Generator in the Primary Loop of Next Generation Nuclear Plant; ANL/EXT-09-25; September 2009.

74. Tapping R., "Steam Generator Aging in Candus: 30 Years of Operation and R\&D," Toronto, Ontario, Canada, November 26-29, 2006.

75. Steam Generator Owners Group, Steam Generator Reference Book. Palo Alto, CA: Electric Power Research Institute, 1985.

76. EPRI, Steam Generator Progress Report; TR-106365-R15.

77. Coriou H., et al., "Sensitivity to Stress Corrosion and Intergranular Attack of High-Nickel Austenitic Alloys," Corrosion, Vol. 22, 1966, p. 280-290.

78. Majumdar S., Argonne National Laboratory, Assessment of Current Understanding of Mechanisms of Initiation, Arrest and Reinitiation of Stress Corrosion Cracks in PWR Steam Generator Tubing; NUREG/CR-5752 ANL-99/4.

79. DuPont J. N., INL, Review of Dissimilar Metal Welding for the NGNP Helical Coil Steam Generator; INL/EXT-10-1849; March 23, 2010.

80. King J. F., et al., "Development of an Improved Stainless Steel to Ferritic Steel Transition Joint," Welding Journal, Vol. 56, 11, 1977, p. 354s-358s.

81. Klueh R. L. and King J. F., Oak Ridge National Laboratory, Elevated-Temperature Tensile and Creep-Rupture Behavior of Alloy 800H/ERNiCr-3 Weld Metal/2.25Cr-1Mo Steel Dissimilar Metal Weldments.

82. Parker J. D. and Stratford G. C., "The High-Temperature Performance of Nickel-Based Transition Joints: I. Deformation Behaviour," Materials Science and Engineering, Vol. A 299, 2001, p. 164-173.

83. Parker J. D. and Stratford G. C., "The High-Temperature Performance of Nickel-Based Transition Joints: II. Fracture Behaviour," Materials Science and Engineering, Vol. A 299, 2001, p. 174-184.

84. Nicholson R., "Effect of Aging on Interfacial Structures of Nickel-Based Transition Joints," Metals Technology, Vol. 11, 1984, p. 115-124. 


\begin{tabular}{|c|lll|}
\hline $\begin{array}{c}\text { NEXT GENERATION NUCLEAR PLANT STEAM } \\
\text { GENERATOR AND INTERMEDIATE HEAT }\end{array}$ & Identifier: & PLN-2804 \\
EXCHANGER MATERIALS RESEARCH & Revision: & 1 & \\
AND DEVELOPMENT PLAN & Effective Date: & $09 / 23 / 10$ & Page: 147 of 252 \\
\hline
\end{tabular}

85. Nicholson R., "Effect of Post-Weld Heat Treatment on Development of Interfacial Structures in Nickel-Based Transition Joints," Materials Science and Technology, Vol. 1, 1985, p. 227-233.

86. Dewson S. J. and Thonon B., "The Development of High Efficiency Heat Exchangers for Helium Gas Cooled Reactors," Proceedings of the International Congress on Advances in Nuclear Power Plants, Cordoba, Spain, May 4-7 2003: p. 1-13.

87. Dewson S. J. and Li X., "Selection Criteria for the High Temperature Reactor Intermediate Heat Exchanger," Proceedings of ICAPP'05, Seoul, Korea, May 15-19, 2005: p. 1-7.

88. Li X., et al., "Heat Exchangers for the Next Generation of Nuclear Reactors," Proceedings of ICAPP '06, Reno, NV, June 4-8. 2006.

89. Schwertel J., et al., "Experimental Investigations on the Ni-Base Superalloy In617 and Their Theoretical Description" in High Temperature Constitutive Modeling - Theory and Application, Freed A.Walker K., Eds. ASME: New York, N.Y., 1991; Vol. MD-Vol. 26, p. 285-295.

90. Roberson D. N. and Bartolotta P. A., NASA, Viscoplastic Constitutive Relationships with Dependence on Thermomechanical History; NASA CR174836.

91. Roberson D. N., "Constitutive Relationship for Anisotropic High Temperature Alloys," Nuclear Engineering and Design, Vol. 83, 1984, p. 389-396.

92. Baldwin D. H., et al., General Electric Company, Design Data for Reference Alloys: Inconel 617 and Alloy 800H; DOE/HTGR-86-041; April 1986.

93. Jetter R. I., “An Alternate Approach to Evaluation of Creep-Fatigue Damage for High Temperature Structural Design Criteria" in PVP Fatigue, Fracture, and High Temperature Design Methods in Pressure Vessels and Piping, ASME: New York, N.Y., 1988; Vol. 5.

94. Chandra S., et al., "Creep Rupture Data Assessments of Alloy 617," Proceedings, Creep \& Fracture in High Temperature Components - Design \& Life Assessment Issues; Shibli I. A. et al., Eds.: p. 178-188.

95. Petten Database. ODIN at JRC of European Commission.

96. Eno D. R., et al., ASME, A Unified View of Engineering Creep Parameters; PVP2008-61129.

97. Inconel 617, UNS N06617, product sheet, Special Metals, 2005.

98. Swindeman M. J. and Ren W., ORNL; ORNL/TM-2005/511.

99. Frost H. J. and Ashby M. F., Deformation Mechanism Maps. Pergamon Press, 1982.

100. Cook, "Creep Properties of Inconel-617 in Air and Helium at 800 to 1000 C," Nuclear Technology, Vol. 66, 1984, p. 283-288.

101. Jetter R. I. and McGreevy T. E., ORNL, Simplified Design Criteria for Very High Temperature Applications in Generation IV Reactors; ORNL/TM-2004/308.

102. Huddleston R. L., “An Improved Multiaxial Creep-Rupture Strength Criterion,” Journal of Pressure Vessel Technology, Vol. 107, 1985, p. 421-429.

103. Rao K. B. S., et al., "Creep-Fatigue Interaction of Inconel 617 at 950c in Simulated Nuclear Reactor Helium," Materials Science and Engineering, Vol. A104, 1988, p. 37-51. 


\begin{tabular}{|c|lll|}
\hline $\begin{array}{c}\text { NEXT GENERATION NUCLEAR PLANT STEAM } \\
\text { GENERATOR AND INTERMEDIATE HEAT }\end{array}$ & Identifier: & PLN-2804 \\
EXCHANGER MATERIALS RESEARCH & Revision: & 1 & \\
AND DEVELOPMENT PLAN & Effective Date: & $09 / 23 / 10$ & Page: 148 of 252 \\
\hline
\end{tabular}

104. Schubert F., et al., "Creep Rupture Behavior of Candidate Materials for Nuclear Process Heat Applications," Nuclear Technology, Vol. 66, 1984, p. 227-240.

105. Swindeman R. W., et al., Cromtech Inc. et al., Task 1. Verification of Allowable Stresses in ASME Section III, Subsection NH with Emphasis on Alloy 800H and Grade 91 Steel Part 2. Creep-Rupture Data Sources, Data Analysis Procedures, and the Estimation of Strength for Alloy $800 \mathrm{H}$ at $750^{\circ} \mathrm{C}$ and Above: Creep; April, 2007.

106. Maziasz P. J., et al., ASME, Austenitic Stainless Steels and Alloys with Improved HighTemperature Performance for Advanced Microturbine Recuperators; GT2004-54239.

107. Shingledecker J. P., Creep Data for Alloy 230, 2008, personal communication with Sham T.-L., ORNL.

108. Martin J. M., Incoloy Alloy 800 Data for Use in Design of Gas Cooled and Liquid Metal Fast Reactors, Huntington Alloys, 1975, personal communication with Duke J. M., Westinghouse Electric Company.

109. Booker M. K., et al., ORNL, Survey of Available Creep and Tensile Data for Alloy 800H ORNL/TM-6029; January 1978.

110. McCoy H. E., ORNL, Tensile and Creep Tests on a Single Heat of Alloy 800H; ORNL/TM12436; September, 1993.

111. NIMS, National Institute for Materials Science, Data Sheets on the Elevated-Temperature Stress Relaxation Properties of Iron Based 21 cr-32ni-Ti-Al Alloy for Corrosion-Resisting and HeatResisting Superalloy Bar (Ncf 800H-B); NIMS Creep Data Sheet No. 47; March 1999.

112. NIMS, National Institute for Materials Science, Long-Term Creep Rupture Data Obtained after Publishing the Final Edition of the Creep Data Sheets; NMIS Creep Data Sheet No. 50; March 2004.

113. NRIM, National Research Institute for Metals, Data Sheets on the Elevated-Temperature Properties of Iron Based 21cr-32ni-Ti-Al Alloy for Heat Exchanger Seamless Tubes (Ncf 800H Tb); NRIM Creep Data Sheet No. 26B; September, 1998.

114. NRIM, National Research Institute for Metals, Data Sheets on the Elevated-Temperature Properties of Iron Based 21cr-32ni-Ti-Al Superalloy for Corrosion-Resisting and Heat-Resisting Superalloy Plates (Ncf 800H-P) NRIM Creep Data Sheet No. 27B; March 2000.

115. EPRI, Electric Power Research Institute, Survey and Guidelines for High Strength Superheater Materials-Alloy 800H; EPRI Program RP1403-14 Task 13; November 1987.

116. Gommans R. J., et al., "Oxidation Cracking and Residual Creep Life of an Incoloy 800H Bottom Manifold in a Steam Reformer at $800^{\circ} \mathrm{C}$," Proceedings of the Fifth International Conference on Creep of Materials, Lake Buena Vista, FL, 18-21 May, 1992: p. 257-263.

117. Swindeman M. J., et al., ASME, Effects of Long-Term Service on the Microstructure and Tensile Properties of Alloy 800H; CREEP2007-26167.

118. Mizia R., INL, Scoping Investigation of Diffusion Bonding for NGNP Process Application Heat Exchangers; PLN-3565, Rev. 0; June 28, 2010. 


\begin{tabular}{|c|lll|}
\hline NEXT GENERATION NUCLEAR PLANT STEAM & Identifier: & PLN-2804 \\
GENERATOR AND INTERMEDIATE HEAT & Revision: & 1 & \\
EXCHANGER MATERIALS RESEARCH & Effective Date: & $09 / 23 / 10$ & Page: 149 of 252 \\
AND DEVELOPMENT PLAN &
\end{tabular}

119. Ren W., "Development of Digital Materials Database for Design and Construction of New Power Plants," Proceedings of 2008 International Congress on Advances in Nuclear Power Plants, Anaheim CA, June 8-12, 2008.

120. Harvego E. A., INL, Evaluation of Next Generation Nuclear Power Plant (NGNP) Intermediate Heat Exchanger (IHX) Operation Conditions; INL/EXT - 06-11109; April 2006.

121. Pua L. M. and Rumbold S. O., "Industrial Microchannel Devices - Where Are We Today?," Rochester, NY, April 24-25, 2003.

122. Tonkovich A. L., "Microchannel Heat Exchangers: Applications and Limitations," slides, Plain City, $\mathrm{OH}$.

123. Wright J. K. and Lloyd W. L., Idaho National Laboratory, Analysis of Potential Materials for the Control Rod Sleeves of the Next Generation Nuclear Plant INL/EXT-06-11614; October, 2006.

124. INEEL, Idaho National Engineering and Environmental Laboratory, Next Generation Nuclear Plant Materials Research and Development Program Plan; INEEL/EXT-03-001128; November 7, 2003.

125. Mizia R. E., INL, Next Generation Nuclear Plant Reactor Pressure Vessel Acquisition Strategy; INL/EXT-08-13951; April 2008. 
Idaho National Laboratory

\begin{tabular}{|c|lll|}
\hline $\begin{array}{c}\text { NEXT GENERATION NUCLEAR PLANT STEAM } \\
\text { GENERATOR AND INTERMEDIATE HEAT }\end{array}$ & Identifier: & PLN-2804 \\
EXCHANGER MATERIALS RESEARCH & Revision: & 1 & \\
AND DEVELOPMENT PLAN & Effective Date: & $09 / 23 / 10$ & Page: 150 of 252 \\
\hline
\end{tabular}

\section{Appendix A}

\section{Test Matrices}

\begin{tabular}{|c|c|c|c|c|c|}
\hline \multicolumn{6}{|c|}{ Table A1. Tensile Test Matrix for $S_{m}$ Confirmatory Testing } \\
\hline Specimen Type & Specimen \# & Material & Product Form & Environment & Temp. $\left({ }^{\circ} \mathrm{C}\right)$ \\
\hline Tensile & 1 & Alloy 617 & PF-1 & air & $\mathrm{T} 1$ \\
\hline Tensile & 2 & Alloy 617 & PF-1 & air & $\mathrm{T} 1$ \\
\hline Tensile & 3 & Alloy 617 & PF-1 & air & $\mathrm{T} 2$ \\
\hline Tensile & 4 & Alloy 617 & PF-1 & air & $\mathrm{T} 2$ \\
\hline Tensile & 5 & Alloy 617 & PF-1 & air & T3 \\
\hline Tensile & 6 & Alloy 617 & PF-1 & air & $\mathrm{T} 3$ \\
\hline Tensile & 7 & Alloy 617 & PF-1 & air & $\mathrm{T} 4$ \\
\hline Tensile & 8 & Alloy 617 & PF-1 & air & $\mathrm{T} 4$ \\
\hline Tensile & 9 & Alloy 617 & PF-1 & air & T5 \\
\hline Tensile & 10 & Alloy 617 & PF-1 & air & $\mathrm{T} 5$ \\
\hline Tensile & 11 & Alloy 617 & PF-1 & air & $\mathrm{T} 6$ \\
\hline Tensile & 12 & Alloy 617 & PF-1 & air & T6 \\
\hline Tensile & 13 & Alloy 617 & PF-1 & air & $\mathrm{T} 7$ \\
\hline Tensile & 14 & Alloy 617 & PF-1 & air & $\mathrm{T} 7$ \\
\hline Tensile & 15 & Alloy 617 & PF-1 & air & $\mathrm{T} 8$ \\
\hline Tensile & 16 & Alloy 617 & PF-1 & air & $\mathrm{T} 8$ \\
\hline Tensile & 17 & Alloy 617 & PF-1 & air & T9 \\
\hline Tensile & 18 & Alloy 617 & PF-1 & air & T9 \\
\hline Tensile & 19 & Alloy 617 & PF-1 & air & $\mathrm{T} 10$ \\
\hline Tensile & 20 & Alloy 617 & PF-1 & air & $\mathrm{T} 10$ \\
\hline & & & & & \\
\hline Tensile & 21 & Alloy 617 & PF-2 & air & $\mathrm{T} 1$ \\
\hline Tensile & 22 & Alloy 617 & PF-2 & air & $\mathrm{T} 1$ \\
\hline Tensile & 23 & Alloy 617 & PF-2 & air & $\mathrm{T} 2$ \\
\hline Tensile & 24 & Alloy 617 & PF-2 & air & $\mathrm{T} 2$ \\
\hline Tensile & 25 & Alloy 617 & PF-2 & air & $\mathrm{T} 3$ \\
\hline Tensile & 26 & Alloy 617 & PF-2 & air & $\mathrm{T} 3$ \\
\hline Tensile & 27 & Alloy 617 & PF-2 & air & $\mathrm{T} 4$ \\
\hline Tensile & 28 & Alloy 617 & PF-2 & air & $\mathrm{T} 4$ \\
\hline Tensile & 29 & Alloy 617 & PF-2 & air & $\mathrm{T} 5$ \\
\hline Tensile & 30 & Alloy 617 & PF-2 & air & $\mathrm{T} 5$ \\
\hline Tensile & 31 & Alloy 617 & PF-2 & air & T6 \\
\hline Tensile & 32 & Alloy 617 & PF-2 & air & T6 \\
\hline Tensile & 33 & Alloy 617 & PF-2 & air & $\mathrm{T} 7$ \\
\hline Tensile & 34 & Alloy 617 & PF-2 & air & $\mathrm{T} 7$ \\
\hline
\end{tabular}


Idaho National Laboratory

NEXT GENERATION NUCLEAR PLANT STEAM GENERATOR AND INTERMEDIATE HEAT EXCHANGER MATERIALS RESEARCH AND DEVELOPMENT PLAN

Identifier: Revision: Effective Date: 09/23/10

1
PLN-2804

Page: 151 of $\mathbf{2 5 2}$

Table A1. Tensile Test Matrix for $S_{m}$ Confirmatory Testing

\begin{tabular}{|c|c|c|c|c|c|}
\hline Specimen Type & Specimen \# & Material & Product Form & Environment & Temp. $\left({ }^{\circ} \mathrm{C}\right)$ \\
\hline Tensile & 35 & Alloy 617 & PF-2 & air & T8 \\
\hline Tensile & 36 & Alloy 617 & $\mathrm{PF}-2$ & air & T8 \\
\hline Tensile & 37 & Alloy 617 & $\mathrm{PF}-2$ & air & T9 \\
\hline Tensile & 38 & Alloy 617 & $\mathrm{PF}-2$ & air & T9 \\
\hline Tensile & 39 & Alloy 617 & $\mathrm{PF}-2$ & air & $\mathrm{T} 10$ \\
\hline Tensile & 40 & Alloy 617 & $\mathrm{PF}-2$ & air & $\mathrm{T} 10$ \\
\hline
\end{tabular}




\begin{tabular}{|c|c|c|c|c|c|c|c|c|c|c|c|c|c|c|c|}
\hline & & 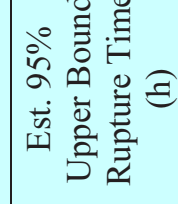 & సิ & 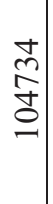 & f & ? & & & $\stackrel{\frac{1}{2}}{\stackrel{2}{\Xi}}$ & $\cong$ & & & & & \\
\hline $\begin{array}{l}\tilde{1} \\
\tilde{c} \\
\mathbb{0} \\
\tilde{0} \\
\dot{t}\end{array}$ & & 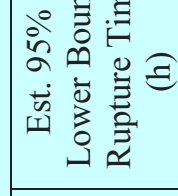 & $\stackrel{2}{\infty}$ & bे & $\begin{array}{l}\omega_{\infty}^{\infty} \\
\infty\end{array}$ & 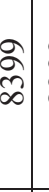 & & & $\infty$ & $\infty$ & & & & & \\
\hline $\begin{array}{l}\overrightarrow{0} \\
\dot{\infty} \\
\ddot{\sigma}\end{array}$ & & 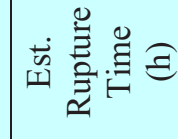 & $\mid \begin{array}{l}\infty \\
0 \\
0 \\
0\end{array}$ & $\begin{array}{l}n \\
\hat{\sigma} \\
n\end{array}$ & م్ & $\frac{7}{4}$ & 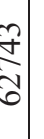 & 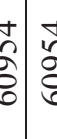 & $b_{0}^{\infty}$ & 8 & مी & 6 & s & $\widehat{\sigma}$ & $\begin{array}{l}n \\
\text { है } \\
\text { ñ }\end{array}$ \\
\hline 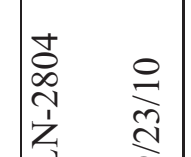 & 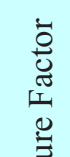 & 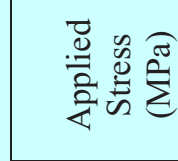 & $\left|\begin{array}{l}n \\
\infty \\
\infty\end{array}\right|$ & $\stackrel{n}{\ddot{2}}$ & & & & $\because F$ & $\mid \begin{array}{l}n \\
0 \\
\infty\end{array}$ & $\infty$ & & & & & $\stackrel{\sim}{g}$ \\
\hline$\left|\begin{array}{rr}a & -0 \\
& \ddot{0} \\
& \stackrel{\tilde{\omega}}{\pi}\end{array}\right|$ & 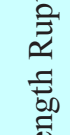 & & §a & ڤू & na & $\infty$ & $\infty$ & ही & छ & 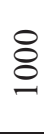 & ํ. & そ) & & $\infty$ & 品 \\
\hline 离 & $\begin{array}{l}\vec{n} \\
\frac{0}{0} \\
3\end{array}$ & 畐 & ॠै & : & चี & $\approx$ & స్ & & 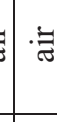 & 䒕 & $\bar{\sigma}$ & : & & $\bar{\epsilon}$ & \\
\hline 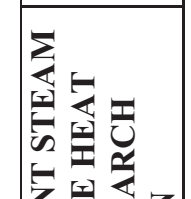 & 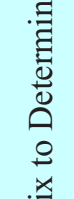 & 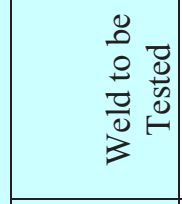 & 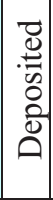 & 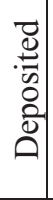 & 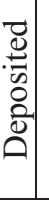 & $\begin{array}{l}0 \\
0 \\
0 \\
0 \\
0 \\
0 \\
0\end{array}$ & & & 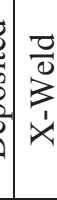 & 齐 & 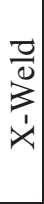 & $\dot{x}$ & & $\begin{array}{l}\frac{\pi}{0} \\
0 \\
\vdots \\
x \\
x\end{array}$ & 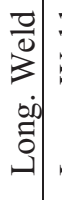 \\
\hline 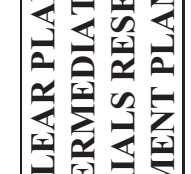 & 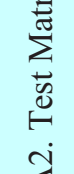 & 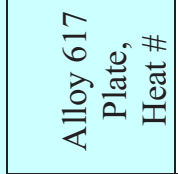 & $\mathbb{Z}$ & $\overleftrightarrow{z}$ & $\mathbb{z}$ & $\mathbb{Z}$ & & 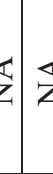 & $\frac{1}{5}$ & $\frac{7}{\frac{1}{5}}$ & $\approx$ & $\Xi$ & 离 & 辛 & \begin{tabular}{l}
7 \\
\multirow{2}{\approx}{} \\
$\frac{1}{1}$ \\
3
\end{tabular} \\
\hline 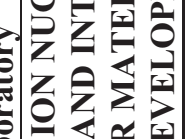 & $\frac{\frac{0}{\pi}}{\frac{\pi}{\sigma}}$ & 30 & U & 비 & E & 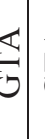 & o & & $\overleftrightarrow{\Xi}$ & E & 8 & 0 & & $\vartheta$ & $\overleftrightarrow{\Xi}$ \\
\hline 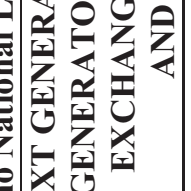 & & 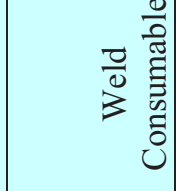 & $\sum_{i}$ & $\begin{array}{l}1 \\
0 \\
i \\
i=1\end{array}$ & $\sum_{I}$ & $\begin{array}{l}\sum_{1}^{1} \\
1 \\
1\end{array}$ & $\Sigma$ & $\begin{array}{lll}0 \\
\vdots \\
\vdots \\
\vdots \\
\vdots\end{array}$ & 旅 & $\sum_{\substack{1 \\
0}}^{i}$ & $\sum_{i}$ & & & $\sum_{i=}$ & 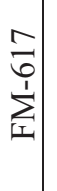 \\
\hline & & & $=$ & 인 & & & & & 흐 & & & & & & \\
\hline & & 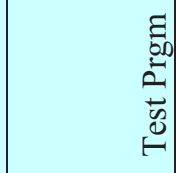 & 18 & 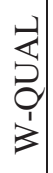 & & & & 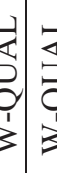 & $\frac{3}{3}$ & & & & & & 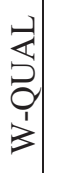 \\
\hline
\end{tabular}




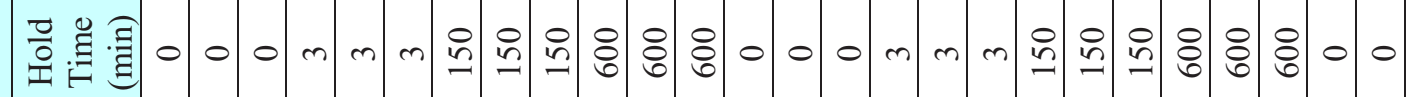

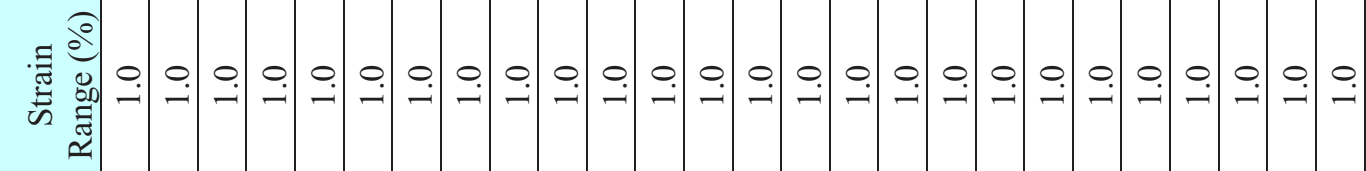

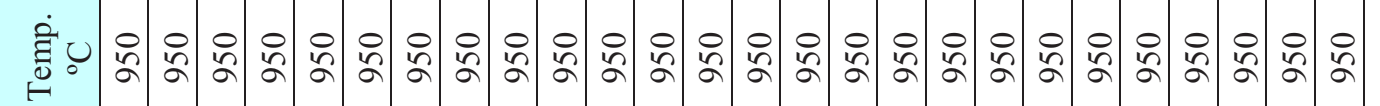

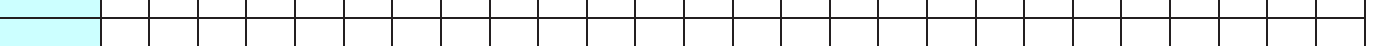

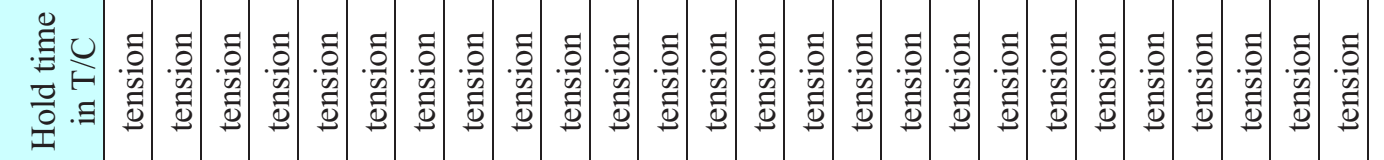

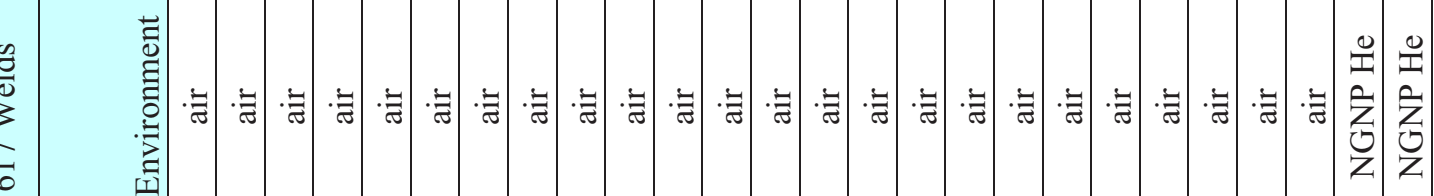
ลे

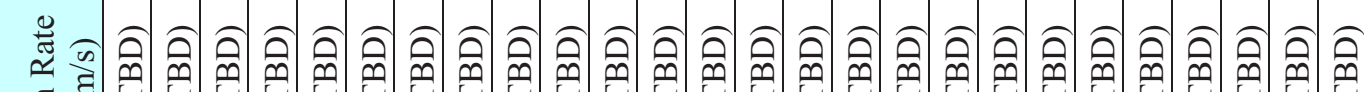

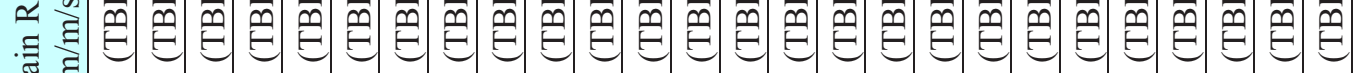
部

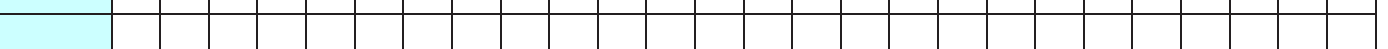

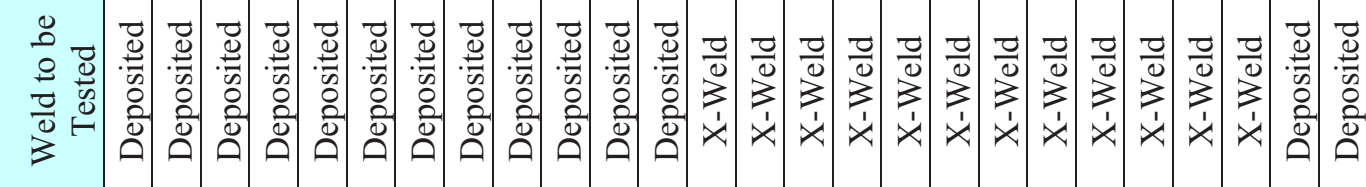

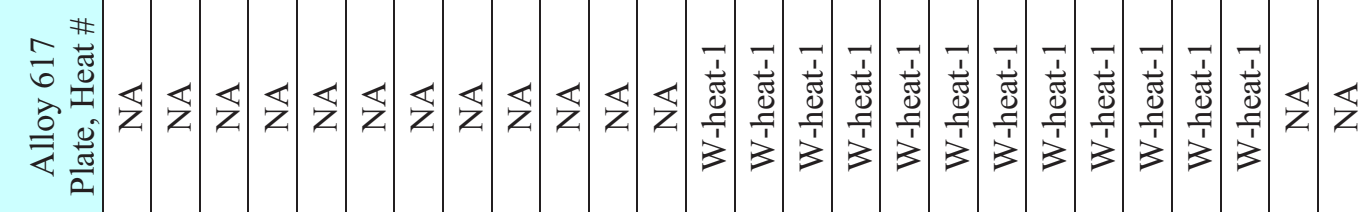

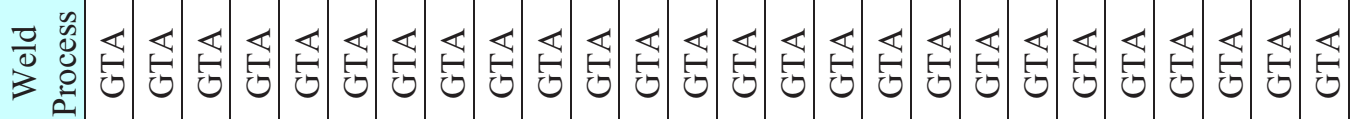

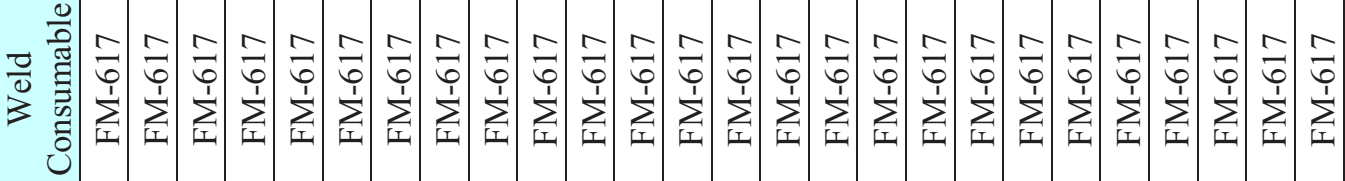

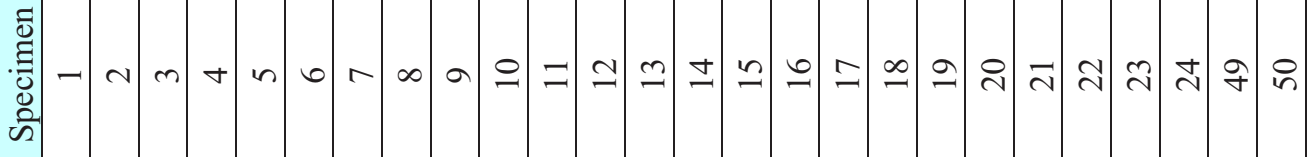




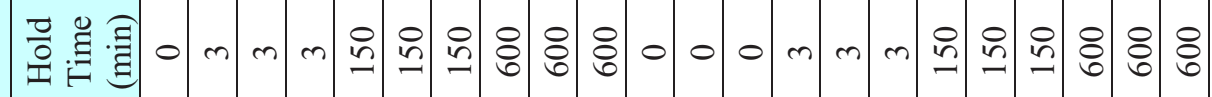

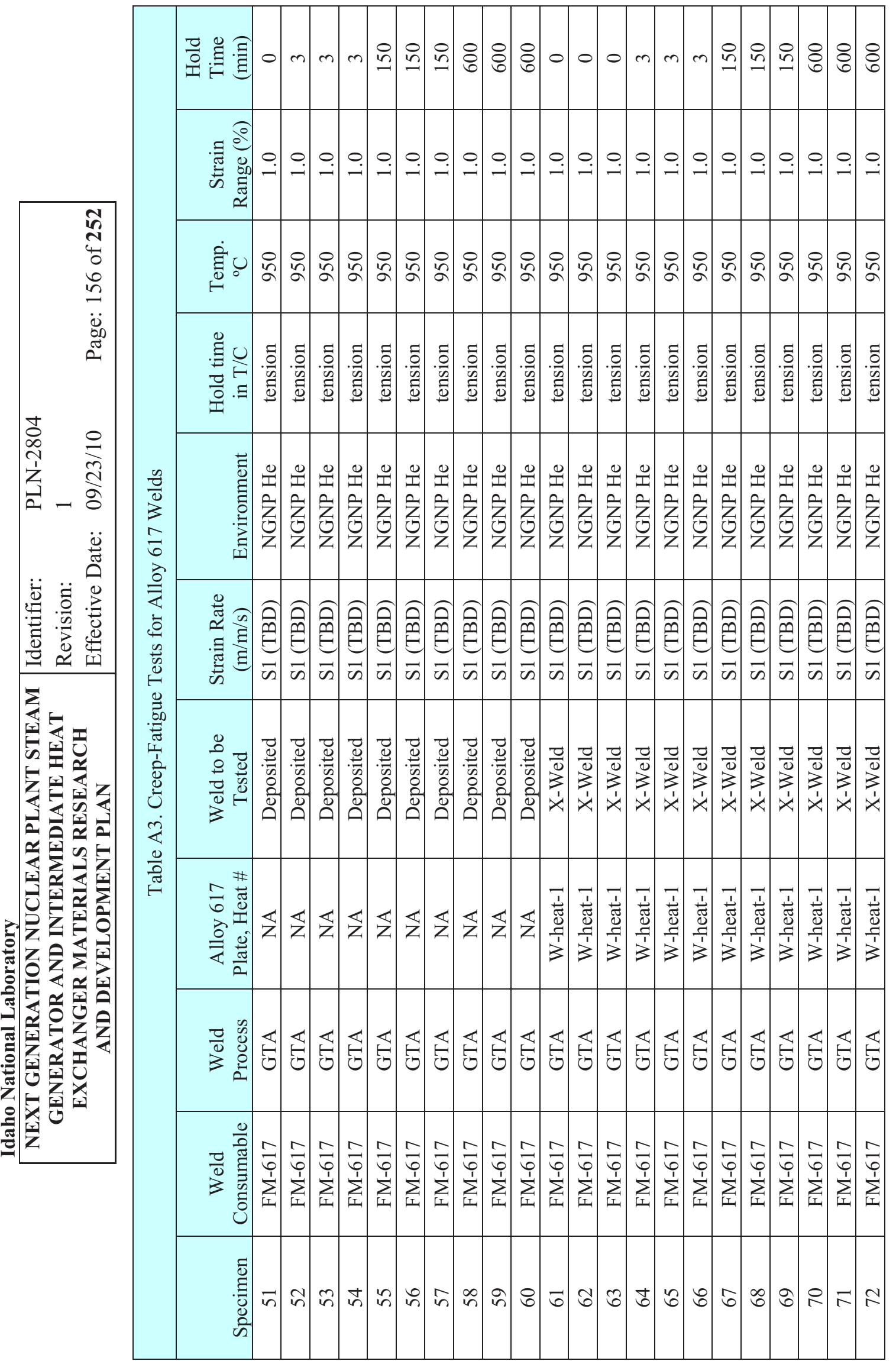




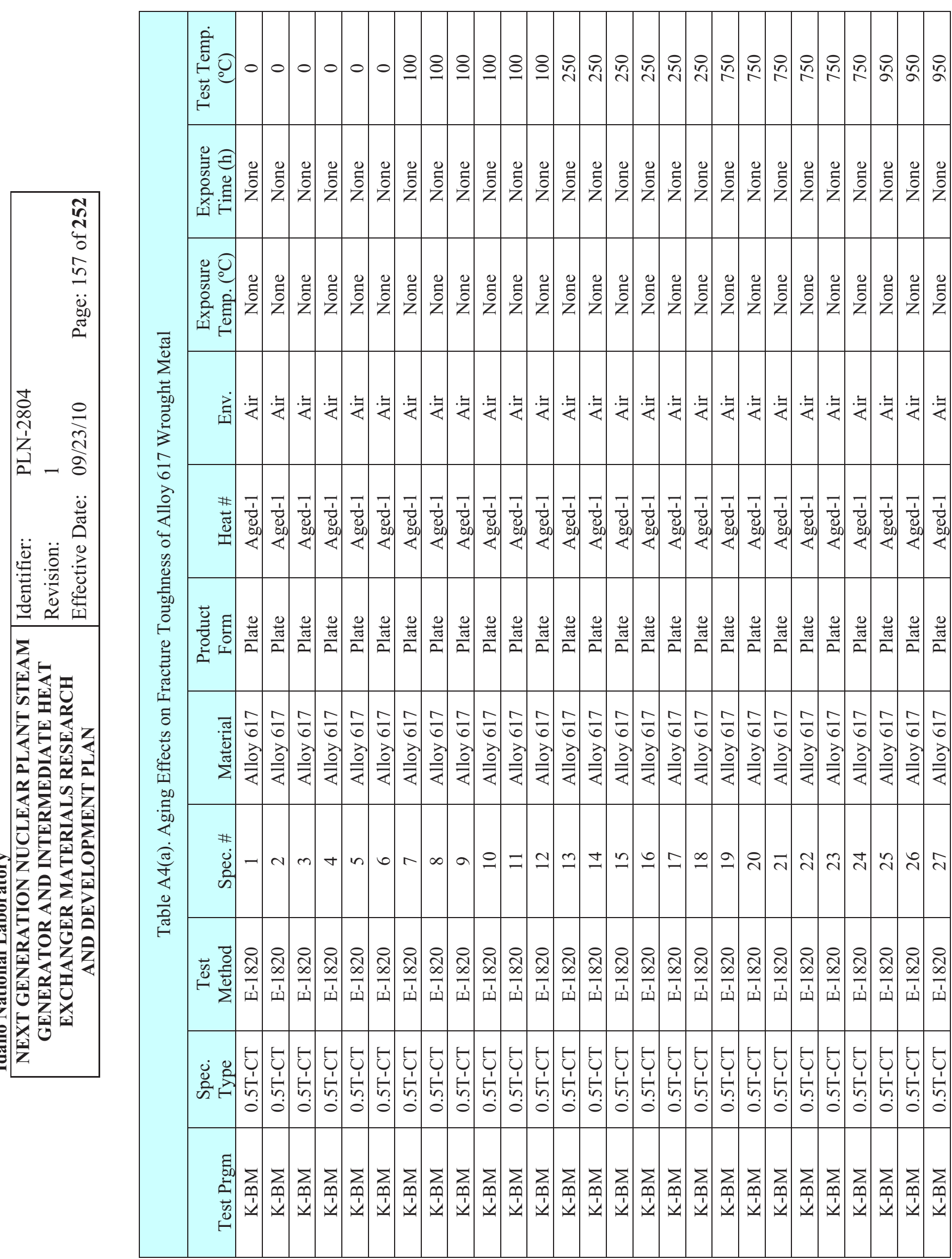




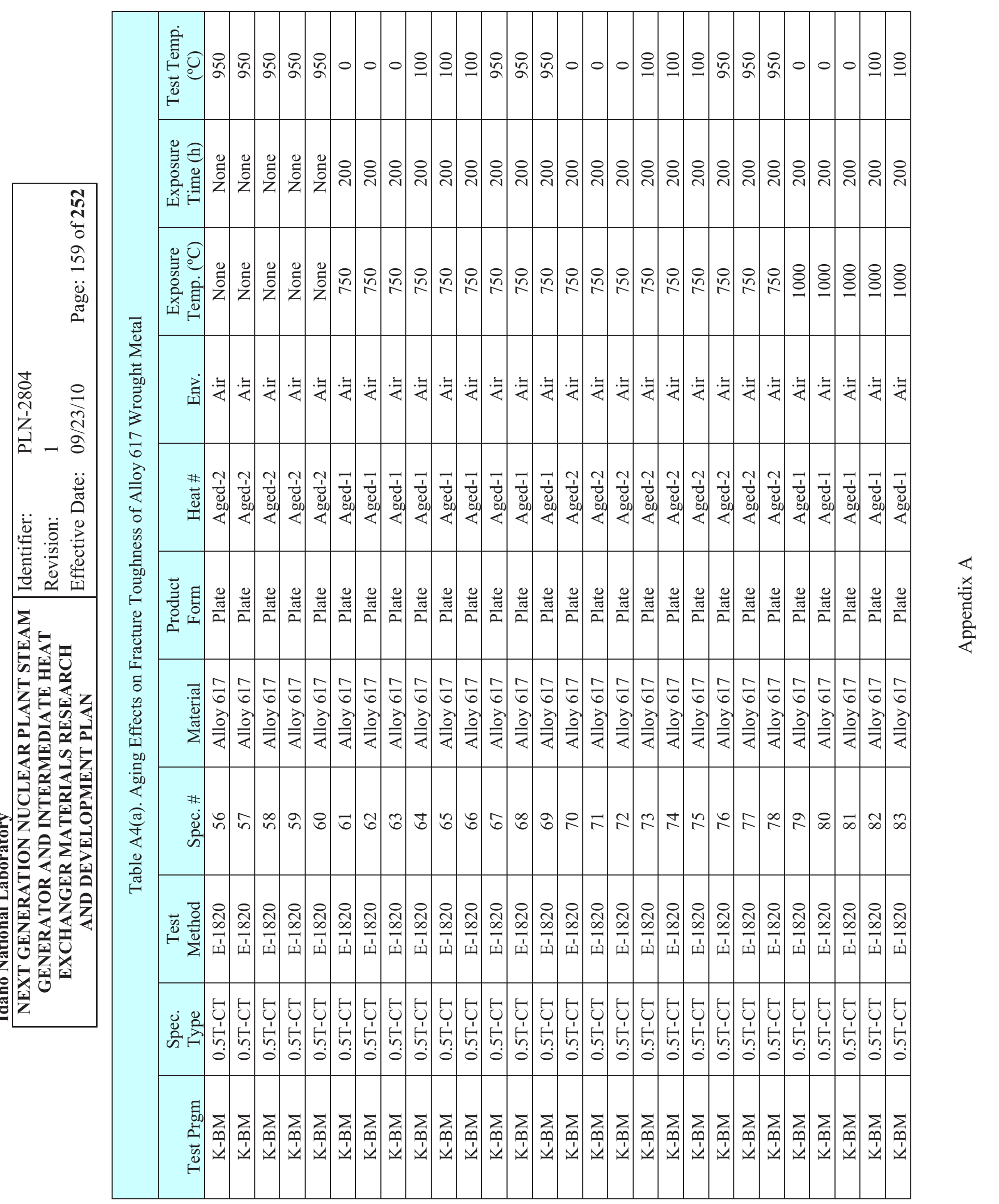




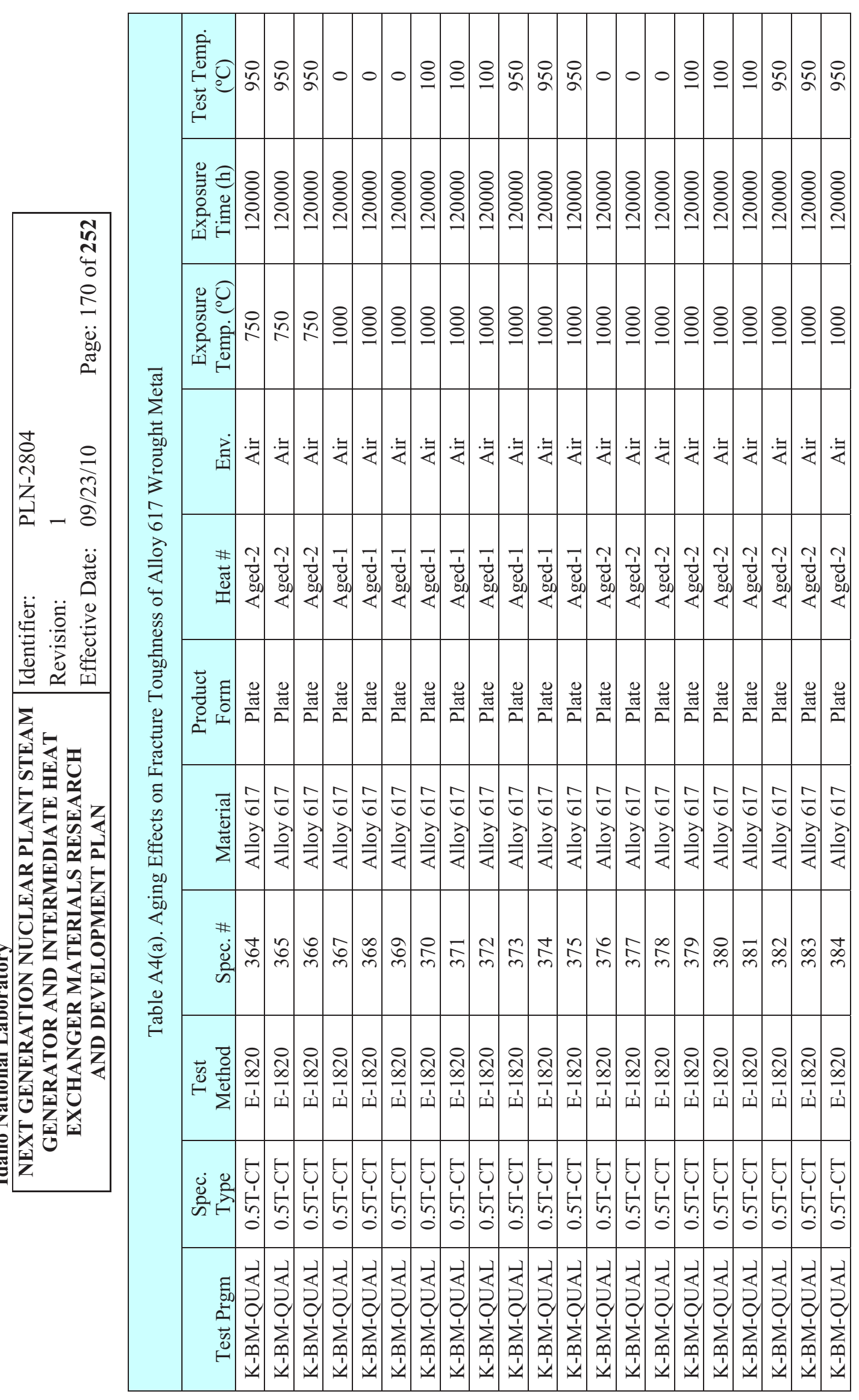




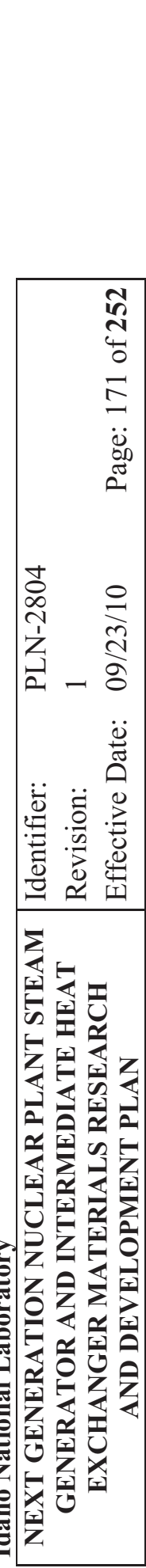

(2)

言 0 $\stackrel{5}{\oplus}$

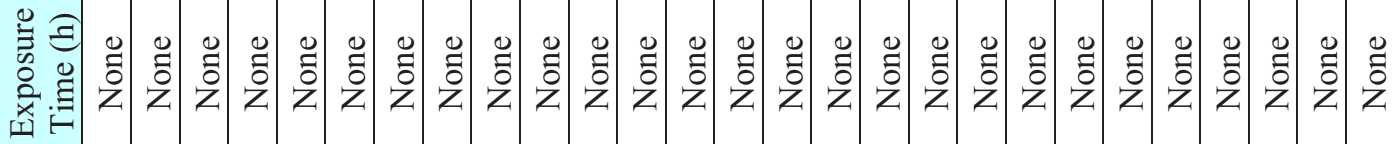

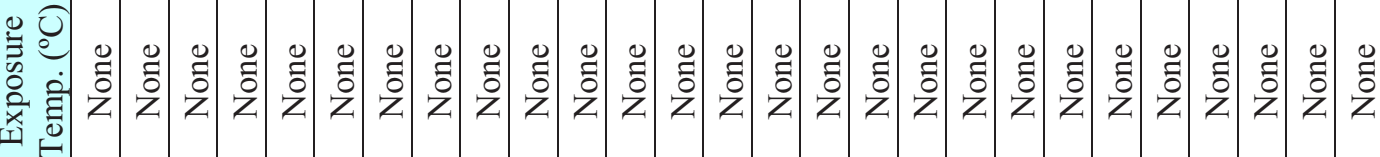

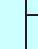

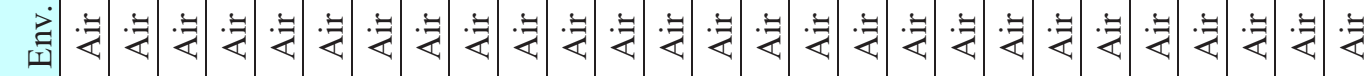

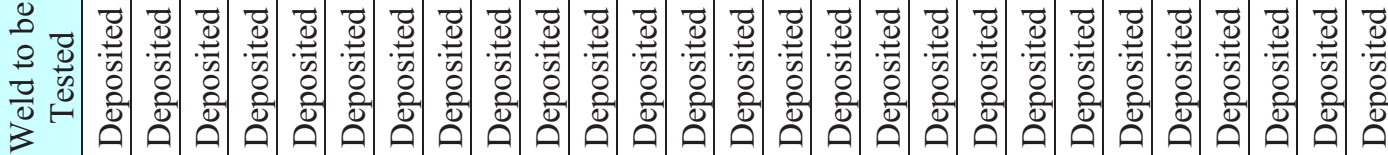
$\cong$

恶

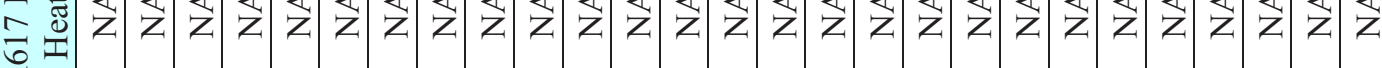
$\varangle$

무

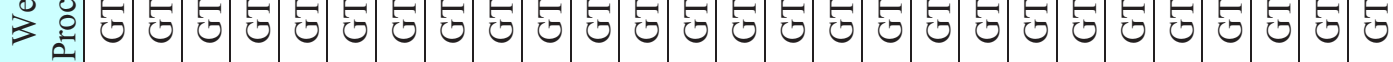

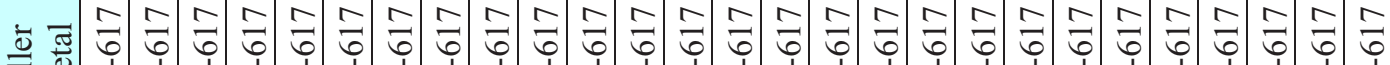

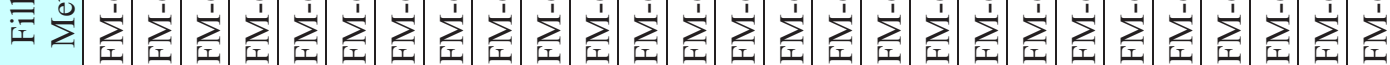

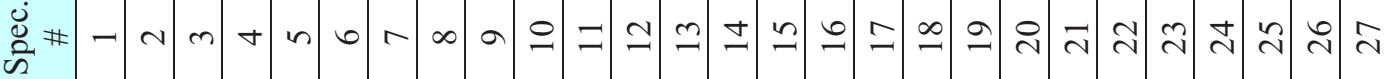

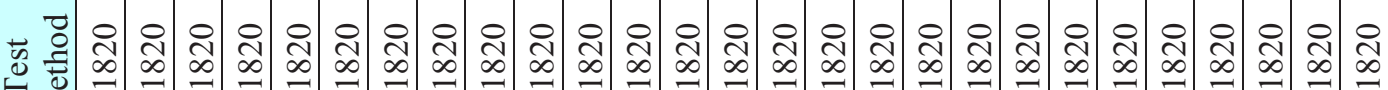

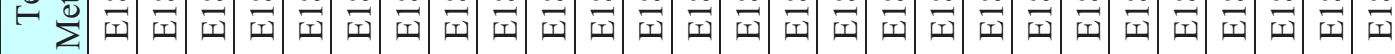

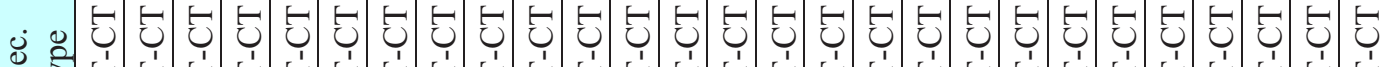

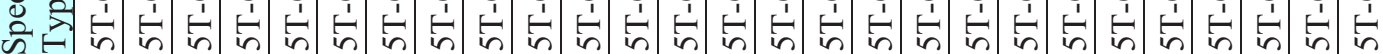

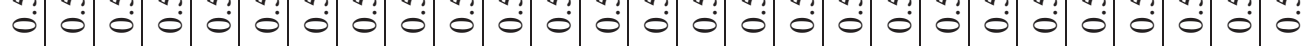

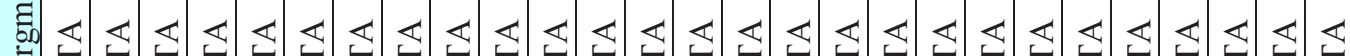
D車

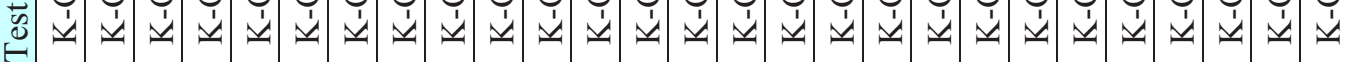




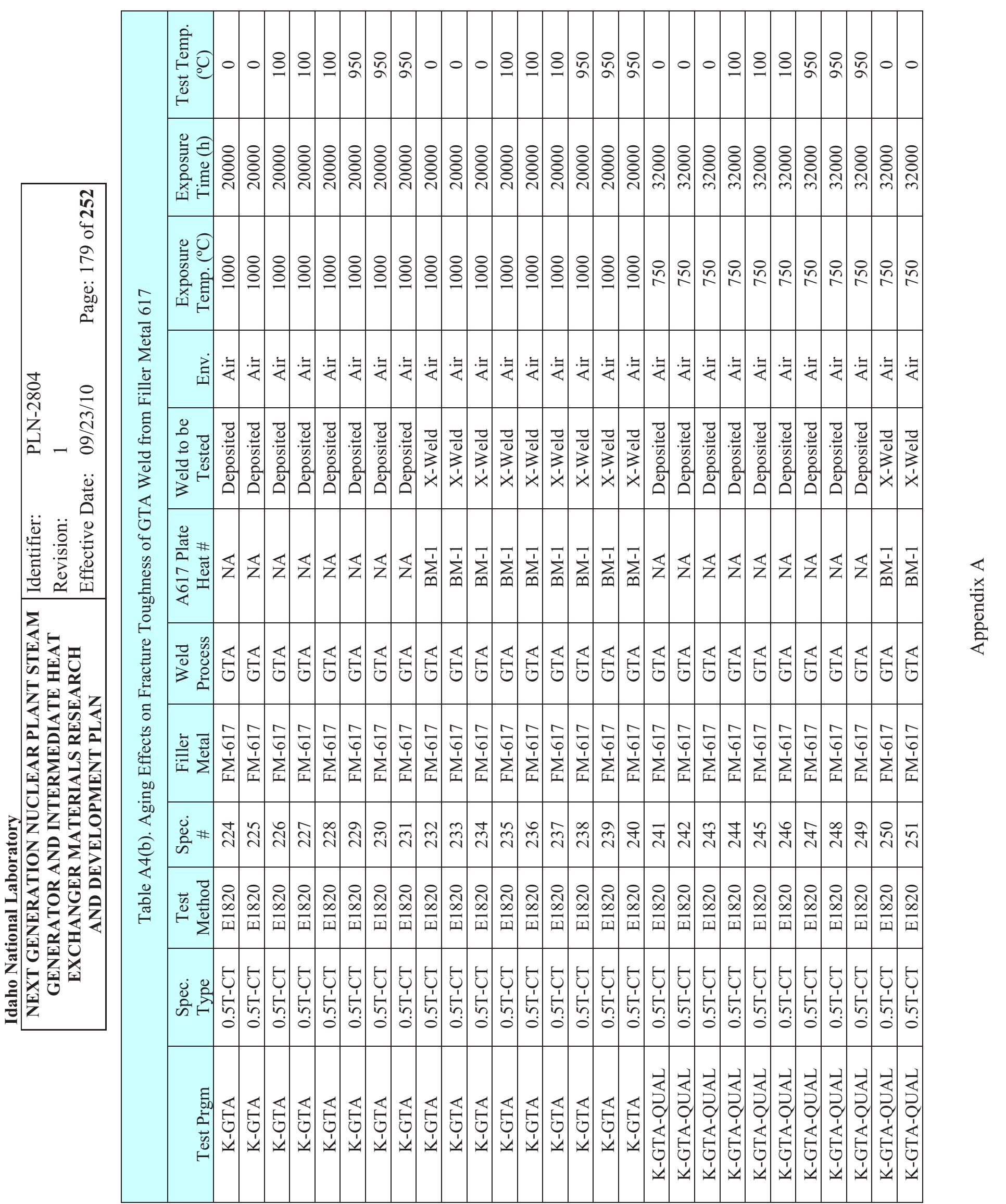




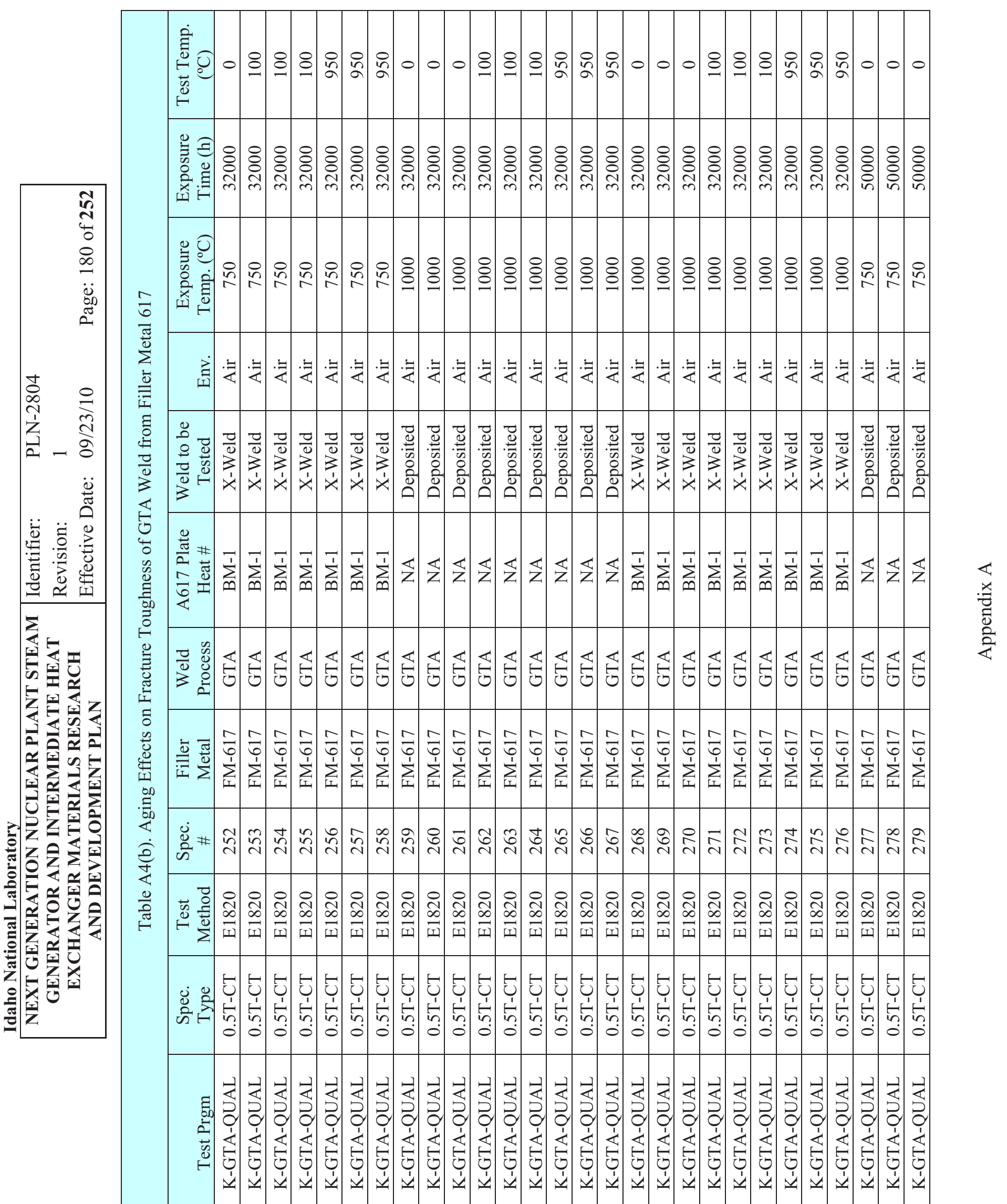




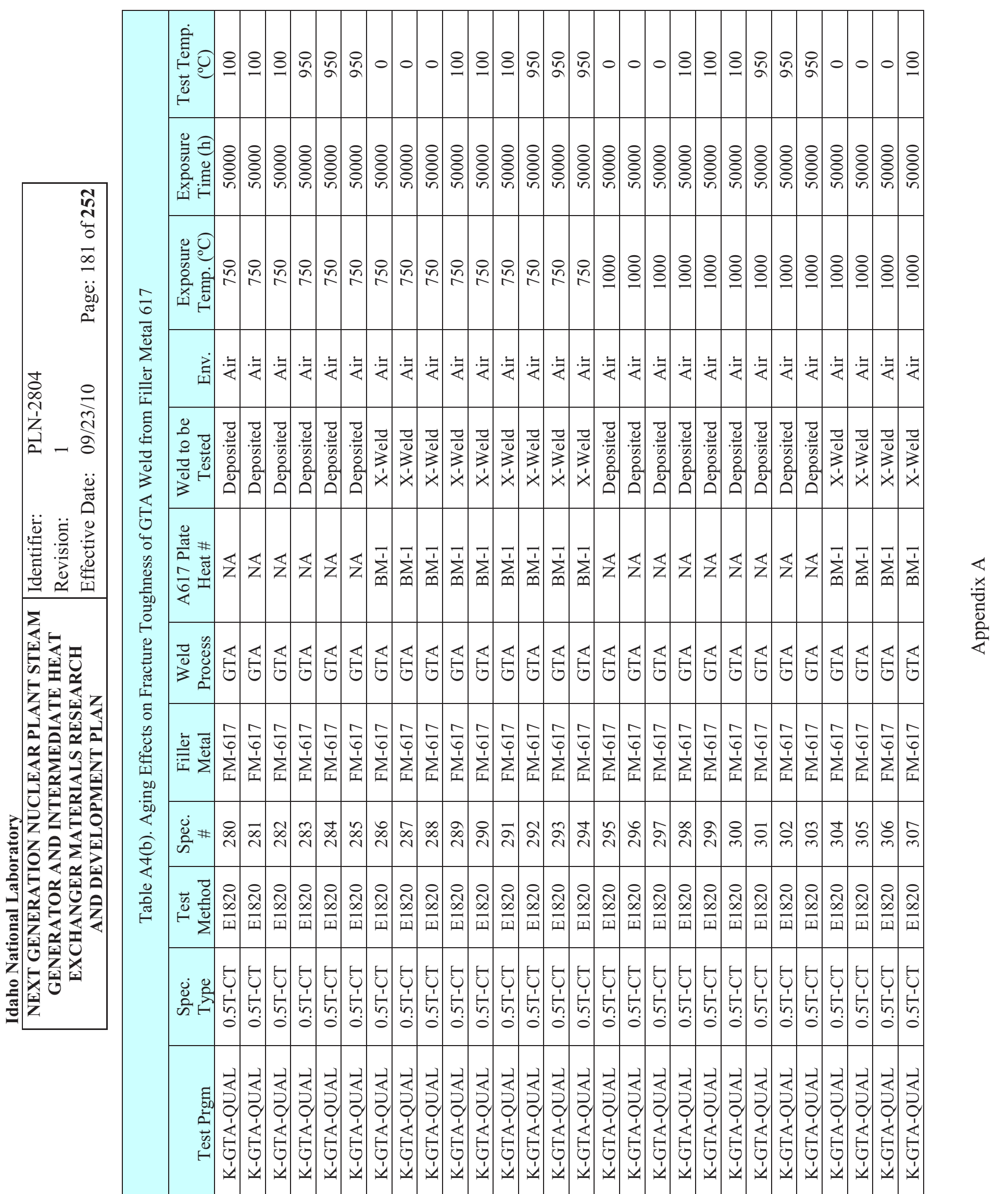




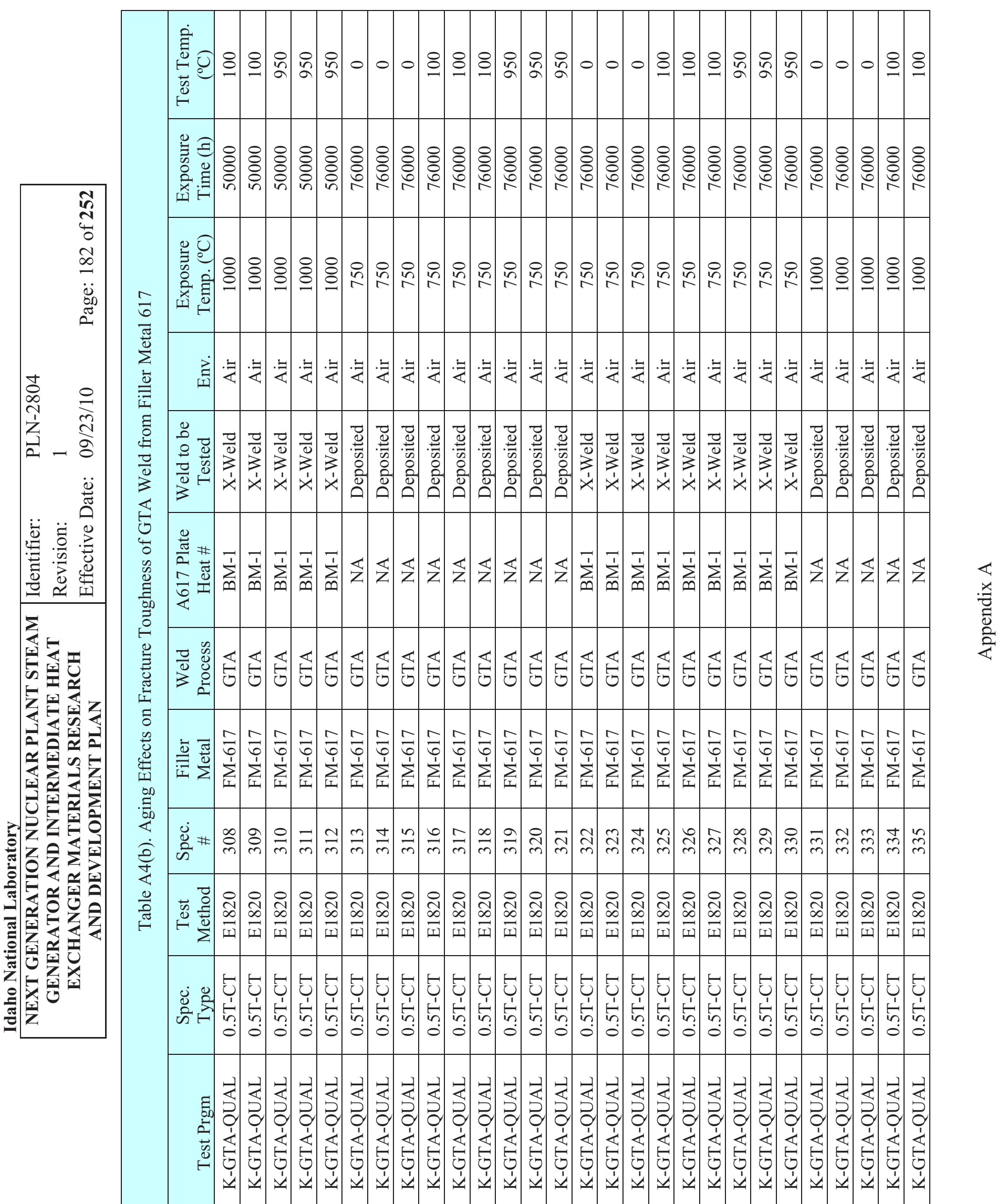




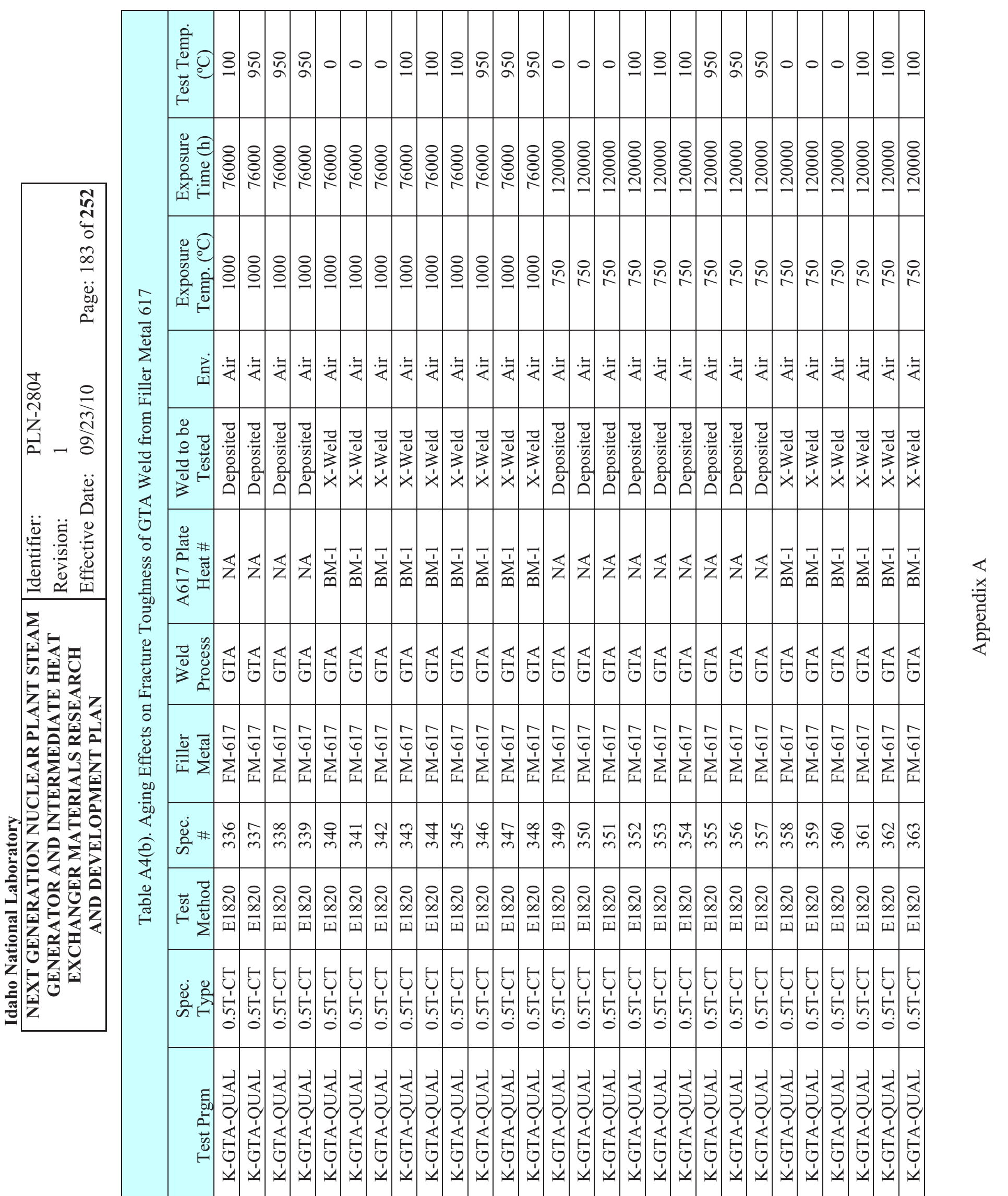




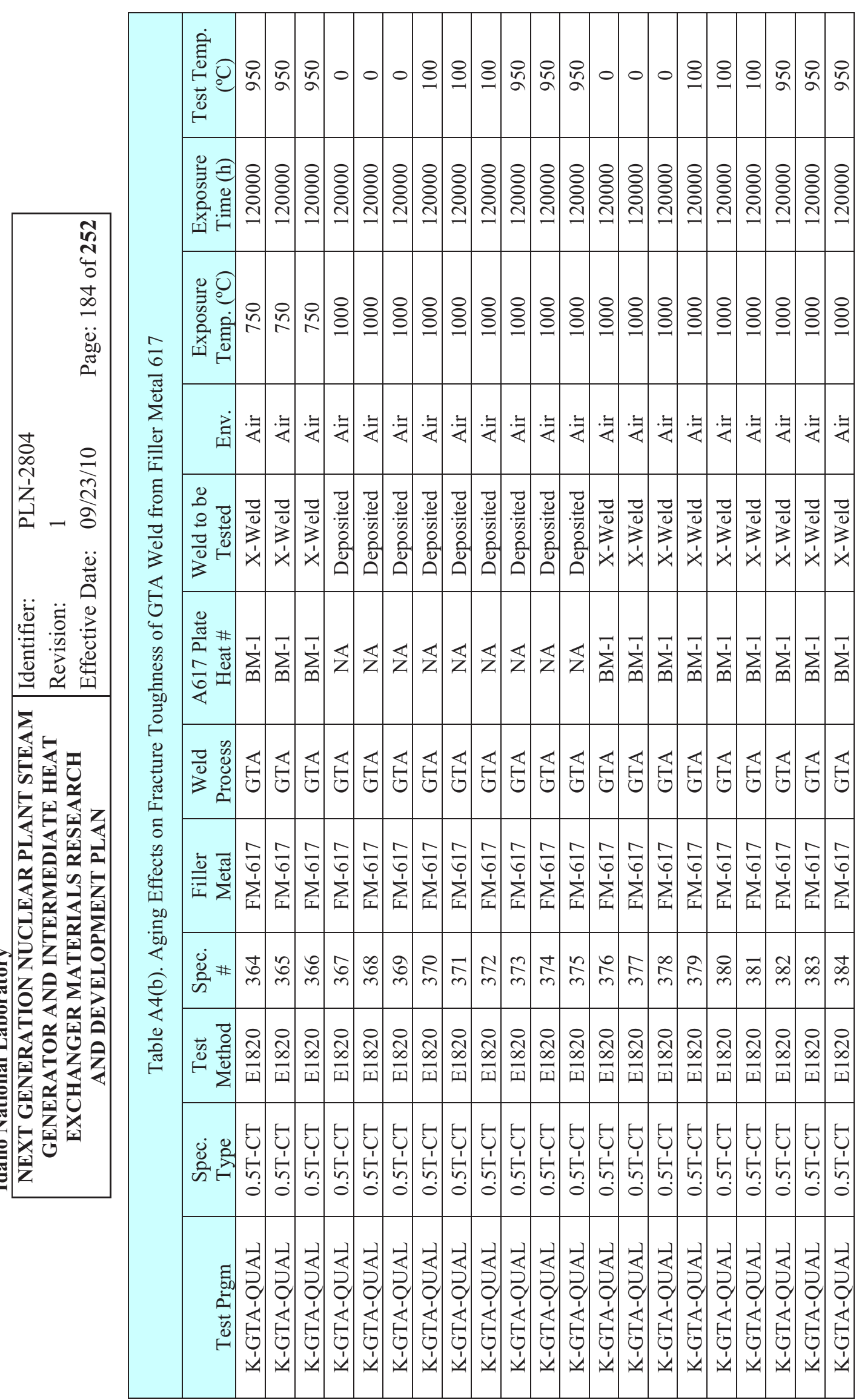




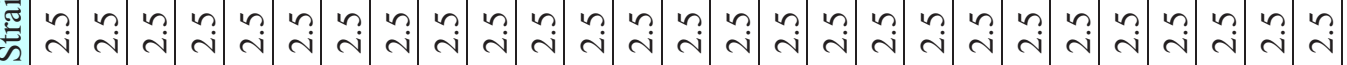

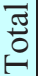

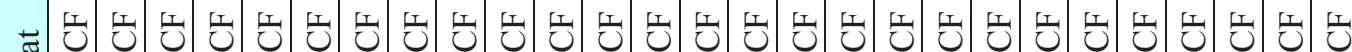

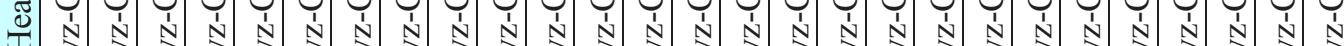

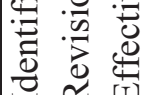

\section{छีุ}

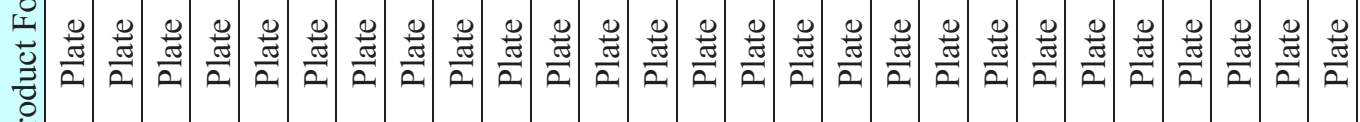
2

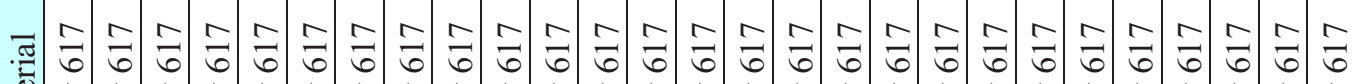

之) 


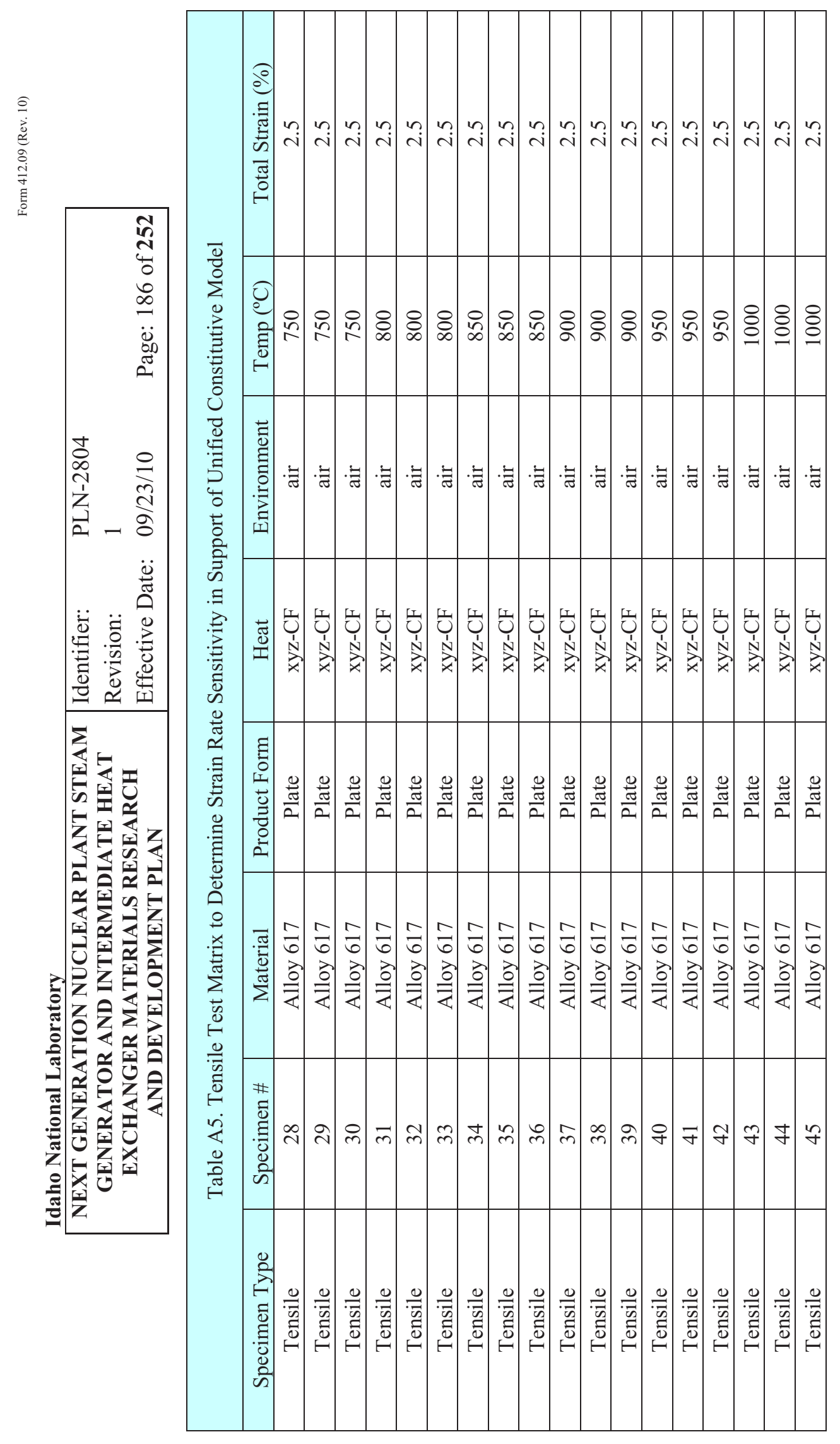

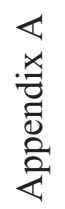




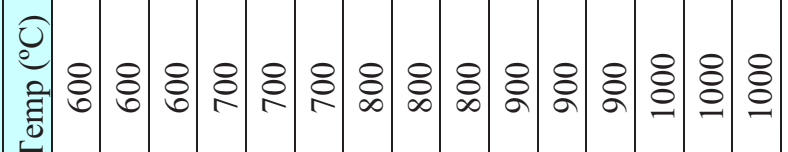

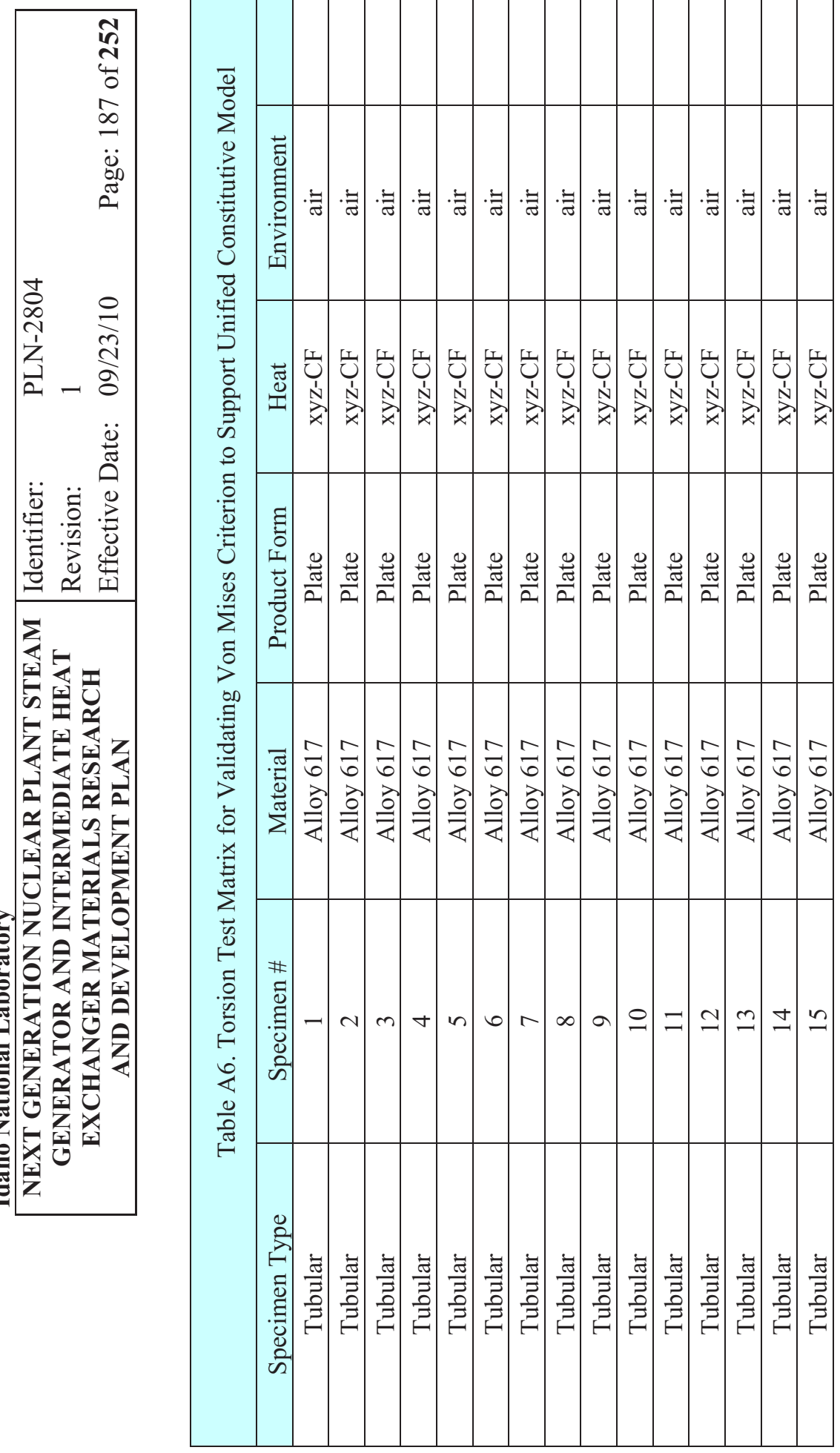




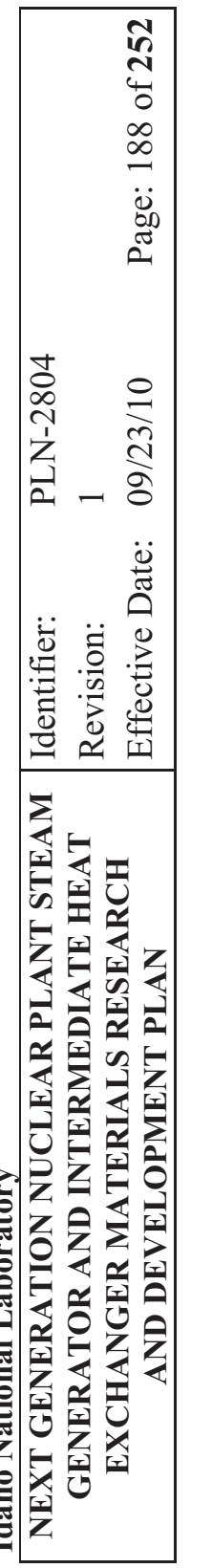

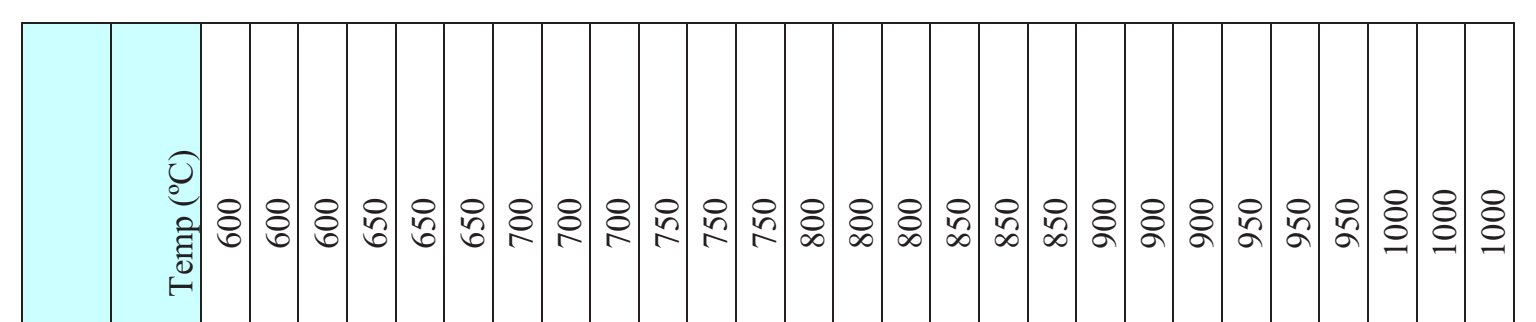

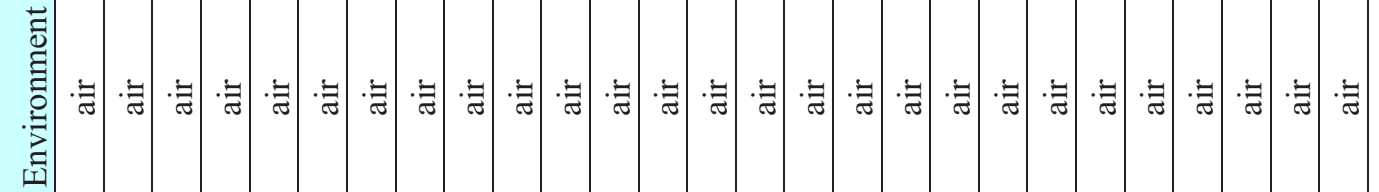
$\frac{\bar{\theta}}{8}$

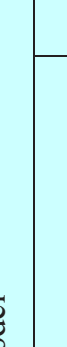

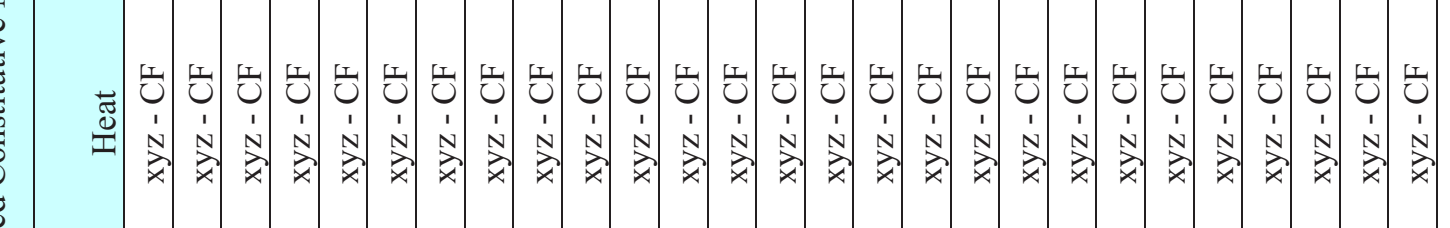

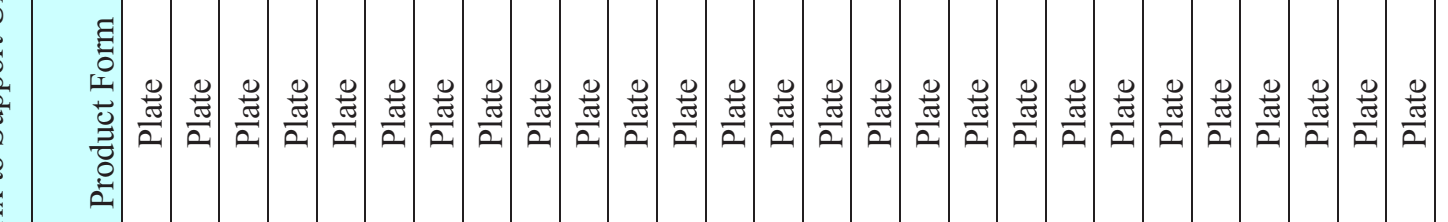

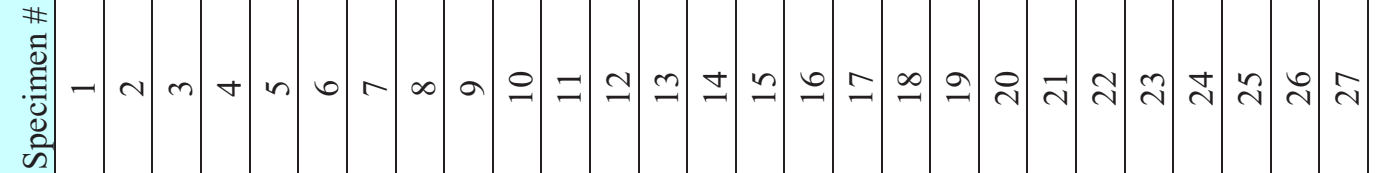

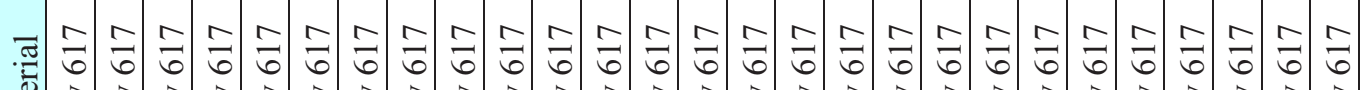

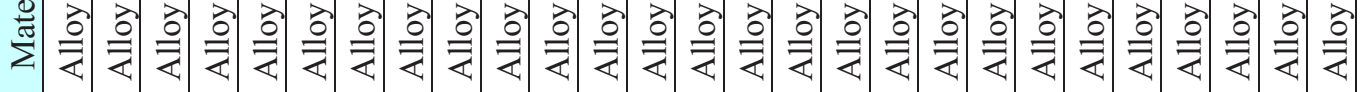

章

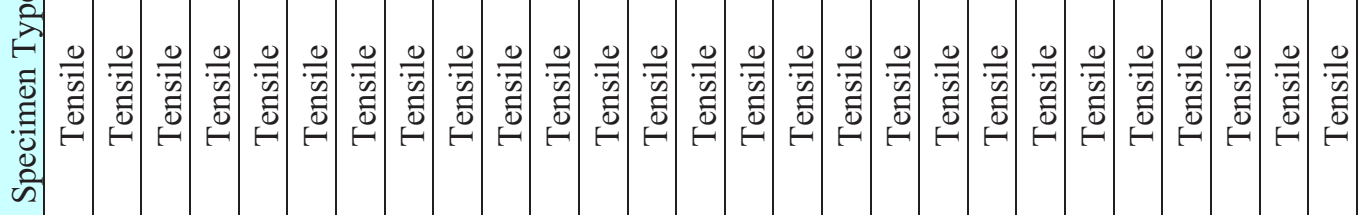




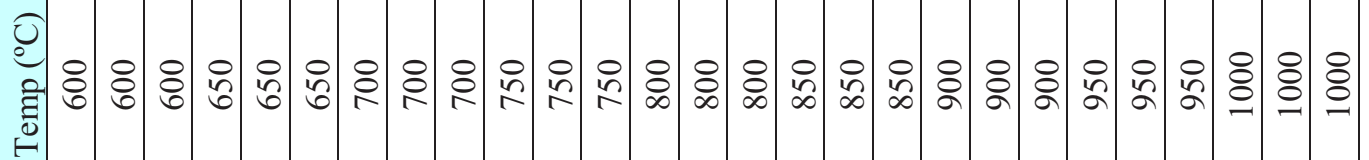
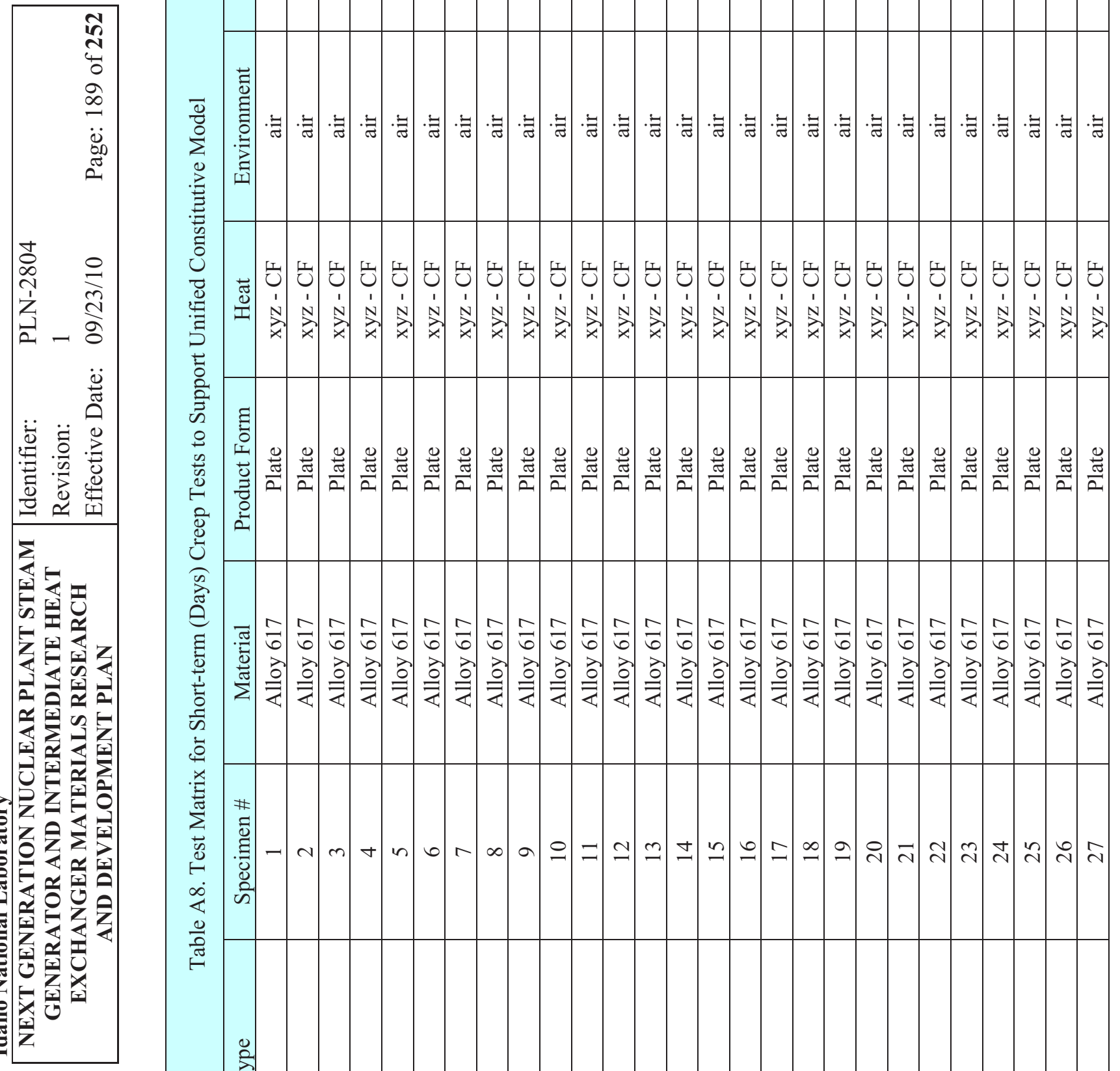

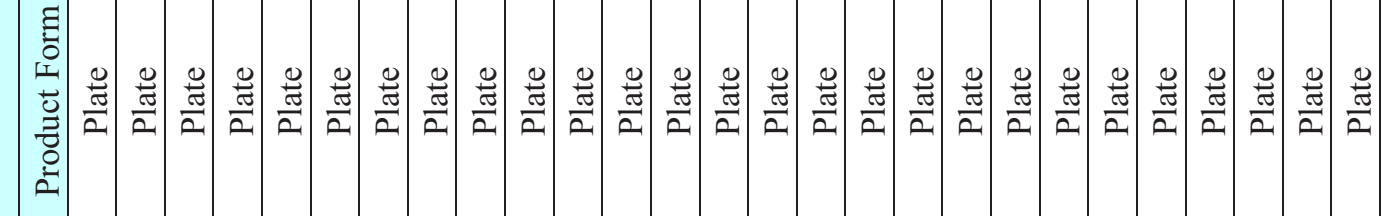

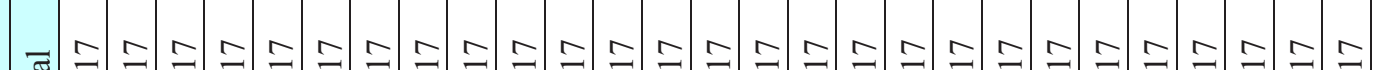

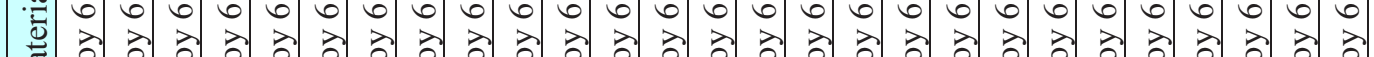

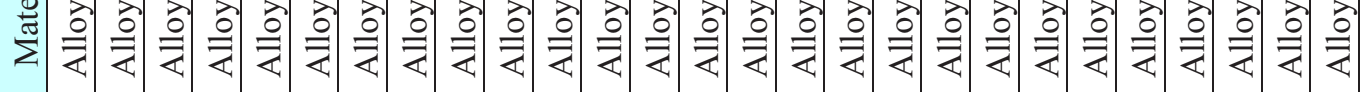

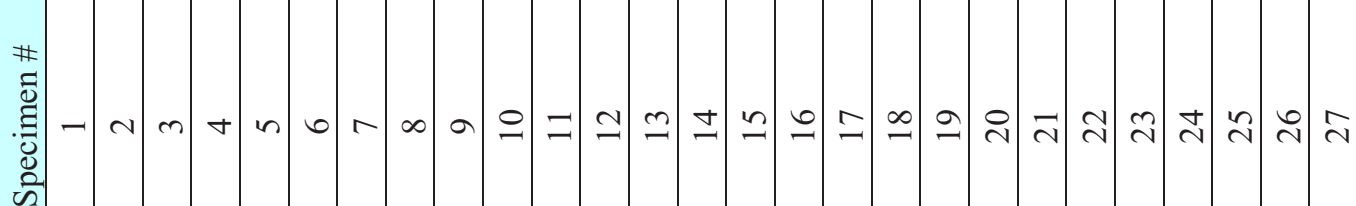
$\frac{\sqrt{\frac{\pi}{0}}}{\frac{\pi}{10}}$

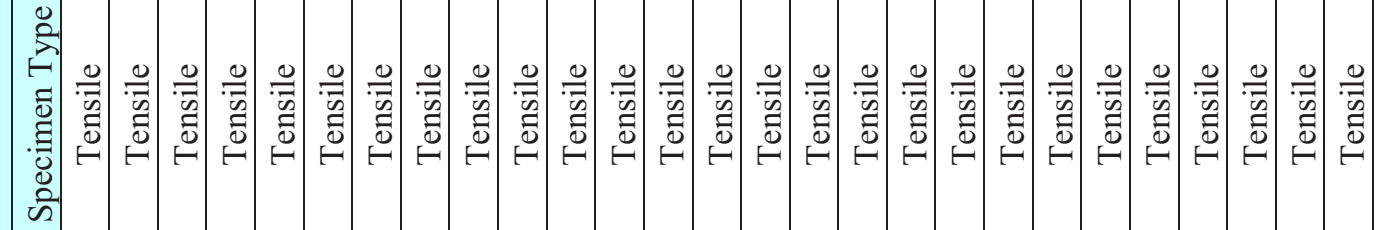




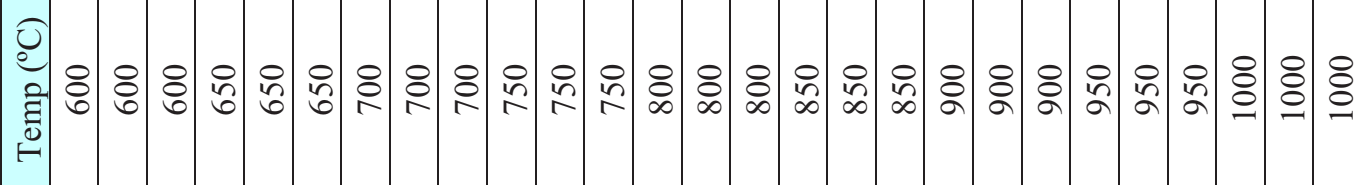
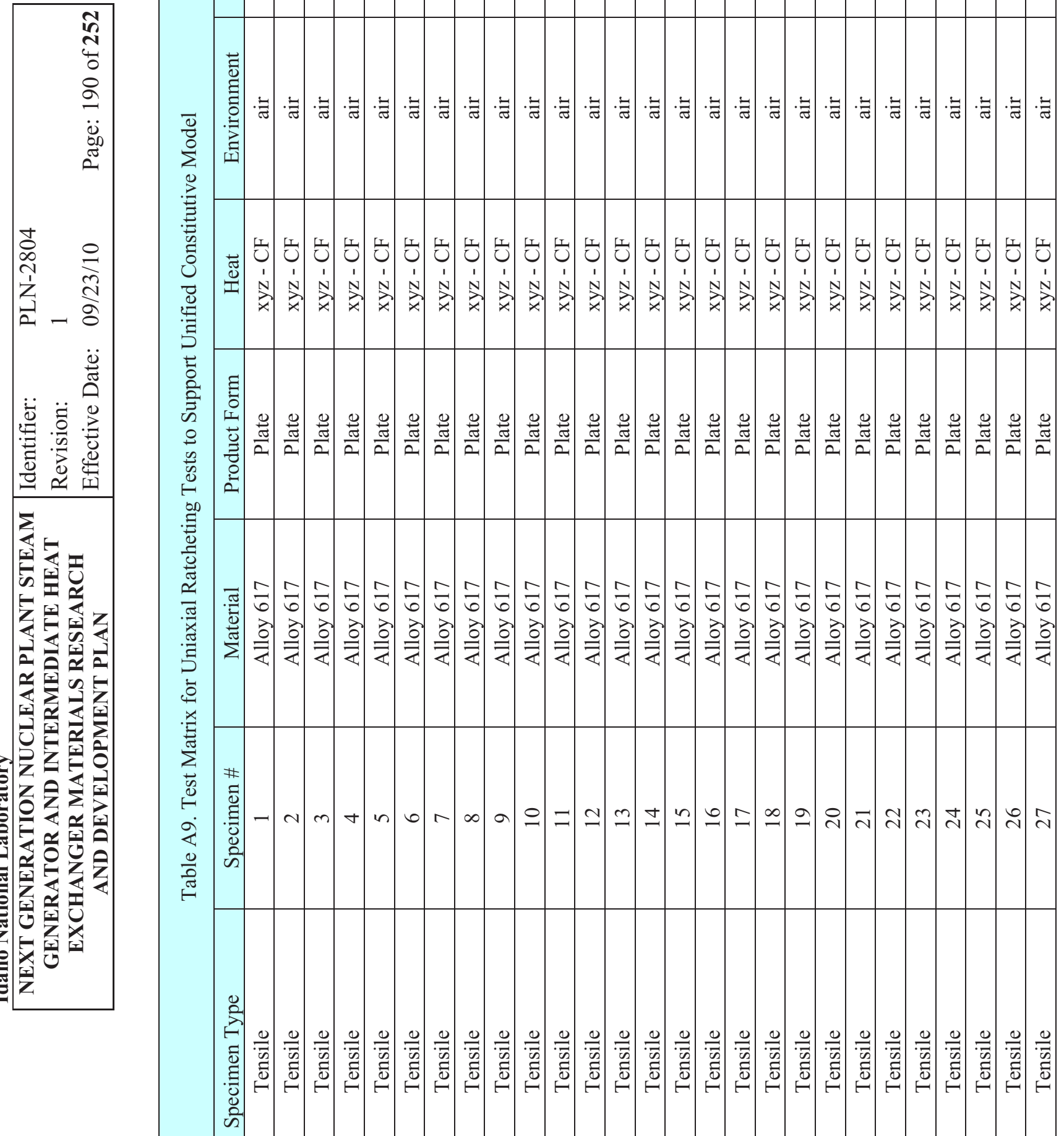


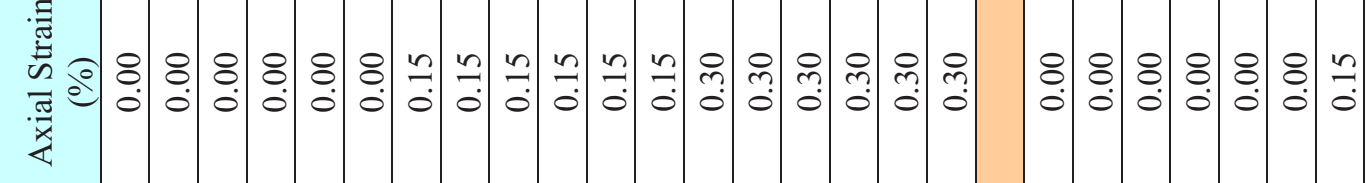

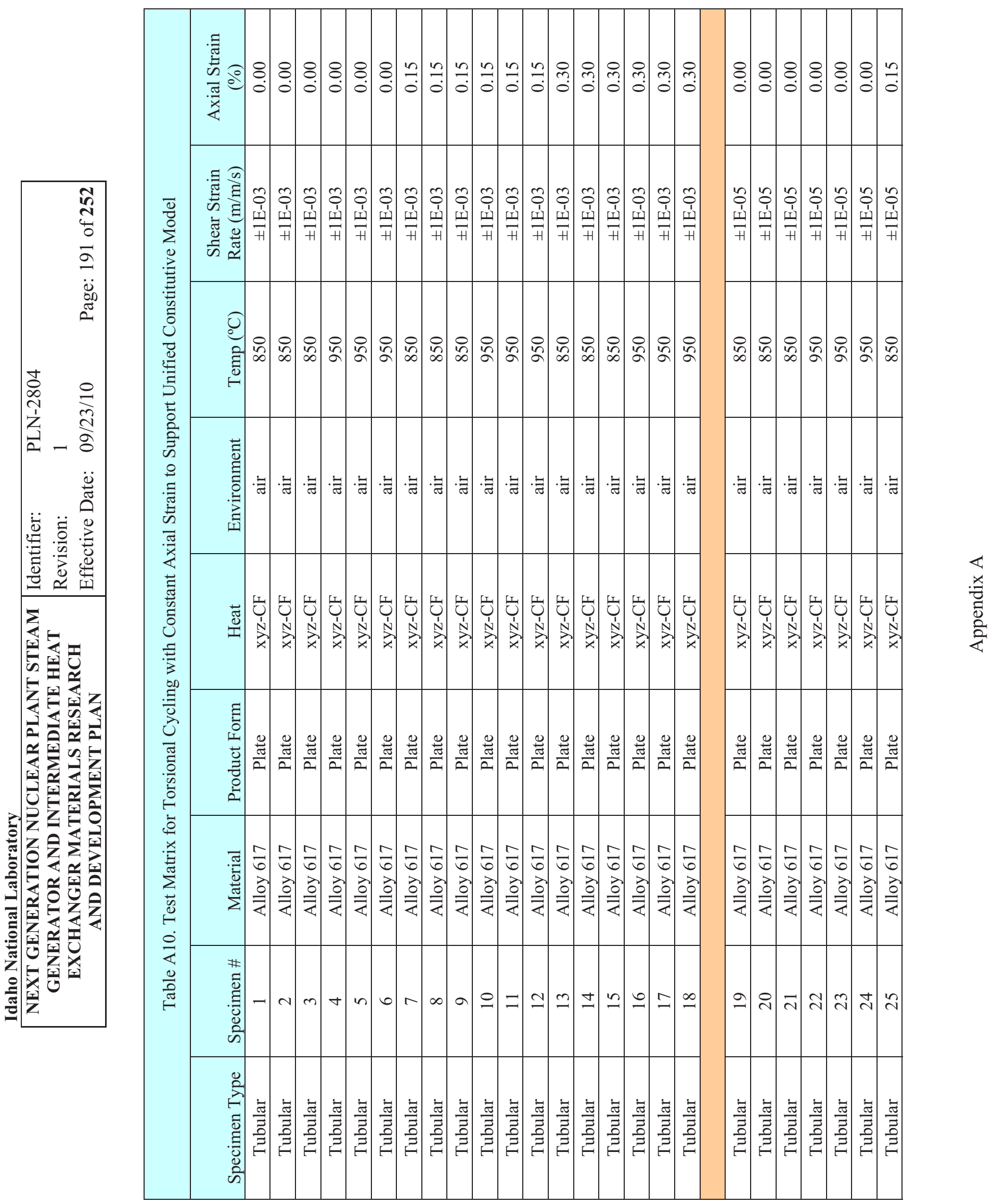

I 


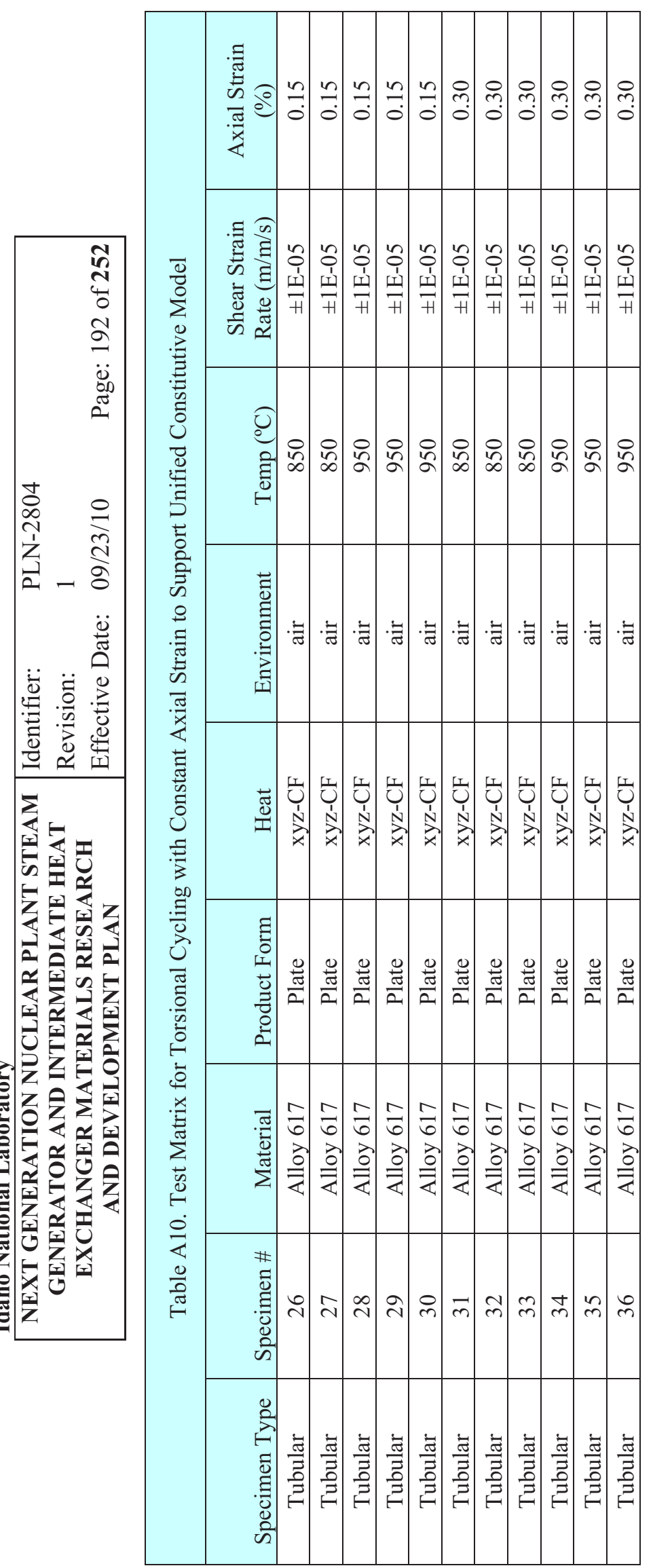




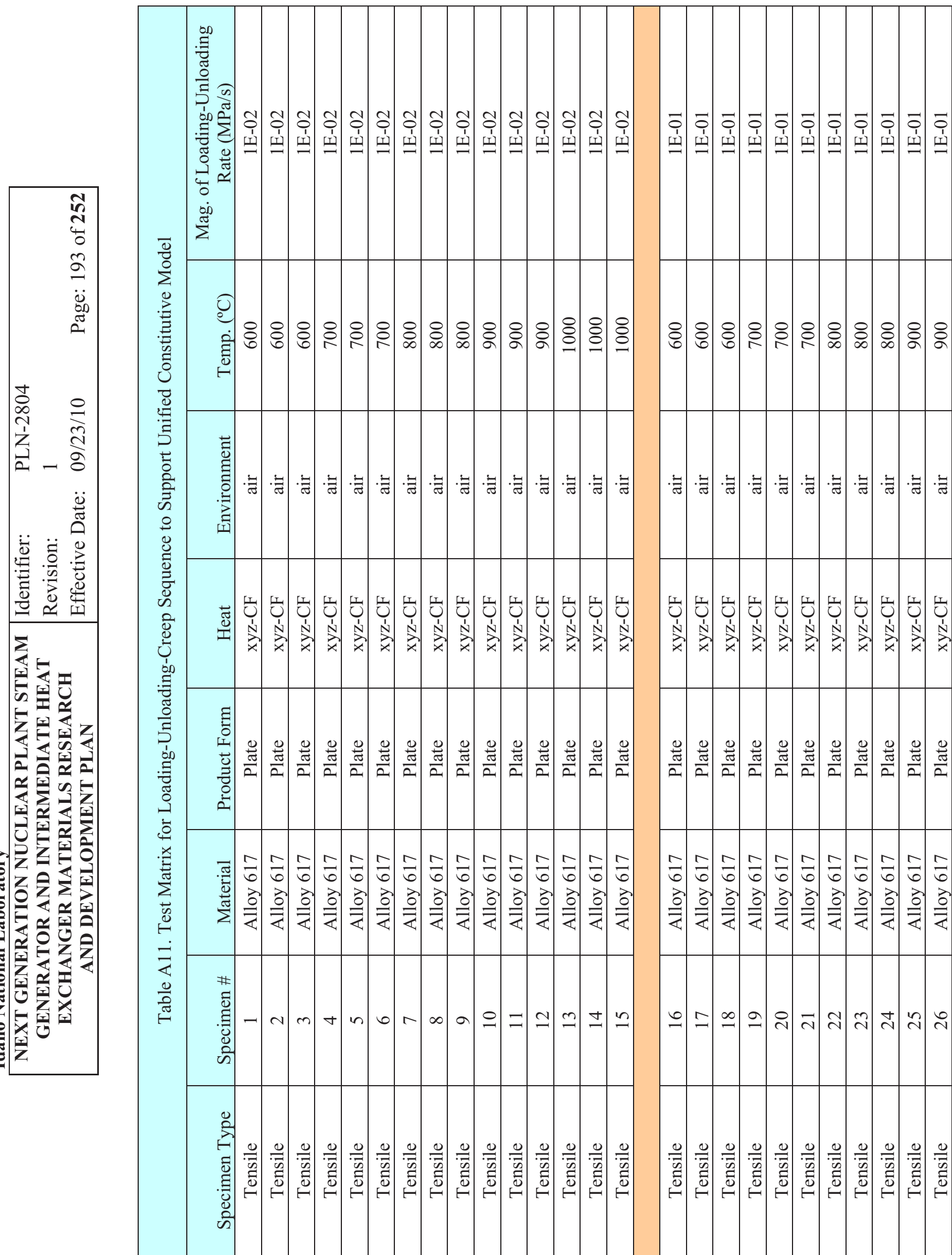




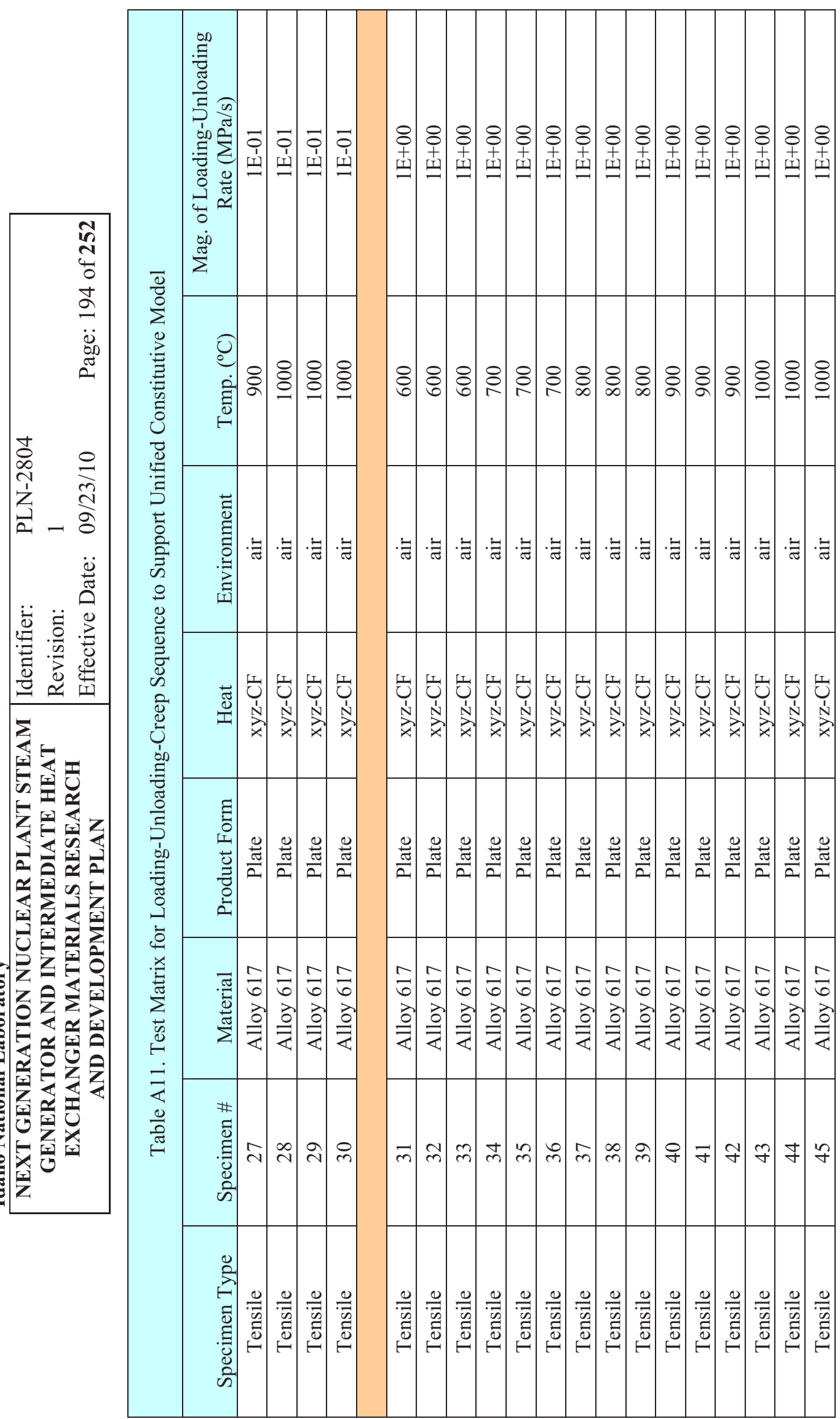




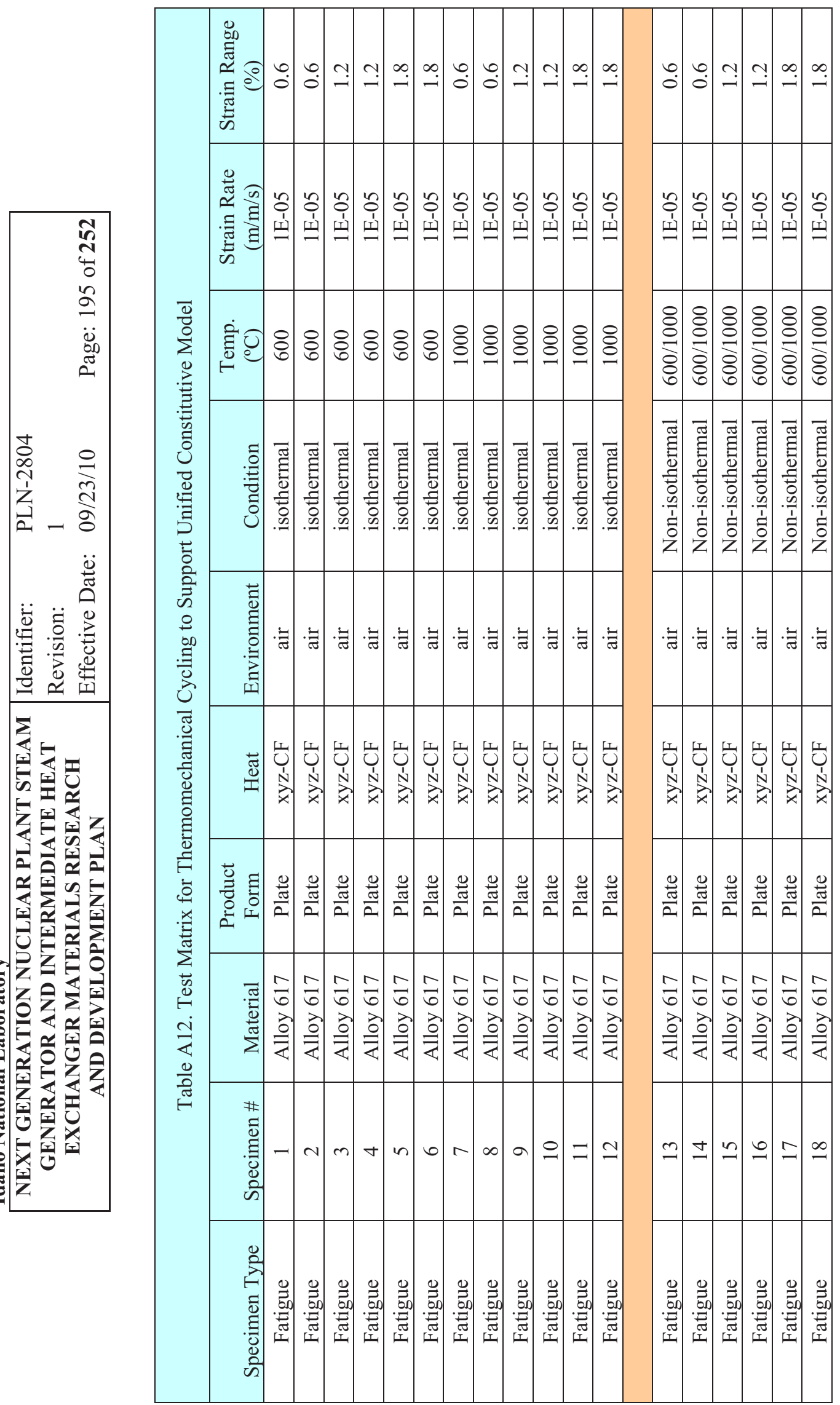




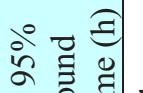

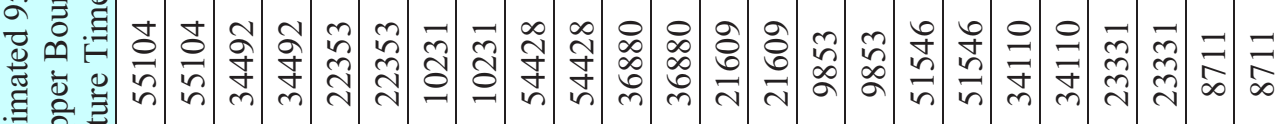
焉点

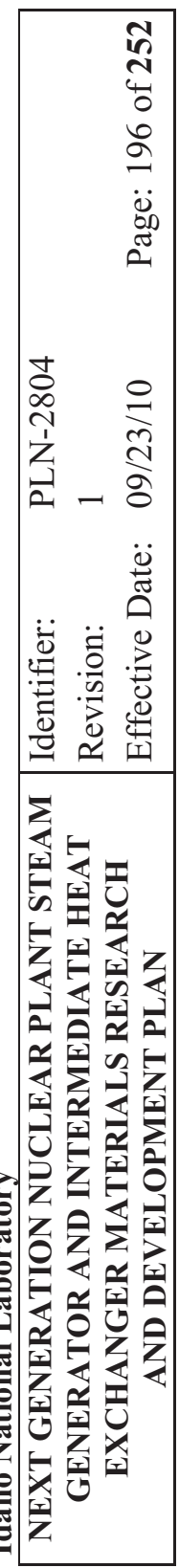

으

นั

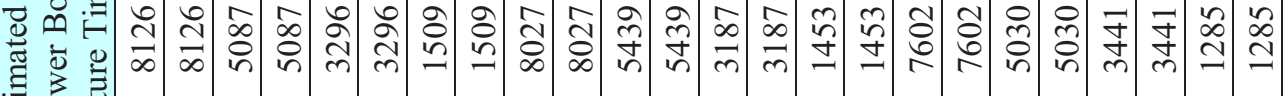

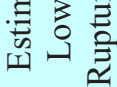

告

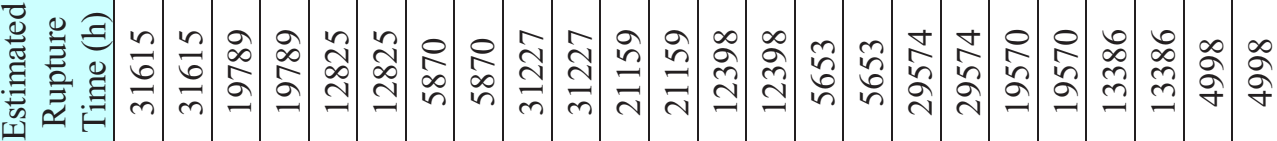

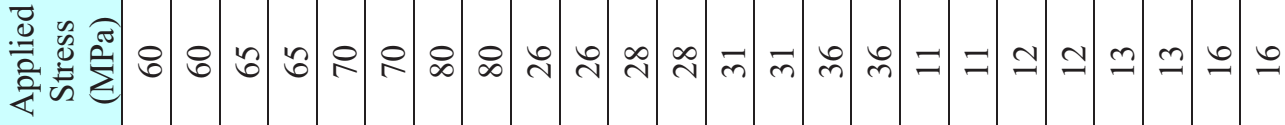

宅

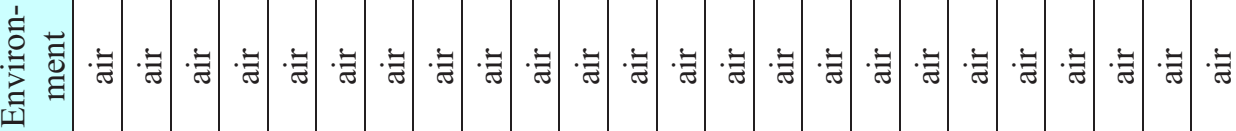

矛至

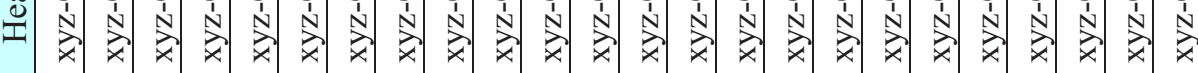

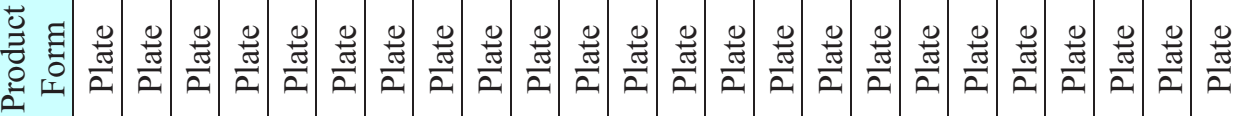

큰 궁 궁

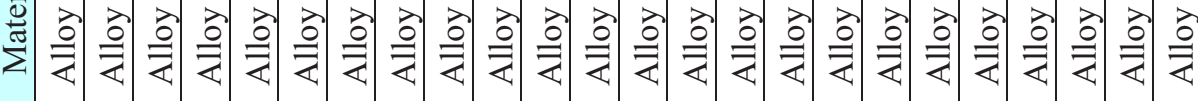

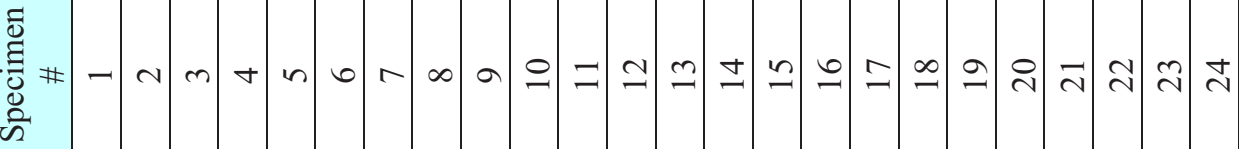
矛 की 


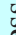

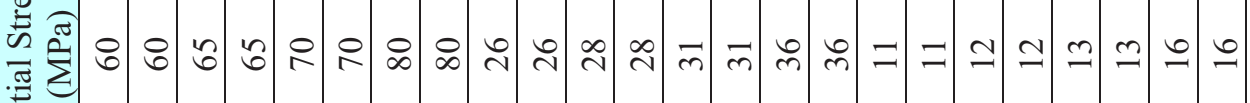
:

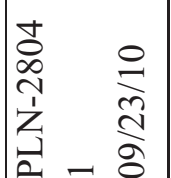

...

宛

离离总

$\simeq$ 工

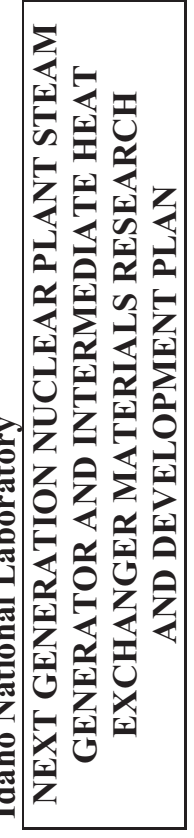

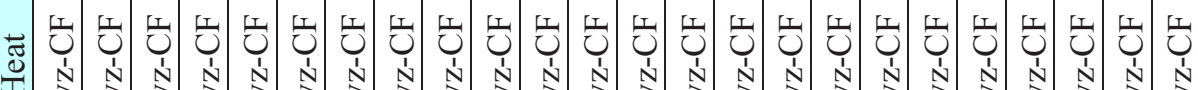

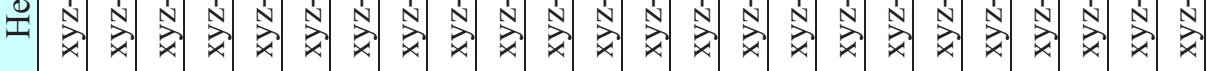

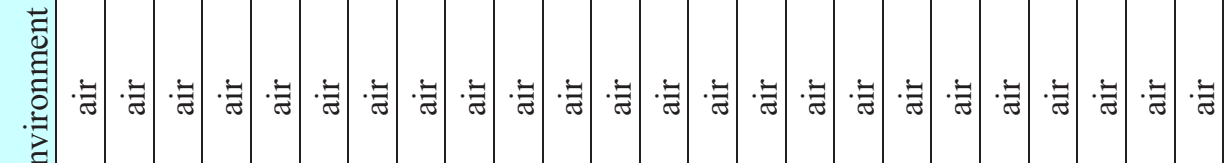
过

:

莺

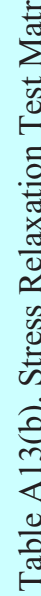

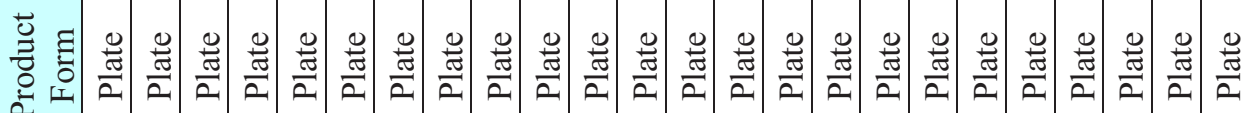

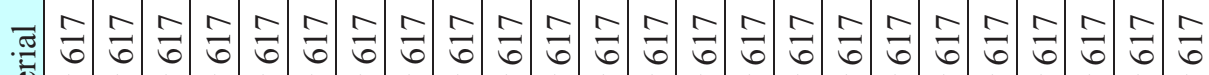

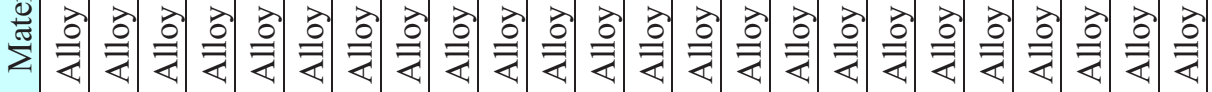

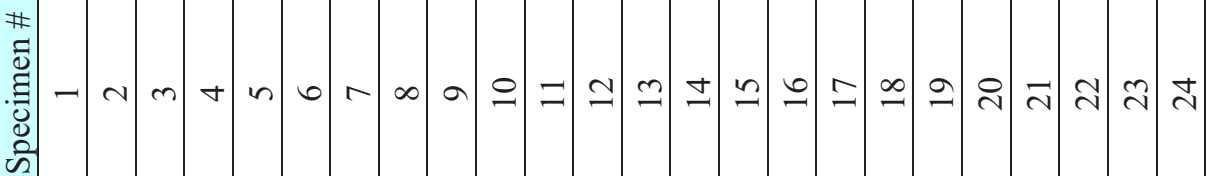

है

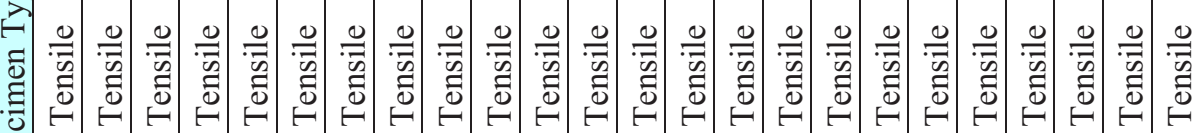
के 


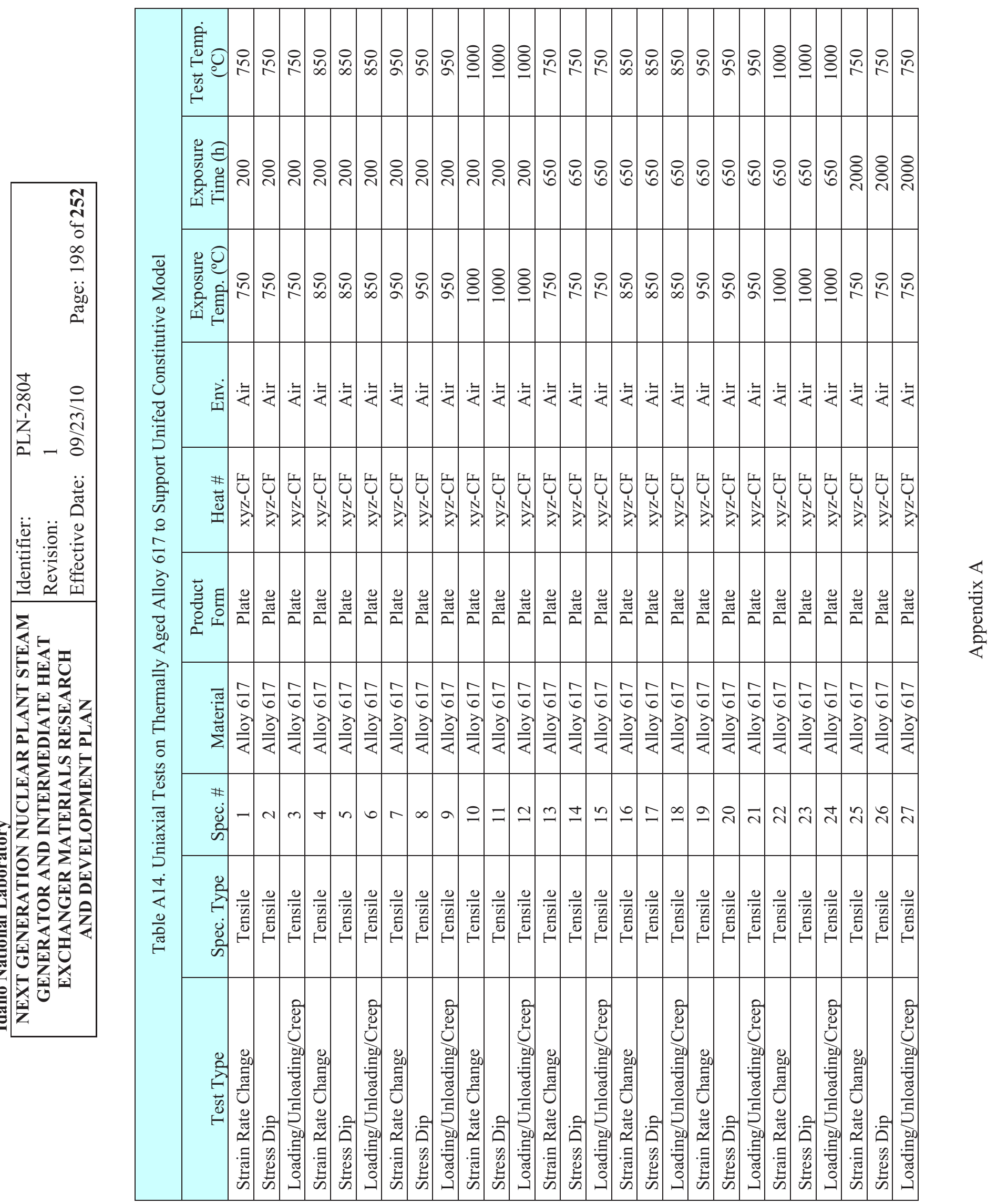




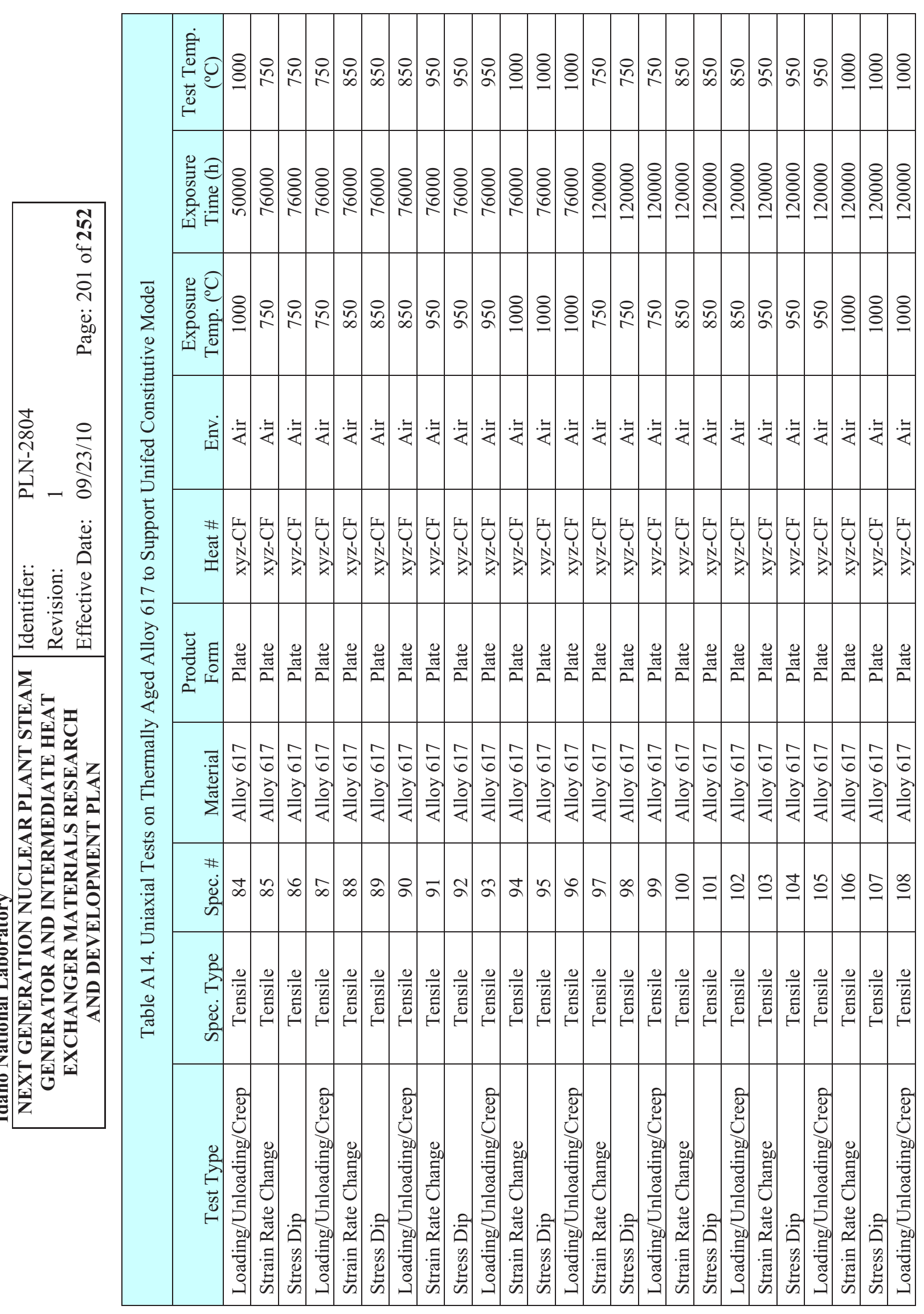



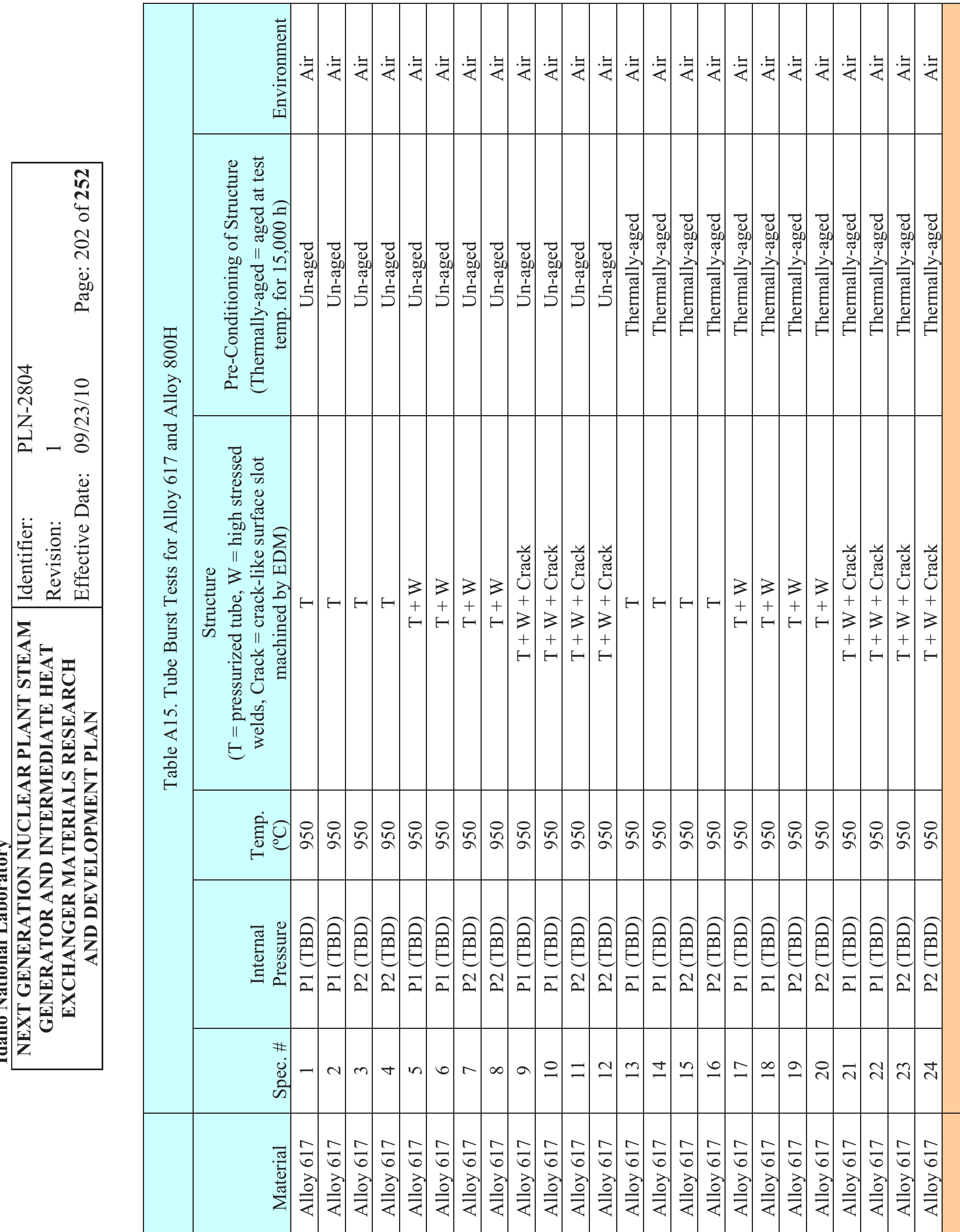


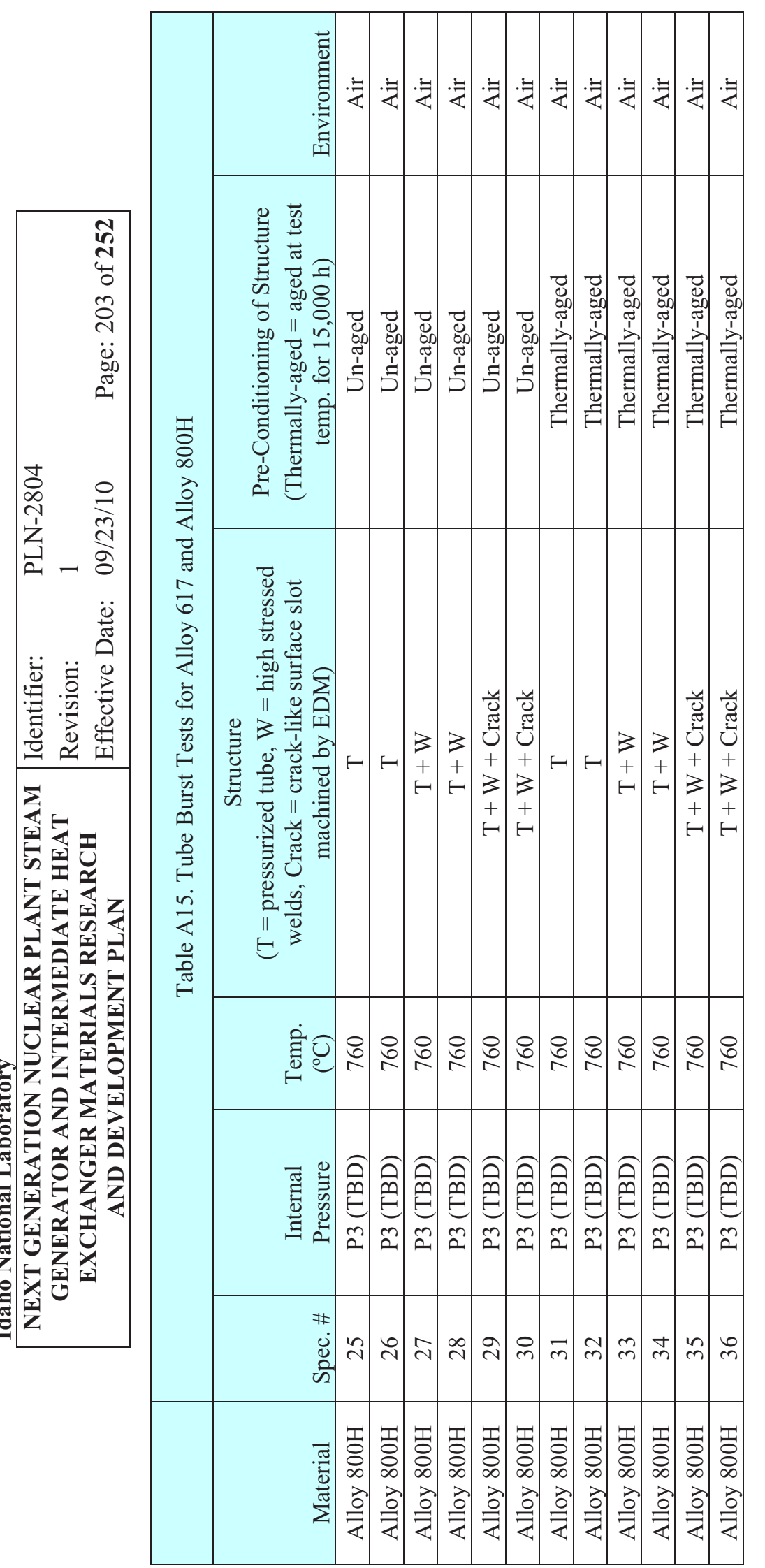




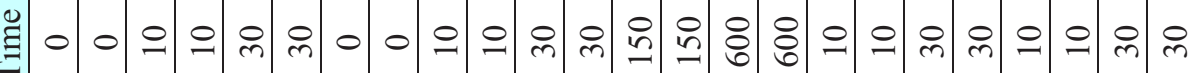

궁

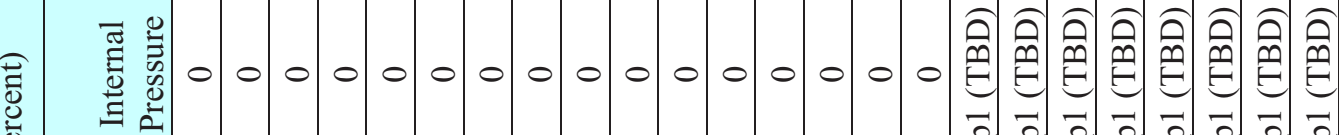

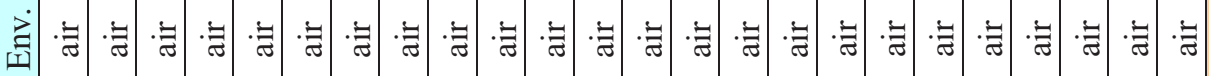

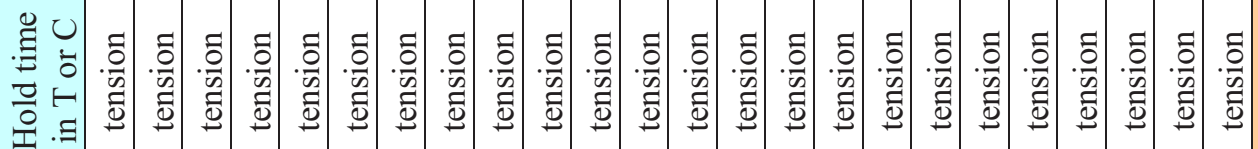
$\omega^{\circ}$

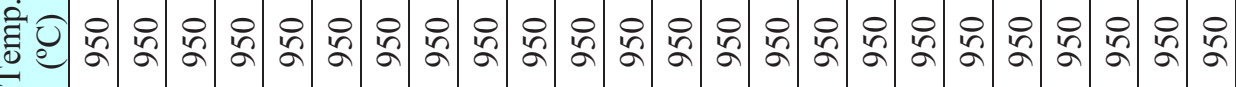

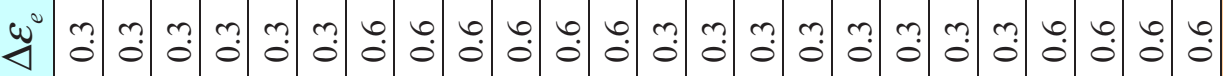

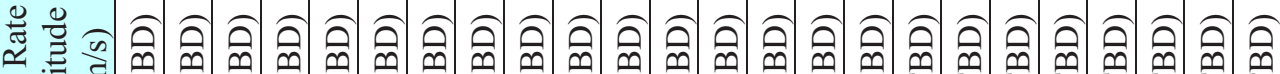

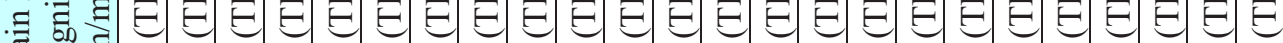

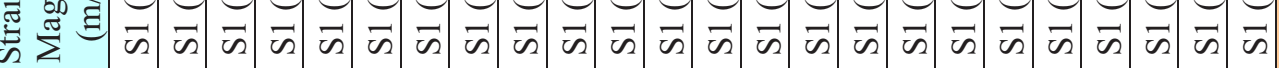

ت

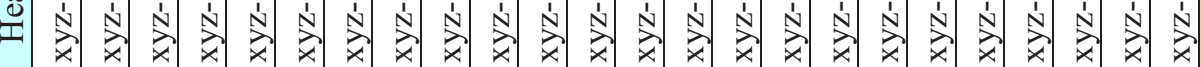

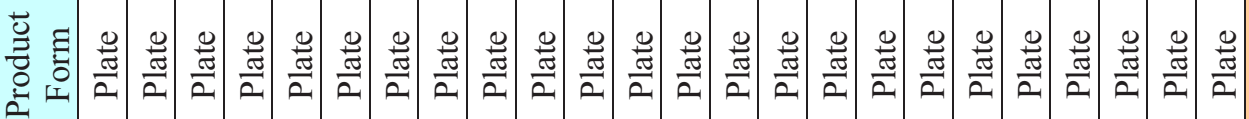
0 $\frac{0}{0}$

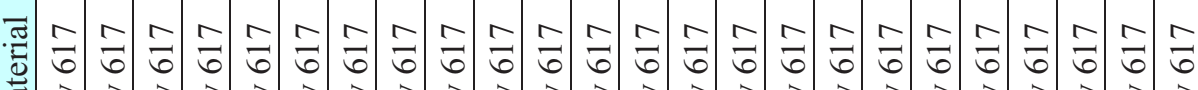
帘

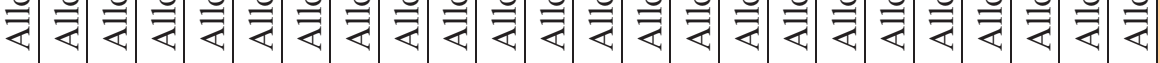

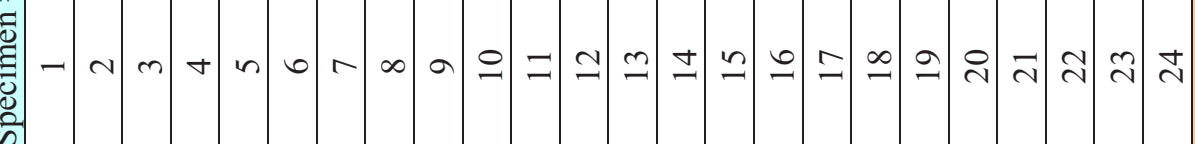




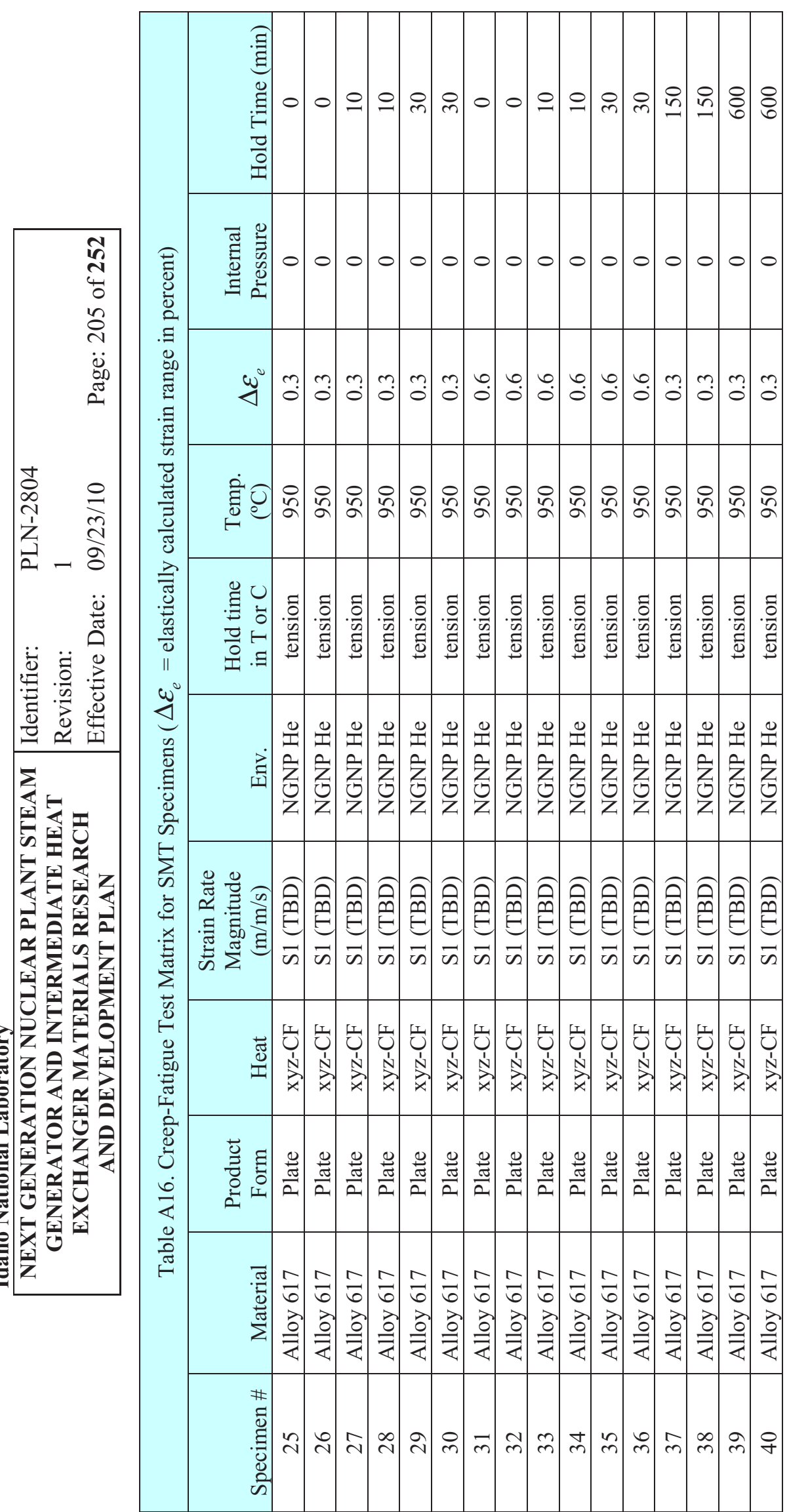




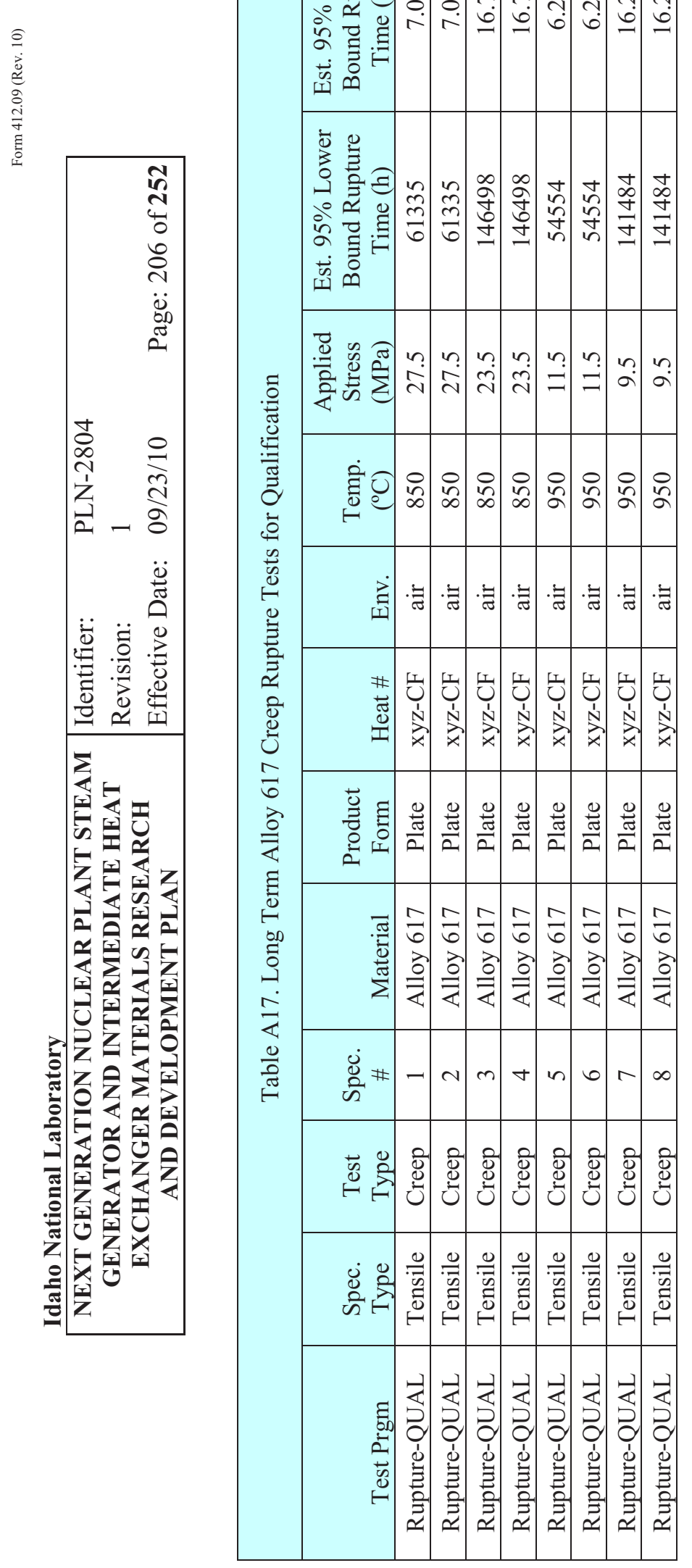




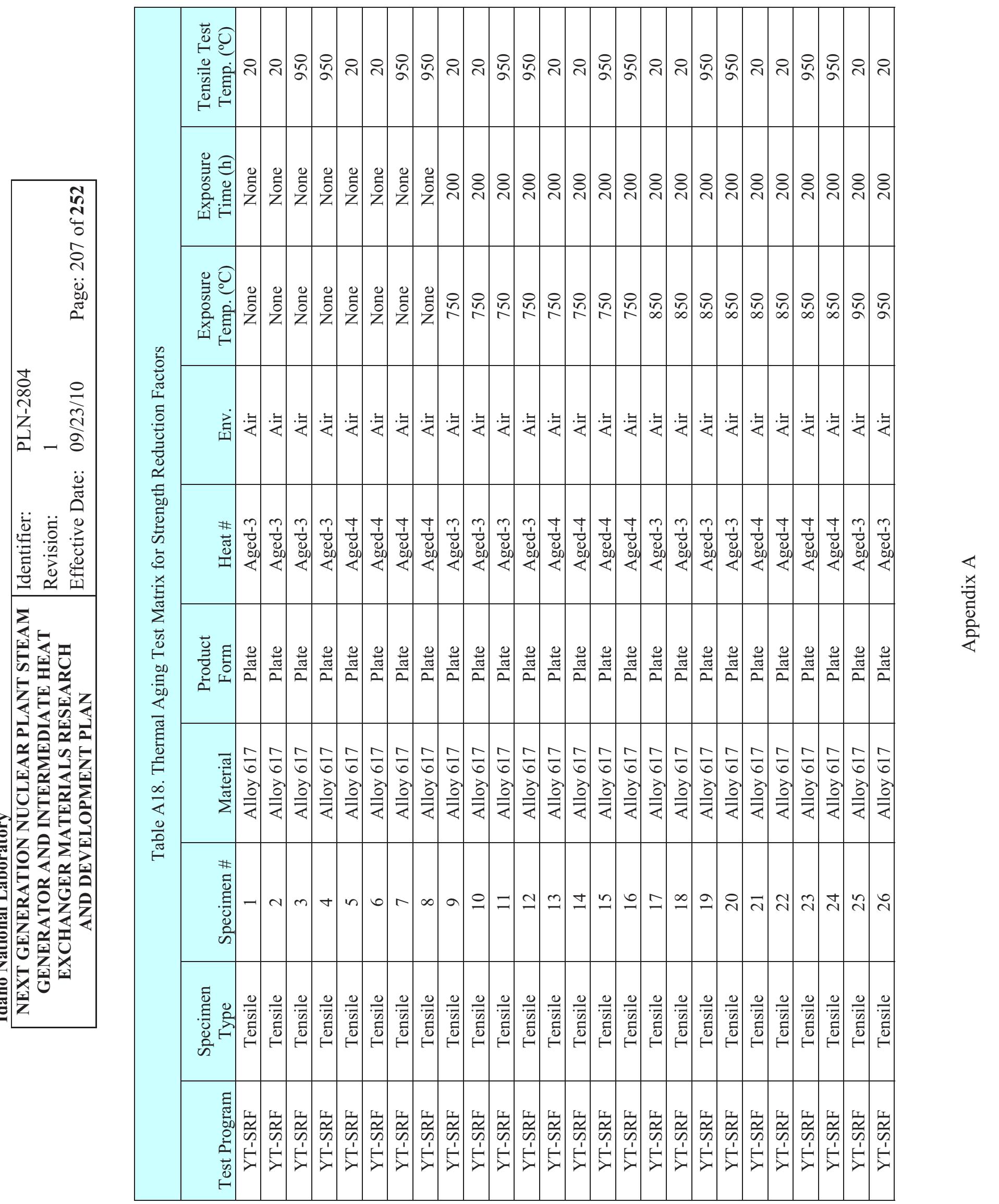




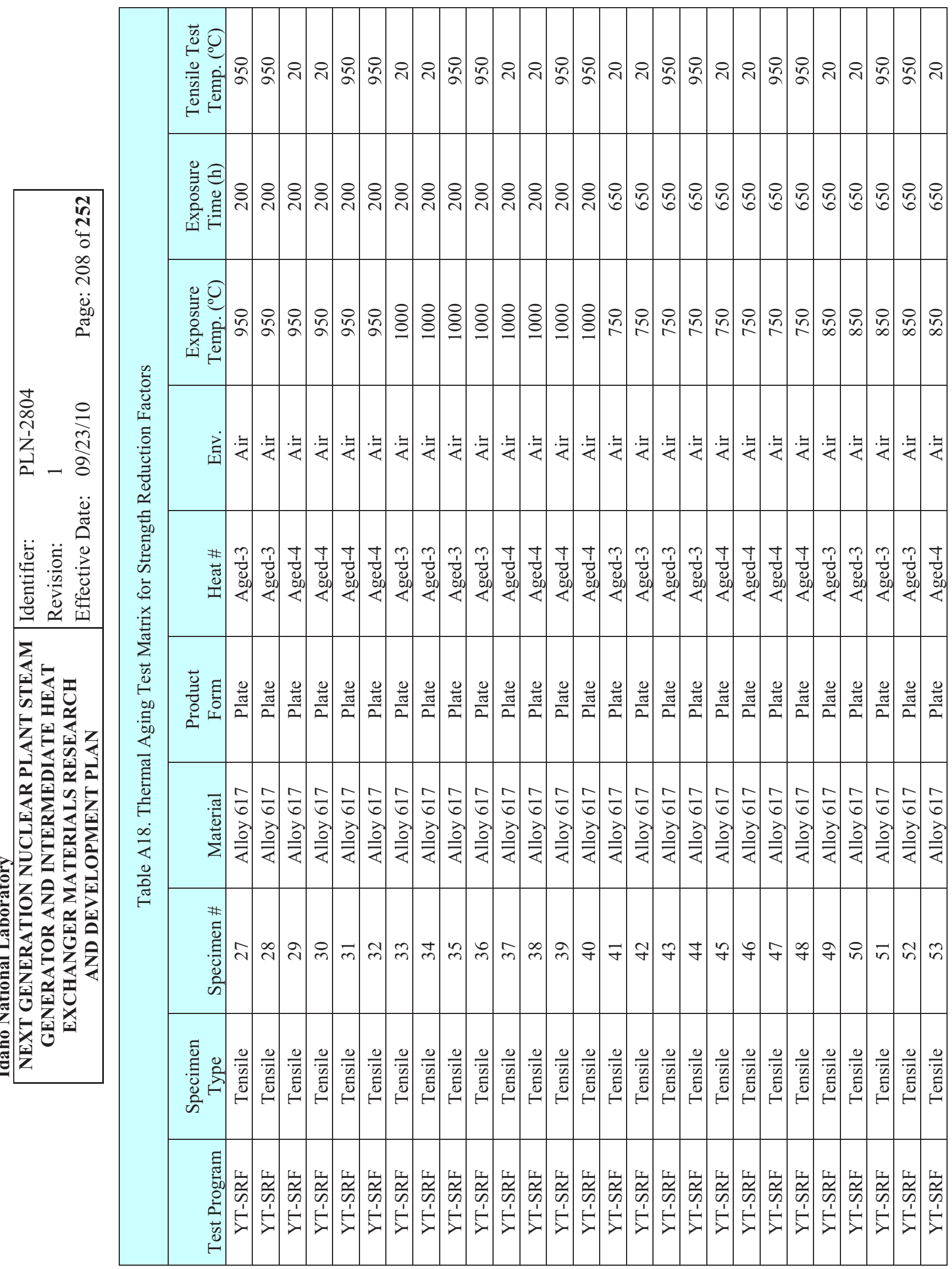




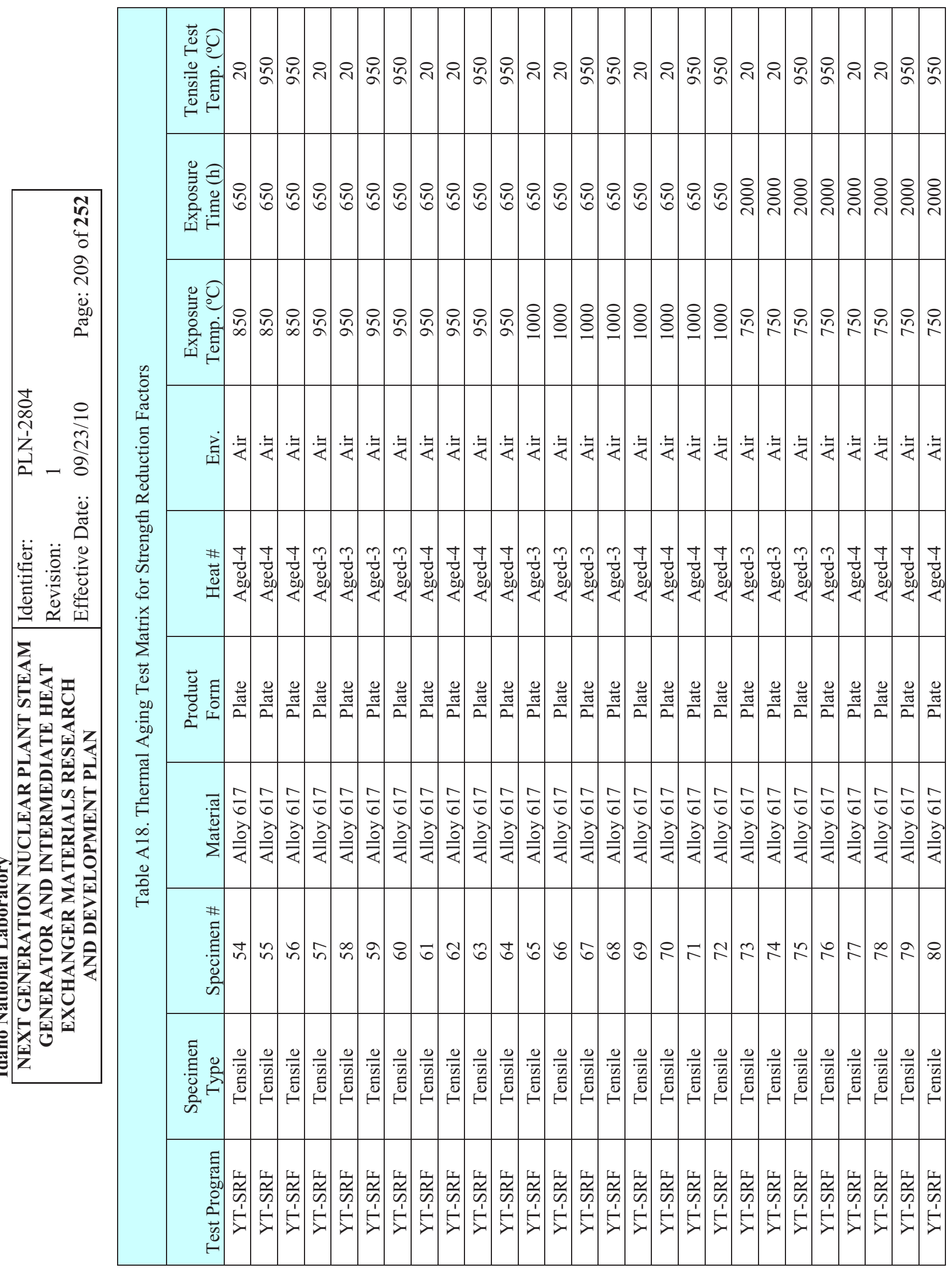




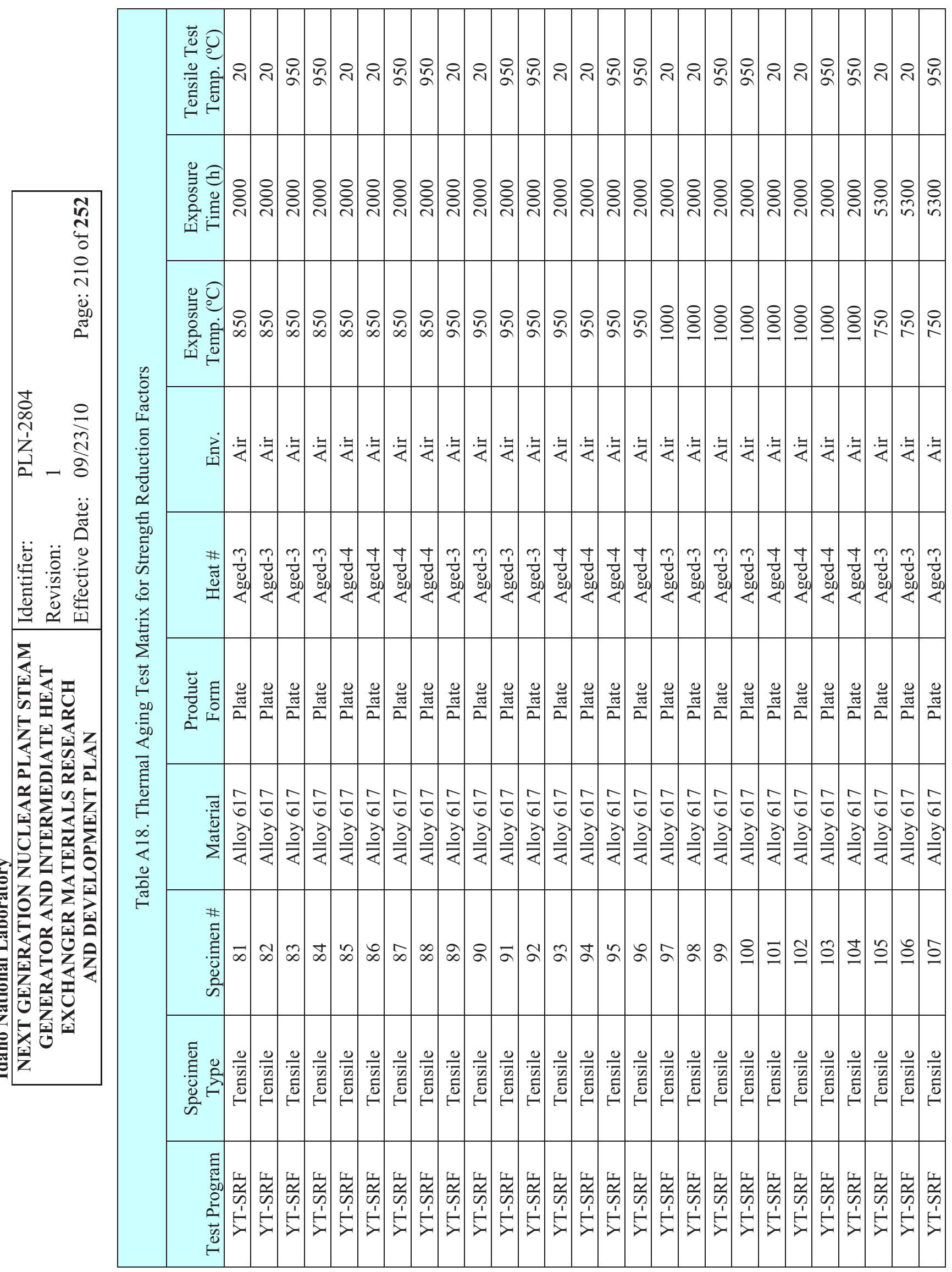




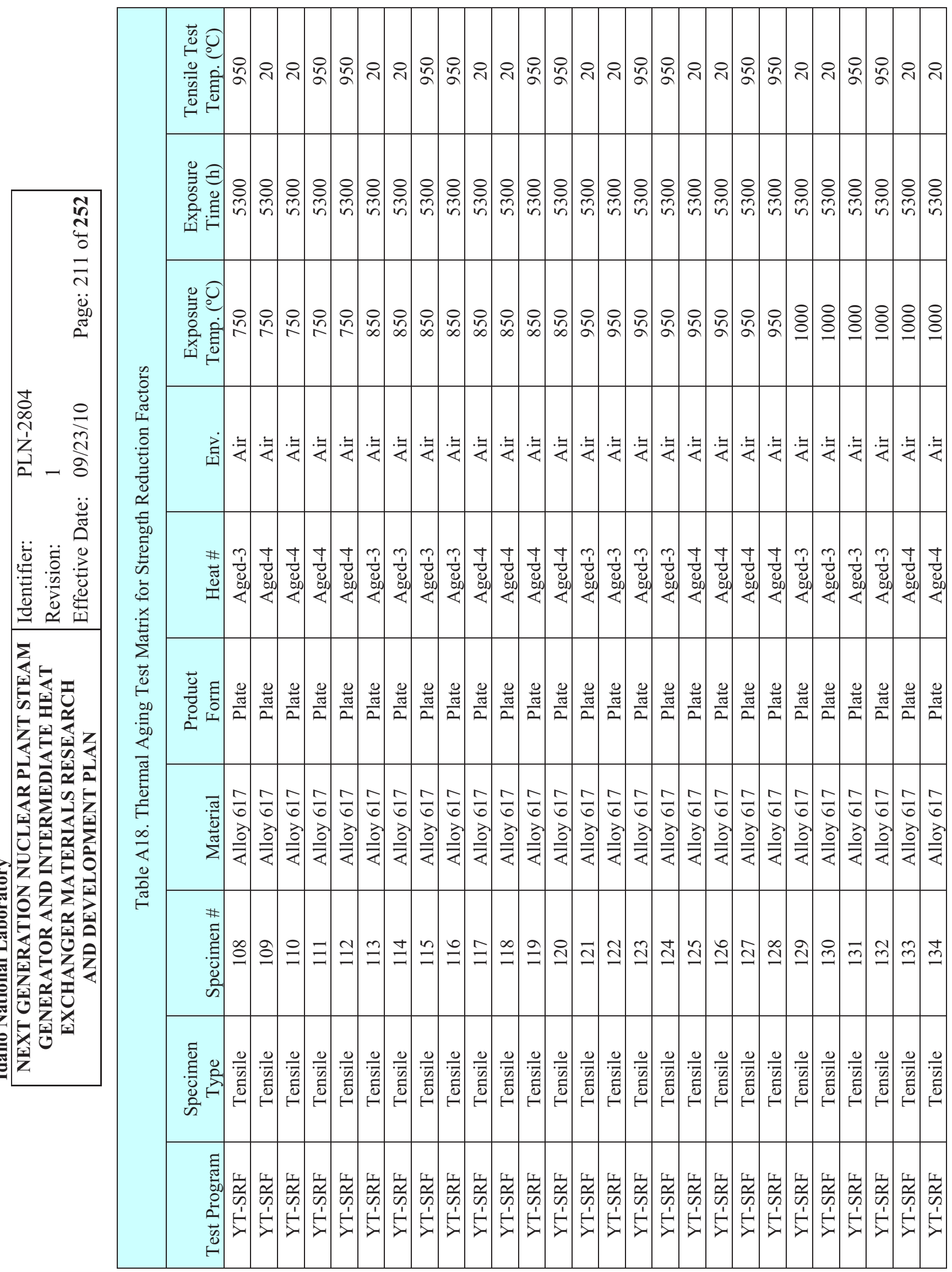




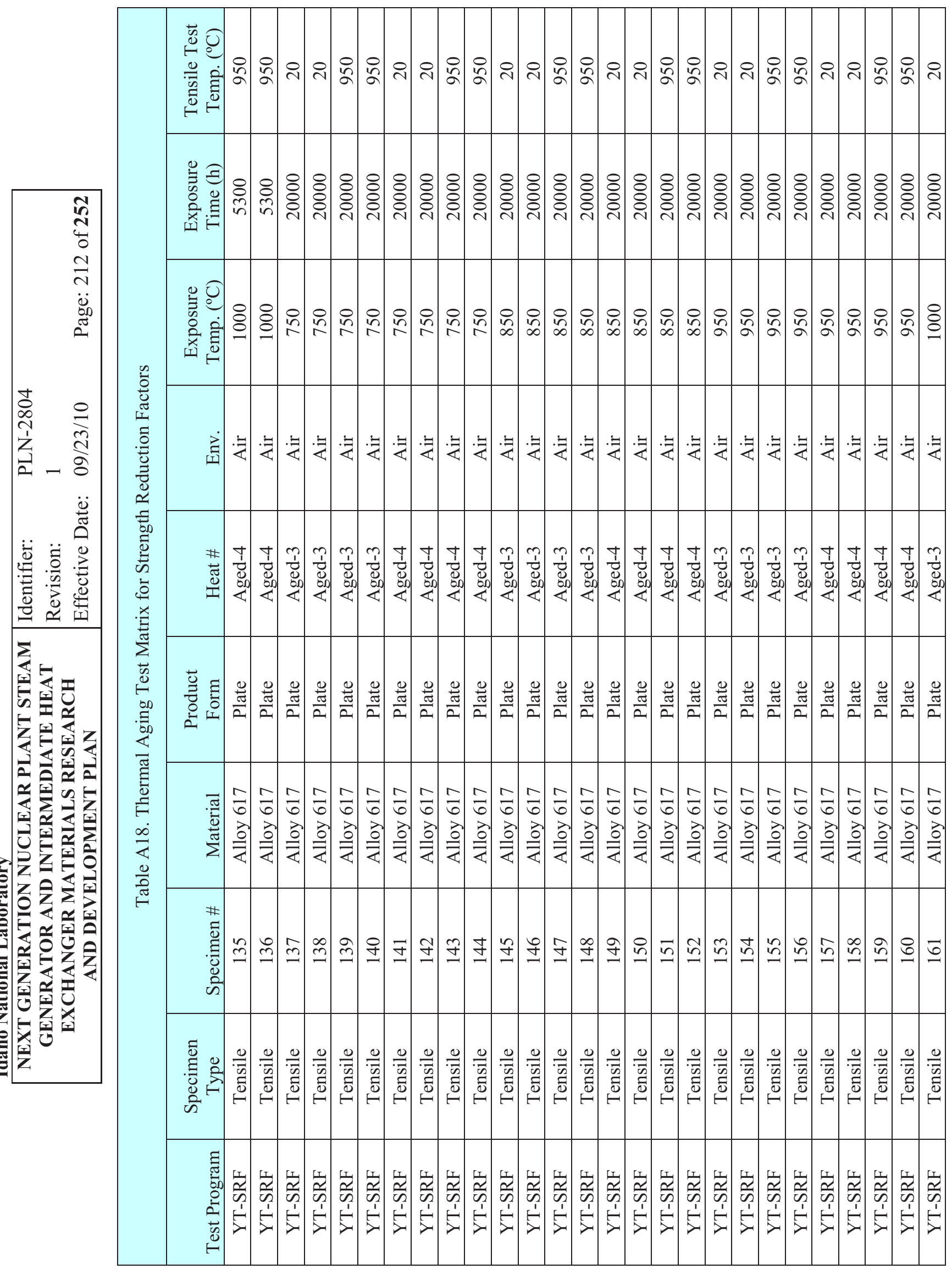




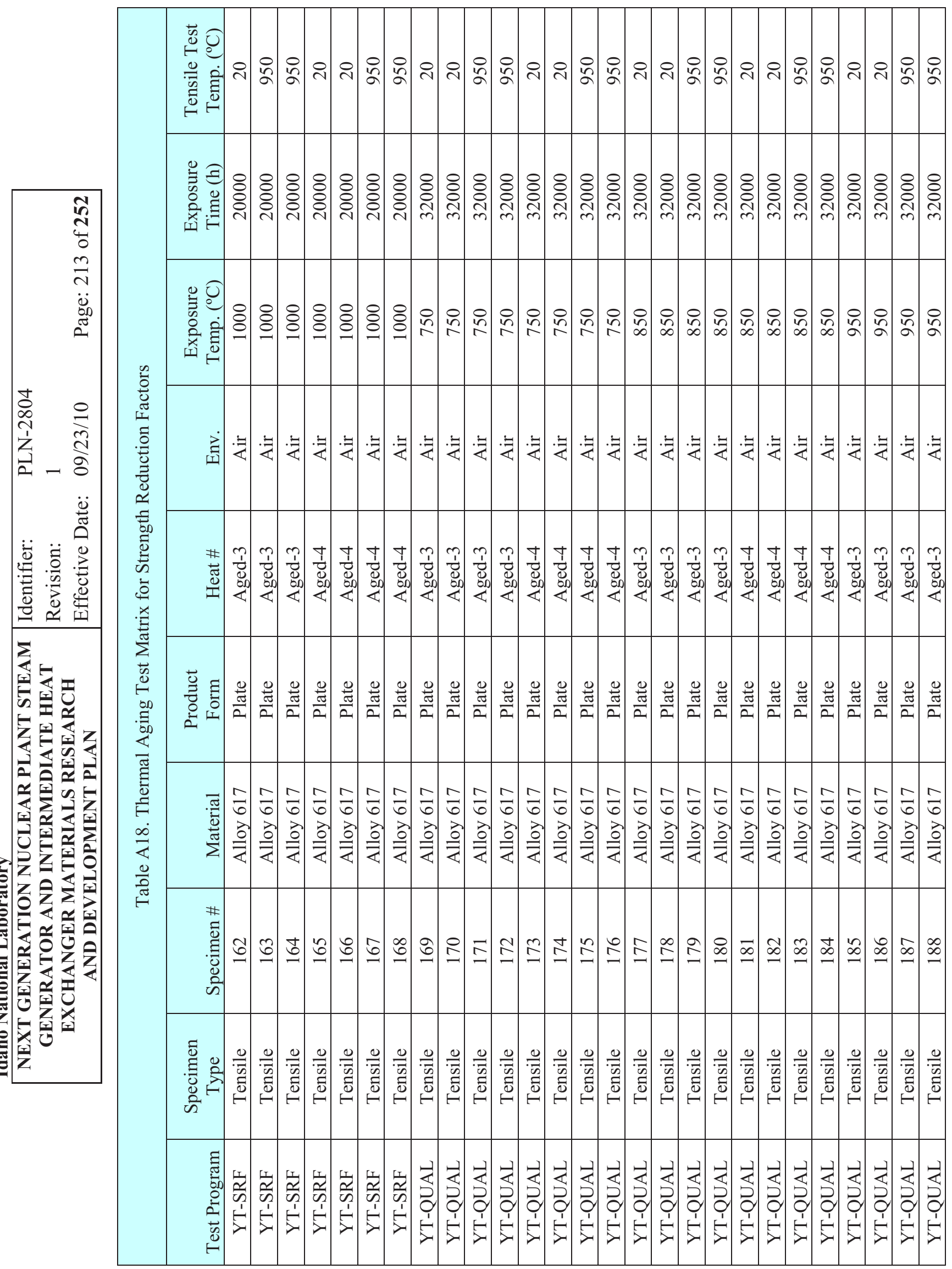




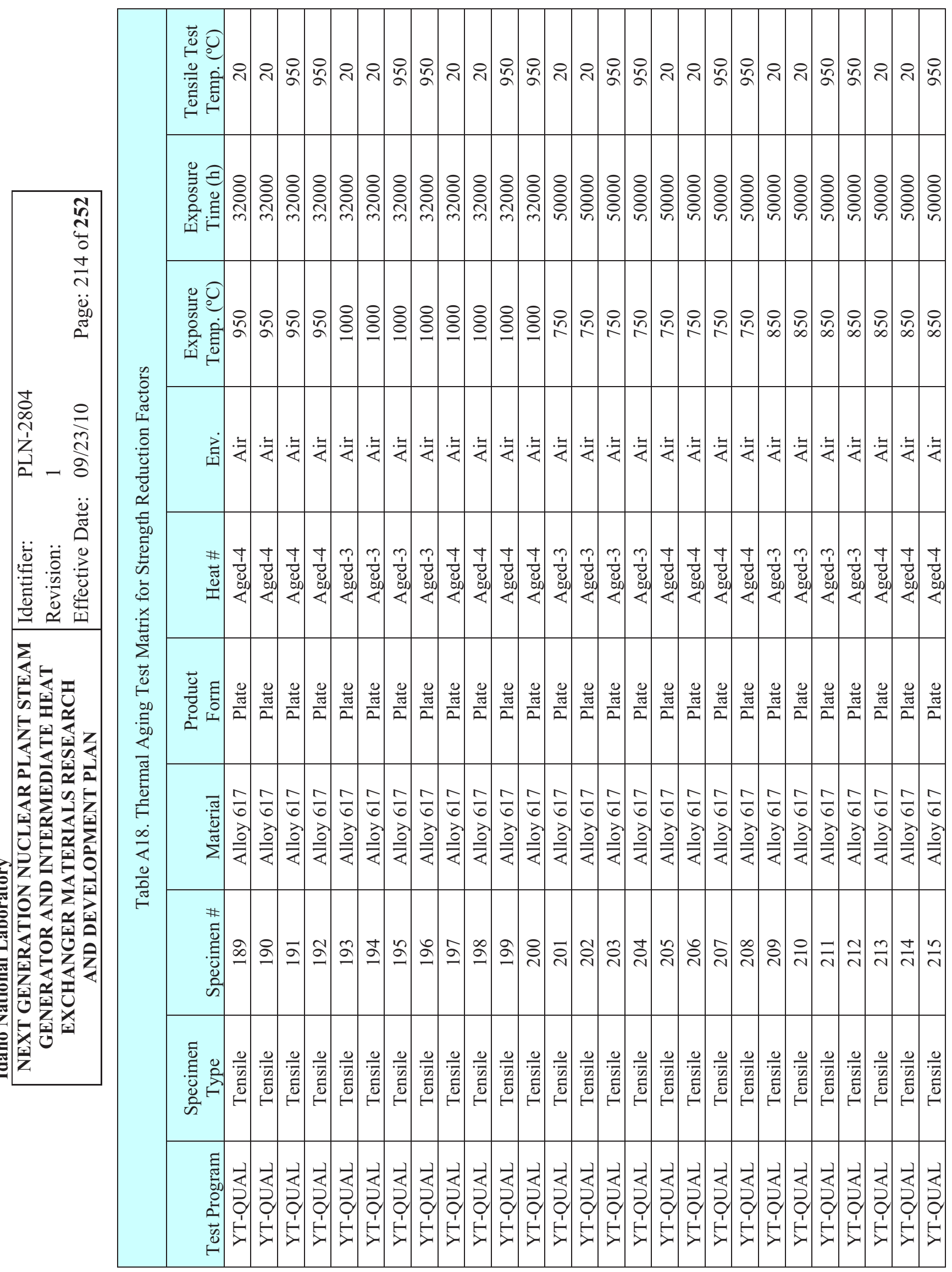




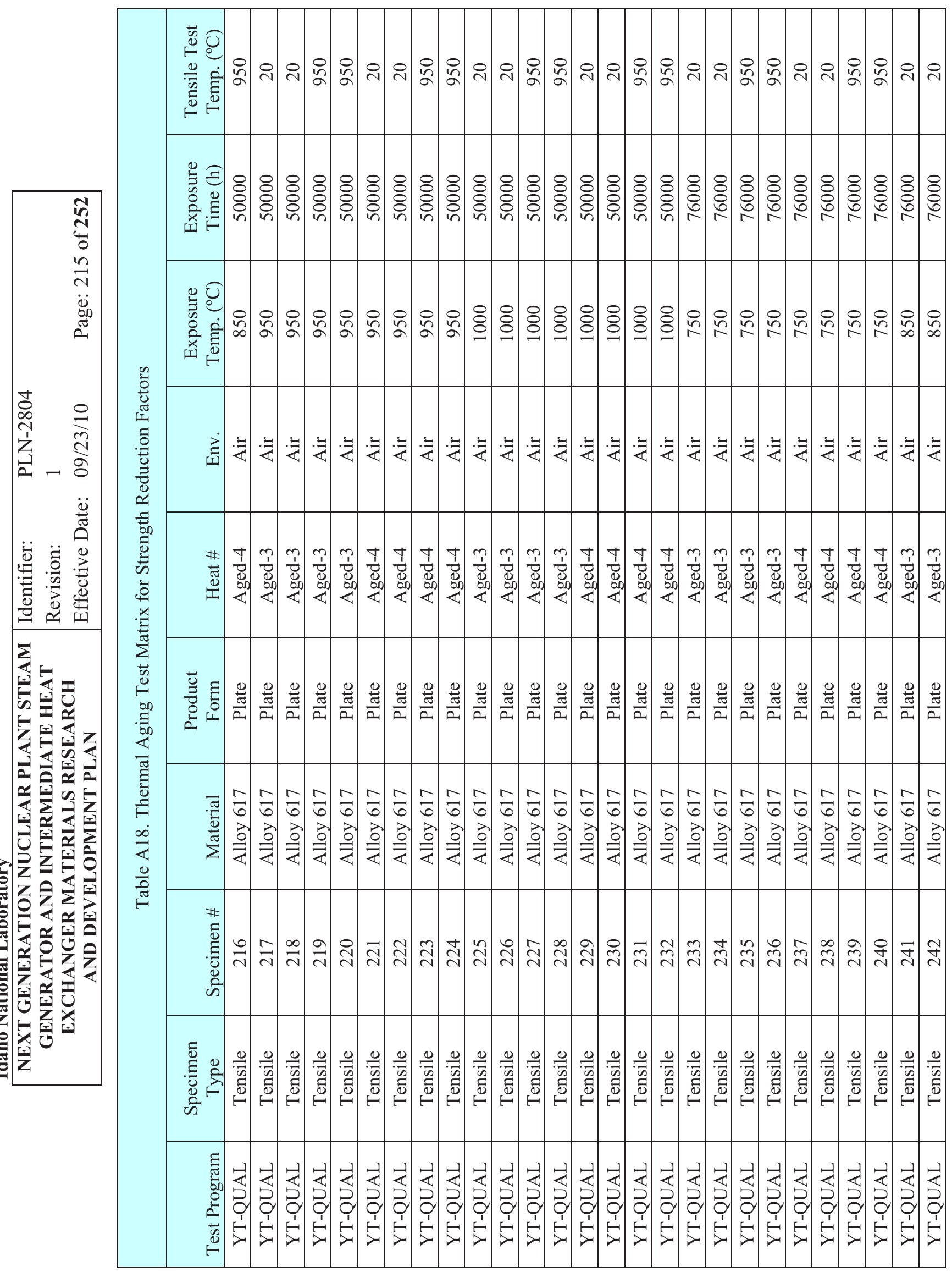




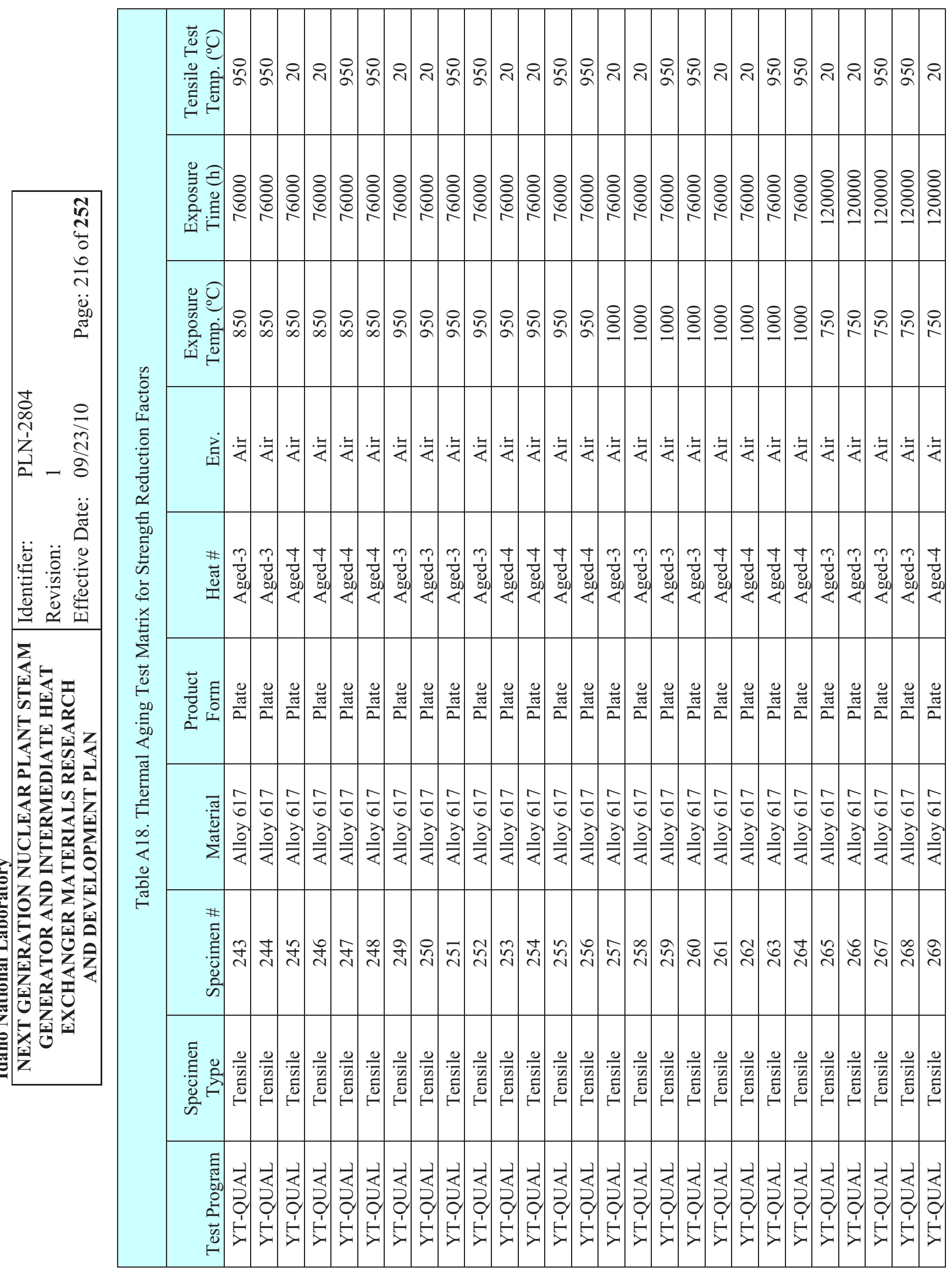




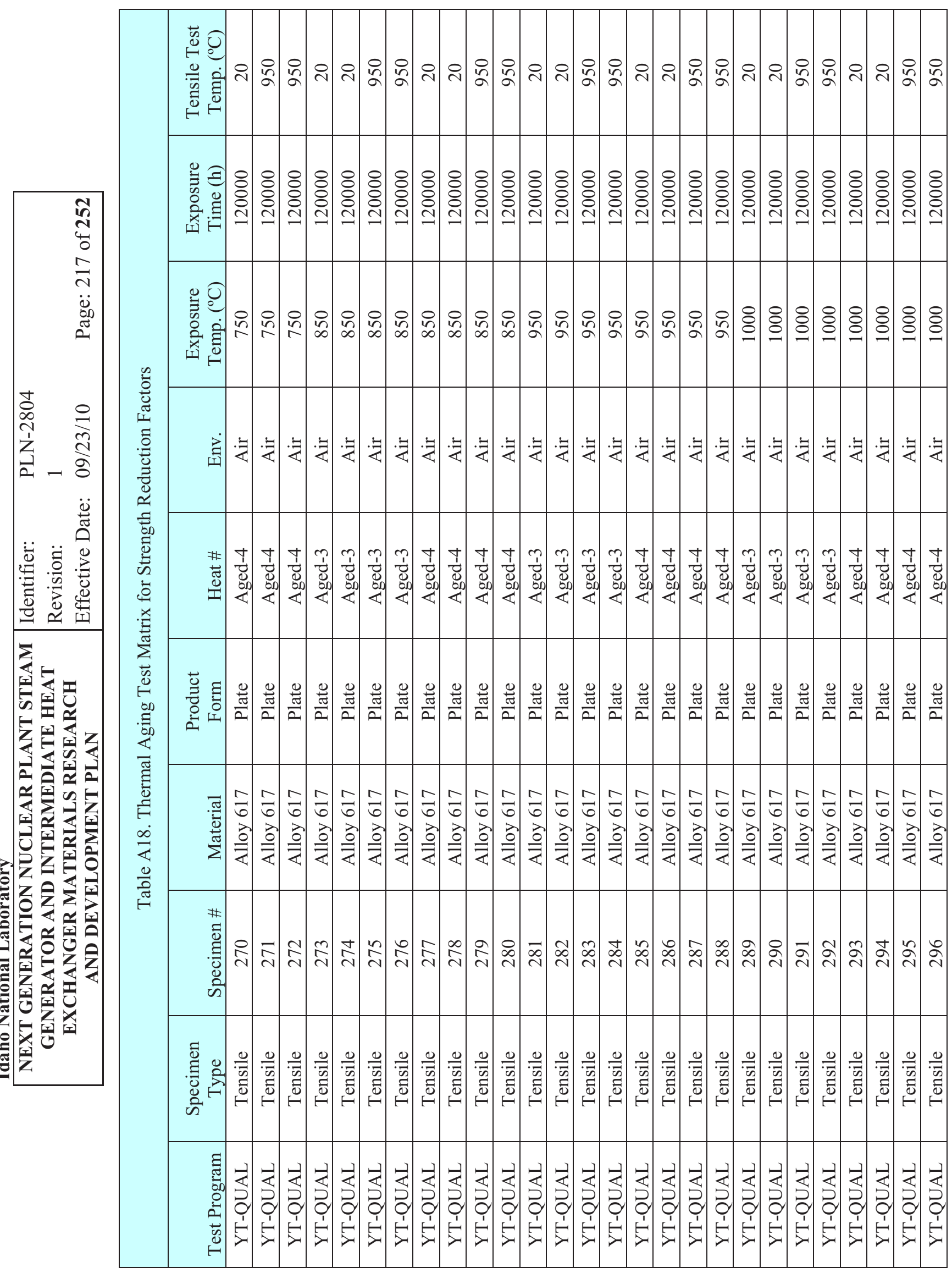




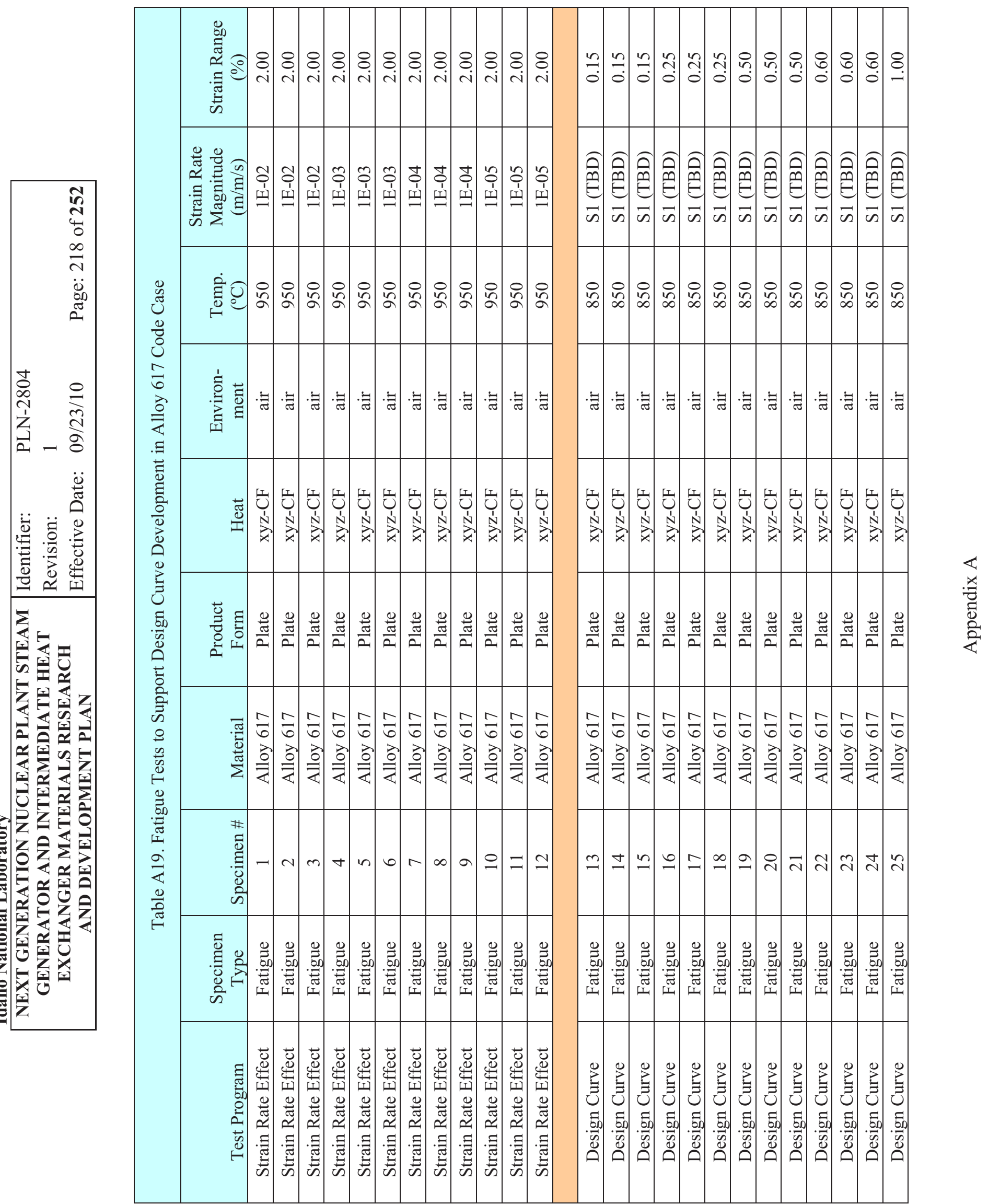




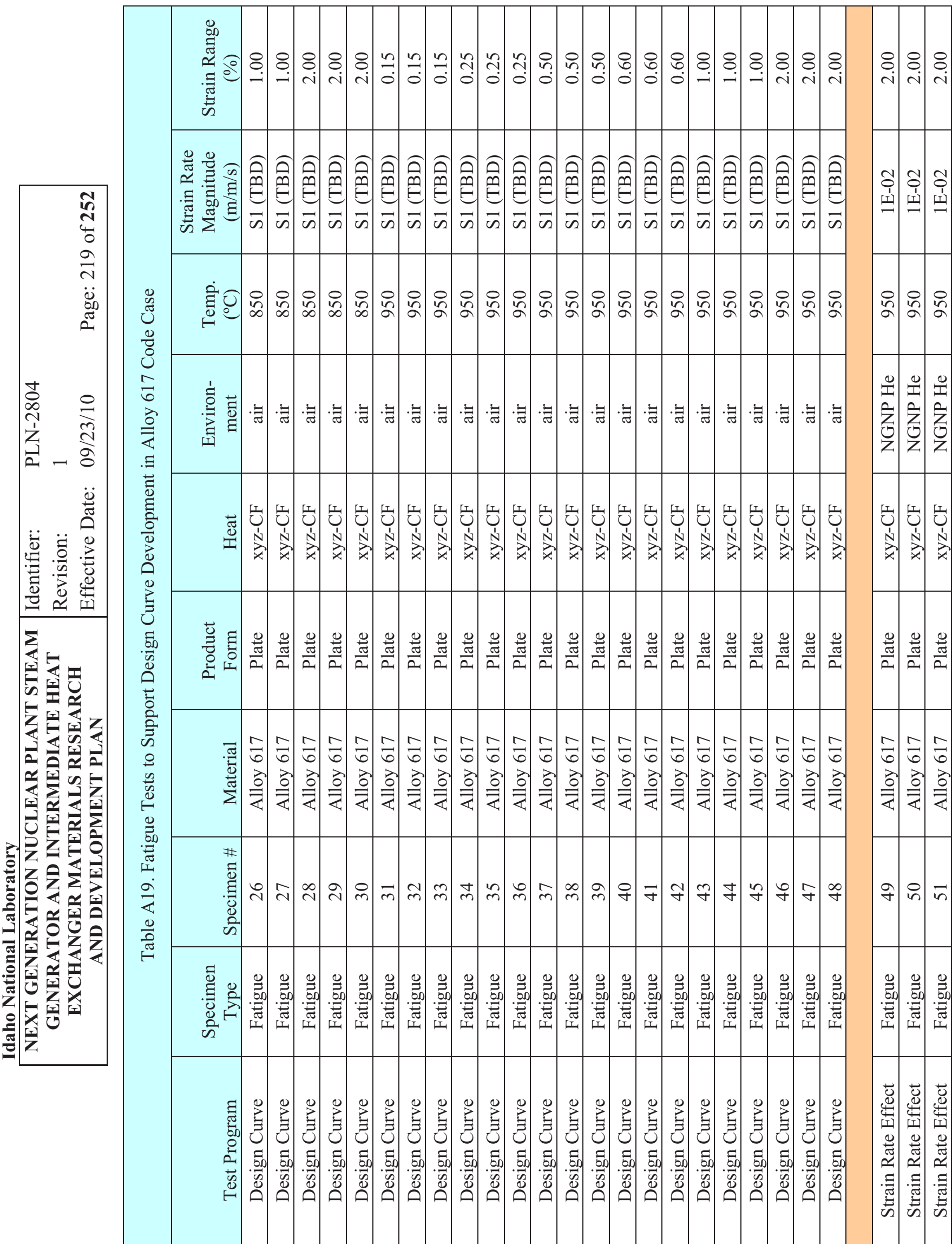




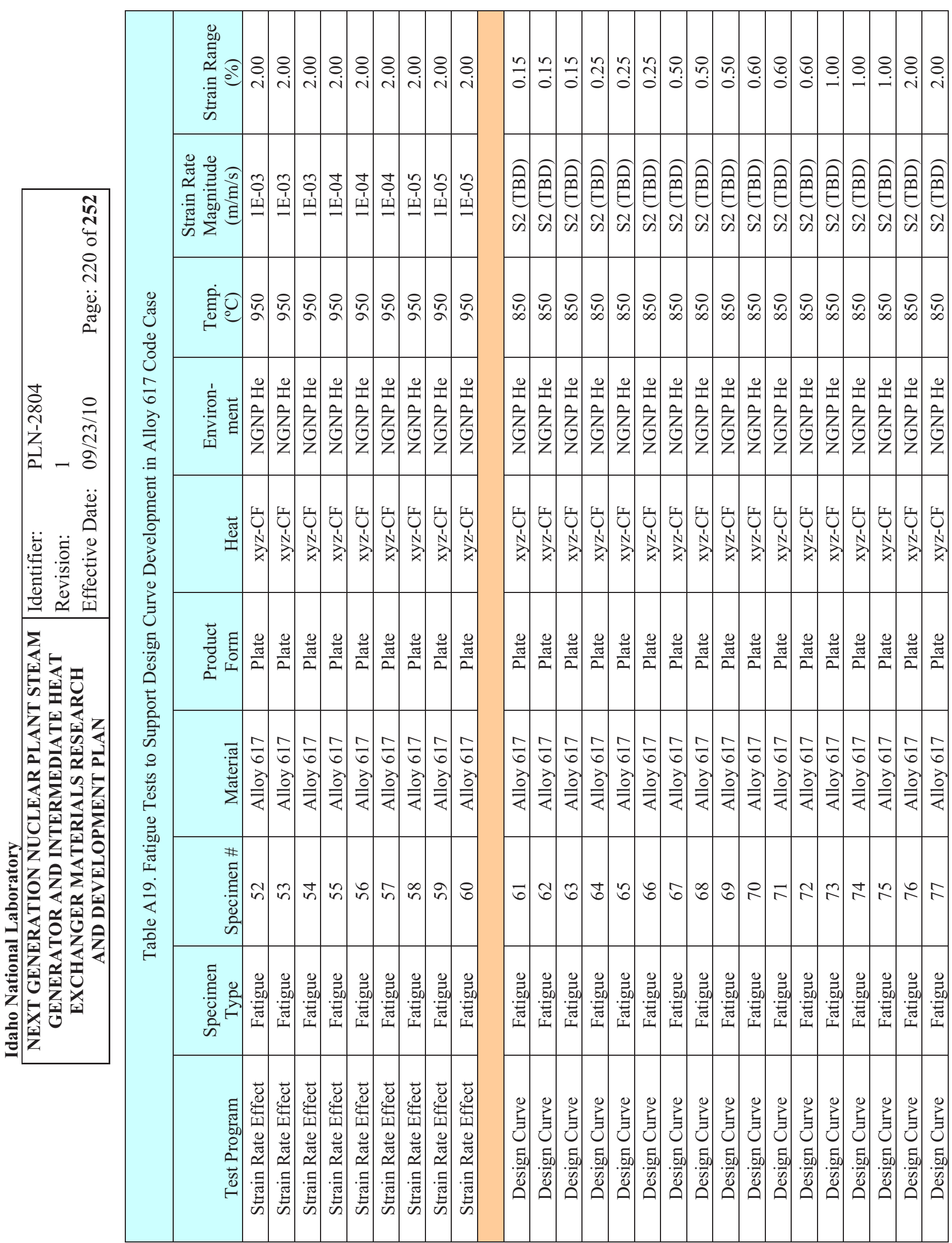




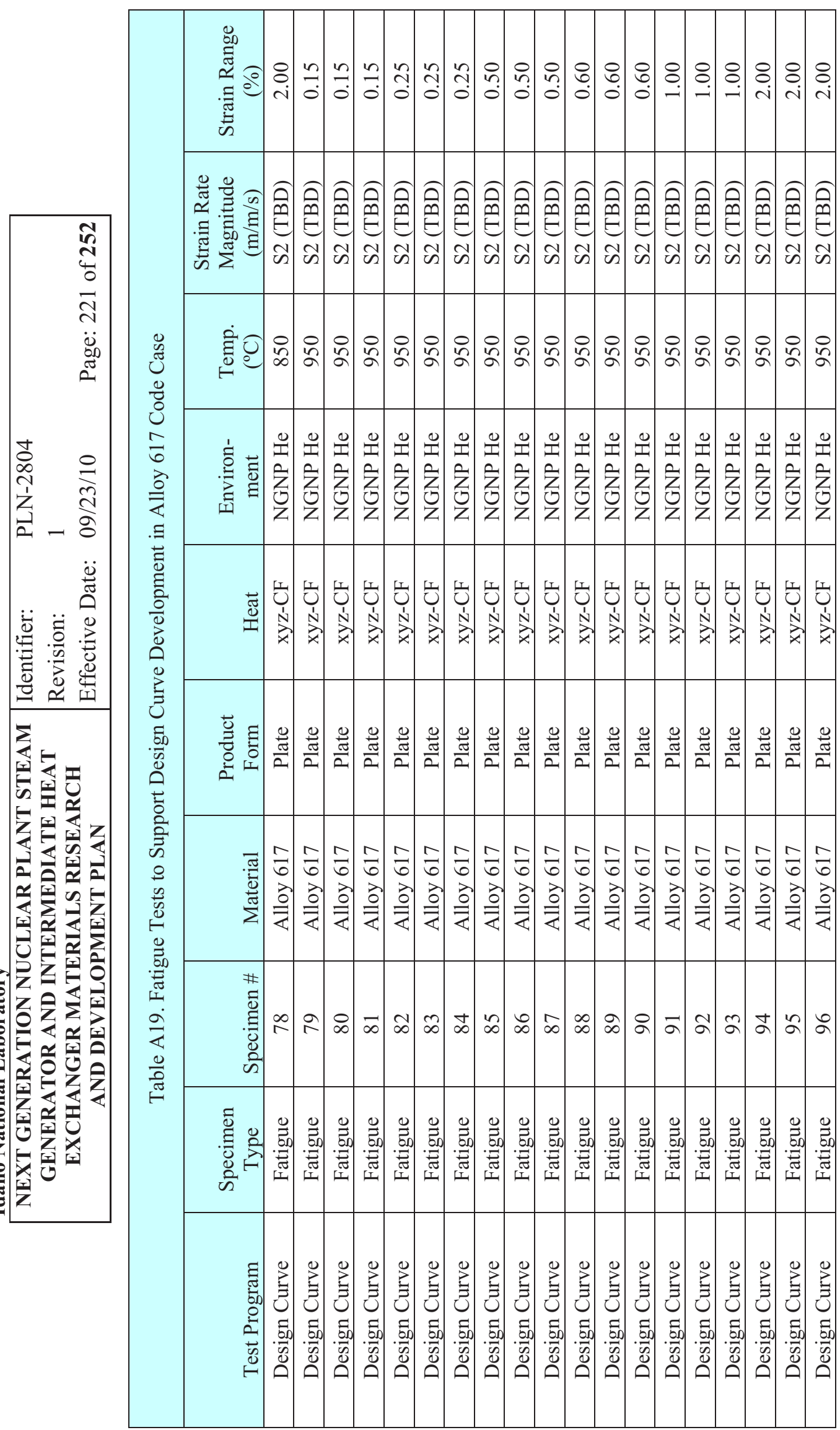




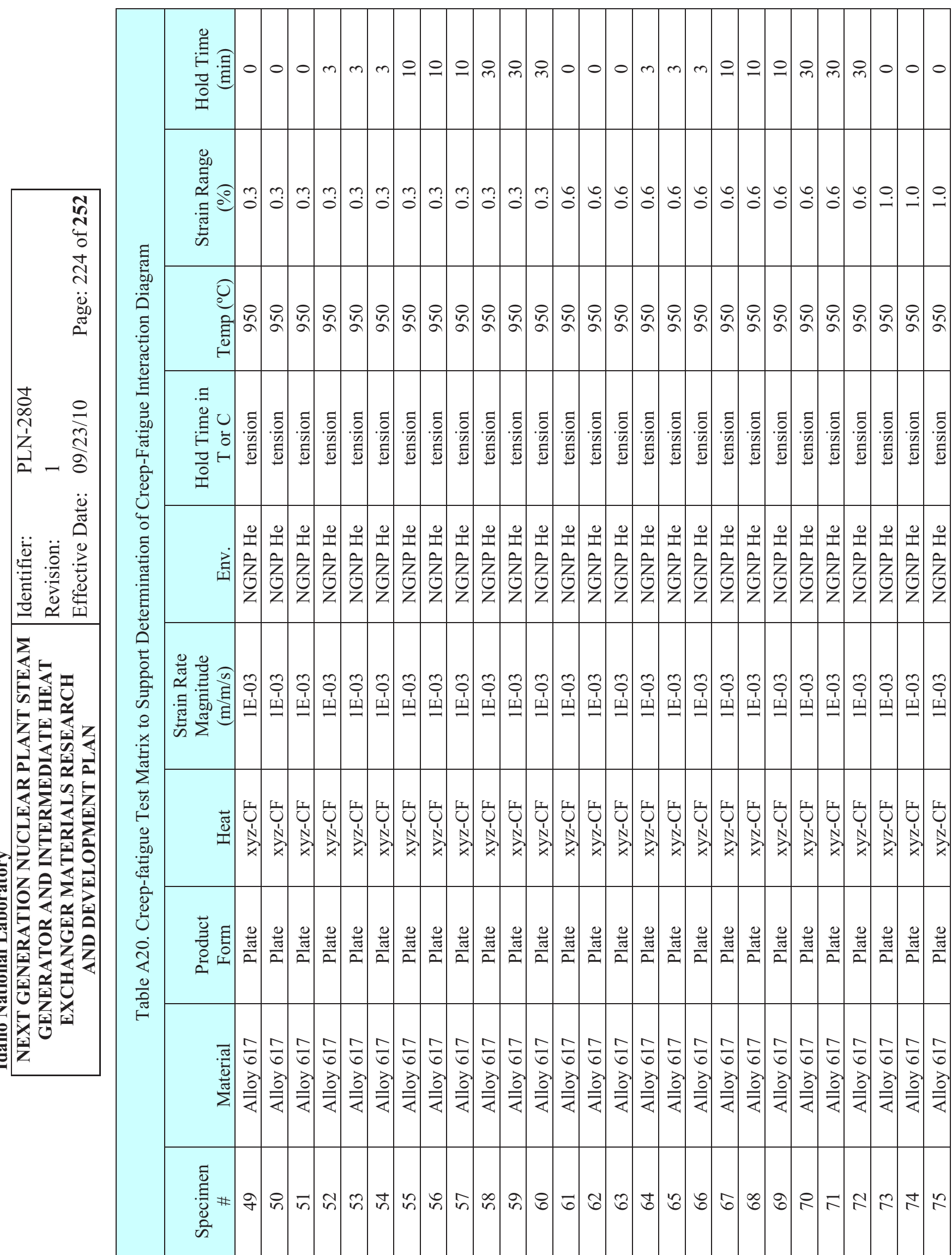




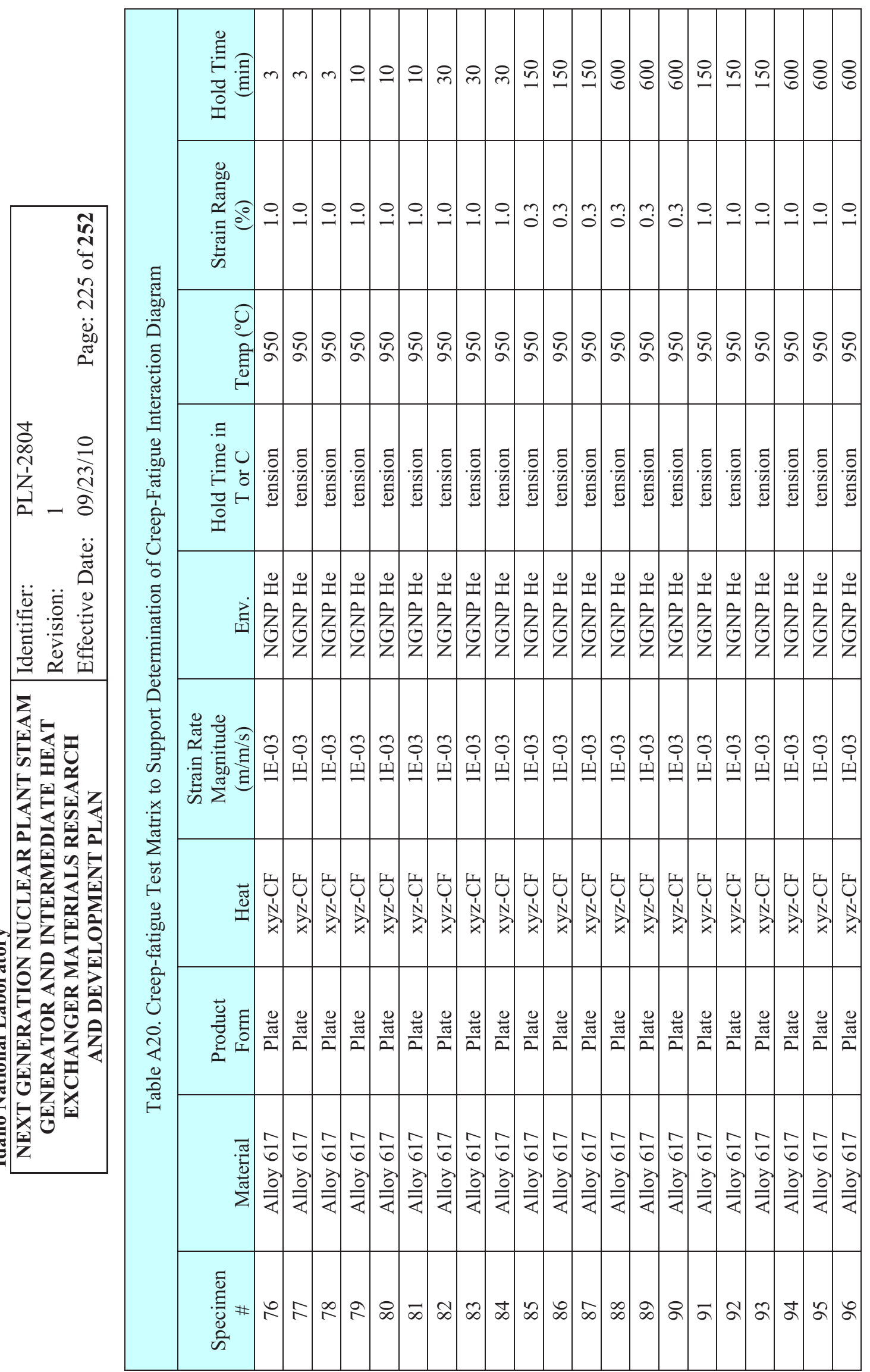




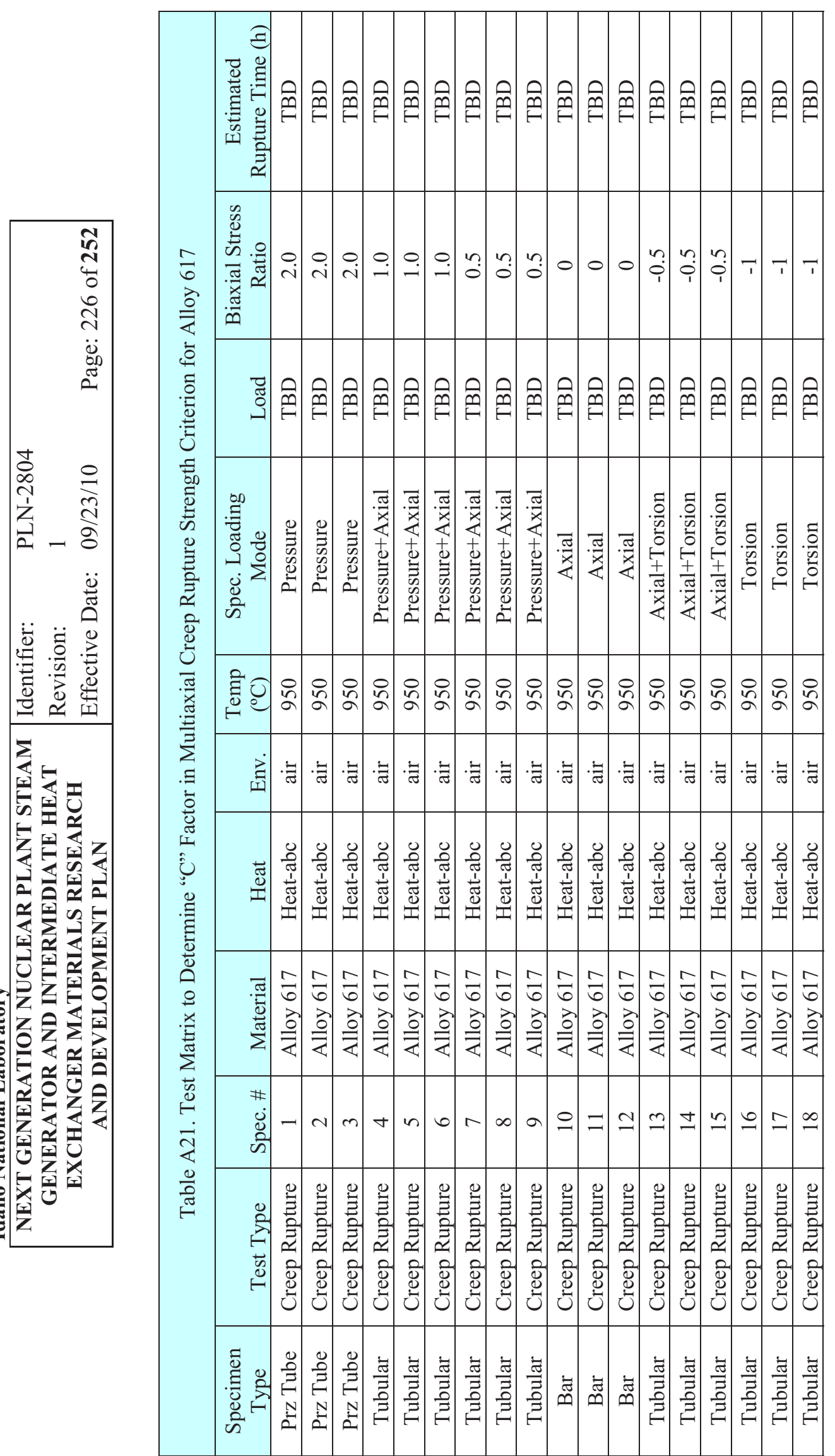




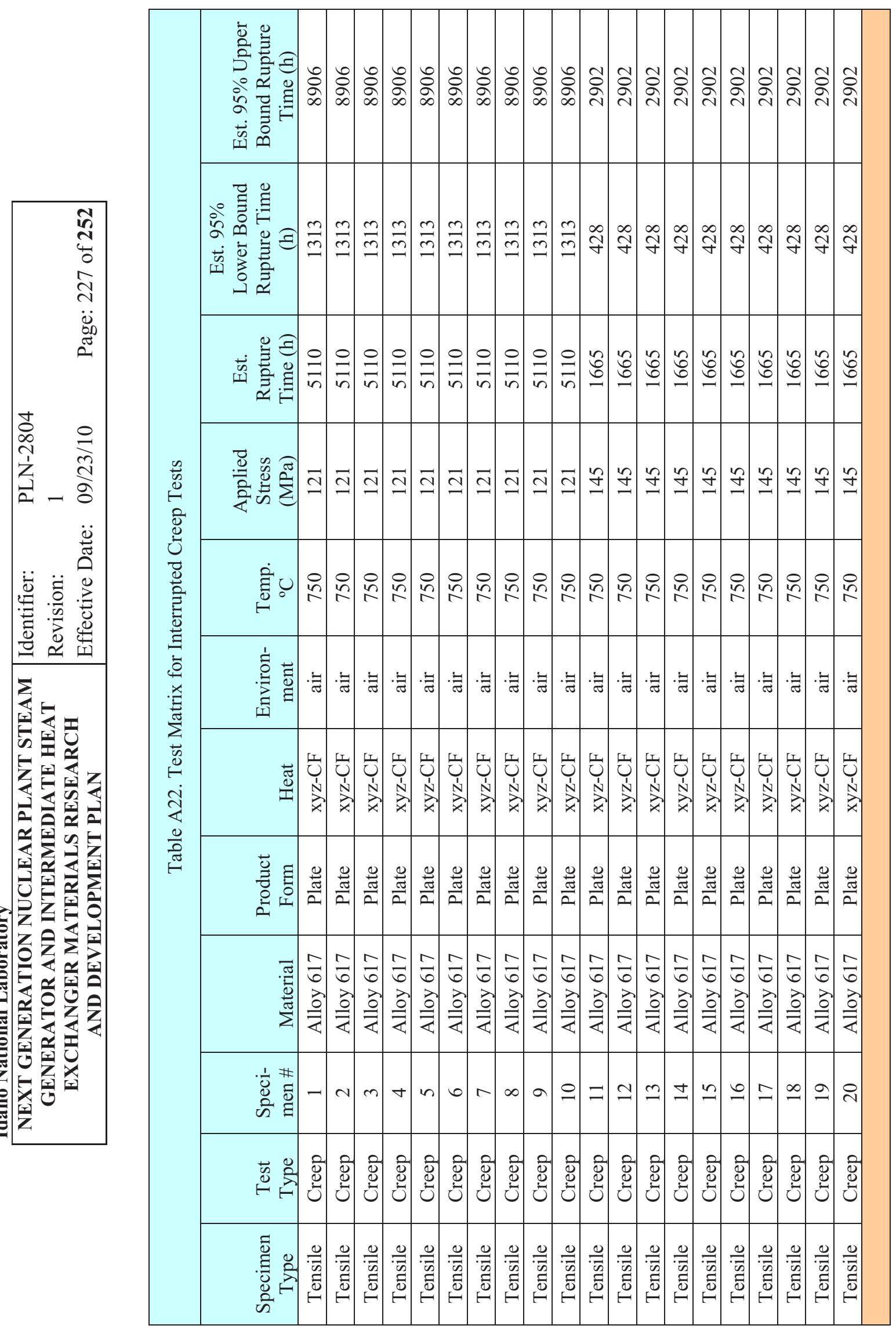




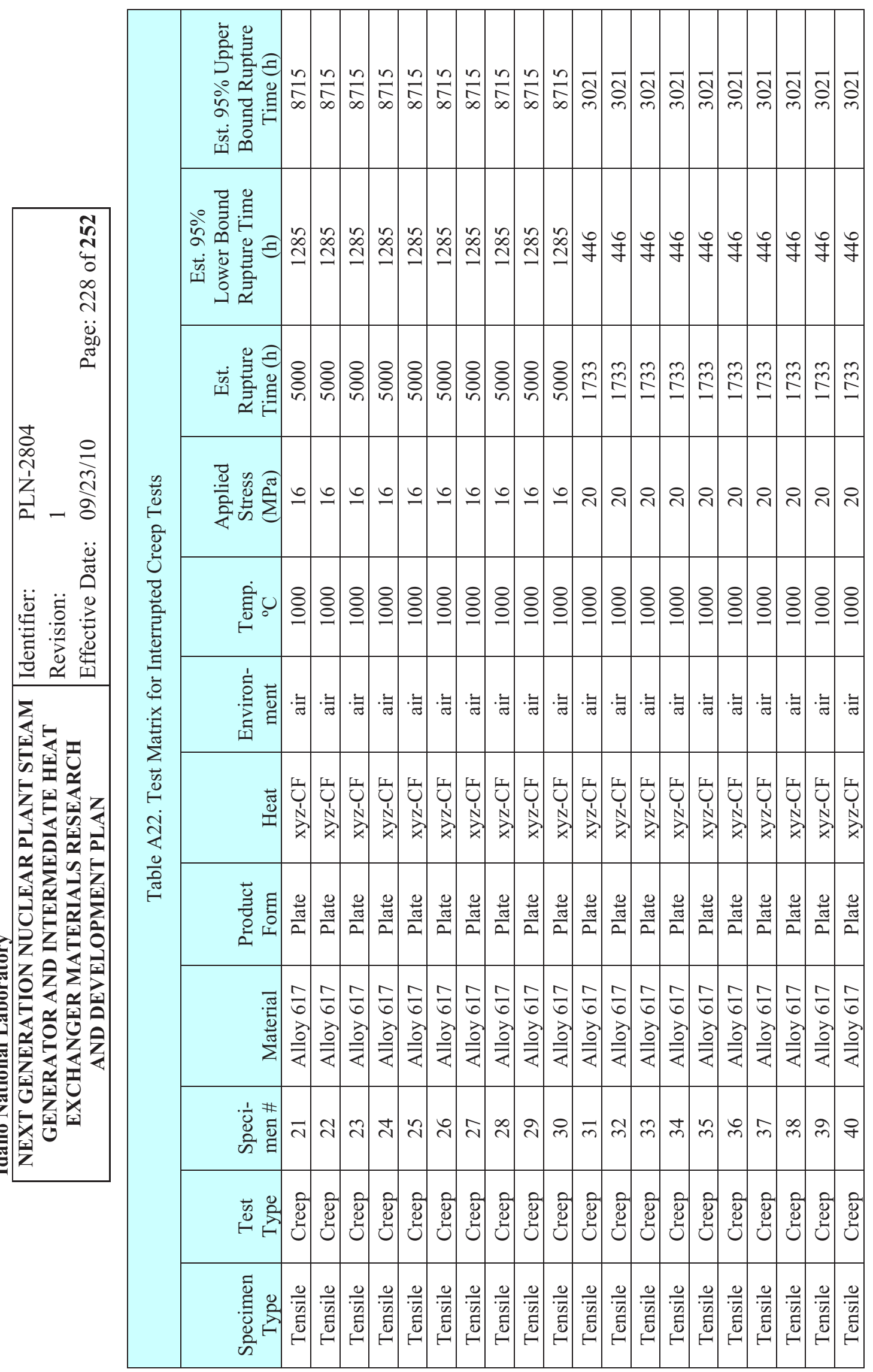




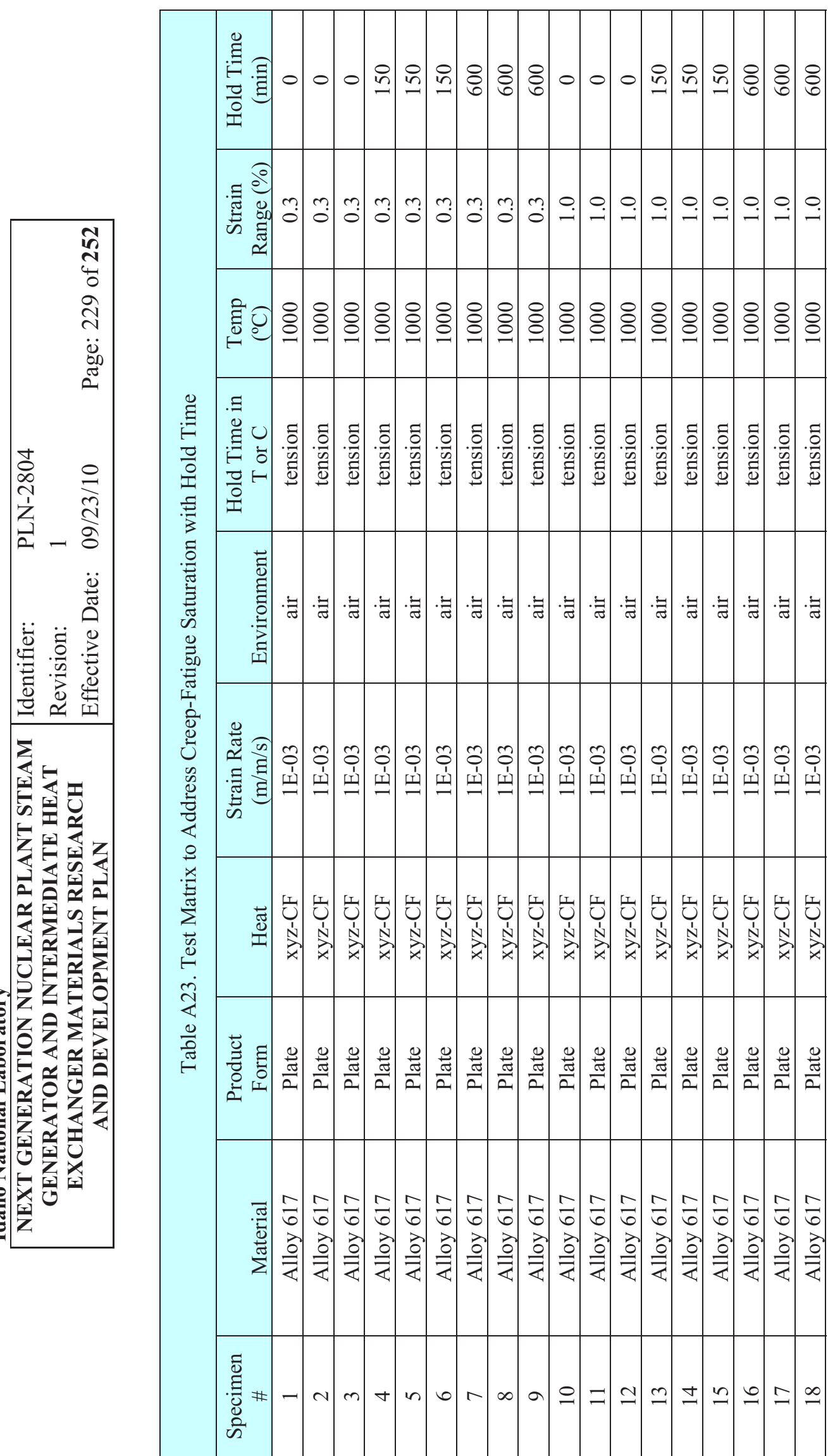




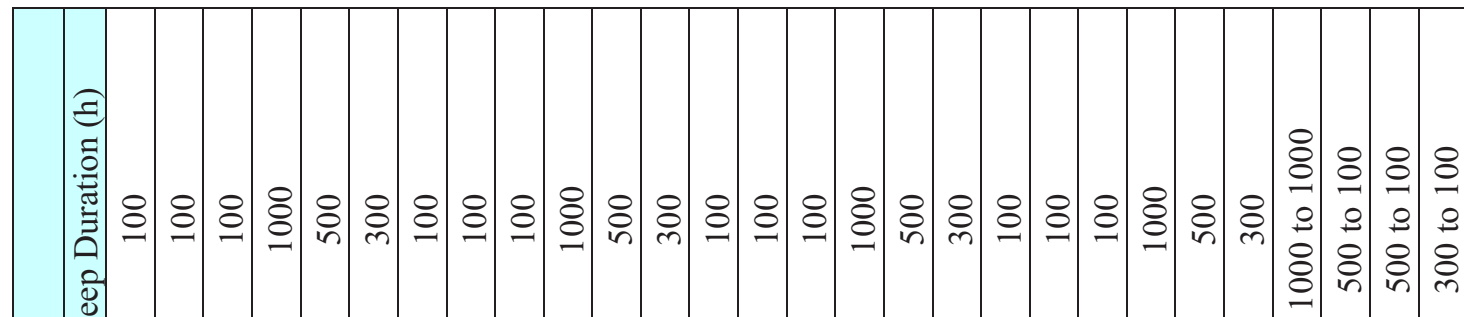

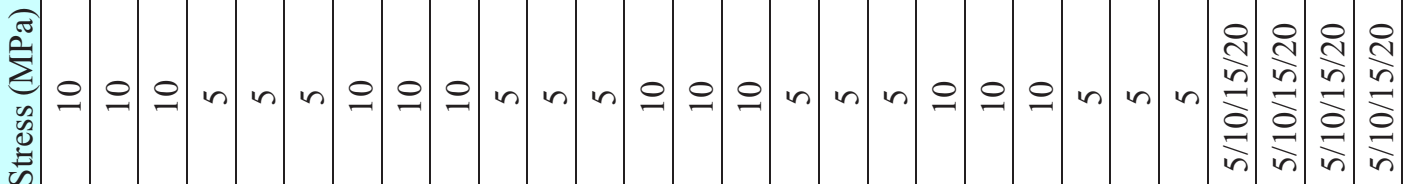
든 咅

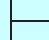

을

\section{各猔}

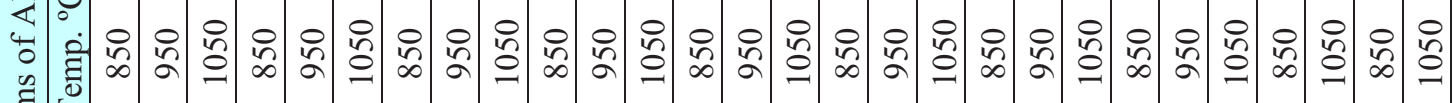

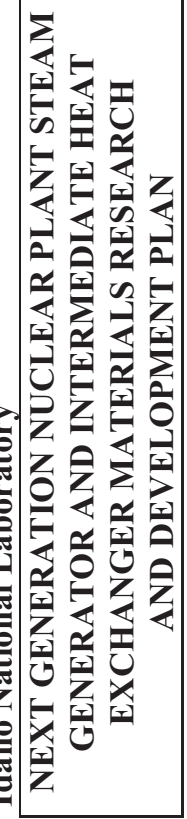

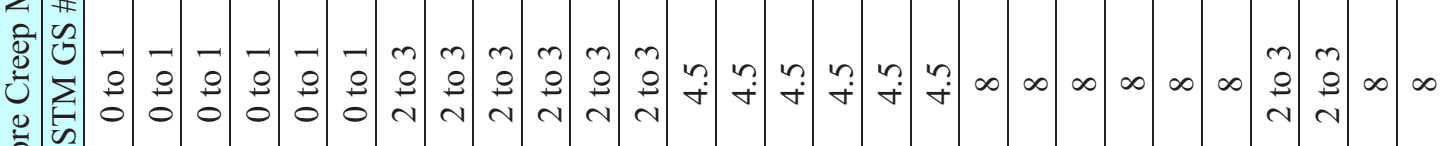
을 .

용

.

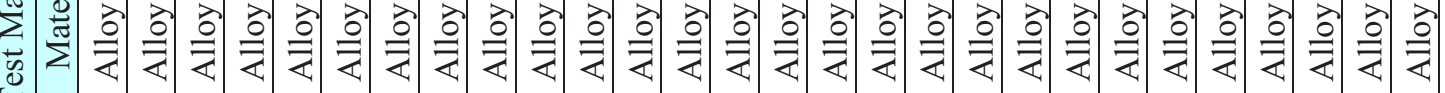
过 \#

吾总

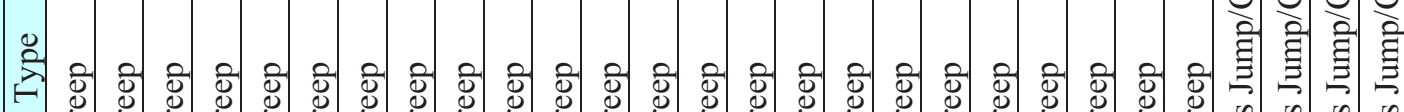
• 齐

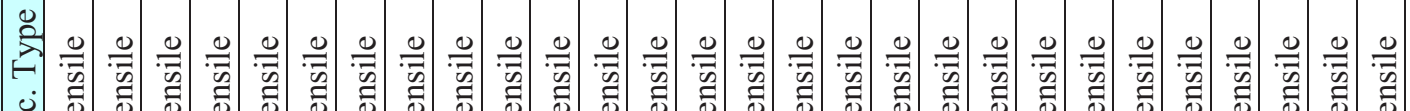
की 


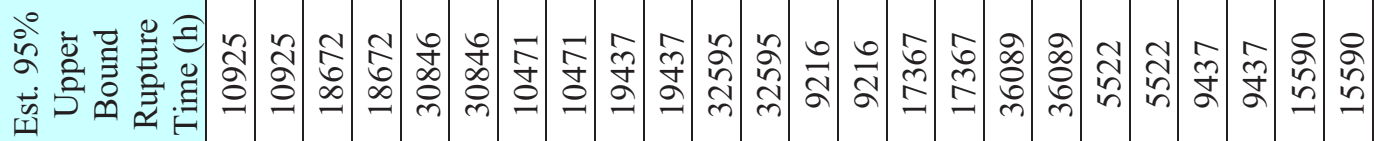

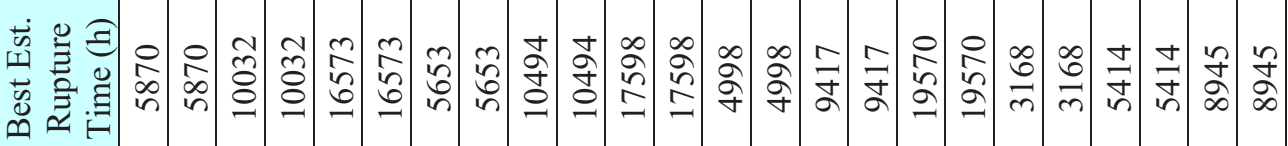

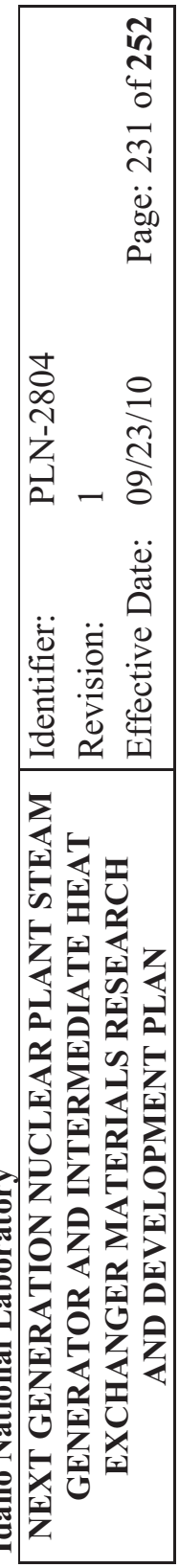

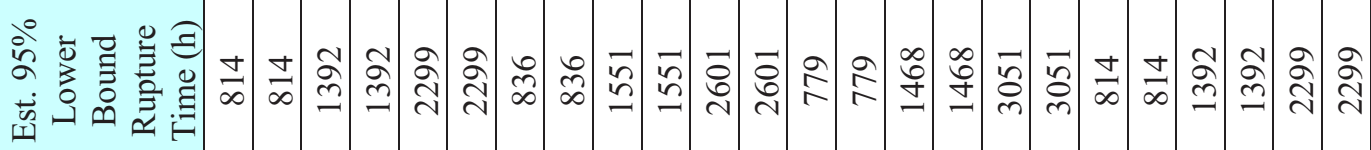

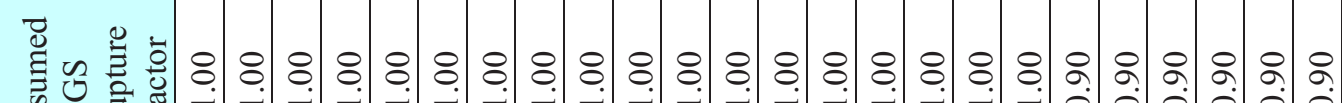

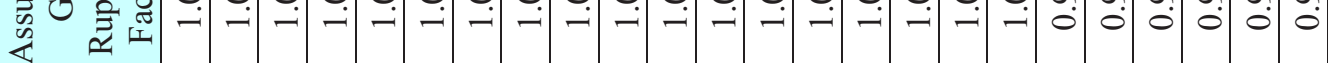

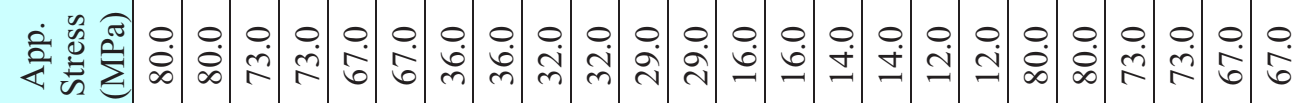

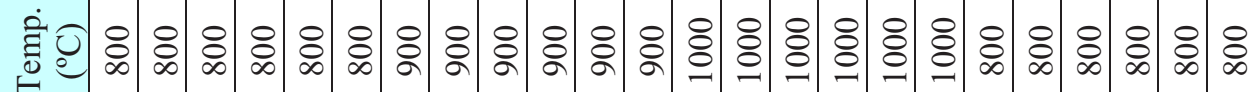

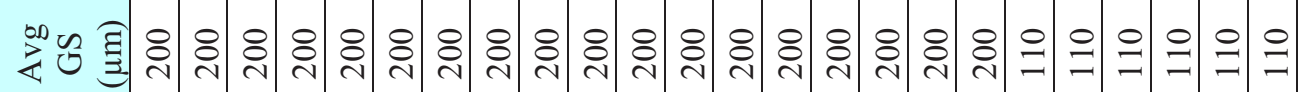

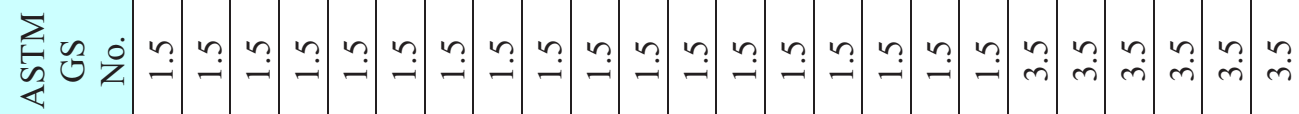

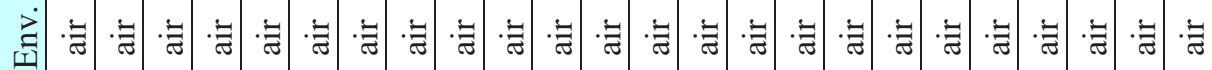

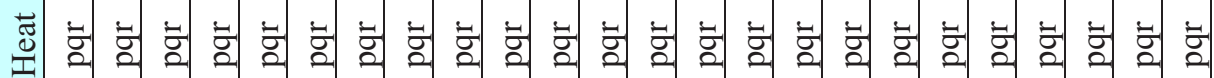

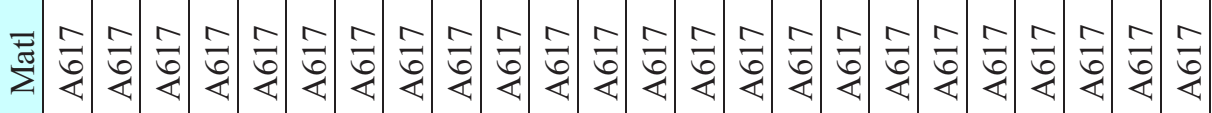
๘

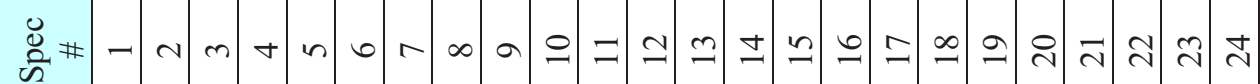

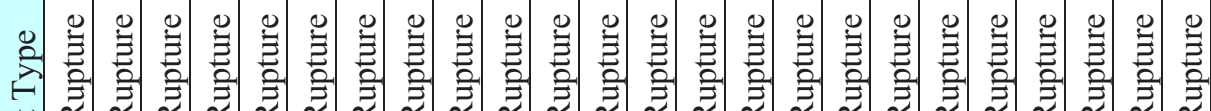

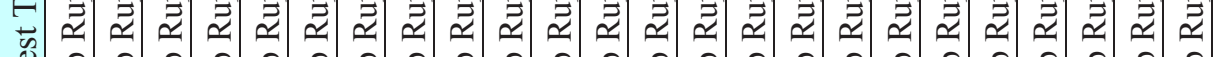

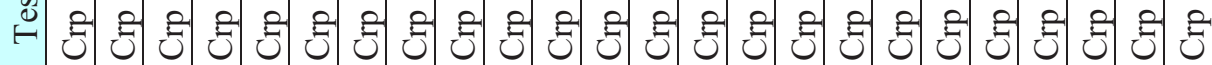

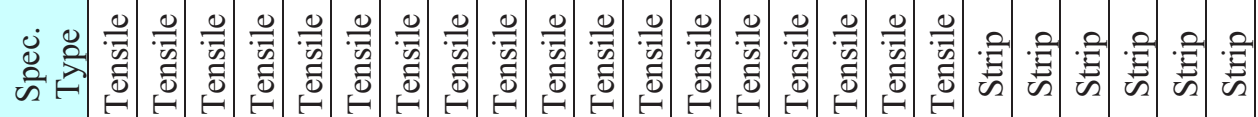

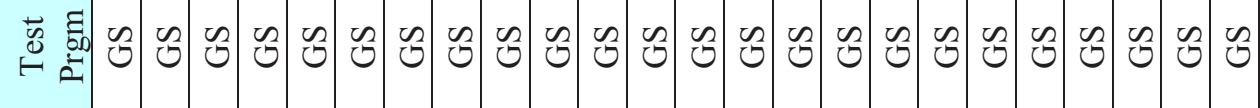




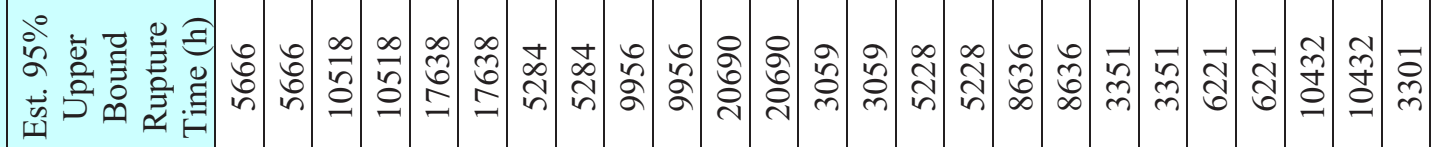

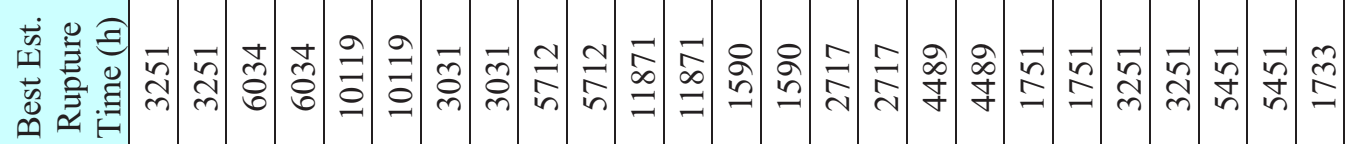

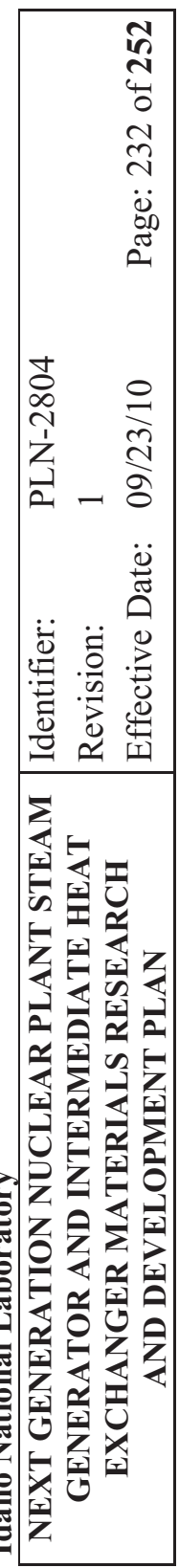

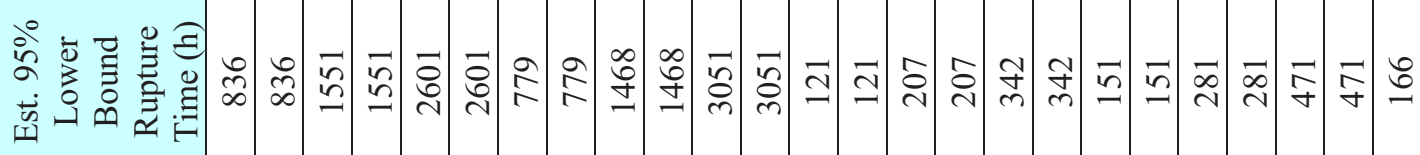

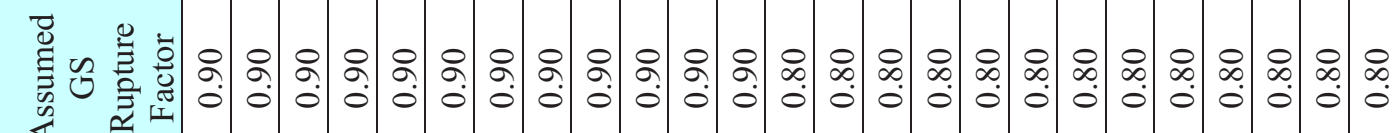

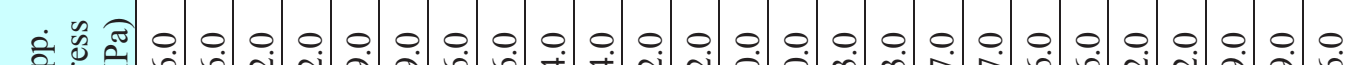
完 言。

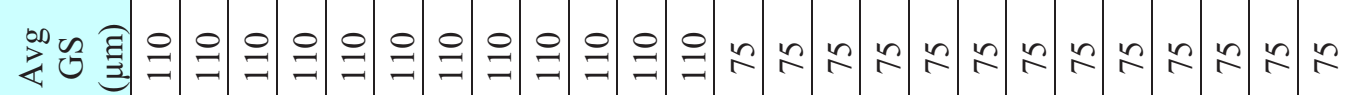

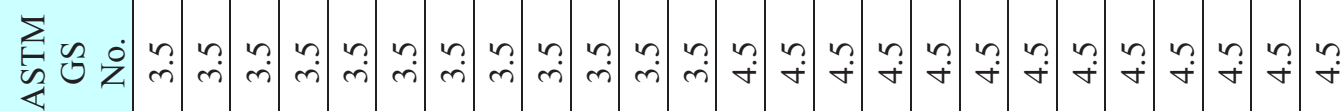

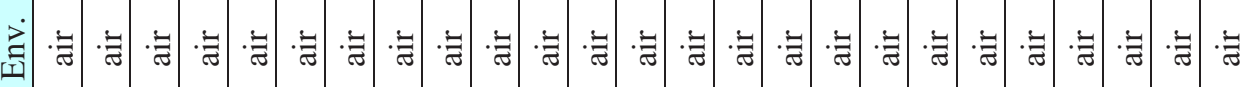

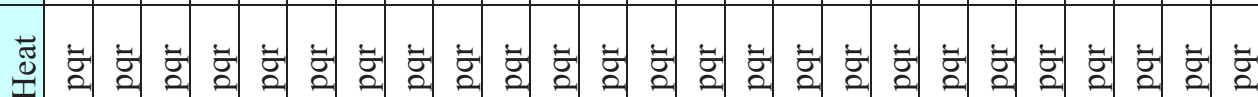

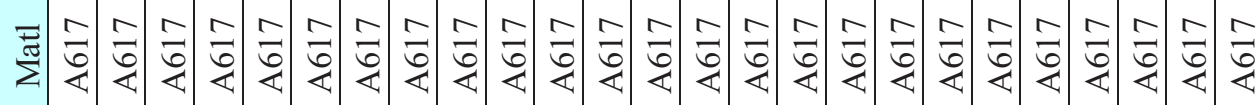

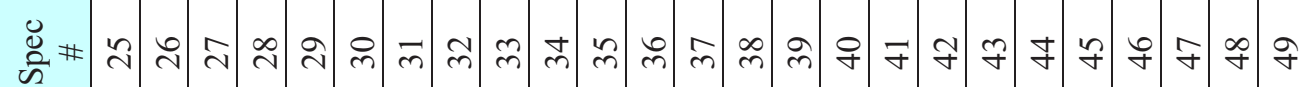

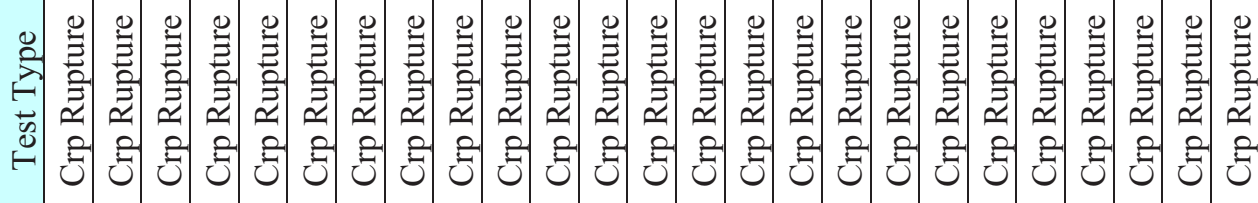

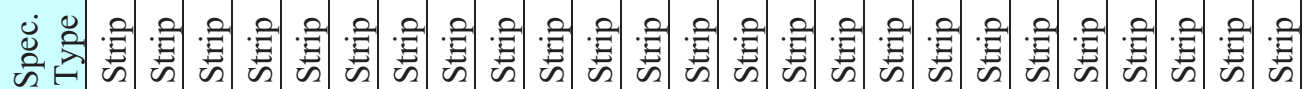

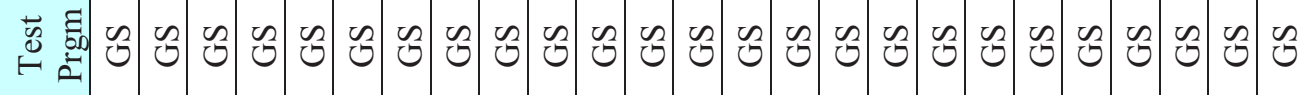




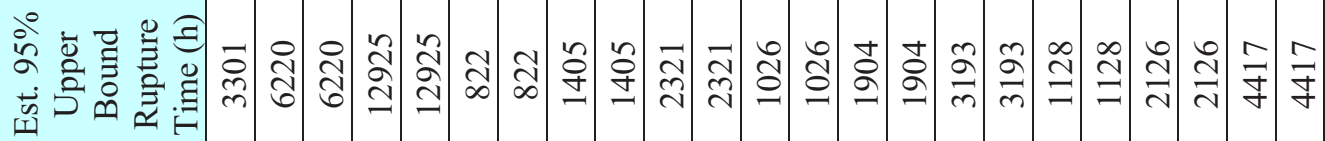

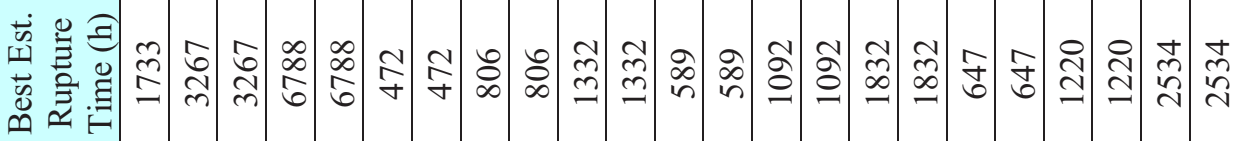

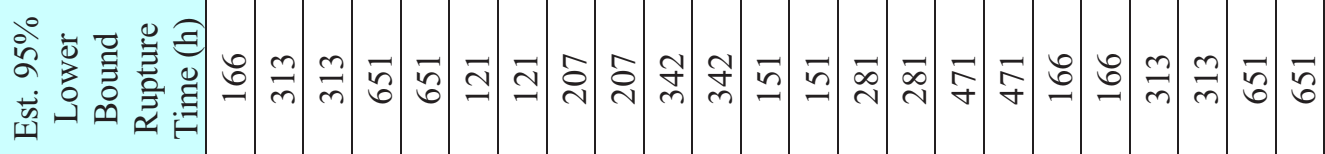

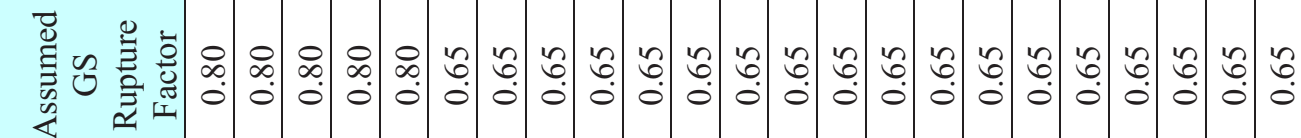
定至

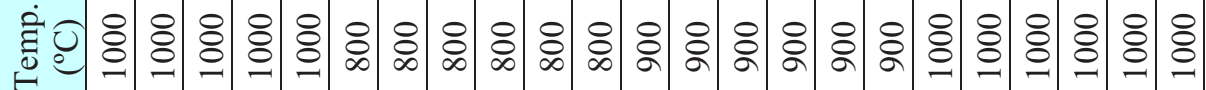

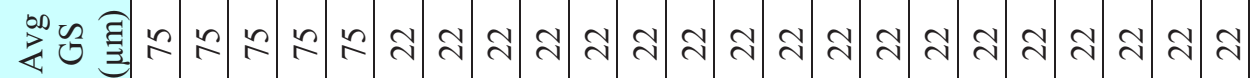

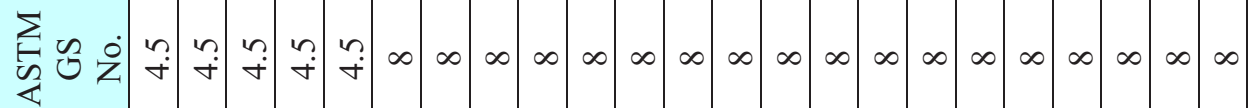

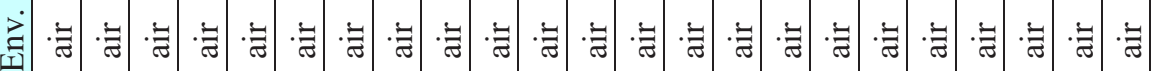

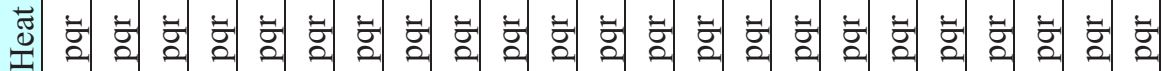

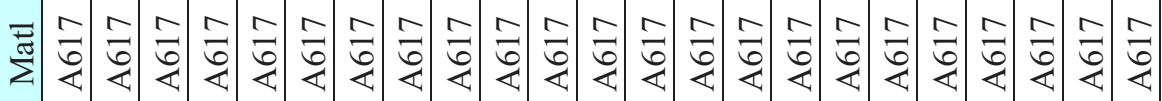

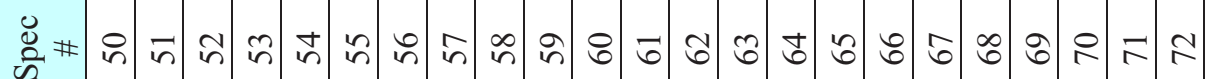

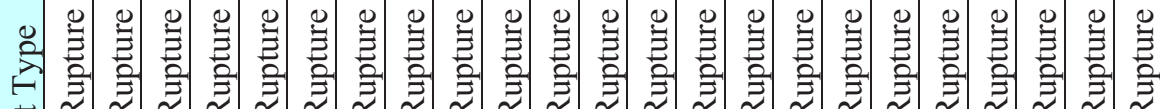
t)

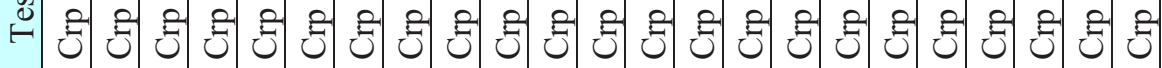

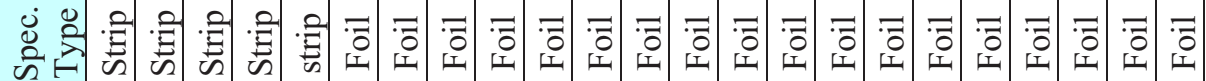

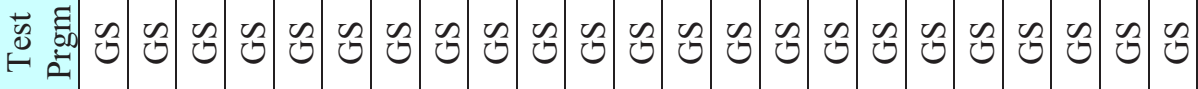




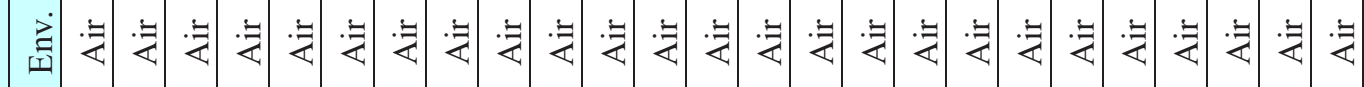

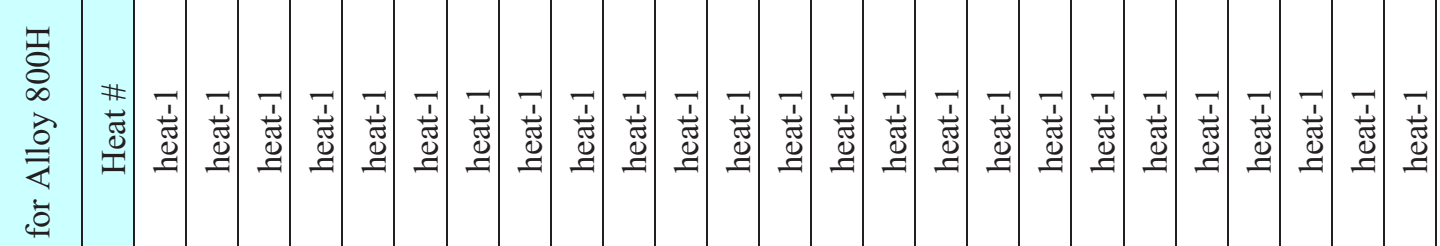
$\overline{\frac{\theta}{8}}$ $\sum^{\circ}$

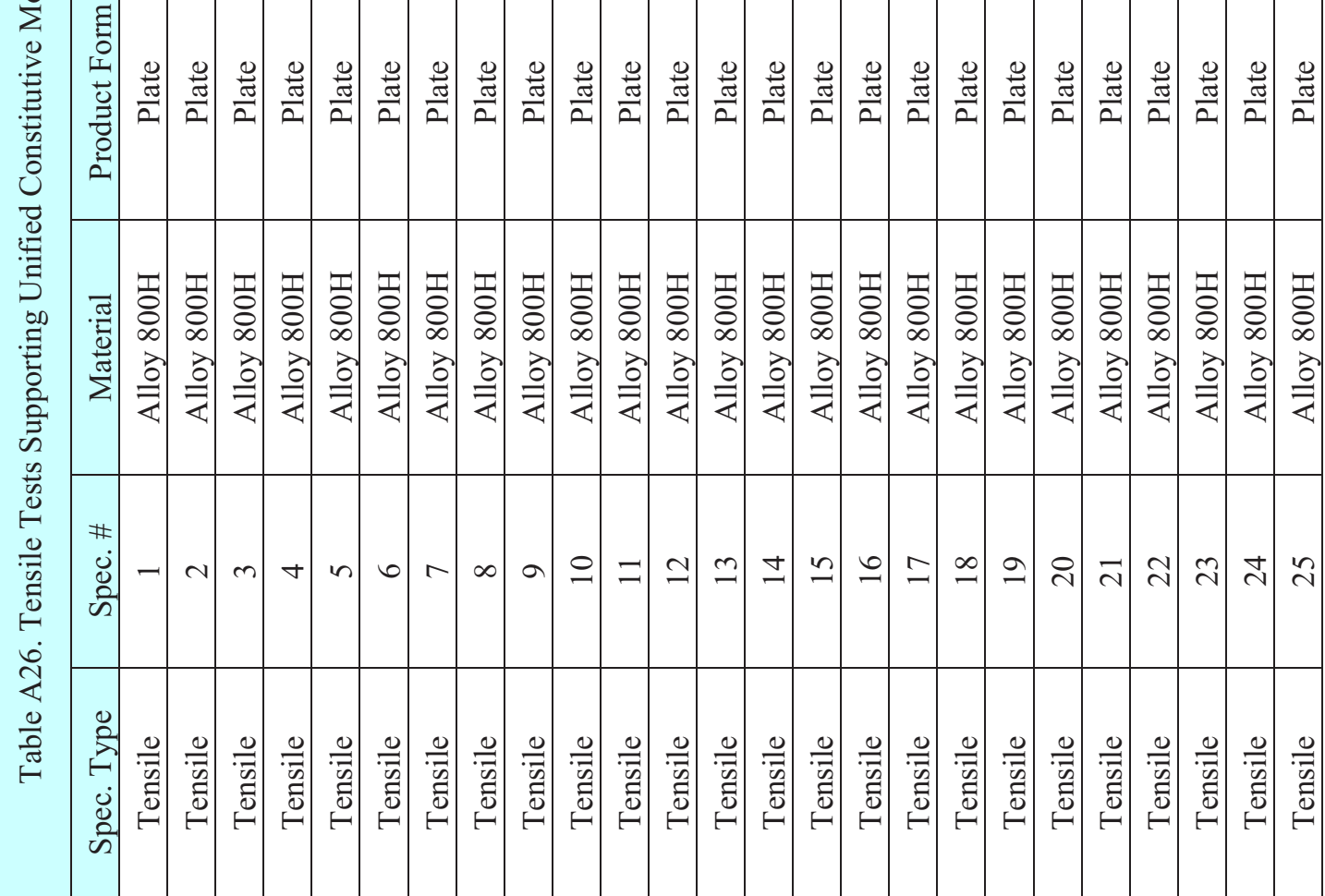

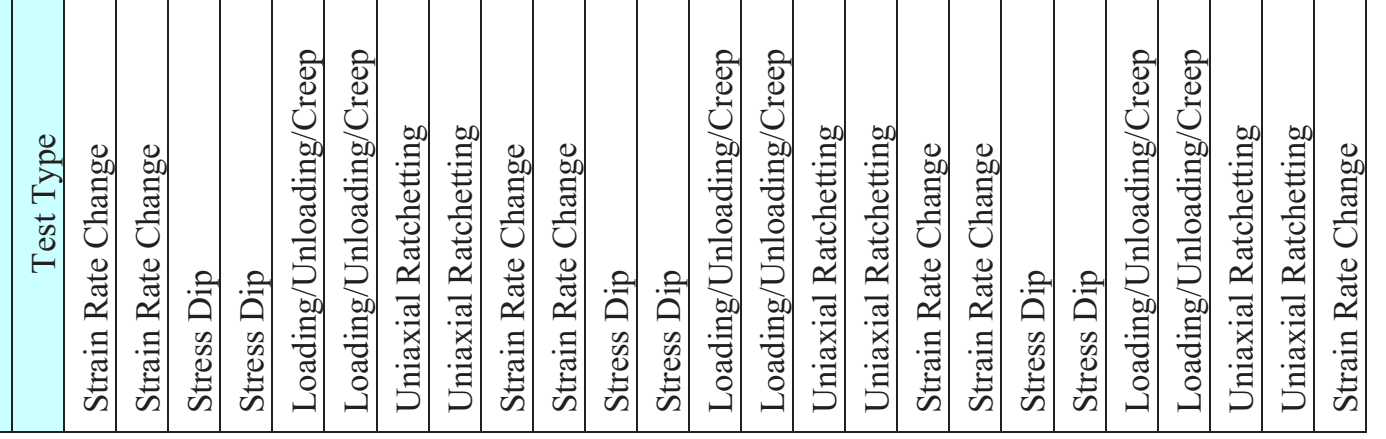




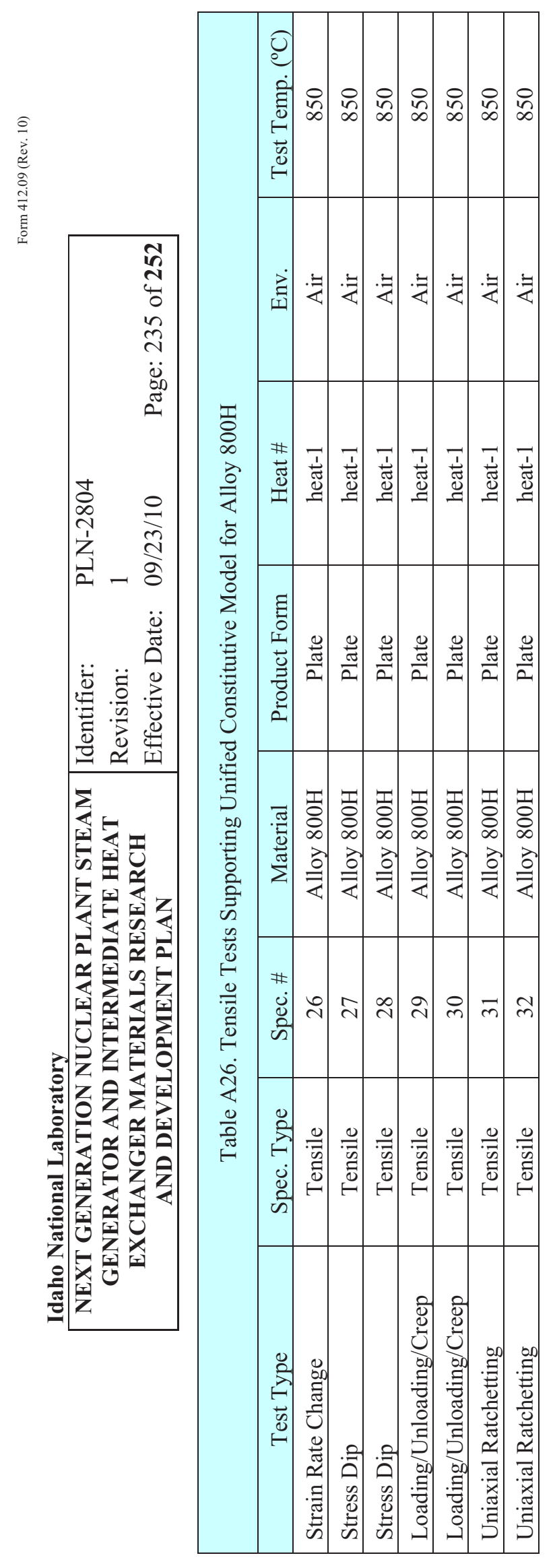




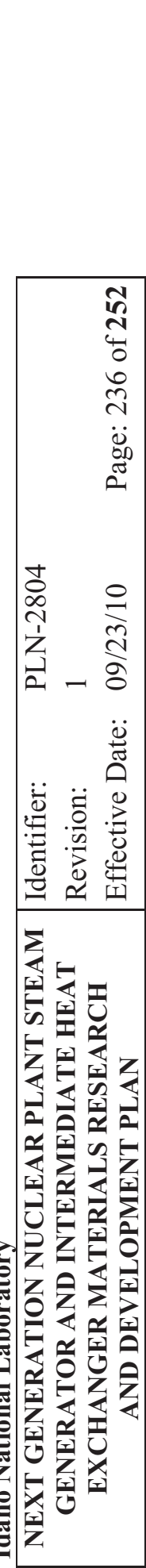

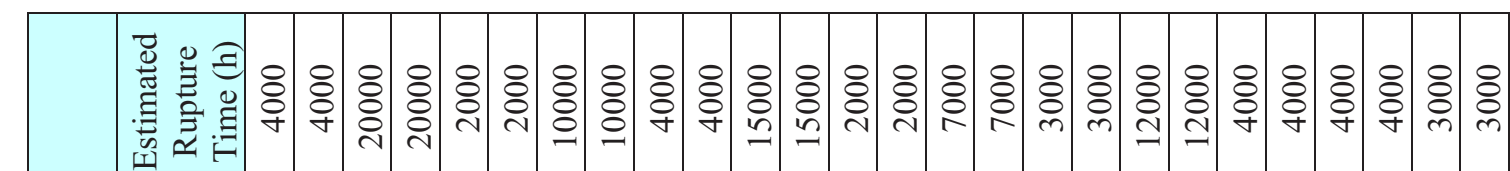

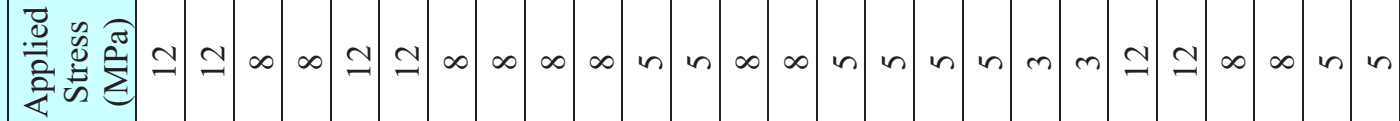

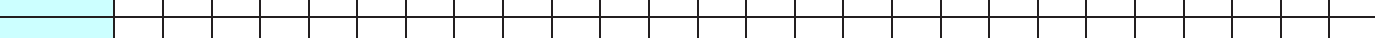

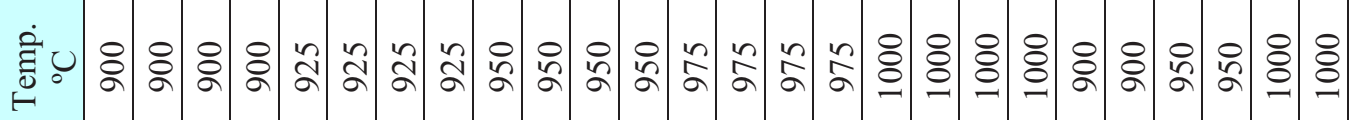

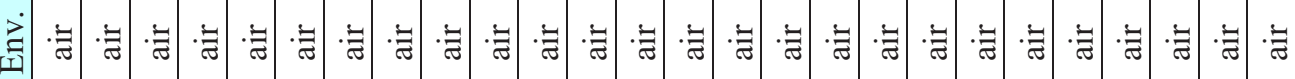

馬 तै

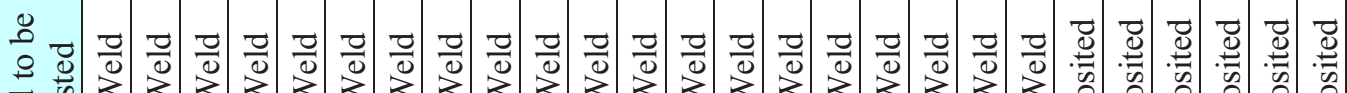

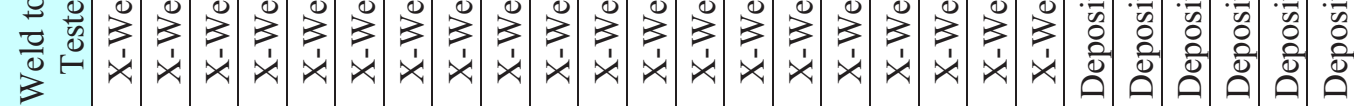

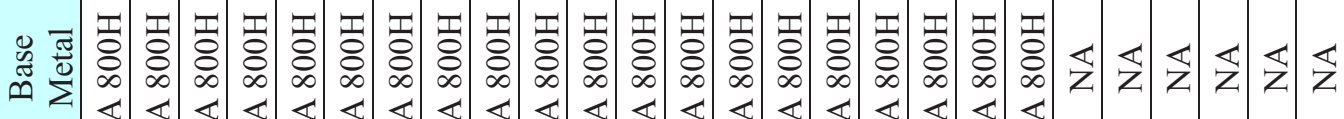

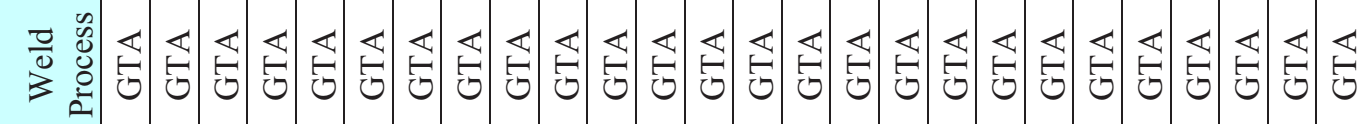

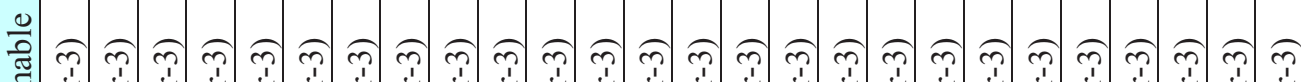

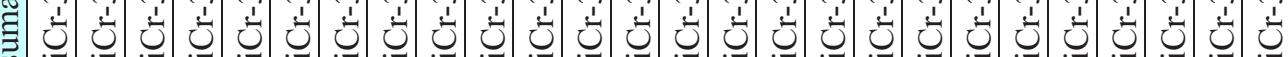

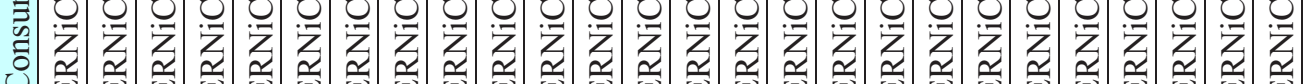

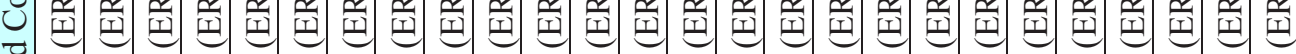

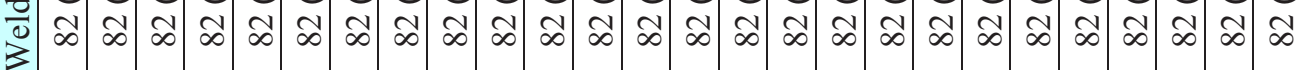

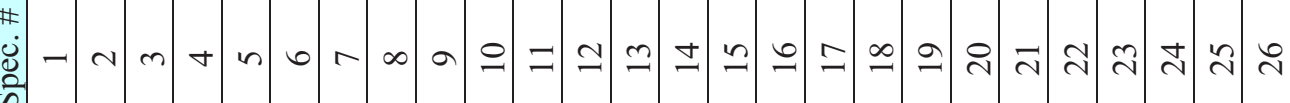

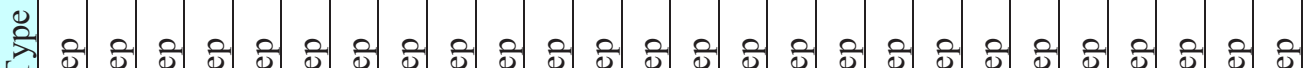

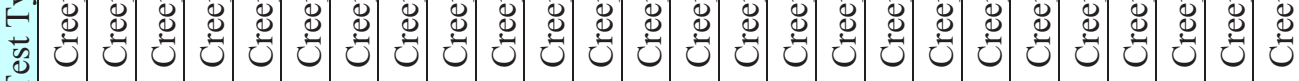

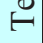

空

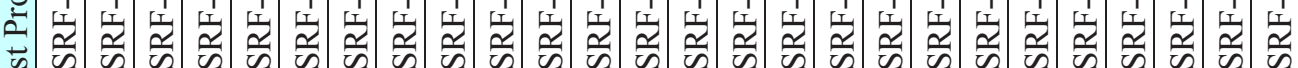

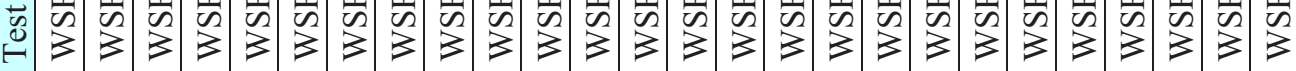




\begin{tabular}{|c|c|c|c|c|c|c|c|c|c|c|c|c|c|c|}
\hline & & 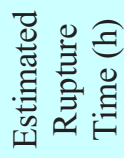 & 8 & 8 & 8 & $\begin{array}{l}8 \\
8 \\
8 \\
\end{array}$ & 8 & 8 & 8 & \begin{tabular}{|c|}
8 \\
8 \\
8 \\
$\circ$ \\
\end{tabular} & \begin{tabular}{l}
8 \\
8 \\
\hdashline
\end{tabular} & \begin{tabular}{|l|}
8 \\
8 \\
8 \\
\end{tabular} & 8 & $\begin{array}{l}8 \\
8 \\
8 \\
0\end{array}$ \\
\hline & & 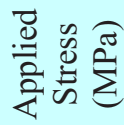 & 이 & లి & 요 & $\infty$ & 二 & $N$ & లి & $\underline{\ddots}$ & 이 & $\simeq$ & $\simeq$ & $r$ \\
\hline กิ & & 官 & ঃু & \&ু & 으 & ำ & ○్̊․ & 8 & ৪ุ & ঃ̊ & 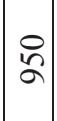 & $\stackrel{2}{2}$ & 8 & 8 \\
\hline $\begin{array}{c}\ddot{0} \\
\underset{\Xi}{E} \\
\tilde{E}\end{array}$ & 苞 & 芒 & $\exists$ & $\exists$ & : & . & . & $\exists$ & . & : & : & . & $\cdot \exists$ & $\exists$ \\
\hline 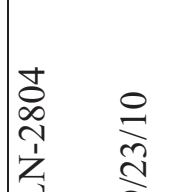 & $\begin{array}{l}\frac{7}{0} \\
3 \\
3 \\
0 \\
0 \\
0\end{array}$ & $\begin{array}{l}0 \\
0 \\
0 \\
0 \\
0 \\
0 \\
3 \\
3\end{array}$ & $\left|\begin{array}{c}\frac{\partial}{0} \\
3 \\
\dot{x} \\
\dot{x}\end{array}\right|$ & $\frac{0}{0}$ & $\begin{array}{l}\frac{0}{0} \\
3 \\
1 \\
x\end{array}$ & $\begin{array}{l}\frac{0}{0} \\
\frac{2}{3} \\
x\end{array}$ & $\mid \begin{array}{l}\frac{0}{0} \\
3 \\
1 \\
x\end{array}$ & $\begin{array}{l}\frac{0}{0} \\
3 \\
1 \\
x\end{array}$ & 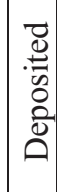 & 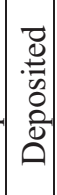 & 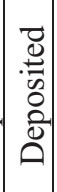 & 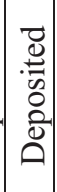 & $\mid$\begin{tabular}{c|}
0 \\
0 \\
.0 \\
0 \\
0 \\
0 \\
0 \\
0 \\
0
\end{tabular} & 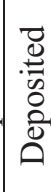 \\
\hline 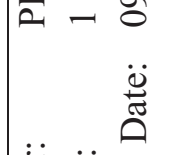 & 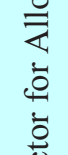 & 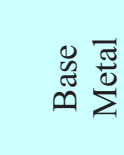 & $\mid \begin{array}{c}\bar{T} \\
\\
8 \\
\infty \\
\varangle\end{array}$ & $\begin{array}{l}T \\
\\
8 \\
\infty \\
< \\
\varangle\end{array}$ & $\begin{array}{l}7 \\
8 \\
8 \\
\infty \\
\varangle\end{array}$ & $\begin{array}{l}\square \\
\\
8 \\
\infty \\
\varangle\end{array}$ & $\begin{array}{l}\mathbb{T} \\
\\
8 \\
\infty \\
\varangle \\
\varangle\end{array}$ & $\begin{array}{l}\mathbb{T} \\
8 \\
8 \\
\infty \\
4\end{array}$ & $\varangle$ & $\begin{array}{l}\varangle \\
Z\end{array}$ & $\mathbb{Z}$ & $\overleftrightarrow{Z}$ & $\overleftrightarrow{Z}$ & $\varangle$ \\
\hline 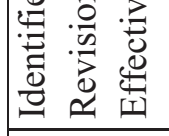 & 号 & $\begin{array}{ll}= & \text { Dे } \\
0 & 0 \\
3 & 0 \\
0 & 0\end{array}$ & 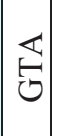 & 岕 & 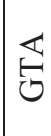 & $\underset{⿱ ㇒}{\longleftarrow}$ & 岕 & 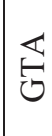 & $\underset{\Xi}{\leftrightarrows}$ & $\begin{array}{l}\varangle \\
\Xi \\
\Xi\end{array}$ & 岕 & $\underset{\Xi}{\Xi}$ & 岕 & 芯 \\
\hline 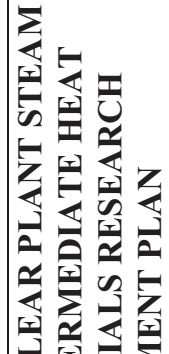 & 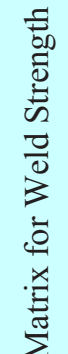 & 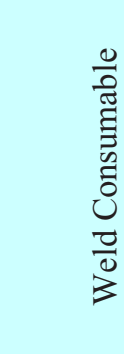 & 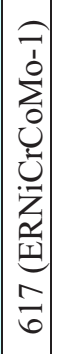 & 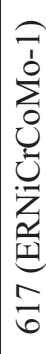 & 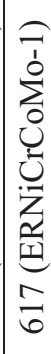 & 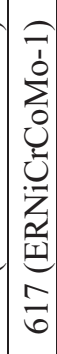 & 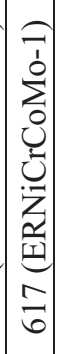 & 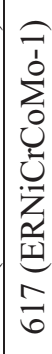 & $\begin{array}{l}n \\
z \\
n \\
z\end{array}$ & $\begin{array}{l}\overrightarrow{0} \\
\tilde{n} \\
\tilde{n} \\
\tilde{\nu}\end{array}$ & 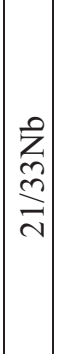 & $\begin{array}{l}\overrightarrow{0} \\
\tilde{n} \\
\end{array}$ & 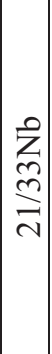 & $\begin{array}{l}z \\
n \\
n \\
\end{array}$ \\
\hline 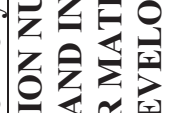 & $\stackrel{0}{\tilde{y}}$ & $\begin{array}{l}\dot{d} \\
\text { के }\end{array}$ & in & $\stackrel{\sim}{n}$ & $n$ & ๑ & in & $\stackrel{\infty}{n}$ & 6 & రి & 6 & $\underset{b}{\infty}$ & فे & $\stackrel{R}{R}$ \\
\hline 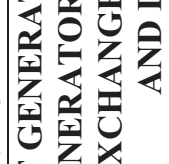 & 司 & 总 & 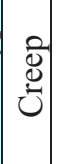 & 巳े & Oे & 过 & 总 & Uి & 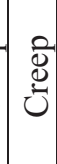 & 总 & 宊 & 完 & 总 & తి \\
\hline & & 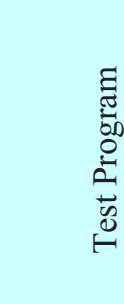 & 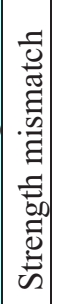 & 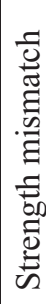 & 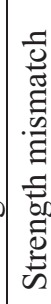 & 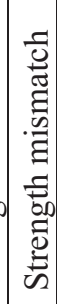 & 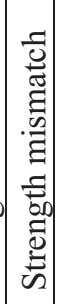 & 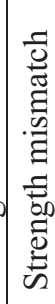 & 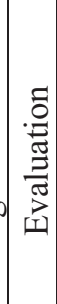 & 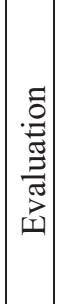 & 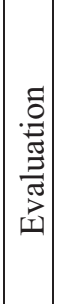 & 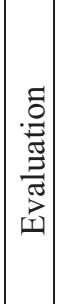 & 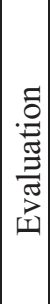 & 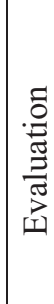 \\
\hline
\end{tabular}


苞

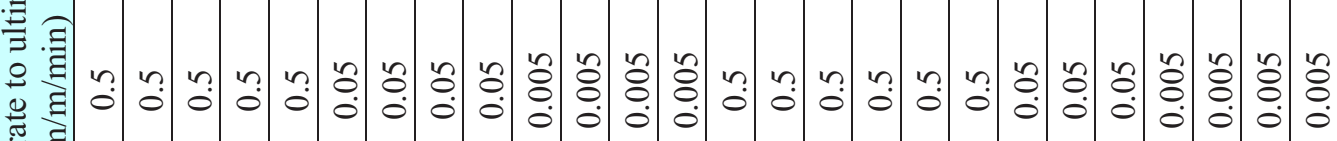
苂 छ 䒿

푱

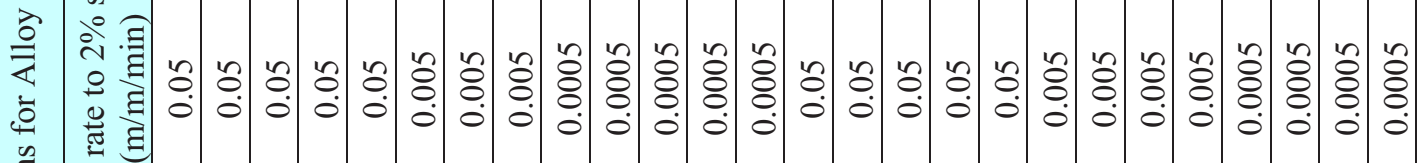
吾 䲶 灵 a

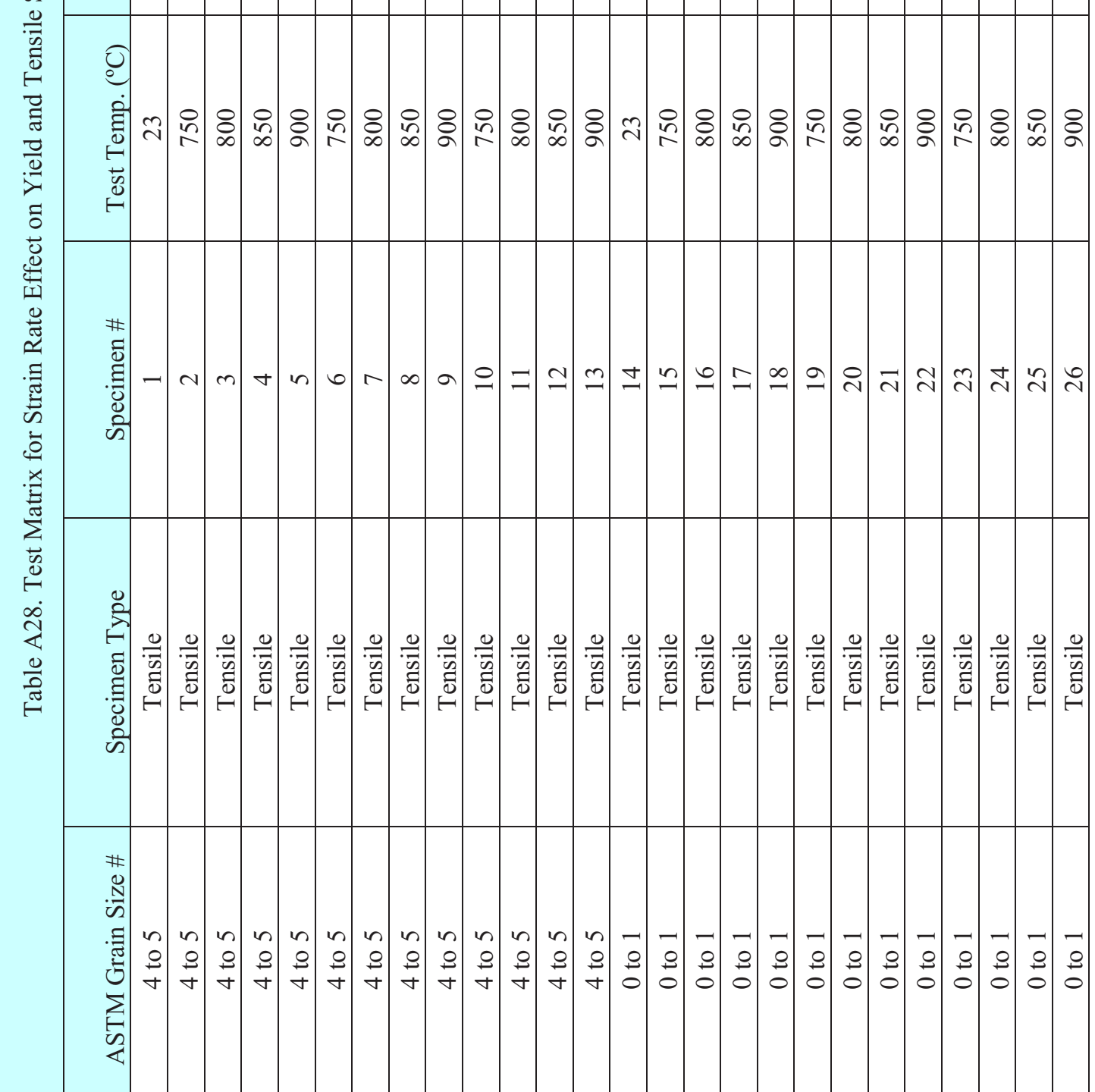



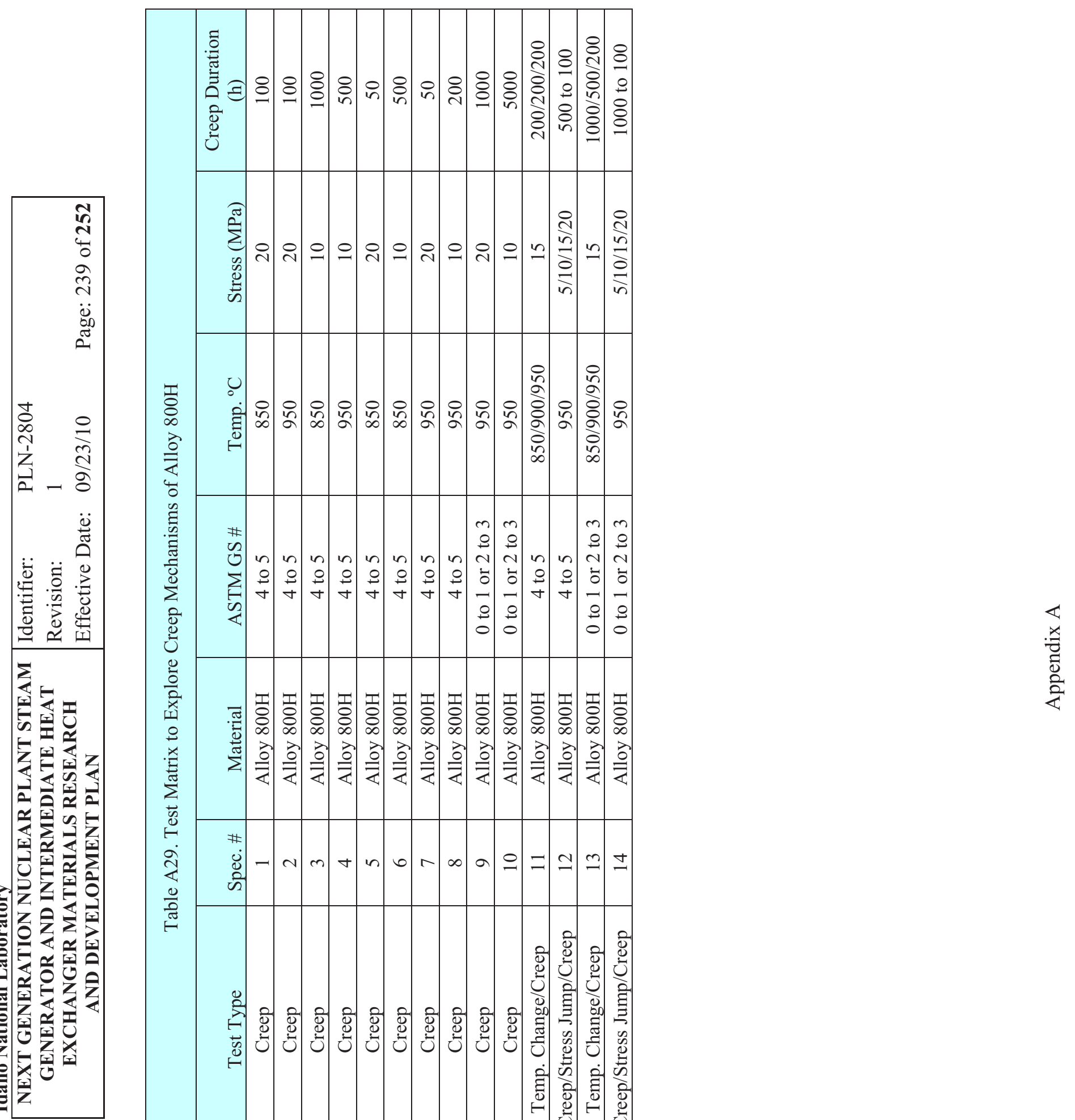

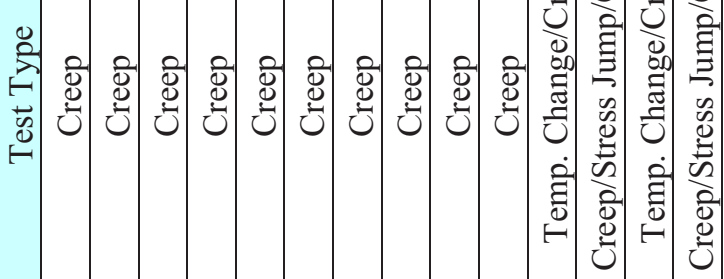

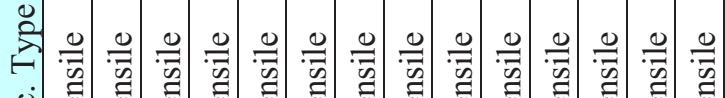
की 


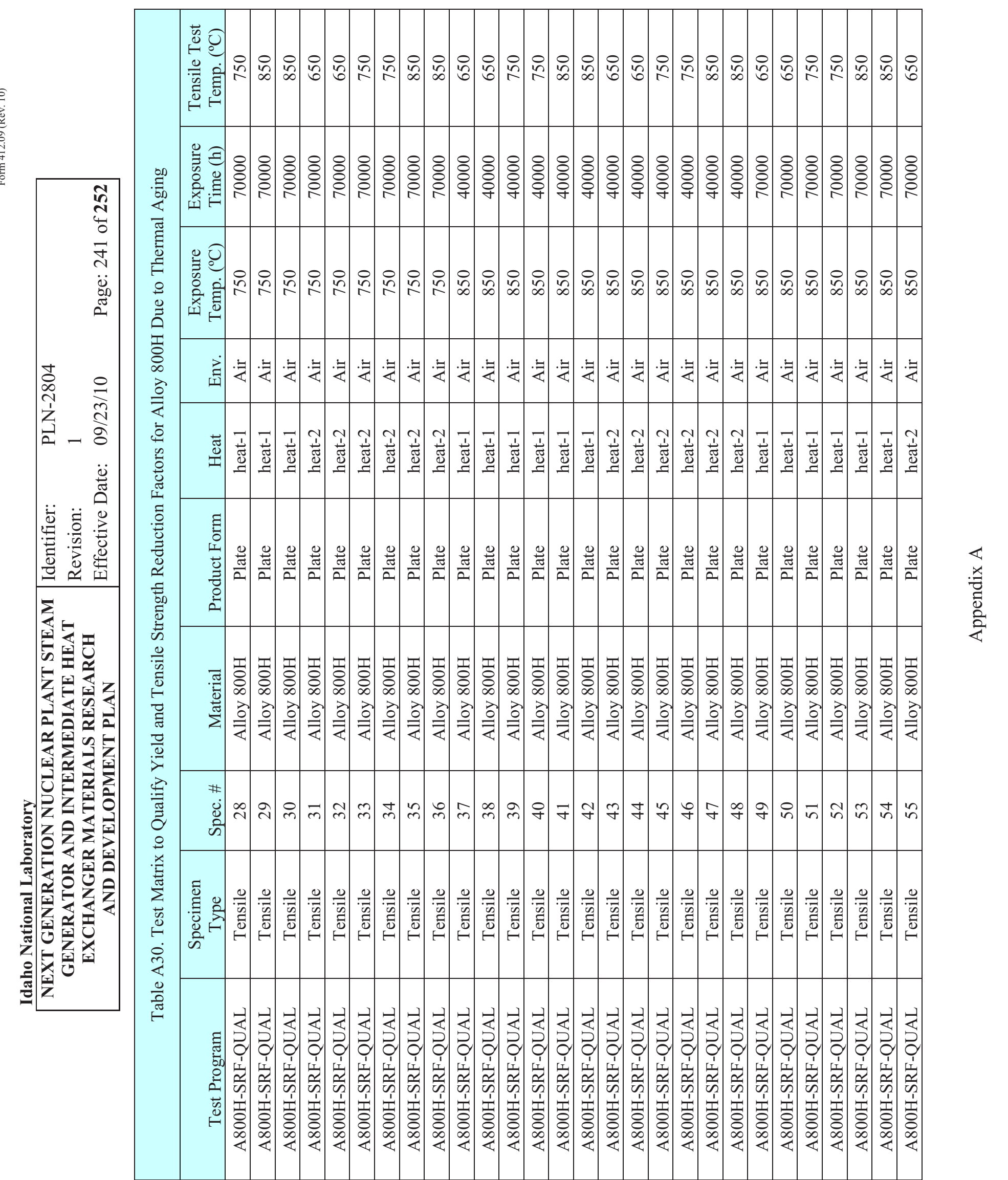




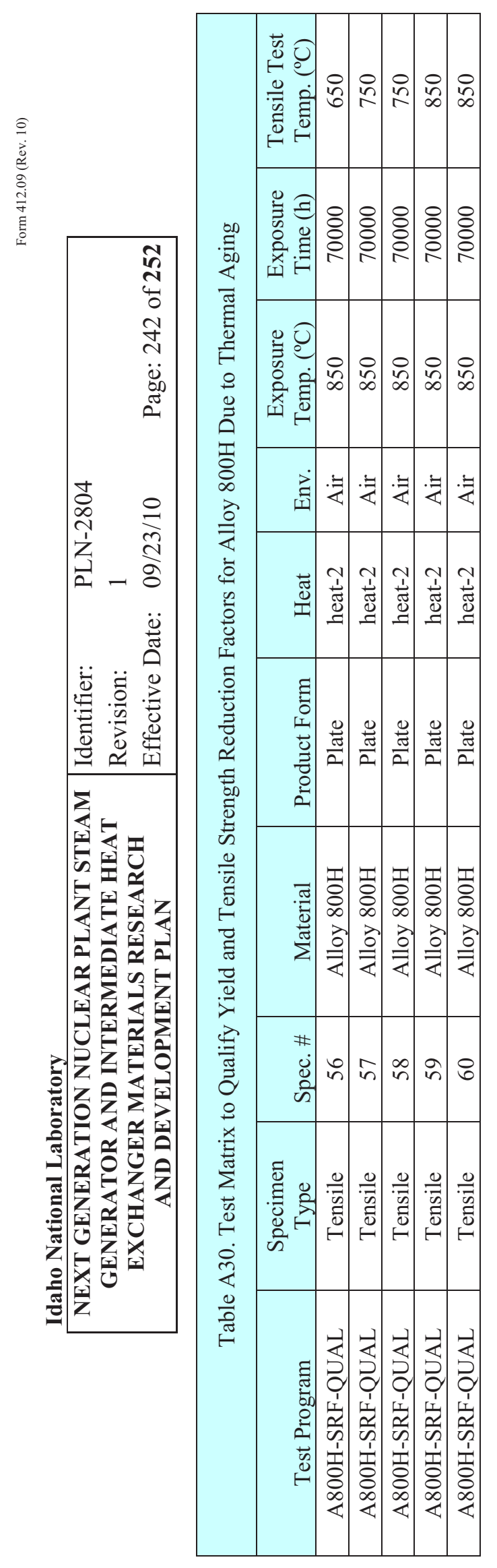

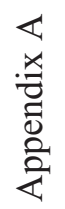




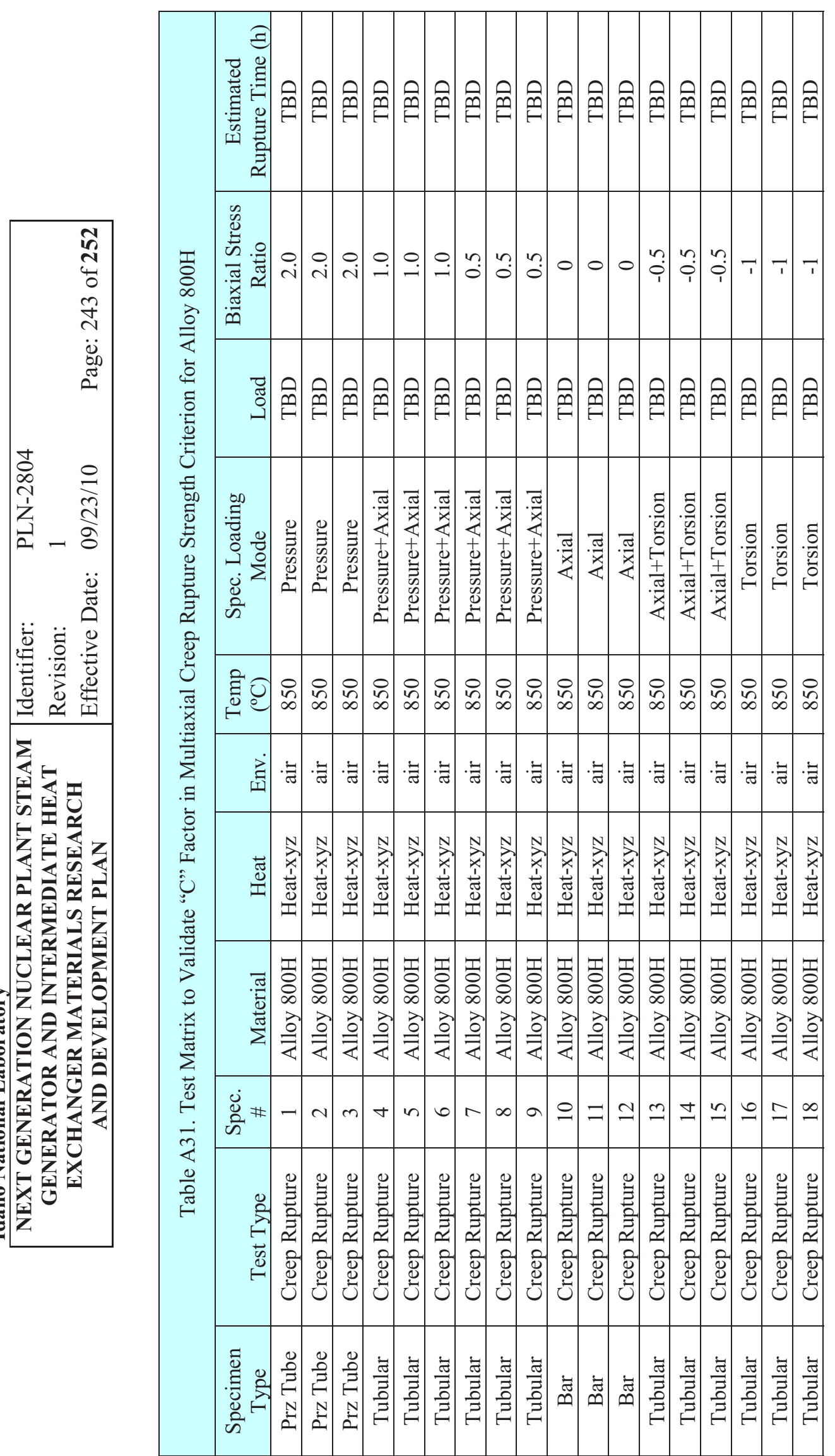




\begin{tabular}{|c|lll|}
\hline NEXT GENERATION NUCLEAR PLANT STEAM & Identifier: & PLN-2804 & \\
GENERATOR AND INTERMEDIATE HEAT & Revision: & 1 & \\
EXCHANGER MATERIALS RESEARCH & Effective Date: & $09 / 23 / 10$ & Page: 244 of 252 \\
AND DEVELOPMENT PLAN &
\end{tabular}

\section{Appendix B}

\section{IHX Design Alternatives}

The IHX may be arranged in parallel or in series with the NGNP PCS. In a serial arrangement, the total primary system flow (reactor outlet gas) passes through the IHX. The IHX receives gas of the highest possible temperature for delivery to the hydrogen production process (with slightly cooler gas going to the PCS), but must be large enough to handle the full primary flow. A parallel configuration splits the reactor outlet gas flow, with only about $10 \%$ entering the IHX for the hydrogen plant, and the remainder of primary flow going to a direct cycle power generation turbine. This results in the smallest possible IHX and the highest overall electrical power efficiency, but lower hydrogen production efficiency because of cooler gas reaching that process.

The IHX design for the hydrogen plant will be influenced by a number of interrelated considerations including the required separation distance between the NGNP reactor and the hydrogen production plant, the heat losses from the intermediate loop piping, the operating pressure, the working fluid, and the target efficiency of the hydrogen plant. The required separation distance will affect the intermediate loop piping size, the intermediate loop pumping requirements and the piping heat losses to the environment. The intermediate loop pressure is critical: a low pressure will produce a high pressure differential between the primary and secondary sides of the IHX - a critical design consideration for the IHX. A high intermediate loop pressure will produce a high pressure differential across the intermediate loop pipe walls and within the hydrogen production equipment unless the SI process pressure is also increased. Pumping power requirements, which also depend on the intermediate loop working fluid, and the fluid temperature and pressure, will have a small effect on the overall NGNP cycle efficiency. ${ }^{120}$

The IHX design has not been decided, but a plate with fin, countercurrent tube and shell, involute heat exchangers, micro-channel heat exchangers and printed circuit heat exchanger (PCHE) designs have all been considered by at least one of the vendors. A tube and shell design has the advantage of technological maturity. Compact heat exchanger designs have the potential for reduced materials cost and greater efficiency; however, they are much less technologically mature and increase the risk of the project.

\section{B-1. SHELL-AND-TUBE}

A shell-and-tube heat exchanger is the most common type of heat exchanger. It consists of a number of tubes (often finned) placed inside a volume (shell). One of the fluids runs through the tubes while the second fluid runs across and along the tubes to be heated or cooled. The heat exchanger that connects the heat transport loop to the hydrogen production plant is referred to as the process heat exchanger (PHX) and is assumed to be a tube-in-shell heat exchanger. The heat transport fluid will flow on the shell side, allowing the tubes to contain the catalysts necessary for hydrogen production. In the simple configurations, the tube axis is parallel to that of the shell. The NGNP IHX proposed design features the tubes arranged in a helical configuration. This type of arrangement increases efficiency due to increased surface area and reduces the size, providing the potential to decrease the materials cost. Tube and shell heat exchangers represent relatively mature technology that has been widely commercialized in both nuclear and fossil energy systems. 


\begin{tabular}{|c|lll|}
\hline NEXT GENERATION NUCLEAR PLANT STEAM & Identifier: & PLN-2804 & \\
GENERATOR AND INTERMEDIATE HEAT & Revision: & 1 & \\
EXCHANGER MATERIALS RESEARCH & Effective Date: & $09 / 23 / 10$ & Page: 245 of 252 \\
AND DEVELOPMENT PLAN &
\end{tabular}

\section{B-2. INVOLUTE}

A relatively new tube-type concept referred to as the involute heat exchanger, shown in Figure B-1, has been considered by Westinghouse. While little detail of the design is available, it appears to be a helical compact heat exchanger and as such would offer the potential to reduce the amount of material required for fabrication. It features high flexibility to mitigate potentially damaging thermal strains; however, detecting, isolating and plugging leaks is complicated by the large number of tubes. Westinghouse is not currently recommending this design.

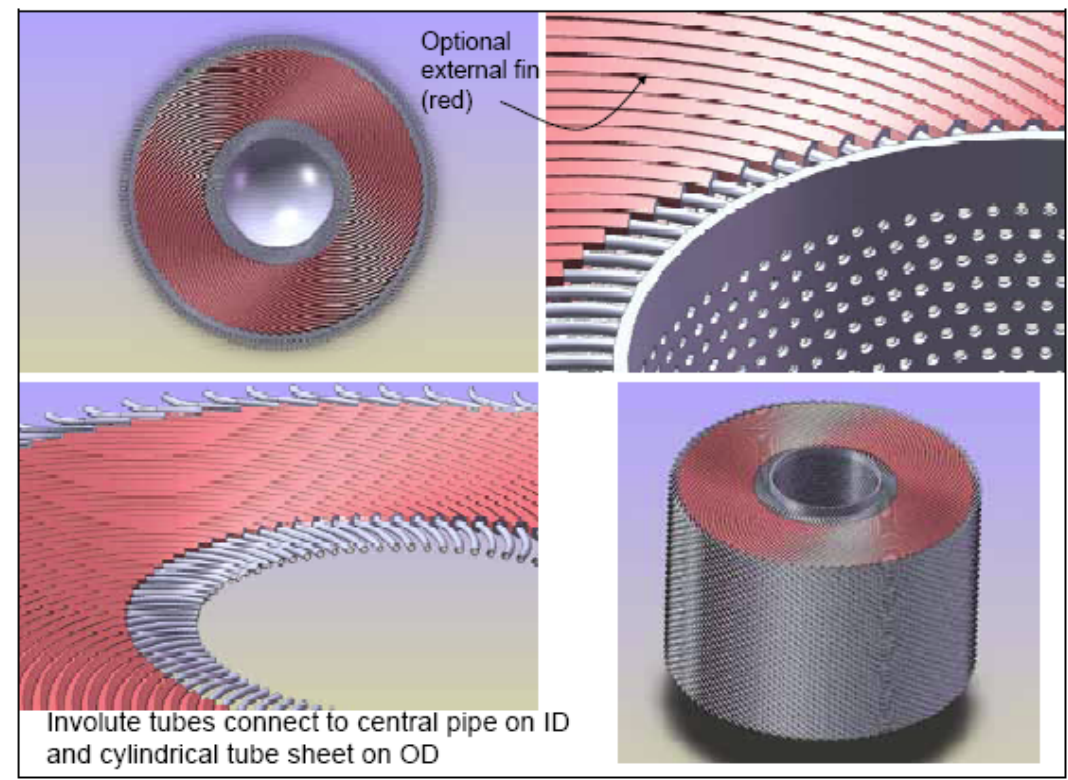

Figure B-1. Involute heat exchanger viewed from several perspectives.

\section{B-3. PLATE WITH FIN}

The plate with fin heat exchanger transfers heat between two fluids by directing flow through baffles so that the fluids are separated by metal plates with very large surface areas. The fluids spread out over the plate, which facilitates the fastest possible transfer of heat. This design has a major advantage over a conventional heat exchanger because the size of the heat exchanger is less, but the same amount of heat is exchanged. However, the candidate heat exchanger materials have relatively low thermal conductivities and will deduce the efficiency of a finned structure. The fins are considered secondary surfaces (the plate is a primary surface). Any finned structure will have reduced efficiency over a design that only has primary surfaces. ${ }^{87}$

Brazing is typically used to join the fins to the plate. Brazed plate heat exchangers are used in many applications, although usually at low or even cryogenic temperatures. The strength and creep properties of brazed joints in an IHX for a high temperature reactor are of great concern, although brazed products have been developed for high temperature aerospace applications. ${ }^{86}$

The unit cell heat exchanger is a typical modular plate-fin design that is being advanced by Brayton Energy. An example is shown in Figure B-2. Many of these individual unit cells would be grouped into larger heat exchanger assemblies. Integration of the modules within the vessel and with the interfacing piping is key. Off-set fin plate heat exchangers have very large heat transfer area density and effective countercurrent flow. 


\begin{tabular}{|c|lll|}
\hline NEXT GENERATION NUCLEAR PLANT STEAM & Identifier: & PLN-2804 & \\
GENERATOR AND INTERMEDIATE HEAT & Revision: & 1 & \\
EXCHANGER MATERIALS RESEARCH & Effective Date: & $09 / 23 / 10$ & Page: 246 of 252 \\
AND DEVELOPMENT PLAN &
\end{tabular}

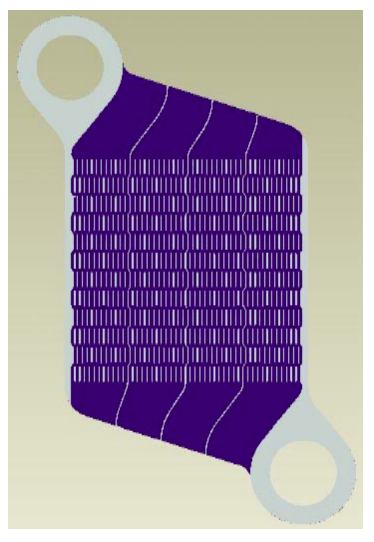

(a)

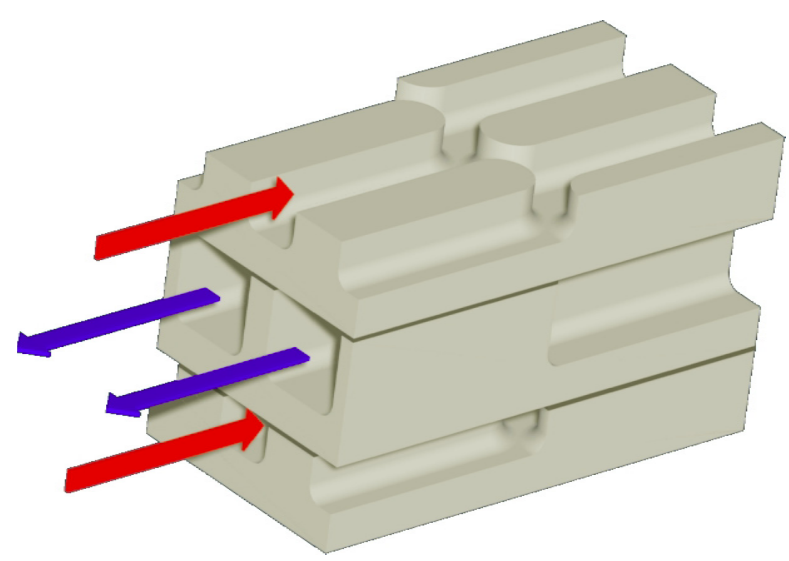

(b)

Figure B-2. Unit cell heat exchanger (a) primary side plate, (b) the unit cell showing counter-current flow.

\section{B-4. ETCHED PLATE}

Etched plate heat exchangers are diffusion-bonded, highly compact heat exchangers that can achieve a thermal effectiveness of over $98 \%$ in a single unit. Compact heat exchangers are four to six times smaller and lighter than conventional shell and tube heat exchangers of the equivalent duty (Figure B-3). The small size gives the compact diffusion-bonded heat exchangers significant benefits over conventional heat exchangers across a range of industries. They are well established in the upstream hydrocarbon processing, petrochemical, and refining industries. In addition they are suitable for a range of corrosive and high purity streams and are particularly advantageous when space is limited and weight is critical. Heatric claims pressure capability in excess of 600 bar (9000 psi) and the ability to withstand temperatures ranging up to $900^{\circ} \mathrm{C}$.

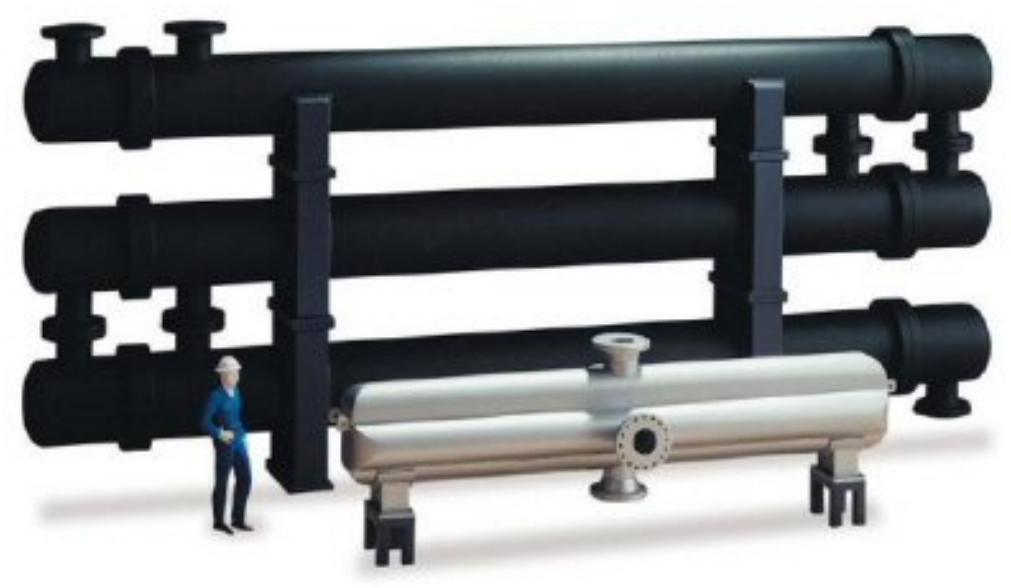

Figure B-3. The diffusion-bonded heat exchanger in the foreground undertakes the same thermal duty, at the same pressure drop, as the stack of three shell and tube exchangers behind. 


\begin{tabular}{|c|lll|}
\hline NEXT GENERATION NUCLEAR PLANT STEAM & Identifier: & PLN-2804 & \\
GENERATOR AND INTERMEDIATE HEAT & Revision: & 1 & \\
EXCHANGER MATERIALS RESEARCH & Effective Date: & $09 / 23 / 10$ & Page: 247 of 252 \\
AND DEVELOPMENT PLAN & .
\end{tabular}

The most widely commercialized etched plate heat exchanger is a PCHE developed by Heatric Division of Meggitt (U.K.) Ltd. PCHE consists of metal plates on the surface of which millimeter-scale semicircular fluid-flow channels are photo-chemically milled, using a process analogous to that used for the manufacture of electronic printed circuit boards, hence the name. ${ }^{86,88}$ The plates are then stacked and diffusion-bonded together to fabricate a heat exchanger core shown schematically in Figure B-4. Note that the channels are straight in this schematic, but in reality they are have a zig-zig configuration. Flow distributors can be integrated into plates or welded outside the core, depending on the design. Several PCHE concepts have been developed by Heatric; a platelet configuration with flow distributors integrated into the plates is shown in Figure B-5. The channel diameter, plate thickness, channel angles, and other attributes can be varied, so each PCHE is custom-built to fit a specified task. Channel dimensions are generally between 3 and $0.2 \mathrm{~mm} .{ }^{121}$ The current fabrication limits are $1.5 \mathrm{~m} \times 0.6 \mathrm{~m}$ plates and $0.6 \mathrm{~m}$ stack height. The diffusion-bonded blocks are modular and multiple blocks can be welded together to form larger units.
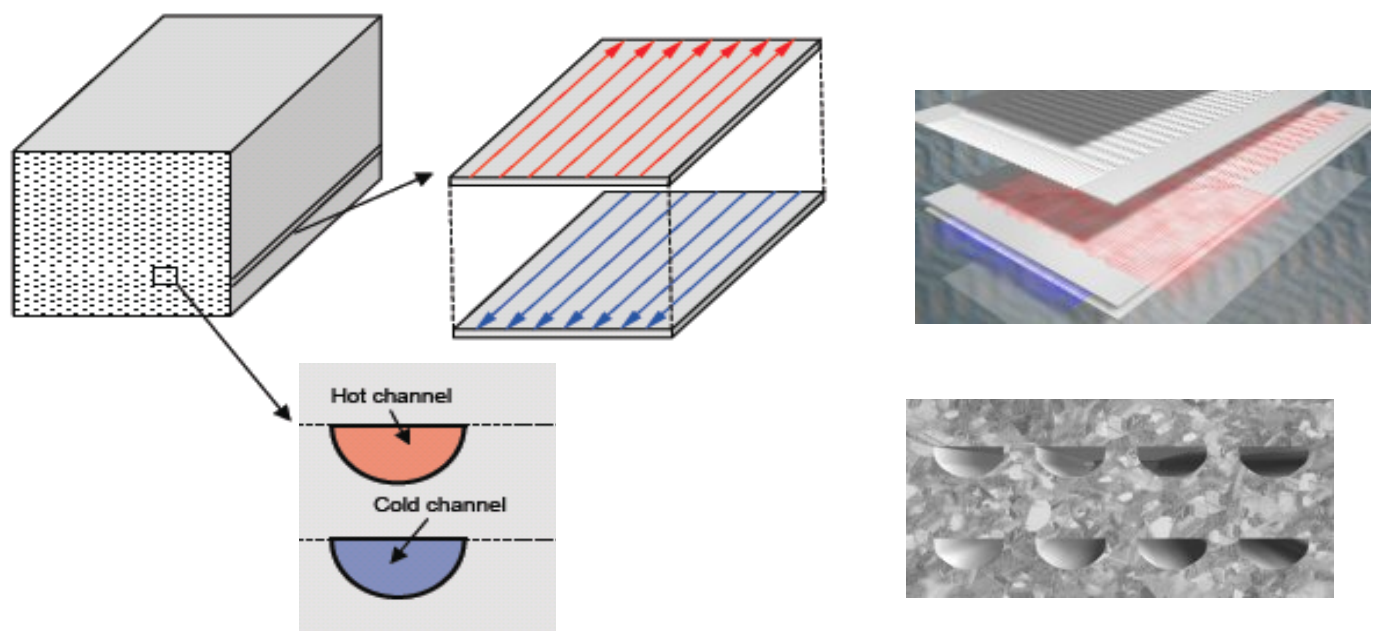

Figure B-4. PCHE configuration for the model.

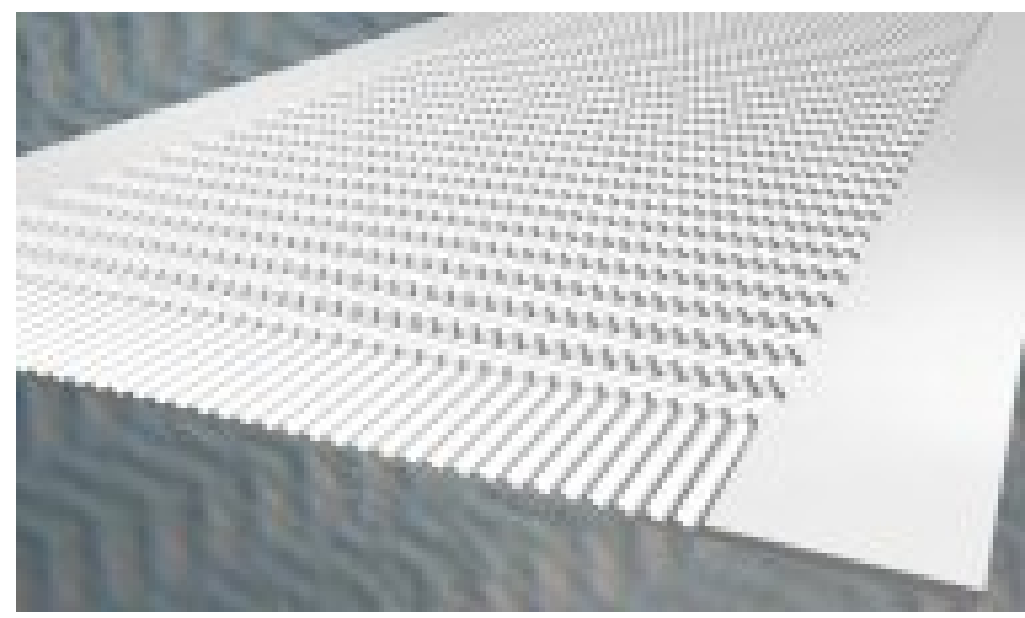

Figure B-5. Heatric PCHE platelet design. 


\begin{tabular}{|c|lll|}
\hline NEXT GENERATION NUCLEAR PLANT STEAM & Identifier: & PLN-2804 & \\
GENERATOR AND INTERMEDIATE HEAT & Revision: & 1 & \\
EXCHANGER MATERIALS RESEARCH & Effective Date: & $09 / 23 / 10$ & Page: 248 of 252 \\
AND DEVELOPMENT PLAN &
\end{tabular}

\section{B-5. MICROCHANNEL HEAT EXCHANGERS}

Microchannel heat exchangers, produced by Velocys, also feature a compact design similar to the etched plate design; however, the manufacturing process is somewhat different. They are constructed from diffusion-bonded corrugated sheets rather than etched plates. The layers of corrugated sheet form many small diameter channels that result in a high surface area/volume ratio and a high heat transfer coefficient, shown in Figure B-6. Velocys claims their microchannel heat exchangers have even better properties than those claimed for other compact heat exchangers, as shown in Table B-1. ${ }^{122}$

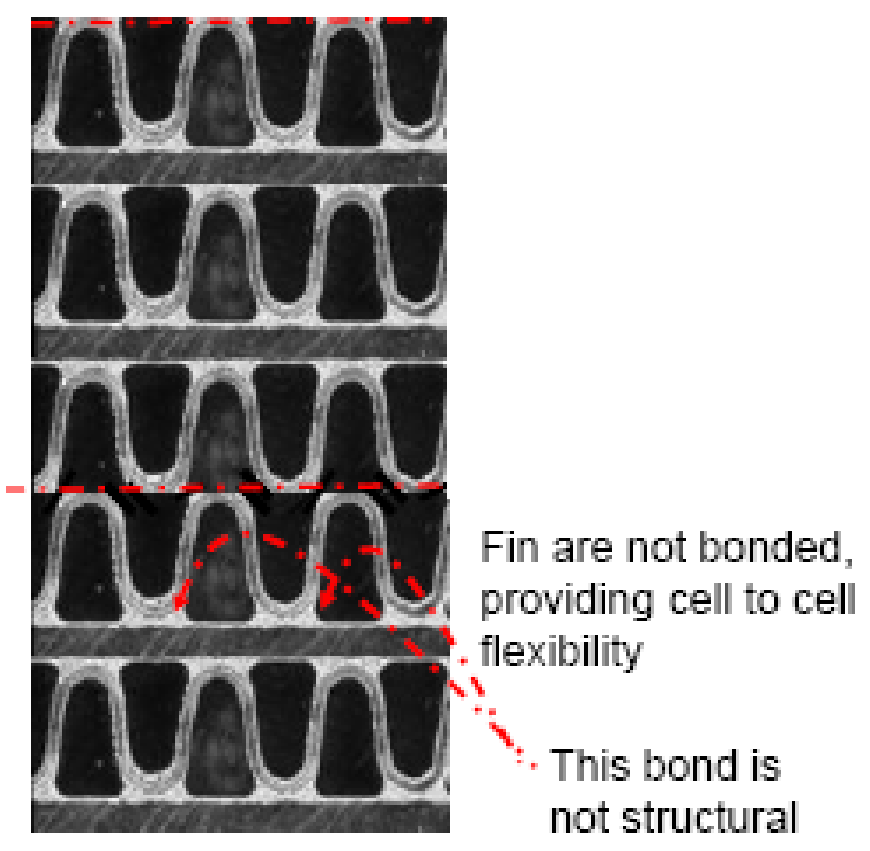

Figure B-6. Section of Velocys heat exchanger showing layers of corrugated sheet.

Table B-1. Properties of heat exchangers as presented by Velocys.

\begin{tabular}{llll}
\hline \multicolumn{1}{c}{ Parameter } & Shell and Tube & Compact & Compact Micro-channel \\
\hline Surface Area/Volume $(\mathrm{m} 2 / \mathrm{m} 3)$ & $50-100$ & $850-1500$ & $>1500$ \\
Heat Transfer Coefficient $(\mathrm{W} / \mathrm{m} 2 / \mathrm{K})(\mathrm{gas})$ & $20-100$ & $50-300$ & $400-2000$ \\
Approach Temperature $\left({ }^{\circ} \mathrm{C}\right)$ & $\sim 20$ & $\sim 10$ & $<10$ \\
Flow Regime & Turbulent & Turbulent & Laminar \\
\hline
\end{tabular}




\begin{tabular}{|c|lll|}
\hline $\begin{array}{c}\text { NEXT GENERATION NUCLEAR PLANT STEAM } \\
\text { GENERATOR AND INTERMEDIATE HEAT }\end{array}$ & Identifier: & PLN-2804 & \\
EXCHANGER MATERIALS RESEARCH & Revision: & 1 & \\
AND DEVELOPMENT PLAN & Effective Date: & $09 / 23 / 10$ & Page: 249 of 252 \\
\hline
\end{tabular}

\section{Appendix C}

\section{Core Internals Research Issues}

This section will detail issues specific to the core internals fabricated from high temperature alloys.

\section{C-1. OPERATIONAL REQUIREMENTS}

\section{C-1.1 Control Rods}

A prior report ${ }^{123}$ studied the potential materials that may be selected for the control rod sleeves and the issues associated with the selection of each material. The report examined past reactor designs and control rod performance. In addition to evaluating the material requirements, the report reviewed the irradiation behavior, testing, codification, cost, availability, and manufacturing issues of three materials: $\mathrm{SiCf} / \mathrm{SiC}$ and $\mathrm{Cf} / \mathrm{C}$ composites and Alloy $800 \mathrm{H}$. The most mature, and therefore lowest risk, concept for control rod sleeves is to use Incoloy 800H. Composites are discussed further in Section C-3.4.

The reactivity control rods for both the prismatic and pebble-bed design could arguably operate under the ASME Code for $800 \mathrm{H}$, as it currently stands, with a maximum use temperature of $760^{\circ} \mathrm{C}$. Although (like all austenitic alloys) $800 \mathrm{H}$ experiences radiation embrittlement, the alloy is being used in HTGRs and the embrittlement can be accounted for in the component design. The primary problem with using $800 \mathrm{H}$ control rods is planning for high temperature off-normal events such as depressurized conduction cooldown (DCC). Procedural solutions such as delayed scram or local temperature monitoring may be required.

The operating conditions for the NGNP control rods shown in Table C-1 were calculated with an assumed gas outlet temperature of $950{ }^{\circ} \mathrm{C} .{ }^{27} \mathrm{It}$ is assumed that the shutdown rods in the prismatic design would be suspended above the core during normal operation and off-normal events. The temperatures seen by the control rods should be somewhat lower than those reported in Table C-1 for an outlet gas temperature of $750^{\circ} \mathrm{C}$. The PBMR Demonstration Project Plant reported its control rods will be exposed to a normal operating temperature of $700^{\circ} \mathrm{C}$, a design basis event maximum temperature of $850^{\circ} \mathrm{C}$, and a maximum end-of-life fast fluence of $5 \times 10^{21} \mathrm{n} / \mathrm{cm}^{2}{ }^{13}$

Table C-1. Estimated operating conditions for NGNP control rods for outlet gas of $950^{\circ} \mathrm{C}$.

\begin{tabular}{llll} 
& Normal temp & Max DCC temp & Lifetime dose \\
\hline Prismatic & $732^{\circ} \mathrm{C}$ & $1153^{\circ} \mathrm{C}$ & $8.4 \mathrm{dpa}$ \\
Pebble bed & $546^{\circ} \mathrm{C}$ & $1017^{\circ} \mathrm{C}$ & $7.9 \mathrm{dpa}$ \\
\hline
\end{tabular}

Control rods are designed to be replaceable. The lifetime of the control rod sleeves is of minimal significance, providing it is reasonable and the component can be changed during scheduled maintenance shutdowns. The replacement schedule of the control rods will be determined primarily by the embrittlement due to temperature and thermal neutron exposure, and by the creep strength of the material. 


\begin{tabular}{|c|lll|}
\hline $\begin{array}{c}\text { NEXT GENERATION NUCLEAR PLANT STEAM } \\
\text { GENERATOR AND INTERMEDIATE HEAT }\end{array}$ & Identifier: & PLN-2804 & \\
EXCHANGER MATERIALS RESEARCH & Revision: & 1 & \\
AND DEVELOPMENT PLAN & Effective Date: & $09 / 23 / 10$ & Page: 250 of 252 \\
\hline
\end{tabular}

\section{C-1.2 Core Barrel}

The core barrel is positioned between the pressure vessel and the graphite outer side reflector. It is not a pressure vessel and does not see significant stress although it supports the graphite core and helps maintain core geometry. The core barrel may be single or double-walled. The double-wall design uses gas flow to cool the core barrel as well as the RPV. The core barrel will be exposed to moderate radiation and temperatures, but must last the lifetime of the plant. Alloy $800 \mathrm{H}$ and $316 \mathrm{H}$ stainless steel are both ASME Code qualified in Subsection NH, and have been suggested as core barrel materials (GA did not specify a material in their preconceptual design report). There may be procurement and fabrication issues because of its large size. It is expected that construction will require some on-site welding.

The 2003 development plan ${ }^{124}$ has reported 0.05 dpa as a lifetime dose. The PBMR Demonstration Project Plant reported its core barrel temperature to be $400^{\circ} \mathrm{C}$ with short-term abnormal temperature excursions of about $557^{\circ} \mathrm{C}$. The maximum End-of-Life Fast Fluence $(\mathrm{E}>0.1 \mathrm{MeV})$ is estimated at $3 \times 10^{18}$ $\mathrm{n} / \mathrm{cm}^{2}{ }^{23}$ The core barrel is not a replaceable part and therefore is expected to survive the full life of the plant.

\section{C-2. PROCUREMENT/AVAILABILITY}

Procurement issues do not appear important for metallic core internals; $316 \mathrm{SS}$ and $800 \mathrm{H}$ are available from a number of vendors. Methods for fabricating these materials are well established so no problems are anticipated in locating satisfactory vendors for the core internals.

Manufacturing the basic shapes required to make the control rod sheathing poses no particular problem. The necessary equipment, capacity, and expertise are available for $800 \mathrm{H}$. Machining is not particularly difficult, but $800 \mathrm{H}$ will be operating in a temperature regime where creep could be significant, so care must be taken with stress concentrations.

The core barrel will be nearly as large as the pressure vessel, and may encounter the same transportation issues as discussed in the RPV acquisition plan. ${ }^{125}$ However, rolling/forging large sections of $316 \mathrm{SS}$ or $800 \mathrm{H}$ should not pose any particular problems. Although on-site fabrication may be required, welding of these materials is well established.

\section{C-3. MATERIAL CHARACTERISTICS AND DEGRADATION}

Most of the material property testing is covered in detail in Section 7 and will be briefly summarized here, emphasizing core internal issues.

\section{C-3.1 Microstructural Stability}

There are no known long-term stability issues with either $316 \mathrm{SS}$ or $800 \mathrm{H}$. These alloys have considerable experience in other reactors and there have been no indications of microstructural instability.

\section{C-3.2 Environmental Effects}

Environmental interaction is not anticipated with either $316 \mathrm{SS}$ or $800 \mathrm{H}$. There is the potential for carburization in the materials, which could cause microstructural changes and embrittlement. The effect of the environment on carbon composites is unknown.

High temperature testing is needed to determine if the control rod with $800 \mathrm{H}$ cladding would deform to the point it could not be extracted from the outer reflector after an off-normal event resulting in elevated temperature exposure. Although $800 \mathrm{H}$ will require additional testing, to fill out the database and 
Idaho National Laboratory

\begin{tabular}{|c|lll|}
\hline NEXT GENERATION NUCLEAR PLANT STEAM & Identifier: & PLN-2804 & \\
GENERATOR AND INTERMEDIATE HEAT & Revision: & 1 & \\
EXCHANGER MATERIALS RESEARCH & Effective Date: & $09 / 23 / 10$ & Page: 251 of 252 \\
AND DEVELOPMENT PLAN &
\end{tabular}

to extend the use temperature specified in the ASME Code, as discussed in Section 7.1.7, these needs appear to be less than what would be required to codify composite materials, which is the alternative material for control rod sleeve applications.

\section{C-3.3 Radiation Embrittlement}

Like all austenitic alloys, $800 \mathrm{H}$ experiences radiation embrittlement. Control rod sleeves will experience a fluence $<0.15 \mathrm{E} 21 \mathrm{n} / \mathrm{cm} 2 / \mathrm{yr}$ fast, $<2.5 \mathrm{E} 21 \mathrm{n} / \mathrm{cm} 2 / \mathrm{yr}$ thermal. However, the alloy is being used in high temperature gas reactors (HTGRs) and the embrittlement can be accounted for in the component design.

Preliminary assessment of the behavior of Alloy $800 \mathrm{H}$ under neutron irradiation was begun as part of the Gen IV cross-cutting R\&D program. Miniature tensile bars were irradiated in the High-Flux Isotope Reactor (HFIR) to a total dose of $1.28 \mathrm{dpa}$ at irradiation temperatures of 580 and $660^{\circ} \mathrm{C}$. Specimens were tested in tension after irradiation at a range of temperatures up to $700^{\circ} \mathrm{C}$. Figure $\mathrm{C}-1$ (a) and (b) show the yield strength and total elongation to failure, along with baseline data for the same material in the unirradiated condition. It is clear from these preliminary tests that the yield strength is influenced by neutron irradiation in a manner that depends on the irradiation temperature. The elongation to failure is reduced to near zero for post-irradiation tensile tests near $700^{\circ} \mathrm{C}$ for either irradiation temperature.
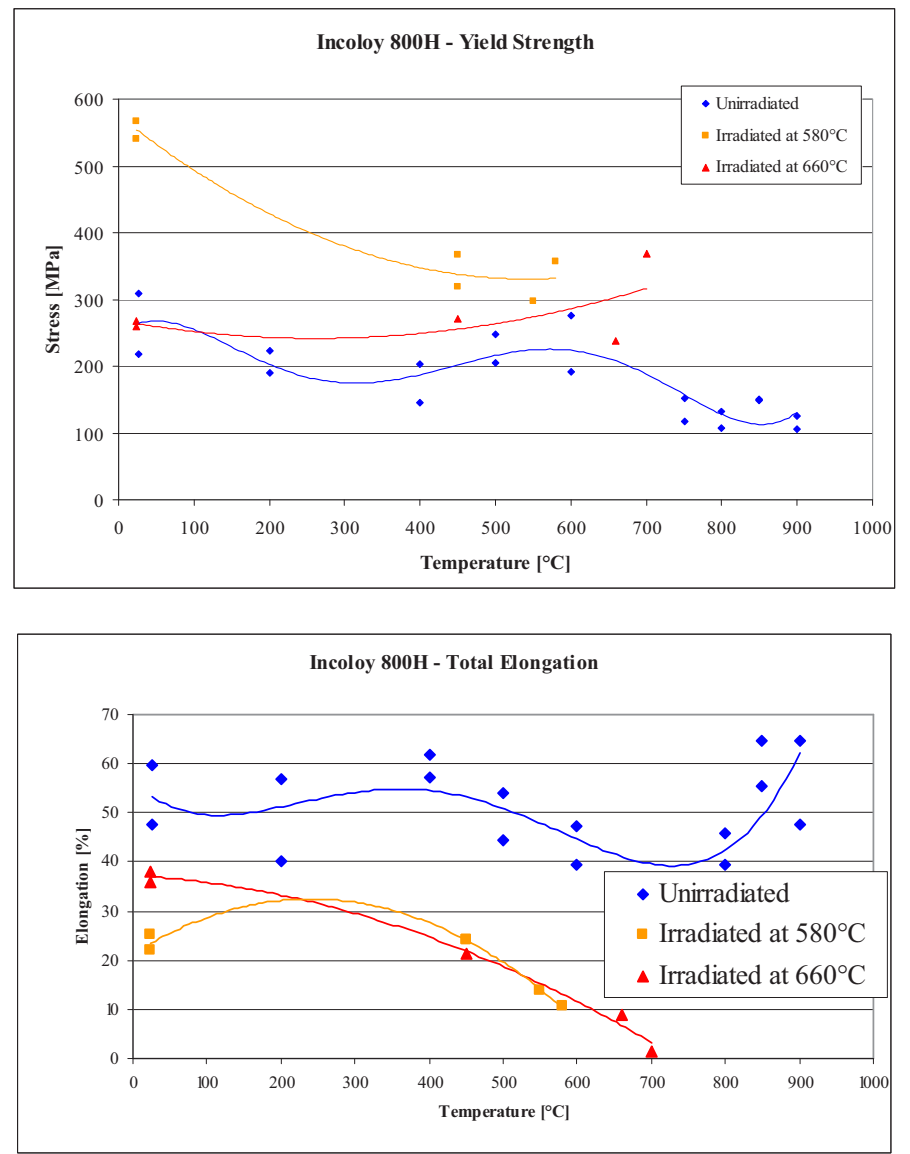

Figure C-1. Tensile data for irradiated $800 \mathrm{H}$ (a) yield strength, (b) total elongation. 


\begin{tabular}{|c|lll|}
\hline NEXT GENERATION NUCLEAR PLANT STEAM & Identifier: & PLN-2804 & \\
GENERATOR AND INTERMEDIATE HEAT & Revision: & 1 & \\
EXCHANGER MATERIALS RESEARCH & Effective Date: & $09 / 23 / 10$ & Page: 252 of 252 \\
AND DEVELOPMENT PLAN &
\end{tabular}

It is usually assumed that the mechanism of irradiation-induced embrittlement in nickel-based alloys irradiated above about $500^{\circ} \mathrm{C}$ is grain boundary failure resulting from nucleation and growth of helium bubbles formed through $(n, \alpha)$ reactions. The microstructure of specimens used in experiments with Alloy $800 \mathrm{H}$ carried out under the Gen IV program was never characterized to confirm this proposed mechanism for embrittlement.

Alloy $800 \mathrm{H}$ will require additional testing, including irradiation testing, to fill out the database. Much of the original data is old, and was generated with samples made from 800 rather than $800 \mathrm{H}$. Creep rate and rupture time: $\mathrm{T} / \mathrm{t}$ limits for off-normal conditions. Low-cycle fatigue data must also be available to determine the allowable number of scram events. Post-irradiation tensile studies will determine the extent of embrittlement.

Alloy 316 SS also has potential for radiation embrittlement, but the radiation exposure of the core barrel should be moderate. Because the core barrel is not structural, radiation damage should be less of an issue for this component.

\section{C-3.4 Composites for Control Rods}

$\mathrm{C}_{\mathrm{f}} / \mathrm{C}$ and $\mathrm{SiC}_{\mathrm{f}} / \mathrm{SiC}$ composites have been considered for the control rod cladding material. These composites are attractive because of their high temperature and irradiation resistance. A composite control rod would be required to push the reactor temperature, and thus the efficiency, higher.

$\mathrm{Cf} / \mathrm{C}$ composites are available from a number of vendors. If ceramic composite control rods are implemented, the control rod design will be altered to accommodate the differences in fabricability, etc. Composites must be designed so that threads are either avoided or properly supported by fibers, with consideration not only towards the integrity of the part, but the difficulty in qualifying the component design. Both processing time and material availability could be issues if composites are chosen. Carbon fibers are mass produced by both domestic and foreign suppliers, but the industry is currently capacity constrained and certain types of fiber are very difficult to obtain. This may not be the case when material is needed for production of control rods, but would affect development.

These composite materials are non-homogeneous and anisotropic, and therefore require unique test methods to measure their properties. Test methods to evaluate these composite materials, particularly at elevated temperature, and including irradiation effects, will need to be developed and formalized. This can be a lengthy process, depending on the complexity of the test method proposed, and would be the first step in the NRC acceptance process.

Following development of standardized test methods, the composite(s) of interest would have to go through the ASME codification process which also has the potential to be a lengthy process. There are no ASME specifications for composite materials to be used in nuclear applications. Entirely different design and performance philosophies must be adopted for composite use. Existing design and assessment rationale are guided by homogeneous material characteristics. Furthermore, not only must the individual constituents of the final material be qualified and approved, but also the method of assembly.

\section{C-3.5 Inspection}

Core barrel welds will need to be inspected, but methods should be standard. In-service inspection of the control rods may be required to ensure that no changes to the planned replacement interval are needed.

The acceptance criteria must be determined for the control rod. Acceptance criteria for the core barrel are already defined because welding of $800 \mathrm{H}$ and 316 is well understood. 